\title{
Prediction of Shrinkage of Concrete Containing Supplementary Cementitious Materials Using Microscale Characterizations and Composite Modeling
}

Arkamitra Kar

West Virginia University

Follow this and additional works at: https://researchrepository.wvu.edu/etd

\section{Recommended Citation}

Kar, Arkamitra, "Prediction of Shrinkage of Concrete Containing Supplementary Cementitious Materials Using Microscale Characterizations and Composite Modeling" (2010). Graduate Theses, Dissertations, and Problem Reports. 4614.

https://researchrepository.wvu.edu/etd/4614

This Thesis is protected by copyright and/or related rights. It has been brought to you by the The Research Repository @ WVU with permission from the rights-holder(s). You are free to use this Thesis in any way that is permitted by the copyright and related rights legislation that applies to your use. For other uses you must obtain permission from the rights-holder(s) directly, unless additional rights are indicated by a Creative Commons license in the record and/ or on the work itself. This Thesis has been accepted for inclusion in WVU Graduate Theses, Dissertations, and Problem Reports collection by an authorized administrator of The Research Repository @ WVU. For more information, please contact researchrepository@mail.wvu.edu. 


\title{
Prediction of Shrinkage of Concrete Containing Supplementary Cementitious Materials Using Microscale Characterizations and Composite Modeling
}

\author{
Arkamitra Kar \\ Thesis submitted to the College of Engineering and Mineral Resources \\ at West Virginia University \\ in partial fulfillment of the requirements \\ for the degree of
}

Master of Science

in

Civil Engineering

\author{
Indrajit Ray, Ph.D., Chair \\ Julio F .Davalos, Ph.D.,Co-Chair \\ Avinash Unnikrishnan, Ph.D. \\ An Chen, Ph.D., P.E. \\ Department of Civil and Environmental Engineering \\ Morgantown, West Virginia \\ 2010
}

Keywords: Calcium-Silicate-Hydrate (C-S-H); Composite modeling; Optimization; SEM/EDS; Shrinkage; Supplementary Cementitious Materials 


\section{Abstract \\ Prediction of Shrinkage of Concrete Containing Supplementary Cementitious Materials Using Microscale Characterizations and Composite Modeling}

Arkamitra Kar

The inclusions of Supplementary Cementitious Materials (SCM) from industrial by products, such as slag, fly ash and silica fume in normal concrete derive several benefits. The use of SCM as partial replacement of portland cement divert these SCM from landfills, reduces $\mathrm{CO}_{2}$ emissions, and produces highly durable concrete leading to development of sustainable and green construction materials. One of the primary aspects of durability is to correctly estimate and predict the shrinkage. Since inclusions of SCM modify the volume, composition, and microstructure of the calcium silicate hydrate (C-S-H) of normal concrete, there are limitations on available prediction equations for shrinkage to concrete containing SCM. Some researchers had used the microstructural properties of the normal cementitious pastes to estimate the shrinkage using multiscale model without considering the complexity of SCM interaction. Other studies that considered the effects of SCM at C-S-H level provided only qualitative estimation of the prediction of shrinkage. Therefore, there is a need to predict the shrinkage of concrete containing fly ash, slag, and silica fume at different percentages using microscale characterizations and subsequent semi-quantitative modeling.

In this study, a new approach to characterize hardened pastes of pure cement as well as those containing cement with SCM was adopted using high resolution scanning electron microscopy (SEM) and energy dispersive $x$-ray spectra (EDS). The volume stoichiometry of the hydration reactions were used to estimate the quantities of the primary and secondary $\mathrm{C}-\mathrm{S}-\mathrm{H}$ and the calcium hydroxide produced by these reactions. The 3D plots of Si/Ca, $\mathrm{Al} / \mathrm{Ca}$ and S/Ca atom ratios given by the microanalyses were compared with the estimated $\mathrm{C}-\mathrm{S}-\mathrm{H}$ quantities to successfully determine the $\mathrm{Ca} / \mathrm{Si}$ ratio of nineteen different cementitious systems at four different ages using a constrained nonlinear least squares optimization formulation by General Algebraic Modeling Software (GAMS). The mixes contained 100\% cement with subsequent replacement by $35 \%$ slag, $45 \%$ slag, $25 \%$ fly ash, $35 \%$ fly ash, $10 \%$ silica fume individually and a few combinations of the SCMs at $\mathrm{w} / \mathrm{cm}$ ratios of 0.3 and 0.4 for each case. The estimated mass fraction of calcium hydroxide from the above method agreed well with the calcium hydroxide content determined using thermogravimetric analyses (TGA). The effect of the $\mathrm{w} / \mathrm{cm}$ ratio and the different SCM content on the rate of hydration of the different mixes were evident from the curves obtained using the results from the isothermal calorimeter. The shrinkage of the cement paste was determined in terms of its volume deformation, as a function of its pore volume and elastic modulus. The results were verified using the capillary shrinkage test.

The concept of composite modeling was used to evaluate the shrinkage of the mortar specimens. The properties of the interfacial transition zone between the paste and the fine aggregate were computed using the Hashin-Shkritman bounds for two-phase composite material extended to three phase material. The results of the mortar shrinkage were validated by experimental data. The concept of composite modeling was further extended to predict the shrinkage of concrete in general. Shrinkage experiments were carried out on laboratory-scale concrete samples and the results were used for validation of the equation.

Finally, the results of the experiments and those predictions equations proposed from the composite model were compared favorably with the available shrinkage models: ACI, B3, CEB MC 90-99, and GL 2000. 


\section{Acknowledgement}

I wish to express my sincere gratitude towards my advisor Dr. Julio F. Davalos for providing me with the scope to work in such an interesting project. I am deeply grateful to have him as my teacher as well as advisor. His magnificent ideas, along with his whole-hearted support guided me through the two years of my M.S. program at West Virginia University. I am grateful to him for providing me the opportunity to work with him.

My sincere appreciation and respect goes to Dr. Indrajit Ray, who provided me with the topic of research and invaluable guidance along with it. His extensive knowledge in the field of concrete science and technology was of utmost help throughout my project. By virtue of his extreme encouragement, suggestions and advice he made my task a lot simpler. I was very fortunate to have worked with Dr. Ray on this topic. Also, I would gratefully acknowledge his help with editing my thesis.

I would also like to express my sincere thanks to Dr. Avinash Unnikrishnan who was present as a member of my committee and provided a lot of technical inputs, especially the statistical analysis.

I would also like to express my gratitude towards Dr. An Chen for being on my committee and for his support during my research.

I would also like to thank Liviu Magean for performing the thermogravimetric analyses of my samples and also Song Chen for polishing my samples.

I appreciate Kolin Brown for his help and training in WVNano shared facility.

Also I would like to thank Nagavardhana Perisetty, Kevin Prendergrast, Sathish Konduru, Arka Bhattacharya, Santiago Velez, John Wattick, Soumya Chowdhury, Adam Burnley, Srinivas Majiga, Kedar Panday, Vishal Narang, Karthik Dandu, Adam Justice, Krishna Nandam, Manish Roy, Subhadeep Ghosh and all the members of B11 for helping me in the laboratory with pouring concrete, performing microscopic studies and other associated tasks.

My hearty regards go to Mr. David Turner for his immense technical assistance in the concrete laboratory.

I am grateful to West Virginia Department of Transportation - Division of Highways for their financial support. I also acknowledge Arrow Concrete Company, BASF and other suppliers for generously donating the materials.

I would like to acknowledge the contribution of my mother, without whose support this work could not have been accomplished. 


\section{TABLE OF CONTENTS}

Pg. No.

Abstract

Acknowledgement iii

Table of Contents iv

List of Tables xii

List of Figures $\quad$ xiii

\section{CHAPTER ONE INTRODUCTION}

1.1 Background of Cementitious Systems Containing SCM 1

1.2 Motivation for the Present Study 1

1.3 Areas of Recommended Research According to ACI 2

1.4 Goals and Objectives 3

1.5 Possible Outcomes 4

1.6 Assumptions in the Study and Their Basis 4

1.7 Flow chart of the Study 7

1.8 Thesis Organization 7

CHAPTER TWO BACKGROUND AND LITERATURE REVIEW

2.1 Approach to Multiscale Modeling 9

2.2 Composition of Cement - Oxide Analysis 11

2.2.1 Equation for the Oxide Composition of

$\begin{array}{ll}\text { Cement } & 11\end{array}$

2.3 Microstructure of Concrete - an Overview 12

$\begin{array}{ll}2.4 \text { Chemistry of Hydration } & 13\end{array}$ 
2.4.1 Hydration of pure cement compounds

2.4.2 Calcium silicates

2.4.3 Hydration of cements containing

slag, fly ash, and silica fume as SCM

2.5 Modeling of C-S-H 16

2.6 Calcium Hydroxide $(\mathrm{CH}) \quad 20$

2.7 Calcium Sulfoaluminates and Aluminoferrites 21

2.8 Porosity and Pore Structures of the Hydrated Pastes 22

2.8.1 Changes in pore size during

shrinkage (or expansion) of cement paste

and concrete 22

2.8.1.1 Homogeneous volume change of a porous solid 23

2.8.1.2 Homogeneous volume change in the presence of an inert phase $\quad 24$

2.8.1.3 Fully restrained deformation $\quad 25$

2.8.1.4 Partially restrained deformation 26

2.8.1.5 Application to cement paste and concrete 27

2.9 Heat and Rate of Hydration 27

2.9.1 Isothermal Calorimetry 29

2.9.2 Thermogravimetric Analyses 29

2.10 Statistical Optimization $\quad 29$

2.11 Shrinkage 31

2.11.1 Factors affecting drying and chemical shrinkage $\quad 32$

2.11.1.1 Water-cementitious materials ratio 32

2.11.1.2 Size and grading of aggregate 33

2.11.1.3 Aggregate modulus of elasticity 33

2.11.1.4 Lightweight aggregates 33

2.11.1.5 Cement properties 33

2.11.1.6 Supplementary cementitious materials (SCM) 34 
2.11.1.7 Admixtures $\quad 34$

2.11.1.8 Curing and storage conditions $\quad 34$

2.11.2 Relationship between shrinkage mechanisms and microstructure $\quad 35$

2.11.2.1 Variation of the surface free energy 35

2.11.2.2 Effect of disjoining pressure 36

2.11.2.3 Capillary condensation effect 37

2.11.3 Shrinkage models 38

2.11.3.1 Data used for model evaluation 39

2.11.3.2 Statistical comparison of the models 40

2.11.3.3 Criteria for prediction models 41

2.11.3.4 Model selection 42

2.11.3.5 Important parameters required for modeling 43

2.11.3.5.1 ACI 209R prediction equation 43

2.11.3.5.2 CEB - MC 90-99 47

2.11.3.5.3 Sakata model (1993) 48

2.11.3.5.4 Bazant model (1996) 49

2.11.3.5.5 Gardner and Lockman model (2001) 50

2.11.3.5.6 Huo et.al model (2001) 51

2.11.3.5.7 Models by other authors $\quad 51$

2.12 Prediction of Concrete Shrinkage Using

Two-Phase Composite Model 53

2.13 Accuracy of Prediction Models for Shrinkage 57

2.14 Updating Concrete Drying Shrinkage Prediction

Models for Local Materials 58

2.15 Interfacial Transition Zone $\quad 59$

2.15.1 Development of ITZ 60

2.15.2 Main characteristics of ITZ 60

2.15.3 Orientation of ITZ 60 
2.16 Synthesis from Literature Review 61

2.17 Research Significance $\quad 62$

\section{CHAPTER THREE MATERIALS AND MIXTURE PROPORTIONS}

3.1 Materials 63

3.1.1 Cement 63

3.1.2 Coarse aggregate 64

3.1.3 Fine aggregate 65

3.1.4 Supplementary Cementitious Materials (SCM) 66

3.1.4.1 Silica fume 66

3.1.4.2 Fly ash 66

3.1.4.3 Slag 67

3.1.5 Chemical admixtures 68

3.1.5.1 High-Range Water Reducing Admixture (HRWRA) 68

3.1.5.2 Air Entraining Agent (AEA) 68

3.1.6 Mixing water 68

3.2 Selection and Criteria of Mix Proportions 69

$\begin{array}{ll}3.3 \text { Mixture Proportioning } & 70\end{array}$

3.4 Mixing Procedure for Concrete Batches 72

3.5 Curing 72

3.6 Sampling Techniques for Microanalyses $\quad 72$

\section{CHAPTER 4 DEVELOPMENT OF MODELING BASED ON MICROANALYSIS}

4.1 Basis of the Model 73

4.2 SEM and EDS Microanalysis Studies 74

4.3 Thermogravimetric Analyses (TGA) 75 
4.4 Isothermal Calorimetry Studies

4.5 Analysis of Test Data Using Volume Stoichiometry and Statistical Optimization

4.5.1 Volume stoichiometry to estimate C-S-H(I),

C-S-H(II) and CH

76

4.5.2 Hydration reactions for pure portland cement

76

4.5.2.1 Hydration of portland cement blended with

fly ash and silica fume

4.6 Estimation of Quantities of C-S-H(I), C-S-H(II) and CH

4.6.1 Estimation of C-S-H(I) for pure cement

4.6.2 Degree of hydration at different ages

4.6.2.1 Effect of low $w / \mathrm{cm}$ ratios

80

4.6.2.2 Isothermal calorimetry - testing and results

81

4.6.3 Estimation of C-S-H(I)and C-S-H(II)

for cement with SCM

84

4.6.3.1 P\% cement containing Q\% slag as SCM

84

4.6.3.2 P\% cement containing $Q \%$ fly ash

or silica fume as SCM

85

4.6.3.3 P\% cement containing Q\% slag and

R\% fly ash as SCM

4.6.3.4 P\% cement containing Q\% fly ash and

$R \%$ silica fume as SCM

87

4.6.4 Estimation of $\mathrm{CH}$ for pure portland cement

88

4.6.5 Estimation of $\mathrm{CH}$ for cement with SCM

88

4.6.5.1 P\% cement blended with Q\% slag

88

4.6.5.2 P\% cement blended with Q\% fly ash

or silica fume

89

4.6.5.3 P\% cement blended with Q\% fly ash and

$R \%$ silica fume

89 
4.7 Estimation of Hydrated Products from Aluminate and Aluminoferrites Hydration

4.7.1 Aluminate hydration 90

4.7.2 Aluminoferrite hydration 90

4.8 Interpretation of Microanalysis Data and

Statistical Optimization $\quad 91$

4.8.1 Significance of microanalysis and optimization 91

4.8.2 Statistical optimization 92

4.8.2.1 Optimization using GAMS 92

4.9 Comparison of Experimental and Predicted Data for C-S-H(I) and C-S-H(II) Based on Optimized Values of $n$ and $n^{\prime}$

4.9.1 Observations from the comparison between experimental and predicted C-S-H(I) and C-S-H(II) 107

4.10 Variation of C-S-H(I) and C-S-H(II) and the Total C-S-H Volumes with Time for

Different Proportions of SCM and Different w/cm Ratios

4.10.1 Observations from the C-S-H(I), C-S-H(II) and total $\mathrm{C}-\mathrm{S}-\mathrm{H}$ volume fractions

4.11 Porosity

4.11.1 Variation of pore volumes with time for different proportions of SCM and different $\mathrm{w} / \mathrm{cm}$ ratios

4.11.1.1 Observations on porosity development 118

4.12 Experimental Validation through TGA

4.12.1 Estimation of $\mathrm{CH}$ volume from optimization and validation through TGA

4.13 Capillary (or Chemical) Shrinkage Testing and Results 
4.13.1 Quantitative estimation of capillary (or chemical) shrinkage of cementitious paste

\section{CHAPTER 5 COMPOSITE MODELING AND PREDICTION OF SHRINKAGE}

5.1 Two-Step Composite Model

5.2 Mortar as Composite

5.2.1 Hashin - Shtrikman bounds

5.2.2 Contribution of different phases to stiffness

5.3 Concrete as Composite

5.4 Proposed Two-Step Composite Model

5.5 Shrinkage Test Procedure for Concrete Prisms

5.6 Proposed Model

5.7 Comparisons of Models with the Shrinkage Data

5.7.1 Comparison with proposed model

5.7.1.1 Plot of mean differences

5.7.2 Comparison with available models

5.7.2.1 ACI and modified ACI (by Huo et al. 2001)

5.7.2.1.1 Observations on comparison of predicted model with $A C I$ (and modified ACI by Huo et al. 2001) model

5.7.2.2 Bazant - Baweja B3 Model

5.7.2.2.1 Observations on comparison of proposed model with B3 model

5.7.2.3 CEB MC 90-99 model

5.7.2.3.1 Observations on comparison of predicted model with CEB MC 90-99 model 
5.7.2.4.1 Observations on comparison of proposed model with GL 2000 model

180

5.8 Effect of $w / c m$ Ratio

181

5.9 Effect of Varying Proportions of SCM

182

5.10 Compressive Strength Measurement

184

5.11 Flow Chart for Sample Calculation

185

\section{CHAPTER 6 CONCLUSIONS}

6.1 Estimation of C-S-H

186

6.2 Shrinkage Model

187

6.3 Suggestions for Future Work

187

References

189

APPENDIX

198 


\section{List of Tables}

Table 2.1 Important parameters required for modeling

Table 2.2 - Correction for $\mathrm{Y}_{c p}$

Table 2.3 - Correction factors for average thickness of method of Members less than $150 \mathrm{~mm}$

Table 3.1: Physical properties of the Type I portland cement used

Table 3.2: Compound composition of the portland cement

Table 3.3: Properties of coarse aggregates

Table 3.4: Sieve analysis result

Table 3.5: Properties of fine aggregate

65

Table 3.6: Sieve analysis of sand

Table 3.7: Basic properties of silica fume and fly ash

Table 3.8: Basic properties of slag

Table 3.9: Mix proportions

Table 3.10 Mixture proportioning for concrete mixes

Table 4.1: Densities and molar volumes of cementitious materials

Table 4.2: Volume of hydrated phases at full hydration (per $100 \mathrm{~mL}$ of hydrating cementitious paste) 
Table 4.4: Reaction degree of blending component

Table 4.5: The $n$ and $n^{\prime}$ values for all the mix proportions

Table 4.6: Comparison between the experimentally obtained values from SEM-EDS and that obtained by the optimization technique for C-S-H(I) at 28-day age of paste

Table 5.1 Compressive strength of cementitious paste and concrete at different ages and different $\mathrm{w} / \mathrm{cm}$ ratios 


\section{List of figures}

Fig 1.1 Schematic diagram showing the length scale assumptions at each scale.

Fig. 2.1 (a) Dimensional range of solids and pores in hydrated cement paste; (b) Orders of magnitude (Mehta and Monteiro, 2005).

Fig 2.2 Powers Model for C-S-H (Courtesy: Powers 1948).

Fig 2.3 Feldman-Sereda Model (Courtesy: Feldman and Sereda 1968).

Fig 2.4 Munich Model (Courtesy: Mindess and Young, 1981).

Fig 2.5 Tokyo Model (Courtesy: Daimon et al. 1977).

Fig 2.6 J-T Model (Courtesy: Tennis and Jennings 1992).

Fig 2.7 Jennings Model (Courtesy: Jennings 2000).

Fig. 2.8 A deforming phase sandwiched between

two nondeforming phases (Thomas and Jennings, 2003).

Fig 2.9 Rate of heat evolution during hydration of tricalcium silicate (Mindess 2002).

Fig 2.10 Schematic diagram of ITZ in cement paste (Mehta and Monteiro, 2005).

Fig 2.11 Orientation of the ITZ between mortar and aggregate in two extreme cases: (a) Mortar phase in parallel with the coarse aggregate phase at the meter scale (or the cementitious paste matrix in parallel with the sand particles at the millimeter scale); and (b) Mortar phase in series with the coarse aggregate phase at the meter scale (or the cementitious paste matrix in parallel with the sand particles at the millimeter scale). 
Fig. 4.1 Test setup for the isothermal calorimetry test using the TAM-Air instrument.

Fig 4.2 Heat flow from $100 \%$ cement mixes and 35\% slag replacement at different $\mathrm{w} / \mathrm{cm}$ ratios.

Fig 4.3 Heat flow from mixes containing replacement of cement by $25 \%$ fly ash and $10 \%$ silica fume at different $\mathrm{w} / \mathrm{cm}$ ratios.

Fig 4.4 Heat flow from mixes containing replacement of cement by ( $35 \%$ slag $+10 \%$ silica fume) and ( $25 \%$ fly ash $+10 \%$ silica fume) at different $\mathrm{w} / \mathrm{cm}$ ratios.

Fig. 4.5. (a to f) Typical EDS images of 28 -day $100 \%$ portland cement specimen with $\mathrm{w} / \mathrm{cm} 0.4$. In this figure, only three out of nine representative locations are shown for each of 2200x (a to c) and 5000x magnification ( $d$ to f). As shown five points were chosen randomly at each location, leading to 90 data points for each sample.

Fig. 4.6. Energy Dispersive X-Ray Spectra (EDS) of 28 -days $100 \%$ portland cement specimen with $w / c m ~ 0.4$. (a to e) Five point analyses and (f) the corresponding area average scan for one out of nine such locations (as mentioned in the text) is shown for 2200x magnification only.

Fig 4.7. (a to d) 3D plots of atomic ratios of silicon, aluminum and sulfur with respect to calcium for a typical pure portland cement paste $(\mathrm{w} / \mathrm{cm}$ ratio of 0.4 ) at four different ages.

Fig 4.8. (a to f) Typical EDS images of 28-day cement with SCM specimen containing $65 \%$ portland cement, $25 \%$ fly ash and $10 \%$ silica fume with $\mathrm{w} / \mathrm{cm}$ ratio 0.4 at three out of nine representative locations are shown for each of 2200x ( $a$ to $c$ ) and 5000x magnification ( $d$ to f). As shown five points were chosen randomly at each location, leading to 90 data points for each sample. 
Figure 4.9. EDS images of 28-day cement specimen with SCM containing $25 \%$ fly ash and $10 \%$ silica fume with $\mathrm{w} / \mathrm{cm}$ ratio 0.4 . (a to e) Five point analyses and ( $f$ ) the corresponding area average scan for one out of nine such locations (as mentioned in the text) is shown for 5000x magnification only.

Figure 4.10. (a to d) 3D plots of atomic ratios of silicon, aluminum and sulfur with respect to calcium for a typical cementitious paste containing $25 \%$ fly ash and $10 \%$ silica fume as SCM (w/cm ratio of 0.3 ) at four different ages.

Fig. 4.11 Comparison of experimental and predicted data for C-S-H(I) at different ages for $100 \%$ cement mixes at three different $\mathrm{w} / \mathrm{cm}$ ratios.

Fig. 4.12 Comparison of experimental and predicted data for C-S-H(I) and C-S-H(II) at different ages for mixes containing 35\% replacement of cement by slag at two different $w / c m$ ratios.

Fig. 4.13 Comparison of experimental and predicted data for C-S-H(I) and C-S-H(II) at different ages for mixes containing $25 \%$ replacement of cement by fly ash at two different $\mathrm{w} / \mathrm{cm}$ ratios.

Fig. 4.14 Comparison of experimental and predicted data for C-S-H(I) and $\mathrm{C}-\mathrm{S}-\mathrm{H}$ (II) at different ages for mixes containing replacement of cement by $10 \%$ silica fume at two different $\mathrm{w} / \mathrm{cm}$ ratios.

Fig. 4.15 Comparison of experimental and predicted data for $\mathrm{C}-\mathrm{S}-\mathrm{H}(\mathrm{I})$ and $\mathrm{C}-\mathrm{S}-\mathrm{H}$ (II) at different ages for mixes containing replacement of cement by $35 \%$ slag and $10 \%$ silica fume at two different $\mathrm{w} / \mathrm{cm}$ ratios.

Fig. 4.16 Comparison of experimental and predicted data for C-S-H(I) and $\mathrm{C}-\mathrm{S}-\mathrm{H}$ (II) at different ages for mixes containing replacement of cement by $25 \%$ fly ash and $10 \%$ silica fume at two different $\mathrm{w} / \mathrm{cm}$ ratios.

Fig. 4.17 Variation of C-S-H(I) at different ages for $100 \%$ cement mixes at three different $\mathrm{w} / \mathrm{cm}$ ratios. 
Fig. 4.18 Variation of C-S-H(I), C-S-H(II) and total C-S-H at different ages for mixes containing replacement of cement by $35 \%$ slag at two different $\mathrm{w} / \mathrm{cm}$ ratios.

Fig. 4.19 Variation of C-S-H(I), C-S-H(II) and total C-S-H at different ages for mixes containing replacement of cement by $35 \%$ slag and $10 \%$ silica fume at two different $\mathrm{w} / \mathrm{cm}$ ratios.

Fig. 4.20 Variation of C-S-H(I), C-S-H(II) and total C-S-H at different ages for mixes containing replacement of cement by $25 \%$ fly ash and $10 \%$ silica fume at two different $\mathrm{w} / \mathrm{cm}$ ratios.

Fig. 4.21 Variation of C-S-H(I), C-S-H(II) and total C-S-H at different ages for mixes containing replacement of cement by $10 \%$ silica fume at two different $\mathrm{w} / \mathrm{cm}$ ratios.

Fig. 4.22 Variation of capillary and gel porosity with increasing degree of hydration for $100 \%$ cement mixes at three different $\mathrm{w} / \mathrm{cm}$ ratios.

Fig 4.23 Variation of capillary and gel porosity with increasing degree of hydration for mixes containing replacement of cement by $35 \%$ slag.

Fig 4.24 Variation of capillary and gel porosity with increasing degree of hydration for mixes containing replacement of cement by $25 \%$ fly ash.

Fig 4.25 Variation of capillary and gel porosity with increasing degree of hydration for mixes containing replacement of cement by $10 \%$ silica fume.

Fig 4.26 Variation of capillary and gel porosity with increasing degree of hydration for mixes containing replacement of cement by $35 \%$ slag and $10 \%$ silica fume.

Fig 4.27 Variation of capillary and gel porosity with increasing degree of hydration for mixes containing replacement of cement by $25 \%$ fly ash and $10 \%$ silica fume.

Fig. 4.28 TGA results for a pure portland cement paste (w/c ratio of 0.4$)$ at 1-day, 7-days and 28-days age. 
Fig. 4.29 TGA results for 1-day, 7-days and 28-days old cement specimen with SCM containing $65 \%$ portland cement, $25 \%$ fly ash and $10 \%$ silica fume with $\mathrm{w} / \mathrm{c}$ ratio 0.3 .

Fig. 4.30 Comparison between the mass fraction of calcium hydroxide from TGA and SEM/EDS results at 28-days age.

Fig. 4.31 Test setup for the capillary shrinkage test according to ASTM C 1608-07.

Fig 4.32 Capillary shrinkage results for $100 \%$ cement mixes at three different $\mathrm{w} / \mathrm{cm}$ ratios.

Fig 4.33 Capillary shrinkage results for mixes containing replacements of cement by $35 \%$ and $45 \%$ slag at various $\mathrm{w} / \mathrm{cm}$ ratios.

Fig 4.34 Capillary shrinkage results for mixes containing replacements of cement by $25 \%$ and $35 \%$ fly ash at various $\mathrm{w} / \mathrm{cm}$ ratios.

Fig 4.35 Capillary shrinkage results for mixes containing replacements of cement by different combinations of SCM at various $\mathrm{w} / \mathrm{cm}$ ratios.

Fig. 4.36 Contribution of autogenous shrinkage to total shrinkage at varying $\mathrm{w} / \mathrm{cm}$ ratios.

Fig. 5.1 Schematic diagram showing three-phase hierarchical model of concrete.

Fig. 5.2 Schematic diagram showing the transition from cementitious paste to mortar composite.

Fig. 5.3 Schematic diagram showing transition from mortar phase to concrete composite.

Fig. 5.4 Comparison of concrete shrinkage experimental data with the upper and lower bounds predicted by the proposed model in case of $100 \%$ cement mixes at three different $\mathrm{w} / \mathrm{cm}$ ratios. 
Fig. 5.5 Comparison of concrete shrinkage experimental data with the upper and lower bounds predicted by the proposed model in case of mixes containing replacement of cement by $35 \%$ slag at two different $\mathrm{w} / \mathrm{cm}$ ratios.

Fig. 5.6 Comparison of concrete shrinkage experimental data with the upper and lower bounds predicted by the proposed model in case of mixes containing replacement of cement by $25 \%$ fly ash at two different $\mathrm{w} / \mathrm{cm}$ ratios.

Fig. 5.7 Comparison of concrete shrinkage experimental data with the upper and lower bounds predicted by the proposed model in case of mixes containing replacement of cement by $10 \%$ silica fume at two different $\mathrm{w} / \mathrm{cm}$ ratios.

Fig. 5.8 Comparison of concrete shrinkage experimental data with the upper and lower bounds predicted by the proposed model in case of mixes containing replacement of cement by $35 \%$ slag and $10 \%$ silica fume at two different $\mathrm{w} / \mathrm{cm}$ ratios.

Fig. 5.9 Comparison of concrete shrinkage experimental data with the upper and lower bounds predicted by the proposed model in case of mixes containing replacement of cement by $25 \%$ fly ash at two different $\mathrm{w} / \mathrm{cm}$ ratios.

Fig 5.10 Plot of mean differences of experimental data with respect to the mean of the predicted upper and lower bounds of the proposed model in case of $100 \%$ cement mixes at different $\mathrm{w} / \mathrm{cm}$ ratios.

Fig 5.11 Plot of mean differences of experimental data with respect to the mean of the predicted upper and lower bounds of the proposed model in case of mixes containing replacement of cement by $35 \%$ slag at different $\mathrm{w} / \mathrm{cm}$ ratios. 
Fig 5.12 Plot of mean differences of experimental data with respect to the mean of the predicted upper and lower bounds of the proposed model in case of mixes containing replacement of cement by $25 \%$ fly ash at different $\mathrm{w} / \mathrm{cm}$ ratios.

Fig 5.13 Plot of mean differences of experimental data with respect to the mean of the predicted upper and lower bounds of the proposed model in case of mixes containing replacement of cement by $10 \%$ silica fume at different $\mathrm{w} / \mathrm{cm}$ ratios.

Fig 5.14 Plot of mean differences of experimental data with respect to the mean of the predicted upper and lower bounds of the proposed model in case of mixes containing replacement of cement by $35 \%$ slag and $10 \%$ silica fume at different $\mathrm{w} / \mathrm{cm}$ ratios.

Fig 5.15 Plot of mean differences of experimental data with respect to the mean of the predicted upper and lower bounds of the proposed model in case of mixes containing replacement of cement by $25 \%$ fly ash and $10 \%$ silica fume at different $\mathrm{w} / \mathrm{cm}$ ratios.

Fig. 5.16 Comparison of the ACI (and the modified ACI by Huo et al. 2001) with the upper and lower bounds of the proposed model with experimental data in case of $100 \%$ cement mixes at three $\mathrm{w} / \mathrm{cm}$ ratios.

Fig. 5.17 Comparison of the ACI (and the modified ACI by Huo et al. 2001) with the upper and lower bounds of the proposed model with experimental data in case of mixes containing replacement of cement by $35 \%$ slag at two $\mathrm{w} / \mathrm{cm}$ ratios.

Fig. 5.18 Comparison of the ACI (and the modified ACI by Huo et al. 2001) with the upper and lower bounds of the proposed model with experimental data in case of mixes containing replacement of cement by $25 \%$ fly ash at two $\mathrm{w} / \mathrm{cm}$ ratios. 
Fig. 5.19 Comparison of the ACI (and the modified ACI by Huo et al. 2001) with the upper and lower bounds of the proposed model with experimental data in case of mixes containing replacement of cement by $10 \%$ silica fume at two $\mathrm{w} / \mathrm{cm}$ ratios.

Fig. 5.20 Comparison of the ACI (and the modified ACI by Huo et al. 2001) with the upper and lower bounds of the proposed model with experimental data in case of mixes containing replacement of cement by $35 \%$ slag and $10 \%$ silica fume at two $\mathrm{w} / \mathrm{cm}$ ratios.

Fig. 5.21 Comparison of the ACI (and the modified ACI by Huo et al. 2001) with the upper and lower bounds of the proposed model with experimental data in case of mixes containing replacement of cement by $25 \%$ fly ash and $10 \%$ silica fume at two $\mathrm{w} / \mathrm{cm}$ ratios.

Fig. 5.22 Comparison of the B3 model with the upper and lower bounds of the proposed model with experimental data in case of $100 \%$ cement mixes at three $\mathrm{w} / \mathrm{cm}$ ratios.

Fig. 5.23 Comparison of the B3 model with the upper and lower bounds of the proposed model with experimental data in case of mixes containing replacement of cement by $35 \%$ slag at two $\mathrm{w} / \mathrm{cm}$ ratios.

Fig. 5.24 Comparison of the B3 model with the upper and lower bounds of the proposed model with experimental data in case of mixes containing replacement of cement by $25 \%$ fly ash at two $\mathrm{w} / \mathrm{cm}$ ratios.

Fig. 5.25 Comparison of the B3 model with the upper and lower bounds of the proposed model with experimental data in case of mixes containing replacement of cement by $10 \%$ silica fume at two $\mathrm{w} / \mathrm{cm}$ ratios.

Fig. 5.26 Comparison of the B3 model with the upper and lower bounds of the proposed model with experimental data in case of mixes containing replacement of cement by $35 \%$ slag and $10 \%$ silica fume at two $\mathrm{w} / \mathrm{cm}$ ratios. 
Fig. 5.27 Comparison of the B3 model with the upper and lower bounds of the proposed model with experimental data in case of mixes containing replacement of cement by $25 \%$ fly ash and $10 \%$ silica fume at two $\mathrm{w} / \mathrm{cm}$ ratios.

Fig. 5.28 Comparison of the CEB MC 90-99 model with the upper and lower bounds of the proposed model with experimental data in case of $100 \%$ cement mixes at three $\mathrm{w} / \mathrm{cm}$ ratios.

Fig. 5.29 Comparison of the CEB MC 90-99 model with the upper and lower bounds of the proposed model with experimental data in case of mixes containing replacement of cement by $35 \%$ slag at two $\mathrm{w} / \mathrm{cm}$ ratios.

Fig. 5.30 Comparison of the CEB MC 90-99 model with the upper and lower bounds of the proposed model with experimental data in case of mixes containing replacement of cement by $25 \%$ fly ash at two $\mathrm{w} / \mathrm{cm}$ ratios.

Fig. 5.31 Comparison of the CEB MC 90-99 model with the upper and lower bounds of the proposed model with experimental data in case of mixes containing replacement of cement by $10 \%$ silica fume at two $\mathrm{w} / \mathrm{cm}$ ratios.

Fig. 5.32 Comparison of the CEB MC 90-99 model with the upper and lower bounds of the proposed model with experimental data in case of mixes containing replacement of cement by $35 \%$ slag and $10 \%$ silica fume at two $\mathrm{w} / \mathrm{cm}$ ratios.

Fig. 5.33 Comparison of the CEB MC 90-99 model with the upper and lower bounds of the proposed model with experimental data in case of mixes containing replacement of cement by $25 \%$ fly ash and $10 \%$ silica fume at two $\mathrm{w} / \mathrm{cm}$ ratios.

Fig. 5.34 Comparison of the GL 2000 model with the upper and lower bounds of the proposed model with experimental data in case of $100 \%$ cement mixes at three $\mathrm{w} / \mathrm{cm}$ ratios. 
Fig. 5.35 Comparison of the GL 2000 model with the upper and lower bounds of the proposed model with experimental data in case of mixes containing replacement of cement by $35 \%$ slag at two $\mathrm{w} / \mathrm{cm}$ ratios.

Fig. 5.36 Comparison of the GL 2000 model with the upper and lower bounds of the proposed model with experimental data in case of mixes containing replacement of cement by $25 \%$ fly ash at two $\mathrm{w} / \mathrm{cm}$ ratios.

Fig. 5.37 Comparison of the GL 2000 model with the upper and lower bounds of the proposed model with experimental data in case of mixes containing replacement of cement by $10 \%$ silica fume at two $\mathrm{w} / \mathrm{cm}$ ratios.

Fig. 5.38 Comparison of the GL 2000 model with the upper and lower bounds of the proposed model with experimental data in case of mixes containing replacement of cement by $35 \%$ slag and $10 \%$ silica fume at two $\mathrm{w} / \mathrm{cm}$ ratios.

Fig. 5.39 Comparison of the GL 2000 model with the upper and lower bounds of the proposed model with experimental data in case of mixes containing replacement of cement by $35 \%$ slag at two $\mathrm{w} / \mathrm{cm}$ ratios.

Fig. 5.40 Comparison of the concrete shrinkage strains at three different $\mathrm{w} / \mathrm{cm}$ ratios in case of $100 \%$ cement mix at different ages.

Fig. 5.41 Comparison of the concrete shrinkage strains with mixes containing a total of $35 \%$ replacement of cement by SCM for at two different $\mathrm{w} / \mathrm{cm}$ ratios.

Fig. 5.42 Comparison of the concrete shrinkage strains with mixes containing a total of $45 \%$ replacement of cement by SCM for at two different $\mathrm{w} / \mathrm{cm}$ ratios. 


\section{CHAPTER ONE}

\section{INTRODUCTION}

This introductory chapter presents background information on cementitious systems containing Supplementary Cementitious Materials (SCM) and their effects on the shrinkage of concrete. Also, the significance, objectives, and organization of the present research work are discussed.

\subsection{Background of Cementitious Systems Containing SCM}

Cementitious systems containing supplementary materials such as fly ash, slag, silica fume are increasingly used as a major construction material for new construction and repair and rehabilitations of civil infrastructure. In spite of its growing applications, the durability of these high-performance materials and its modeling remains a critical issue as the constituents, properties, and microstructures are widely different from normal concrete. The SCM are commonly used for producing high performance cementitious materials to reduce $\mathrm{CO}_{2}$, construct durable structures, and divert industrial by-products from landfills. Among the durability parameters, the shrinkage and creep at early age play significant role in determining its long term performance. A cursory review of shrinkage and durability modeling of concrete (Bazant and Panula (1978), Pickett (1956), Hobbes(1971) shows that most of the researches have been conducted to model and predict the durability of shrinkage and creep of normal concrete. There is limited information available regarding the prediction of early-age creep and shrinkage models for high-performance cementitious materials; and that available information do not consider the behavior at different scales or levels at which certain parameters are dominant or exists.

\subsection{Motivation for the Present Study}

A better understanding of the cement hydration and the formation of C-S-H with different $\mathrm{Ca} / \mathrm{Si}$ ratios for pastes with or without SCM is extremely important to model cementitious systems from micro to macro level in order to establish the structure-property relations. The calcium silicate hydrate (C-S-H) is regarded as the principal and most complex component in the cementitious systems. 
According to ACI-209.R1-05, factors affecting shrinkage and creep of hardened concrete are presented to enable those involved in the evaluation and formulation of concrete mixtures to determine the effects of these factors.

\subsection{Areas of Recommended Research According to ACI}

The ACI 209R-92 committee believes that the following factors affecting shrinkage and creep require additional study:

- Effects of aggregate;

- Characteristics and composition of cement;

- Effect of chemical and mineral admixtures;

- Effect of curing period;

- Effect of drying before loading to determine creep;

- Behavior of high-performance concrete; and

- Effect of outdoor exposures.

So, it is evident that the inclusions of SCM are an aspect that has not been studied in detail by the researchers so far. So, the present study aims to identify the influence of the SCM on the shrinkage of concrete, starting from their effects on the microstructure. But the SCMs complicate the process of the hydration of cement by producing a secondary $\mathrm{C}-\mathrm{S}-\mathrm{H}$ which has a different $\mathrm{Ca} / \mathrm{Si}$ ratio than the primary $\mathrm{C}-\mathrm{S}-\mathrm{H}$. It is very difficult to distinguish the primary and the secondary $\mathrm{C}-\mathrm{S}-\mathrm{H}$ by ordinary chemical methods and it requires the use of microanalyses (Gallucci et al. 2010).

Based on the above considerations, the proposed research shall follow a multiscale approach to develop shrinkage model of high-performance cementitious materials. The proposed scales in this study are:

- Microscale $\rightarrow$ The nanometer level and micrometer levels are combined at this scale. At this stage, the role of cementitious pastes is most important. The variations and amounts of $\mathrm{C}-\mathrm{S}-\mathrm{H}$ and pore structures formed due to changes in constituents of cementitious materials with SCM and $\mathrm{w} / \mathrm{cm}$ ratios will be considered to predict the mechanisms.

- Mesoscale $\rightarrow$ This stage shall deal the material at millimeter level to consider the composite behavior of the cement paste and the aggregates including interfacial 
transition zone. The restraining effects of aggregates, its size, shape and stiffness will be considered.

- Macroscale $\rightarrow$ This stage shall consider the coupon or member level of the advanced cementitious materials. The external parameters like size and shape of the specimens, relative humidity of the surroundings will be incorporated at this stage.

Eguchi and Teranishi (2005) proposed a model to study the drying shrinkage strain and Young's Modulus of ordinary concrete and also of mortar. They assumed a two-phase material at each step and based their model on the equations given by Kishitani and Baba(1975). They also did not consider creep and creep recovery, and factors like relative humidity and age of concrete. Their study was undertaken at mesoscale or millimeter level.

There is evidence of multiscale modeling being used to study the interactive diffusion process in concrete (Xi et al. 2000) and also simulation of damage in concrete structures (Eckardt and Konke 2006). These concepts shall be used to propose an adaptive multiscale model in the case of high-performing cementitious materials. However, no systematic studies were made to predict shrinkage from paste level to large scale coupon level incorporating different types and quantities of SCM such as fly ash, slag, and silica fume.

Therefore, the present study aims to develop prediction model of shrinkage of concrete containing fly ash, slag, silica fume as single, binary, and ternary combinations beginning from paste level to coupon level for practical use.

\subsection{Goals and Objectives}

- To review the existing shrinkage models for ordinary concrete and for cementitious materials with SCM.

- To identify all the required parameters which affect shrinkage of cementitious materials with SCM.

- To combine microanalysis results and optimization and obtain a representative $\mathrm{Ca} / \mathrm{Si}$ atomic ratio for pure cement.

- Extend this concept to cementitious system containing slag, fly ash, and silica fume as SCM. 
- To estimate the quantities of primary and secondary $\mathrm{C}-\mathrm{S}-\mathrm{H}$ based on optimized $\mathrm{Ca} / \mathrm{Si}$ atomic ratios.

- Ultimately, to extend the same formulation for other types of SCM.

- To predict the shrinkage of the cementitious paste (at mesoscale) from this microscale data

- To develop a multiscale model consisting of the two-step three phase composite as described earlier.

- To validate the model using experimental data and compare the results with available prediction models.

\subsection{Possible Outcomes}

- Representative $\mathrm{Ca} / \mathrm{Si}$ ratio for the primary $\mathrm{C}-\mathrm{S}-\mathrm{H}$ in case of pure portland cement and additionally for the secondary $\mathrm{C}-\mathrm{S}-\mathrm{H}$ in case of the cementitious systems containing SCM.

- Two-step composite model which emphasizes on the structure of the material at the micro-level as well as its physical composition.

- Incorporation of the influence of SCMs and different $\mathrm{w} / \mathrm{cm}$ ratios at different ages on the shrinkage of concrete.

- To prepare a shrinkage prediction model that can manifest the mutual effects of the three stages or levels on each other.

- Extension of the model to cementitious materials of other types and from different sources, if possible.

\subsection{Assumptions in the study and Their Basis}

The following assumptions were made at the various scales for the purpose of this study.

(a) Overall:

- For the model, the fine and coarse aggregate was assumed spherical.

- System is homogeneous below the scale it was analyzed.

- Chemical (also known as autogenous) and drying shrinkage not separated. 
(b) Microscale:

- At paste scale, C-S-H, unhydrated cement, $\mathrm{CH}$, sulfoaluminates, and other hydrated structures assumed homogeneous.

- C-S-H acted as shrinking component and rest of the products as restraining or non-shrinking component.

(c) Mesoscale:

- At mortar scale, paste and sand were individually assumed homogeneous.

- Three distinct phases as follows:

- Paste as shrinking, sand as restraining and the ITZ represented the pasteaggregate interaction.

- Interface was of uniform thickness.

- Each phase individually homogeneous and uniformly distributed within the medium.

- No sand to sand interaction was considered.

(d) Macroscale:

- At coupon scale, mortar and aggregates were individually assumed homogeneous.

- Three distinct phases as follows:

- Mortar as shrinking, coarse aggregates as non-shrinking and ITZ between the mortar and aggregates.

- ITZ was of uniform thickness.

- Each phase individually homogeneous and uniformly distributed within the medium.

- $\quad$ No coarse aggregate to coarse aggregate interaction was considered.

The assumptions were based on the findings of the previous works of Neubauer et al. (1996). Moreover, complications that would occur if irregular shape of aggregates and nonuniform thickness of the ITZ were assumed.

A schematic diagram showing the length scale assumptions at each of the three scales has been shown in Fig 1.1. 


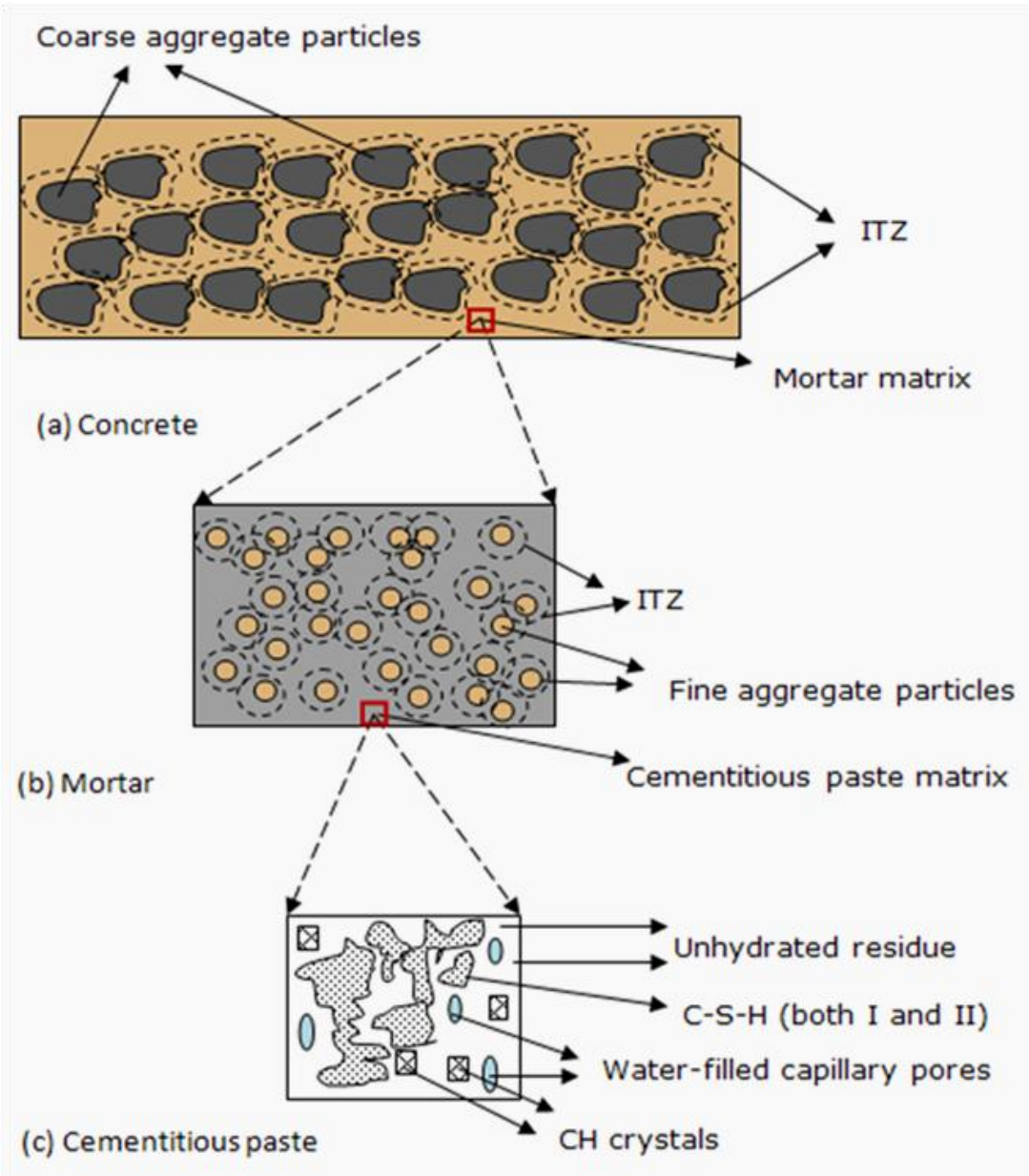

Length scale: meter

(Millimeter phases assumed homogeneous)

Length scale: millimeter (Micrometer phases assumed homogeneous)

Length scale: micrometer (Nanometer phases assumed homogeneous)

Fig 1.1 Schematic diagram showing the length scale assumptions at each scale. 


\subsection{Flow Chart of the Study}

The different steps followed in this study along with the corresponding parameters to be used as inputs at each scale have been shown in the flow chart below.

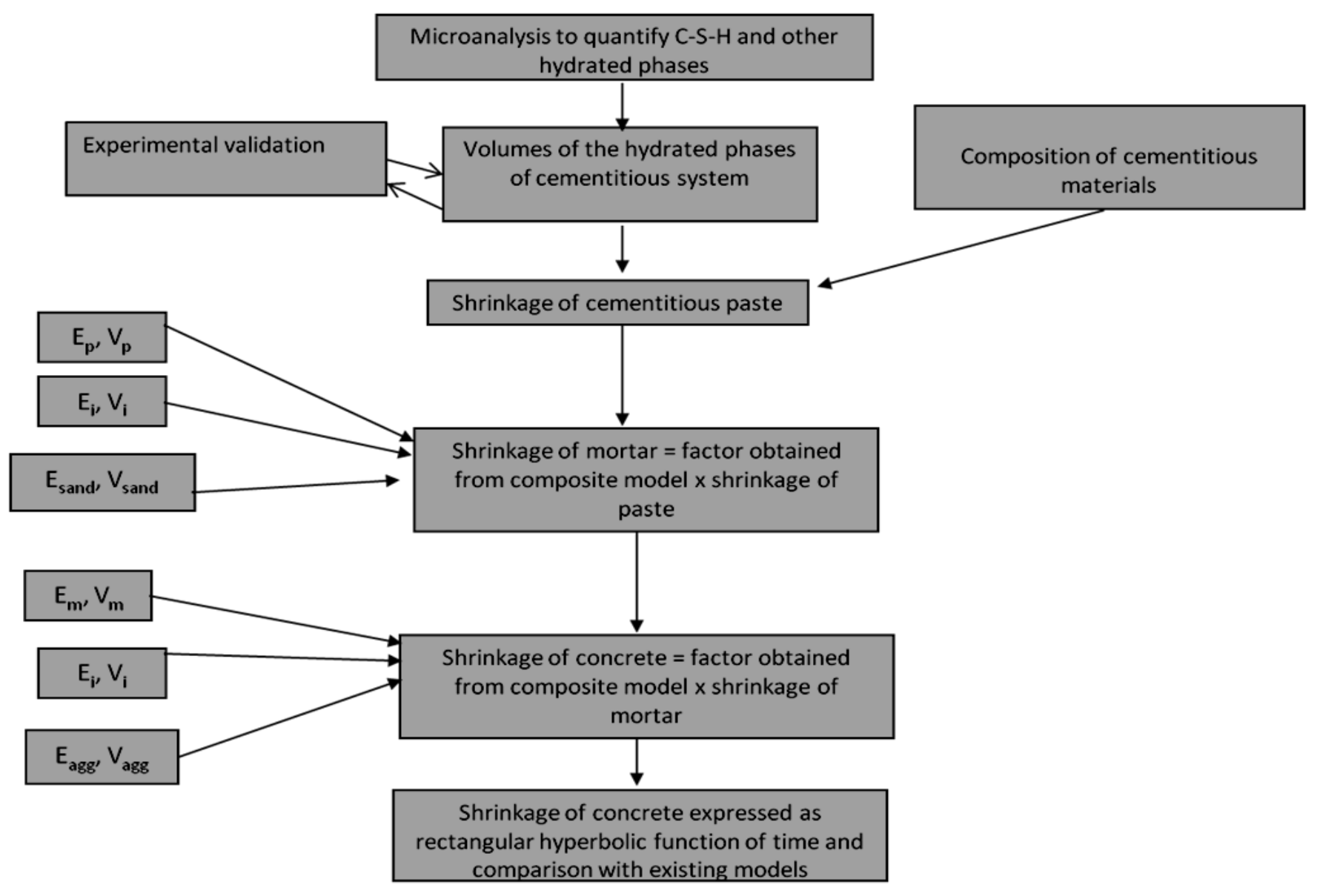

\subsection{Thesis Organization}

This thesis is organized into eight chapters as follows: Chapter 1 gives a brief introduction to the cementitious systems containing SCM, discusses the motivation for this study, objectives of the research, the possible outcomes or scope of the work and also outlines the organization of the thesis. In chapter 2, a detailed literature review is carried out regarding the cementitious systems containing SCM, hydration kinetics of the systems containing SCMs, structure-property relations of the hydrated cement pastes like porosity and pore- 
size distribution, chemical shrinkage and modulus of elasticity, multiscale modeling of hydrated cementitious paste, mortar and concrete for shrinkage and strength. It also includes a summary of the review and the limitations of the current research, concluding with the significance and importance of the proposed research. Chapter 3 discusses about the materials, the mix proportions, the criteria for their selection, based on the micro, meso and macroscale requirements and the sampling procedures for the relevant experiments. Chapter 4 elaborates on the development of the model considering the micro, meso and macroscales separately and connecting them through composite modeling. Special emphasis is given to the oxide analysis, the oxide composition of the blended cements, their heats and rates of hydration, porosity and pore structure of the hydrated cementitious pastes, the shrinkage strain and the modulus of elasticity of the pastes at microscale. This chapter also focuses on the various experiments performed to generate data for the models at different scales and to validate them subsequently. The tests include Scanning Electron Microscopy (SEM), isothermal calorimetry and test for chemical shrinkage at micro scale. In Chapter 5, these parameters are extended to meso and macroscales by use of the two-step composite model. The equations governing each parameter are described in details in this chapter. This is followed by the results and discussions from the data with subsequent experimental validation. It also deals with the amalgamation of the models at micro and mesoscale and using them to predict the macroscale parameters. Chapter 6 provides a general summary of the entire study and the conclusions of the key findings. Also, it specifies the recommendations for future work based on the conclusions. 


\section{CHAPTER TWO}

\section{BACKGROUND AND LITERATURE REVIEW}

In this chapter, the history and development of the different models of predicting the shrinkage of concrete are reviewed. Those include history of development of multiscale modeling, compound composition, microstructural studies, modeling of $\mathrm{C}-\mathrm{S}-\mathrm{H}$, hydration characteristics, pore structures, statistical optimizations and the currently available models to predict the shrinkage of concrete.

\subsection{Approach to Multiscale Modeling}

Concrete is, and has been, one of the major construction materials that are currently in vogue. In designing a concrete structure, the most important aspects that must be kept in mind are the load-bearing capacity of the structure and its durability. The durability can be defined in various ways. Most commonly, it is defined as the ability of the structure to resist deformation over its service life. Thus, the shrinkage of concrete has become a matter of utmost concern for researchers all over the world. The microstructural characteristics of concrete control the durability of the structure (Chindraprasirt et al., 2005). So, it is extremely important to have knowledge of the microscale properties of concrete - the most important among them are the rate of hydration and the volume of the hydrated products. The volume of the gel pores and the capillary pores and their degree of saturation also influence the shrinkage strains of the concrete (Gaboczi 2000; Maekawa, 2009). Complications increase with the addition of SCM like slag, fly ash and silica fume, which are industrial by-products admixed with cement to impart high strength to concrete and to increase the performance of concrete structures (Sarkar and Ghosh 1993). The addition of the supplementary materials has two-fold effect on the environment. Firstly, there is substantial reduction in the amount of carbon dioxide released to the atmosphere by each unit weight of concrete. The manufacture of concrete using ordinary portland cement contributes about $6 \sim 7 \%$ of the total carbon dioxide content of the atmosphere. The addition of the supplementary materials reduces this amount significantly. Secondly, the use of the SCM in the manufacture of concrete reduces the amount of the disposable industrial byproducts. They are usually disposed of by their use as materials for landfill. By using a part of the by-products in the manufacture of concrete, the service life of the landfills can be enhanced. Thus, the use of the SCM plays a major role in making the construction 
sustainable in nature, from both the above points of view. Thus, it is of utmost importance to have in-depth knowledge regarding the effect of the SCMs on the behavior of concrete especially, its durability and resistance to deformation.

The inclusion of the SCM influences the microstructure of the cementitious paste to which it is added; and that effect is manifested at the laboratory scale and the macroscale through the change in the shrinkage strain and in compressive strength of the concrete. Most of the available literatures have reported studies regarding the bulk properties of the cement paste and the concrete properties as a whole (Chindraprasirt et al. 2005; Maekawa et al. 2009; Gallucci et al. 2009; Wong et al. 2010).

There are some researchers who have studied the microstructural properties of the cementitious pastes through SEM, EDS, AFM (Feng et al. 2004; Gallucci et al. 2009), etc. But most of the studies are qualitative in nature. Moreover, the few quantitative studies that are available do not consider the effect of the SCM on the cementitious systems.

When SCMs are added, the hydration process produces two different kinds of calcium silicate hydrates, C-S-H(I) and C-S-H(II). Also, the interfacial transition zone (ITZ) between the cementitious paste and the aggregates, gets modified with the addition of the SCMs. This makes the multiscale model extremely important in order to understand and enhance the behavior of concrete.

Maekawa and his fellow researchers proposed a multiscale that amalgamates both material science and structural engineering. They proposed an object-oriented computational scheme for life-span simulation of reinforced concrete. The model includes evaluation of microscale properties and linking them to the macroscale properties, using the concept of composites. A major component of their model was the porosity of the system. The rate of hydration and the volume of the hydrated products have a great influence on the porosity.

Various theories are in vogue and various hydration models are available for pure portland cement (Maekawa 2009; Garboczi 2000; Taylor 1997). But the inclusion of SCM makes the matter complex and very little information is available to model the hydration for cementitious systems containing SCM. The concepts provided by the researchers at NIST based on the volume stoichiometry of the hydration reactions was adopted as the basis for our research study. The equations provided by NIST were modified according to our needs, 
taking into account the different source from which the materials were collected for our research. The most common method to determine the degree of hydration is by the determination of the non-evaporable water content (Mindess 1999, Garboczi 2000, ASTM C 1084). The works of Parrot and Killoh (1984) explained the influence of the $\mathrm{w} / \mathrm{cm}$ ratio on the rate of hydration of cement. The relevant changes were made in our model to maintain conformity with the above concepts.

\subsection{Composition of Cement - Oxide Analysis}

The compound composition of the Portland cement is possible to detect, by direct analysis, but the methods are complex and they involve special skills and expensive equipments. Thus, it is usually estimated by calculations based on the ideal stoichiometries of the compounds and oxide analyses determined by standard methods (usually x-ray fluorescence and spectroscopy). Such analyses are usually provided by the cement suppliers.

\subsubsection{Equation for the Oxide Composition of the Cement}

The calculation of the phases from the composition is called the "Bogue Calculation", after R.H. Bogue who proposed this method of calculation. ASTM C 150 suggests the use of a simple Bogue calculation, although more sophisticated procedures have been devised later on for this purpose. The relevant equations are as follows:

$$
\begin{aligned}
& \text { Case A: } A / F \geq 0.64 \\
& C_{3} S=4.071 \mathrm{C}-7.600 \mathrm{~S}-6.718 \mathrm{~A}-1.430 \mathrm{~F}-2.852 \overline{\mathrm{S}} \\
& \mathrm{C} 2 \mathrm{~S}=2.867 \mathrm{~S}-0.7544 \mathrm{C} 3 \mathrm{~S} \\
& \mathrm{C} 3 \mathrm{~A}=2.650 \mathrm{~A}-1.692 \mathrm{~F} \\
& \mathrm{C} 4 \mathrm{AF}=3.043 \mathrm{~F} \\
& \text { Case B: } \\
& \mathrm{C}_{3} \mathrm{~S}=4.071 \mathrm{C}-7.600 \mathrm{~S}-4.479 \mathrm{~A}-2.859 \mathrm{~F}-2.852 \overline{\mathrm{S}} \\
& \mathrm{C} 2 \mathrm{~S}=2.867 \mathrm{~S}-0.7544 \mathrm{C} 3 \mathrm{~S} \\
& \mathrm{C} 3 \mathrm{~A}=0 \\
& \mathrm{C} 4 \mathrm{AF}=2.100 \mathrm{~A}+1.702 \mathrm{~F}
\end{aligned}
$$


From the results obtained by Aldrige (1982), based on six clinkers tested in different laboratories, it was concluded that light microscopy gave much more accurate results, compared to Bogue's calculation.

The errors in Bogue's calculation originate from the fact that in reality, the phases do not have the compositions assumed for them.

Harrisson et al. (1985) and Taylor (1997) used the best available estimates of the four phases instead of those of the pure compounds and modified the phase calculation, based on the approach by Yamaguchi and Takagi (1969).

The modified Bogue calculation has been validated using Kristmann's data (1977).

\subsection{Microstructure of Concrete - An Overview}

Concrete is made up of the hydrated cement paste, fine aggregate, coarse aggregate, the interfacial transition zone between the cement paste and the aggregates, and water and air voids. The hydrated cement paste is composed of the different products of hydration namely calcium silicate hydrate, calcium hydroxide, hydrogarnet, calcium sulfoaluminates, i.e. monosulfate and ettringite, along with traces of ferric hydroxide in some cases depending upon the composition of the cement used. The rates of the hydration reactions depend upon the ratio of the water to cementitious materials. The replacement of cement by SCM gives rise to two different kinds of calcium silicate hydrates having different chemical compositions. The relative scales of the different phases are shown in Fig. 2.1(a) and (b).

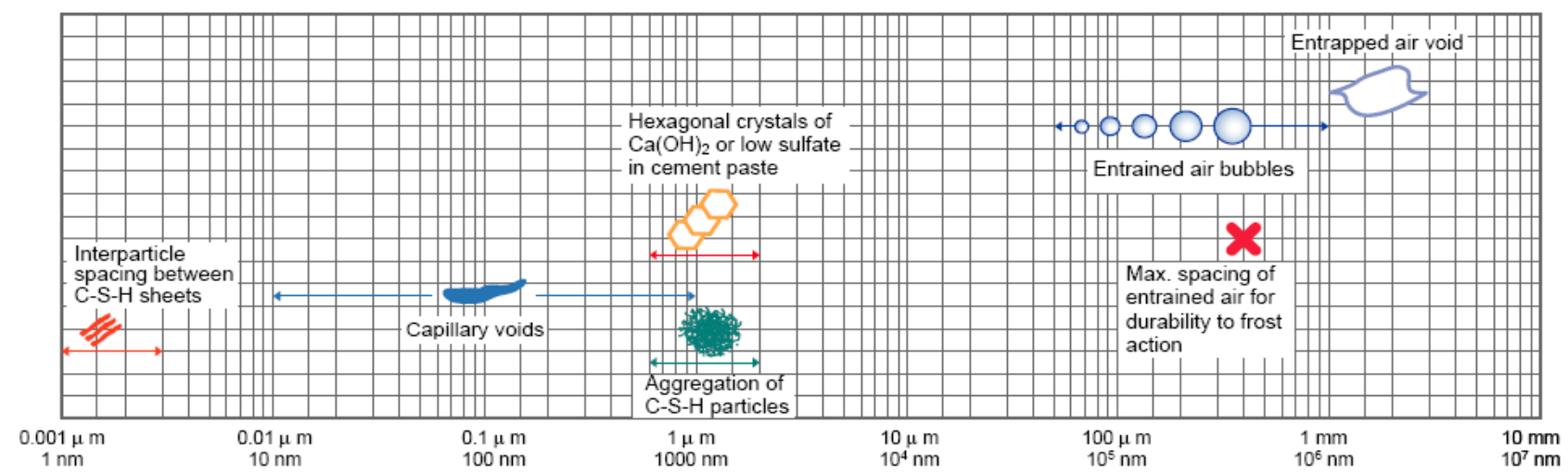

(a) 


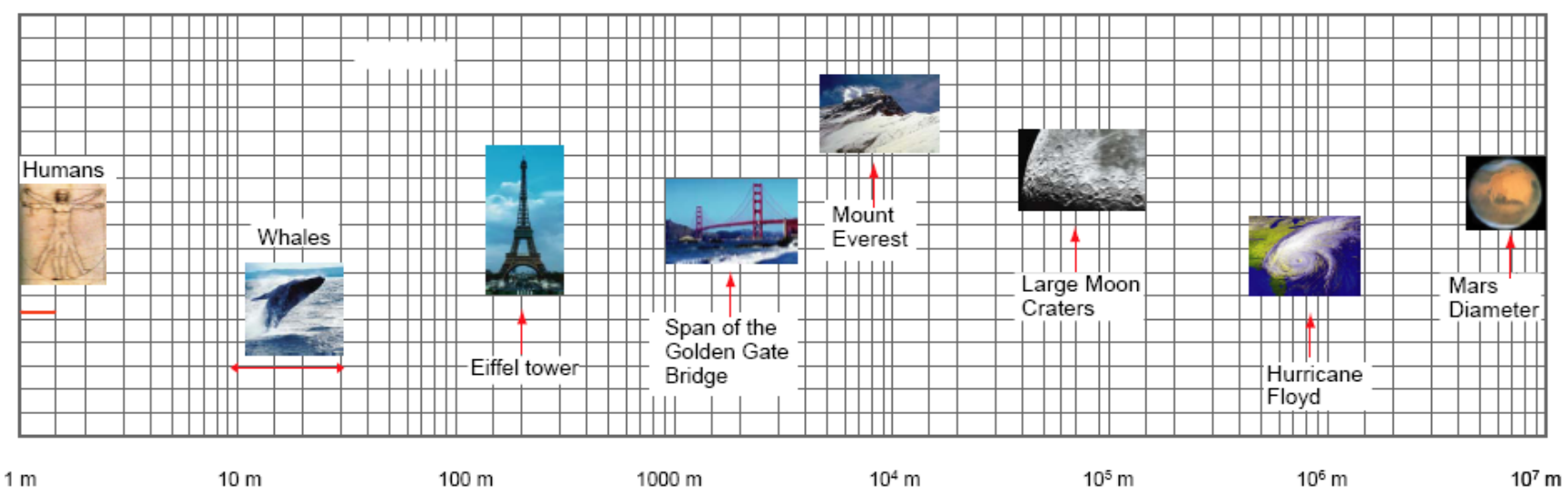

(b)

Fig. 2.1 (a) Dimensional range of solids and pores in hydrated cement paste; (b) Orders of magnitude (Mehta and Monteiro, 2005).

\subsection{Chemistry of Hydration}

The setting and hardening of concrete are borne out of the chemical and physical processes that occur when cement comes in contact with water. Thus, adequate emphasis must be imparted on the chemistry of cement hydration. In cement chemistry, the term 'hydration' encompasses all the changes that occur when an anhydrous cement or one of its constituents, react with water. The subsequent chemical reactions are usually more complex than the simple conversion of the anhydrous compounds into their respective hydrates.

Setting refers to the stiffening of the cement paste (a mixture of cement and water in proportions by mass, designated as the water/cement ratio) without significant development of strength and generally occurs within the first few hours of mixing. Hardening is significant development of strength and is a much slower process.

\subsubsection{Hydration of Pure Cement Compounds}

Portland cement is composed of pulverized cement clinker and gypsum. Cement clinker is made up of four major minerals, namely alite (mainly $C_{3} S$ ), belite (mainly $C_{2} S$ ), aluminate phase (mainly $\mathrm{C}_{3} \mathrm{~A}$ ) and ferrite phase (mainly $\mathrm{C}_{4} \mathrm{AF}$ ) along with some impurities. Alite and belite which are calcium silicates, comprise nearly $85 \%$ of the cement clinker, while the aluminate and the ferrite, together known as the interstitial phase, take up the spaces around the silicates when the clinker is burnt. The chemical reactions that take place when pure cement reacts with water are assumed to take place independently, without influencing one another. This assumption is not entirely valid but it provides a reasonable approximation. 


\subsubsection{Calcium Silicates}

$2 \mathrm{C}_{3} \mathrm{~S}+11 \mathrm{H} \rightarrow \mathrm{C}_{3} \mathrm{~S}_{2} \mathrm{H}_{8}+3 \mathrm{CH}$

$2 \mathrm{C}_{2} \mathrm{~S}+9 \mathrm{H} \rightarrow \mathrm{C}_{3} \mathrm{~S}_{2} \mathrm{H}_{8}+\mathrm{CH}$

The primary hydration product is a calcium silicate hydrate. The formula given (Mindess 2002 ) is only approximate because its composition has quite a wide range of variation. The water content mentioned here refers to saturated condition. C-S-H is a poorly crystalline material consisting of extremely small particles in the size range of colloidal matter $(<1 \mu \mathrm{m})$ in any dimension. On the contrary, calcium hydroxide has well-defined crystals with fixed composition. For both $\mathrm{C}_{3} \mathrm{~S}$ and $\mathrm{C}_{2} \mathrm{~S}$, the rates of reaction are governed by the particle size distribution and other factors, such as their relative proportion in the cement.

In reality, the $\mathrm{Ca} / \mathrm{Si}$ ratio in the $\mathrm{C}-\mathrm{S}-\mathrm{H}$ is not a constant entity and it varies from one cement to another (Taylor 1997, Ramachandran and Beaudoin 2001). But the ratio does not show any systematic variation with age. It is typically in the range of 1.57 to 2.1 (Taylor 1997). Based on this theory, the researchers at NIST modified the hydration reactions for their cement. The representative $\mathrm{Ca} / \mathrm{Si}$ ratio in their case was 1.7 . The modified hydration reactions (Bentz 1995) are as follows:

$\mathrm{C}_{3} \mathrm{~S}+5.3 \mathrm{H} \rightarrow \mathrm{C}_{1.7} \mathrm{SH}_{4}+1.3 \mathrm{CH}$

$\begin{array}{llll}1 & 1.34 & 1.521 & 0.61\end{array}$

$\mathrm{C}_{2} \mathrm{~S}+4.3 \mathrm{H} \rightarrow \mathrm{C}_{1.7} \mathrm{SH}_{4}+0.3 \mathrm{CH}$

$\begin{array}{llll}1 & 1.49 & 2.077 & 0.191\end{array}$

The numbers provided below each compound indicate their respective volume stoichiometries in the hydration reactions.

\subsubsection{Hydration of Cements Containing Slag, Fly Ash, And Silica Fume as SCM}

The silica present in the SCM (fly ash or silica fume) reacts with the calcium hydroxide produced from the hydration of the pure portland cement to form a secondary calcium silicate hydrate, C-S-H (II), at a different reaction rate (Taylor 1997). The Ca/Si ratio in C$\mathrm{S}-\mathrm{H}$ (II) is different from that in the primary $\mathrm{C}-\mathrm{S}-\mathrm{H}$. The ratio depends on the supplementary material present in the system, as each SCM has its own degree of reaction with the calcium 
hydroxide (Sarkar and Ghosh 1993). In fact, fly ash and silica fume combine with the Calcium hydroxide through pozzolanic reactions forming

C-S-H(II), whereas slag behaves as a weak cement and it forms C-S-H(II) in a similar manner as the cement itself. From the works of several researchers, it has been found that the value $\mathrm{Ca} / \mathrm{Si}$ ratio in $\mathrm{C}-\mathrm{S}-\mathrm{H}$ (II) is in the region of $1.4-1.55$ in case of slag (Taylor 1997); 1.1-1.6 for class F fly ash (Ravina 1981; Uchikawa 1986) and 1.1-1.2 in case of silica fume (Tratteberg 1978; Huang Cheng-yi 1985; Feldman and Sereda 1970). The researchers at NIST assumed a value of 1.1 for the $\mathrm{Ca} / \mathrm{Si}$ ratio in $\mathrm{C}-\mathrm{S}-\mathrm{H}$ (II) for their experiments on cementitious systems containing fly ash and silica fume as SCM (Bentz 1995). Then, the balanced chemical equation for the hydration of the cement with SCM is given by:

$1.1 \mathrm{CH}+\mathrm{SiO}_{2}+2.8 \mathrm{H}=\mathrm{C}_{1.1} \mathrm{SH}_{3.9}$ 


\subsection{Modeling of C-S-H}

Several theories are in vogue for the modeling of C-S-H. Three kinds of microstructural models are used in general for cement pastes, as follows: (i) the Munich model based on adsorption tests conducted by researchers like Feldman-Sereda (1968), and Powers (1948), (ii) phase analysis by X-ray diffraction such as the work done by Taylor (1986); and (iii) the Jennings-Johnson (1986) model developed from examination of hydration process with subsequent simulation by computerized techniques.

A model commonly known as the Powers Model was suggested by Powers and Brownyard (1948) and it was corroborated by the water adsorption test (Fig. 2.2). According to this model, C-S-H consists of two or three thin layers bonded together by surface forces. The surface water is known as adsorbed water and that between the layers is interlayer water. The maximum average interlayer distance is $3 \mathrm{~nm}$ and the minimum is $0.4 \mathrm{~nm}$. It was assumed that the interlayer water once removed, would not come back into the layers, thereby giving rise to an irreversible shrinkage. According to this model, $\mathrm{N}_{2}$ adsorption method gives a lower estimation of C-S-H surface area, as compared to water adsorption, as $\mathrm{N}_{2}$ cannot enter all the pore spaces during.

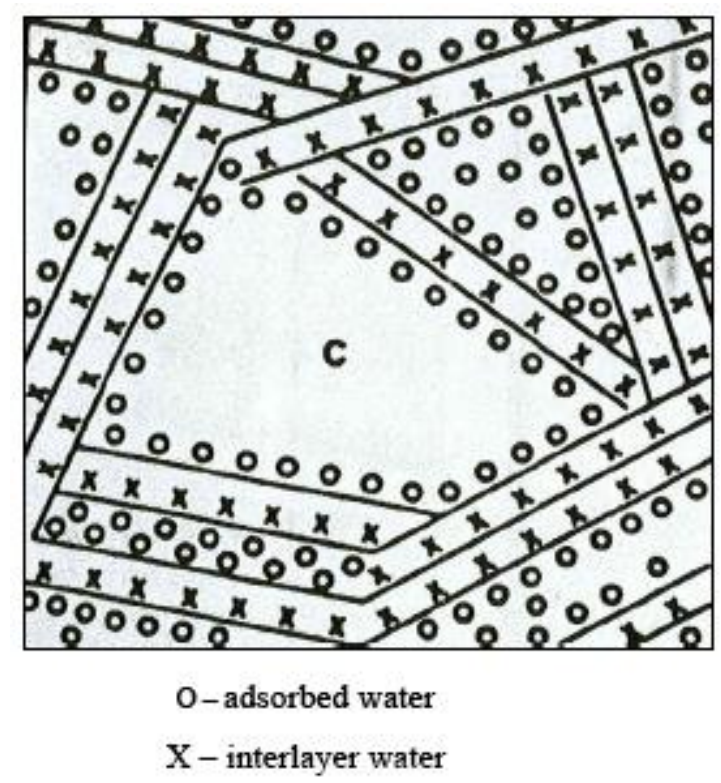

Fig 2.2 Powers Model for C-S-H (Courtesy: Powers 1948) 
Feldman and Sereda (1968) proposed the concept that C-S-H is made up of a completely irregular array of single layers (Fig. 2.3) and the interlayer bonding occurs through solidsolid interactions. Also, they did not consider the interlayer space to be a part of the surface. In addition, according to this model, water can be transported irreversibly in and out of the interlayer spaces. Nitrogen adsorption method gives fairly accurate estimate of the specific surface area, as nitrogen cannot enter the interlayer spaces.

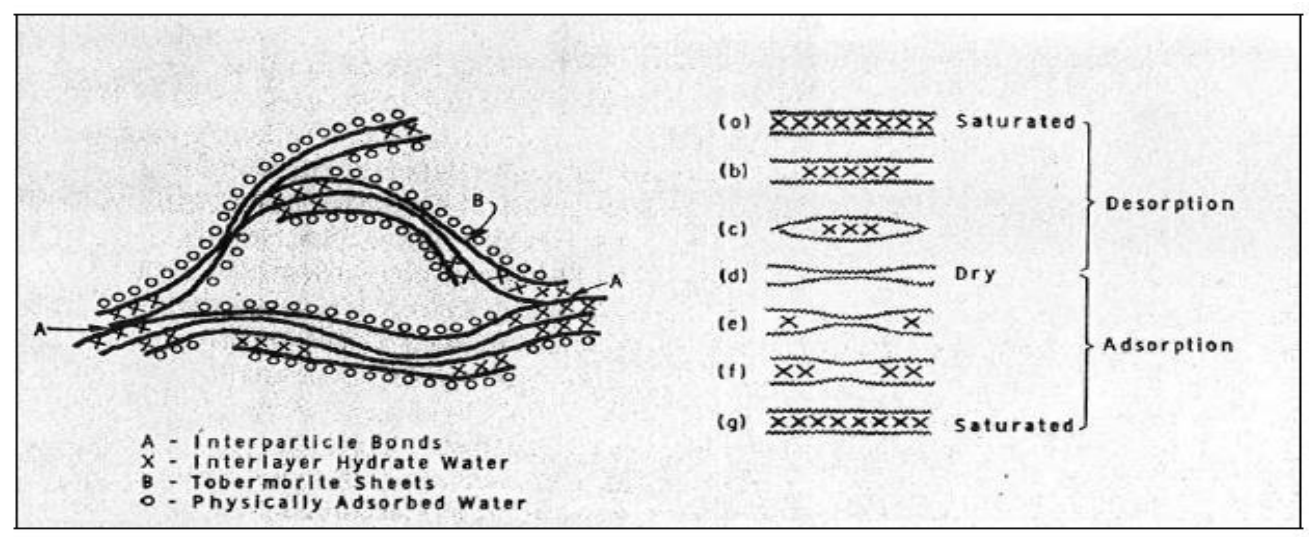

Fig 2.3 Feldman-Sereda Model (Courtesy: Feldman and Sereda 1968)

According to the Munich model (Fig. 2.4) suggested by Whittman (1968), a three dimensional xerogel composed of a network of separate colloidal particles forms the $\mathrm{C}-\mathrm{S}-\mathrm{H}$. The chemical bonds and van der Waals forces of attraction help in the bonding of gel particles. Inter-particle moisture transport has an impact on disjoining pressure at high humidity levels and surface free energy at low humidity levels.

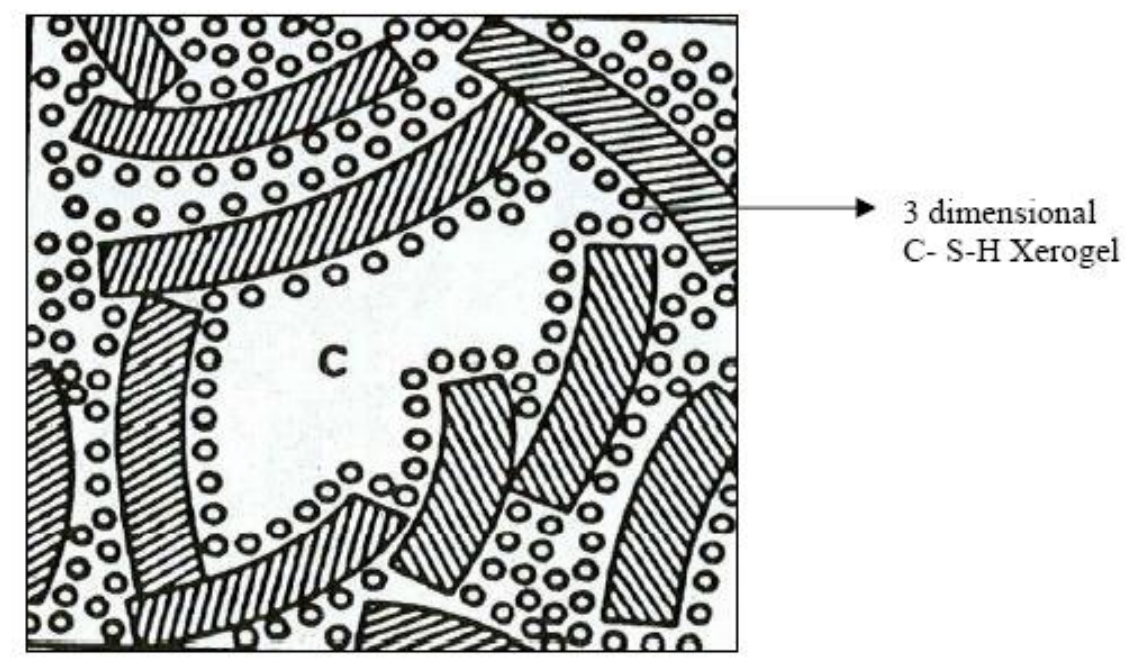

Fig 2.4 Munich Model (Courtesy: Mindess and Young, 1981) 
The Tokyo model (Fig. 2.5) which is a combination of the Powers and the Feldman-Sereda model was introduced by Daimon et al. (1977). The gel particles are assumed to be composed of layers and there are two kinds of pores - the smaller intragel and the wider intergel (observed in the inner C-S-H). The intragel pores are of two types:

(i) intercrystallite pores, resembling the micropores in Powers' model, and (ii) the intracrystallite pores, analogous to the interlayer spaces in the Feldman-Sereda model. The capillary pores constitute the pores between gel particles.
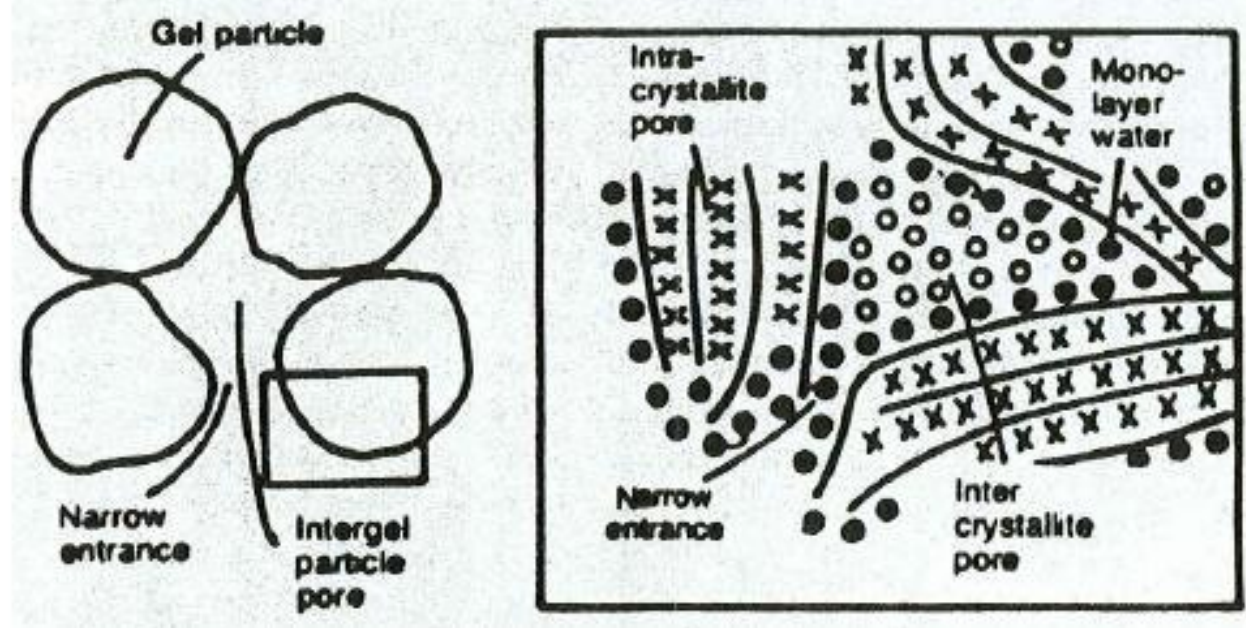

Fig 2.5 Tokyo Model (Courtesy: Daimon et al. 1977)

In Taylor's model (1986), the C-S-H was thought to be made up of a layered structure containing mostly structurally imperfect jennite layers $\left(\mathrm{C}_{9} \mathrm{~S}_{6} \mathrm{H}_{11}\right)$ and a smaller portion similar to a $1.4 \mathrm{~nm}$ tobermonite instead of $1.1 \mathrm{~nm}$ tobermonite. The first one is generally called C-S-H (II) and the second one is called C-S-H (I). A main layer, made up of a sandwich where the central layer having an empirical structure of $\mathrm{CaO}_{2}$ is surrounded on top and bottom by parallel rows of infinite chains of empirical formula $\mathrm{Si}_{3} \mathrm{O}_{9} \mathrm{H}$ and an interlayer, containing $\mathrm{H}_{2} \mathrm{O}$ molecules along with additional Ca ions having a combined thickness of $1.4 \mathrm{~nm}$ comprise each tobermorite layer. Heating to $110^{\circ} \mathrm{C}$ or D-drying releases four molecules of $\mathrm{H}_{2} \mathrm{O}$ giving rise to the $1.1 \mathrm{~nm}$ tobermorite. The main layer and an interlayer structure of tobermonite are visible in Jennite as well. The combined thickness of the main layer and the interlayer in Jennite is $1.05 \mathrm{~nm}$. D-drying releases four molecules water reducing the layer thickness to $0.87 \mathrm{~nm}$. 
A mathematical model which simulates the microstructural formations during the hydration of $\mathrm{C}_{3} \mathrm{~S}$ was put forward by Jennings and Johnson (1986). The simulation model made up of a large computer program with numerous subroutines can predict microstructure as well as bulk properties resulting from a wide variety of hydration conditions. A data file containing numerical information about the size of the volume in which hydration occurs and about all the materials contained within the volume, serves as the core of the model.

The J-T model by Tennis and Jennings (2000) came up with the concept of two types of C-S-H: (i) a lower density (LD C-S-H) and (ii) a higher density (HD C-S-H) (Fig. 2.6). These could account for the larger surface areas of smaller volume of gel pores accessible to $\mathrm{N}_{2}$ (as measured by $\mathrm{N}_{2}$ absorption method) and vice versa. The relative volume fractions of these two types of $\mathrm{C}-\mathrm{S}-\mathrm{H}$, which vary with the $\mathrm{w} / \mathrm{cm}$ ratios and degree of hydration, can also be estimated by this model.

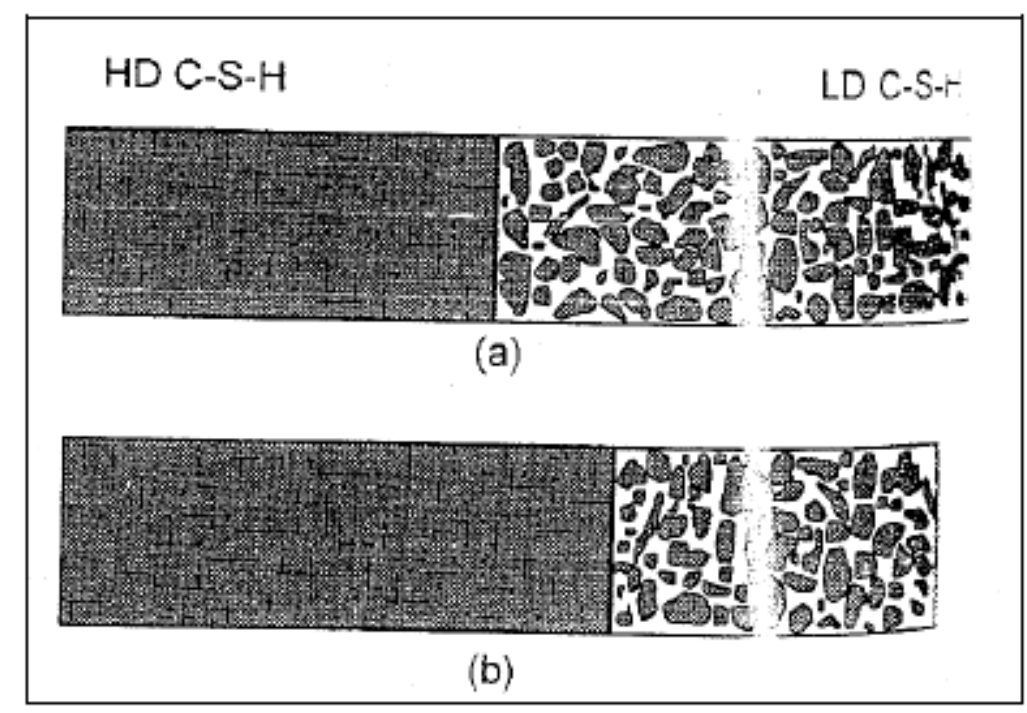

Fig 2.6 J-T Model (Courtesy: Tennis and Jennings 1992)

As mentioned in the J-T model (1992), Jennings (2000) proposed a structure for the LD $\mathrm{C}-\mathrm{S}-\mathrm{H}$ and the HD C-S-H (Fig. 2.7). According to this structure, particles having dimensions in the order of $1.1-1.2 \mathrm{~nm}$, cluster together to form globules of around $2.8-3.2 \mathrm{~nm}$ size, which subsequently agglomerate to form the two types of C-S-H. The LD C-S-H has a radius of $9 \mathrm{~nm}$. But the radius of the HD C-S-H cannot be determined with desired accuracy. The model, being quantitative at each scale, can estimate the size, density and packing efficiency of each of the mentioned structures. 


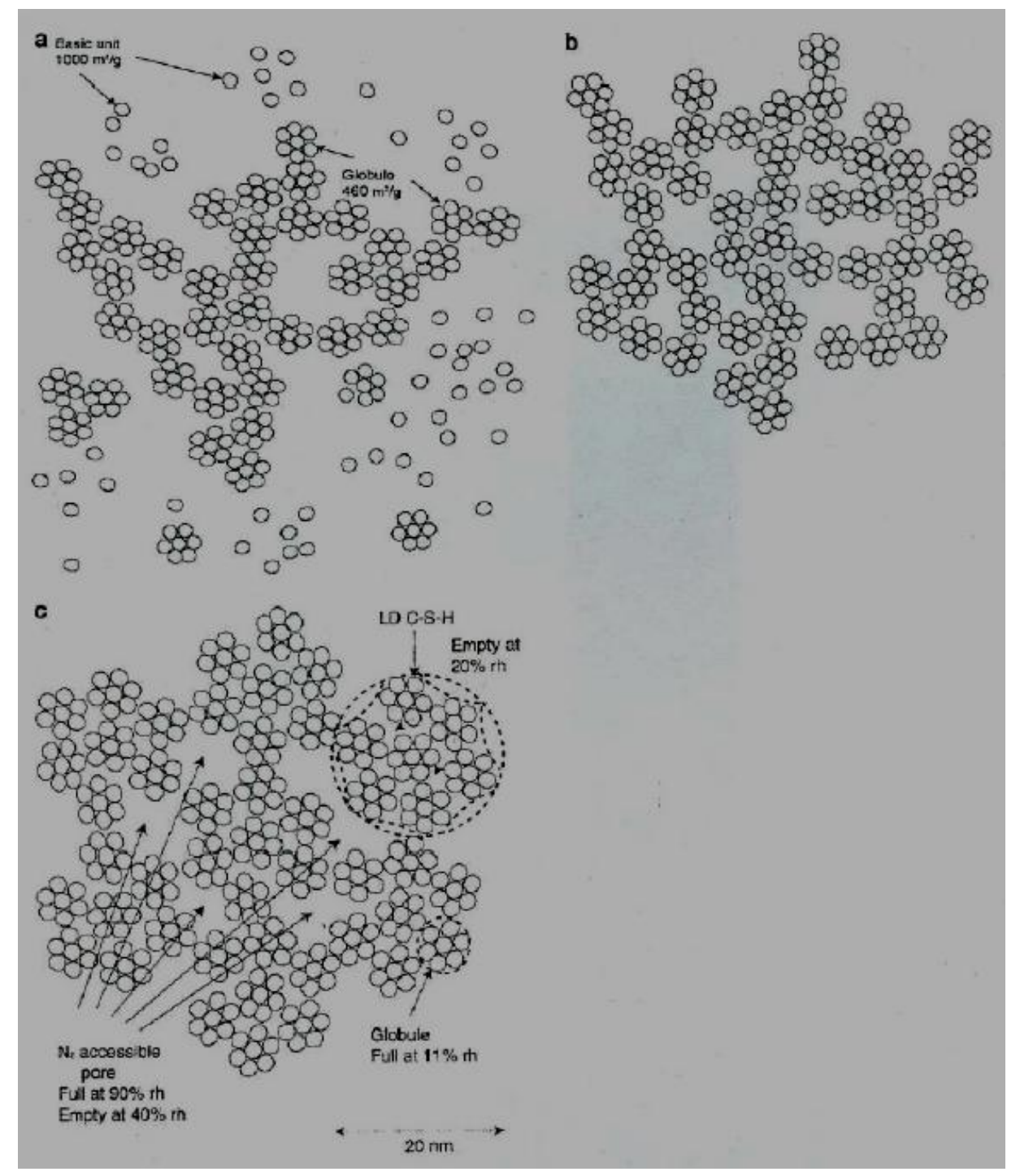

Fig 2.7 Jennings Model (Courtesy: Jennings 2000)

\subsection{Calcium Hydroxide $(\mathrm{CH})$}

Calcium hydroxide plays a significant role in cement hydration. Calcium hydroxide crystals comprise about $20-25 \%$ of the paste volume in cement pastes (Mindess 2002). Calcium hydroxide grows depending upon the availability of free space. $\mathrm{CH}$ crystals nucleate and grow within capillary pore space during stage 3 (Fig. 2.9) of $\mathrm{C}_{3} \mathrm{~S}$ hydration. A particular $\mathrm{CH}$ crystal may stop growing or may grow in another direction if its growth is obstructed by another $\mathrm{CH}$ crystal; it may also grow around unhydrated cement residue, if that is available. 
Diamond (2004) conducted microanalyses (SEM studies) and from the grayscale image analysis, he showed that $\mathrm{CH}$ can be separated from C-S-H by a slightly brighter gray level. $\mathrm{CH}$ appears as irregular masses of various sizes within cement in spite of possessing a good crystalline structure. This is probably a result of occlusion of hydrating cement grains. Admixtures and temperatures of hydration do influence the morphology of $\mathrm{CH}$. The $\mathrm{CH}$ produced by cement hydration, reacts with the reactive silica in SCMs to form additional secondary C-S-H or C-S-H(II) and this reaction is generally called pozzolanic reaction.

\subsection{Calcium Sulfoaluminates and Aluminoferrites}

Aluminate and ferrite reactions:

$\mathrm{C}_{3} \mathrm{~A}+6 \mathrm{H} \rightarrow \mathrm{C}_{3} \mathrm{AH}_{6}$ (hydrogarnet formation)

$1 \quad 1.21 \quad 1.69$

$\mathrm{C}_{3} \mathrm{~A}+3 \mathrm{C} \overline{\mathrm{S}} \mathrm{H}_{2}+26 \mathrm{H} \rightarrow \mathrm{C}_{6} \mathrm{~A} \overline{\mathrm{S}}_{3} \mathrm{H}_{32}$ (AFt phase)

$\begin{array}{llll}.4 & 1 & 2.1 & 3.3\end{array}$

$$
\begin{aligned}
& 2 \mathrm{C}_{3} \mathrm{~A}+\mathrm{C}_{6} \mathrm{AS}_{3} \mathrm{H}_{32}+4 \mathrm{H} \rightarrow 3 \mathrm{C}_{4} \mathrm{~A} \overline{\mathrm{S}} \mathrm{H}_{12} \text { (AFm phase) } \\
& \begin{array}{llll}
.2424 & 1 & .098 & 1.278
\end{array} \\
& \mathrm{C}_{4} \mathrm{AF}+3 \mathrm{CSH}_{2}+30 \mathrm{H} \rightarrow \mathrm{C}_{6} \mathrm{AS}_{3} \mathrm{H}_{32}+\mathrm{CH}+\mathrm{FH}_{3} \\
& \begin{array}{llllll}
.575 & 1 & 2.426 & 3.3 & .15 & .31
\end{array} \\
& 2 \mathrm{C}_{4} \mathrm{AF}+\mathrm{C}_{6} \mathrm{~A}_{3} \mathrm{H}_{32}+12 \mathrm{H} \rightarrow 3 \mathrm{C}_{4} \mathrm{~A} \overline{\mathrm{S}} \mathrm{H}_{12}+2 \mathrm{CH}+2 \mathrm{FH}_{3} \\
& \begin{array}{llllll}
.348 & 1 & .294 & 1.278 & .09 & .19
\end{array} \\
& \mathrm{C}_{4} \mathrm{AF}+10 \mathrm{~F} \rightarrow \mathrm{C}_{3} \mathrm{AH}_{6}+\mathrm{CH}+\mathrm{FH}_{3} \\
& \begin{array}{lllll}
1 & 1.41 & 1.17 & .26 & .545
\end{array}
\end{aligned}
$$

Regarding the present study, the Calcium sulfoaluminates are somewhat less important component of cement pastes. They usually occupy a 5-10\% volume (Mindess 2002). $\mathrm{C}_{3} \mathrm{~A}$ 
reacts with gypsum to form ettringite which is a stable compound only when adequate amount of sulfate ions are present. Ettringite reacts with remaining $\mathrm{C}_{3} \mathrm{~A}$ to form more stable monosulfates if the sulfate ion concentration goes down. Ettringite consists of needle like structure which grows into the capillary spaces. Monosulfates, on the other hand, have a platy morphology (Mindess 2002, Taylor 1997).

\subsection{Porosity and Pore Structures of the Hydrated Pastes}

One of the major components of the microstructure of the cementitious pastes is the porosity. Pores are roughly divided into three categories:

(1) Capillary pores, which are large or medium capillaries, having diameters in the range of $10 \mathrm{~nm}$ to $10,000 \mathrm{~nm}$.

(2) Gel pores, which are small isolated capillaries, having diameters in the range of $0.5 \mathrm{~nm}$ to $10 \mathrm{~nm}$.

(3) Interlayer pores, which have diameters less than $0.5 \mathrm{~nm}$.

Studies by SEM observations show that, as hydration progresses, the capillary porosity decreases. However, it is difficult to measure and interpret the pore sizes and their distributions. Firstly, the paste must be dried in order to make measurements, but the drying deforms the pore structure to a certain extent, which cannot be measured. Secondly, a definite geometrical shape must be assumed for a pore during quantitative studies, but microscopic studies show otherwise. But, an approximate estimation of the pore size distribution can be made using mercury intrusion porosimetry (Taylor1997 and Bentz 2000) and nitrogen adsorption method (Bentz 2000).

However, the total pore volume at any instant of time can be estimated quite accurately (Chindraprasirt et al., 2005) and it has a marked influence on the shrinkage of the paste (Maekawa 2009).

\subsubsection{Changes in pore size during shrinkage (or expansion) of cement paste and concrete}

The relation between the bulk shrinkage of concrete and the size of its pores is an issue which has yet to find a unanimous solution. This model shows that the pores in a composite system comprising of both shrinking and nonshrinking solid phases can themselves shrink 
or expand with the shrinkage of the matrix. This is governed by the nature of restraint in the system. The analysis is also applicable to expansive deformations which may accompany some chemical attacks of cement paste. The gaps between the aggregate and paste in the concrete are explained by mathematical relationships between the degree of restraint in a composite and that between bulk volume changes and pore volume changes (Thomas and Jennings, 2003).

Microscopic studies of concrete reveal gaps between the paste and the aggregate particles, indicating that set of cement causes the change in volume of the paste. There is no clear evidence as to whether the paste undergoes contraction or expansion. There are many factors which influence this phenomenon such as moisture and temperature changes, sulfate exposure, freezing and other exposure conditions.

Considering a two-phase system containing solid and pores, uniform expansion of the solid phase will result in enlargement of the pores if the system is unrestrained. On the other hand, if the same system is completely restrained, so that its external dimension remains unchanged, then the expansion of the solids would lead to decrease in pore volume. Concrete is composed of solid phases that shrink or expand (such as C-S-H), inert solid phases like aggregates and $\mathrm{CH}$ and pores, along with ettringite and gypsum which can cause swelling. The presence of the inert aggregates provides a certain degree of restraint in the system, thus preventing any of the extreme cases mentioned above.

The mathematical formulation of the relationships is based on the following approaches:

\subsubsection{Homogeneous volume change of a porous solid}

For a solid sphere of radius $R$, the homogeneous volume change may be represented as $V_{f}=k V_{i}$

Where the subscripts $f$ and $i$ denote the volume $V$ in the final and initial states respectively; $\mathrm{k}$ represents the ratio of the final and initial volume of the solid. So, the final radius is

$$
R_{f}=\sqrt[3]{k} R_{i}
$$

The deformation is homogeneous. So there is no stress developed anywhere inside the sphere and the deformation at any particular location is independent of that at other locations. For a porous solid of radius $R$, represented by a single pore of radius $r$ at the center, 
$V_{i}=4 \pi / 3 *\left(R_{i}^{3}-r_{i}^{3}\right)$

and

$V_{f}=4 \pi / 3 *\left(R_{f}^{3}-r_{f}^{3}\right)=k V_{i}$

So, $R_{f}^{3}-r_{f}^{3}=k\left(R_{i}^{3}-r_{i}^{3}\right)$

or, $r_{f}=\sqrt[3]{k}$,

Thus homogeneous expansion of a solid phase in a porous solid results in larger pores whereas shrinkage leads to smaller pores.

\subsubsection{Homogeneous volume change in the presence of an inert phase}

A three-phase system consisting of a deforming matrix phase, nondeforming inclusions and pores are considered for this purpose. The inclusions do not affect the deformantions of the matrix. The initial volume of the composite system is

$\mathrm{V}_{\mathrm{i}}=\mathrm{V}_{\text {def }}+\mathrm{V}_{\text {nondef }}+\mathrm{V}_{\mathrm{p}}$

And the final volume after deformation is

$\mathrm{V}_{\mathrm{f}}=\mathrm{k}_{\mathrm{def}} \mathrm{V}_{\text {def }}+\mathrm{V}_{\text {nondef }}+\mathrm{K}_{\mathrm{p}} \mathrm{V}_{\mathrm{p}}$

Where $k_{\text {def }}$ and $k_{p}$ are the ratios of the final to the initial volumes of the deforming matrix phase and the pores respectively.

The ratio of the initial to the final volume of the whole system is given by

$\mathrm{k}_{\mathrm{tot}}=\mathrm{k}_{\mathrm{def}} \mathrm{X}_{\mathrm{def}}+\mathrm{X}_{\text {nondef }}+\mathrm{k}_{\mathrm{p}} \mathrm{X}_{\mathrm{p}}$

where $X$ denotes the initial volume fraction of a particular phase.

As there is no restraint in the system, the pores deform identically to the external dimensions of the composite. 
Thus,

$\mathrm{K}_{\mathrm{p}}=\mathrm{k}_{\mathrm{tot}}$

$k_{\text {tot }}=\frac{k_{\text {def }} X_{\text {def }}+X_{\text {nondef }}}{\left(X_{\text {def }}+X_{\text {nondef }}\right)}$

(2.23)

If $\mathrm{k}_{\text {def }}>1$, then $1<\mathrm{k}_{\text {tot }}<\mathrm{k}_{\text {def }}$

If $\mathrm{k}_{\mathrm{def}}<1$, then $\mathrm{k}_{\mathrm{def}}<\mathrm{k}_{\text {tot }}<1$

Thus, due to presence of the inert phase, the volume change of the composite will have the same sign as that of the deforming phase, but lesser in magnitude.

\subsubsection{Fully restrained deformation}

Keeping the above three phase composite system fully restrained, the initial and final volumes will remain unchanged, even after deformation.

So, $k_{\text {def }} X_{\text {def }}+X_{\text {nondef }}+k_{p} X_{p}=V_{\text {def }}+V_{\text {nondef }}+V_{p}$

$\mathrm{Or}_{p}=1+\frac{V_{d e f}\left(1-k_{d e f}\right)}{V_{p}}$

It is evident that if $k_{\text {def }}>1$, then $k_{p}<1$ and viceversa. In other words, under restrained condition, the growth of the solid phase causes the pores to shrink. 


\subsubsection{Partially restrained deformation}

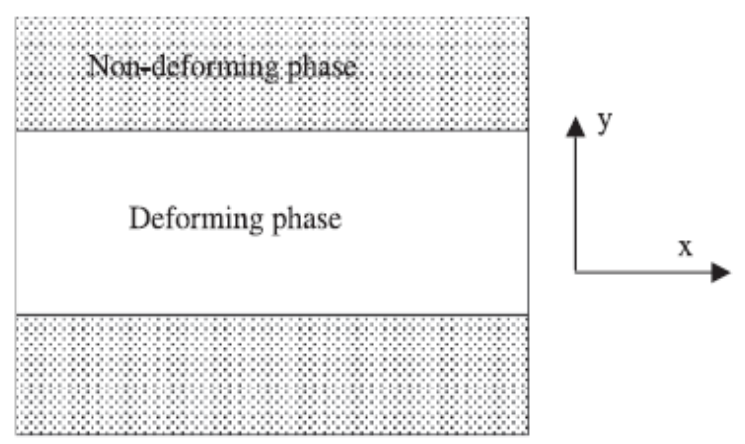

Fig. 2.8 A deforming phase sandwiched between two nondeforming phases (Thomas and Jennings, 2003)

The conditions of perfect homogeneity and completely restrained deformation represent two extreme cases. These rarely occur in reality. Fig. 2.8 shows a deforming phase sandwiched between two nondeforming phases. This composite is completely restrained in the $x-$ direction and unrestrained in the $y$-direction. The effect of deformation of a solid phase on pore size varies from the restrained condition to the unrestrained. So, there must be a partially restrained case, for which the deformation of the solid phase does not affect the pore size.

The equation for the deformation of the partially restrained three-phase composite is obtained by modifying the equation (put number) above.

$\mathrm{k}_{\mathrm{tot}}=\mathrm{k}_{\mathrm{def}} \mathrm{X}_{\mathrm{def}}+\mathrm{X}_{\text {nondef }}+\mathrm{X}_{\mathrm{p}}$

[since, $\mathrm{kp}=1$ at the "critical" degree of restrained such that pore size remains unchanged.]

Or,

$$
\mathrm{k}_{\mathrm{tot}}=1+\mathrm{X}_{\mathrm{def}}\left(\mathrm{k}_{\mathrm{def}}-1\right)
$$

This represents the relation between the deformation of the composite and the deformation of the deforming phase so that the pore size does not change. 
This relation can be expressed in general as:

If,

$\mathrm{k}_{\text {tot }}>1+\mathrm{X}_{\text {def }}\left(\mathrm{k}_{\text {def }}-1\right)$, then pores grow

$\mathrm{k}_{\mathrm{tot}}<1+\mathrm{X}_{\mathrm{def}}\left(\mathrm{k}_{\mathrm{def}}-1\right)$, then pores shrink

The relationship between $\mathrm{k}_{\text {tot }}$ and $\mathrm{k}_{\mathrm{def}}$ can be written as:

$k_{\text {tot }}=1+(1-R)\left\{\left[\frac{k_{\text {def }} X_{\text {def }}+X_{\text {nondef }}}{1-X_{p}}\right]-1\right\}$

Where $\mathrm{R}=$ degree of restraint $=0$ (no restraint)

$$
=1 \text { (fully restrained) }
$$

The critical value of the degree of restrain, $\mathrm{Rc}$, can be obtained from the above equations as $R_{c}=X_{p}$, that is the initial volume fraction of the composite occupied by the pores.

Thus, greater the size of pores, greater is the degree of restrain required to prevent the pore size from changing.

\subsubsection{Application to cement paste and concrete}

The deforming phase in cement paste comprises of solid $\mathrm{C}-\mathrm{S}-\mathrm{H}$, intermixed nanocrystalline $\mathrm{CH}$ and the gel pores. The remaining solid phases are nondeforming and the residual volume is made up of meso and capillary pores. The volume change of the $\mathrm{C}-\mathrm{S}-\mathrm{H}$ on drying is greater than $6 \%$. The capillary pores are expected to expand on drying. This is the possible cause of microcracks on drying.

\subsection{Heat and Rate of Hydration}


Heat is released as the hydration reaction proceeds. The heat of hydration represents the residual energy present in the cementitious system, following the breaking and making of chemical bonds during the hydration process. It is usually measured by enthalpy $(\Delta \mathrm{H})$, a thermodynamic quantity, that can be calculated experimentally or theoretically (Mindess 1999). A typical calorimetric curve for the various components of cement is furnished in the figure below.

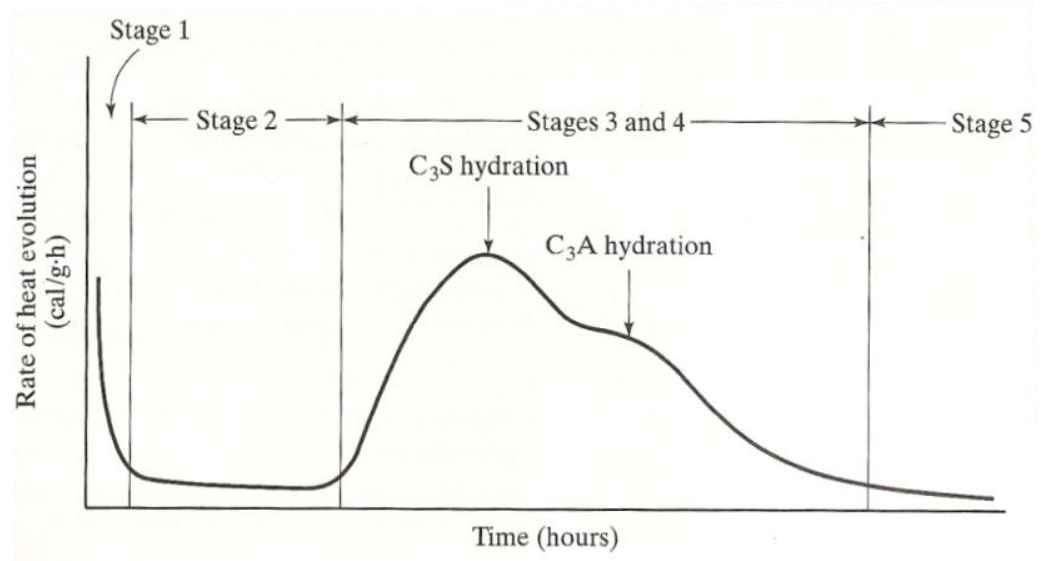

Fig 2.9 Rate of heat evolution during hydration of tricalcium silicate (Mindess 2002).

The kinetics of cement hydration are governed by how the degree of hydration, a, varies with time, $t$ and the factors affecting them. The plots of the variation of a with time are known as the kinetic curves and they determine the development of the physical properties with progress of time. It is difficult to measure the degree of hydration of cement as a whole, owing to different degrees of hydration of each individual clinker material. For simplicity, $\alpha$ is defined as the mass fraction of cement that has reacted at any instant of time as the degree of hydration (Taylor 1997).

The degree of hydration may be determined individually for each phase experimentally using QXDA (Taylor 1997, Ramachandran and Beaudoin, 2001) or by an estimation of the non-evaporable water content present at any instant (Garboczi 2000, Mindess 2002).

The rates of hydration are usually affected by the relative humidity of the atmosphere. For our study, we maintained a constant relative humidity of $50 \pm .2 \%$ to get rid of that influence. But another important factor that must be taken into account in case of the rate of hydration is the water-cementitious material $(\mathrm{w} / \mathrm{cm})$ ratio. The works of Parrott and Killoh provide extensive information regarding the influence of $\mathrm{w} / \mathrm{cm}$ ratio on the rate of hydration of cementitious pastes. According to them, the rate of hydration, da/dt, was reduced by a 
factor $\mathrm{f}(\mathrm{w} / \mathrm{c})$ in case of cementitious systems having low $\mathrm{w} / \mathrm{cm}$ ratios below 0.35 . But that factor applied only at values of $\alpha$ greater than $1.333 \times$ w/c (Parrott and Killoh, 1984). The factor $\mathrm{f}(\mathrm{w} / \mathrm{c})$ was given as:

$f(w / c)=\{1+4.444(w / c)-3.333 \alpha\}^{4}$

This hydration was studied in the lab using an isothermal calorimeter.

\subsubsection{Isothermal Calorimetry}

The fact put forward by Parrott and Killoh (1984) is corroborated by the results obtained from the calorimetry results conducted for our research purpose. Some researchers like Maekawa used a conduction calorimeter which was an approximate method. So, later on, with the development of sophisticated equipments, researchers started using the isothermal calorimeter (Jayapalan, NIST) which gives much more accurate results because of the constant temperature at which the test is carried out. The calorimeter provides the variation in the rate of hydration with time in terms of the power and also it can give an idea about the total energy of the reaction at any instant of time.

\subsubsection{Thermogravimetric Analyses}

Thermogravimetric techniques have been in vogue for quite a while in measurement of the degree of hydration of cement pastes (Almeida, Sicheri, 2006) and for determining the calcium hydroxide content in the hydrating paste (Mounanga et al. 2004). The cement paste is heated at a predetermined rate in a crucible from room temperature upto about $950 \sim$ $1000^{\circ} \mathrm{C}$ and the mass of the specimen remaining at any instant and the corresponding temperature are noted down. The difference in mass with change in temperature from $105^{\circ} \mathrm{C}$ to $950^{\circ} \mathrm{C}$ gives an idea about the degree of hydration using the concept of nonevaporable water content of the hydrating paste. The calcium hydroxide content can be determined similarly as will be explained later.

\subsection{Statistical Optimization}

Engineers are often confronted with problems that need to be solved in order to arrive at an optimal design, allocating scarce resources or planning industrial operations. In engineering 
design, a large factor of safety is usually assumed to develop an acceptable design. But that incurs a lot of additional cost. In the modern day and age of continued competition between contemporaries, merely an adequate design will not suffice. The design must make use of limited resources and also keep the expenditure to an acceptable level. This calls for accurate designs and more sophisticated computing techniques. Moreover, most of the reallife problems faced by engineers, involve systems that are structurally complex in nature. So, before the system can be viewed as a whole, it is necessary to have in-depth knowledge regarding its various components. The developments in the techniques of measurement, together with that in statistical methods to test hypotheses facilitate the solution of the above problem to a large extent.

One of those advanced statistical techniques is the concept of nonlinear optimization (Bazaraa et al. 2006). A basic nonlinear optimization problem looks like:

Minimization of a given function, $f(x)$

Subject to the condition: $g_{i}(x) \leq 0$, for $\mathrm{i}=1,2, \ldots \ldots, \mathrm{m}$

$$
\begin{aligned}
& h(x)=0 \text { for } i=1,2, \ldots \ldots, l \\
& x \in X
\end{aligned}
$$

where $f, g_{1}, \ldots, g_{m}, h_{1}, \ldots, h_{m}$ are functions defined on $R^{n}, X$ is a subset of $R^{n}$, and $x$ is a vector of $n$ components $x_{1}, \ldots, x_{n}$. The above problem must be solved for the variables $x_{1}$, $\ldots, x_{n}$ that satisfy the restrictions while minimizing the function $\mathrm{f}$.

The function $f$ is usually called the objective function, or the criterion function. Each of the constraints $g_{i}(x) \leq$ Ofor $\mathrm{i}=1, \ldots, \mathrm{m}$ is called an inequality constraint and each of the constraints $\mathrm{h}_{\mathrm{i}}(\mathrm{x})=0$ for $\mathrm{i}=1$, $\ldots, \mathrm{I}$ is called an equality constraint. The set $\mathrm{X}$ might typically include lower and upper bounds on the variables, which even if implied by the other constraints can play a useful role in some algorithms. Alternatively, this set might represent some specially structured constraints that are highlighted to be exploited by the optimization routine. It might also represent certain regional containment or other complicating constraints that are to be handled separately via a special mechanism.

A vector $\mathbf{x} \in X$ satisfying all the constraints is called a feasible solution to the problem. The collections of all such solutions form the feasible region. The nonlinear programming problem then, is to find a feasible point $\bar{X}$ such that $f(x) \geq f(\bar{X})$ for each feasible point $x$. Such a point $\mathrm{X}$ is called an optimal solution, or simply a solution, to the problem. If more 
than one optimum solution exists, they are referred to collectively as alternate optimal solutions.

\subsection{Shrinkage}

Shrinkage can be defined as time dependent volumetric deformation of concrete due to loss of moisture from the surface or within the concrete, or due to the carbonation of concrete containing SCM. The following types of shrinkage are generally considered:

1. Plastic Shrinkage

2. Autogenous Shrinkage

3. Drying Shrinkage

4. Carbonation Shrinkage

Plastic Shrinkage: Shrinkage of concrete due to loss of water to the surroundings through evaporation while the concrete is in the plastic stage.

Autogenous Shrinkage: Shrinkage caused by loss of water from the capillary spaces of hardened concrete due to cement hydration. This is also known as chemical shrinkage.

Drying Shrinkage: Shrinkage of concrete caused by loss of water from the hardened concrete is called drying shrinkage.

Carbonation Shrinkage: Shrinkage caused by the dissolving of $\mathrm{CH}$ while under a compressive stress and depositing of $\mathrm{CaCO}_{3}$ in spaces free from stress.

The current study is based on shrinkage of hardened concrete due to moisture loss internally or externally as concrete containing SCM is particularly prone to these two shrinkages. Therefore the time dependent shrinkage due to drying and autogenous effect or self desiccation will be taken into account in the current research. 


\subsubsection{Factors affecting drying and chemical shrinkage}

Factors that affect the drying and chemical shrinkage of concrete have been summarized in the following sections.

\subsubsection{Water-cementitious materials ratio}

For normal concrete, shrinkage increases with increasing water to cementitious materials ratio $(\mathrm{w} / \mathrm{cm})$, since the $\mathrm{w} / \mathrm{cm}$ determines the amount of evaporable water in the cement paste. Brooks (1989) showed that shrinkage of hydrated cement paste varies directly with the $\mathrm{w} / \mathrm{cm}$ ratio, between the values of 0.2 to 0.6 . Above the $0.6 \mathrm{w} / \mathrm{cm}$ ratio, water is evaporated without causing shrinkage. With constant $\mathrm{w} / \mathrm{cm}$ ratio, increase in cement content increases shrinkage due to greater volume of the cementitious paste. If workability is kept constant, that is, if the water content is kept constant, increase in cement content decreases shrinkage since the effective $\mathrm{w} / \mathrm{cm}$ is reduced.

Smadi et al. (1987) compared the shrinkages of different categories of concrete: (i) low strength (20-24 MPa), (ii) medium strength (34-41 MPa) and (ii) high strength (58-69 $\mathrm{MPa}$ ). They found that the long term drying shrinkage for low strength concrete exceeds those in case of medium and high strength concretes. Higher w/cm facilitates water diffusion and also decreases the rigidity of the solid matrix and its capacity to resist deformation. High strength concretes having a low w/cm showed higher early age shrinkage probably due to the higher paste content. In case of concretes containing SCM (particularly silica fume) and low $\mathrm{w} / \mathrm{cm}(\leq 0.4)$ the early age shrinkage values are much greater due to internal loss of moisture with subsequent self desiccation and additional shrinkage. The aggregates provide a restraining effect which reduces the amount of shrinkage. The ratio of shrinkage of concrete to that of pure portland cement paste is governed by the aggregate content in the concrete. Pickett (1956) proposed the following relation for the concrete shrinkage.

$S_{c}=S_{p}(1-a)^{\mathrm{n}}$

$\mathrm{S}_{\mathrm{c}}=$ Shrinkage of concrete

$\mathrm{S}_{\mathrm{p}}=$ Shrinkage of paste 
$a=$ aggregate content

$\mathrm{n}=\mathrm{n}$ has a value between 1.2 to 1.7

Hansen and Almudaiheem (1987) validated the estimation of the shrinkage of concrete from the shrinkage of pure portland cement paste having same $\mathrm{w} / \mathrm{cm}$ ratio and the same degree of hydration, by considering the aggregate content and the modulus of elasticity of the aggregate.

\subsubsection{Size and grading of aggregate}

The size and grading of aggregate do not have any marked impact on the magnitude of shrinkage. However, the use of larger size aggregates make the mix leaner, hence it leads to lower shrinkage. As the smaller size aggregate usually needs more paste, the shrinkage can be higher.

\subsubsection{Aggregate modulus of elasticity}

Aggregates with greater modulus of elasticity have greater restraining effect on shrinkage. Hence the concretes containing such aggregates undergo a lower shrinkage. If the aggregates have a tendency to shrink, then the overall shrinkage of concrete will increase.

\subsubsection{Lightweight Aggregates}

Lightweight aggregates usually result in higher shrinkage because of their low modulus of elasticity.

\subsubsection{Cement properties}

Cement properties impact the shrinkage to a relatively lesser degree as compared with the other factors. Fineness of cement plays some role in shrinkage as the cement particles larger than $75 \mu \mathrm{m}$ in size hydrate very slowly which leads to a restraining effect. Cements deficient in gypsum generally exhibit considerably greater shrinkage as compared to normal portland cement. Bentz et al. (1995) pointed out that fine cements increase hydration kinetics which leads to greater chemical shrinkage. 


\subsubsection{Supplementary cementitious materials (SCM)}

The influence of the addition of SCM on the shrinkage strain of concrete is governed by the type and the quantity of the SCM added, as shown in ACI 209.1R-05. Addition of slag increases the shrinkage while the addition of fly ash decreases shrinkage. The addition of silica fume has very little influence on shrinkage if the replacement of cement is less than $7.5 \%$. In a previous study, Brooks and Neville (1992) showed that this increase is generally 20 to 60 percent more than a concrete containing $100 \%$ portland cement and same $\mathrm{w} / \mathrm{cm}$.

ACI committee 226 suggested that addition of silica fume less than $15 \%$ usually do not influence the later age shrinkage with respect to normal concrete containing pure portland cement. However, incorporation of a greater amount of silica fume increases early age as well as later age shrinkages.

Khatri et al. (1995) investigated the effect of fly ash, silica fume and slag on shrinkage. They found that the addition of silica fume increased early age shrinkage whereas later age shrinkage was reduced. On the contrary, the inclusion of slag with silica fume increases drying shrinkage whereas, the combination of fly ash and silica fume was found to increase drying shrinkage. But, the effect of variation of fly ash content from 15 to $25 \%$ did not produce any remarkable change.

\subsubsection{Admixtures}

According to Neville (1996) both water-reducing admixtures and superplasticizers (High range water reducing admixtures) increase shrinkage. WRA results in small increase in shrinkage, whereas 10 to $20 \%$ more shrinkage is observed in the case of superplasticizers.

\subsubsection{Curing and storage conditions}

Extended moist curing retards the onset of shrinkage and it also decreases the ultimate shrinkage of concrete. However for neat cement pastes, greater amount of hydrated paste 
results in lesser amount of restraint. Hence extended curing periods cause a higher amount of shrinkage in neat cement pastes.

\subsubsection{Relationship between shrinkage mechanisms and microstructure}

The loss of free water from the capillary spaces has negligible influence on shrinkage. According to Neville (1996) the change in the volume of unrestrained concrete is nearly equal to the loss of adsorbed water having a thickness of one molecule from the surface of all the gel particles. The effect of gel particle size is evident from the low shrinkages of coarse grained natural building stones and from the high shrinkage of fine grained shale.

Three mechanisms can be identified as the main cause of shrinkage:

i. Variations of the surface free energy

ii. Disjoining pressure or hindered adsorption in restricted spaces

iii. Capillary condensation effects

\subsubsection{Variation of the surface free energy}

Stress is exerted on the free surface of a solid particle due to the asymmetrical forces of attraction between atoms and molecules at this location. Hua, Acker and Ehrlacher (1995) proposed that the water molecules adsorbed on the solid surface and intercrystalline spaces greatly impact the volume stability of highly divided solids such as $\mathrm{C}-\mathrm{S}-\mathrm{H}$. The adsorbed water on the surface of a solid alters its surface energy.

Gibbs' adsorption equation gives the reversible change in free energy of a pure adsorbent from its initial state to the combining state (Bissonnette et al., 2001)

$\Delta \mathrm{G}=R T \int_{0}^{p} n \frac{d p}{p}$

where,

$\Delta G=$ surface free energy

$\mathrm{n}=$ number of moles adsorbate in a fixed mass of adsorbent

$\mathrm{R}=$ ideal gas constant 
$\mathrm{T}=$ absolute temperature

$\mathrm{P}=$ vapor pressure of the adsorbent

It can also be written that

$\Delta G=\delta . \Delta Y$

Where $\delta=$ constant solid surface area

$\Delta \mathrm{Y}=$ change in surface tension due to adsorption

Combining (2.33) and (2.34) -

$\Delta=-\frac{R T}{\delta} \int_{0}^{p} n \frac{d p}{p}$

$\Delta y$ denotes the change in state of stress of the solid by the adsorbed water as a result of its interaction with the forces at the liquid/solid interface which effectively places the solid in a state of compressive stress. Adsorption of water on cement gel particles reduces surface free energy leads to a net expansion. As a solid surface experiences maximum stress in vacuum, the removal of adsorbed water causes the gel particles to contract. In 1939, Bangham (Bissonnette et al., 2001) suggested that change in length of a solid can be expressed as:

$\frac{\Delta L}{L}=k_{1} \cdot \Delta \gamma$

where k1 is a material parameter and Young's modulus of a solid can be calculated as -

$Y=\rho \cdot \frac{\delta}{k_{1}}$

where $\rho=$ density of the solid

The influence of changes in surface free energy on shrinkage is considered to be a significant factor at low humidities but the removal of second or third layer remarkably reduces this influence.

\subsubsection{Effect of disjoining pressure}

This mechanism assumes that hydrated cementitious paste is composed of discrete particles separated by narrow spaces. At relative humidities greater than $0 \%$, the hydrated cementitious particles or $\mathrm{C}-\mathrm{S}-\mathrm{H}$ particles begin adsorbing water. At locations where interparticle distances are restricted, the adsorbed waters induce a pressure known as disjoining pressure, resulting in expansion. Ferraris and Wittman (1987) evaluated the different 
components of disjoining pressure. Hence the loss of adsorbed water from cementitious particles leads to contraction in the cementitious paste system. Ferraris and Wittman (1987) established that for hydrated cement paste, the volume change, due to disjoining pressure increases steadily in the range of RH between approximately $40 \%$ and $100 \%$.

\subsubsection{Capillary condensation effect}

As the hydration reaction gradually proceeds in concrete, the volume of the products of hydration exceed the volume of the reactants. This increase in volume is not enough to compensate the volume of water that has participated in the reaction. As concrete hardens, this excess volume is occupied by air, giving rise to pores. The pores in concrete have different size distributions. The pores which are greater than $10 \mathrm{~nm}$ are called capillary pores. Some of the capillaries remain void, some contain water and the rest contain air. This phenomenon can be explained by

Kelvin's equation

$p_{c}-p_{v}=\frac{R T}{M v} \ln \left(p_{v} / p_{0}\right)$

$p_{c}=$ capillary pressure

$v=$ molar volume of the adsorbate

$p_{v}=$ equilibrium vapor pressure

$\mathrm{R}=$ ideal gas constant

$\mathrm{T}=$ absolute temperature

$M=$ molar volume of the liquid (water)

and Laplace's equation -

$p_{c}-p_{v}=\frac{2 \sigma}{r}$

Combining (2.38) and (2.39)

$$
r=\frac{2 \sigma}{\frac{R T}{M v} \ln \left({ }^{p_{v}} / p_{0}\right)}
$$

where

$\sigma=$ surface tension

$r=$ radius of menisci

if $r_{p}$ is radius of the pore then we can assume $r=r_{p} \cos \theta$ 
As relative humidity within the concrete reduces the capillaries begin to get empty according to equation 2.39 .

Capillary pressure contributes to concrete shrinkage upto a relative humidity of $40 \%$. Juenger and Jennings (2001) studied the relationship between the microstructure of C-S-H and drying shrinkage of cement paste. According to them reversible shrinkage depends mainly on the capillary porosity and is independent of C-S-H surface area. The irreversible shrinkage, however, is dependent on the morphology of $\mathrm{C}-\mathrm{S}-\mathrm{H}$, unhydrated residue and gel pores. The relative amounts of two types of C-S-H present in the cement paste - LD C-S-H, and HD C-S-H influences the drying shrinkage, as the HD C-S-H has greater resistance to shrinkage than the LD C-S-H. Also, the LD C-S-H shrinks reversibly but the HD C-S-H provides restrain, and the relative proportion of these two C-S-H changes with curing temperature and admixtures. Other researchers such as Richardson (1999), and Taylor (1997) also mentioned that C-S-H plays a significant role in drying shrinkage.

\subsubsection{Shrinkage models}

Several models have been proposed to estimate the drying shrinkage of concrete by different researchers over the years. The following section describes the models which are most commonly used and referenced by researchers. The time-dependant deformations of hardened concrete have a prominent impact on its serviceability. Keeping this in mind, the prediction of shrinkage is of great importance for any structural engineer. According to the ACI-209R.1, the following factors influence the mechanical properties of concrete:

- Temperature of surroundings

- Ambient relative humidity

- Moisture availability while curing takes place

- Concrete composition including the aggregates

The most popular available models for estimation of hardened concrete shrinkage are:

- ACI 209R-92 (ACI Committee 209, 2009)

- Bazant - Baweja B3 (Bazant and Baweja 1995, 2000)

- CEB - MC90-99 (Muller and Hillsdorf 1990; CEB 1991, 1993, 1999) (ACI 209R92) 
- GL 2000 (Gardner and Lockman 2001)

These models hold good for specimens moist cured for at least 24 hours. The models were calibrated with pure portland cement concrete and not with concrete containing SCM such as slag, fly ash, silica fume and other natural pozzolans.

According to ACI 209R-92 (2009), the fundamental assumptions for developing shrinkage models are as follows:

1. Shrinkages are additive in nature.

2. Difference in strain gradients decrease as concrete gains maturity.

3. Stresses occurring during curing are not taken into account.

Autogenous shrinkage - "The shrinkage occurring when there is no moisture exchange (as in a sealed concrete specimen), due to the hydration reactions taking place in the cement matrix. Generally, it is termed basic shrinkage or chemical shrinkage" (ACI 209R-92, 2009).

Drying shrinkage - "Drying shrinkage is defined as the shrinkage which occurs in a specimen that is allowed to dry" (ACI 209R-92, 2009).

Shrinkage - "The strain measured on a load-free concrete specimen" (ACI 209R-92, 2009).

Total strain - "the total change in length per unit length measured on a concrete specimen under a sustained constant load at uniform temperature" (ACI 209R-92, 2009).

\subsubsection{Data used for model evaluation}

A major hindrance for all prediction models is the description of concrete. Most models are sensitive to the types of cement and their corresponding strength development properties. But, many types of cement conform to the requirements of the standard types, viz. ASTM C 150 Types I, II, and III simultaneously. Hence, the simple expression in terms of standard cement types used in the database involves a lot of complications regarding their interpretation. Moreover, the multiple additions to the clinker allowed in ASTM C595 or in other standards increase the uncertainties for the researchers and designers (ACI 209R-92, 2009). 
Keeton in 1965 tested nominally identical concretes stored in different environments (ACI 209R-92, 2009), and found different strength development rates. This information, depending upon its availability, must be considered for model development. Also, cement descriptions are different in different countries. Hence, the results from cement concretes in the USA may not be directly compared with those obtained from European cement concretes. Some researchers have advocated correlation with recent and relevant data only. In addition, separate shrinkage curves should be plotted for European, Japanese, North American, and South Pacific concretes (McDonald 1990; McDonald and Roper 1993; Sakata 1993; Sakata et al. 2001; and Videla et al. 2004). Although shrinkage may vary depending on local conditions, it has been found that short-term shrinkage measurements improve the predictions irrespective of location as shown by Bažant in 1987; Bažant and Baweja in 2000; and Aguilar 2005 in (ACI 209R-92, 2009). So, the ACI committee recommends shortterm testing to evaluate the shrinkage, creep, and elastic modulus of the concrete thereby enhancing the accuracy of the long-term predictions of the concrete deformations (ACI 209R-92, 2009).

According to the ACI 209R-92 (2009), some other factors must be considered while evaluating the prediction models:

- A significant amount of the data sets in the database were measured over relatively short time-periods, which reduces the usefulness of the data to predict long-term effects; and

- Majority of the tests were conducted on relatively small specimens as compared to the real-life structural elements. The curing environment and corresponding mechanical properties of concrete in the interior of large elements may not be well represented by such small specimens, as pointed out by Bažant et al. in 1975 (ACI 209R-92, 2009).

Despite these drawbacks, it is essential that databases such as the RILEM database are well maintained and updated regularly as they provide an indispensable source of data as well as a basis for comparison of prediction models (ACI 209R-92, 2009).

\subsubsection{Statistical comparison of the models}

A number of methods have been used to validate the accuracy of prediction models. A single set of data may be described by its mean, mode, median, standard deviation, and maximum and minimum. Similarly, a prediction model for shrinkage data may have 
numerous techniques to measure its deviation from the data. The ACI 209R-92 committee could not single out a unique method to compare test data with those from shrinkage prediction models. Representation of the comparison between a large number of experimental results and a prediction method by a single number incurs a lot of uncertainty. Therefore, the committee strongly urges designers to perform sensitivity analysis of the response of the structure using the models in 209.2R-6 ACI COMMITTEE REPORT and ACI 209R-92, 2009 (ACI 209R-92, 2009).

Owing to the above considerations, statistical optimization techniques were employed for the purpose of the present study. Comparisons were made between the experimentally obtained values of the hydrated phases, using 3D plots of the EDS data and the predicted hydrated phase volumes using theoretical volume stoichiometries.

\subsubsection{Criteria for prediction models}

According to the ACI 209R-92 (2009), the principal criteria for the prediction models include, but are not limited to the following:

- $\quad$ The model may be simple or complex according to the requirements of the researcher, but the inputs to the model must be mentioned clearly;

- $\quad$ The data to be used for the evaluation of the model must be indicated clearly;

- $\quad$ The desired proximity of the model to physical phenomena/behavior must be mentioned;

- $\quad$ The statistical methods/tools necessary to evaluate the model must be well defined.

However, the committee does not provide any strict guidelines upon which information should be required to determine the time-dependent properties of concrete; that is, if the mechanical properties of the concrete specified at the time of design is sufficient or if the mixture proportions are also necessary (ACI 209R-92, 2009).

The minimum requirements for shrinkage models according to the committee include the following information:

- Description of the concrete in terms of as mixture proportions or mechanical properties like strength or modulus of elasticity;

- $\quad$ Ambient relative humidity; 
- Duration of drying; and

- $\quad$ Size of specimen (ACI 209R-92, 2009).

Additionally, the prediction models should also possess the following characteristics:

- $\quad$ Experimental values of concrete strength and modulus of elasticity must be substituted easily in the model;

- $\quad$ Extrapolation of measured shrinkage results must provide long-term values; and

- Mathematical expressions in the model should not be highly sensitive to small changes in input parameters and must be easily usable (ACI 209R-92, 2009).

\subsubsection{Model selection}

ACI 209R-92 suggests the following practical considerations for selecting shrinkage prediction models:

- Mathematical form of their time-dependent component; and

- $\quad$ Fitting of the parameters and the resulting expressions.

If the mathematical form of the model does not simulate its time-dependent component accurately, the extrapolations of shrinkage results will deviate from reality. Once the mathematical form has been established, the prediction model should be compared with individual data sets for validation (ACI 209R-92, 2009).

The models selected for comparison are as follows:

(1) ACI 209R-92 (ACI Committee 209 1992),

(2) Bažant-Baweja B3 developed by Bažant and Baweja (1995, 2000),

(3) CEB Model Code 1990-99 (CEB MC90-99) (Muller and Hillsdorf 1990; CEB 1991, 1993, 1999), and

(4) GL2000 developed by Gardner and Lockman (2001). 


\subsubsection{Important parameters required for modeling}

Table 2.1: Important parameters required for modeling

\begin{tabular}{|c|c|c|c|c|c|}
\hline \multirow[b]{2}{*}{ Input variables } & \multicolumn{5}{|c|}{ Model } \\
\hline & ACI $209 \mathrm{R}-92$ & $\begin{array}{c}\text { Bažant-Baweja } \\
\text { B3 }\end{array}$ & CEB MC90 & CEB MC90-99 & GL2000 \\
\hline$f_{c m 28}, \mathrm{MPa}$ & - & 17 to 70 & 20 to 90 & 15 to 120 & 16 to 82 \\
\hline$a / c$ & - & 2.5 to 13.5 & - & - & - \\
\hline $\begin{array}{c}\text { Cement content, } \\
\mathrm{kg} / \mathrm{m}^{3}\end{array}$ & 279 to 446 & 160 to 720 & - & - & - \\
\hline$w / c$ & - & 0.35 to 0.85 & - & - & 0.4 to 0.6 \\
\hline $\begin{array}{c}\text { Relative } \\
\text { humidity, \% }\end{array}$ & 40 to 100 & 40 to 100 & 40 to 100 & 40 to 100 & 20 to 100 \\
\hline $\begin{array}{l}\text { Type of cement, } \\
\text { European (U.S.) }\end{array}$ & $\mathrm{R}$ or RS & $R, L S, R S$ & $R, L S, R S$ & $R, L S, R S$ & $R, L S, R S$ \\
\hline$t_{c}$ (moist cured) & $\geq 1$ day & $\geq 1$ day & $<14$ days & $<14$ days & $\geq 1$ day \\
\hline$t_{c}$ (steam cured) & 1 to 3 days & - & - & - & - \\
\hline$t_{o}$ & $\geq 7$ days & $t_{o}>t_{c}$ & $>1$ day & $>1$ day & $t_{o} \geq t_{c} \geq 1 \mathrm{day}$ \\
\hline
\end{tabular}

Note: See the notations used in ACI 209R-92 (2009).

\subsection{ACI 209R prediction equation}

The ACI prediction equation for concrete shrinkage strain is:

$\left(\varepsilon_{s h}\right)_{t}=\frac{t^{\alpha}}{f+t^{\alpha}}\left(\varepsilon_{s h}\right)_{u}$

$\alpha$ is within the values 0.9 to 1.3

$\mathrm{f}$ is within the values 20 to 130 days

$\left(\varepsilon_{s h}\right)_{u}$ is ultimate shrinkage with values between $415 \times 10^{-6}$ and $1070 \times 10^{-6}(\mathrm{~m} / \mathrm{m})$ 
$\mathrm{t}=$ time from end of initial curing

Based on normal weight, sand light weight and all light weight concretes using both moisture and steam curing the appropriate value of $a$ and $\left(\varepsilon_{s h}\right)_{u}$ were determine as 1 and $780 \times 10^{-6} \mathrm{~m} / \mathrm{m}$ respectively. These values are presented by ACI $209 \mathrm{R}$.

Therefore the recommended equation for shrinkage under standard conditions is

$\left(\alpha_{s h}\right)_{t}=\frac{t}{35+t}\left(\varepsilon_{h}\right)_{u}$ for shrinkage after 7 days of moist cured concrete

$\left(\alpha_{s h}\right)_{t}=\frac{t}{55+t}\left(\varepsilon_{h}\right)_{u}$ for shrinkage after 1-3 days of steam cured concrete

ACI has also recommended different correction factors to ultimate shrinkage strain value when the conditions are different than the ones mentioned above.

Different corrections are described below:

1. Differential shrinkage: For shrinkage considered for other than 7 days for moist cured concrete and other than 1-3 days for steam cured concrete, the difference in equations 2.11 and 2.12 (as the case may be) is determined for any period starting after this time.

2. Initial moist curing: To determine shrinkage of concrete moist cured other than 7 days moist curing a $\mathrm{Y}_{c p}$ factor is used. Table 2.2 shows $c p$ Y factor corresponding to different moist curing duration.

Table 2.2: Correction for $\gamma_{c p}$

\begin{tabular}{|c|c|}
\hline Moist curing duration, days & $Y_{c p}$ \\
\hline 1 & 1.2 \\
\hline 3 & 1.1 \\
\hline 7 & 1.0 \\
\hline 14 & .93 \\
\hline 28 & .86 \\
\hline 90 & .75 \\
\hline
\end{tabular}


3. Ambient relative humidity: If ambient relative humidity is greater than $40 \% Y_{\lambda}$ is used as a correction factor for ultimate shrinkage-

$Y_{\lambda}=1.4-.01 \lambda$, for $40 \leq \lambda \leq 80$

$=3.0-.03 \lambda$, for $80 \leq \lambda \leq 100$

Where, $\lambda=$ relative humidity in $\%$

For ambient humidity lower than $40 \%$ a value higher than 1 should be used for $Y_{\lambda}$

4. Correction for size and shape:

(a). Avg. thickness method correction $\left(Y_{h}\right)$

Table 2.2 shows the correction factors for members having average thickness less than $150 \mathrm{~mm}$

Table 2.3: Correction factors for average thickness of method of members less than $150 \mathrm{~mm}$

\begin{tabular}{|c|c|}
\hline Average thickness of member & Shrinkage, $\mathrm{Yh}_{\mathrm{h}}$ \\
\hline $\mathrm{mm}$ & $\leq 1 \mathrm{yr}$. \\
\hline 51 & 1.35 \\
\hline 76 & 1.25 \\
\hline 104 & 1.17 \\
\hline 127 & 1.08 \\
\hline
\end{tabular}

For average thickness of members greater than $150 \mathrm{~mm}$ and up to $300 \mathrm{~mm}$ to $375 \mathrm{~mm}$ the following equations are used for correction

During the first year of drying:

Shrinkage $Y_{h}=1.23-.00015 \mathrm{~h}$

where $\mathrm{h}$ is the avg. thickness of the member in $\mathrm{mm}$

For ultimate values 
Shrinkage $\mathrm{Y}_{h}=1.17-.00114 \mathrm{~h}$

where $\mathrm{h}$ is the avg. thickness of the member in $\mathrm{mm}$

(b) Volume-surface ratio method ( $\left.\mathrm{Y}_{\mathrm{vs}}\right)$ (more accurate method)

Shrinkage $\gamma_{v s}=1.2 \exp (-.00472 \mathrm{v} / \mathrm{s})$

where, $\mathrm{v} / \mathrm{s}$ is the volume to surface ratio (in $\mathrm{mm}$ )

In either method $\mathrm{Y}_{s h}$ should be taken not less than 0.2 . Also $\mathrm{Y}_{s h}\left(\varepsilon_{s h}\right)_{u} \geq 100 \times 10^{-6}(\mathrm{~m} / \mathrm{m})$ is used if concrete is under seasonal wetting and drying cycles and $\gamma_{s h}\left(\varepsilon_{s h}\right)_{u} \geq 150 \times 10^{-6}$ $(\mathrm{m} / \mathrm{m})$, if concrete is under sustained drying condition.

5. Temperature other than $21^{\circ} \mathrm{C}$ :

This effect is usually considered to be less important than relative humidity since the operating range of most structures is small.

6. Correction factors for concrete composition:

(i) Slump:

Shrinkage $\mathrm{Y}_{s}=0.89+.00161 \mathrm{~s}$

Where $\mathrm{s}$ is the observed slump (in $\mathrm{mm}$ ).

(ii) Fine aggregate percentage:

For $\Psi \leq 50$ percent

Shrinkage $Y_{\psi}=0.30+0.14 \Psi$

For $\Psi>50$ percent

Shrinkage $Y_{\psi}=0.90+0.002 \Psi$

$\psi$ is the ratio of the fine aggregate to total aggregate by weight expressed as percentage

(iii) Cement content: 
Shrinkage $\mathrm{Y}_{c}=0.75+.00061 \mathrm{c}$

where, $\mathrm{c}$ is cement content in $\mathrm{Kg} / \mathrm{m}^{3}$

(iv) Air content:

Shrinkage $Y_{\alpha}=.95+.008 \alpha$

where $\alpha$ is the air content in percent

7. Shrinkage ratio of concrete with equivalent paste quality:

Shrinkage strain is mainly a function of shrinkage characteristic of the cement paste and of the aggregate volume concentration.

$\frac{\left(\varepsilon_{s h}\right)_{u 1}}{\left(\varepsilon_{s h}\right)_{u 2}}=\frac{1-\left(v_{1}\right)^{1 / 3}}{1-\left(v_{2}\right)^{1 / 3}}$

where $\left(\varepsilon_{s h}\right)_{u 1} /\left(\varepsilon_{s h}\right)_{u 2}$ is the ratio of shrinkage strain of two mixes with different content of paste with equivalent paste quality and $v_{1}$ and $v_{2}$ are the total aggregate solid volumes per unit volume of concrete for each one of the mixes.

\subsection{CEB - MC 90-99}

The standard model of the European board, CEB-FIP (1990) defined total shrinkage or swelling strain $\varepsilon_{c s}\left(t, t_{s}\right)$ as:

$\varepsilon_{c s}\left(t, t_{s}\right)=\varepsilon_{c s o} \beta_{s}\left(t-t_{s}\right)$

where,

$\varepsilon_{c s o}$ is the notional shrinkage coefficient

$\beta_{s}$ is the coefficient to describe development of shrinkage with time

$t$ is the age of concrete (days)

$t_{s}$ is the age of concrete (days) at the beginning of shrinkage or swelling

$\varepsilon_{\text {cso }}$ can be obtained from the following relationship

$\varepsilon_{c s o}=\varepsilon_{s}\left(f_{c m}\right) \beta_{R H}$

with

$\varepsilon_{s}\left(f_{c m}\right)=\left[160+10 \beta_{s c}\left(9-f_{c m} / f_{c m o}\right)\right] \times 10^{-6}$

where, $\mathrm{f}_{\mathrm{cm}}$ is the mean compressive strength of the concrete at the ages of 28 days (MPa) 
$\mathrm{f}_{\mathrm{cmo}}=10 \mathrm{MPa}$

$\beta_{s c}$ is a coefficient which depends on the type of cement: $\beta_{s c}=4$ for slow hardening cements, $\beta_{s c}=5$ for normal or rapid hardening cements ( $N$ and $R$ ); and $\beta_{s c}=8$ for rapid hardening high strength cement (RS).

$\beta_{R H}=-1.55 \beta_{S R H} \quad$ for $40 \% \leq \mathrm{RH}<90 \%$

$\beta_{R H}=+.25 \quad$ for $\mathrm{RH} \geq 99 \%$

where,

$\beta_{s R H}=1-\left(\frac{\mathrm{RH}}{\mathrm{RH}_{\mathrm{o}}}\right)^{3}$

$\mathrm{RH}$ is the relative humidity of the ambient atmosphere (\%)

$\mathrm{RH}_{0}=100 \%$

The development of shrinkage with time is given by

$\beta_{s}\left(t-t_{s}\right)=\left[\frac{\left(t-t_{s}\right) / t_{1}}{350\left(h / h_{0}\right)^{2}+\left(t-t_{s}\right) / t_{1}}\right]^{0.5}$

where

$\mathrm{h}=\frac{2 \mathrm{~A}_{\mathrm{c}}}{\mathrm{u}}=$ notational size of member $(\mathrm{mm}), A c$ is the cross-section and $\mathrm{u}$ is the perimeter of the member in contact with the atmosphere

$\mathrm{t}_{1}=1$ day

$\mathrm{h}_{0}=100 \mathrm{~mm}$

\subsection{Sakata model (1993)}

Shrinkage prediction by a statistical method based on several experimental results was proposed by Sakata in 1993 (ACI 209R-92, 2009), as shown below:

$\varepsilon_{\text {sh }}\left(t, t_{0}\right)=\varepsilon_{\text {sho }}\left[1-\exp \left\{-0.108\left(t-t_{0}\right)^{0.56}\right]\right.$

$\varepsilon_{\text {sho }}=-60+78\{1-\exp (\mathrm{RH} / 100)\}+38 \ln \mathrm{W}-5\{\ln (\mathrm{v} / \mathrm{s})\}^{2}+4\left(\ln \mathrm{t}_{0}\right)$

where, $\varepsilon_{s h}\left(t, t_{0}\right)$ is predicted shrinkage $\left(\times 10^{-5}\right)$ and $\varepsilon_{\text {shoo }}$ is ultimate shrinkage $\left(\times 10^{-5}\right)$. 


\subsection{Bazant model (1996)}

The B3 model, shown below, was put forward by Bazant in 1996 (ACI 209R-92, 2009). Mean Shrinkage strain in the cross section:

$\varepsilon_{s h}\left(t, t_{c}\right)=-\varepsilon_{s h \infty} k_{h} S\left(t-t_{c}\right)$

Time function:

$\mathrm{S}\left(\mathrm{t}-\mathrm{t}_{\mathrm{c}}\right)=\tanh \left(\frac{\mathrm{t}-\mathrm{t}_{\mathrm{c}}}{\tau_{\mathrm{sh}}}\right)^{1 / 2}$

Humidity dependence:

$$
\begin{aligned}
k_{h} & =1-h^{3} & & \text { for } h \leq .98 \\
& =-0.2 & & \text { for } h=1 \text { (swelling in water) } \\
& =\text { linear interpolation } & & \text { for } .98 \leq h \leq 1
\end{aligned}
$$

Size dependence:

$\tau_{s h}=0.085 \mathrm{t}_{\mathrm{c}}^{-0.08} \mathrm{f}_{\mathrm{cm} 28}{ }^{-0.25}\left[2 \mathrm{k}_{\mathrm{s}}(\mathrm{V} / \mathrm{S})\right]^{2}$

where $k_{s}$ is the effective cross-section shape factor and V/S is the volume-surface ratio

$$
\begin{aligned}
\mathrm{k}_{\mathrm{s}} & =1.00 \\
& =1.15 \\
& =1.25 \\
& =1.3 \\
& =1.55
\end{aligned}
$$

for infinite slab for infinite cylinder for infinite square prism for sphere for a cube

Time dependence of ultimate shrinkage-

$$
\begin{array}{rlr}
\varepsilon_{\mathrm{sh} \infty}= & -\varepsilon_{\mathrm{s} \infty} \frac{\mathrm{E}_{\mathrm{cm} 607}}{\mathrm{E}_{\mathrm{cm}}\left(\mathrm{t}_{\mathrm{c}}+\tau_{\mathrm{sh}}\right)} & \\
\varepsilon_{\mathrm{s} \infty}= & -\alpha_{1} \alpha_{2}\left[0.019 \mathrm{w}^{2.1} \mathrm{f}_{\mathrm{cm}}^{-0.28}+270\right] \times 10^{-6} \\
\mathrm{E}_{\mathrm{cmt}}=\mathrm{E}_{\mathrm{cm} 28}(\mathrm{t} / 4+0.85 \mathrm{t}) & \\
& =1.0 & \text { for Type I cement } \\
\alpha_{1} & =.85 & \text { for Type II cement }
\end{array}
$$




$$
\begin{array}{rlrl} 
& =1.1 & \text { for Type III cement } \\
\text { and } \alpha_{2}=.75 & \text { for steam cured specimens } \\
=1.0 & \text { for } 100 \% \mathrm{RH} \\
=1.2 & \text { for specimens sealed during curing } \\
\mathrm{E}_{\mathrm{cm} 28}=4734 \sqrt{\mathrm{f}_{\mathrm{cm} 28}} &
\end{array}
$$

\subsection{Gardner and Lockman model (2001)}

This is basically a design office procedure for evaluating shrinkage. Compressive strength at 28 days and a factor $\mathrm{K}$ were introduced to incorporate different types of cement.

Gardner and Lockman (2001) worked on the possibility of including the effects of fly ash and slag by incorporating different values of $\mathrm{K}$.

Shrinkage can be estimated using the following equation:

$$
\varepsilon_{s h}\left(t, t_{c}\right)=\varepsilon_{s h u} \beta(h) \beta\left(t-t_{c}\right)
$$

$\beta(h)=\left(1-1.18 h^{4}\right)$

$\varepsilon_{\text {shu }}=900 \mathrm{k}\left(\frac{30}{\mathrm{f}_{\mathrm{cm} 28}}\right)^{1 / 2} \times 10^{-6}$

$\beta\left(t-t_{c}\right)=\left[\frac{\left(t-t_{c}\right)}{\left(t-t_{c}\right)+0.12(V / S)^{2}}\right]^{1 / 2}$

where

$\mathrm{h}=$ humidity expressed as a decimal;

$\mathrm{t}=$ age of concrete, days;

tc = age drying commenced, end of moist curing, days;

$k=1 \quad$ for Type I cement;

$$
=.70 \quad \text { for Type II cement }
$$$$
=1.15 \text { for Type III cement; }
$$

$\mathrm{V} / \mathrm{S}=$ volume-surface ratio, $\mathrm{mm}$;

$\mathrm{f}_{\mathrm{cm} 28}=$ concrete mean compressive strength at 28 days, $\mathrm{MPa}$ 


\subsection{Huo et.al model (2001)}

The ACI 209R-92 expression for shrinkage prediction usually overestimates shrinkage strains for high strength concretes, whose early age shrinkage strains develop faster than those of normal concrete (Huo et al. 2001). It was also observed that the ultimate shrinkage strains of pure portland cement concrete exceed those of high strength concrete. To accommodate two features of shrinkage strains of high strength concrete, they proposed the following equation-

$\varepsilon_{\mathrm{sh}}=\left(\varepsilon_{\mathrm{sh}}\right)_{\mathrm{u}} \frac{\mathrm{t}}{\mathrm{K}_{\mathrm{s}}+\mathrm{t}}$

where $\mathrm{K}_{\mathrm{s}}$ is an adjustment factor to reflect the rapidly developed shrinkage at an early age of concrete. To include the effect of compressive strength of the concretes, $\mathrm{K}_{\mathrm{s}}$ was expressed as function of 28 days compressive strength for concretes. Ks is 35 for normal strength concretes, $\mathrm{fc}^{\prime}=28 \mathrm{MPa}$ as in the ACI 209 equation and it is equal to 15 for $\mathrm{fc}^{\prime}=83 \mathrm{MPa}$ based on their test results.

$K_{s}=45-.3626 . f_{c}^{\prime}$ in $\mathrm{MPa}$

where $\mathrm{fc}^{\prime}=$ compressive strength of concrete at 28 days

They also proposed a correction factor $Y_{s t, s}$ other than ACI 209R equation correction factors to consider the lower ultimate shrinkage strains of HPC. The strength adjustment factor $\mathrm{Y}_{s t, s}$ is a linear function of compressive strengths of concrete.

$\mathrm{Y}_{s t, s}=1.20-.0073 f_{\mathrm{c}}{ }^{\prime}$ in $\mathrm{MPa}$

They developed this formula from measured data and $\mathrm{Y}_{s t, s}=1$ when $\mathrm{fc}^{\prime}=28 \mathrm{MPa}$.

\subsection{Models by other authors}

A probabilistic model taking care of the uncertainties in the parameters influencing drying shrinkage was proposed by Basma and Jawad (1995). They introduced the parameter -

$\mathrm{R}_{\mathrm{cp}}=\left(\frac{\varepsilon_{\mathrm{c}}}{\varepsilon_{\mathrm{p}}}=\left(1-\mathrm{V}_{\mathrm{a}}\right)^{\beta}\right)$

based on Pickett's (1956) model and that modified by Almudaiheem (1992); 
Where $\varepsilon_{c} / \varepsilon_{p}$ is the ratio of the shrinkage of concrete to that of the paste, $V_{a}$ is the volume of aggregate and $\beta$ is a function of $U_{c}, U_{a}, E_{c}$ and $E_{a}$. They suggested a simplified model $\mathrm{R}_{\mathrm{cp}}=\varepsilon_{\mathrm{c}} / \varepsilon_{\mathrm{p}}=\left(.0541+.4 \alpha-.94 \mathrm{~V}_{\mathrm{a}}\right)$

Where $\alpha$ is a function of curing time in days, curing temperature in degree Celsius and the $\mathrm{w} / \mathrm{cm}$ ratio. The variation of $R_{c p}$ with the variation in temperature and volume of aggregate was studied using a probabilistic approach.

A statistical method to extrapolate short term shrinkage test results to obtain long term shrinkage values and their standard deviations was put forward by Bazant et al. (1987). Prediction of long term strains from short term tests are most accurate when the shrinkage formula is fitted to experimental results with the help of non-linear optimizations with subsequent linear regression in transformed variables to obtain the confidence limits for long term predictions.

Hansen and Almudaiheem (1987) examined the effect of major parameters on ultimate drying shrinkage of concrete using the following expression:

$\varepsilon_{\mathrm{c}}=\varepsilon_{\mathrm{p}}\left(1-\mathrm{V}_{\mathrm{a}}\right)^{1.7}$

Where-

$\varepsilon_{\mathrm{c}}=$ ultimate shrinkage of concrete

$\varepsilon_{\mathrm{p}}=$ ultimate shrinkage of paste

$\mathrm{V}_{\mathrm{a}}=$ relative aggregate content by overall volume of concrete

It was found that concretes composed of 65 to 70 percent aggregate content by volume have significantly distinct ultimate drying shrinkage. Also, the decrease of modulus of elasticity of the aggregates increases the ultimate shrinkage strain. RH impacts mortar and paste shrinkage quite remarkably.

It was also found that the volume and size of the specimen does not affect the ultimate shrinkage of concrete but has a significant influence on the early age shrinkage strains. The shrinkage half time value $f$ was expressed in terms of the typical time function of shrinkage as 
$\epsilon_{\mathrm{s}}=\mathrm{t} /(\mathrm{f}+\mathrm{t}) \epsilon_{\text {shu }}$

by $\mathrm{V} / \mathrm{S}$ ratio.

\subsection{Prediction of Concrete Shrinkage Using Two-Phase Composite Model}

The two-phase composite model for prediction of drying shrinkage of concrete consists of the aggregate and matrix. The input values for the prediction equation are obtained using experimental formula of drying shrinkage and Young's modulus of cement paste and aggregate.

Drying shrinkage plays a very important role in the development of cracks in concrete structures. The prediction equations mentioned above are useful when the mix proportions are known. Moreover they incorporate the external factors like relative humidity, shape of the member, age and so on. But, their accuracy varies within a range of $40 \%$ on either side of the experimental value (JCI 2001). These errors occur because the equations are empirical in nature and they do not take into account the effect of material properties, as that would make the models less practicable (Eguchi and Teranishi 2004).

A different approach to the theoretical models is taken by researchers who considered concrete or mortar as a two phase material composed of aggregate and matrix. Thus both the aggregate and the matrix contribute to the drying shrinkage separately. Thus the influence of material properties can be taken into account. The drawbacks of this approach are:

- $\quad$ Three types of material cannot be considered in two-phase model

- $\quad$ The equation has no direct expression to denote the effect of external factors like age

- $\quad$ The input values have to be obtained in a complicated manner

The factors depending on the material properties are considered and a complex equation is proposed to predict the drying shrinkage.

The two-phase model is applied in two stages:

1. The mortar component of the concrete - made up of the matrix and fine aggregates

2. The concrete as a whole - made up of the mortar and coarse aggregates. 
The complex model for drying shrinkage proposed by Kishitani and Baba (1975) were found to give the most accurate results. The equation used is :

$$
\frac{\varepsilon_{s c}}{\varepsilon_{s m}}=\frac{\left[1-(1-m n) V_{a}\right]\left[n+1-(n-1) V_{a}\right]}{n+1+(n-1) V_{a}}
$$

Where $n=E_{a} / E_{m}$

$$
\begin{aligned}
m & =\varepsilon_{s a} / \varepsilon_{s m} \\
E & =\text { Young's Modulus }\left(\mathrm{N} / \mathrm{mm}^{2}\right) \\
V_{a} & =\text { aggregate volume ratio }
\end{aligned}
$$

The suffixes c, a, m denote the two-phase material, the aggregate and the matrix, respectively.

The modified equation for the two-phase mortar component (fine aggregate and cement paste) is:

$\frac{\varepsilon_{s}\left(V_{s}^{\prime}, 0\right)}{\varepsilon_{s p}}=\frac{\left[1-\left(1-m_{1} n_{1}\right) V_{s}^{\prime}\right]\left[n_{1}+1-\left(n_{1}-1\right) V_{s}^{\prime}\right]}{n_{1}+1+\left(n_{1}-1\right) V_{s}^{\prime}}$

For the two-phase concrete (coarse aggregate and mortar), the equation takes the form:

$$
\frac{\varepsilon_{s}\left(V_{s}^{\prime}, V_{g}\right)}{\varepsilon_{s}\left(V_{s}^{\prime}, 0\right)}=\frac{\left[1-\left(1-m_{2} n_{2}\right) V_{g}\right]\left[n_{2}+1-\left(n_{2}-1\right) V_{g}\right]}{n_{2}+1+\left(n_{2}-1\right) V_{g}}
$$

where $n_{1}=E_{s} / E_{p}$;

$$
\begin{aligned}
& n_{2}=E_{g} / E\left(V_{s}{ }^{\prime}, 0\right) ; \\
& m_{1}=\varepsilon_{s s} / \varepsilon_{s p} ;
\end{aligned}
$$

$m_{2}=\varepsilon_{s g} / \varepsilon\left(V_{s}^{\prime}, 0\right)$;

$\varepsilon_{s}$ : drying shrinkage strain;

E: Young's Modulus;

$V_{s}^{\prime}$ : volume ratio of fine aggregate to mortar

$V_{g}$ : volume ratio of coarse aggregate to concrete

The suffixes s, $g$ and $p$ denote the fine aggregate, coarse aggregate and cement paste, respectively. 
The basis of the prediction equation proposed by the authors is the stepwise application of these two equations in determining the drying shrinkage strain of concrete. The applicability of this method was verified by an experiment carried out on a sample according to JIS A 1129. The drying shrinkage strains were measured by a dial gauge at varying levels of $\mathrm{w} / \mathrm{cm}$ ratio and aggregate volume ratios.

The mix design was chosen so as to maintain the desired aggregate volume ratio. The air content was not specified and the aspect of bleeding was neglected, leaving a scope for further research.

The test for the Young's Modulus was carried out under the same conditions of temperature and relative humidity as that for the shrinkage test.

The values of the basic parameters in the equations were determined experimentally. The estimated values of drying shrinkage strain are then verified by graphically comparing theoretical and experimental results. The desired parameter, namely the drying shrinkage strain was determined at various ages. Its variation with the fine aggregate volume ratio was plotted to give the time-dependent change in shrinkage strain.

The equation for drying shrinkage strain and Young's Modulus of the cement paste was derived based on the above experiment. The equation resembles the famous Branson's equation and it connects the time-dependent change of drying shrinkage with the ultimate shrinkage strain.

$\varepsilon_{s p}(t)=\frac{t}{\alpha+t} \varepsilon_{s p \infty}$

where $\varepsilon_{s p}(t)=$ drying shrinkage of the cement paste;

$\mathrm{t}=$ drying period in days

$\varepsilon_{s p \infty o}=$ ultimate value of drying shrinkage strain for the cement paste

$a=a$ constant which incorporates the effect of the type of cement and $\mathrm{w} / \mathrm{c}$ ratio

The whole equation can be presented in terms of the w/c ratio.

$\varepsilon_{s p}(t)=\frac{t}{\alpha W / C+\beta+t}(\lambda W / C+\delta)$

where $\mathrm{W} / \mathrm{C}=$ water-cement ratio 
$a, \beta, \lambda, \delta \rightarrow$ constants depending on the type of cement

The Young's Modulus is also expressed in terms of the w/c ratio.

$E_{p}=\gamma C / W+\eta$

The strain for concrete \& E for aggregates are described below:

The equations for estimation of drying shrinkage for the concrete and the Young's Modulus for the aggregate were proposed based on those for the cement paste. Tests were carried out to verify the results. The experimental results were compared to the regression results.

The drying shrinkage for concrete is estimated from the following equations:

$$
\begin{aligned}
& \frac{\varepsilon_{s}\left(V_{s}, 0, t\right)}{\varepsilon_{s p}(t)}=\frac{\left[1-V_{g}-\left(1-m_{1} n_{1}\right) V_{s}\right]\left[\left(n_{1}+1\right)\left(1-V_{g}\right)-\left(n_{1}-1\right) V_{s}\right]}{\left[\left(n_{1}+1\right)\left(1-V_{g}\right)+\left(n_{1}-1\right) V_{s}\right]\left(1-V_{g}\right)} \\
& \frac{\varepsilon_{s}\left(V_{s}, V_{g}, t\right)}{\varepsilon_{s}\left(V_{s}, 0, t\right)}=\frac{\left[1-\left(1-m_{2} n_{2}\right) V_{g}\right]\left[n_{2}+1-\left(n_{2}-1\right) V_{g}\right]}{n_{2}+1+\left(n_{2}-1\right) V_{g}}
\end{aligned}
$$

The Young's Modulus is estimated based on the complex model of the Hashin-Hansen's Equation:

$$
\frac{E_{c}}{E_{m}}=\frac{n+1+(n-1) V_{a}}{n+1-(n-1) V_{a}}
$$

The estimated values from the complex model furnished above do not always agree with the experimental results, as in case of high aggregate volume ratio (Chou and Kobayashi 1974 and Kosaka et al. 1968). This is usually explained by the increase in the entrapped air due to the increase in the aggregate volume ratio. Another possible reason may be some reduction in the Young's Modulus of the aggregate during their manufacture from raw materials. But this has not been conclusively proved and is mentioned as a scope for future studies. Morever the testing procedure in case of aggregates is a difficult task as it must be carried out under constant temperature and humidity, which is not available during the testing carried out by the researchers during the course of this study. 


\subsection{Accuracy of Prediction Models for Shrinkage}

The accuracy of a cosen model to predict shrinkage, creep and moduli of concrete is a very significant matter of concern for the structural engineer, due to the lack of extensive database containing the long-term behavior of the mix proportions selected in design (McDonald and Roper 1993). Clifford and Koretsky (1986) performed some tests and suggested modification for the CEB-FIP and NAASRA models. The models are based on certain design codes and they depend on various factors to predict creep or shrinkage. The methods for evaluating the accuracy of the models are:

1. A plot of the residuals between the experimental and predicted values against the logarithm of time. A number of data sets based on different models are plotted on the same graph, so as to get an idea about the relative accuracy of the models.

2. The second method involves the calculation of the coefficients of variation for each particular prediction model from the experimental results. The coefficients are usually calculated for the entire drying period as shown below.

$$
w=\frac{\left[1 /(n-1) \sum_{0}^{n} \delta^{2}\right]^{1 / 2}}{1 / n \sum_{0}^{n} J}
$$

where $\mathrm{w}=$ coefficient of variation

$$
\mathrm{J}=\text { experimental value }
$$

$\mathrm{n}=$ no. of observations

$\delta=$ residual $=$ experimental - predicted value

Observations:

i. For small sized specimens, a larger deviation from predicted values was observed, especially in case of ACI 209 model.

ii. The prediction for the Bazant-Panula model becomes more conservative shows a tendency to deviate from the experimental values as drying periods increase.

iii. The shrinkage prediction of the CEB-FIP model is non-conservative at almost all ages. 
3. For the present study, the accuracy of the proposed model was checked by comparing the experimental data with the mean of the predicted upper and lower bounds using the plots of mean difference values (section 5.7.1).

\subsection{Updating Concrete Drying Shrinkage Prediction Models for Local Materials}

The RILEM database which is used to develop or compare the prediction models for creep and shrinkage of concrete has some difficulties associated with it. Firstly, the database cannot represent all types of concrete currently in vogue. Secondly, there is a dearth of research regarding Portland pozzolan cement concrete, which is used quite regularly. Moreover the models should be able to incorporate the influence of the local factors when used under different conditions. The concept is to modify the time-dependent strain functions given by the different standard models so that they can manifest the local influences (Videla et al. 2004).

The general form of the shrinkage strain equation is

$\varepsilon_{s h}^{\prime}\left(t, t_{0}\right)=\coprod_{i=1}^{n} K_{i} f\left(t, t_{0}\right) \varepsilon_{s h, \infty}^{\prime}$

where, $\varepsilon^{\prime}{ }_{s h}\left(t, t_{0}\right)$ is the calculated drying shrinkage strain at the time $\left(t-t_{0}\right)$ of drying, $t$ is the concrete age and $t_{0}$ is the time when drying is initiated.

The physical and chemical tests were performed conforming to the ASTM standards. The different variables considered were analysed by an analysis of variance. It was evident that the type of cement and the dimensions of the specimen had a major impact on the drying shrinkage-strain time function. The effect of the dimensions gradually dies out as time progresses (Almudaiheem and Hansen). The water content and the size of the aggregate affect only the magnitude of the drying-shrinkage strain, but not the time function. Comparisons between predicted and experimental values are obtained by plotting shrinkage vs. time graphs. For each prediction model, the time functions as well as the final dryingshrinkage strain equations are calibrated based on the deviation of the experimental results from the predicted values. 


$$
\varepsilon^{\prime \prime}{ }_{s h, \infty}=\varepsilon_{s h, p}\left[1-\frac{g \times E_{a}}{E_{c}}\right]
$$

The models were verified graphically by plotting the measured values of the drying shrinkage against its calculated value.

The models have to be adjusted to account for local influences. The drying shrinkage for Portland pozzolan cement was larger than that of a portland cement mixture having equal strength. The shrinkage of the Portland pozzolan cement concretes increase rapidly at the beginning but they slow down earlier than portland cement concretes. The updated model requires variables which are assumed during design. But the variables have a very limited range while applied in the updated model.

\subsection{Interfacial Transition Zone (ITZ)}

The ITZ represents a small region next to the particles of coarse aggregate. Existing as a thin shell, typically 10 to $50 \mu \mathrm{m}$ thick around large aggregate, the interfacial transition zone is generally weaker than either of the two main components of concrete, namely, the aggregate and the bulk hydrated cement paste. It has a far greater influence on the mechanical behavior of concrete than is reflected by its size.

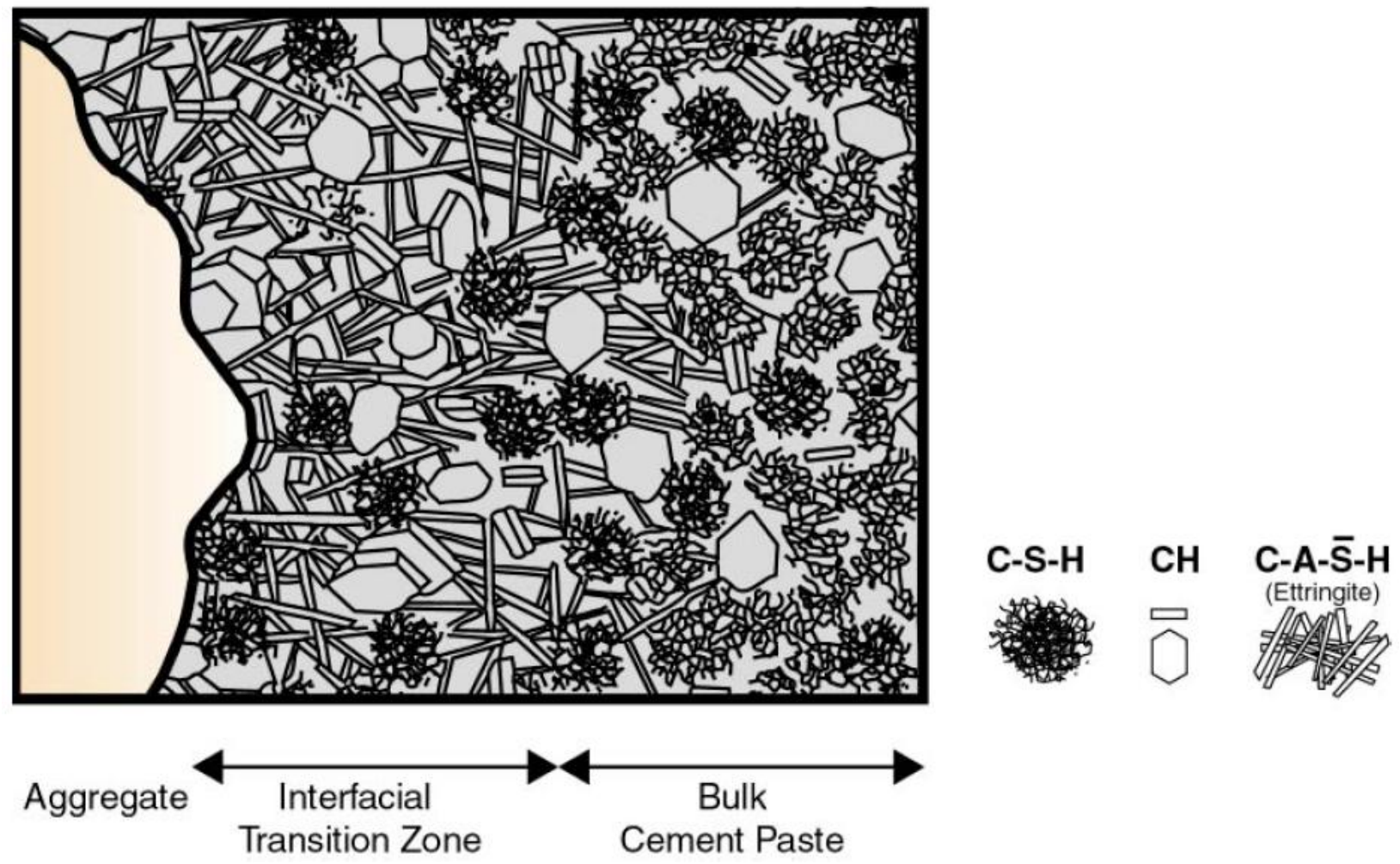


Fig 2.10 Schematic diagram of ITZ in cement paste (Mehta and Monteiro, 2005)

\subsubsection{Development of ITZ}

In freshly compacted concrete, water films form around the large aggregate particles. This would account for a higher $\mathrm{w} / \mathrm{cm}$ ratio closer to the larger aggregate than away from it. Due to the high $\mathrm{w} / \mathrm{cm}$ ratio, calcium hydroxide and ettringite in the vicinity of the coarse aggregate consist of relatively larger crystals, and therefore form a more porous framework than in the bulk cement paste or mortar matrix. The platelike calcium hydroxide crystals tend to form in oriented layers with the -axis perpendicular to the aggregate surface.

\subsubsection{Main characteristics of ITZ}

- ITZ has larger porosity than the matrix

- Precipitation of $\mathrm{CH}$ with a preferred orientation

- $\quad$ Larger crystals

\subsubsection{Orientation of ITZ}

The orientation of the ITZ between the cementitious paste and the fine aggregate particles in the mortar or that between the mortar and the coarse aggregate particles in the concrete cannot be defined clearly due to the heterogeneity in the behavior of the ITZ. For the purpose of this study, the possibility of the two extreme cases was considered as follows.

(a) Mortar phase in parallel with the coarse aggregate phase at the meter scale (or the cementitious paste matrix in parallel with the sand particles at the millimeter scale), together with the ITZ at the respective length scale

(b) Mortar phase in series with the coarse aggregate phase at the meter scale (or the cementitious paste matrix in parallel with the sand particles at the millimeter scale), together with the ITZ at the respective length scale. 


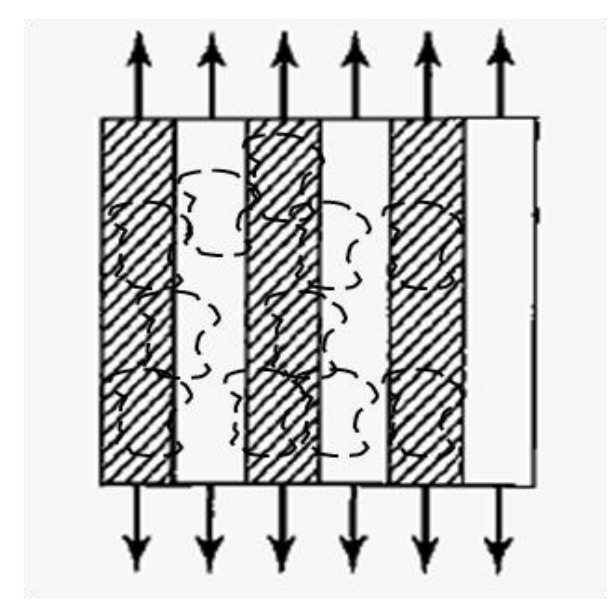

(a)

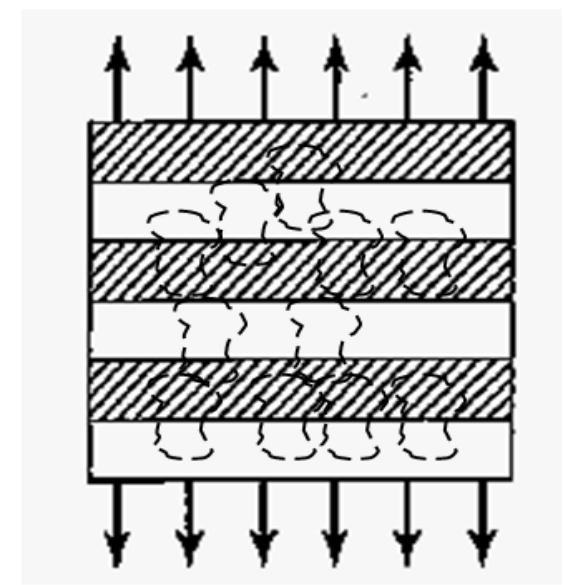

(b)

Fig 2.11 Orientation of the ITZ between mortar and aggregate in two extreme cases: (a) Mortar phase in parallel with the coarse aggregate phase at the meter scale (or the cementitious paste matrix in parallel with the sand particles at the millimeter scale); and (b) Mortar phase in series with the coarse aggregate phase at the meter scale (or the cementitious paste matrix in parallel with the sand particles at the millimeter scale).

The heterogeneity of the ITZ and the uncertainty regarding its orientation in the system at both the scales makes it difficult to specify one particular value for the elastic modulus.

\subsubsection{Effect of SCM}

Use of silica fume reduces the porosity of the ITZ due to the geometrical effect and reduces the amount of $\mathrm{CH}$ due to the pozzolanic reaction.

\subsection{Synthesis from Literature Review}

From the detailed literature review, the following information can be summarized 1. Shrinkage is mainly governed by three types of mechanisms as follows -

(a) Capillary tension at high humidity levels, (b) disjoining pressure at low humidities and

(c) surface energy at low humidities. 
2. $\mathrm{C}-\mathrm{S}-\mathrm{H}$ is the main contributing factor to shrinkage which is the mass that is prone to volume deformation and the other components such as aggregate, unhydrated paste and calcium hydroxide provides a restraining or non-shrinking effects to a varying degree, depending on other conditions.

3. Due to addition of SCM, the change in shrinkage depends on the quantity and the type of the SCM added. Also, the rate of hydration and pozzolanic reactions and/or slag reaction govern the shrinkage development with time.

4. Several models exist for the prediction of shrinkage. However none of them considered the effects of SCM directly into their equations. Some models suggested the use of cement type (Type II or III) to make it applicable for fly ash, slag or silica fume. But none of them introduce the effect of SCM directly in the formula.

5. Since SCM can be of different types such as slag, fly ash, and silica fume, their roles in hydration and formation of C-S-H(II) have not been considered systematically in any available model.

6. Those models which considered the behavior from microlevel to mesolevel in details, did not extend them to macrolevel formulation due to various limitations.

\subsection{Research Significance}

The existing prediction models for shrinkage of cementitious sytems containing SCM with binary and ternary admixture are not accurate enough. The current study will introduce the effects of fly ash, slag, and silica fume in shrinkage and strength prediction equation, by incorporating the influence of the formation of two different types of C-S-H. Results are based on typical commercial silica fume, local slag and fly ash and local aggregate can be used for predicting shrinkage and compressive strength for cementitious systems containing wide range of SCM. The analyses of cementitious systems have been carried out from the microscale to determine the shrinkage of cementitious pastes. The results obtained at the microscale have been used as input for a two-step composite model at the mesoscale and later on at the macroscale, to determine the shrinkage of mortar and concrete respectively. Thus all the three phases of concrete and their mutual interactions have been considered, while predicting the shrinkage at the macroscale, starting from microscale results. It is agreed that the model has been developed based on a number of assumptions. However, 
most of them are well justified and the rest have been done logically to account for different scales and achieve a simplified practical prediction model.

\section{CHAPTER THREE}

\section{MATERIALS AND MIXTURE PROPORTIONS}

This chapter describes the materials and mixture proportions for a total of nineteen different cementitious mixtures that were developed for the evaluation of microstructural, mortar scale and laboratory scale hardened concrete properties.

\subsection{Materials}

\subsubsection{Cement}

Commercially available Type I portland cement conforming to ASTM C 150 was used in this research work. The basic physical properties and compound composition of the type I cement are furnished in the following tables -

Table 3.1: Physical properties of the Type I portland cement used

\begin{tabular}{|c|c|c|c|}
\hline \multirow{2}{*}{ Sp. Gravity } & Fineness & \multicolumn{2}{|c|}{ Setting time } \\
\cline { 3 - 4 } & & Initial (min.) & Final (min.) \\
\hline 3.15 & $320 \mathrm{~m}^{2} / \mathrm{kg}$ & 90 & 260 \\
\hline
\end{tabular}


Table 3.2: Compound composition of the portland cement

\begin{tabular}{|c|c|c|c|}
\hline Compounds & Compound formula & $\%$ by mass & $\%$ by volume \\
\hline Tricalcium silicate & $\mathrm{C}_{3} \mathrm{~S}$ & 49.0 & 50.55 \\
\hline Dicalcium silicate & $\mathrm{C}_{2} \mathrm{~S}$ & 25.0 & 25.24 \\
\hline Tricalcium aluminate & $\mathrm{C}_{3} \mathrm{~A}$ & 12.0 & 13.11 \\
\hline Tetracalcium aluminoferrite & $\mathrm{C}_{4} \mathrm{AF}$ & 8.0 & 7.10 \\
\hline Gypsum & $\mathrm{CS} \mathrm{H}_{2}$ & 2.8 & 3.99 \\
\hline Free lime & $\mathrm{CaO}$ & 0.8 & 0.01 \\
\hline Free magnesia & $\mathrm{MgO}$ & 1.4 & 0.01 \\
\hline Others & - & 2.0 & - \\
\hline
\end{tabular}

${ }^{a}$ Volume fractions were calculated based on specific gravity values provided in Table 4.1.

\subsubsection{Coarse aggregate}

One type of crushed limestone from Arrow Concrete, WV was used. Aggregates used conformed to ASTM C 33 (Standard Specifications for Concrete Aggregates). Tables 3.5 and 3.6 show some physical properties of the aggregate and the sieve analysis data.

Table 3.3: Properties of coarse aggregates

\begin{tabular}{|c|c|}
\hline Properties & Values \\
\hline Nominal size (mm) & 12.5 \\
\hline Absorption (\%) & 0.53 \\
\hline SSD specific gravity & 2.69 \\
\hline Bulk specific gravity & 2.68 \\
\hline Apparent specific gravity & 2.719 \\
\hline
\end{tabular}


Table 3.4: Sieve analysis result

\begin{tabular}{|c|c|}
\hline Sieve size & Percentage passing \\
\hline $12.5 \mathrm{~mm}$ & 100 \\
\hline $9.5 \mathrm{~mm}$ & 88.1 \\
\hline $4.75 \mathrm{~mm}$ & 13.67 \\
\hline $2.36 \mathrm{~mm}$ & 1.3 \\
\hline $1.18 \mathrm{~mm}$ & 1.02 \\
\hline
\end{tabular}

\subsubsection{Fine aggregate}

Locally available river sand which conformed to ASTM C 33 was used for this study. Tables 3.5 and 3.6 show the properties of sand and the sieve analysis results, respectively.

Table 3.5: Properties of fine aggregate

\begin{tabular}{|c|c|}
\hline Properties & Values \\
\hline SSD specific gravity & 2.61 \\
\hline Bulk specific gravity & 2.59 \\
\hline Apparent specific gravity & 2.65 \\
\hline Absorption (\%) & 1.0 \\
\hline Fineness modulus & 2.79 \\
\hline
\end{tabular}


Table 3.6: Sieve analysis of sand

\begin{tabular}{|c|c|}
\hline \multirow{2}{*}{ Sieve size } & Percentage passing \\
\cline { 2 - 2 } & River sand \\
\hline $19 \mathrm{~mm}$ & 100 \\
\hline $4.75 \mathrm{~mm}$ & 97.2 \\
\hline $2.36 \mathrm{~mm}$ & 82.3 \\
\hline $1.18 \mathrm{~mm}$ & 69 \\
\hline $600 \mu \mathrm{m}$ & 54.6 \\
\hline $300 \mu \mathrm{m}$ & 16.1 \\
\hline $150 \mu \mathrm{m}$ & 2.0 \\
\hline $75 \mu \mathrm{m}$ & 0.7 \\
\hline
\end{tabular}

\subsubsection{Supplementary cementitious materials (SCM)}

\subsubsection{Silica fume}

Silica fume is a by-product for producing silicon or ferrosilicon alloys. Because of its chemical and physical properties, it is highly reactive pozzolan of very nature, and is able to pack between cement particles. The silica fume used in this study was commercially available and supplied by BASF. It conformed to AASHTO M 307/ ASTM C 1240 (Standard Specification for Silica Fume for Use in Hydraulic-Cement Concrete and Mortar). The specific gravity, specific surface area and oxide composition are listed in Table 3.7.

\subsubsection{Fly ash}

The Class F fly ash used in this study conforming to ASTM C 618 (Standard Specification for Coal Fly Ash and Raw Calcined Natural Pozzolan for Use as a Mineral Admixture in Portland Cement Concrete), was obtained from Arrow Concrete, WV. The specific gravity, specific surface area and oxide composition are listed in Table 3.7. 
Table 3.7: Basic properties of silica fume and fly ash

\begin{tabular}{|c|c|c|}
\hline Materials & Silica Fume & Fly Ash \\
\hline Specific gravity & 2.18 & 2.47 \\
\hline Specific surface $\left(\mathrm{m}^{2} / \mathrm{kg}\right)$ & 21400 (nitrogen absorption) & 490 (Blaine) \\
\hline Loss of ignition, \% & 1.64 & 3.00 \\
\hline $\mathrm{SiO}_{2}, \%$ & 98 & 49.34 \\
\hline $\mathrm{Al}_{2} \mathrm{O}_{3}, \%$ & 0.20 & 22.73 \\
\hline $\mathrm{CaO}, \%$ & 0.20 & 3.09 \\
\hline $\mathrm{MgO}^{2} \%$ & 0.25 & 1.06 \\
\hline $\mathrm{SO}_{3}, \%$ & 0.15 & 0.97 \\
\hline $\mathrm{Na}_{2} \mathrm{O}, \%$ & 0.20 & 1.15 \\
\hline $\mathrm{K}_{2} \mathrm{O}_{1} \%$ & 0.50 & 1.60 \\
\hline $\mathrm{Fe}_{2} \mathrm{O}_{3} \%$ & 0.50 & 16.01 \\
\hline
\end{tabular}

\subsubsection{Slag}

Ground granulated blast furnace slag or slag (SG) is defined as a finely ground glassy granular material formed when molten blast-furnace slag is rapidly chilled. Slag is varying in size depending on its chemical composition and method of production as well as that of its iron source. Slag used for this study was from Arrow Concrete, WV conforming to AASHTO M 302/ ASTM C 989 (Standard Specification for Ground Granulated Blast-Furnace Slag for Use in Concrete and Mortar). Typical properties of the slag are shown in Table 3.8. 
Table 3.8: Basic properties of slag

\begin{tabular}{|c|c|}
\hline Properties & Values \\
\hline Specific Gravity & 2.88 \\
\hline Specific Surface $\left(\mathrm{m}^{2} / \mathrm{kg}\right)$ & 581 (Blaine) \\
\hline Tricalcium silicate, $\%$ & 48 \\
\hline Dicalcium silicate, \% & 19 \\
\hline Tricalcium aluminate, \% & 7.73 \\
\hline Tetracalcium aluminoferrite, \% & 0.67 \\
\hline Sodium oxide, $\%$ & $10.5-12.7$ \\
\hline pH value (in water) & $0.1-1.0$ \\
\hline Solubility in water, \% & $1300-1350$ \\
\hline Melting point $\left({ }^{0} \mathrm{C}\right)$ & 8 \\
\hline
\end{tabular}

\subsubsection{Chemical admixtures}

\subsubsection{High-Range Water Reducing Admixture (HRWRA)}

The commercially available high-range water reducing admixture used in this study was the Glenium NS 3030, which was a polycarboxylate-based superplasticizer conforming to ASTM C 494 Type F.

\subsubsection{Air Entraining Agent (AEA)}

The air entraining agent used in the study conforming to ASTM C 260 was MB-AE 90, based on neutralized vinol resin.

\subsubsection{Mixing water}


Mixing water used in this study was locally manufactured distilled water. It was assumed to have a density of $1000 \mathrm{~kg}$ per cubic meter.

\subsection{Selection and Criteria of Mix Proportions}

The mix proportions were selected so as to compare their influences on the microstructural properties of the cementitious systems for different combinations of cement with SCM at different water to cementitious materials $(w / c m)$ as well as at different ages. The same proportion of cementitious materials was maintained for batching the concrete mixes for macroscale (or coupon level) specimens. A total of nineteen mixes were produced as follows:

(1) Three pure portland cement mixes having $w / \mathrm{cm}$ of $0.3,0.4$ and 0.5 , respectively;

(2) Cement mixes with $35 \%$ slag and $45 \%$ slag replacement, respectively by weight of cement having $w / \mathrm{cm}$ of 0.3 and 0.4 for each case;

(3) $25 \%$ fly ash and $35 \%$ fly ash replacement, respectively by weight of cement having $\mathrm{w} / \mathrm{cm}$ of 0.3 and 0.4 for each case;

(4) Cement with $10 \%$ silica fume replacement of cement by weight having $\mathrm{w} / \mathrm{cm}$ of both 0.3 and $0.4 ;$

(5) Cement with $35 \%$ slag and $10 \%$ silica fume replacement by weight of cement for w/cm of both 0.3 and 0.4 ;

(6) Cement with $25 \%$ fly ash and $10 \%$ silica fume replacement by weight of cement for $\mathrm{w} / \mathrm{cm}$ of both 0.3 and 0.4 ; and

(7) Cement with 35\% slag and $15 \%$ fly ash replacement by weight of cement for $w / \mathrm{cm}$ of both 0.3 and 0.4 .

The specimens were studied at ages of 1 day, 7 days, 28 days, and 90 days for all the mixes. The average room temperature was $23^{\circ} \pm 2^{\circ} \mathrm{C}$ and the heat transfer conditions were adiabatic. The mixes are shown in Table 3.1. 
Table 3.9: Mix proportions

\begin{tabular}{|c|c|c|c|c|c|c|}
\hline Mixes & $\begin{array}{l}\text { Short } \\
\text { names }\end{array}$ & $\mathrm{w} / \mathrm{cm}$ & $\begin{array}{c}\text { Cement } \\
(\%)\end{array}$ & $\begin{array}{l}\text { Slag } \\
(\%)\end{array}$ & $\begin{array}{c}\text { Fly ash } \\
(\%)\end{array}$ & $\begin{array}{c}\text { Silica } \\
\text { fume } \\
(\%)\end{array}$ \\
\hline $100 \%$ Cement & $\mathrm{CC}$ & $\begin{array}{c}0.3,0.4, \\
0.5\end{array}$ & 100 & - & - & - \\
\hline $35 \%$ Slag & SG 35 & $0.3,0.4$ & 65 & 35 & - & - \\
\hline $45 \%$ Slag & SG 45 & $0.3,0.4$ & 55 & 45 & - & - \\
\hline $25 \%$ Fly ash & FA 25 & $0.3,0.4$ & 75 & - & 25 & - \\
\hline $35 \%$ Fly ash & FA 35 & $0.3,0.4$ & 65 & - & 35 & - \\
\hline $10 \%$ Silica fume & SF 10 & $0.3,0.4$ & 90 & - & - & 10 \\
\hline $\begin{array}{c}35 \% \text { Slag, } \\
\text { 10\% Silica fume }\end{array}$ & $\begin{array}{c}\text { SG } 35 \text { SF } \\
10\end{array}$ & $0.3,0.4$ & 55 & 35 & - & 10 \\
\hline $\begin{array}{l}25 \% \text { Fly ash, } \\
10 \% \text { Silica fume }\end{array}$ & FA 25 SF 10 & $0.3,0.4$ & 65 & & 25 & 10 \\
\hline $\begin{array}{l}\text { 35\% Slag, } \\
\text { 15\% Fly ash }\end{array}$ & $\begin{array}{c}\text { SG } 35 \text { FA } \\
15\end{array}$ & $0.3,0.4$ & 50 & 35 & 15 & - \\
\hline
\end{tabular}

Note: Replacements are by weight of cement

\subsection{Mixture Proportioning}

The combination of cement with SCM and the respective replacement levels of cement by different proportions of SCM have been selected according to the mixes that are used in general for the preparation of high performance concrete. In all the cases, the aggregate to 
cementitious paste ratio was maintained at a constant value of 2.3. The total quantity of cementitious materials in each concrete mix was kept nearly constant in the range of 387 to $396 \mathrm{~kg} / \mathrm{m}^{3}$. Glenium NS 3030 was used as the High Range Water Reducing Admixture (HRWRA) and MB-AE 90 was used as the air-entraining agent (AEA). They were added in such a proportion that a slump of $150-200 \mathrm{~mm}$ and an air-content of 5.5 to $6 \%$ could be achieved for each of the mixtures. Table 3.2 shows the details of the mix proportions for all the concrete mixtures including the $100 \%$ portland cement case.

Table 3.10 Mixture proportioning for concrete mixes



* HRWRA used was Glenium NS 3030.

** AEA used was MB-AE 90.

\subsection{Mixing Procedure for Concrete Batches}


The following protocol was used for all the concrete mixtures:

1. The materials were batched by weight.

2. AEA and was added to sand and stirred thoroughly.

3. About $3 / 4^{\text {th }}$ of the mixing water (including WRA already mixed) was added to the mixer machine.

4. The coarse aggregate was added, followed by the rotation of the drum for 1 minute.

5. The sand (including AEA already mixed) was added and mixed for another 1 minute.

6. The cementitious materials were added along with the remaining amount of water in the subsequent step.

7. The materials were mixed for 3 minutes, followed by 3 minutes of rest and again mixed for 2 minutes.

8. The HRWRA was added till the desired workability was achieved.

\subsection{Curing}

All the specimens for shrinkage and compressive strength were cured in the molds under wet burlap for 24 hours at room temperature. They were then demolded; the shrinkage specimens were kept in the environmental (humidity-controlled) chamber with an $\mathrm{RH}$ of $50 \%$ and temperature of $23 \pm 2^{\circ} \mathrm{C}$. The compressive strength cylinders were cured under water at $23 \pm 2{ }^{\circ} \mathrm{C}$ until they were tested.

\subsection{Sampling Techniques for Microanalyses}

The sampling techniques for the Microscale studies - SEM, EDS, TGA, isothermal calorimetry studies, and capillary shrinkage tests have been discussed in chapter 4 along with the procedures and the results of the corresponding experiments. 


\section{CHAPTER 4 \\ DEVELOPMENT OF MODELING BASED ON MICROANALYSIS}

In this chapter, the approach to the modeling of the microstructural changes in the cementitious systems containing SCM has been discussed, along with the different testing methods and the corresponding test results.

\subsection{Basis of the Model}

The changes in composition of the cement mixes lead to changes in shrinkage strain and compressive strength of the concrete. These changes originate from the differences in the microstructure of the blended cements. The model is developed keeping this phenomenon in mind. The change in microstructure due to the change in composition is taken as the starting point of the development of the model. The equations related to this phenomenon are classified as the microscale model. The equations at the microstructural level are modified so as to formulate the changes at the meso scale (i.e. taking the aggregate phase into account) and the macro scale (i.e. taking the effects of size, shape, temperature and relative humidity into account).

The structure of the hydrated cement paste refers to the type, amount, size, shape and the distribution of the phases present in it. The structure can be broadly classified into macro (if it can be seen without the aid of a microscope) and micro (which cannot be observed by the naked eye). Macroscopically, concrete can be thought to be comprised of two phases paste and aggregate. The microstructure of the hydrated cement paste is greatly influenced by the hydration products.

When portland cement is mixed with water, its constituent components undergo a series of chemical reactions. This contributes to the final hardening and strength development of concrete. The participants in the hydration reaction are mainly tricalcium silicate $\left(\mathrm{C}_{3} \mathrm{~S}\right)$, dicalcium silicate $\left(C_{2} S\right)$, tricalcium aluminate $\left(C_{3} A\right)$, and tetracalcium aluminoferrite $\left(C_{4} A F\right)$. The relative proportions of these chemical compounds in the cement are governed by the oxide composition of the raw materials used for clinkering. 


\subsection{SEM and EDS Microanalysis Studies}

After adequate hand mixing (cement and SCM were always pre-mixed) with small quantity at a time, the samples for the SEM and microanalysis by EDS were cast in cylindrical plastic moulds having $10 \mathrm{~mm}$ diameter and $25 \mathrm{~mm}$ in height. A cylindrical disc of approximately 3 $\mathrm{mm}$ thickness and $10 \mathrm{~mm}$ in diameter was then cut out from the central portion of each specimen using a hand-held diamond cutting machine manufactured by Dremel Inc. The samples were then polished mechanically and the final average thickness was about 2.5 $\mathrm{mm}$. Before SEM and microanalysis by EDS, the specimens were allowed to dry at $50 \%$ humidity and $40^{\circ} \mathrm{C}$ for 48 hours in an environmental chamber to reduce the time of vacuum. Then they were coated with a $15 \mathrm{~nm}$ layer of platinum in argon gas atmosphere at a high vacuum of $5.0 \times 10^{-6}$ Torrs, in order to make them electrically conductive in nature. The samples were stored in $99.8 \%$ laboratory grade methanol in air-tight vial until the SEM studies were conducted to stop the continued hydration at respective ages.

A state-of-the-art thermal Field Emission Scanning Electron Microscope (FE-SEM), JSM$7600 \mathrm{~F}$ (accompanied by an EDS analyzer), supplied by JEOL Limited was used for the imaging process. The JSM-7600F incorporates a large specimen chamber which can accommodate specimen stages containing multiple samples at a time. The EDS microanalyzer had an adequate take off angle and the samples need not be tilted for analysis. The samples were fixed on the appropriate specimen stage and copper tapes were attached to the surface of the samples and the specimen holder to ensure uniform electrical conductivity of the assembly. The operating voltage was $15 \mathrm{kV}$ and the current at the surface of the specimen was $65.4 \sim 67.0 \mu \mathrm{A}$. The images were captured at two different magnifications of $2200 x$ and $5000 x$ respectively, at nine different locations for each specimen, at a vacuum of $9.6 \times 10^{-5} \mathrm{~Pa}$.

For each location, five EDS spectra were acquired with the help of the INCA systems software that is used by the Oxford spectrometer. The working distance was maintained at $15 \mathrm{~mm}$ and the probe current $8(65.4 \sim 67.0 \mu \mathrm{A})$ in order for the EDS analyzer to work properly. Each sample was approximately divided in three locations. The microanalysis was done at five randomly chosen points for each location at each magnification for every sample. Thus for each sample, for three locations, at each magnification, 45 points were analyzed. Finally for two magnifications (2200x and 5000x), 90 points were analyzed for each of the eleven different mixes at every age $(1,7,28$, and 90 days). The points for 
microanalysis were chosen randomly to minimize the influence of the microstructural heterogeneity of the cementitious system. In selected locations of sample, also average microanalysis (not point analysis) was conducted to verify the variations compared to point analysis. Comparative studies show no discernible variations in elemental analysis. As a typical example for a given mix and 2200x magnification, Fig. 4.5 shows how points on each location are selected for the microanalysis. A similar procedure was followed for the other cases. Fig. 4.6 furnishes the corresponding EDS of the typical example.

\subsection{Thermogravimetric Analyses (TGA)}

The TGA tests were conducted using a proximate analyzer called LECO 701 on 180 to 850 $\mathrm{mg}$ of powdered cementitious paste samples which were cast in a manner similar to the SEM-EDS studies. The powders which passed through $75 \mu \mathrm{m}$ sieve were obtained by crushing the pastes using a mortar and pestle. Replicate samples were studied for each specimen at each age. The thermal analysis was carried out between $20^{\circ} \mathrm{C}$ and $950^{\circ} \mathrm{C}$ in air with the rate of heating at $10^{\circ} \mathrm{C}$ per minute. The TGA was conducted to determine the degree of hydration of the hardened paste at a given age and to estimate the mass fraction of calcium hydroxide in the hardened paste.

\subsection{Isothermal Calorimetry Studies}

The calorimetry tests were carried out on all the cementitious pastes as mentioned in section 2.2.1, as per ASTM C 1679-08 (Standard Practice for Measuring Hydration Kinetics of Hydraulic Cementitious Mixtures Using Isothermal Calorimetry). The calorimeter used was the TAM-Air model manufactured by TA Instruments. The sealed ampoule arrangement was followed for our studies and the data were collected using the TAM Assistant software which came along with the machine. The calorimetry test was conducted to evaluate the rate of hydration. The experiments were carried out on 5 grams of each cementitious paste sample at a temperature of $23 \pm 0.2^{\circ} \mathrm{C}$. The plots of heat flow against time indicated the relative rates of hydration of the different cementitious pastes at different $\mathrm{w} / \mathrm{cm}$ ratios. 


\subsection{Analysis of Test Data Using Volume Stoichiometry and statistical Optimization}

\subsubsection{Volume stoichiometry to estimate C-S-H(I), C-S-H(II) and CH}

The concept of the cement hydration model, originally developed in two dimensions by NIST and later extended to three dimensions, is used as the basis of the equations here to estimate the quantities of the hydration products. NIST used a value of 1.7 (Bentz 1995) for the atomic ratio (which is also the molar ratio) of calcium to silicon ( $\mathrm{Ca} / \mathrm{Si}$ ) present in C-S-H (I), which held good for the cement they used. As the cement used in this study was from a different source, a Ca/Si ratio having unknown value of ' $n$ ' was assumed. Then, optimization techniques were used on the microanalysis results and the estimated quantities of hydrated products to determine ' $n$ '.

\subsubsection{Hydration reactions for pure portland cement}

The hydration process of the pure portland cement is composed of two steps - (a) silicate hydration and (b) aluminate and ferrite hydrations. The reactions involved are:

Silicate reactions:

$\mathrm{C}_{3} \mathrm{~S}+(7-n) \mathrm{H} \rightarrow \mathrm{C}_{n} \mathrm{SH}_{4}+(3-n) \mathrm{CH}$

$\mathrm{C}_{2} \mathrm{~S}+(6-n) \mathrm{H} \rightarrow \mathrm{C}_{n} \mathrm{SH}_{4}+(2-n) \mathrm{CH}$

Aluminate and ferrite reactions:

$\mathrm{C}_{3} \mathrm{~A}+6 \mathrm{H} \rightarrow \mathrm{C}_{3} \mathrm{AH}_{6}$ (hydrogarnet formation)

$\mathrm{C}_{3} \mathrm{~A}+3 \mathrm{C} \overline{\mathrm{S}} \mathrm{H}_{2}+26 \mathrm{H} \rightarrow \mathrm{C}_{6} \mathrm{~A} \bar{S}_{3} \mathrm{H}_{32}$ (AFt phase)

$2 \mathrm{C}_{3} \mathrm{~A}+\mathrm{C}_{6} \mathrm{AS}_{3} \mathrm{H}_{32}+4 \mathrm{H} \rightarrow 3 \mathrm{C}_{4} \mathrm{~A} \overline{S H}_{12}$ (AFm phase)

$\mathrm{C}_{4} \mathrm{AF}+3 \mathrm{CSH}_{2}+30 \mathrm{H} \rightarrow \mathrm{C}_{6} \mathrm{AS}_{3} \mathrm{H}_{32}+\mathrm{CH}+\mathrm{FH}_{3}$

$2 \mathrm{C}_{4} \mathrm{AF}+\mathrm{C}_{6} \mathrm{~A} \overline{\mathrm{S}}_{3} \mathrm{H}_{32}+12 \mathrm{H} \rightarrow 3 \mathrm{C}_{4} \mathrm{~A} \overline{S H}_{12}+2 \mathrm{CH}+2 \mathrm{FH}_{3}$

$\mathrm{C}_{4} \mathrm{AF}+10 \mathrm{~F} \rightarrow \mathrm{C}_{3} \mathrm{AH}_{6}+\mathrm{CH}+\mathrm{FH}_{3}$

The set of equations furnished above shows the formation of the products of cement hydration. 


\subsubsection{Hydration of portland cement blended with fly ash and silica fume}

The silica present in the SCM (fly ash or silica fume) reacts with the calcium hydroxide produced from the hydration of the pure portland cement to form a secondary calcium silicate hydrate, C-S-H (II), at a different reaction rate. The Ca/Si ratio in C-S-H(II) is assumed to be $n^{\prime}$. Then, the balanced chemical equation for the hydration of the cement with SCM is given by:

$n^{\prime} \mathrm{CH}+\mathrm{SiO}_{2}+\left(3.9-n^{\prime}\right) \mathrm{H}=\mathrm{C}_{n} \mathrm{SH}_{3.9}$

The chemical formula for $\mathrm{C}-\mathrm{S}-\mathrm{H}$ (II) is modified from the one proposed by NIST, due to the fact that the $\mathrm{Si} / \mathrm{Ca}$ atomic ratio varies in cements, when the source in changed.

The volume stoichiometries for the hydration reactions for both pure portland cement and cements with SCM have been provided by NIST. These are based on the molar stoichiometries of the compounds and their molar volumes were used for all our calculations. A $100 \mathrm{~mL}$ basis was assumed for the cement paste and the volumes of all the hydrated paste, each individual hydrated product and the total paste volume at any instant of time was calculated as a function of ' $n$ ' and the degree of hydration, $\alpha$.

\subsection{Estimation of Quantities of C-S-H(I), C-S-H(II) and CH}

\subsubsection{Estimation of C-S-H(I) for pure cement}

Using Eq. (4.1) and the specific gravity values given in Table 4.1 (Bentz 1995), it is found that 1 volume of $\mathrm{C}_{3} \mathrm{~S}$ produces $\frac{(56.08 n+132.14) / 1.85}{228 / 3.21}$ volume of $\mathrm{C}-\mathrm{S}-\mathrm{H}(\mathrm{I})$ at full hydration. From Table 3.4, the $100 \mathrm{~mL}$ of pure portland cement used by us contains $50.6 \mathrm{~mL}$ of $\mathrm{C}_{3} \mathrm{~S}$. So, $50.6 \mathrm{~mL}$ of $\mathrm{C}_{3} \mathrm{~S}$ contributes

$$
50.6 \times \frac{(56.08 n+132.14) / 1.85}{228 / 3.21}
$$

$\mathrm{mL}$ of $\mathrm{C}-\mathrm{S}-\mathrm{H}(\mathrm{I})$ per $100 \mathrm{~mL}$ of the unreacted cement.

Similarly, using Eq. (4.2), 1 volume of $\mathrm{C}_{2} \mathrm{~S}$ produces $\frac{(56.08 n+132.14) / 1.85}{172 / 3.28}$ volume of $\mathrm{C}-\mathrm{S}-\mathrm{H}(\mathrm{I})$ at full hydration. Now, $100 \mathrm{~mL}$ of the portland cement used by us contains $25.2 \mathrm{~mL}$ of $\mathrm{C}_{2} \mathrm{~S}$. So, C2S contributes

$$
25.2 \times \frac{(56.08 n+132.14) / 1.85}{172 / 3.28}
$$

$\mathrm{mL}$ of $\mathrm{C}-\mathrm{S}-\mathrm{H}(\mathrm{I})$ per $100 \mathrm{~mL}$ of the unreacted cement. 
So, at any instant of time, $t$ or any degree of hydration, $a$, the total volume of C-S-H(I) due to $\mathrm{C}_{3} \mathrm{~S}$ and $\mathrm{C}_{2} \mathrm{~S}$ hydration, $\mathrm{V}_{\mathrm{C}-\mathrm{S}-\mathrm{H}(\mathrm{I})}$ can be obtained by adding the above two expressions. It can be expressed as

$$
V_{C-S-H(I)}=\propto \times(21.6 n+50.9)
$$

$\mathrm{mL}$ per $100 \mathrm{~mL}$ of the unreacted cement.

Table 4.1: Densities and molar volumes of cementitious materials

\begin{tabular}{|c|c|c|c|}
\hline Compound Name & $\begin{array}{l}\text { Compound } \\
\text { formula }\end{array}$ & Density $\left(\mathrm{g} \mathrm{cm}^{-3}\right)$ & $\begin{array}{l}\text { Molar Volume } \\
\left(\mathrm{cm}^{-3} \mathrm{~mol}^{-1}\right)\end{array}$ \\
\hline Tricalcium silicate & $\mathrm{C}_{3} \mathrm{~S}$ & 3.21 & 71 \\
\hline Dicalcium silicate & $\mathrm{C}_{2} \mathrm{~S}$ & 3.28 & 52.4 \\
\hline Tricalcium aluminate & $\mathrm{C}_{3} \mathrm{~A}$ & 3.03 & 89.1 \\
\hline Tetracalcium aluminoferrite & $\mathrm{C}_{4} \mathrm{AF}$ & 3.73 & 128 \\
\hline Gypsum & $\mathrm{CS} \mathrm{H}_{2}$ & 2.32 & 74.2 \\
\hline Calcium silicate hydrate & $\mathrm{C}_{\mathrm{n}} \mathrm{SH}_{4}$ & 1.85 & 124 \\
\hline Pozzolanic C-S-H & $\mathrm{C}_{\mathrm{n}} \mathrm{SH}_{3.9}$ & 1.69 & 81 \\
\hline Calcium hydroxide & $\mathrm{CH}$ & 2.24 & 33.1 \\
\hline Ettringite & $\mathrm{C}_{6} \mathrm{~A} \overline{\mathrm{S}}_{3} \mathrm{H}_{32}$ & 1.75 & 715 \\
\hline Monosulfate & $\mathrm{C}_{4} \mathrm{~A} \overline{\mathrm{S}} \mathrm{H}_{12}$ & 1.99 & 313 \\
\hline Hydrogarnet & $\mathrm{C}_{3} \mathrm{AH}_{6}$ & 2.52 & 150 \\
\hline Iron hydroxide & $\mathrm{FH}_{3}$ & 2.2 & 95.2 \\
\hline Pozzolanic silica & $\mathrm{S}$ & 2.2 & 27 \\
\hline
\end{tabular}

Note: Notations are according to those followed in cement chemistry

From the heat evolution vs. time plot (as shown in details in section 4.6.2.2), using isothermal calorimetry studies, it is evident that the peaks of mixes with low $\mathrm{w} / \mathrm{cm}$ appeared later and had lower magnitude compared to the higher w/cm mixes (Figs. 4.2 through 4.4). 
Therefore, for low $\mathrm{w} / \mathrm{cm}$ ratios, the rate of hydration, $\mathrm{d} \alpha / \mathrm{dt}$, has been reduced by a factor, $\mathrm{f}(\mathrm{w} / \mathrm{cm})$ to account for the slow progress of the reaction. From the works of Parrot and Killoh (1984) the following relationship is obtained:

$$
f(w / c m)=[1+4.444(w / c)-3.333 \alpha]^{4}
$$

The degree of hydration, $\alpha^{\prime}$ for the low $w / c m$ cases is subsequently expressed as

$$
\alpha_{1}=\mathrm{A} * \mathrm{t} *[1+4.444(\mathrm{w} / \mathrm{cm})-3.333 \alpha]^{4}
$$

where $t$ denotes the age of the hydrated paste (in days)

and $\mathrm{A}=286.51 \alpha^{3}-352.82 \alpha^{2}+142.38 \alpha-18.604$

So, the resulting volume of $\mathrm{C}-\mathrm{S}-\mathrm{H}$ becomes

$$
V_{C-S-H(I)}=\alpha_{1} \times(21.6 n+50.9)
$$

The volumes of the other hydrated products were calculated in a similar manner as shown in the subsequent sections and the results are provided in Table 4.2.

Table 4.2: Volume of hydrated phases at full hydration (per $100 \mathrm{~mL}$ of hydrating cementitious paste)

\begin{tabular}{|c|c|c|}
\hline Compound Name & Compound formula & Volume (in $\mathrm{mL}$ ) \\
\hline Calcium silicate hydrate & $\mathrm{C}_{\mathrm{n}} \mathrm{SH}_{4}$ & $21.6 n+50.9$ \\
\hline Calcium hydroxide & $\mathrm{CH}$ & $102.3-39.4 n+1.753 \gamma_{\mathrm{AF}}$ \\
\hline Ettringite & $\mathrm{C}_{6} \mathrm{AS}_{3} \mathrm{H}_{32}$ & $12.12 \gamma_{\mathrm{AF}}$ \\
\hline Monosulfate & $\mathrm{C}_{4} \mathrm{ASH}_{12}$ & $23.69 \gamma_{\mathrm{AF}}$ \\
\hline Hydrogarnet & $\mathrm{C}_{3} \mathrm{AH}_{6}$ & 3.68 \\
\hline Iron hydroxide & $\mathrm{FH}_{3}$ & \\
\hline
\end{tabular}

The total volume of the hydrated paste at any degree of hydration is given by

$$
V_{h c p}=\propto \times\left(153.2+45.998 \gamma_{A F}-17.8 n\right)
$$

$\mathrm{mL}$ per $100 \mathrm{~mL}$ of the unreacted cement.

\subsubsection{Degree of hydration at different ages}

The degree of hydration at different ages was found out using the non-evaporable water content of the cementitious pastes as suggested by Powers (1949). The calculated values of 
the degree of hydration, $\alpha$ were plotted against time, $t$, and the equation of $\alpha$ as a function of time was obtained in the form of a rectangular hyperbola, as shown below:

$$
\alpha=\frac{t}{A+B t}
$$

where $A$ and $B$ are constants which vary depending on the $\mathrm{w} / \mathrm{cm}$ ratio. Also, $\alpha$ is in terms of $\%$ and $t$ is in days. The values are provided in table 4.3 below:

Table 4.3: Constants for degree of hydration expression as function of time

\begin{tabular}{|c|c|c|}
\hline w/cm ratio & A & B \\
\hline 0.3 & 1.919 & 1.561 \\
\hline 0.4 & 1.164 & 1.328 \\
\hline 0.5 & 1.052 & 1.182 \\
\hline
\end{tabular}

\subsubsection{Effect of low $w / \mathrm{cm}$ ratios}

For the low $\mathrm{w} / \mathrm{cm}$ ratio cases, the expression is modified and written as

$$
V_{h c p}=\alpha_{1} \times\left(153.2+45.998 \gamma_{A F}-17.8 n\right)
$$

$\mathrm{mL}$ per $100 \mathrm{~mL}$ of the unreacted cement.

The factor $Y_{A F}$ accounts for the hydration of the aluminates and the aluminoferrites which occur at a rate that is different from the rate of the silicate hydration.

The corresponding unhydrated fraction of cement paste is given by $100 *(1-\alpha) \mathrm{mL}$ per unit volume of the unreacted cement.

Thus, the volume of C-S-H(I) expressed as a fraction of the total cement paste volume at any degree of hydration a is given by

$v_{C-S-H(I)}=V_{C-S-H(I)} /\left[V_{h c p}+100(1-\alpha)\right]$ for normal $\mathrm{w} / \mathrm{cm}$ ratio

and $v_{C-S-H(I)}=V_{C-S-H(I)} /\left[V_{h c p}+100\left(1-\alpha_{1}\right)\right]$ for low $\mathrm{w} / \mathrm{cm}$ ratio cases

It is important to note here that the reduction factor $A$ as mentioned in Eq. 4.14 denotes the decrease in volume of C-S-H formed. However, the decrease in $\mathrm{C}-\mathrm{S}-\mathrm{H}$ volume influences the shrinkage but not the strength of the concrete.

The above findings were corroborated by isothermal calorimetry studies. 


\subsubsection{Isothermal calorimetry - testing and results}

The isothermal calorimetry experiments were carried out according to the ASTM C 1679-09. The procedure is described in detail as follows:

(a) The cement, SCMs (if any) and water to be mixed were weighed accurately with the balance that is accurate to the $10000^{\text {th }}$ gram. The total weight of the cementitious materials was kept at $5 \mathrm{~g}$ for all cases.

(b) The calorimeter is set at the desired temperature, at least 24 hours before the start of the test.

(c) The new experiment wizard is started on the computer.

(d) The channels to be loaded are selected and the relevant data are entered.

(e) The reference channels are loaded with the blank ampoules, as slowly and as carefully as possible, so as to avoid disturbing the calorimeter because of the vibration due to this loading process.

(f) The baseline correction is chosen or rejected, according to the will and need of the user.

(g) If chosen, the baseline correction starts a countdown timer, set as 30 minutes, by default.

(h) This is the time when all the samples to be measured by the calorimeter are mixed simultaneously.

(g) The mixing time is noted and must be kept consistent for all subsequent tests with similar samples.

(h) Once all the samples have mixed uniformly and placed in the respective ampoules, they are simultaneously loaded into the calorimeter as slowly as possible.

(i) The "measuring time" button is pressed on the software window and the TAM-Air starts measuring the heats of hydration.

The test setup is shown in Fig. 4.1. 


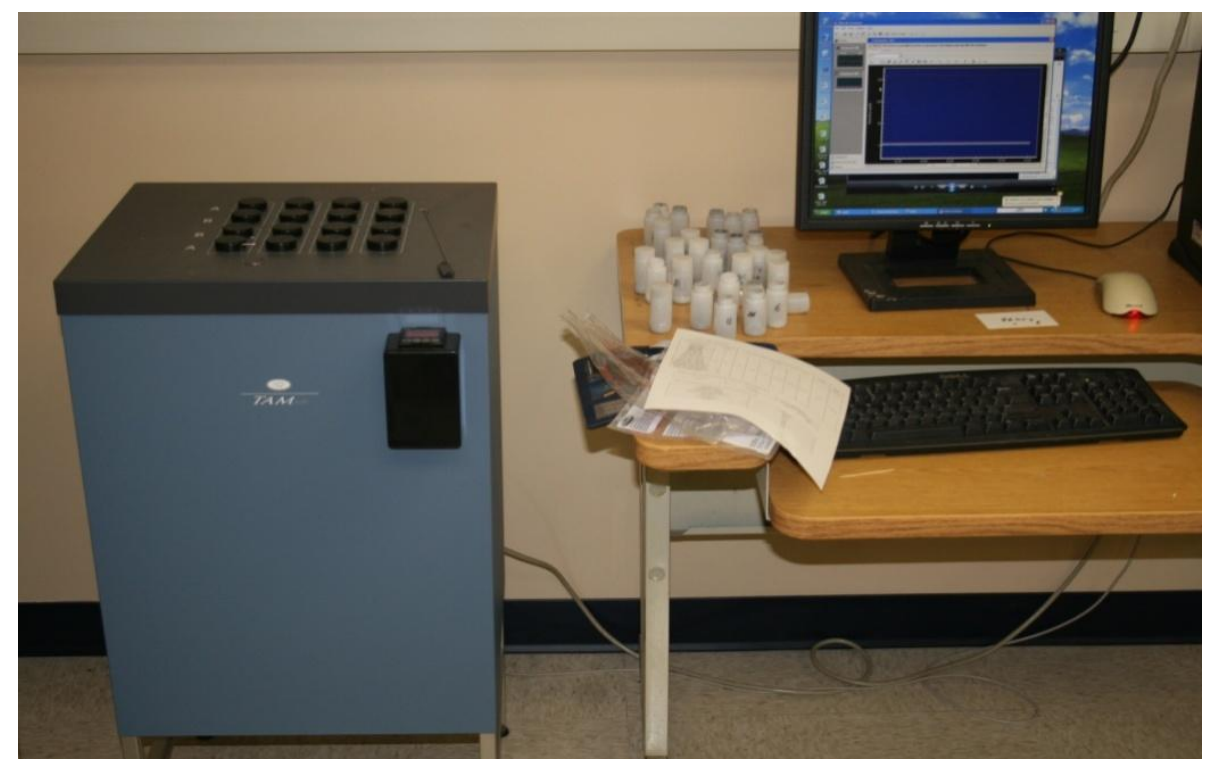

Fig. 4.1 Test setup for the isothermal calorimetry test using the TAM-Air instrument.

The data obtained from the experiments, as described above, are provided in the following plots of the heat flow from the cementitious pastes with respect to time. In general, as predicted by Parrot and Killoh (1984), it was observed that the cementitious mixes containing high w/cm ratios showed higher peak values of the heat flow; also, they attained the peak values faster, as compared to the lower $\mathrm{w} / \mathrm{cm}$ ratio mixes in all the cases (Fig. 4.2 to Fig. 4.4). This was evident for in case of both the $100 \%$ portland cement cases as well as the cementitious systems containing replacements by SCM. Figs. 4.2 through 4.4 show the results for the different mixes - pure cement and also the mixes containing replacements of cement by varying proportions of slag, fly ash, and silica fume, in binary as well as ternary mixes. For the present study, the isothermal calorimetry curves have mainly been used for qualitative purposes. In addition, the activation energy of the hydration reactions can be calculated using the isothermal calorimetry curves. That will give a better idea about the shrinkage behavior of the cementitious paste but it requires further in-depth study of thermodynamics related to the hydration reactions. 

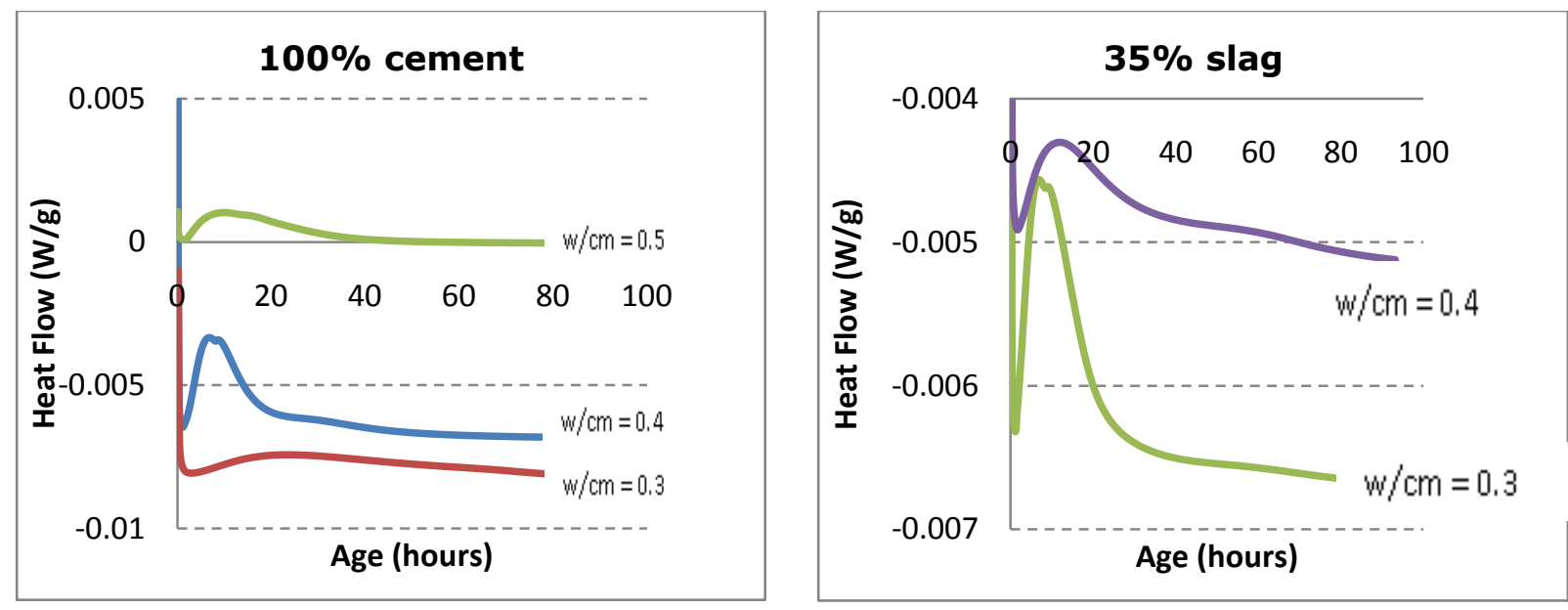

Fig 4.2 Heat flow from $100 \%$ cement mixes and 35\% slag replacement at different $\mathrm{w} / \mathrm{cm}$ ratios.
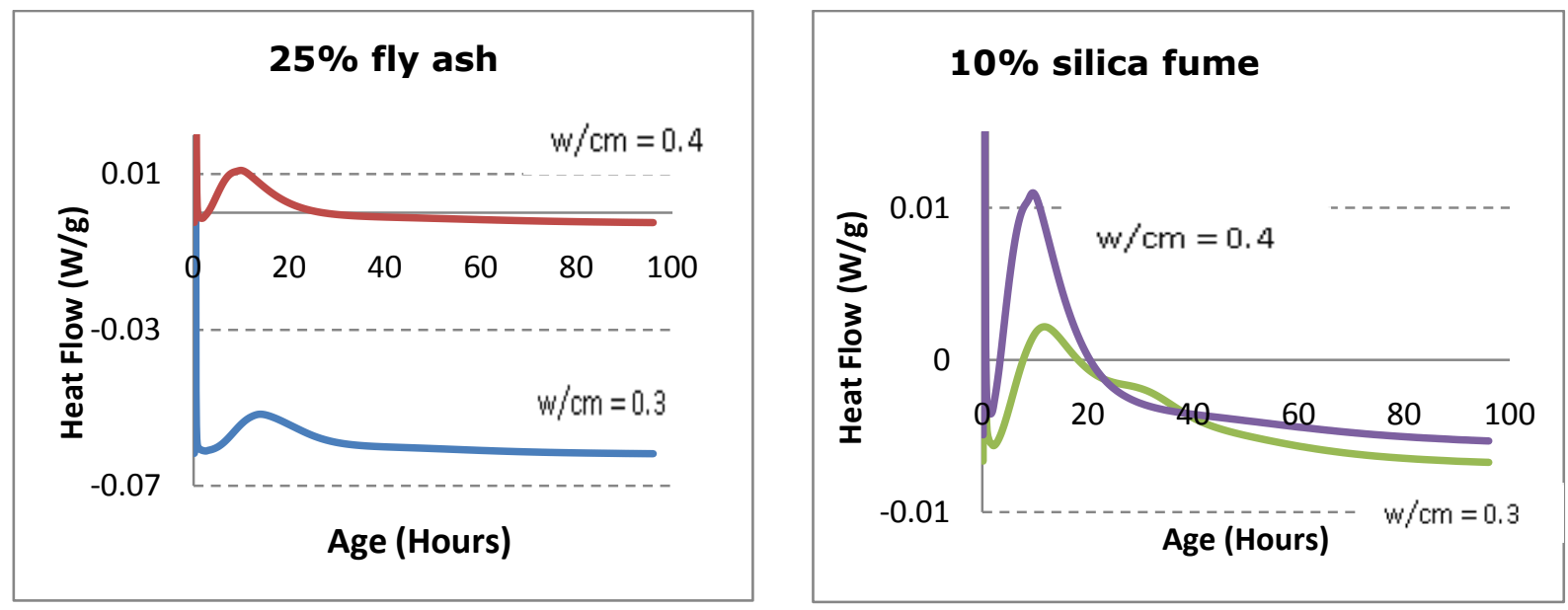

Fig 4.3 Heat flow from mixes containing replacement of cement by $25 \%$ fly ash and $10 \%$ silica fume at different $\mathrm{w} / \mathrm{cm}$ ratios.
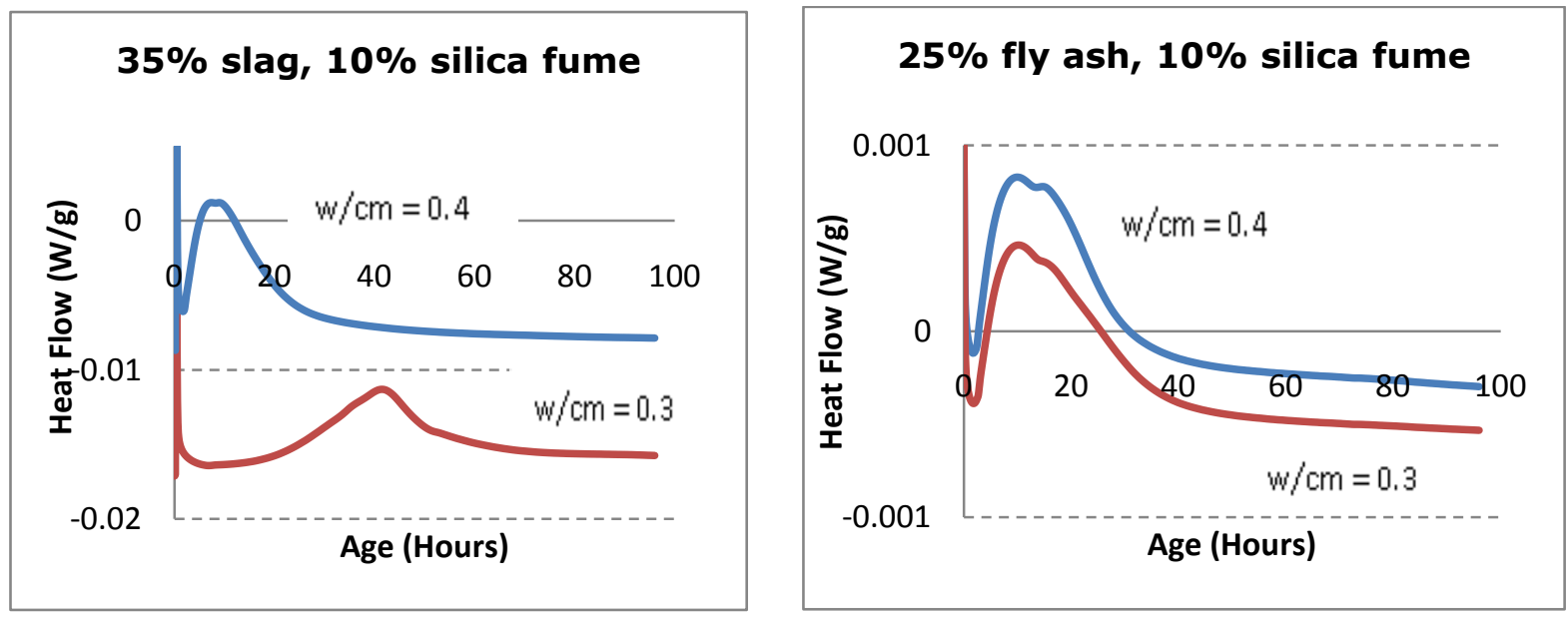

Fig 4.4 Heat flow from mixes containing replacement of cement by (35\% slag $+10 \%$ silica fume) and ( $25 \%$ fly ash $+10 \%$ silica fume) at different $\mathrm{w} / \mathrm{cm}$ ratios. 


\subsubsection{Estimation of C-S-H(I)and C-S-H(II) for cement with SCM}

\subsubsection{P\% cement containing Q\% slag as SCM}

Using the previous approach, the volume of $\mathrm{C}-\mathrm{S}-\mathrm{H}(\mathrm{I})$ produced by the blend containing P\% of portland cement is

$$
V_{C-S-H(I)}^{\prime}=\frac{P}{100} \times V_{C-S-H(I)}
$$

$\mathrm{mL}$ per $100 \mathrm{~mL}$ of the unreacted cement with SCM.

Slag is assumed to behave like weak cement. Hence, it undergoes the same hydration reactions as cement, but with different rates of reaction. As mentioned in case of $100 \%$ cement, it is found that 1 volume of $\mathrm{C}_{3}$ S produces $\frac{(56.08 n+130.2) / 1.69}{228 / 3.21}$ volume of C-S-H(II) at full hydration. Now, $100 \mathrm{~mL}$ of slag used for the present study contains $52.5 \mathrm{~mL}$ of $\mathrm{C}_{3} \mathrm{~S}$. So, $52.5 \mathrm{~mL}$ of $\mathrm{C}_{3} \mathrm{~S}$ contributes

$$
52.5 \times \frac{(56.08 n+130.2) / 1.69}{228 / 3.21}
$$

$\mathrm{mL}$ of C-S-H(II) per $100 \mathrm{~mL}$ of the unreacted cement.

Similarly, using Eq. (4.2), 1 volume of $\mathrm{C}_{2} \mathrm{~S}$ produces $\frac{(56.08 n+132.14) / 1.85}{172 / 3.28}$ volume of C-S-H(II) at full hydration. Now, $100 \mathrm{~mL}$ of the slag used for the present study contains $21.7 \mathrm{~mL}$ of $\mathrm{C}_{2} \mathrm{~S}$. So, C2S contributes

$$
21.7 \times \frac{(56.08 n+130.2) / 1.69}{172 / 3.28}
$$

$\mathrm{mL}$ of C-S-H(II) per $100 \mathrm{~mL}$ of the unreacted cement.

So, at any instant of time, $t$ or any degree of hydration, $\alpha_{\text {slag, }}$ the total volume of C-S-H(II) due to $\mathrm{C}_{3} \mathrm{~S}$ and $\mathrm{C}_{2} \mathrm{~S}$ hydration, $\mathrm{V}_{\mathrm{C}-\mathrm{S}-\mathrm{H}(\mathrm{II})}$ can be obtained by adding the above two expressions.

It comes out to be

$$
V_{C-S-H(I I)}=\propto_{\text {slag }} \times\left(39.9 n^{\prime}+92.6\right) \times \frac{Q}{100}
$$

$\mathrm{mL}$ per $100 \mathrm{~mL}$ of the slag. 


\subsubsection{P\% cement containing Q\% fly ash or silica fume as SCM}

Using the previous approach, the volume of $\mathrm{C}-\mathrm{S}-\mathrm{H}(\mathrm{I})$ produced by the blend containing $\mathrm{P} \%$ of portland cement is obtained using Eqn. 4.18 as

$$
V_{C-S-H(I)}^{\prime}=\frac{P}{100} \times V_{C-S-H(I)}
$$

$\mathrm{mL}$ per $100 \mathrm{~mL}$ of the unreacted cement with SCM.

Using Eq. 9 and the specific gravity values given in Table 4 [13], it is found that 1 volume of pozzolanic $\mathrm{SiO}_{2}$ reacts with $1.21 \mathrm{n}^{\prime}$ volume of $\mathrm{CH}$ and produces

$\left(1.215 n^{\prime}+2.821\right)$ volume of C-S-H(II) at full hydration. Let us consider unit weight of SCM to contain's\%' of $\mathrm{SiO}_{2}$ by weight. Then, the volume of $\mathrm{C}-\mathrm{S}-\mathrm{H}(\mathrm{II})$ is given by

$$
V_{C-S-H(I I)}=\frac{s Q \alpha^{\prime}}{100} \times\left(1.215 n^{\prime}+2.821\right) / 2.2
$$

$\mathrm{mL}$ per $100 \mathrm{~mL}$ of the unreacted cement containing Q\% of fly ash or silica fume as SCM

Here, $\alpha^{\prime}$ denotes the degree of reaction of the pozzolanic $\mathrm{SiO}_{2}$ with the $\mathrm{CH}$ from the portland cement hydration. The list of values for the degree of reaction of the pozzolanic materials at different ages has been given in Table 4.4 (Sarkar and Ghosh 1993).

Table 4.4 : Reaction degree of blending component

\begin{tabular}{|c|c|c|c|c|}
\hline Age & 1 day & 7 days & 28 days & 180 days \\
\hline Slag & $0.1-0.2$ & $0.2-0.3$ & $0.3-0.4$ & $0.5-0.6$ \\
\hline Fly ash cement & $0.01-0.02$ & $0.02-0.05$ & $0.05-0.10$ & $0.15-0.20$ \\
\hline Silica fume cement & $0.35-0.60$ & $0.80-0.90$ & $>0.90$ & $\approx 0.98$ \\
\hline
\end{tabular}

The total volume of the hydrated paste in case of the cement with SCM can be computed similarly as in the case of pure portland cement. It comes out to be

$V^{\prime}{ }_{h c p}=\left[\frac{P \alpha}{100} \times\left(153.2+45.998 \gamma_{A F}-17.8 n\right)+\frac{s Q \alpha^{\prime}}{220} \times\left(0.005 n^{\prime}+2.821\right)\right]$

$\mathrm{mL}$ per $100 \mathrm{~mL}$ of the unreacted cement with SCM.

The volume of the unhydrated paste in case of cement with SCM at any instant of time is given by

$V_{\text {unhyd }}^{\prime}=P^{*}(1-\alpha)+Q^{*}(1-\alpha) \mathrm{mL}$ per $100 \mathrm{~mL}$ of the unreacted cement with SCM. 
The total volume of the paste for cement with SCM at any instant of time is given by $V_{\text {paste with } S C M}=V_{h c p}^{\prime}+V_{\text {unhyd }}^{\prime}$

Thus, the volume of C-S-H(I)expressed as a fraction of the total cement paste volume at any degree of hydration $\alpha$ is given by

$v_{C-S-H(I I)}=V_{C-S-H(I I)} / V_{\text {paste with } S C M}$

In all the above cases, the degree of hydration, a for pure portland cement must be replaced by $a^{\prime}$ for the low $w / c m$ ratio cases.

\subsubsection{P\% cement containing Q\% slag and R\% fly ash as SCM}

Just as in the previous case, the volume of $\mathrm{C}-\mathrm{S}-\mathrm{H}(\mathrm{I})$ produced by the blend containing $\mathrm{P} \%$ of portland cement is

$$
V_{C-S-H(I)}^{\prime}=\frac{P}{100} \times V_{C-S-H(I)}
$$

$\mathrm{mL}$ per $100 \mathrm{~mL}$ of the unreacted cement with SCM.

Let us consider unit weight of fly ash to contain ' $s_{f} \%$ ' by weight of $\mathrm{SiO}_{2}$ respectively. Then, the volume of C-S-H(II) is given by

$$
V_{C-S-H(I I)}=\propto_{\text {slag }} \times\left(39.9 n^{\prime}+92.6\right) \times \frac{Q}{100}+\frac{s_{f} R \alpha^{\prime}}{100} \times\left(1.215 n^{\prime}+2.821\right) / 2.2
$$

$\mathrm{mL}$ per $100 \mathrm{~mL}$ of the unreacted cement containing Q\% of slag and fly ash as SCM.

Here, $\alpha^{\prime}$ and $\alpha^{\prime \prime}$ denote the degrees of reaction of the pozzolanic $\mathrm{SiO}_{2}$ present in fly ash and silica fume respectively, with the $\mathrm{CH}$ from the portland cement hydration. The list of values for the degree of reaction of the pozzolanic materials at different ages has been given in Table 4.3 (Sarkar and Ghosh 1993).

The total volume of the hydrated paste in case of the cement with SCM can be computed similarly as in the case of pure portland cement. It comes out to be

$V^{\prime}{ }_{h c p}=\left[\frac{P \alpha}{100} \times\left(153.2+45.998 \gamma_{A F}-17.8 n\right)+\propto_{\text {slag }} \times\left(0.2 n^{\prime}+198\right) \times \frac{Q}{100}+\frac{\left(s_{f} R \alpha^{\prime}\right)}{220} \times\left(0.005 n^{\prime}+2.821\right)\right]$

$\mathrm{mL}$ per $100 \mathrm{~mL}$ of the unreacted cement with SCM.

The volume of the unhydrated paste for cement with SCM at any instant of time is given by $V_{\text {unhyd }}^{\prime}=P^{*}(1-\alpha)+Q^{*}\left(1-\alpha_{\text {slag }}\right)+R^{*}\left(1-\alpha^{\prime}\right) \mathrm{mL}$ per $100 \mathrm{~mL}$ of the unreacted cement with SCM.

The total volume of the paste for cement with SCM at any instant of time is given by $V_{\text {paste with } S C M}=V_{h c p}^{\prime}+V_{\text {unhyd }}^{\prime}$ 
Thus, the volume of C-S-H(I)expressed as a fraction of the total cement paste volume at any degree of hydration a is given by

$V_{C-S-H(I I)}=V_{C-S-H(I I)} / V_{\text {paste with SCM }}$

Again, $\alpha$ must be replaced by $\alpha_{1}$ for all the low $\mathrm{w} / \mathrm{cm}$ ratio cases.

\subsubsection{P\% cement containing Q\% fly ash and R\% silica fume as SCM}

Just as in the previous case, the volume of C-S-H(I) produced by the blend containing P\% of portland cement is

$$
V_{C-S-H(I)}^{\prime}=\frac{P}{100} \times V_{C-S-H(I)}
$$

$\mathrm{mL}$ per $100 \mathrm{~mL}$ of the unreacted cement with SCM.

Let us consider unit weight of fly ash and silica fume to contain ' $s_{f} \%$ ' and ' $s_{s} \%$ 'by weight of $\mathrm{SiO}_{2}$ respectively.

Then, the volume of C-S-H(II) is given by

$$
V_{C-S-H(I I)}=\frac{\left(s_{f} Q \alpha^{\prime}+s_{S} R \alpha^{\prime \prime}\right)}{100} \times\left(1.215 n^{\prime}+2.821\right) / 2.2
$$

$\mathrm{mL}$ per $100 \mathrm{~mL}$ of the unreacted cement containing Q\% of fly ash or silica fume as SCM.

Here, $\alpha^{\prime}$ and $\alpha^{\prime \prime}$ denote the degrees of reaction of the pozzolanic $\mathrm{SiO}_{2}$ present in fly ash and silica fume respectively, with the $\mathrm{CH}$ from the portland cement hydration. The list of values for the degree of reaction of the pozzolanic materials at different ages has been given in Table 4.4 (Sarkar and Ghosh 1993).

The total volume of the hydrated paste in case of the cement with SCM can be computed similarly as in the case of pure portland cement. It comes out to be

$V_{h c p}^{\prime}=\left[\frac{P \alpha}{100} \times\left(153.2+45.998 \gamma_{A F}-17.8 n\right)+\frac{\left(s_{f} Q \alpha^{\prime}+s_{S} R \alpha^{\prime \prime}\right)}{220} \times\left(0.005 n^{\prime}+2.821\right)\right]$

$\mathrm{mL}$ per $100 \mathrm{~mL}$ of the unreacted cement with SCM.

The volume of the unhydrated paste for cement with SCM at any instant of time is given by $V_{\text {unhyd }}^{\prime}=P^{*}(1-\alpha)+Q^{*}\left(1-\alpha^{\prime}\right)+R^{*}\left(1-\alpha^{\prime \prime}\right) \mathrm{mL}$ per $100 \mathrm{~mL}$ of the unreacted cement with SCM. The total volume of the paste for cement with SCM at any instant of time is given by $V_{\text {paste with } S C M}=V_{h c p}^{\prime}+V_{\text {unhyd }}^{\prime}$

Thus, the volume of C-S-H(I)expressed as a fraction of the total cement paste volume at any degree of hydration a is given by 
$V_{C-S-H(I I)}=V_{C-S-H(I I)} / V_{\text {paste with SCM }}$

Again, $\alpha$ must be replaced by $\alpha_{1}$ for all the low $\mathrm{w} / \mathrm{cm}$ ratio cases.

\subsubsection{Estimation of $\mathrm{CH}$ for pure portland cement}

The volume of calcium hydroxide $(\mathrm{CH})$ present in the cement paste at any instant of time is composed of the $\mathrm{CH}$ produced by the hydration of the silicates as well as that of the aluminoferrites. A similar technique is followed to the one applied to the estimation of the quantity C-S-H(I).

At full hydration, 1 volume of $\mathrm{C}_{3} \mathrm{~S}$ produces $[(74 *(3-n) / 2.24) /(228 / 3.21)]$ volumes of $\mathrm{CH}$ (using Eq. (1) and Table 5). At the same time, 1 volume of $\mathrm{C}_{2} \mathrm{~S}$ produces $[(74 *(2-n) / 2.24) /$ (172/3.28)] volumes of $\mathrm{CH}$. Thus, the total $\mathrm{CH}$ produced by silicate hydration at degree of hydration, $\alpha$ for the cement used comes out to be

$V_{C H}$, silicate $=\alpha^{*}(102.3-39.4 n) \mathrm{mL}$ of $\mathrm{CH}$ per $100 \mathrm{~mL}$ of the unreacted cement paste.

Proceeding similarly, the aluminoferrites have been found to produce $1.753 \mathrm{~mL}$ of $\mathrm{CH}$ per $100 \mathrm{~mL}$ of the unreacted paste, at full hydration.

Thus the total volume of $\mathrm{CH}$ produced at any degree of hydration, $\alpha$ is given as

$V_{C H}=\left(102.3-39.4 n+1.753 \gamma_{A F}\right) \alpha$

$\mathrm{mL}$ per $100 \mathrm{~mL}$ of the unreacted cement paste

The expression must incorporate the $\alpha_{1}$ values instead of $\alpha$ for the low $\mathrm{w} / \mathrm{cm}$ ratio cases.

\subsubsection{Estimation of $\mathrm{CH}$ for cement with SCM}

\subsubsection{P\% cement blended with Q\% slag}

Slag was assumed to behave like weak cement. So, the formation of $\mathrm{CH}$ is similar to that in case of pure portland cement. At full hydration, for slag, 1 volume of $\mathrm{C}_{3} \mathrm{~S}$ produces $[(74 *(3-n) / 2.24) /(228 / 3.21)]$ volumes of $\mathrm{CH}$ (using Eq. (1) and Table 5). At the same time, 1 volume of $\mathrm{C}_{2} \mathrm{~S}$ produces $[(74 *(2-n) / 2.24) /(172 / 3.28)]$ volumes of $\mathrm{CH}$. Thus, the total $\mathrm{CH}$ produced by silicate hydration at degree of hydration, $\alpha_{\text {slag }}$ for the cement used comes out to be 
$V_{C H}$, silicate $=\alpha^{*}(105.4-39.7 n) \mathrm{mL}$ of $\mathrm{CH}$ per $100 \mathrm{~mL}$ of the unreacted slag.

Proceeding similarly, the aluminoferrites have been found to produce $1.753 \mathrm{~mL}$ of $\mathrm{CH}$ per $100 \mathrm{~mL}$ of the unreacted paste, at full hydration.

Thus the total volume of $\mathrm{CH}$ produced at any degree of hydration, $\alpha$ is given as

$V_{C H}=(\mathrm{P} / 100) *\left(102.3-39.4 n+1.753 \gamma_{A F}\right) \alpha+(\mathrm{Q} / 100) *\left(105.4-39.7 n^{\prime}\right) \alpha_{\text {slag }}$

$\mathrm{mL}$ per $100 \mathrm{~mL}$ of the unreacted cement paste

The expression must incorporate the $\alpha_{1}$ values instead of $\alpha$ for the low $\mathrm{w} / \mathrm{cm}$ ratio cases.

\subsubsection{P\% cement blended with Q\% fly ash or silica fume}

Following the same approach as in the previous case, the volume of $\mathrm{CH}$ due to the pure portland cement is given by

$V_{C H}^{\prime}=\frac{P}{100} \times V_{C H}$

As the reaction with pozzolanic $\mathrm{SiO}_{2}$ proceeds, the $\mathrm{CH}$ remaining in the cementitious system decreases.

The resultant volume of $\mathrm{CH}$ is then expressed as

$V_{C H}^{\prime}=V_{C H}-s Q n^{\prime} \alpha^{\prime} / 220$

where $\alpha^{\prime}$ denotes the degree of reaction and s stands for the silica content

\subsubsection{P\% cement blended with Q\% fly ash and R\% silica fume}

The volume of $\mathrm{CH}$ due to the pure portland cement is given by

$V_{C H}^{\prime}=\frac{P}{100} \times V_{C H}$

The volume of $\mathrm{CH}$ remaining after the reaction with the pozzolanic $\mathrm{SiO}_{2}$

$V_{C H}^{\prime}=V_{C H}-\left(s_{f} Q \alpha^{\prime}+s_{s} R \alpha^{\prime \prime}\right) n^{\prime} / 220$

In all the low $\mathrm{w} / \mathrm{cm}$ ratio cases, the values of $\alpha$ must be replaced by $\alpha_{1}$. 


\subsection{Estimation of Hydrated Products from Aluminate and Aluminoferrites Hydration}

\subsubsection{Aluminate hydration}

From Table 3.2, it is seen that the portland cement used for our study contains $13.11 \%$ of $\mathrm{C}_{3} \mathrm{~A}, 7.1 \%$ of $\mathrm{C}_{4} \mathrm{AF}$ and $4 \%$ of gypsum by volume. Let us assume that the gypsum reacts simultaneously with the $\mathrm{C}_{3} \mathrm{~A}$ and the $\mathrm{C}_{4} \mathrm{AF}$ and equal amounts of the gypsum participates in both the reactions. As done in the previous cases, we consider 100 volumes of the cementitious paste as basis for all the calculations. So, 2 volumes of gypsum participate in each of the hydration reactions for the cementitious system under consideration.

It was mentioned in Chapter 2 that each volume of gypsum can react with 0.4 volumes of $\mathrm{C}_{3} \mathrm{~A}$ and produce 3.3 volumes of ettringite at full hydration. The volumes of all the hydration products were computed at full hydration. Using Eq. 4 , it is seen that 2 volumes of gypsum will react with 0.8 volumes of $C_{3} A$ to produce 6.6 volumes of ettringite. The subsequent reaction will give rise to 8.44 volumes of monosulfoaluminate, since each volume of ettringite can produce 1.278 volumes of monosulfoaluminate, if it reacts with 0.2424 volumes of $C_{3} A$. So, the remaining $C_{3} A=13.11-2 * 0.4-6.6 * 0.2424=10.71$ volumes.

Each volume of $\mathrm{C}_{3} \mathrm{~A}$ can produce 1.69 volumes of hydrogarnet. So, from the above reaction, the amount of hydrogarnet produced will be $=1.69 * 10.71=18.1$ volumes.

\subsubsection{Aluminoferrite hydration}

Proceeding in identical manner as the aluminate hydration, the first two steps of the reaction (as provided earlier) will produce 6.66 volumes of ettringite, which, in turn produces 8.44 volumes of monosulfoaluminate.

The total calcium hydroxide produced from these reactions of the aluminoferrites with 2 volumes of gypsum comes out to be $(0.15+0.09+0.26) * 2=1.753$ volumes per 100 volumes of the cement.

The hydrogarnet produced $=5.85$ volumes .

The remaining $\mathrm{C}_{4} \mathrm{AF}=3.305$ volumes.

The ferric hydroxide produced $=(0.31 * 2+0.19 * 6.6+0.545 * 3.305)=3.675$ volumes. 
The details of the total volumes of the hydrated phases with varying degrees of hydration have been shown in Table 4.2.

\subsection{Interpretation of Microanalysis Data and Statistical Optimization}

\subsubsection{Significance of microanalysis and optimization}

As mentioned earlier, the cementitious pastes were observed under the SEM at two different magnifications - 2200x and 5000x. EDS microanalysis was carried out on a total of ninety data points for each cementitious sample. The results obtained from the microanalysis were in terms of the atomic percentages of the different elements present in the cementitious system. The relative percentages of the aluminum, silicon and sulfur were computed with respect to the corresponding calcium atom for each of the 90 data points. They were plotted on 3D axes using OriginPro 8.1 software (Figs. 4.7 and 4.10). The concept of 3D plot was used by Famy et al. (2003) to characterize the C-S-H and its phase compositions in case of of portland cement mortars through the solution of simultaneous algebraic equations. The results of the works done by previous researchers showed that for all pure portland cement pastes, the Si/Ca atom ratio lies in the range of 0.48 to 0.61 for the C-S-H (Taylor 1997). The total number of points, for each sample, composed of Si/Ca ratio in the given range and $\mathrm{Al} / \mathrm{Ca}$ and $\mathrm{S} / \mathrm{Ca}$ ratios less than 0.1 were counted as representing the $\mathrm{C}-\mathrm{S}-\mathrm{H}$ component of the total paste volume. As mentioned earlier in section 2.2.2, the SEM/EDS microanalyses were carried out at randomly chosen points to account for the heterogeneity of the microstructure of the cement paste. Each of the scanned areas was approximately $120 \mu \mathrm{m}$ by $120 \mu \mathrm{m}$ square. The C-S-H was detected from SEM morphology and features, both at early stage and later. They were present as common fibrous to irregular grains forming reticular network. The ratio of the number of points representing $\mathrm{C}-\mathrm{S}-\mathrm{H}$ to the total number of data points for each sample was taken as the representative volume fraction of $\mathrm{C}-\mathrm{S}-\mathrm{H}$ for each sample. This approach was somewhat similar to the point-count procedure as proposed by Feng et al. (2004). The volume fraction from SEM was compared with the results from the proposed algebraic equation and the square of the errors was minimized using optimization technique with the help of GAMS software. The optimization was done for the $\mathrm{Ca} / \mathrm{Si}$ atomic ratio for each specimen in the range of 1.57 to 2.1 . The $\mathrm{Ca} / \mathrm{Si}$ ratios remain more or less consistent, irrespective of the age of the specimen, for both the inner product as well as the outer product C-S-H (Taylor 1997 and Richardson 1993). Thus, a 
unique ' $n$ ' value was obtained which most nearly represents the $\mathrm{Ca} / \mathrm{Si}$ atomic ratio of each specimen.

Similar approach was followed to find the volume fraction of $\mathrm{CSH}$ (II) in case of cements with SCM. The range of $\mathrm{Ca} / \mathrm{Si}$ atom ratio in $\mathrm{CSH}(\mathrm{II})$ in case of fly ash cements is about 1.5 to 1.6 (Taylor 1997). For silica fume cements, it is about 1.1 to 1.4 (Taylor, 1997 and Traetteberg, 1978). Thus, from the 3D plots of the microanalysis data, the number of points at which the $\mathrm{Si} / \mathrm{Ca}$ ratio lies in the range of $\mathrm{CSH}$ (II) were counted and expressed as a fraction of the total number of data points. The volume fraction of $\mathrm{CSH}(\mathrm{I})$ from the theoretical approach was computed using the ' $n$ ' value derived from the optimization technique. This was compared with the experimental values in case of the pastes with SCM and they showed very good agreement. The details are discussed in section 4.6.2.

\subsubsection{Statistical optimization}

The statistical optimization was carried out according to the concepts provided in Chapter 2, section 2.10. The definitions of the problem and the variables have been described elaborately in the following section.

\subsubsection{Optimization using GAMS}

The unknown parameters that needed to be solved in our case, were the $\mathrm{Ca} / \mathrm{Si}$ ratio in the $\mathrm{C}-\mathrm{S}-\mathrm{H}$ and the co-efficient that differentiates between the rate of hydration of the aluminates and ferrites from that of the silicates. The parameters were obtained by comparing experimental values with theoretical predictions using a constrained nonlinear least squares approach. Let $t$ denote an index for time. Note that $t$ can take values $1,2,3$ and 4 corresponding to 1 day, 7 days, 28 days and 90 days respectively. Let

$v_{C-S-H}^{\text {exp,t }}$ denote the experimentally determined volume fraction of $\mathrm{C}-\mathrm{S}-\mathrm{H}$ at time $t$ and $v_{C-S-H}^{\text {pred, } t}$ denote the predicted volume fraction of $\mathrm{C}-\mathrm{S}-\mathrm{H}$ at time $t$. For pure cement, the values of $n$ and $\gamma_{A F}$ can be determined by solving the nonlinear constrained optimization problem for the high water/cement ratio case.

$$
\begin{aligned}
& \min \sum_{t=1}^{4}\left(v_{C-S-H}^{\text {exp,t }}-v_{C-S-H}^{\text {pred }, t}\right)^{2} \\
& 1.57 \leq n \leq 2.1 \\
& 0.4 \leq \gamma_{A F} \leq 0.5
\end{aligned}
$$


For cement with fly ash as SCM, knowing the volume of C-S-H(I) at time $t, v_{C-S-H(I)}^{t}$ can be determined using the formula provided in equation (4.17). The values of $n^{\prime}$ and $\alpha^{\prime, t}$ can be determined by minimizing the sum of square differences between $v_{C-S-H(I I)}^{\text {exp,t }}$ and $v_{C-S-H(I I)}^{\text {pred,t }}$ as shown below.

$$
\begin{gathered}
\min \sum_{t=1}^{4}\left(v_{C-S-H(I I)}^{\exp , t}-v_{C-S-H(I I)}^{\text {pred }, t}\right)^{2} \\
1.5 \leq n^{\prime} \leq 1.6 \\
0.01 \leq \alpha^{\prime, 1} \leq 0.02 \\
0.02 \leq \alpha^{\prime, 2} \leq 0.05 \\
0.05 \leq \alpha^{\prime, 3} \leq 0.1 \\
0.15 \leq \alpha^{\prime, 4} \leq 0.2
\end{gathered}
$$

Similarly, for cement with silica fume as SCM, the values of $n^{\prime}$ and $\alpha^{\prime \prime, t}$ can be determined by minimizing the sum of square differences between $v_{C-S-H(I I)}^{\text {exp,t }}$ and $v_{C-S-H(I I)}^{\text {pred,t }}$ as shown below.

$$
\begin{gathered}
\min \sum_{t=1}^{4}\left(v_{C-S-H(I I)}^{\text {exp,t }}-v_{C-S-H(I I)}^{\text {pred,t }}\right)^{2} \\
1.1 \leq n^{\prime} \leq 1.4 \\
0.35 \leq \alpha^{\prime \prime, 1} \leq 0.6 \\
0.8 \leq \alpha^{\prime \prime, 2} \leq 0.9 \\
0.9 \leq \alpha^{\prime \prime, 3} \leq 0.95 \\
0.95 \leq \alpha^{\prime \prime, 4} \leq 0.99
\end{gathered}
$$

In the same way, for cement containing both silica fume and fly ash as SCM, the values of ' , $\alpha^{\prime, t}$ and $\alpha^{\prime \prime, t}$ can be determined by solving the following nonlinear optimization problem.

$$
\begin{gathered}
\min \sum_{t=1}^{4}\left(v_{C-S-H(I I)}^{\text {exp,t }}-v_{C-S-H(I I)}^{\text {pred, }}\right)^{2} \\
1.1 \leq n^{\prime} \leq 1.2 \\
0.35 \leq \alpha^{\prime \prime, 1} \leq 0.6 \\
0.8 \leq \alpha^{\prime \prime, 2} \leq 0.9 \\
0.9 \leq \alpha^{\prime \prime, 3} \leq 0.95 \\
0.95 \leq \alpha^{\prime \prime, 4} \leq 0.99 \\
0.01 \leq \alpha^{\prime, 1} \leq 0.02 \\
0.02 \leq \alpha^{\prime, 2} \leq 0.05 \\
0.05 \leq \alpha^{\prime, 3} \leq 0.1 \\
0.15 \leq \alpha^{\prime, 4} \leq 0.2
\end{gathered}
$$


All the above formulations were coded in the General Algebraic Modeling System (GAMS) (Rosenthal 2008) and solved using the in-built CONOPT solver (Drud 2004)- a popular solver for nonlinear optimization problems (Baazara et al. 2006).

The optimization technique discussed above gives the representative value of the $\mathrm{Ca} / \mathrm{Si}$ atomic ratio, $n$ as 1.753 for the pure portland cement. The microanalysis data was used to calculate the atomic ratios of silicon, aluminum and sulfur with respect to calcium, for the pure portland cement. The scanned regions for EDS analyses (Fig. 4.5) and the corresponding spectra (Fig. 4.6) are shown at one location and particular magnification for a 28-days old pure portland cement paste with $\mathrm{w} / \mathrm{cm}$ ratio of 0.4 . The relevant $3 \mathrm{D}$ atom-ratio plots at different ages, namely 1 day, 7 days, 28 days and 90 days (Fig. 4.7) are shown in the figures below. Fig. 4.5, 4.6, and 4.7 are shown as typical example for pure pastes. 


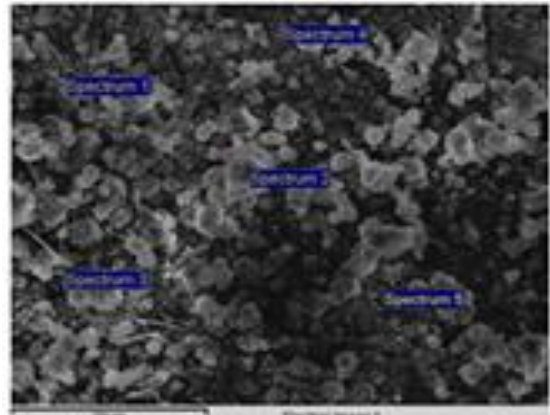

a.

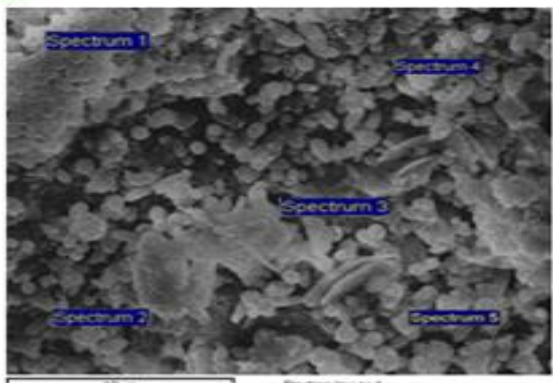

d

e
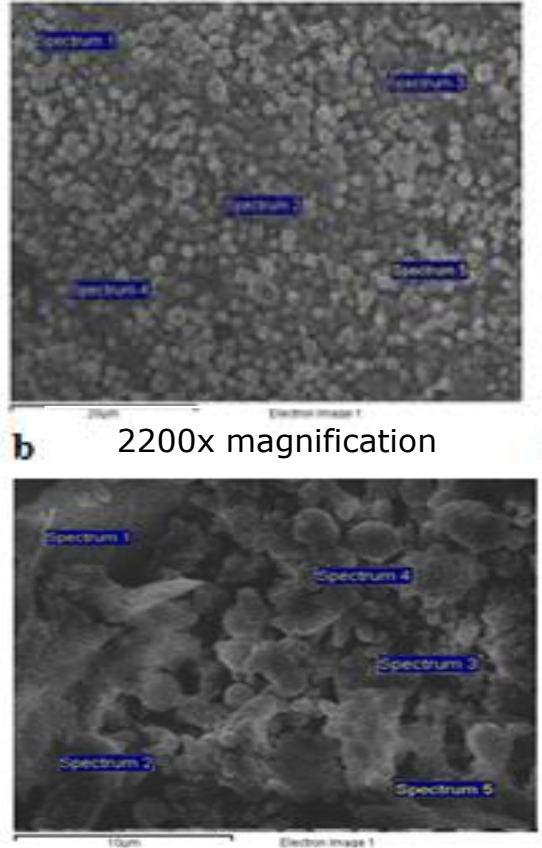

5000x magnificatiorf b 2200x magnification

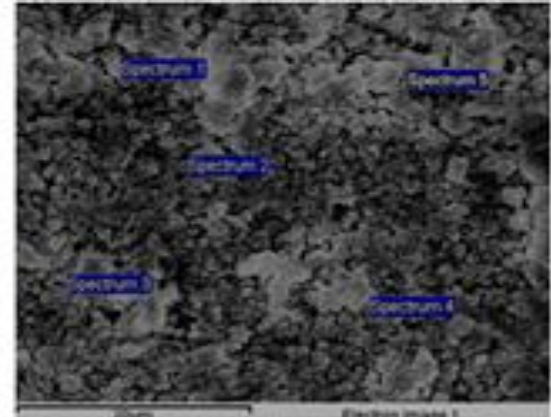

c

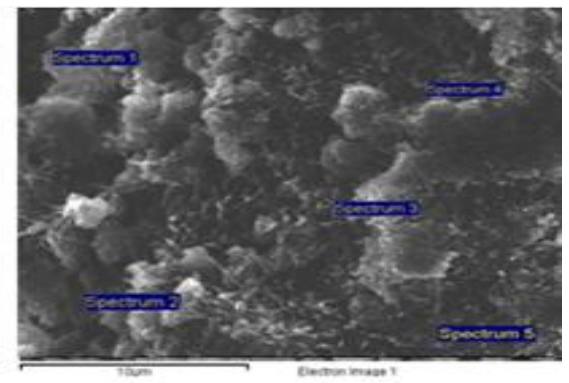

Fig. 4.5. (a to f) Typical EDS images of 28 -day $100 \%$ portland cement specimen with w/cm 0.4. In this figure, only three out of nine representative locations are shown for each of 2200x (a to c) and 5000x magnification ( $d$ to f). As shown five points were chosen randomly at each location, leading to 90 data points for each sample.

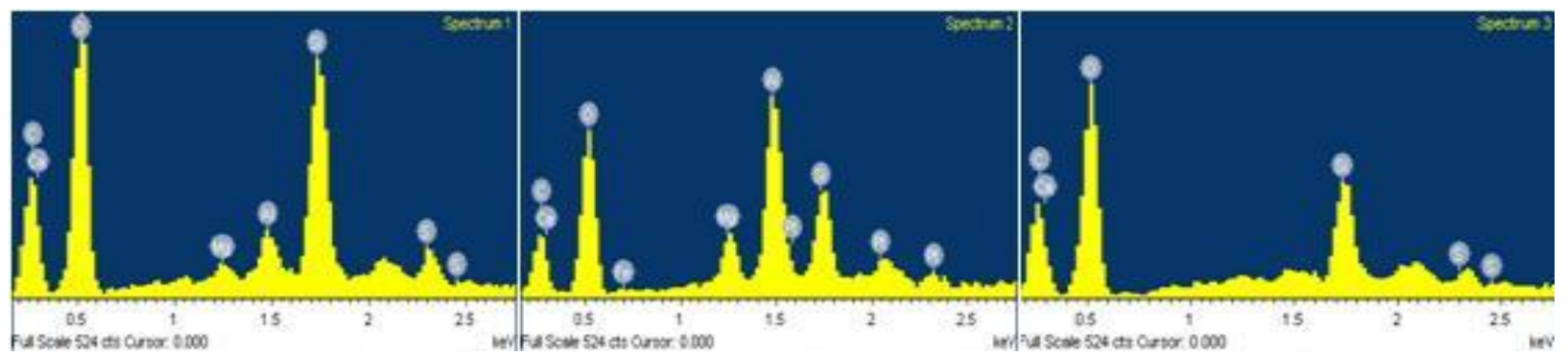

a

b 2200x magnification

C

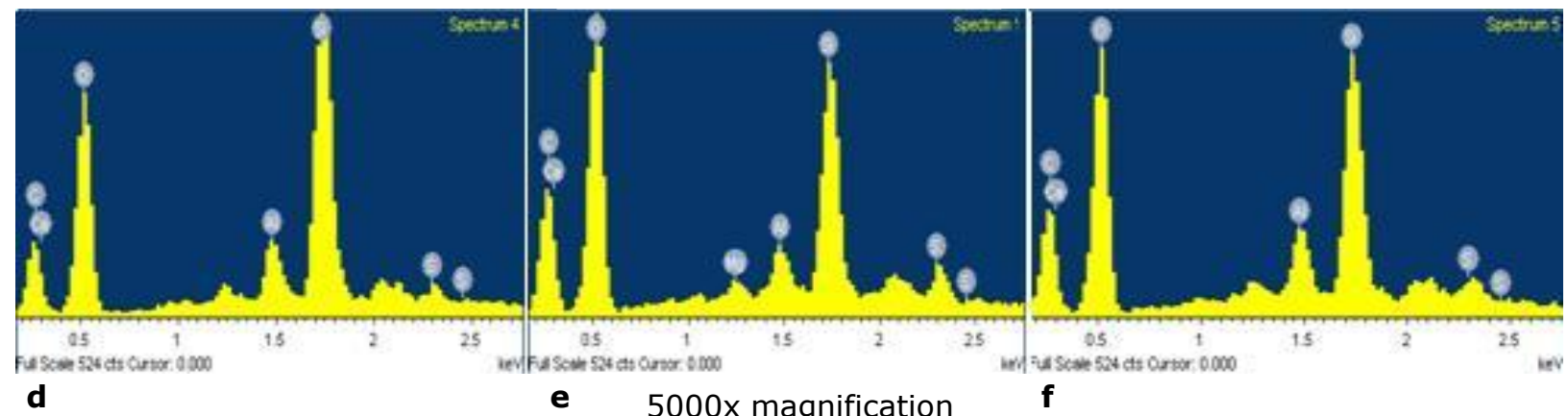

Fig. 4.6. Energy Dispersive X-Ray Spectra (EDS) of 28-days $100 \%$ portland cement specimen with $\mathrm{w} / \mathrm{cm}$ 0.4. (a to e) Five point analyses and (f) the corresponding area average scan for one out of nine such locations (as mentioned in the text) is shown for $2200 x$ magnification only. 

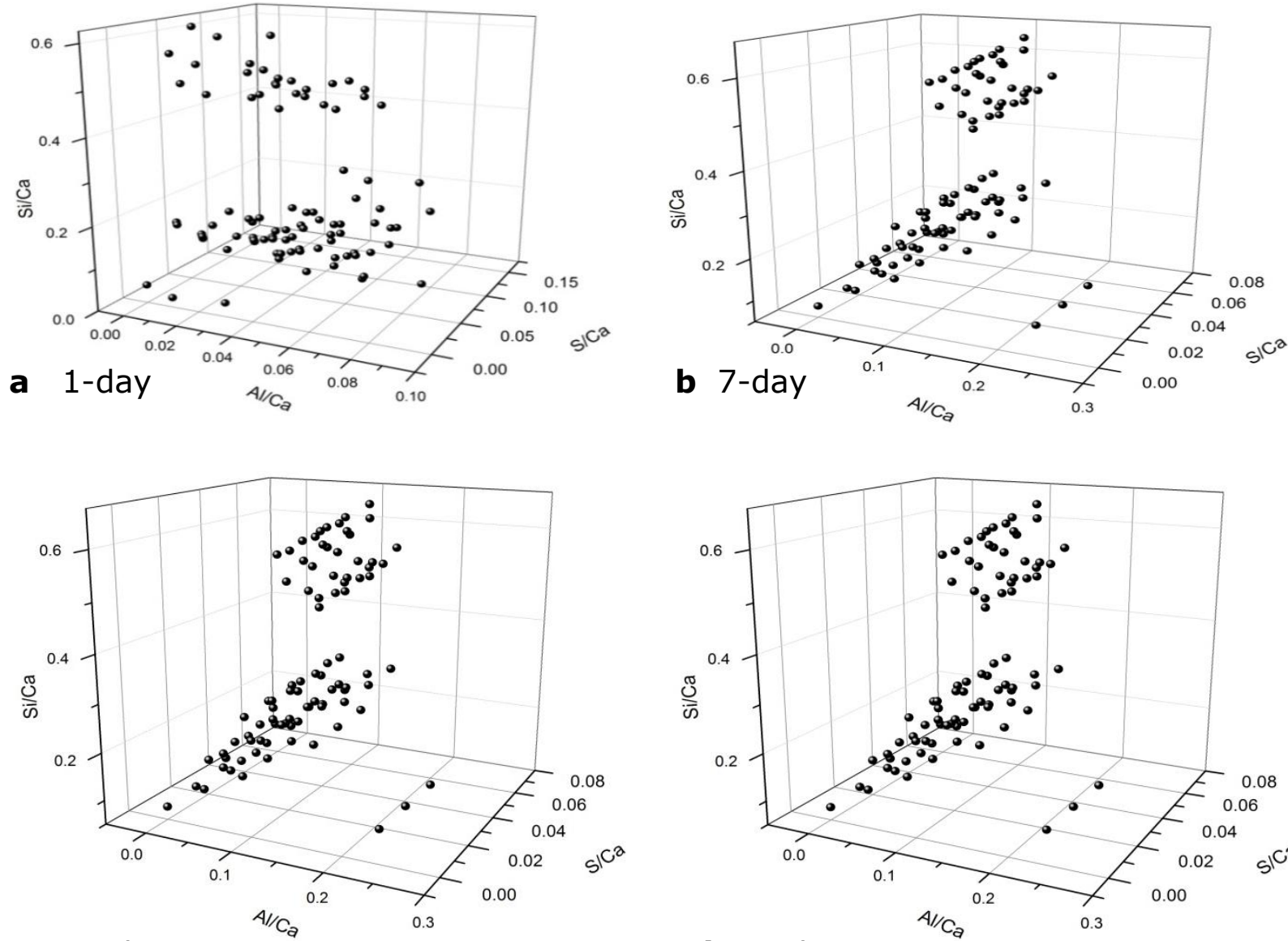

c 28-day

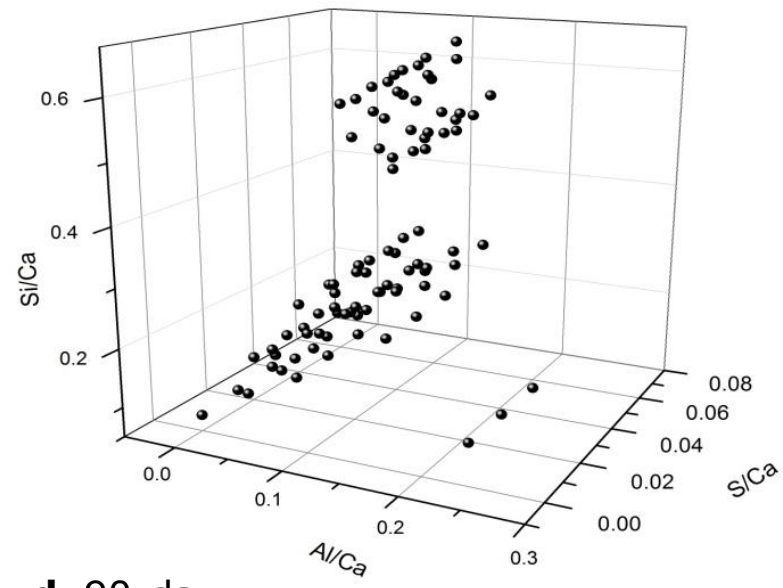

d 90-day

Fig 4.7. (a to d) 3D plots of atomic ratios of silicon, aluminum and sulfur with respect to calcium for a typical pure portland cement paste $(\mathrm{w} / \mathrm{cm}$ ratio of 0.4$)$ at four different ages.

The cements with SCM were optimized individually for each separate mix. The $n$ value was used as 1.753 for all of them. Based on this, a unique $n^{\prime}$ was computed for each mix. The $n^{\prime}$ values for each cement with SCM mix is furnished in Table 4.5. The mix containing 65\% cement, $25 \%$ fly ash, $10 \%$ silica fume and $\mathrm{w} / \mathrm{cm}$ ratio of 0.3 is used as an example and the various analyses carried out on a 28-day old specimen of this mix proportion is shown in the images below (Fig. 4.8, Fig. 4.9, and Fig. 4.10) as typical example for cement and SCM cases. The 3D plots of the atom ratios for all the other cementitious mixes at different ages and different $\mathrm{w} / \mathrm{cm}$ ratios are provided in the Appendix. The comparison between the experimentally obtained value from SEM-EDS and those obtained by the optimization technique for $\mathrm{CSH}(\mathrm{I})$ is shown in Table 4.6 for all the different mix proportions at 28-day age only. 


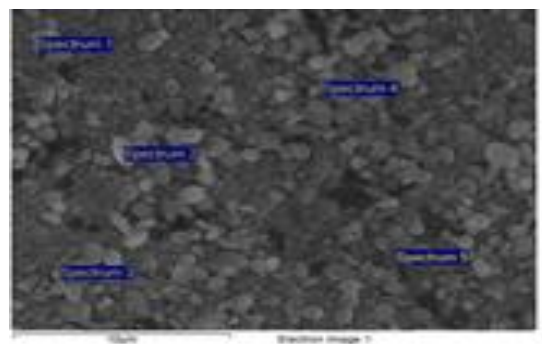

a.

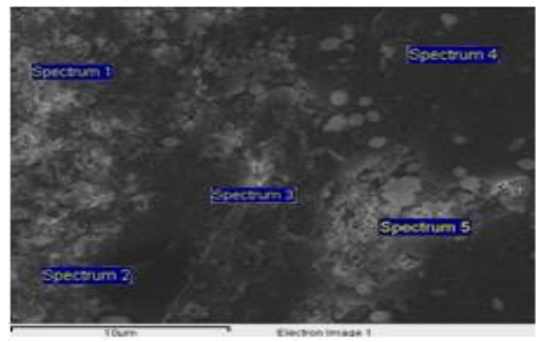

d

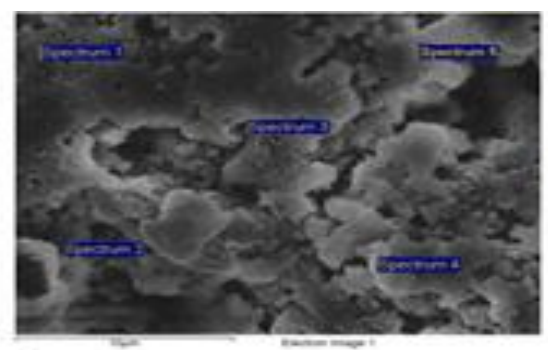

b

2200x magnification

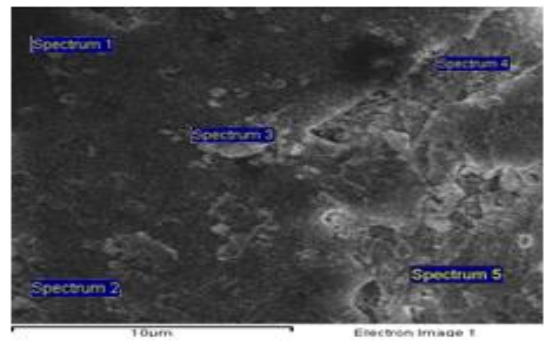

5000x magnification

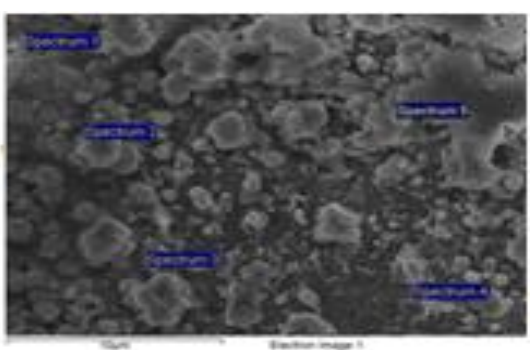

c

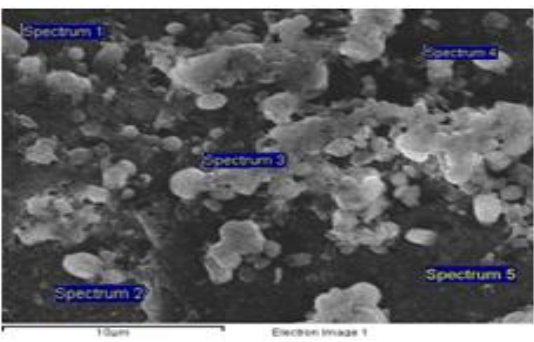

f

Fig 4.8. (a to f) Typical EDS images of 28-day cement with SCM specimen containing $65 \%$ portland cement, $25 \%$ fly ash and $10 \%$ silica fume with $\mathrm{w} / \mathrm{cm}$ ratio 0.4 at three out of nine representative locations are shown for each of 2200x (a to c) and 5000x magnification ( $d$ to f). As shown five points were chosen randomly at each location, leading to 90 data points for each sample.
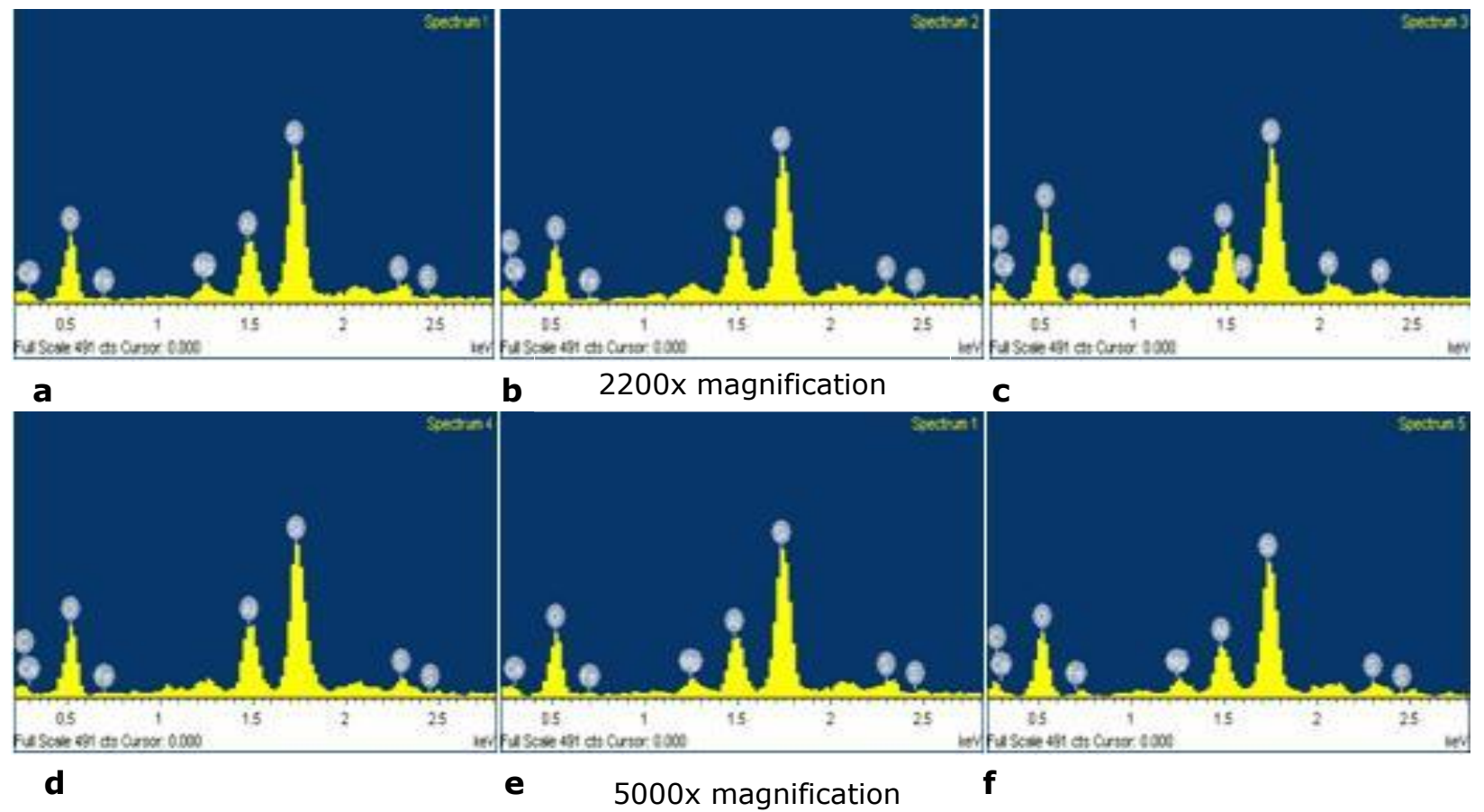

Figure 4.9. EDS images of 28 -day cement specimen with SCM containing $25 \%$ fly ash and $10 \%$ silica fume with $w / \mathrm{cm}$ ratio 0.4 . (a to e) Five point analyses and (f) the corresponding area average scan for one out of nine such locations (as mentioned in the text) is shown for 5000x magnification only. 


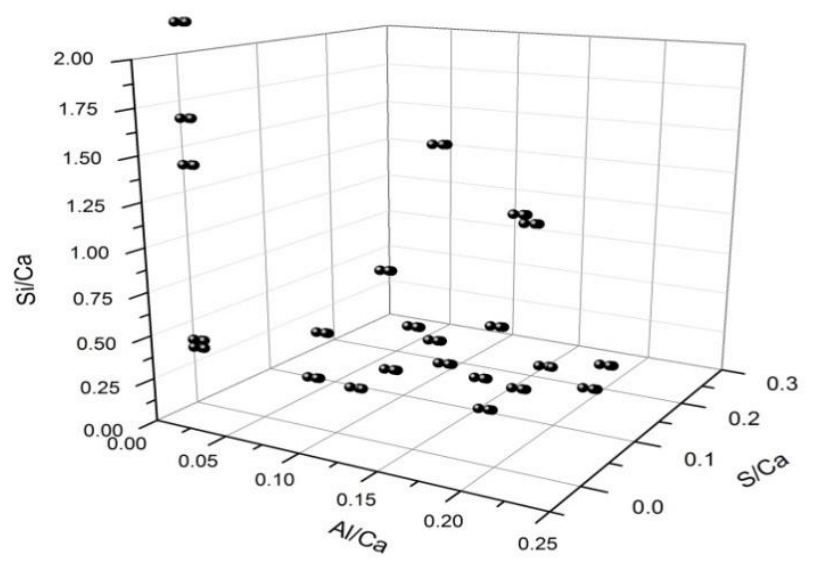

a 1-day

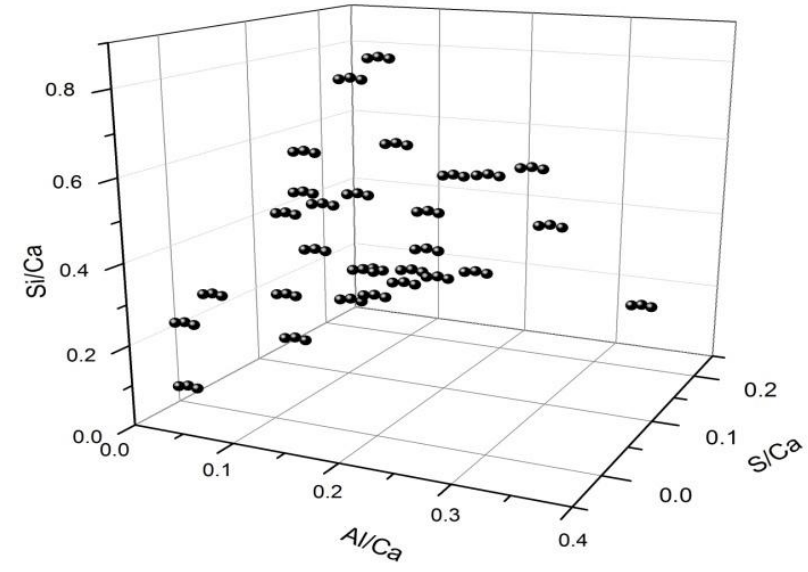

c 28-day

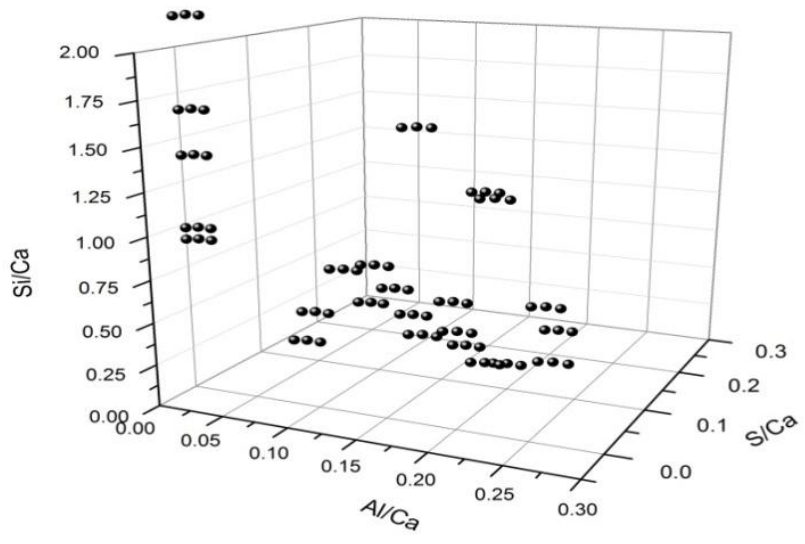

b 7-day

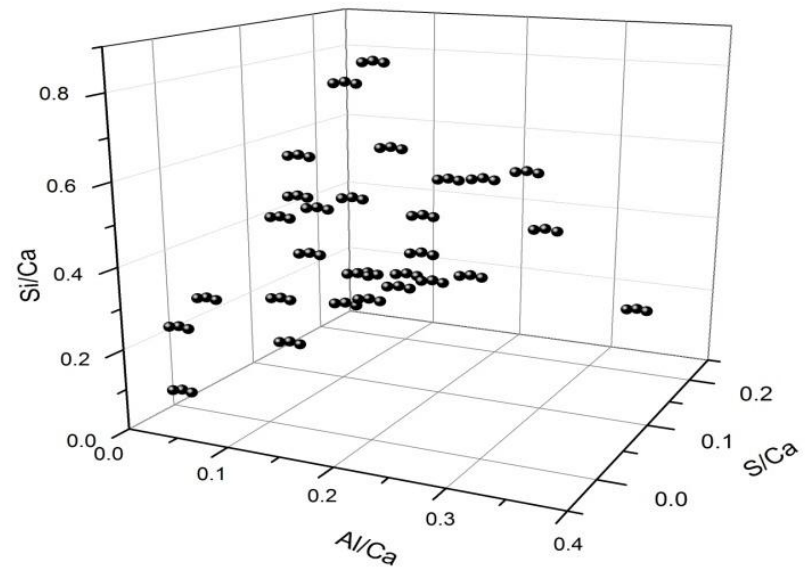

d 90-day

Figure 4.10. (a to d) 3D plots of atomic ratios of silicon, aluminum and sulfur with respect to calcium for a typical cementitious paste containing $25 \%$ fly ash and $10 \%$ silica fume as SCM $(\mathrm{w} / \mathrm{cm}$ ratio of 0.3 ) at four different ages. 
Table 4.5: The $n$ and $n$ ' values for all the mix proportions

\begin{tabular}{|c|c|c|c|}
\hline Mix proportion & $\mathrm{w} / \mathrm{cm}$ & $\mathrm{n}$ & $\mathrm{n}^{\prime}$ \\
\hline $100 \%$ cement & 0.3 & 1.753 & - \\
\hline $100 \%$ cement & 0.4 & 1.753 & - \\
\hline $100 \%$ cement & 0.5 & 1.753 & - \\
\hline $35 \%$ Slag & 0.3 & 1.753 & 1.4 \\
\hline $35 \%$ Slag & 0.4 & 1.753 & 1.4 \\
\hline $45 \%$ Slag & 0.3 & 1.753 & 1.55 \\
\hline $45 \%$ Slag & 0.4 & 1.753 & 1.55 \\
\hline $25 \%$ fly ash & 0.3 & 1.753 & 1.5 \\
\hline $25 \%$ fly ash & 0.4 & 1.753 & 1.5 \\
\hline $35 \%$ fly ash & 0.3 & 1.753 & 1.6 \\
\hline $35 \%$ fly ash & 0.4 & 1.753 & 1.6 \\
\hline $10 \%$ silica fume & 0.3 & 1.753 & 1.1 \\
\hline $10 \%$ silica fume & 0.4 & 1.753 & 1.1 \\
\hline $35 \%$ Slag, 10\% silica fume & 0.3 & 1.753 & 1.41 \\
\hline $35 \%$ Slag, 10\% silica fume & 0.4 & 1.753 & 1.41 \\
\hline $25 \%$ fly ash, 10\% silica fume & 0.3 & 1.753 & 1.1 \\
\hline $25 \%$ fly ash, 10\% silica fume & 0.4 & 1.753 & 1.1 \\
\hline $35 \%$ Slag, 15\% fly ash & 0.3 & 1.753 & 1.4 \\
\hline $35 \%$ Slag, 15\% fly ash & 0.4 & 1.753 & 1.4 \\
\hline
\end{tabular}

Note: The $\mathrm{C}-\mathrm{S}-\mathrm{H}(\mathrm{I})$ is contributed by the given portland cement portion of the mix. So, the values of ' $n$ ' remain constant for all mixes (Bentz 2000). The $n$ ' values vary with the varying proportions of the SCMs, but remains constant for all $\mathrm{w}-\mathrm{cm}$ ratios for each mix. 
Table 4.6: Comparison between the experimentally obtained value from SEM-EDS and that obtained by the optimization technique for $\mathrm{CSH}(\mathrm{I})$ at 28-day age of paste

\begin{tabular}{|c|c|c|c|}
\hline Mix proportion & $\mathrm{w} / \mathrm{cm}$ & $\begin{array}{c}\text { Experimental } \\
\text { CSH (I) }\end{array}$ & $\begin{array}{l}\text { Predicted } \\
\mathrm{CSH}(\mathrm{I})\end{array}$ \\
\hline $100 \%$ cement & 0.3 & 0.400 & 0.415 \\
\hline $100 \%$ cement & $0.4^{*}$ & - & - \\
\hline $100 \%$ cement & 0.5 & 0.700 & 0.702 \\
\hline $35 \%$ Slag & 0.3 & 0.200 & 0.266 \\
\hline $35 \%$ Slag & 0.4 & 0.300 & 0.308 \\
\hline $45 \%$ Slag & 0.3 & 0.200 & 0.220 \\
\hline $45 \%$ Slag & 0.4 & 0.200 & 0.254 \\
\hline $25 \%$ fly ash & 0.3 & 0.367 & 0.387 \\
\hline $25 \%$ fly ash & 0.4 & 0.433 & 0.461 \\
\hline $35 \%$ fly ash & 0.3 & 0.300 & 0.335 \\
\hline $35 \%$ fly ash & 0.4 & 0.400 & 0.399 \\
\hline $10 \%$ silica fume & 0.3 & 0.400 & 0.464 \\
\hline $10 \%$ silica fume & 0.4 & 0.533 & 0.554 \\
\hline $35 \%$ Slag, $10 \%$ silica fume & 0.3 & 0.300 & 0.251 \\
\hline $35 \%$ Slag, $10 \%$ silica fume & 0.4 & 0.233 & 0.286 \\
\hline $25 \%$ fly ash, $10 \%$ silica fume & 0.3 & 0.333 & 0.335 \\
\hline $25 \%$ fly ash, $10 \%$ silica fume & 0.4 & 0.400 & 0.399 \\
\hline $35 \%$ Slag, $15 \%$ fly ash & 0.3 & 0.200 & 0.209 \\
\hline $35 \%$ Slag, $15 \%$ fly ash & 0.4 & 0.233 & 0.243 \\
\hline
\end{tabular}

* The values for $100 \%$ portland cement having a $\mathrm{w} / \mathrm{cm}$ ratio of 0.4 is not shown here, because it was used as the datum for the optimization.

The volume fractions of the C-S-H(I) and C-S-H(II) and the total C-S-H for all the mixes have been plotted with time and shown below: 


\subsection{Comparison of Experimental and Predicted Data for C-S-H(I) and C-S-H(II) Based on Optimized Values of $\mathbf{n}$ and $\mathbf{n}^{\prime}$}

Mix: $100 \%$ cement

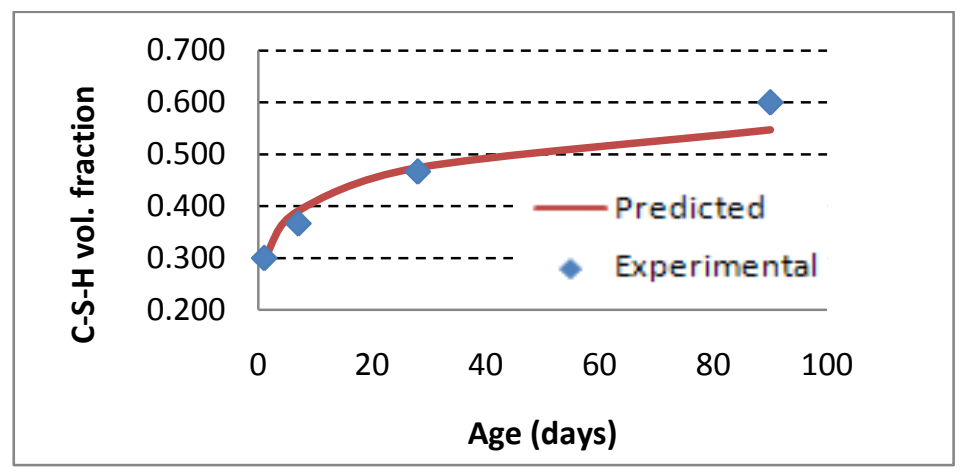

(a) $w / c m=0.4$

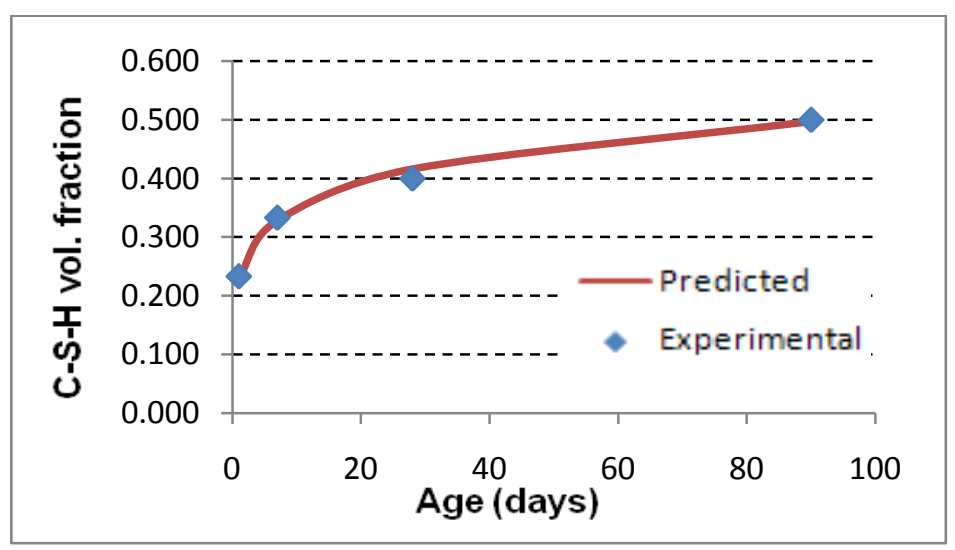

(b) $w / c m=0.3$

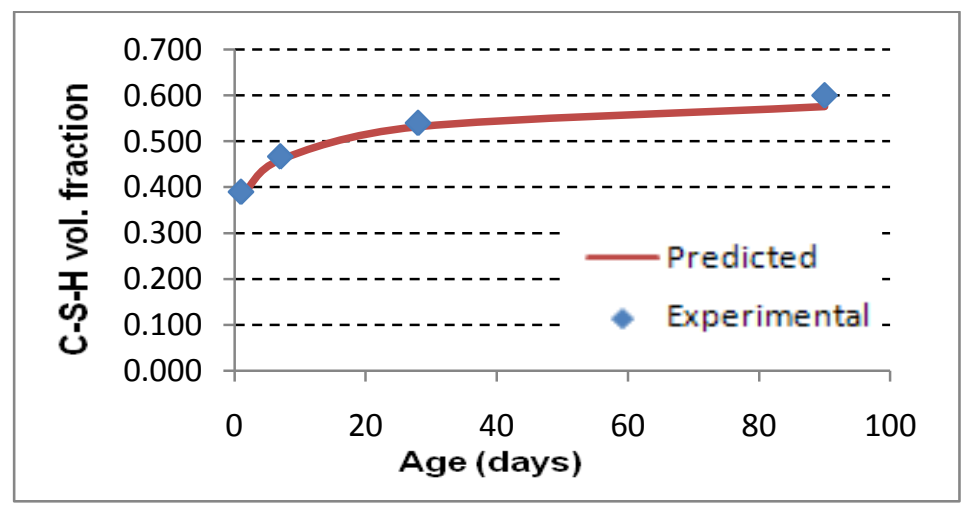

(c) $\mathrm{w} / \mathrm{cm}=0.5$

Fig. 4.11 Comparison of experimental and predicted data for C-S-H(I) at different ages for $100 \%$ cement mixes at three different $\mathrm{w} / \mathrm{cm}$ ratios. 
Mix: $35 \%$ slag
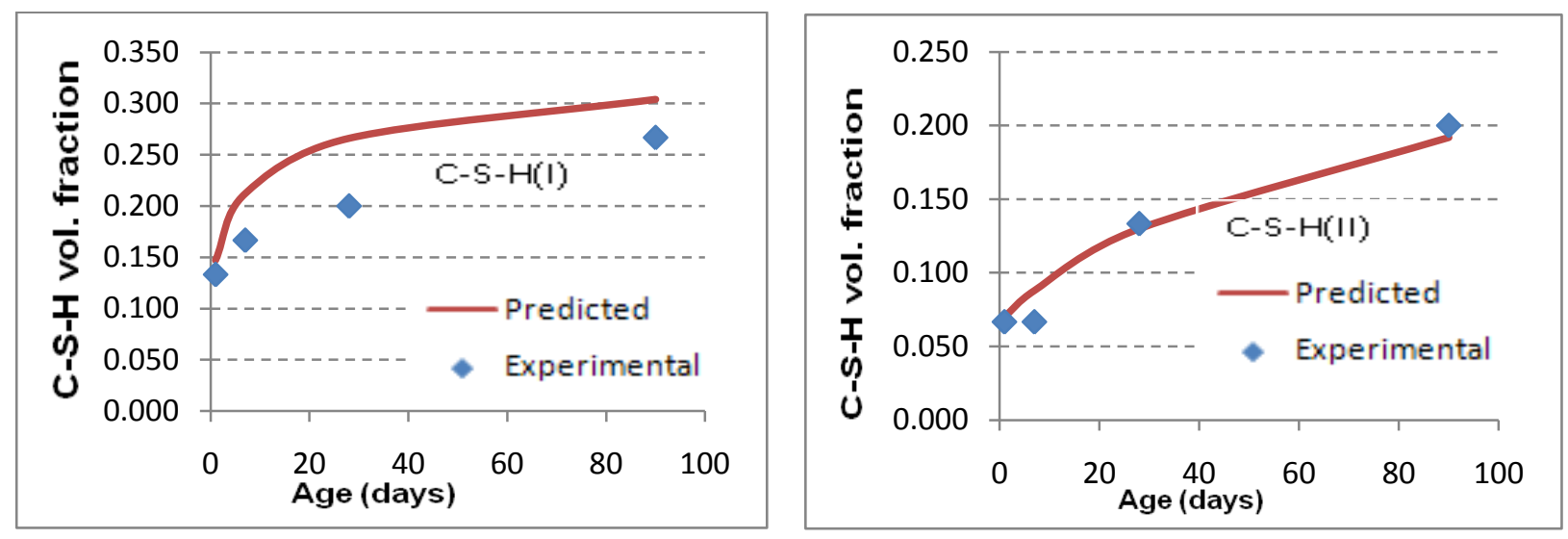

(a) $\mathrm{w} / \mathrm{cm}=0.3$
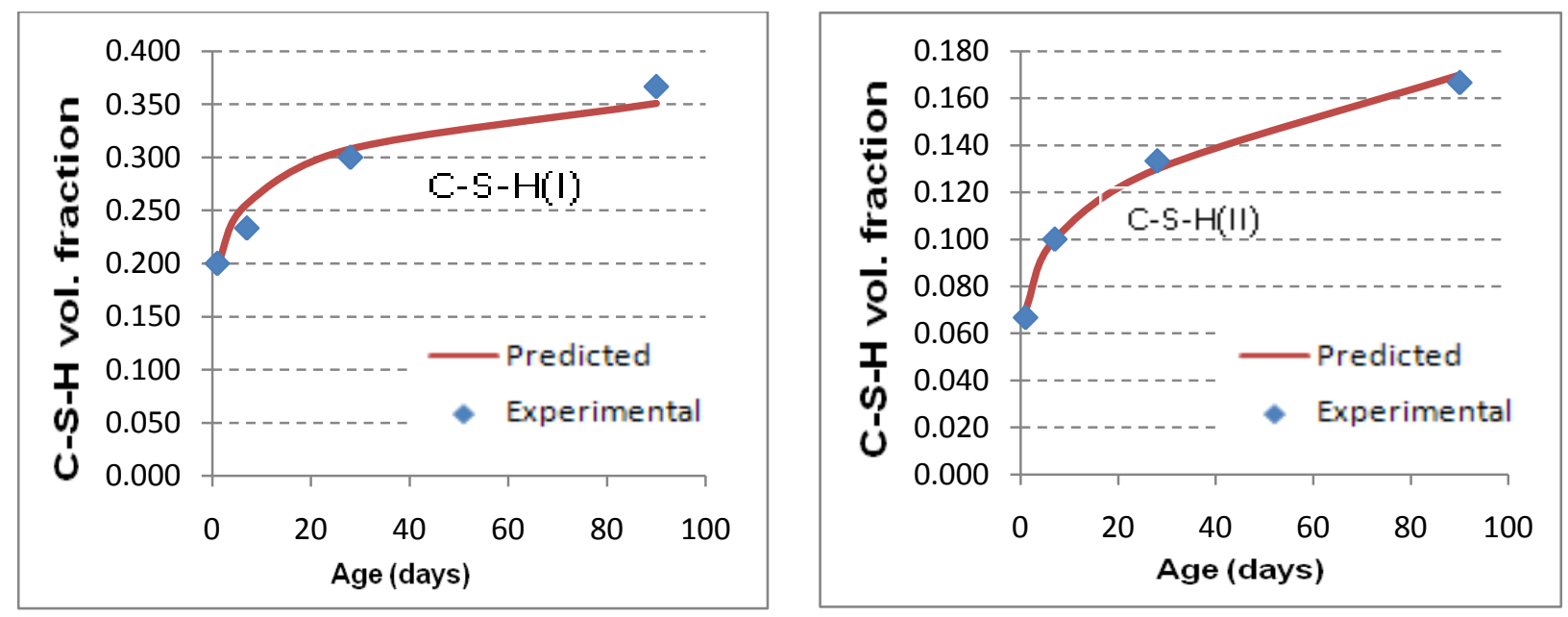

(b) $w / c m=0.4$

Fig. 4.12 Comparison of experimental and predicted data for C-S-H(I) and C-S-H(II) at different ages for mixes containing $35 \%$ replacement of cement by slag at two different $\mathrm{w} / \mathrm{cm}$ ratios. 
Mix: $25 \%$ fly ash
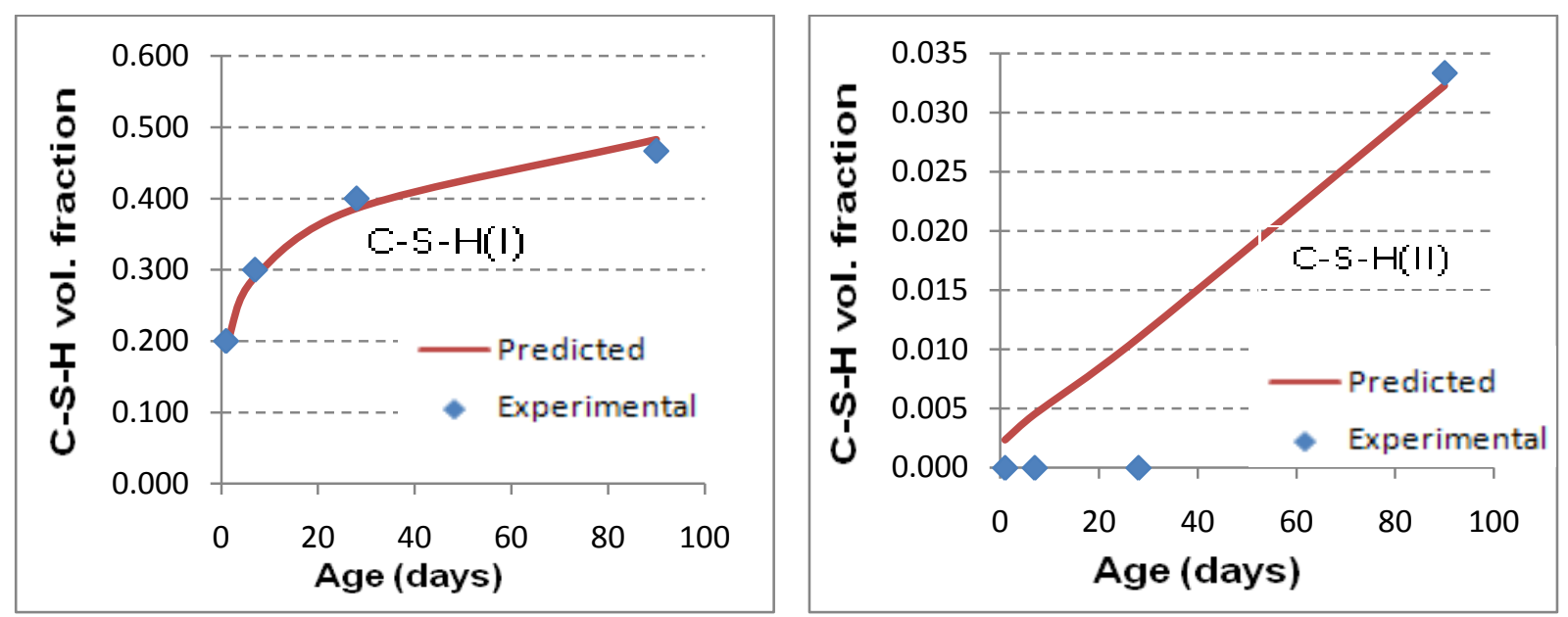

(a) $\mathrm{w} / \mathrm{cm}=0.3$
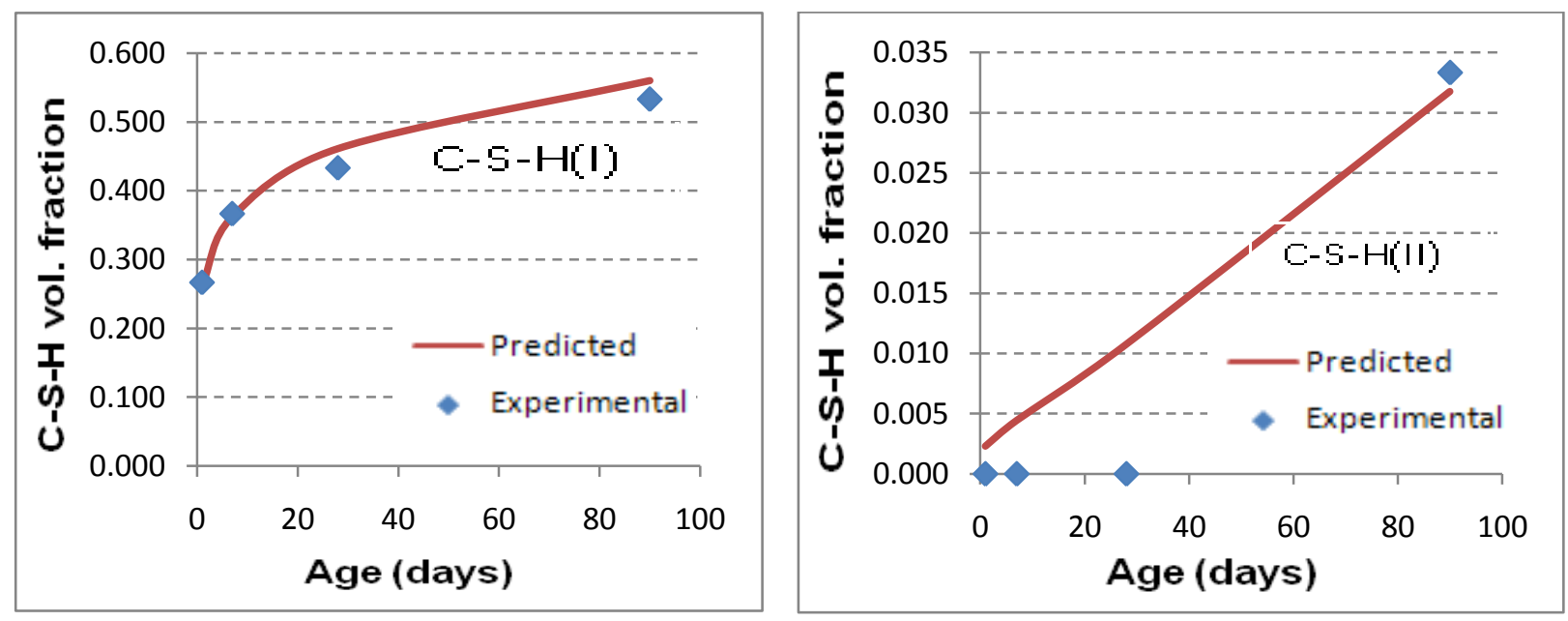

(b) $w / c m=0.4$

Fig. 4.13 Comparison of experimental and predicted data for $\mathrm{C}-\mathrm{S}-\mathrm{H}$ (I) and $\mathrm{C}-\mathrm{S}-\mathrm{H}$ (II) at different ages for mixes containing $25 \%$ replacement of cement by fly ash at two different $\mathrm{w} / \mathrm{cm}$ ratios. 
Mix: $10 \%$ silica fume
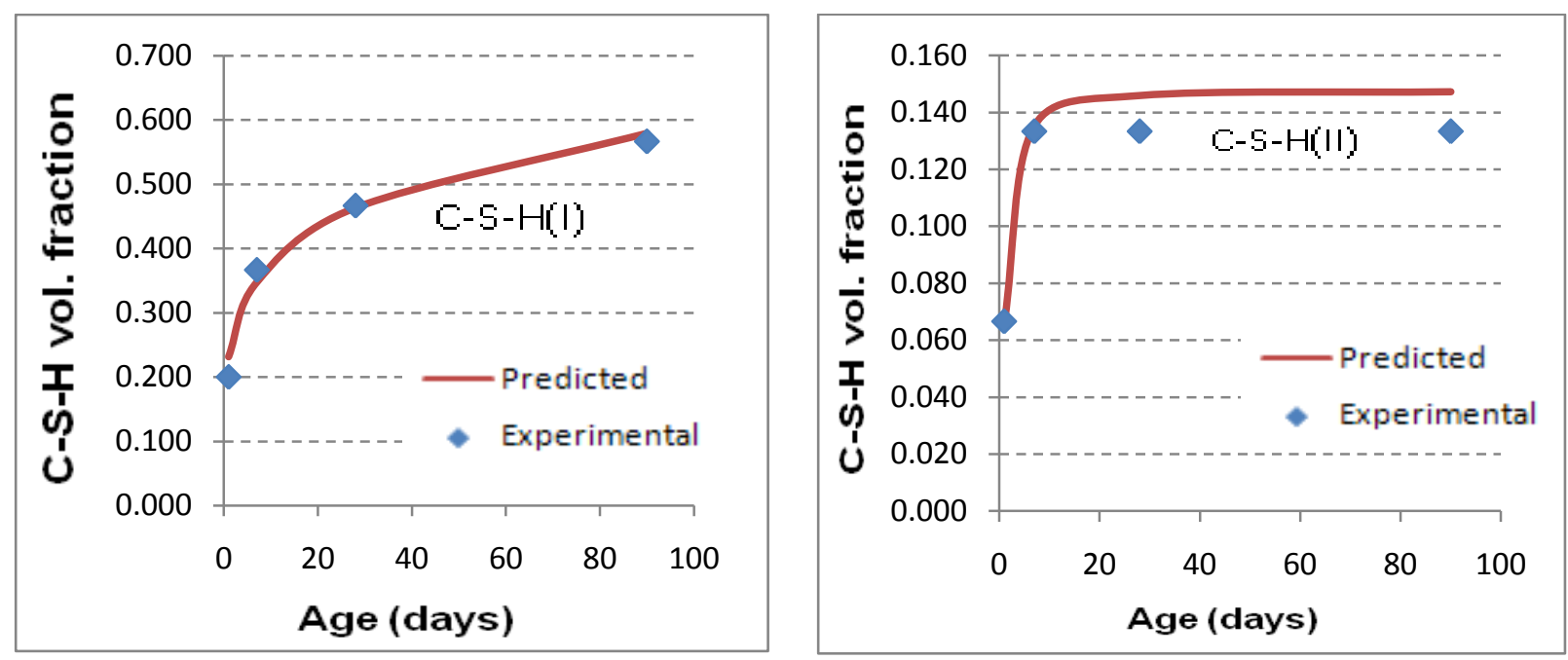

(a) $\mathrm{w} / \mathrm{cm}=0.3$
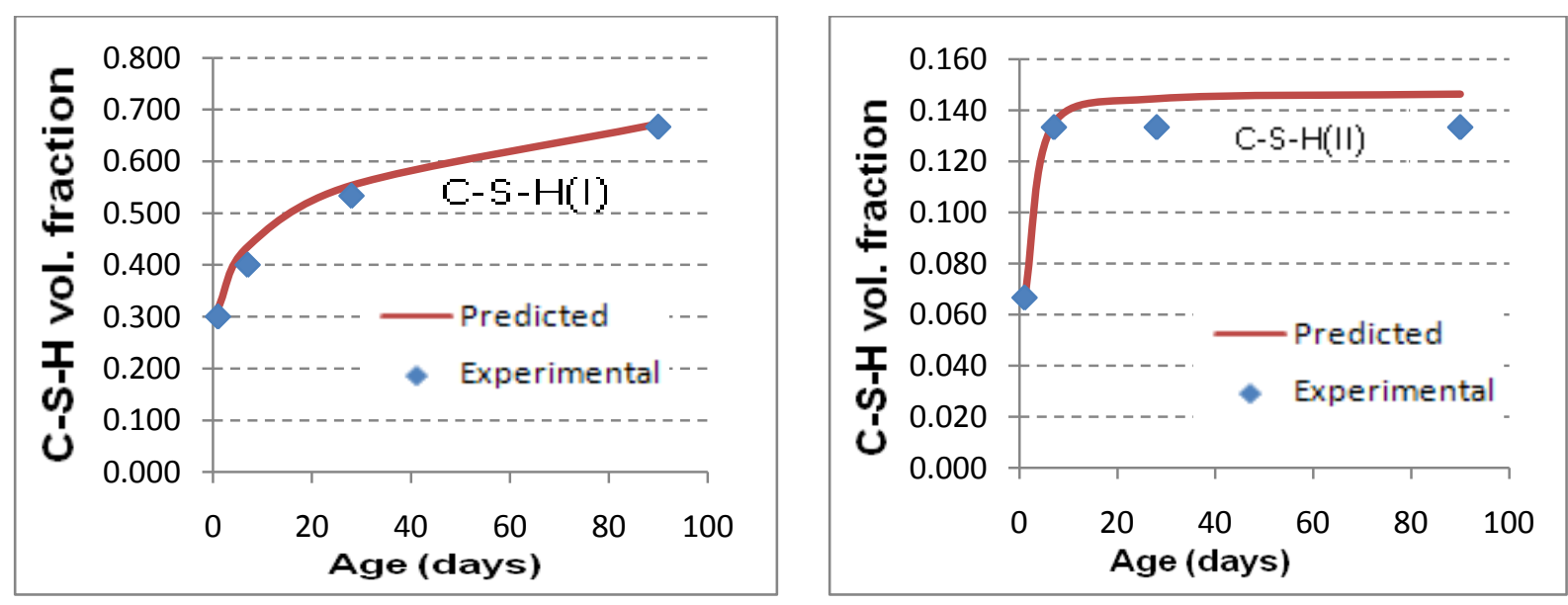

(b) $w / c m=0.4$

Fig. 4.14 Comparison of experimental and predicted data for C-S-H(I) and C-S-H(II) at different ages for mixes containing replacement of cement by $10 \%$ silica fume at two different $\mathrm{w} / \mathrm{cm}$ ratios. 


\section{Mix: $35 \%$ slag, $10 \%$ silica fume}
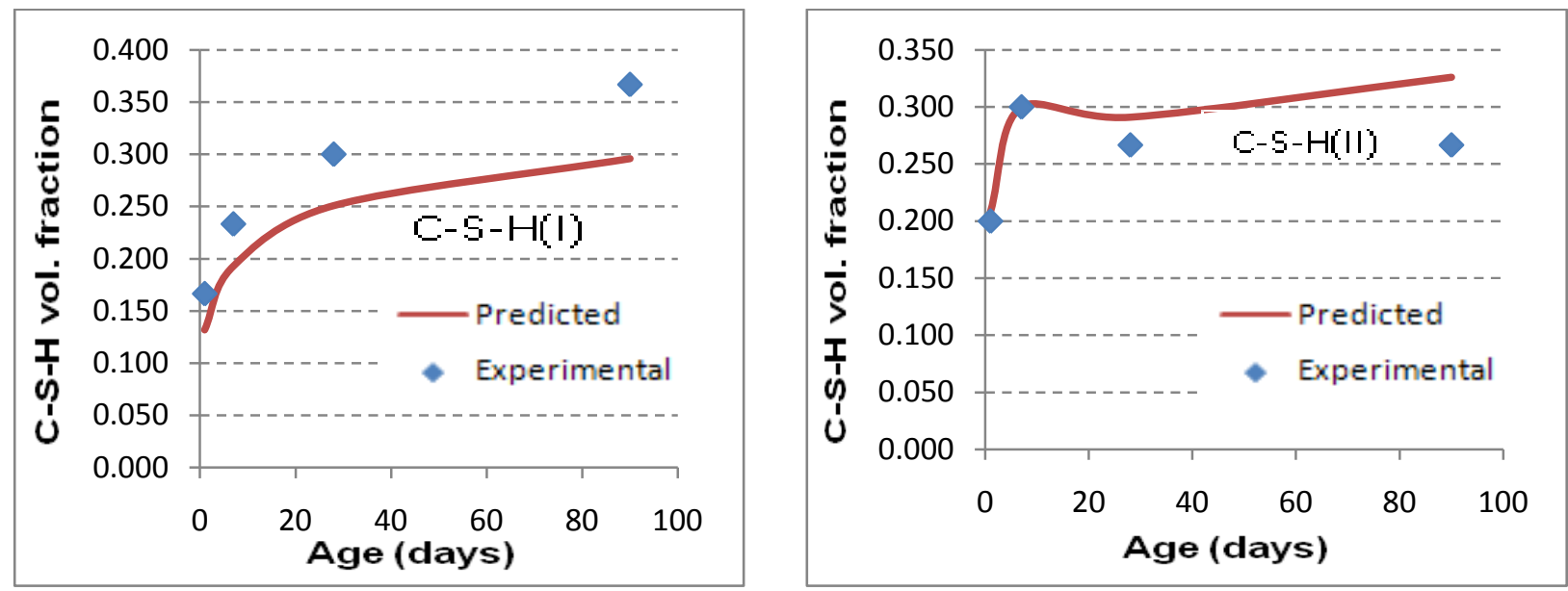

(a) $\mathrm{w} / \mathrm{cm}=0.3$
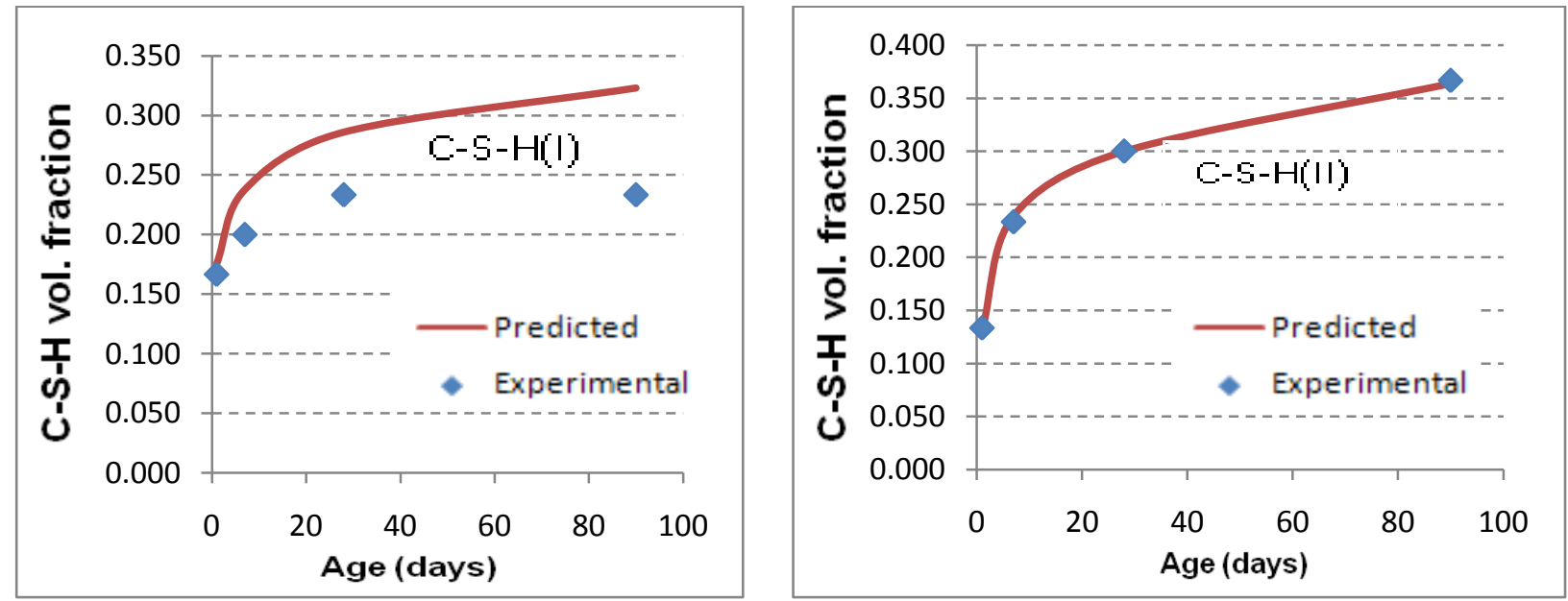

(b) $w / c m=0.4$

Fig. 4.15 Comparison of experimental and predicted data for C-S-H(I) and C-S-H(II) at different ages for mixes containing replacement of cement by $35 \%$ slag and $10 \%$ silica fume at two different $\mathrm{w} / \mathrm{cm}$ ratios. 
Mix: $25 \%$ fly ash, $10 \%$ silica fume
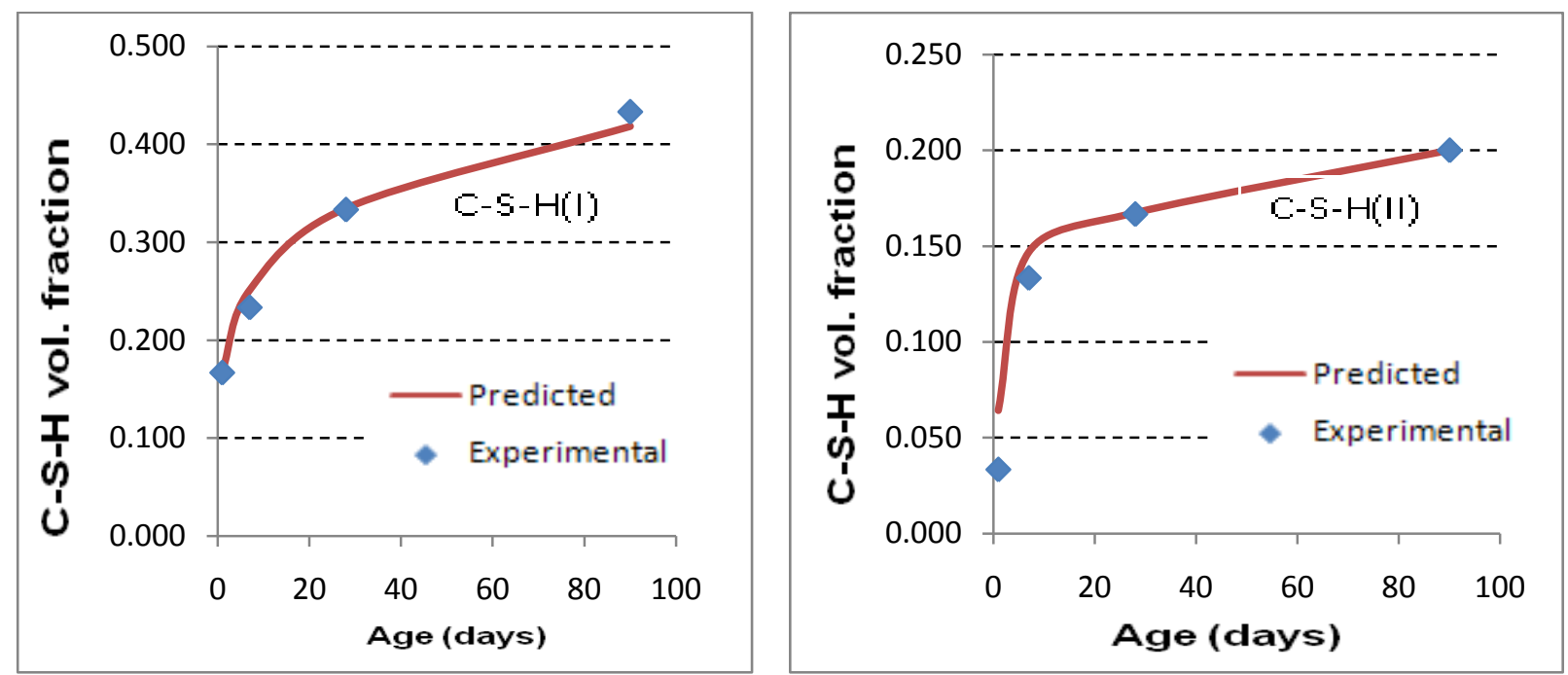

(a) $\mathrm{w} / \mathrm{cm}=0.3$
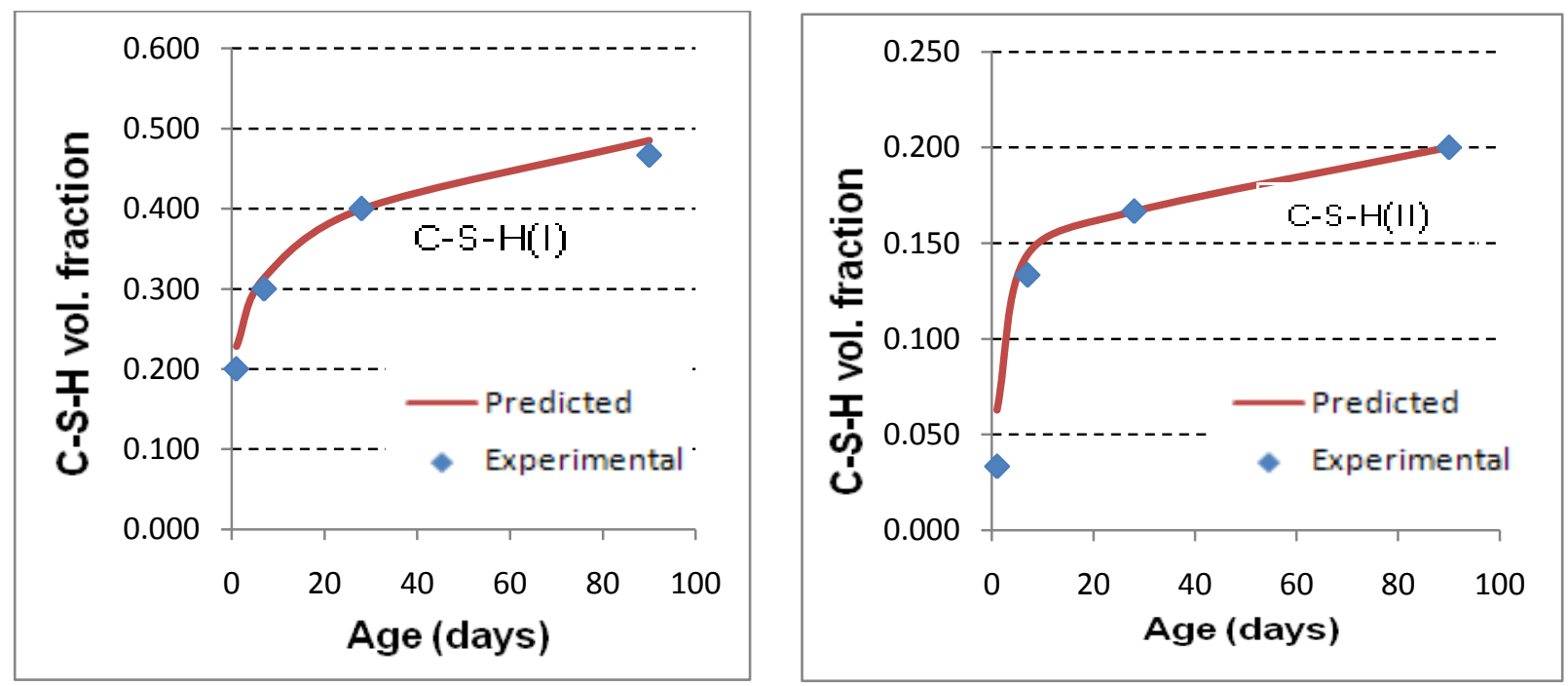

(b) $w / c m=0.4$

Fig. 4.16 Comparison of experimental and predicted data for C-S-H(I) and C-S-H(II) at different ages for mixes containing replacement of cement by $25 \%$ fly ash and $10 \%$ silica fume at two different $\mathrm{w} / \mathrm{cm}$ ratios. 


\subsubsection{Observations from the comparison between experimental and predicted C-S-H(I) and C-S-H(II)}

\section{(A) C-S-H(I)}

Based on the plots of the comparison of experimental and predicted $\mathrm{C}-\mathrm{S}-\mathrm{H}$ values in section 4.9 (Figs. 4.11 through 4.16), it is evident that the experimental and predicted values are very closely matched in most cases, except in the cases of (i)35\% slag (Fig 4.12) and (ii) $35 \%$ slag and $10 \%$ (Fig 4.15) silica fume. This indicates that the optimization technique adopted for the analysis of microscale data is fairly accurate and can be used for any combinations of the SCMs. The discrepancies mentioned in the two cases were most likely to have been due to the lack of representative sampling points, which made it difficult to capture the full behavior of the slag component and the corresponding development of C-S-H(I).

\section{(B) C-S-H(II)}

The experimental and predicted values in case of C-S-H(II) show very good correlation (Figs 4.11 through 4.16 ), except in the cases of early-age hydration of the $25 \%$ fly ash cement (Fig 4.13). This shows the applicability of the optimization technique for both $\mathrm{C}-\mathrm{S}-\mathrm{H}(\mathrm{I})$ and C-S-H(II). The discrepancies mentioned were negligible. They occurred due to the very slow degree of reaction (about 0.01 at 1 -day age) of the fly ash at early age. It is near impossible to capture this hydration behavior through EDS studies only. 


\subsection{Variation of C-S-H(I) and C-S-H(II) and the Total C-S-H Volumes with Time for Different Proportions of SCM and Different $\mathbf{w} / \mathbf{c m}$ ratios}

The following figures furnish the results for C-S-H(I), C-S-H(II), and the total C-S-H volume for all the mixes at different $\mathrm{w} / \mathrm{cm}$ ratios and at different ages. The corresponding tables are present in the Appendix.

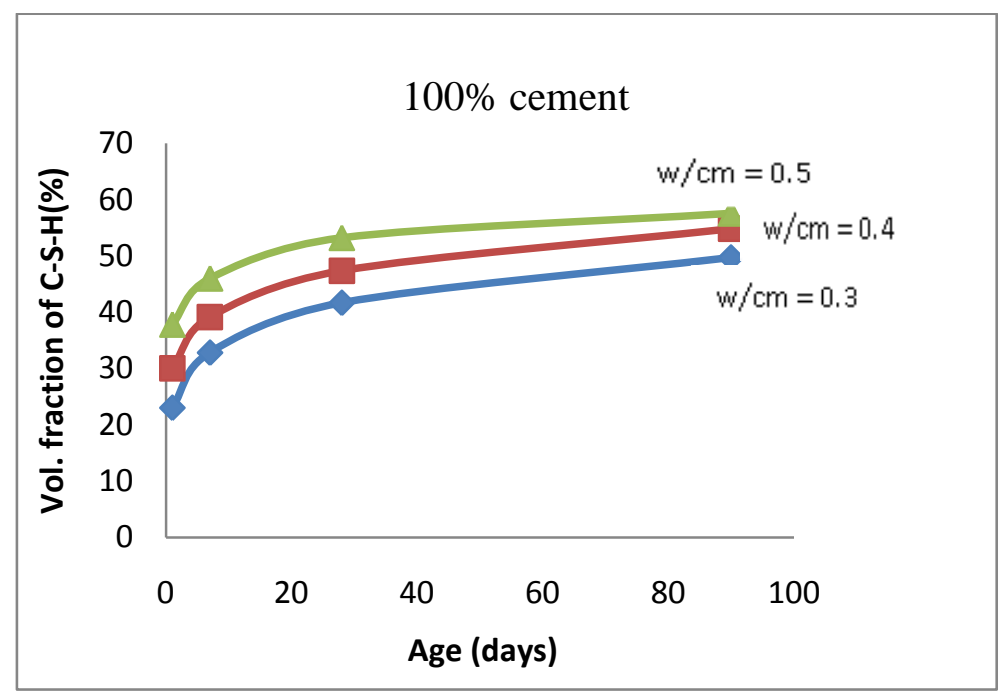

Fig. 4.17 Variation of C-S-H(I) at different ages for $100 \%$ cement mixes at three different w/cm ratios.
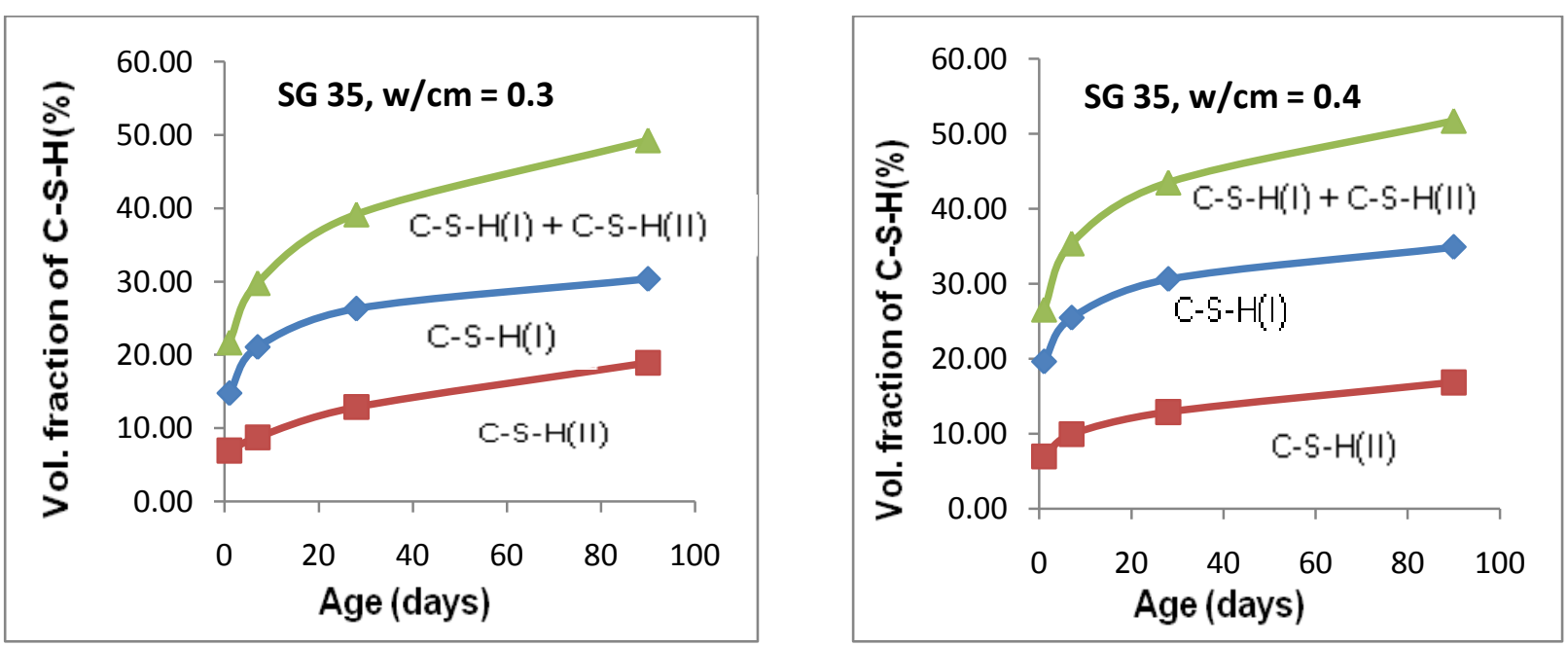

Fig. 4.18 Variation of C-S-H(I), C-S-H(II) and total C-S-H at different ages for mixes containing replacement of cement by $35 \%$ slag at two different $\mathrm{w} / \mathrm{cm}$ ratios. 

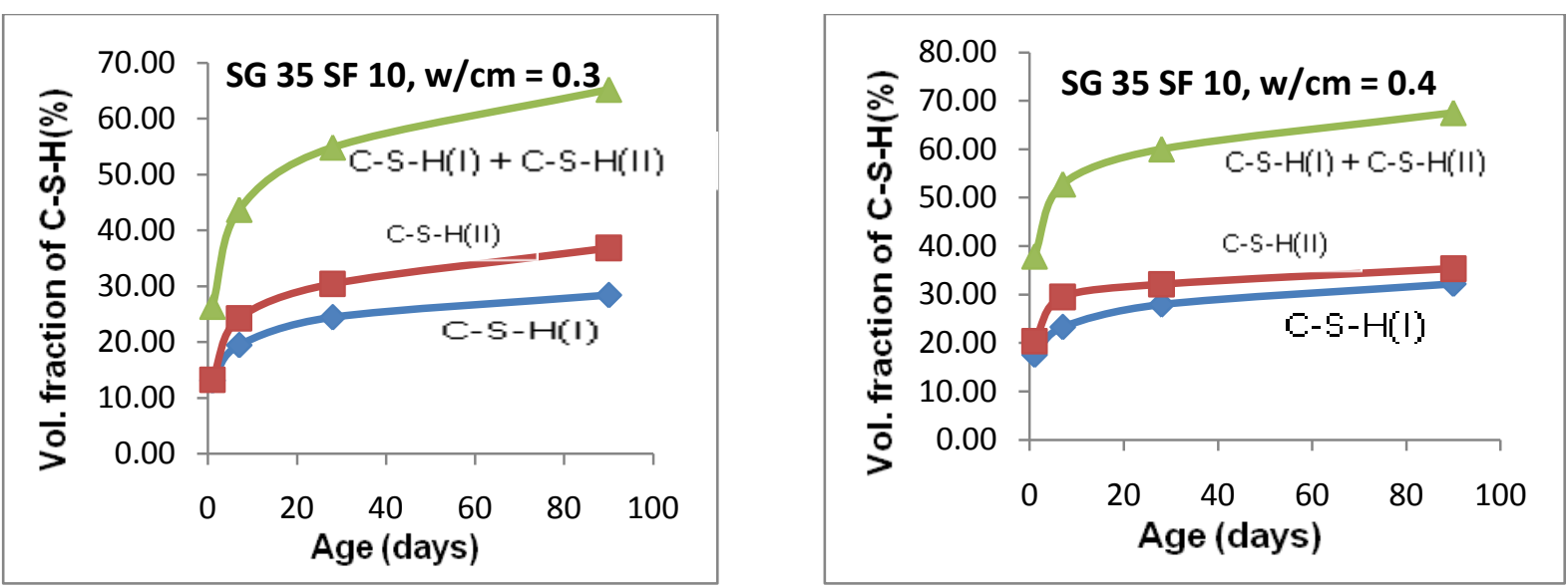

Fig. 4.19 Variation of C-S-H(I), C-S-H(II) and total C-S-H at different ages for mixes containing replacement of cement by $35 \%$ slag and $10 \%$ silica fume at two different $\mathrm{w} / \mathrm{cm}$ ratios.
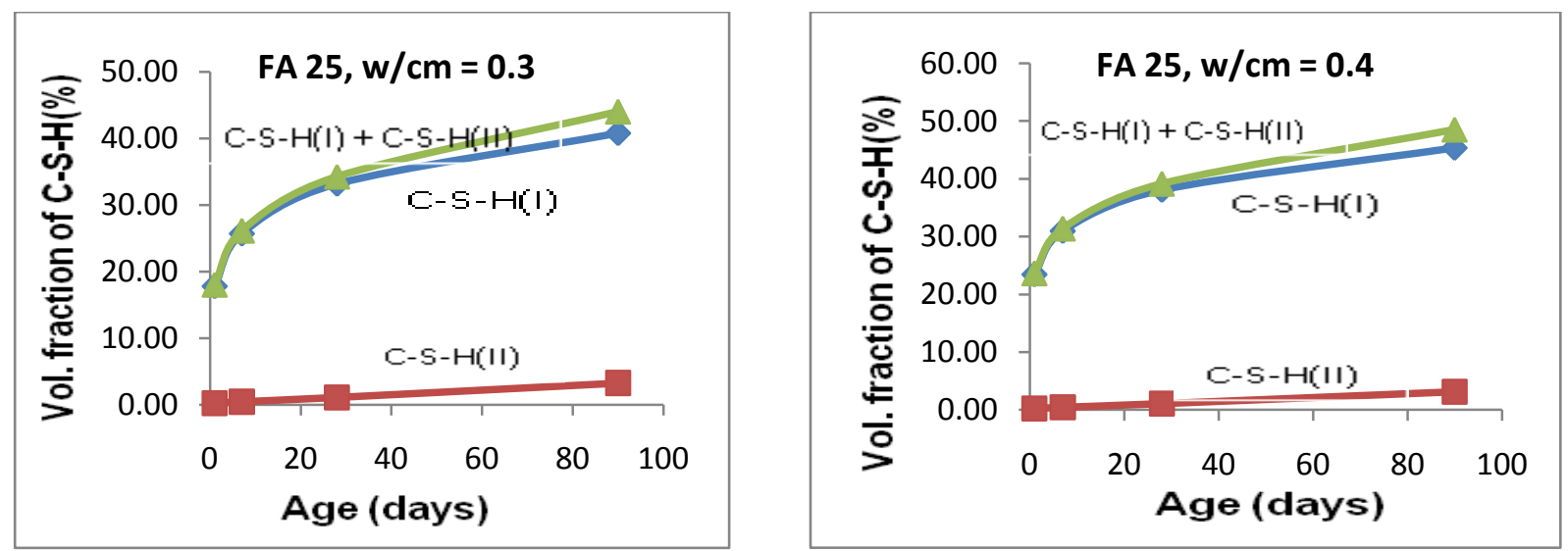

Fig. 4.20 Variation of C-S-H(I), C-S-H(II) and total C-S-H at different ages for mixes containing replacement of cement by $25 \%$ fly ash at two different $\mathrm{w} / \mathrm{cm}$ ratios.
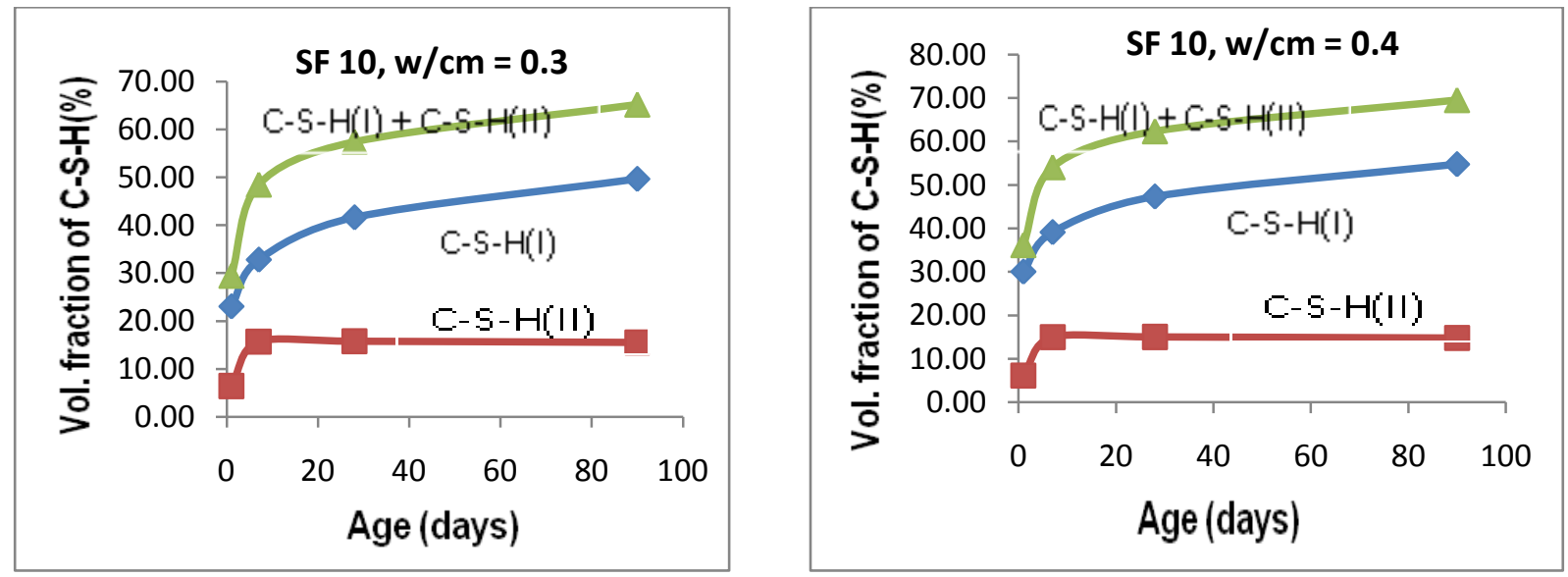

Fig. 4.21 Variation of C-S-H(I), C-S-H(II) and total C-S-H at different ages for mixes containing replacement of cement by $10 \%$ silica fume at two different $\mathrm{w} / \mathrm{cm}$ ratios. 


\subsubsection{Observations from the C-S-H(I), C-S-H(II) and total C-S-H volume fractions}

\section{(A) Total C-S-H}

In general, it is observed that the volume fraction of the C-S-H(I), C-S-H(II) and the total $\mathrm{C}-\mathrm{S}-\mathrm{H}$ increases with increasing $\mathrm{w} / \mathrm{cm}$ ratio for all the cases, irrespective of age and proportion of SCM (Fig. 4.17 through 4.21).

In case of portland cement containing no SCM, there is no C-S-H(II). The volume fraction of $\mathrm{C}-\mathrm{S}-\mathrm{H}$ is found to increase with the addition of SCM in all the cases, due to the formation of the secondary $\mathrm{C}-\mathrm{S}-\mathrm{H}$ along with the primary $\mathrm{C}-\mathrm{S}-\mathrm{H}$.

\section{(B) C-S-H(I)}

The volume fraction of C-S-H(I) has been found to decrease with the addition of SCM in all the cases. The $\mathrm{C}-\mathrm{S}-\mathrm{H}(\mathrm{I})$ is produced by the hydration of pure portland cement only. So, the replacement of cement by SCM automatically causes a reduction in the volume fraction of C-S-H(I) produced.

\section{(C) C-S-H(II)}

The volume fraction of C-S-H(II) is less than the volume fraction of C-S-H(I) in case of (i) $35 \%$ slag (Fig. 4.18), (ii) $25 \%$ fly ash (Fig 4.20 ) and (iii) $10 \%$ silica fume (Fig. 4.21). The volume of C-S-H(II) is very small in case of $25 \%$ fly ash due to the very slow rate of reaction of fly ash cement. The volume of C-S-H(II) is greater than the volume of C-S-H(I) in case of replacement by $35 \%$ slag and $10 \%$ silica fume (Fig 4.19 ). This happened due to the presence of silica fume along with slag both of which have higher rates of reaction as compared to slag cement. 


\subsection{Porosity}

As mentioned in Chapter 2, Taylor (1997) calculated the porosities of cementitious pastes based on the Powers-Brownyard model. The volume of capillary pores per unit mass of the cement is obtained by subtracting the volumes of the hydration products and the unhydrated residue from the total volume of the hydrating paste. The volume of the gel pores is calculated as $v_{g}=\alpha^{*}\left(\mathrm{~m}_{\mathrm{g}} \mathrm{v}_{\mathrm{g}}\right)$. The gel porosity was assumed to be 0.28 times the volume of the hydrated paste for both the pure portland cement and the cementitious systems containing SCM. The capillary porosity was determined by subtracting the gel porosity, the volume of the hydrated phases and the unhydrated residue from the initial volume of the hydrating cementitious system.

$\mathrm{V}_{\text {cap }}=\left(\mathrm{v}_{\mathrm{c}}+\mathrm{w} / \mathrm{cm}\right)-\mathrm{v}_{\mathrm{hcp}}-\mathrm{v}_{\mathrm{g}}-\mathrm{v}_{\text {unhyd }}$

Where

$\mathrm{V}_{\text {cap }}=$ Capillary porosity

$\mathrm{v}_{\mathrm{c}}=$ initial volume of unhydrated cementitious materials

$\mathrm{w} / \mathrm{cm}=$ water-cement ratio $=$ initial water-content in unit volume of cementitious system undergoing hydration

$\mathrm{V}_{\mathrm{hcp}}=$ volume of hydrated products at any instant of time

$\mathrm{v}_{\mathrm{g}}=$ volume of gel pores

$\mathrm{v}_{\text {unhyd }}=$ volume of unhydrated residue

\subsubsection{Variation of pore volumes with time for different proportions of SCM and different $w / \mathrm{cm}$ ratios}

The following figures furnish the results for capillary porosity of all the mixes at different $\mathrm{w} / \mathrm{cm}$ ratios and at different ages. The porosity values were found to decrease on addition of the SCM, owing to the low specific gravity and hence higher volume of the $\mathrm{C}-\mathrm{S}-\mathrm{H}$ (II) than the $\mathrm{CH}$ from which it ts formed by pozzolanic reactions. The corresponding tables are present in the Appendix. 

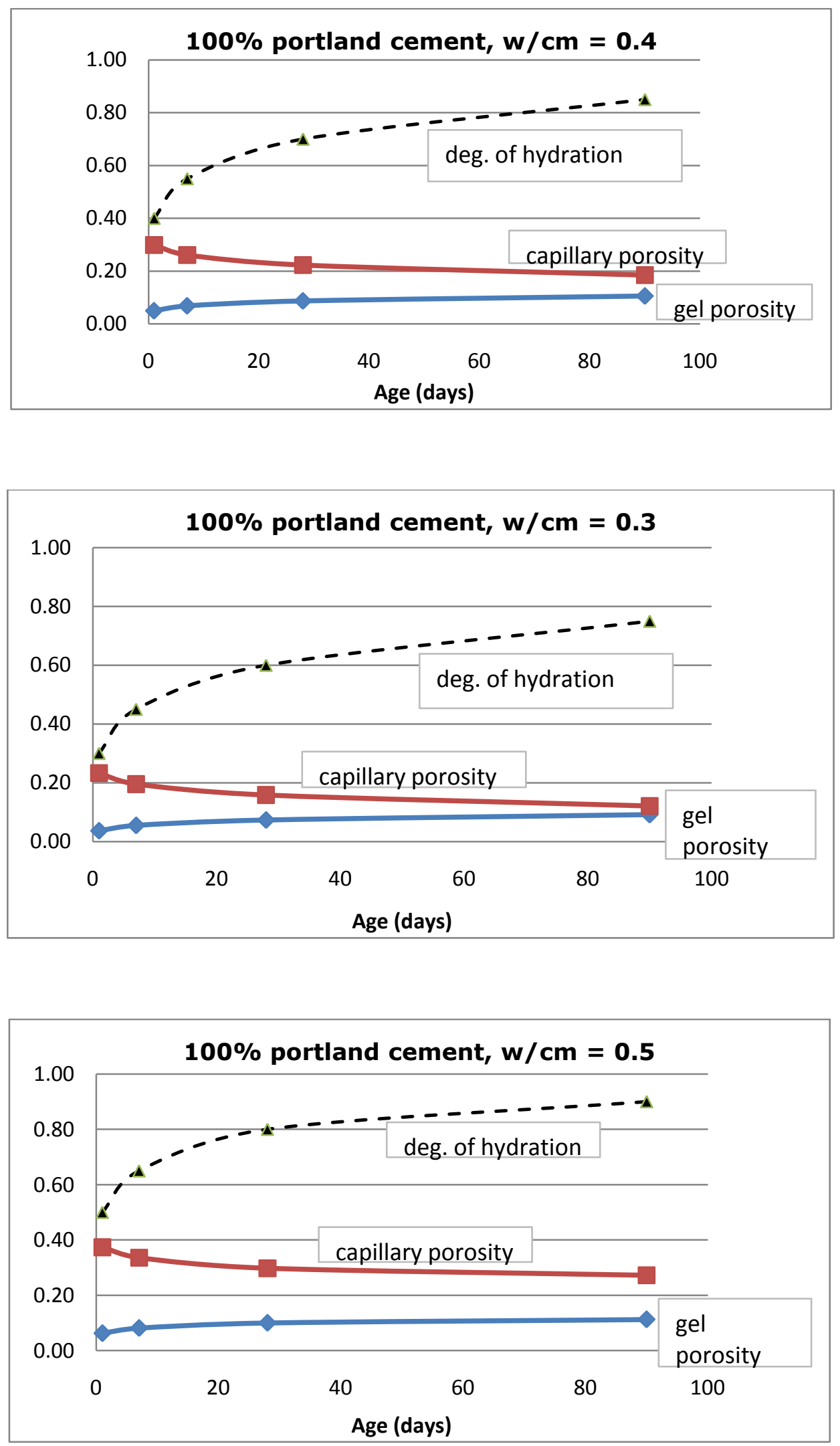

Fig 4.22 Variation of capillary and gel porosity with increasing degree of hydration for $100 \%$ cement mixes at three different $\mathrm{w} / \mathrm{cm}$ ratios. 

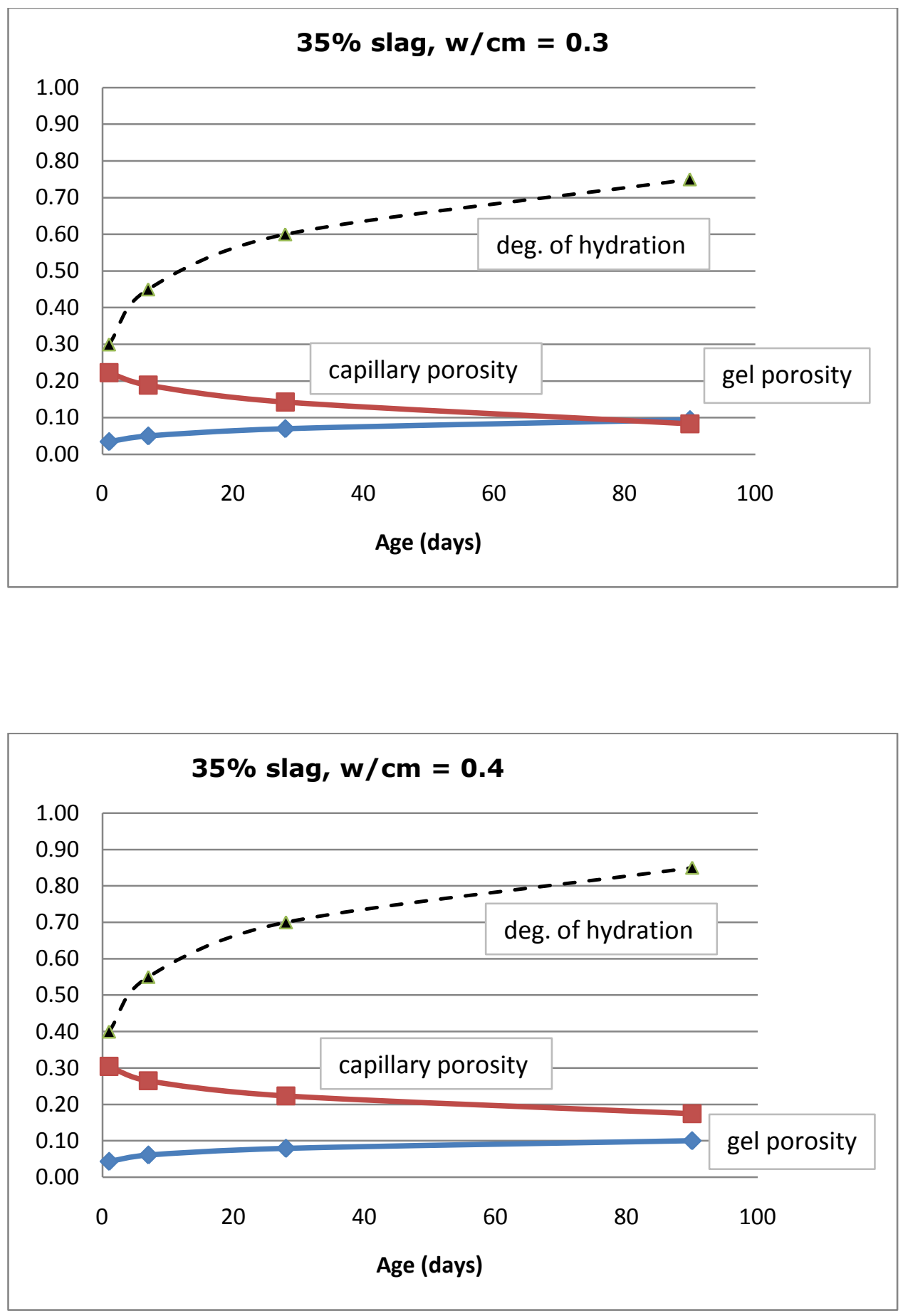

Fig 4.23 Variation of capillary and gel porosity with increasing degree of hydration for mixes containing replacement of cement by $35 \%$ slag. 

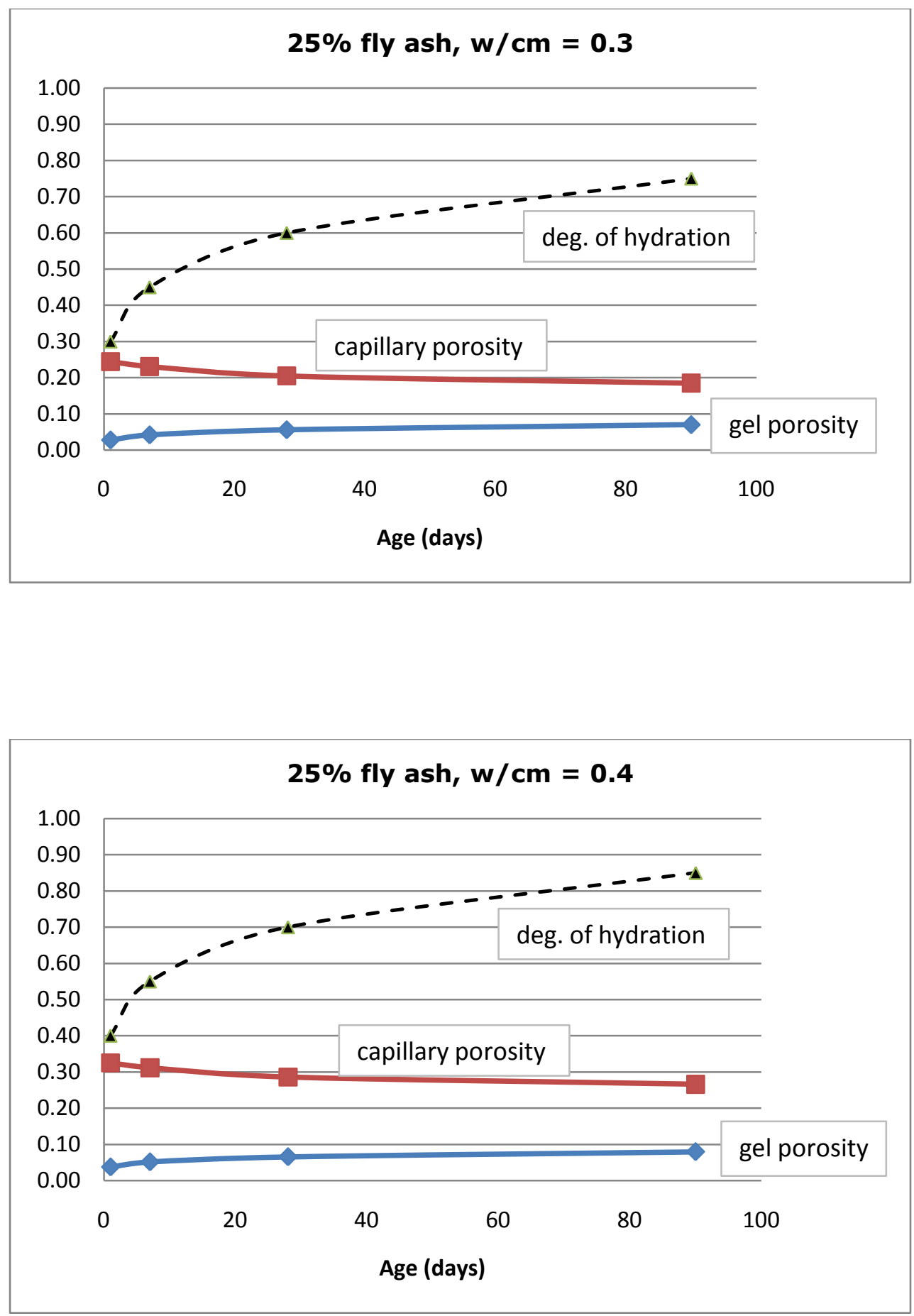

Fig 4.24 Variation of capillary and gel porosity with increasing degree of hydration for mixes containing replacement of cement by $25 \%$ fly ash. 

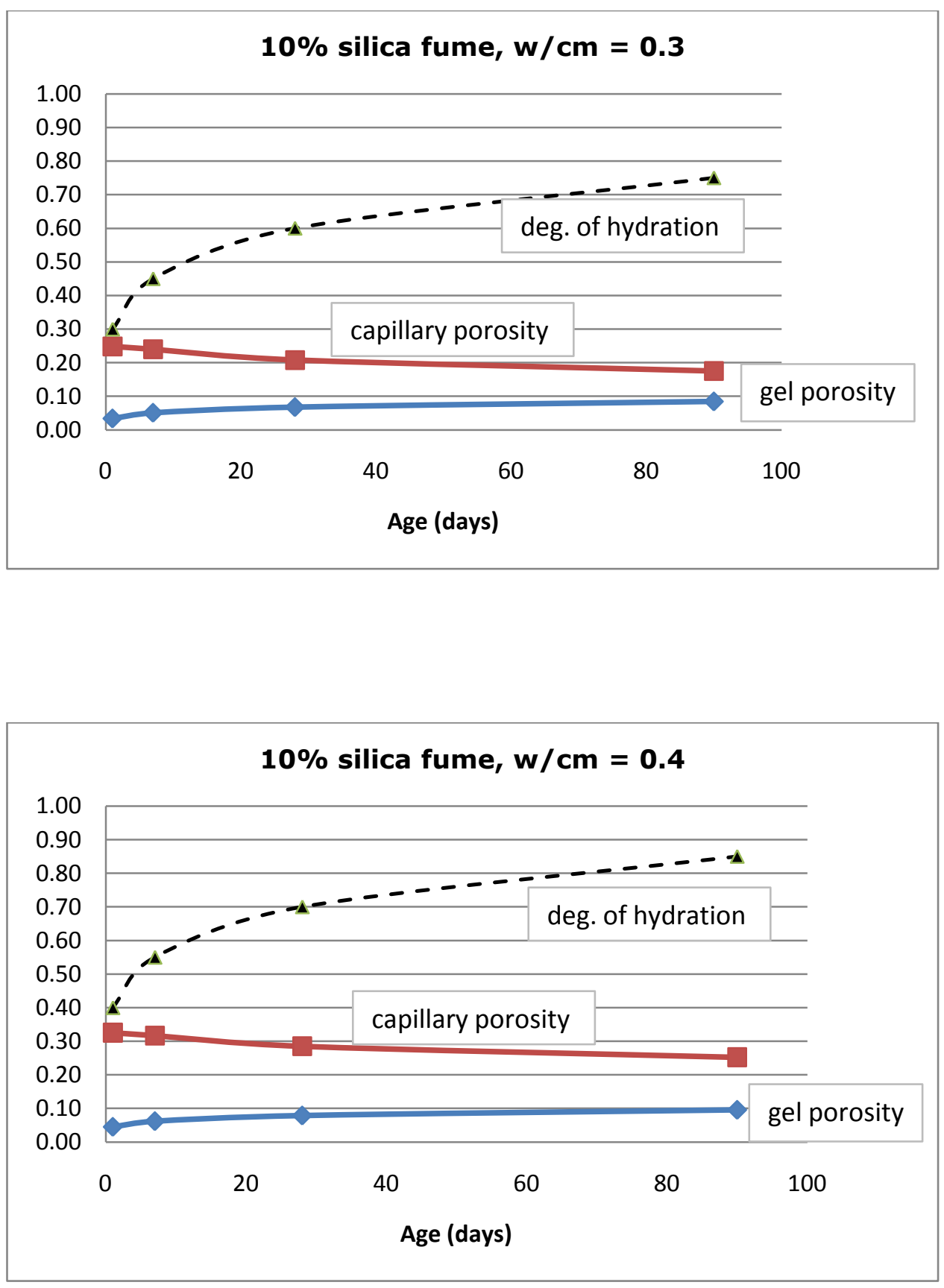

Fig 4.25 Variation of capillary and gel porosity with increasing degree of hydration for mixes containing replacement of cement by $10 \%$ silica fume. 

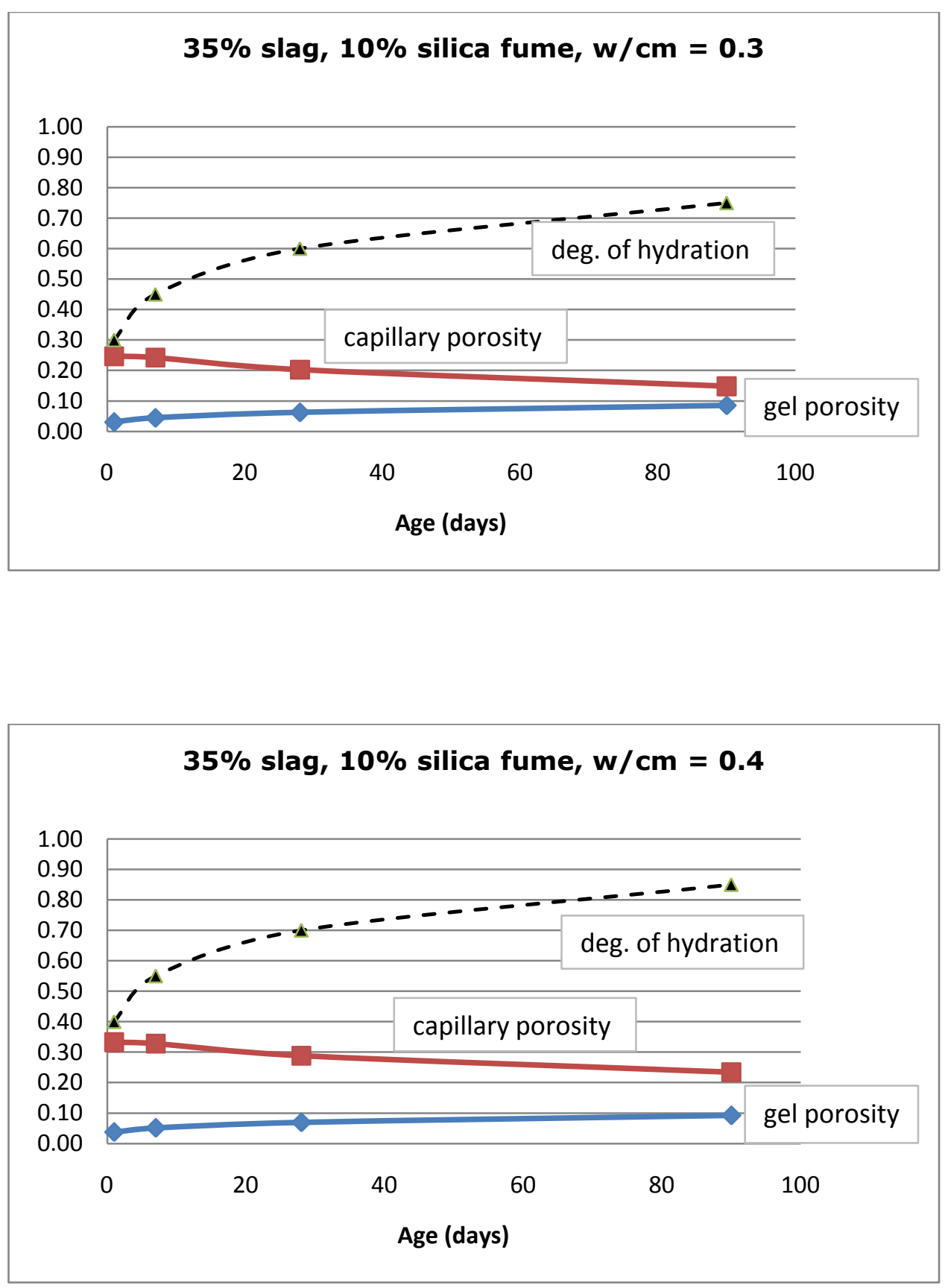

Fig 4.26 Variation of capillary and gel porosity with increasing degree of hydration for mixes containing replacement of cement by $35 \%$ slag and $10 \%$ silica fume. 

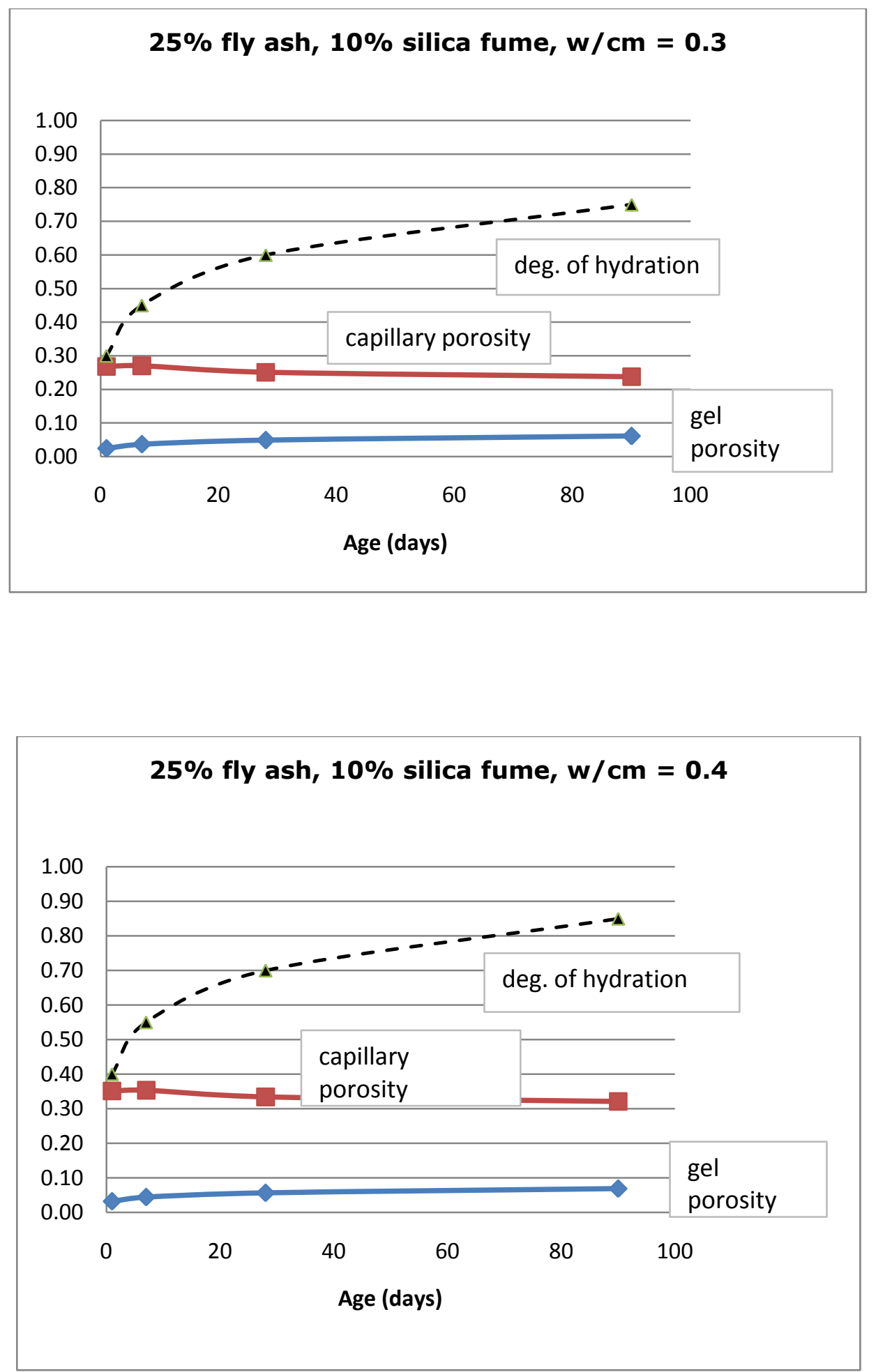

Fig 4.27 Variation of capillary and gel porosity with increasing degree of hydration for mixes containing replacement of cement by $25 \%$ fly ash and $10 \%$ silica fume. 


\subsubsection{Observations on porosity development}

\section{(A) Total porosity}

The total porosity was found to decrease with increase in hydration in all of the cases (Figs 4.22 through 4.27 ).

\section{(B) Capillary porosity}

The capillary porosity was found to decrease rapidly with increase in degree of hydration in all of the cases. The capillary porosity at full hydration was found to be greater at greater $\mathrm{w} / \mathrm{cm}$ ratios which conform to the findings of Powers and Brownyard (1936). The capillary porosity was found to be the least in case of $35 \%$ replacement of portland cement by slag (Fig 4.23).

\section{(C) Gel porosity}

The gel porosity was assumed to be 0.28 of the volume of the hydrated cementitious paste at any degree of hydration and the plots show the corresponding change in the gel porosities. 


\subsection{Experimental Validation through TGA}

\subsubsection{Estimation of $\mathrm{CH}$ volume from optimization and validation through TGA}

The values of $n$ and $n^{\prime}$ obtained by the optimization technique was used as input into Eqs. (4.31) through (4.35) to estimate the volume fractions of $\mathrm{CH}$ produced by pure portland cement and the cement with SCM pastes. The volume fractions were then converted to the corresponding mass fractions using the specific gravity values furnished earlier. The expressions for the volumes of $\mathrm{CH}$ produced by the hydration of the different cementitious pastes were obtained from Eqs. (4.40) through (4.47). The volumes are converted to the corresponding mass quantities by multiplying them with the specific gravity of $\mathrm{CH}$. Using Eqs. (4.3) through (4.8), the volumes of the different products of the aluminate and aluminoferrite hydration were obtained for the different cementitious pastes. They are subsequently converted to the corresponding masses and the total mass of the pastes are found out by adding the mass of the hydration products with the mass of the unhydrated residues for each specimen. The mass of $\mathrm{CH}$ is divided by the total mass to get the $\mathrm{CH}$ mass fraction of the paste.

The mass fractions of $\mathrm{CH}$ thus obtained using stoichiometry and statistical optimization was then compared with the corresponding mass fractions obtained from the TGA results. As an example, the TGA results are showed for the pure portland cement paste with $\mathrm{w} / \mathrm{cm}$ ratio of 0.4 (Fig. 4.28) and also for a cement with SCM paste containing $25 \%$ fly ash and $10 \%$ silica fume with a w/cm ratio of 0.3 at 28-day age (Fig. 4.29). The concept suggested by Mounanga et al. (2004) was used for this purpose. The water of crystallization of $\mathrm{CH}$ is released in the temperature range of $400^{\circ} \mathrm{C}$ to $600^{\circ} \mathrm{C}$. The mass of water released in this range of temperature is directly proportional to the corresponding mass of $\mathrm{CH}$. From the molecular formula of $\mathrm{CH}$, it is evident that each mole of $\mathrm{CH}$ contains 1 mole of water. Or, in other words, $74.09 \mathrm{gm}$ of $\mathrm{CH}$ contains $18.01 \mathrm{gm}$ of water. So, if the rise in temperature from $400^{\circ} \mathrm{C}$ to $600^{\circ} \mathrm{C}$ releases $18.01 \mathrm{gm}$ of water, the corresponding mass of $\mathrm{CH}$ would be $74.09 \mathrm{gm}$. This approach was used to estimate the mass of $\mathrm{CH}$ in the cementitious paste through TGA. 
The $\mathrm{CH}$ content in the cementitious paste is thus expressed as

$$
M_{C H}=\left[(74.09 / 18.01) /\left\{\left(M_{400}-M_{600}\right) / M_{C}\right\}\right]
$$

gm per gm of the hydrating cementitious paste.

where $\mathrm{M}_{\mathrm{CH}}$ is the mass fraction of $\mathrm{CH}$ in the cementitious paste;

$\mathrm{M}_{400}$ is the mass of the paste specimen at $400^{\circ} \mathrm{C}$;

$M_{600}$ is the mass of the paste specimen at $600^{\circ} \mathrm{C}$;

$M_{C}$ is the initial mass of the specimen.

The TGA results were plotted in terms of mass of the specimen remaining at any instant of time with respect to temperature of the crucible. The comparison of the 28-day data is shown for all the mixes in Fig. 4.30. Linear regression shows a correlation coefficient of 0.93 which shows good agreement.

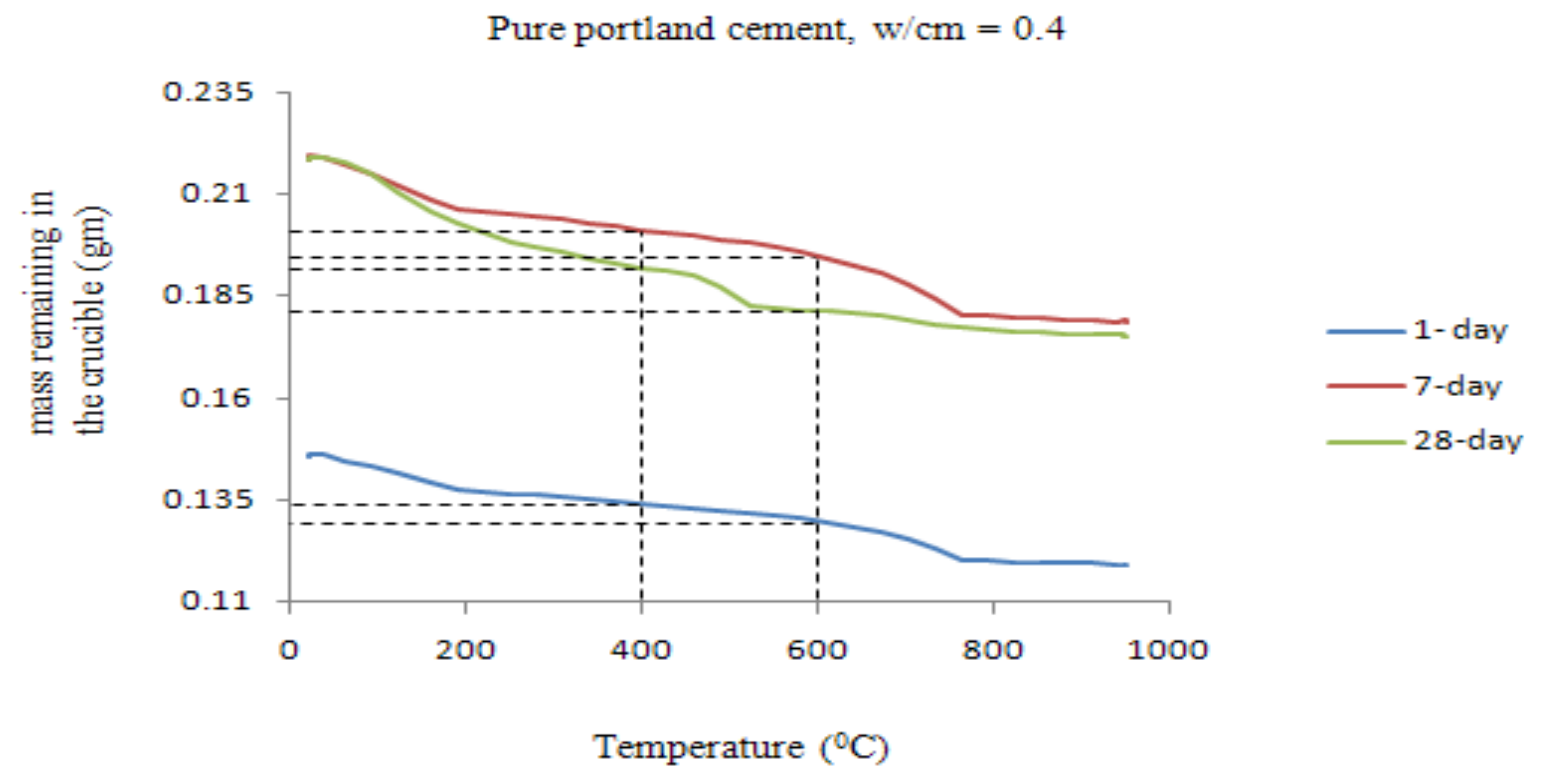

Fig. 4.28 TGA results for a pure portland cement paste (w/c ratio of 0.4 ) at 1 -day, 7-days and 28-days age. 


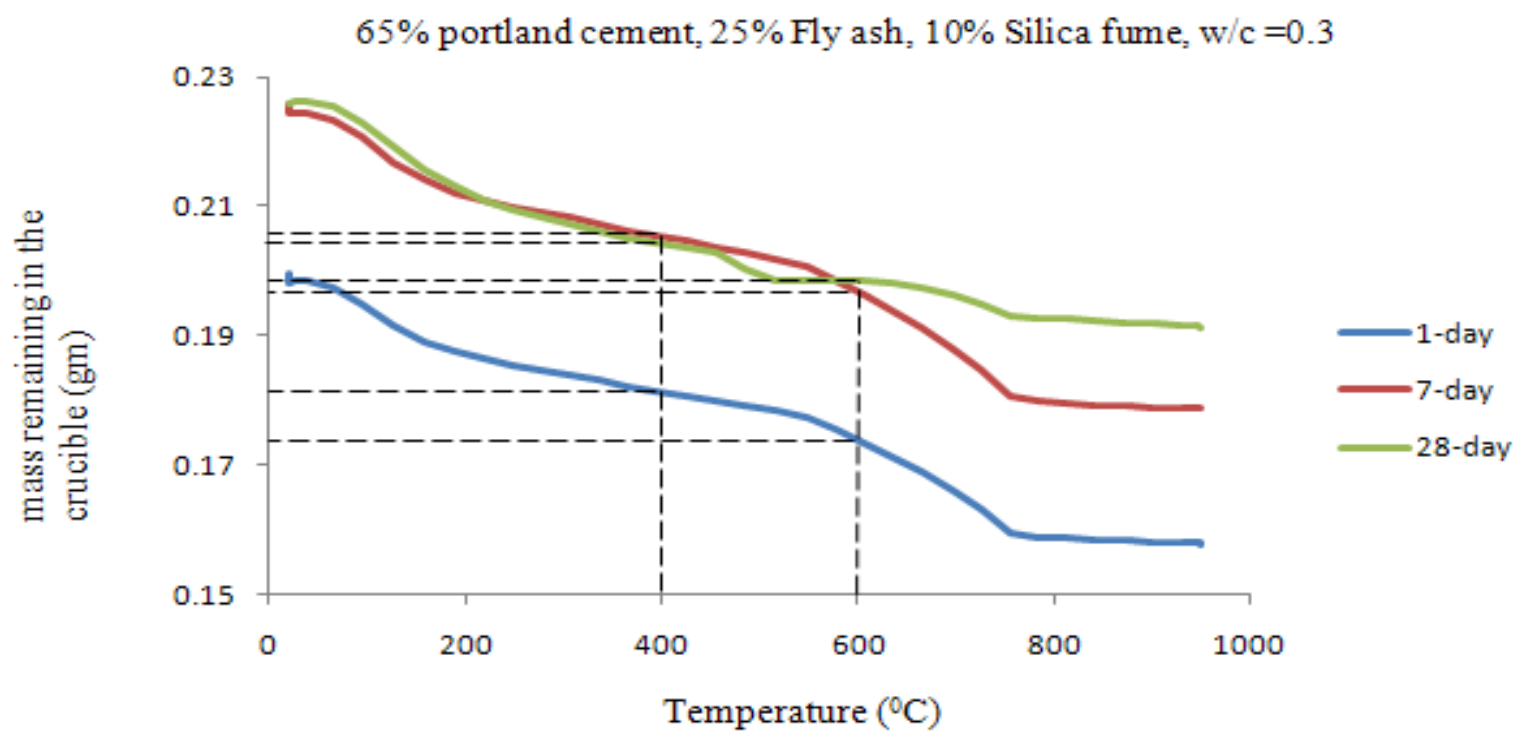

Fig. 4.29 TGA results for 1-day, 7-days and 28-days old cement specimen with SCM containing $65 \%$ portland cement, $25 \%$ fly ash and $10 \%$ silica fume with $\mathrm{w} / \mathrm{c}$ ratio 0.3 .

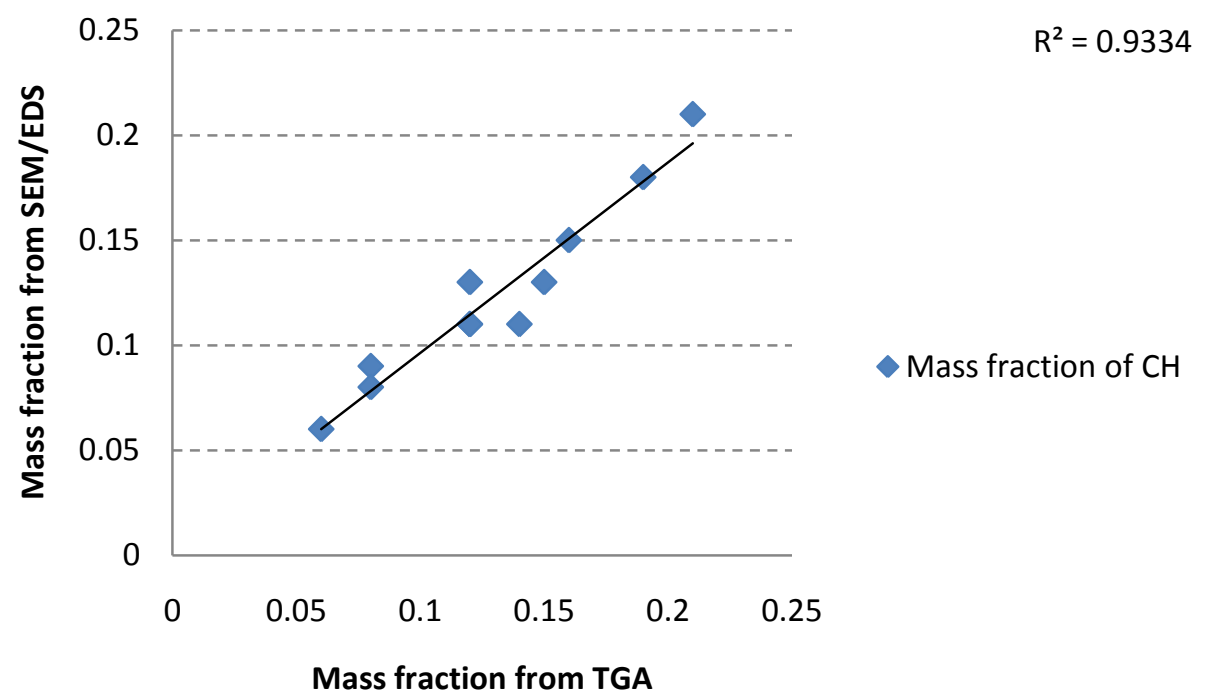

Fig. 4.30 Comparison between the mass fraction of calcium hydroxide from TGA and SEM/EDS results at 28-days age. 


\subsection{Capillary (or Chemical) Shrinkage Testing and Results}

The capillary (or chemical) shrinkage measurements of the cementitious pastes were carried out according to the specifications of the ASTM C 1608-07. This test was conducted to measure the absolute internal volume change of hydraulic cement paste due to the hydration of cementitious materials. In other words, this test corroborates the fact that the products of the hydration reaction physically occupy less volume than the reactants. The duration of the test is only 24 hours and thus it gives only a trend of the early age shrinkage characteristics of the paste. The phenomenon of chemical shrinkage within the cementitious paste continues throughout its hydration period, which is usually taken as 90 days for laboratory scale specimens.

The test setup is shown in Fig. 4.31.
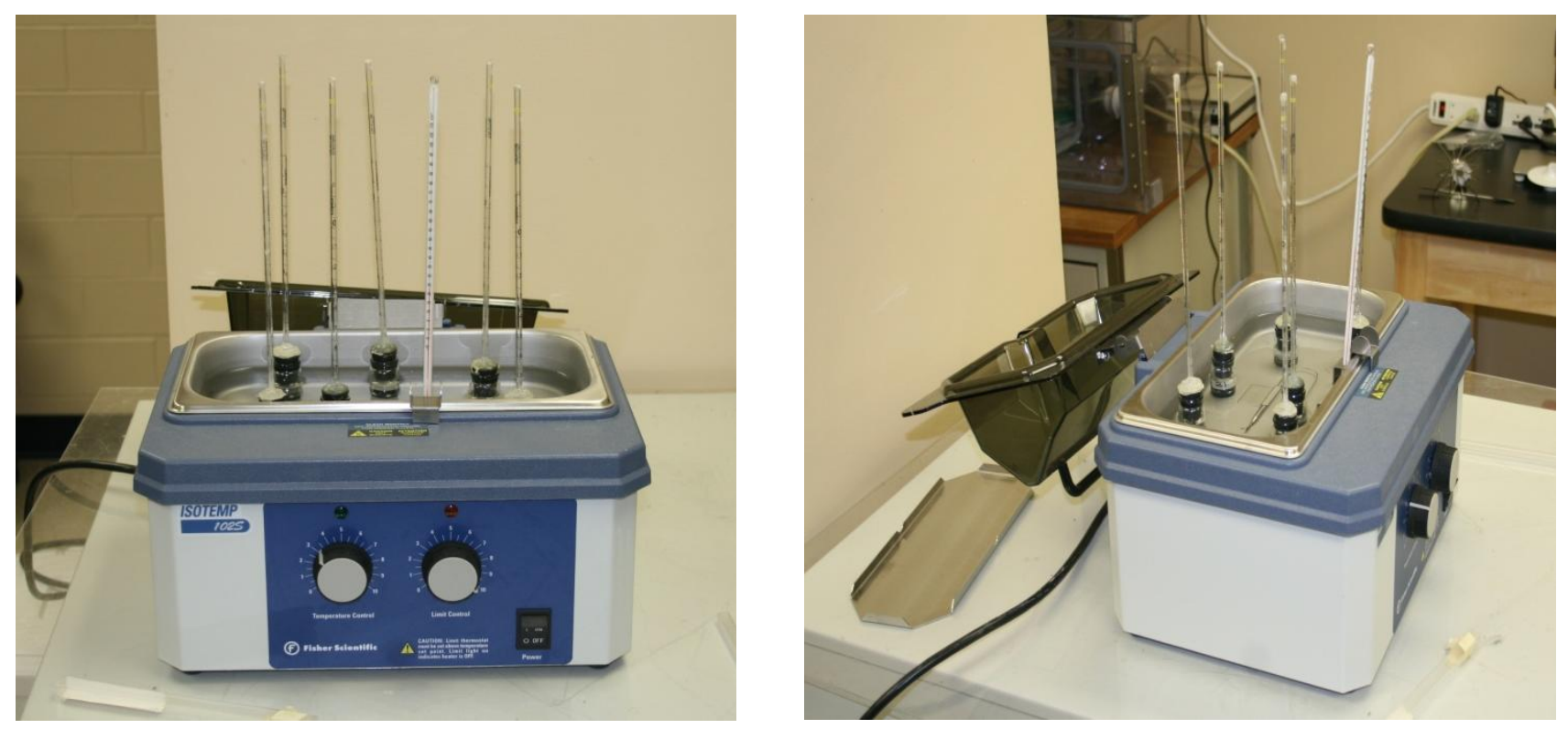

Fig. 4.31 Test setup for the capillary shrinkage test according to ASTM C 1608-07.

The empty glass vials were weighed first; the vials containing the cementitious pastes were then weight to obtain the weight of the paste by subtraction. The test was carried out in a constant temperature water-bath maintained at $23 \pm 2{ }^{\circ} \mathrm{C}$ throughout the procedure. The capillary tubes attached to the glass vials through the rubber stoppers were covered with a layer of paraffin oil to avoid evaporation of water from the surface. Otherwise, the test would yield erroneous results. The readings of the water level in the capillary tubes were 
observed at regular intervals one hour for the first 8 hours and then at an interval of eight hours each for the next two readings upto 24 hours. The reading taken at 1 hour after the start of the test is crucial, as it serves as datum or zero point for the other readings.

The capillary or chemical shrinkage was computed as the measured volume of sorbed water (in $\mathrm{mL}$ ) by unit weight (in $\mathrm{gm}$ ) of cementitious paste from the equation provided in ASTM C 1608-07 (Eqn. 4.54).

The mass of cement powder in the vial is given by

$$
M_{\text {cement }}=\frac{M_{\text {vial }+ \text { paste }}-M_{\text {vial }, \text { empty }}}{\left(1.0+\frac{w}{c}\right)}
$$

Where

$M_{\text {cement }}=$ mass of cement in the vial $(\mathrm{gm})$

$M_{\text {vial+paste }}=$ mass of the glass vial with the added cement paste $(\mathrm{gm})$

$M_{\text {vial,empty }}=$ mass of the empty vial $(\mathrm{gm})$

$w / c=$ water-cement ratio of the prepared paste (by weight), and assuming a density of $1000 \mathrm{~kg} / \mathrm{m}^{3}$ for water.

The capillary or chemical shrinkage per unit mass of cement at time, $t$, is computed as

$$
C S(t)=\frac{[h(t)-h(60 \mathrm{~min})]}{M_{\text {cement }}}
$$

Where

$\mathrm{CS}(t)=$ chemical shrinkage at time $\mathrm{t}(\mathrm{mL} / \mathrm{g}$ cement $)$

$h(t)=$ water level in capillary tube at time $t(\mathrm{~mL})$

The decrease in absolute volume of the cementitious paste with age is manifested by its increase in shrinkage as shown in Figs. 4.32 through 4.35. However, this is only a qualitative representation. The quantitative estimation of the capillary or chemical shrinkage of the cementitious paste has been described in details in section 4.13.1. 


\section{Mix: $100 \%$ portland cement}

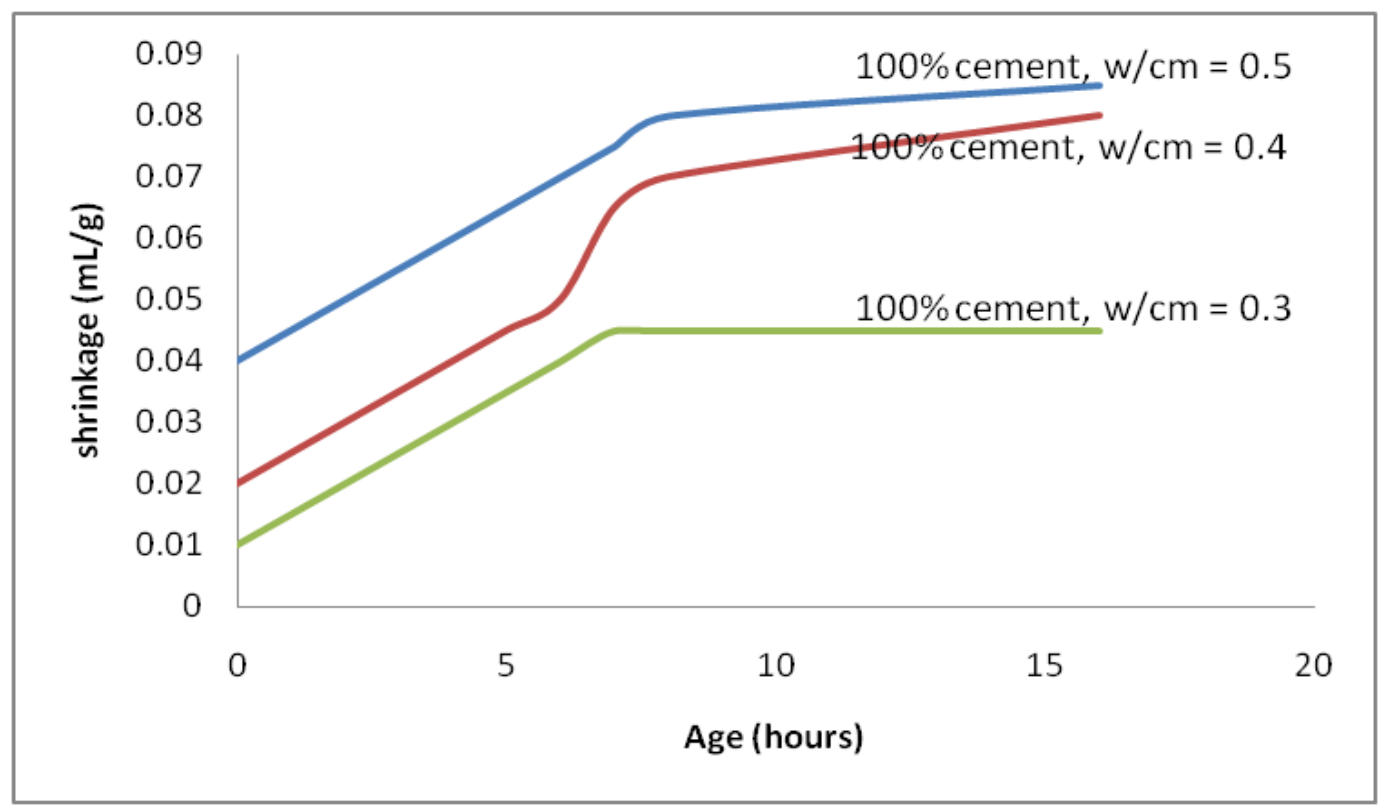

Fig 4.32 Capillary shrinkage results for $100 \%$ cement mixes at three different $\mathrm{w} / \mathrm{cm}$ ratios.

Mix: Replacement by $35 \%$ slag and $45 \%$ Slag

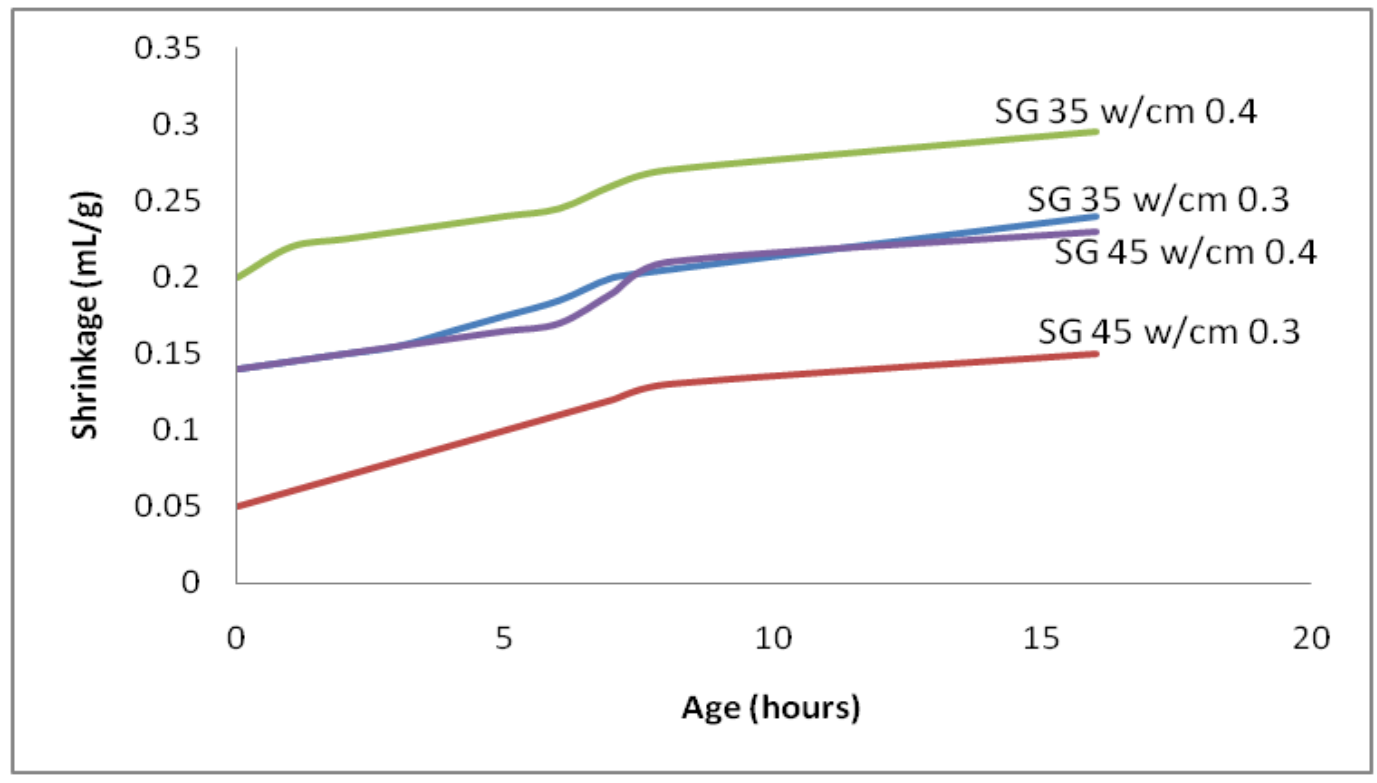

Fig 4.33 Capillary shrinkage results for mixes containing replacements of cement by $35 \%$ and $45 \%$ slag at various $\mathrm{w} / \mathrm{cm}$ ratios. 


\section{Mix: Replacement by 25\% Fly Ash and 35\% Fly Ash}

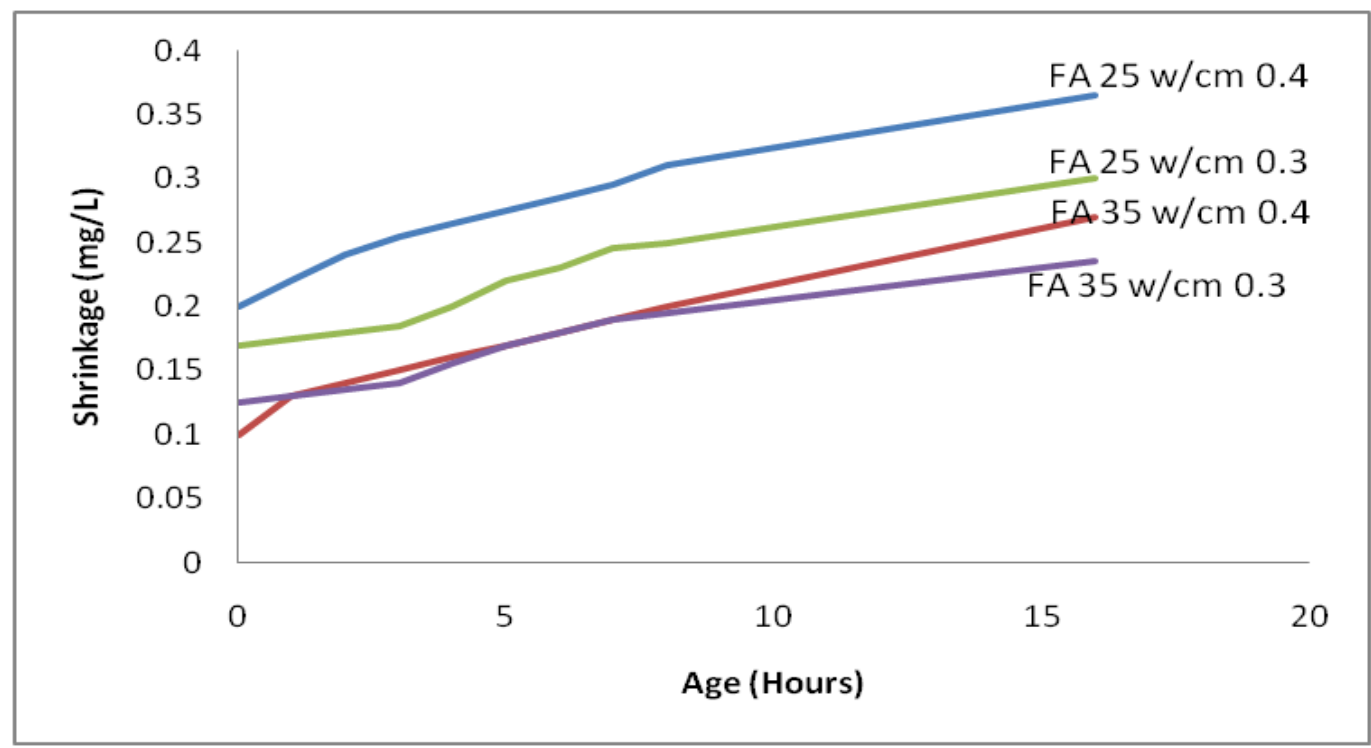

Fig 4.34 Capillary shrinkage results for mixes containing replacements of cement by $25 \%$ and $35 \%$ fly ash at various $\mathrm{w} / \mathrm{cm}$ ratios.

\section{Mix: Replacement of all the above cases by $10 \%$ silica fume and combination of slag and fly ash}

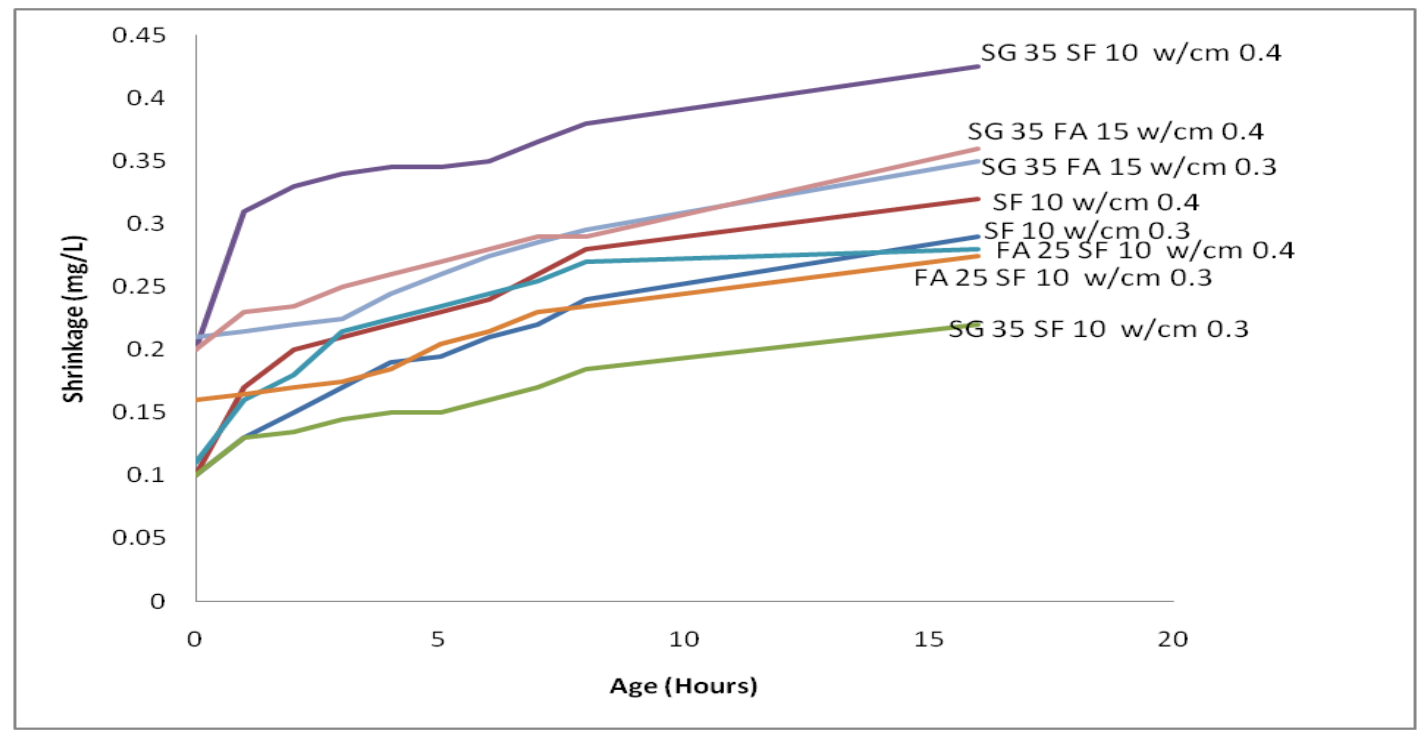

Fig 4.35 Capillary shrinkage results for mixes containing replacements of cement by different combinations of SCM at various $\mathrm{w} / \mathrm{cm}$ ratios. 


\subsubsection{Quantitative estimation of capillary (or chemical) shrinkage of cementitious paste}

The capillary (or chemical) shrinkage of the cementitious paste is typically measured in terms of its volume change. It involves knowledge of the deformation of the paste on a linear scale with the conversion of directional measurements to total volume change given in the following equation. Linear drying shrinkage values are on the order of 500 to $1000 \mu \varepsilon$ $(0.5$ to $1 \mathrm{~mm} / \mathrm{m})$ over a long duration but can exceed $5000 \mu \varepsilon(5 \mathrm{~mm} / \mathrm{m})$ during some cases, included accelerated drying during early ages (Holt 2001).

Volume Change $=1-(1-$ shrinkage/length $)$

A part of the long term drying shrinkage can be reversible, due to the fact that the concrete will swell upon subsequent re-wetting.

The chemical shrinkage is based merely on the volumes of initial and final products. Thus, it is possible to calculate the chemical shrinkage based on molecular weights and specific gravities of the reactants and products involved in hydration. The general equation (Eqn. 4.57) for chemical shrinkage is given below. The difficulty with this calculation is that it is often difficult to know the exact volume of various components within the concrete without performing extensive experiments.

$$
C S=\frac{(V C+V w)-V h y}{(V c i+V w i)} \times 100
$$

where: CS = capillary or chemical shrinkage,

$\mathrm{V}_{\mathrm{ci}}=$ volume of cement before mixing,

$\mathrm{V}_{\mathrm{c}}=$ volume of hydrated cement,

$\mathrm{V}_{\mathrm{wi}}=$ volume of water before mixing,

$\mathrm{V}_{\mathrm{w}}=$ volume of reacted water, and

$\mathrm{V}_{\mathrm{hy}}=$ volume of hydrated products.

The first person to report measurements of chemical shrinkage in cement by measuring the volume contraction of paste in a glass beaker connected to a water-filled tube was Le Chatelier (Holt 2001). He assumed the contraction was only due to the contraction of the water. At a $\mathrm{w} / \mathrm{cm}$ ratio of 0.40 he established the amount of non-evaporable water to be 
dependent on the cement chemistry, as shown in Eqn. 4.58. Here, the chemical shrinkage, CS, is expressed as $\mathrm{ml} / 100 \mathrm{~g}$ cement and the cement clinker compounds are entered as percentages of the total cement content. When applied to normal portland cement, this equation predicts a chemical shrinkage of about $6 \mathrm{ml}$ per $100 \mathrm{~g}$ cement, or approximately $9 \%$ of the volume of the hydrated products, as pointed out by Gange et al. in 1999 (Holt 2001).

$\mathrm{CS}=0.266 \mathrm{C}_{3} \mathrm{~S}+0.194\left(\mathrm{C}_{2} \mathrm{~S} / 0.982\right)+0.510 \mathrm{C}_{3} \mathrm{~A}+0.097 \mathrm{C}_{4} \mathrm{AF}+0.149 \mathrm{CaSO}_{4}$

In a separate method to estimate chemical shrinkage based on the individual shrinkage of the 4 clinker minerals, i.e. $\mathrm{C}_{3} \mathrm{~S}, \mathrm{C}_{2} \mathrm{~S}, \mathrm{C}_{3} \mathrm{~A}$ and $\mathrm{C}_{4} \mathrm{AF}$, Powers and Brownyard in 1948 showed that chemical shrinkage occurs only below a $w / \mathrm{cm}$ ratio of 0.42 , as all the mixing water is consumed at this ratio (Holt 2001). As theoretically calculated by Powers, $0.23 \mathrm{~g}$ of water would fully react with $1 \mathrm{gram}$ of cement to get a chemical shrinkage of $5.9 \mathrm{ml} / 100 \mathrm{~g}$ of cement, which nearly matched Le Chatelier's observation (Holt 2001). The above methods have been studied in detail by many researchers like Tazawa \& Miyazawa in 1995, Paulini in 1992, and Gangé et al. in 1999 as cited by Holt (2001). Modern technology facilitates precise measurements of clinker minerals and their reaction products, thereby making these methods easier to understand and execute.

For the present study, however, the chemical shrinkage of the cementitious paste was calculated mathematically by the volume stoichiometries mentioned in section 4.5. The initial and final volumes of the reactants and the products are computed based on weight and density. As seen in Eqns. (4.1) through (4.8), each of the four cement clinker compounds requires water for reactions. These processes are exothermic and result in a decreased volume of the reaction products. This volume reduction, or chemical shrinkage, begins immediately as the cement is mixed with water and the rate of reaction is at its peak at early stage. The magnitude of chemical shrinkage can be found out by deducting the volume of hydrated products at any stage from the initial volume of the reactants (cementitious materials and water) participating in the reaction.

For the present study, the volume shrinkage of the cementitious paste was computed using Eq 4.57, in terms of the total volume of hydrated products present in the system at any given instant of time and the corresponding degree of hydration. 
The volume shrinkage was then expressed as the corresponding cementitious paste shrinkage in terms of the degree of hydration using Eqn. 4.59 as shown below:

$$
\varepsilon_{C S}=\frac{\alpha\left(v_{c_{i}}+V_{w_{i}}\right)-V_{h c p}}{\left(v_{c_{i}}+V_{w_{i}}\right)}
$$

But in a previous study by Neubauer et al. (1996), they showed that the shrinkage of the cementitious paste is almost solely governed by the shrinking characteristic of the C-S-H. The $\mathrm{CH}$ and the unreacted $\mathrm{C}_{3} \mathrm{~S}$ and $\mathrm{C}_{2} \mathrm{~S}$ present in the system are assumed to be nonshrinking. So, they offer a kind of restrain to the shrinkage. The pores are taken as inert. As they have zero static moduli, the magnitude of their unrestrained shrinkage is negligible in any case (Neubauer et al. 1996).

So, for the present study, the chemical shrinkage of the cementitious paste is solely considered to be due to the volume deformation accompanying the formation of $\mathrm{C}-\mathrm{S}-\mathrm{H}$ from $\mathrm{C}_{3} \mathrm{~S}$ and $\mathrm{C}_{2} \mathrm{~S}$ hydrations.

The shrinkage of paste determined using the above formula considers the volume deformation due to the formation of $\mathrm{C}-\mathrm{S}-\mathrm{H}$ and $\mathrm{CH}$ from the hydration reaction; but it does not take into account, the restraining or non-shrinking characteristics of the unreacted $\mathrm{C}_{3} \mathrm{~S}$ and $\mathrm{C}_{2} \mathrm{~S}$. So, the paste shrinkage obtained as above was in fact an over estimation of the actual deformation that takes place in the paste. This paste shrinkage was then modified by multiplying it with a factor considering the respective volume fractions of the $\mathrm{C}-\mathrm{S}-\mathrm{H}$ and the silicates $\left(\mathrm{C}_{3} \mathrm{~S}\right.$ and $\left.\mathrm{C}_{2} \mathrm{~S}\right)$ and their corresponding elastic moduli. Thus, the final expression for the shrinkage of the cementitious paste was given as,

$$
\varepsilon_{p}=\varepsilon_{C S} \times \frac{v_{f, C-S-H} \cdot E_{C-S-H}}{\left(v_{f, C 3 S} \cdot E_{C 3 S}+v_{f, C 2 S} \cdot E_{C 2 S}\right)}
$$

The effect of the modification factor mentioned above in Eqn 4.60 is significant at early age (about 1 day) only. At later ages ( $>1$ day), the factor has a value of about 1.0 and is thus not taken into account for the corresponding calculations.

The shrinkage strain equation (Eqn. 4.60) mentioned above gives the equivalent linear shrinkage of the cementitious paste form its chemical shrinkage. The chemical shrinkage accounts for only the autogenous component of the total shrinkage of the paste and not its 
drying component. This is a material property. There are some available techniques to determine the total shrinkage from the autogenous shrinkage.

According to Holt (2001), the total shrinkage should be taken as the sum of each individual volume change due to the different modes of shrinkage - carbonation, thermal expansion, drying and chemical (or autogenous) deformations.

Since a major part of the later age thermal expansion is reversible, it is usually not considered as contributing to total shrinkage. In practice, design codes use a measure of only the long term drying shrinkage as the ultimate shrinkage strain. This is incorrect, since the early age shrinkage can sometimes equal or even exceed the standard long-term strains. Moreover, for high strength concrete where there is a $\mathrm{w} / \mathrm{cm}$ ratio under 0.42 there is a high probability of autogenous shrinkage contributing to the ultimate shrinkage (Holt 2001).

For the laboratory scale specimens, it was assumed that carbonation shrinkage is negligible at ages of upto 90 days. So, total shrinkage consists of chemical shrinkage and drying shrinkage.

In normal strength concrete where the $\mathrm{w} / \mathrm{cm}$ ratio exceeds 0.42 , chemical (or autogenous) shrinkage may not be perceptible, as the concrete can undergo full hydration in presence of adequate water. In some cases chemical (or autogenous) shrinkage can be completely eliminated as done by Radocea in 1992 (Holt 2001). In other cases, shrinkage may be replaced by swelling, which would eradicate the chemical shrinkage, as observed by Whiting et al. 2000, due to the imbibitions of the curing water. A w/cm ratio below 0.42 or lack of curing water may lead to immediate shrinkage at early age which is very harmful.

Tazawa \& Miyazawa in 1995 (Holt 2001) observed that with decreasing w/cm ratio, chemical (or autogenous) shrinkage predominates drying shrinkage in terms of contribution to total shrinkage (Fig 4.36). Thus, at low $\mathrm{w} / \mathrm{cm}$ ratios the total shrinkage may be taken as nearly equal to the chemical (or autogenous) shrinkage. Figure 4.36 shows that at a $w / c m$ ratio of 0.40 the chemical (or autogenous shrinkage) contributes $40 \%$ of the total shrinkage magnitude, while at a w/cm ratio of 0.23 the contribution rises to about $80 \%$ of the total shrinkage (Holt 2001). 
So, the shrinkages of the cementitious paste computed from Eqn. (4.60) were converted to the corresponding total shrinkage using the concept provided by Holt (2001) as mentioned above.

For example, the paste shrinkage was divided by 0.4 in case of $\mathrm{w} / \mathrm{cm}$ ratio of 0.4 whereas it was divided by 0.5 in case of $w / c m$ of 0.3 . The coefficients were taken from the plot provided by Tazawa and Miyazawa in 1995 as suggested by Holt (2001).

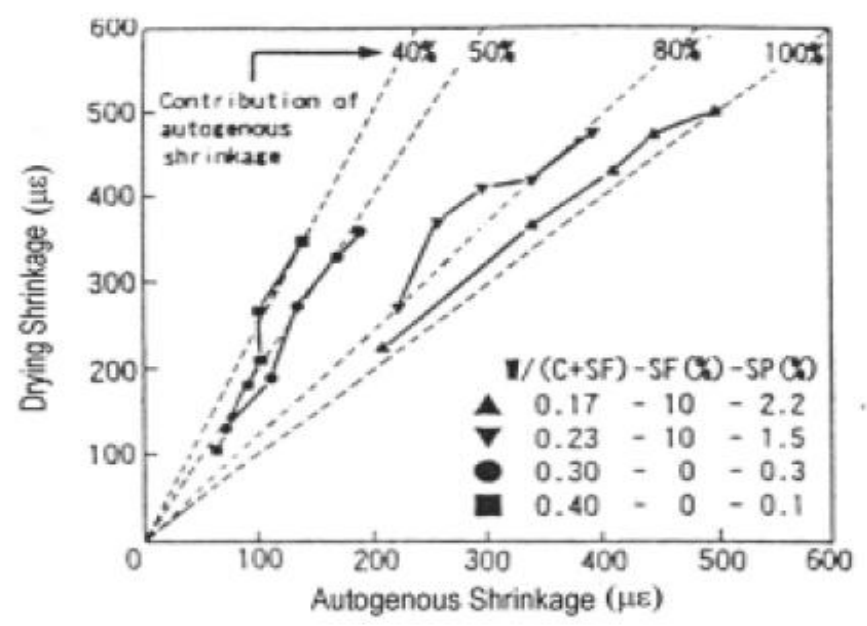

Fig. 4.36 Contribution of chemical (or autogenous shrinkage) to total shrinkage at varying w/cm ratios (Courtesy: Holt, 2001).

Incorporating the effect of the $\mathrm{w} / \mathrm{cm}$ ratio into the chemical shrinkage expression

(Eq. 4. 60), the expression of the total shrinkage is obtained as shown in Eq. 4.61.

The equation of shrinkage for the cementitious paste is finally expressed as

$$
\begin{gathered}
\varepsilon_{p}=\frac{\left[\alpha \times \frac{\left(v_{c_{i}}+V_{w_{i}}\right)-V_{h c p}}{\left(v_{c_{i}}+V_{w_{i}}\right)} \times \frac{v_{f, C-S-H} \cdot E_{C-S-H}}{\left(v_{f, C 3 S} \cdot E_{C 3 S}+v_{f, C 2 S} \cdot E_{C 2 S}\right)}\right]}{f(w / c m)} \\
\varepsilon_{p}=\frac{\left[\frac{t}{A+B t} \times \frac{\left(v_{c_{i}}+V_{w_{i}}\right)-v_{h c p}}{\left(v_{c_{i}}+V_{w_{i}}\right)} \times \frac{v_{f, C-S-H} \cdot E_{C-S-H}}{\left(v_{f, C 3 S} \cdot E_{C 3 S^{+}} v_{f, C 2 S} \cdot E_{C 2 S}\right)}\right]}{f(w / c m)}
\end{gathered}
$$

if the degree of hydration is expressed as a function of time as explained in section 4.6.2. 
The following table presents the final results for the total paste shrinkage of the different mixes at different $\mathrm{w} / \mathrm{cm}$ ratios and different ages. They were then converted to the equivalent total shrinkages for the composite model in two stages:

(i) For the mortar and

(ii) For the concrete.

The details are discussed in the following chapter (Chapter 5). 


\section{CHAPTER 5}

\section{COMPOSITE MODELING AND PREDICTION OF SHRINKAGE}

In the first portion of this chapter, the prediction equation of concrete shrinkage is formulated using the concept of composite modeling in two steps. Firstly, the shrinkage of the mortar is evaluated from the shrinkage of the cementitious paste as discussed in the previous chapter. In the second step, the concrete shrinkage is predicted using the mortar shrinkage obtained in step 1.

In the second portion of this chapter, the effect of the different SCM on the shrinkage of concrete will be dealt with. From the previous work of Khatri et al. (1995), it is evident that the addition of SCM has significant influence on the shrinkage properties of concrete. A model to predict the shrinkage of the concrete specimen has been proposed, based on the shrinkage of the cement paste at microscale and also taking into account, the effect of the different SCM.

\subsection{Two-step Composite Model}

The concept of two-step modeling adopted by Eguchi and Teranishi based on the formulation suggested by Kishitani and Baba (1975), as mentioned in chapter 2, section 2.12, was taken as the basis for the approach to modeling in course of the current study. The above mentioned model had the drawback of not being able to incorporate the interfacial transition zone (ITZ). This model was modified in the present study so as to take the influence of the ITZ in account, using the concept put forward by Hashin and Shtrikman (1963). They provided the range of elastic moduli for concrete, based on the bulk and shear moduli and gave the corresponding upper and lower limits known as $\mathrm{H}-\mathrm{S}$ bounds. This concept has been modified for the present study, which assumes the following two-step composite model incorporating all the three phases present in concrete at two different stages. 


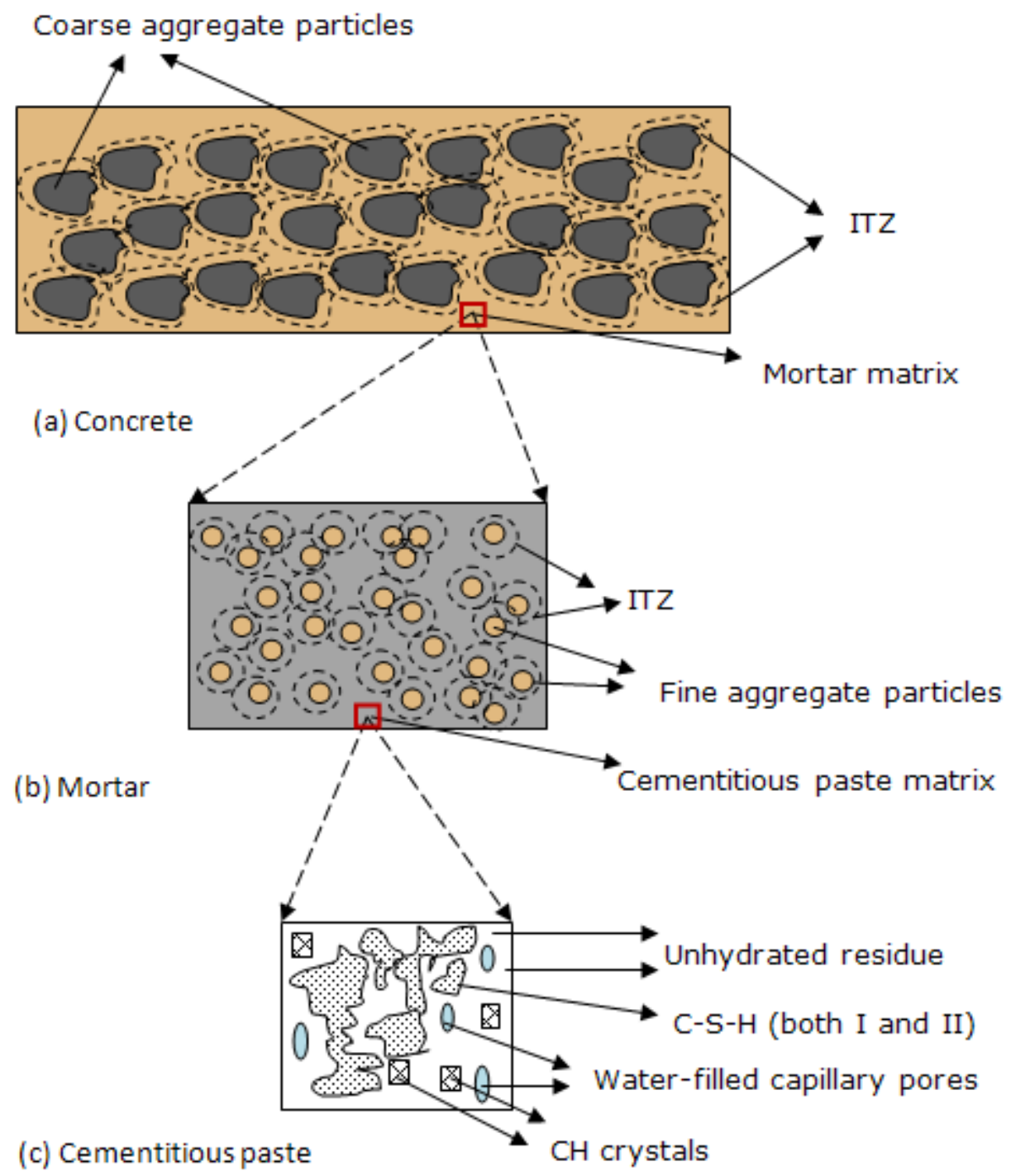

Length scale: meter;

Millimeter phases assumed homogeneous

Length scale: millimeter; Micrometer phases assumed homogeneous

Length scale: micrometer;

Nanometer phases assumed homogeneous

Fig. 5.1 Schematic diagram showing three-phase hierarchical model of concrete.

\subsection{Mortar as Composite}

In the first step of the model the mortar shrinkage is computed first and then the concrete shrinkage is determined in the second step based on this mortar shrinkage.

In this step, the mortar in itself is assumed to be made up of

(i) the cementitious paste matrix,

(ii) the fine aggregate and

(iii) an interfacial zone between the cementitious paste and the fine aggregate. 
For the model at his step, the thickness of the ITZ is an important factor that must be taken into account. It is usually in the region of $20-50 \mu \mathrm{m}$. For our study, it is taken as $20 \mu \mathrm{m}$, based on the study of Neubauer et al. (1996). The different phases present in the hydrating paste have different levels of influence on the stiffness of the paste. Their influences have been studied by some researchers using nanoindentation techniques. The majority of the shrinkage takes place in the $\mathrm{C}-\mathrm{S}-\mathrm{H}$, while the $\mathrm{C}_{3} \mathrm{~S}$ and $\mathrm{CH}$ are relatively non-shrinking. Porosity is also assumed to have no inherent shrinkage.

(a) Mortar
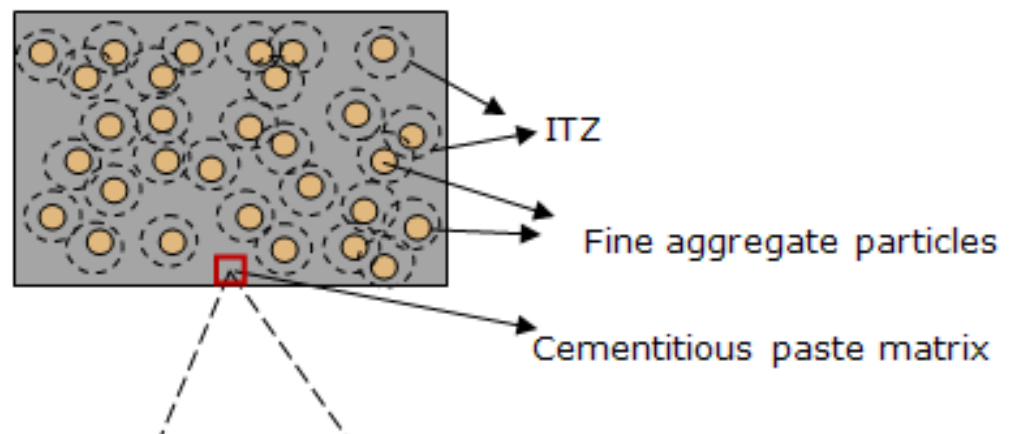

(b) Cementitious paste

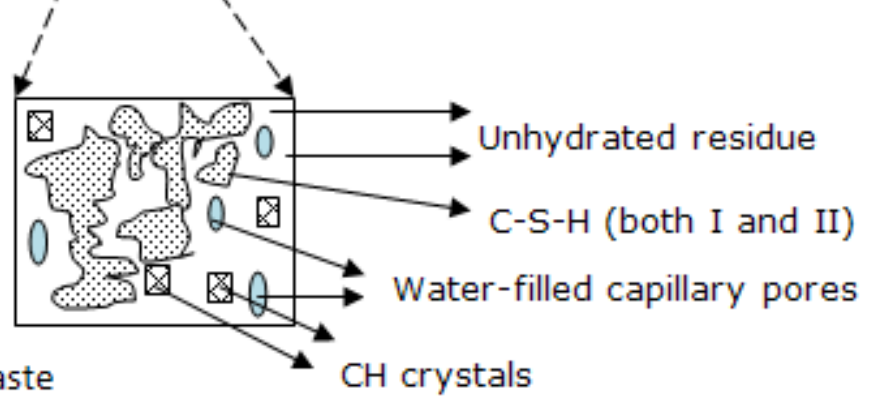

Fig. 5.2 Schematic diagram showing the transition from cementitious paste to mortar composite.

The ITZ has a Young's modulus of between one-third and one half of the bulk cement paste, while its shrinkage is close to that of the bulk paste. For the sake of simplicity, all shrinkages must be taken as elastic and reversible; and, the properties of the ITZ are homogenously distributed. As the ITZ becomes very soft, the bulk paste gets slowly detached from the restraining aggregate, increasing the shrinkage. On the contrary, if the stiffness of the ITZ increases, the shrinkage decreases. But increasing stiffness of the ITZ may ultimately lead to overall increase in stiffness of the non-aggregate component of the concrete. This can resist the restraining attribute of the aggregate and consequently increase the ultimate shrinkage (Neubauer et al. 1996). 
Given the constraints of time and the sake of simplicity, this approach has not been adopted for our studies.

\subsubsection{Hashin - Shtrikman bounds}

According to Hashin and Shtrikman (1963), the measured values of elastic modulus, $E_{c}$ for some concretes differ from the predictions by the available two-phase models due to the presence of the ITZ. By using the three-phase model proposed by Hashin and Shtrikman (1963), the elastic modulus of the mortar can be determined from the knowledge of the corresponding bulk and shear moduli. Their formula gives the upper and lower bounds for the elastic modulus. Also, it takes into account, the influence of the ITZ. The bulk modulus and the shear modulus of the ITZ and tr, the ratio of the thickness of the ITZ to the equivalent radius of the spherical inclusions (aggregate particles), must be known in order to use this model. The bulk modulus of the ITZ is taken as half of that of the cementitious paste. The shear modulus of the ITZ is taken as 0.4 times that of the paste.

The model provides the upper and lower bounds for the range of the elastic modulus of the concrete (or mortar). They are known as Hashin bounds or H-S Bounds. The upper and lower bounds represent the two possible extreme cases - (a) the mortar phase in parallel with the coarse aggregate phase at the meter scale (or the cementitious paste matrix in parallel with the sand particles at the millimeter scale), together with the ITZ at the respective length scale; and (b) the mortar phase in series with the coarse aggregate phase at the meter scale (or the cementitious paste matrix in parallel with the sand particles at the millimeter scale), together with the ITZ at the respective length scale. But the heterogeneity of the ITZ and the uncertainty regarding its orientation in the system at both the scales makes it difficult to specify one particular value for the elastic modulus. Thus, the concepts of composite modeling for two-phase materials were extended to the tree-phase material and Hashin and Shkritman (1963) came up with the upper and lower bounds for the elastic moduli as shown below:

Hashin - Shtrikman bounds:

$$
\frac{1}{K_{(-)}}=\frac{v_{p}}{K_{p}}+\frac{v_{a}}{K_{a}}+\frac{3 V_{a} t_{r}}{K_{i}+4 G_{i} / 3}
$$




$$
\begin{gathered}
K_{(+)}=V_{p} K_{p}+\frac{V_{a} K_{a}}{1+\frac{3 K_{a} t_{r}}{K_{i}+4 G_{i} / 3}} \\
\frac{1}{G_{(-)}}=\frac{V_{p}}{G_{p}}+\frac{V_{a}}{G_{a}}+0.4 V_{a} t_{r}\left(\frac{2}{K_{i}+4 G_{i} / 3}+\frac{6}{G_{i}}\right) \\
G_{(+)}=V_{p} G_{p}+\frac{V_{a} G_{a}}{1+\frac{2.5 G_{a} t_{r}}{\left(K_{i}+4 G_{i} / 3\right)+2 G_{i}}}
\end{gathered}
$$

Where $\mathrm{Va}=$ volume fraction of aggregate in the concrete

$\mathrm{Vp}=$ volume fraction of paste in the concrete

The above expression was modified according to the present study in case of mortar. The symbols mentioned above represent the following for this purpose:

Va $=$ volume fraction of sand in mortar and

$\mathrm{Vp}=$ volume fraction of cementitious paste in mortar

Also, in the above expression, $\mathrm{K}$ and $\mathrm{G}$ denote the bulk and shear moduli of the concrete (in the meter scale) and the mortar (in the millimeter scale), respectively. $K_{i}$ and $G_{i}$ represent the bulk and the shear moduli of the ITZ (at respective length scales).

$t_{r}=$ ratio of the thickness of the ITZ to the radius of the spherical inclusions

$$
=0.1
$$

For the millimeter scale, the average radius of the sand particles was taken as $200 \mu \mathrm{m}$ and the thickness of the ITZ between the sand particles and the cementitious paste as $20 \mu \mathrm{m}$.

For the meter scale, the average radius of the coarse aggregate particles was taken as $12 \mathrm{~mm}$ and the thickness of the ITZ between the coarse aggregate particles and the mortar as $1.2 \mathrm{~mm}$. 
Subsequently, the elastic modulus of the mortar was computed in terms of the upper and lower bounds as:

$$
\begin{aligned}
& E_{(-)}=\frac{9 K_{(-)} G_{(-)}}{3 K_{(-)}+G_{(-)}} \\
& E_{(+)}=\frac{9 K_{(+)} G_{(+)}}{3 K_{(+)}+G_{(+)}}
\end{aligned}
$$

\subsubsection{Contribution of different phases to stiffness}

In a document by Garboczi (2000), he mentioned that the three phases that play the major role in the elastic moduli of the cement paste are the clinker materials, calcium hydroxide and the $\mathrm{C}-\mathrm{S}-\mathrm{H}$. That is due to their volumetric abundance in the cementitious system. Ettringite is another phase that appears to a lesser quantity in the paste and thus has a minor effect on the elastic modulus. The researchers at NIST used cement paste samples at later ages to identify the influence of each phase on the elastic modulus with the help of grayscale analyses of 3D images of the microstructure, which were simulated using the CEMHYD3D software. The values of bulk and shear moduli for the standard clinker materials and the hydrated phases must be known apriori. This requires the help of nanoindentation techniques. Attempts to determine the elastic modulus of cementitious phases were made by other researchers also.

For $\mathrm{w} / \mathrm{cm}$ ratio of 0.3 ,

$\mathrm{K}_{\mathrm{p}}=(0.32) \mathrm{K}_{\mathrm{C}-\mathrm{S}-\mathrm{H}}+(0.27) \mathrm{K}_{\text {cement }}+(0.22) \mathrm{K}_{\mathrm{CH}}+(0.005) \mathrm{K}_{\text {pores }}+(0.15) \mathrm{K}_{\text {others }}$

$\mathrm{G}_{\mathrm{p}}=(0.35) \mathrm{G}_{\mathrm{C}-\mathrm{S}-\mathrm{H}}+(0.27) \mathrm{G}_{\text {cement }}+(0.2) \mathrm{G}_{\mathrm{CH}}+(0.17) \mathrm{G}_{\text {others }}$

For $\mathrm{w} / \mathrm{cm}=0.4$,

$\mathrm{K}_{\mathrm{p}}=(0.4) \mathrm{K}_{\mathrm{C}-\mathrm{S}-\mathrm{H}}+(0.14) \mathrm{K}_{\text {cement }}+(0.25) \mathrm{K}_{\mathrm{CH}}+(0.01) \mathrm{K}_{\text {pores }}+(0.18) \mathrm{K}_{\text {others }}$

$\mathrm{G}_{\mathrm{p}}=(0.43) \mathrm{G}_{\mathrm{C}-\mathrm{S}-\mathrm{H}}+(0.14) \mathrm{G}_{\text {cement }}+(0.23) \mathrm{G}_{\mathrm{CH}}+(0.18) \mathrm{G}_{\mathrm{others}}$

For $\mathrm{w} / \mathrm{cm}=0.5$,

$\mathrm{K}_{\mathrm{p}}=(0.45) \mathrm{K}_{\mathrm{C}-\mathrm{S}-\mathrm{H}}+(0.05) \mathrm{K}_{\text {cement }}+(0.26) \mathrm{K}_{\mathrm{CH}}+(0.03) \mathrm{K}_{\text {pores }}+(0.2) \mathrm{K}_{\text {others }}$ 
$\mathrm{G}_{\mathrm{p}}=(0.48) \mathrm{G}_{\mathrm{C}-\mathrm{S}-\mathrm{H}}+(0.05) \mathrm{G}_{\text {cement }}+(0.28) \mathrm{G}_{\mathrm{CH}}+(0.21) \mathrm{G}_{\text {others }}$

The values of $\mathrm{Kp}$ and $\mathrm{Gp}$ were modified in the case of the cementitious systems containing the SCMs. The effect of the C-S-H (II) was incorporated such that its stiffness was $20 \%$ more than that of C-S-H(I). Also, the contribution of the unhydrated cement clinker materials was modified, keeping in mind the replacement of cement by the SCMs.

So, the modified equations were:

For $\mathrm{w} / \mathrm{cm}$ ratio of 0.3 ,

$$
\begin{aligned}
\mathrm{K}_{\mathrm{p}}= & (0.16) \mathrm{K}_{\mathrm{C}-\mathrm{S}-\mathrm{H}}+(0.16)(1.2) \mathrm{K}_{\mathrm{C}-\mathrm{S}-\mathrm{H}}+(0.27)\left(\mathrm{V}_{\text {cement }} \mathrm{K}_{\text {cement }} \mathrm{V}_{\text {slag }} \mathrm{K}_{\text {slag }}+\mathrm{V}_{\text {fly ash }} \mathrm{K}_{\text {fly ash }}\right. \\
& \left.+\mathrm{V}_{\text {silica fume }} \mathrm{K}_{\text {silica fume }}\right)+(0.22) \mathrm{K}_{\mathrm{CH}}+(0.005) \mathrm{K}_{\text {pores }}+(0.15) \mathrm{K}_{\text {others }} \\
\mathrm{G}_{\mathrm{p}}= & (0.175) \mathrm{G}_{\mathrm{C}-\mathrm{S}-\mathrm{H}}+(0.175)(1.2) \mathrm{G}_{\mathrm{C}-\mathrm{S}-\mathrm{H}}+(0.27)\left(\mathrm{V}_{\text {cement }} \mathrm{G}_{\text {cement }} \mathrm{V}_{\text {slag }} \mathrm{G}_{\text {slag }}+\mathrm{V}_{\text {fly ash }} \mathrm{G}_{\text {fly ash }}\right. \\
& \left.+\mathrm{V}_{\text {silica fume }} \mathrm{G}_{\text {silica fume }}\right)+(0.2) \mathrm{G}_{\mathrm{CH}}+(0.17) \mathrm{G}_{\text {others }}
\end{aligned}
$$

For $\mathrm{w} / \mathrm{cm}=0.4$,

$$
\begin{aligned}
\mathrm{K}_{\mathrm{p}}= & (0.2) \mathrm{K}_{\mathrm{C}-\mathrm{S}-\mathrm{H}}+(0.2)(1.2) \mathrm{K}_{\mathrm{C}-\mathrm{S}-\mathrm{H}}+(0.27)\left(\mathrm{V}_{\text {cement }} \mathrm{K}_{\text {cement }} \mathrm{V}_{\text {slag }} \mathrm{K}_{\text {slag }}+\mathrm{V}_{\text {fly ash }} \mathrm{K}_{\text {fly ash }}\right. \\
& \left.+\mathrm{V}_{\text {silica fume }} \mathrm{K}_{\text {silica fume }}\right)+(0.22) \mathrm{K}_{\mathrm{CH}}+(0.005) \mathrm{K}_{\text {pores }}+(0.15) \mathrm{K}_{\text {others }} \\
\mathrm{G}_{\mathrm{p}}= & (0.215) \mathrm{G}_{\mathrm{C}-\mathrm{S}-\mathrm{H}}+(0.215)(1.2) \mathrm{G}_{\mathrm{C}-\mathrm{S}-\mathrm{H}}+(0.27)\left(\mathrm{V}_{\text {cement }} \mathrm{G}_{\text {cement }} \mathrm{V}_{\text {slag }} \mathrm{G}_{\text {slag }}+\mathrm{V}_{\text {fly ash }} \mathrm{G}_{\text {fly ash }}\right. \\
& \left.+\mathrm{V}_{\text {silica fume }} \mathrm{G}_{\text {silica fume }}\right)+(0.2) \mathrm{G}_{\mathrm{CH}}+(0.17) \mathrm{G}_{\text {others }}
\end{aligned}
$$

The values of the bulk and shear moduli for the SCMs have been taken from available research data (Rohatgi et al, Matsunaga et al).

\subsection{Concrete as Composite}

Firstly, concrete is assumed to be composed of three distinct phases -

(i) the mortar,

(ii) the coarse aggregate and

(iii) the interfacial transition zone between the mortar and the coarse aggregate. At this step, it is assumed that the shrinkage of concrete is mostly contributed to by the shrinkage of the mortar and the aggregates offer a restraining effect; the influence of the 
interfacial zone, in reality, has a gradient that decreases from the paste to the aggregate. It is also assumed that there is no direct contact between the aggregates to maintain the simplicity of the model. The three-phase systems are converted into equivalent two-phase systems. The mechanical properties of the interfacial zone were incorporated into the twophase paste-aggregate model using the concept of the Hashin Bounds. The concept of the step-wise composite model was inspired by the work of Kishitani and Baba, which was also used later on by Eguchi and Teranishi.

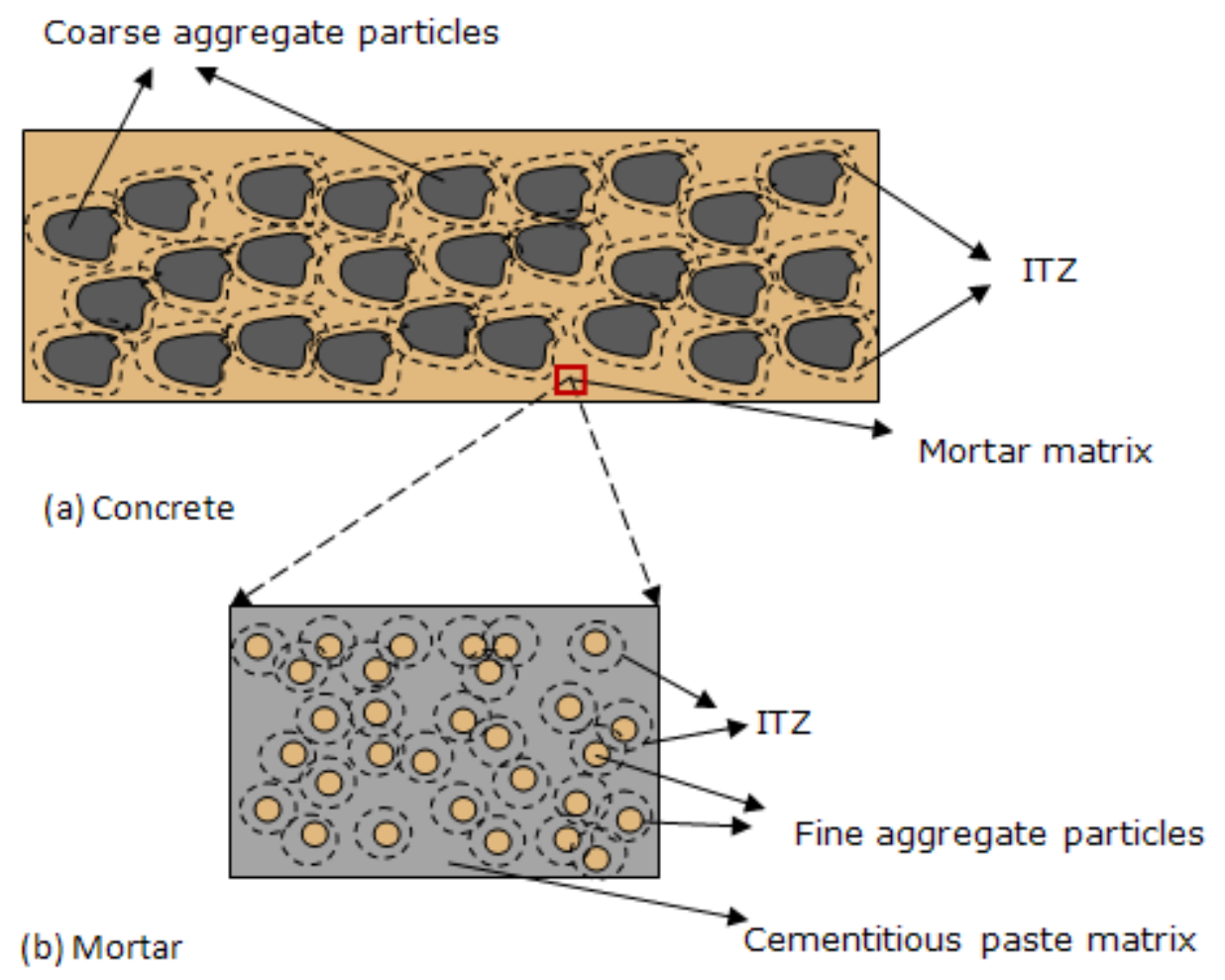

Fig. 5.3 Schematic diagram showing transition from mortar phase to concrete composite.

According to Neubauer et al. (1996), mortar and concrete are both composite materials. The arrangement and characteristics of each component of the microstructure influence the overall properties. The shrinkage of mortar and concrete must be described, based on a three-phase component model, comprising the bulk cement paste, the aggregate and the interfacial transition zone. The properties of the ITZ between the paste and the aggregate have significant influence on the mechanical properties of the concrete.

\subsection{Proposed Two-Step Composite Model}


The purpose of the two-step composite model for our study is to find the shrinkage of mortar from that of the paste and then the range of the concrete shrinkage using the shrinkage of the mortar and the Hashin bounds for the corresponding elastic moduli. The aggregates are assumed to have negligible shrinkage strain values as they mainly restrain the shrinkage of the concrete. The composite model is based on the formulae provided by Eguchi and Teranishi from the works of Kishitani and Baba.

As mentioned in Chapter 2, section (), Eguchi's formula had two steps so that he could incorporate the composite model into the prediction of the shrinkage of concrete. For our study, the two-step equation can be re-written as

$$
\begin{gathered}
\frac{\varepsilon_{m}}{\varepsilon_{p}}=\frac{\left[1-\left(1-m_{1} n_{1}\right) V_{s}\right]\left[n_{1}+1-\left(n_{1}-1\right) V_{s}\right]}{n_{1}+1+\left(n_{1}-1\right) V_{s}} \\
\frac{\varepsilon_{c}}{\varepsilon_{m}}=\frac{\left[1-\left(1-m_{2} n_{2}\right) V_{a}\right]\left[n_{2}+1-\left(n_{2}-1\right) V_{a}\right]}{n_{2}+1+\left(n_{2}-1\right) V_{a}}
\end{gathered}
$$

Where

$\varepsilon_{\mathrm{p}, \mathrm{C}-\mathrm{S}-\mathrm{H}}=$ shrinkage of paste, expressed as a function of the C-S-H deformation

$\varepsilon_{\mathrm{m}}=$ shrinkage of mortar

$\varepsilon_{\mathrm{c}}=$ shrinkage of concrete

$\mathrm{m}_{1}=$ ratio of shrinkage strain of sand to that of paste $=\varepsilon_{\text {sand }} / \varepsilon_{\text {paste }} \rightarrow$ tends to zero, as we assumed the fine aggregate (sand) to be resisting shrinkage

$\mathrm{m}_{2}=$ ratio of shrinkage strain of coarse aggregate to that of mortar $=\varepsilon_{\text {agg }} / \varepsilon_{m} \rightarrow$ tends to zero, as we assumed the coarse aggregate to be resisting shrinkage

$\mathrm{n}_{1}=$ ratio of elastic modulus of sand to that of cementitious paste $=E_{\text {sand }} / E_{\text {paste }}$

$\mathrm{n}_{2}=$ ratio of elastic modulus of coarse aggregate to that of mortar $=E_{a g g} / E_{m}$

$\mathrm{V}_{\mathrm{s}}=$ volume fraction of sand in the mortar 


$$
\begin{aligned}
& =\frac{W_{\text {sand }} / \rho_{\text {sand }}}{W_{\text {cem }} / \rho_{\text {cem }}+\Sigma W_{S C M} / \rho_{S C M}+W_{\text {sand }} / \rho_{\text {sand }}} \\
V_{a}= & \text { volume fraction of coarse aggregate in the concrete } \\
& =\frac{W_{a g g} / \rho_{\text {agg }}}{W_{\text {cem }} / \rho_{\text {cem }}+\Sigma W_{S C M} / \rho_{S C M}+W_{\text {sand }} / \rho_{\text {sand }}+W_{\text {agg }} / \rho_{\text {agg }}}
\end{aligned}
$$

Putting $m_{1}=0$ and $m_{2}=0$ in the above equations, they can be written as

$$
\frac{\varepsilon_{m}}{\varepsilon_{p}}=\frac{\left[1-V_{s}\right]\left[n_{1}+1-\left(n_{1}-1\right) V_{s}\right]}{n_{1}+1+\left(n_{1}-1\right) V_{s}}
$$

$$
\frac{\varepsilon_{c}}{\varepsilon_{m}}=\frac{\left[1-V_{a}\right]\left[n_{2}+1-\left(n_{2}-1\right) V_{a}\right]}{n_{2}+1+\left(n_{2}-1\right) V_{a}}
$$

For the above equations, the values of the elastic modulus of the paste, Ep, were calculated in terms of the corresponding compressive strength of the paste. According to Maekawa, the elastic modulus of the paste varies with the compressive strength as

$$
\begin{aligned}
E_{p} & =8500 *\left(f_{c}{ }^{\prime}\right)_{p}{ }^{(1 / 3)} & & \text { (in } \mathrm{MPa}) \\
& =8.5 *\left(f_{c}{ }^{\prime}\right)_{p}{ }^{(1 / 3)} & & \text { (in GPa) }
\end{aligned}
$$

For the second step of the model, the elastic modulus of the mortar, $E_{m}$, was found out considering the mortar to be composed of the cementitious paste, the fine aggregate (sand) and the ITZ. The formulation mentioned above was followed to determine the range of the values using the concept of the $\mathrm{H}-\mathrm{S}$ bounds.

Thus, when these ranges were plugged into the second step of the composite model, the range of shrinkage strains were predicted for any given concrete at each age.

The equation for the shrinkage strain of the concrete can thus be expressed as

$$
\varepsilon_{c}=\frac{\left[1-V_{a}\right]\left[n_{2}+1-\left(n_{2}-1\right) V_{a}\right]}{n_{2}+1+\left(n_{2}-1\right) V_{a}} \times \frac{\left[1-V_{s}\right]\left[n_{1}+1-\left(n_{1}-1\right) V_{s}\right.}{n_{1}+1+\left(n_{1}-1\right) V_{s}} \times \varepsilon_{p}
$$


$\mathrm{Or}, \varepsilon_{c}=\frac{\frac{\left[1-V_{a}\right]\left[n_{2}+1-\left(n_{2}-1\right) V_{a}\right]}{n_{2}+1+\left(n_{2}-1\right) V_{a}} \times \frac{\left[1-V_{S}\right]\left[n_{1}+1-\left(n_{1}-1\right) V_{S}\right.}{n_{1}+1+\left(n_{1}-1\right) V_{S}} \times\left[\frac{t}{A+B t} \times \frac{\left(V_{c_{i}}+V_{w_{i}}\right)-V_{h c p}}{\left(V_{c_{i}}+V_{w_{i}}\right)} \times \frac{v_{f, C-S-H} \cdot E_{C-S-H}}{\left(v_{f, C 3 S} \cdot E_{C 3 S}+v_{f, C 2 S} \cdot E_{C 2 S}\right)}\right]}{f(w / c m)}$

This equation predicts the range of the concrete shrinkage strains. The upper and lower values were obtained by plugging in the respective upper bound and lower bound for the elastic modulus of the mortar, which were computed using the modified $\mathrm{H}-\mathrm{S}$ bounds, as described earlier in section 5.3.

The final shrinkage equation has to be modified by incorporating the effects of the size and shape of the specimen and other environmental factors, as explained in detail in the next chapter.

\subsection{Shrinkage Test Procedure for Concrete Prisms}

$76 \mathrm{~mm} \times 76 \mathrm{~mm} \times 254 \mathrm{~mm}$ prisms were cast for the mixes mentioned in chapter 3 for length change measurement due to drying shrinkage. Lengthchange measurements were conducted according to ASTM C 150 (Standard Test Method for Length Change of Hardened Hydraulic-Cement Mortar and Concrete). All the specimens were cured for 24 hours under wet burlap and were placed in an environmental chamber maintained at $23 \pm 2{ }^{\circ} \mathrm{C}$ and $50 \pm 2 \% \mathrm{RH}$, immediately after the demolding. Length change of two replicate specimens were measured for a period of 90 days at an interval of 2 seconds each. From the values of length change, the free shrinkage strains were computed in terms of microstrain for each individual mix. The data for the length change at ages of 1-day, 3-day, 7-day, 28-day, 56day and 90-day were compared with the predicted values from the shrinkage model for validation. The results have been furnished in Appendix.

\subsection{Proposed Model}

In chapter 2, it has been discussed that according to the ACI 209R-92, the following factors have an influence on the shrinkage of concrete:

- Volume-to-surface ratio;

- Curing time;

- Relative humidity; 
- Slump factor;

- Fine aggregate factor;

- Cement content factor; and

- Air-content factor.

The equation for concrete shrinkage has proposed in Chapter 5 () does not take into account the influence of the factors mentioned above. These factors were incorporated into the concrete shrinkage equation by multiplication with the coefficients suggested by ACI.

$\varepsilon_{C}=\frac{\gamma_{s h} \cdot \frac{\left[1-V_{a}\right]\left[n_{2}+1-\left(n_{2}-1\right) V_{a}\right]}{n_{2}+1+\left(n_{2}-1\right) V_{a}} \times \frac{\left[1-V_{S}\right]\left[n_{1}+1-\left(n_{1}-1\right) V_{S}\right.}{n_{1}+1+\left(n_{1}-1\right) V_{S}} \times\left[\frac{t}{A+B t} \times \frac{\left(V_{c_{i}}+V_{w_{i}}\right)-V_{h c p}}{\left(V_{c_{i}}+V_{w_{i}}\right)} \times \frac{v_{f, C-S-H} \cdot E_{C-S-H}}{\left(v_{f, C 3 S} \cdot E_{C 3 S}+v_{f, C 2 S} \cdot E_{C 2 S}\right)}\right]}{f(w / c m)}$

where $\gamma_{\text {sh }}$ denotes the combined effect of all the factors mentioned above.

$\gamma_{\mathrm{sh}}=\gamma_{\mathrm{sh}, \mathrm{tc}} \gamma_{\mathrm{sh}, \mathrm{RH}} \gamma_{\mathrm{sh}, \mathrm{vs}} \gamma_{\mathrm{sh}, \mathrm{s}} \gamma_{\mathrm{sh}, \psi} \gamma_{\mathrm{sh}, \mathrm{c}} \gamma_{\mathrm{sh}, \mathrm{a}}$

These factors have discussed in detail in chapter2, section 2.11.3.5.

In a nutshell,this model has been developed on cementitioussystems containing varying proportions of SCM with $\mathrm{w} / \mathrm{cm}$ ratios of 0.3 and 0.4 . After studying all the models the ACI model has been chosen as a baseline and modifications have been done to incorporate the effects of SCM on drying shrinkage. For all the mixtures the aggregate cement paste ratio have been kept constant (2.3) and the amount of cementitious material, used is fairly constant with the value $375 \mathrm{~kg} / \mathrm{m}^{3}$ to $395 \mathrm{~kg} / \mathrm{m}^{3}$. The slump and air content values were also kept constant $180-200 \mathrm{~mm}$ and $6 \pm 1 \%$ respectively. 


\subsection{Comparisons of Models with the Shrinkage Data}

In general, the shrinkage data for concrete with or without SCM are compared with the predicted values from existing models.

As mentioned by McDonald and Roper, 1993 that a residual plot can give a good idea about the accuracy of a prediction model. But as mentioned in Chapter 2, section 2.13, the accuracy of the proposed model was first checked by plotting the experimental data and the predicted upper and lower bounds of the proposed model along the same axes, as shown in section 5.7.1. This was done for all the mixes and all the cases showed that the experimental data lied between the predicted limits. But in certain cases, there was a distinct randomness regarding how the experimental data lies within the predicted values, i.e. in some case, it was very close to the upper bound whereas in other cases, it was very close to the lower bound. This randomness was accounted for by plotting the mean difference that is, the difference between the experimental data and the mean value of the predicted ranges for each mix at different ages, as explained in section 5.7.1.1. 


\subsubsection{Comparison with proposed model}

Firstly, the results obtained from the shrinkage tests mentioned in section 6.1 were compared with the range of the shrinkage predicted by the proposed equation. The results were tested to find out if they lied within the lower and upper bounds of the predicted model and the residuals were computed by subtracting the mean of the predicted values from the experimental data.

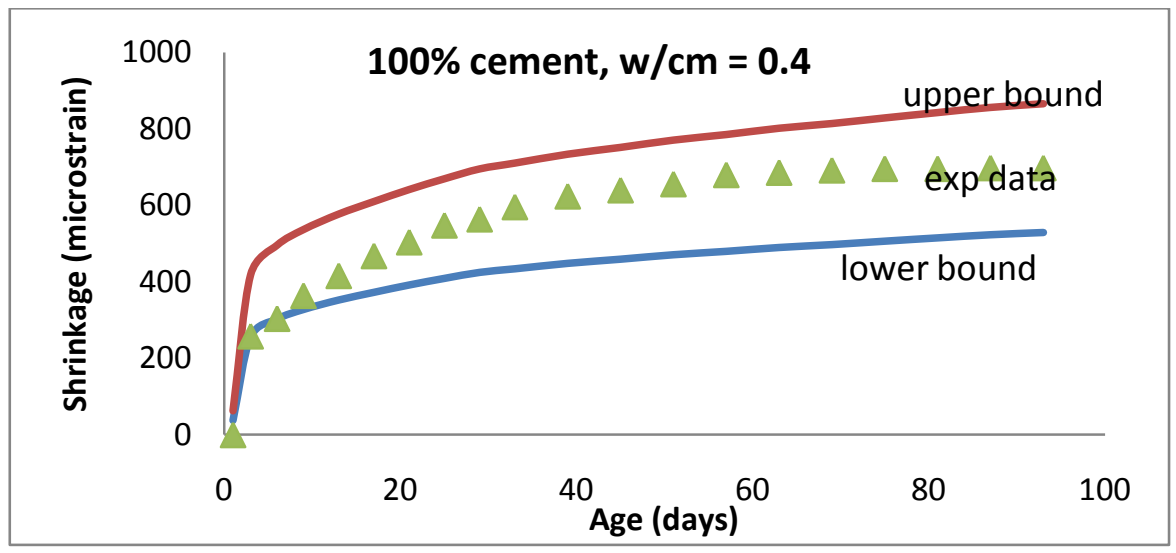

(a) $\mathrm{w} / \mathrm{cm}=0.4$

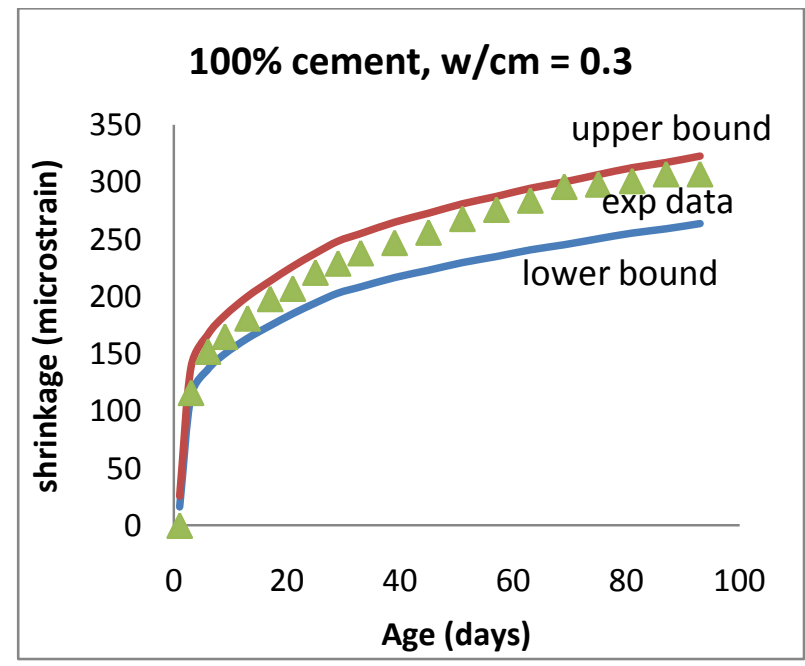

(b) $w / c m=0.3$

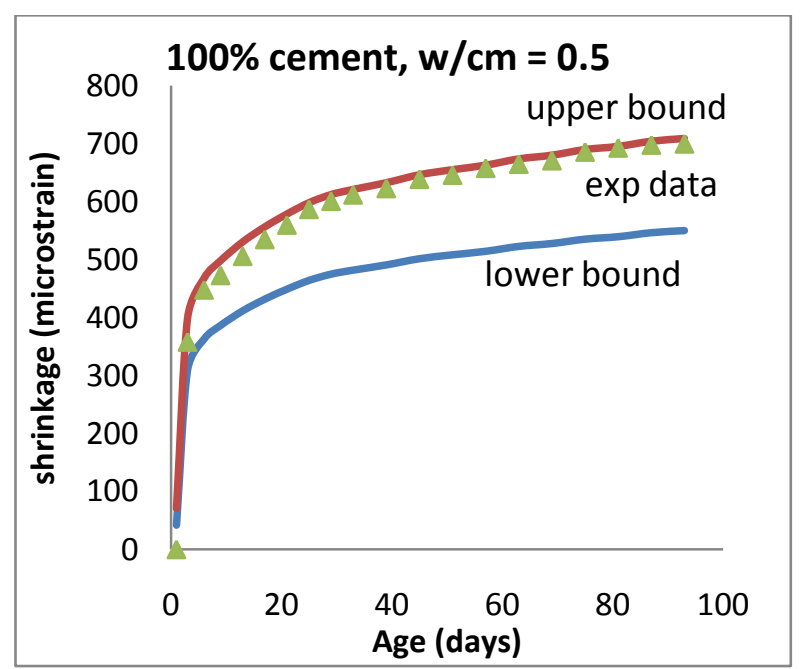

(c) $\mathrm{w} / \mathrm{cm}=0.5$

Fig. 5.4 Comparison of concrete shrinkage experimental data with the upper and lower bounds predicted by the proposed model in case of $100 \%$ cement mixes at three different $\mathrm{w} / \mathrm{cm}$ ratios. 


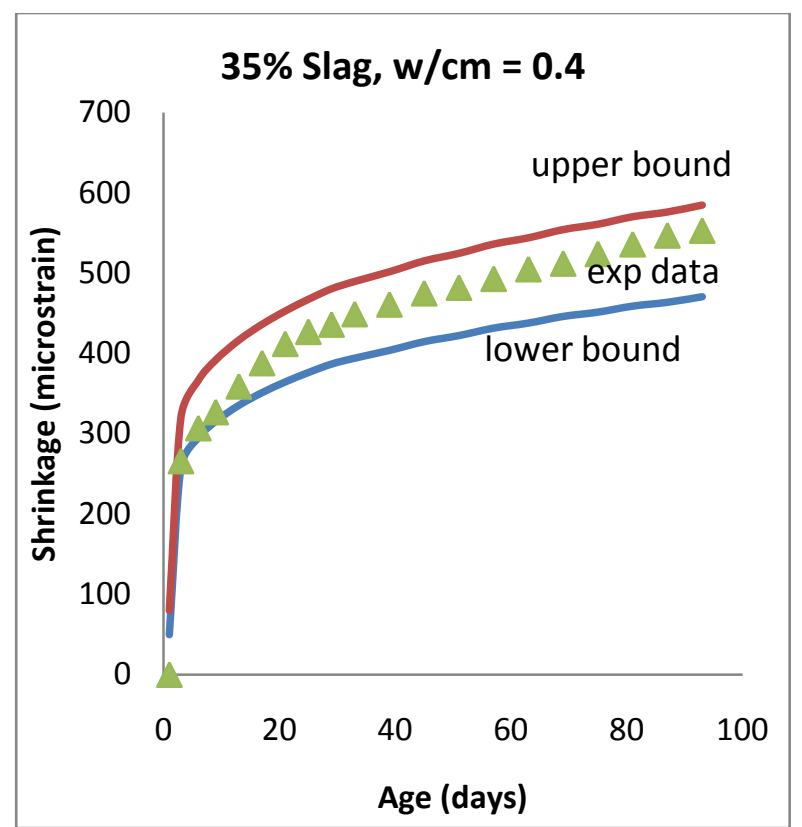

(a) $\mathrm{w} / \mathrm{cm}=0.4$

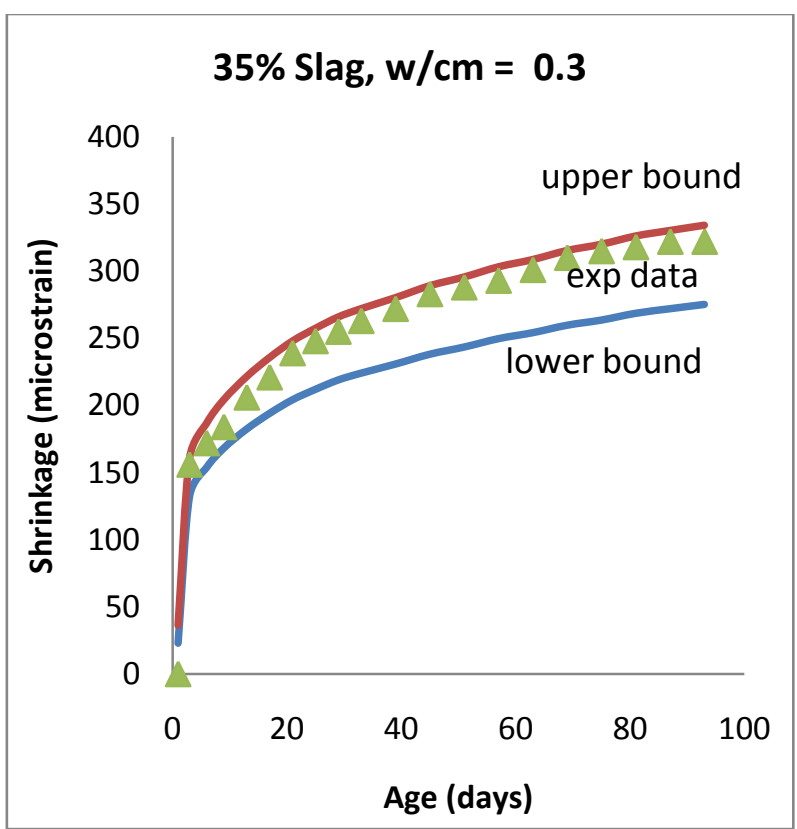

(b) $w / c m=0.3$

Fig. 5.5 Comparison of concrete shrinkage experimental data with the upper and lower bounds predicted by the proposed model in case of mixes containing replacement of cement by $35 \%$ slag at two different $\mathrm{w} / \mathrm{cm}$ ratios.

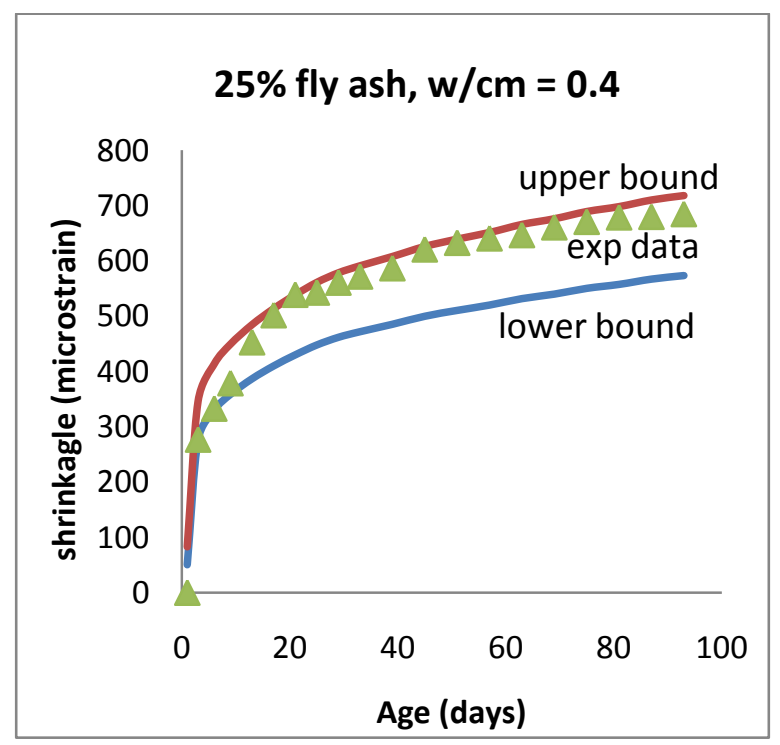

(a) $\mathrm{w} / \mathrm{cm}=0.4$

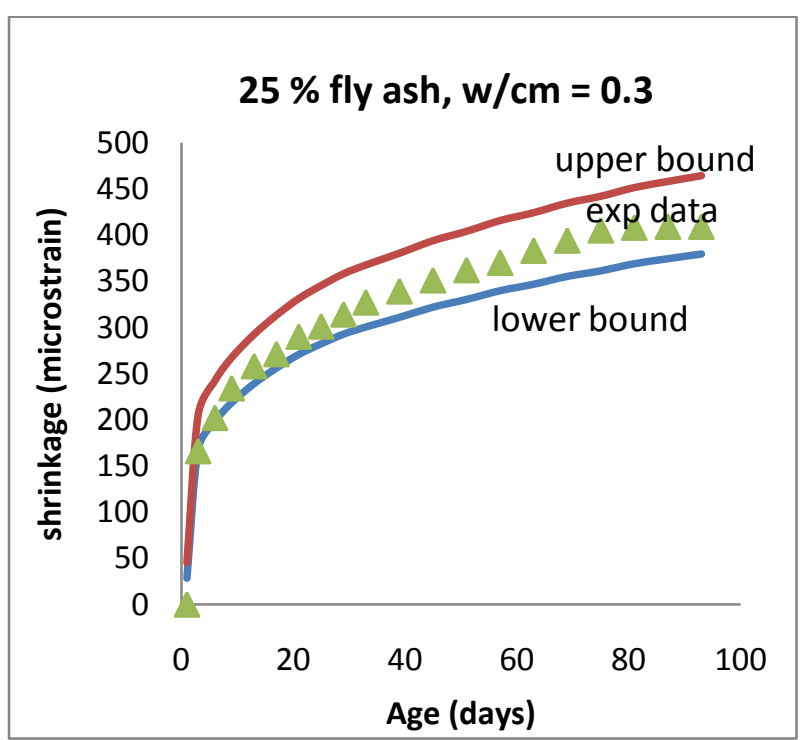

(b) $w / c m=0.3$

Fig. 5.6 Comparison of concrete shrinkage experimental data with the upper and lower bounds predicted by the proposed model in case of mixes containing replacement of cement by $25 \%$ fly ash at two different $\mathrm{w} / \mathrm{cm}$ ratios. 


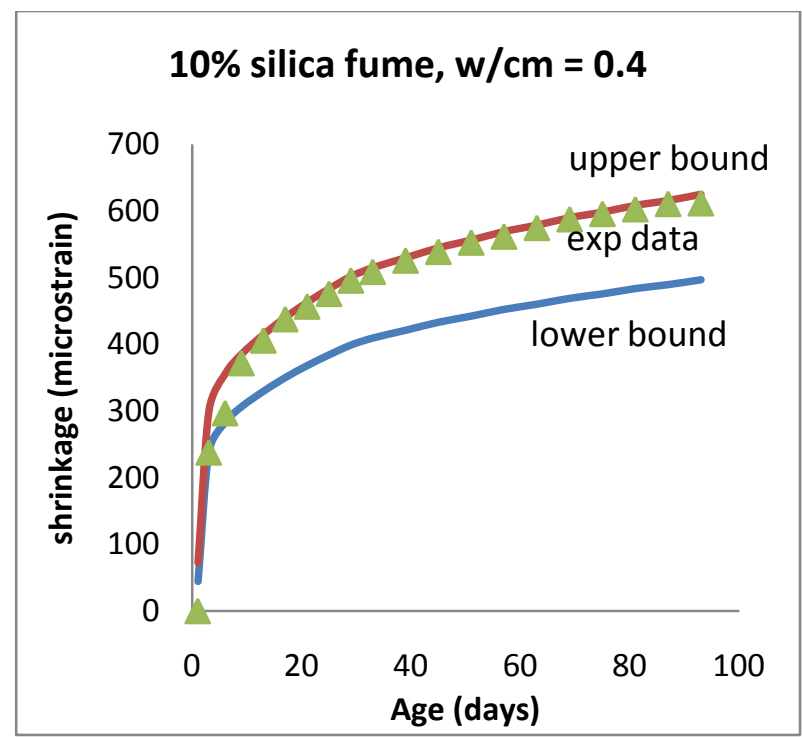

(a) $\mathrm{w} / \mathrm{cm}=0.4$

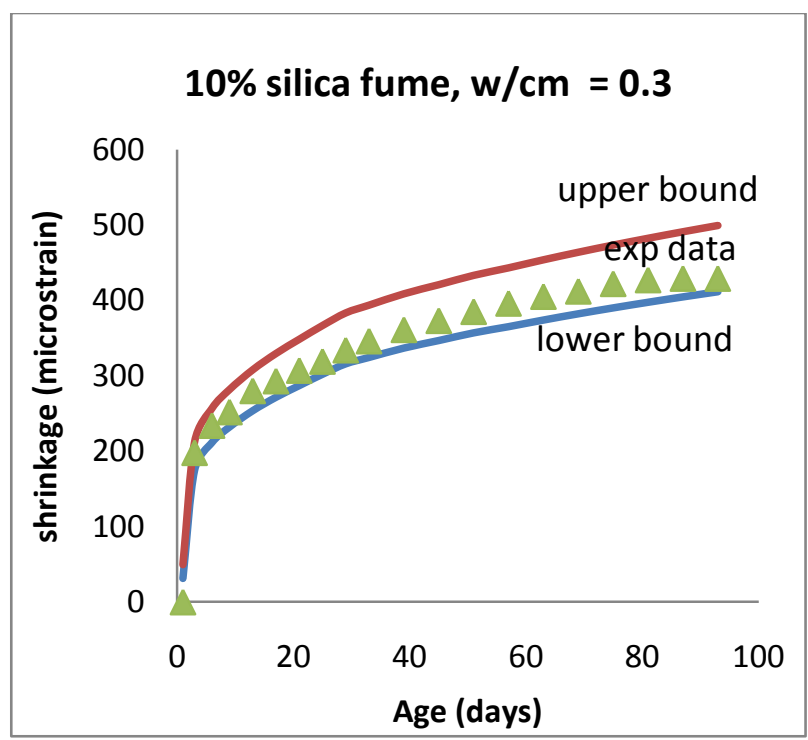

(b) $\mathrm{w} / \mathrm{cm}=0.3$

Fig. 5.7 Comparison of concrete shrinkage experimental data with the upper and lower bounds predicted by the proposed model in case of mixes containing replacement of cement by $10 \%$ silica fume at two different $\mathrm{w} / \mathrm{cm}$ ratios.

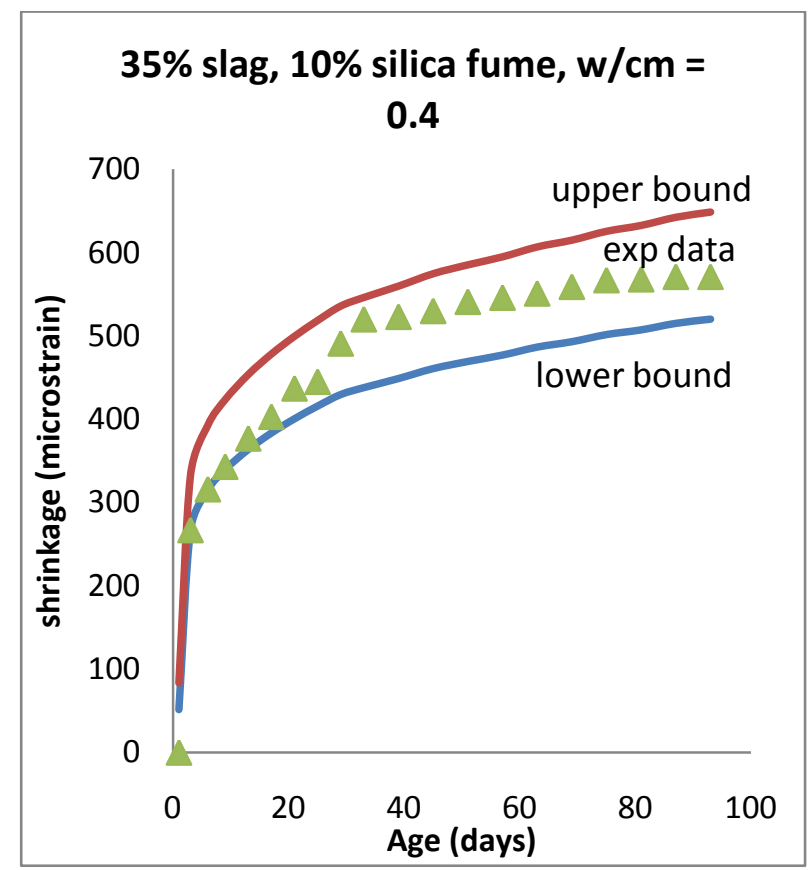

(a) $\mathrm{w} / \mathrm{cm}=0.4$

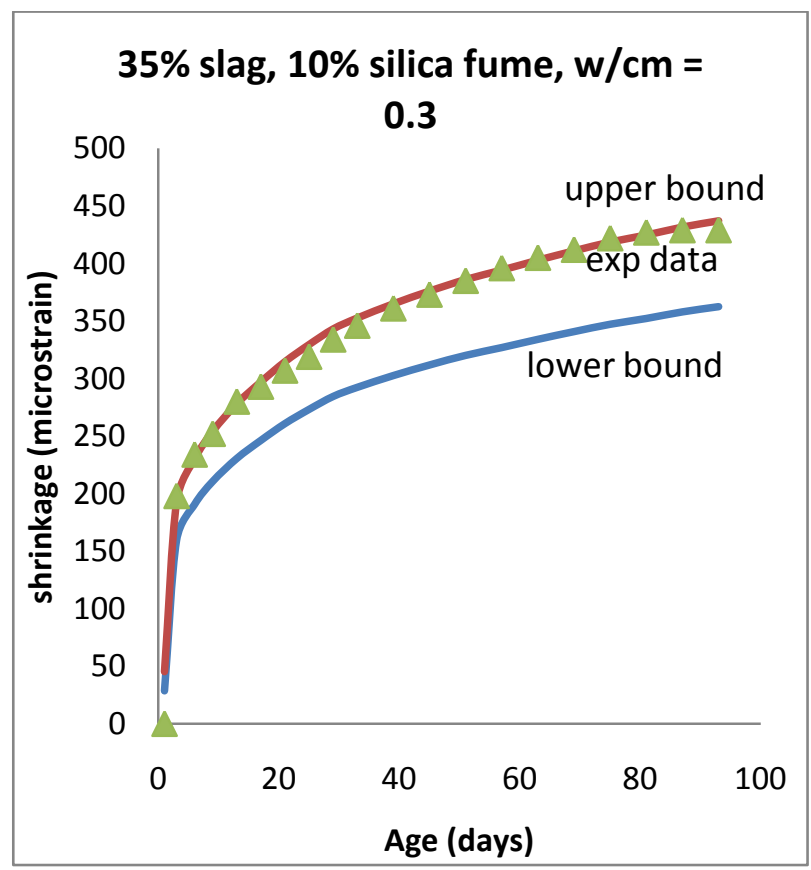

(b) $\mathrm{w} / \mathrm{cm}=0.3$

Fig. 5.8 Comparison of concrete shrinkage experimental data with the upper and lower bounds predicted by the proposed model in case of mixes containing replacement of cement by $35 \%$ slag and $10 \%$ silica fume at two different $\mathrm{w} / \mathrm{cm}$ ratios. 


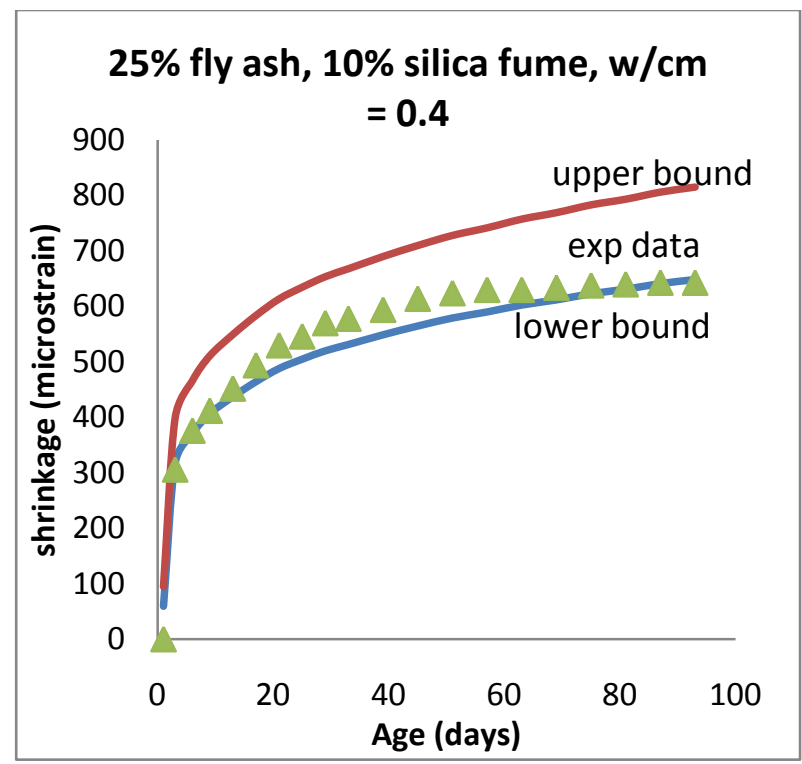

(a) $\mathrm{w} / \mathrm{cm}=0.4$

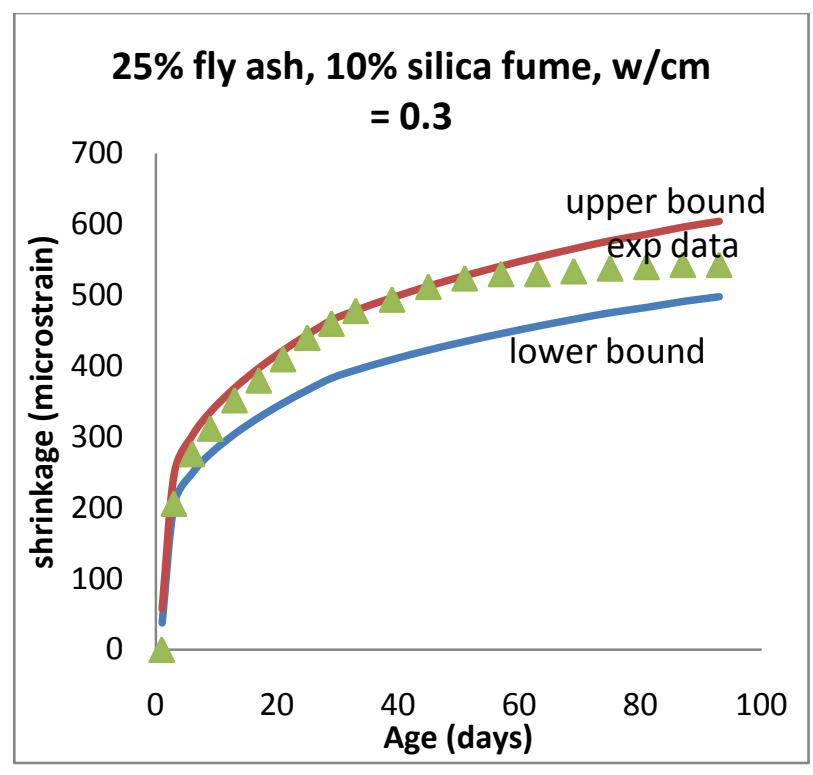

(b) $\mathrm{w} / \mathrm{cm}=0.3$

Fig. 5.9 Comparison of concrete shrinkage experimental data with the upper and lower bounds predicted by the proposed model in case of mixes containing replacement of cement by $25 \%$ fly ash at two different $\mathrm{w} / \mathrm{cm}$ ratios.

The plots of the experimental data with the ranges given by the proposed model have been furnished in Figs 5.3 through 5.9. The experimental data in all of the cases have been found to lie within the upper and the lower bounds predicted by the proposed model. This shows the effectiveness of the model in providing an estimate of the shrinkage strains of concrete containing SCM of varied types and proportions. In some cases (Figs 5.6a, 5.7a, 5.8b and $5.9 \mathrm{~b})$, the experimental data have been found to lie very close to the predicted upper bound, whereas, in a few other cases (Figs. 6b and 9a), the experimental data approach the predicted lower bound values. To analyze these occurrences further, the plots of the residuals were obtained by subtracting the mean value of the predicted upper and lower bounds, as shown in section 5.7.1.1. 


\subsubsection{Plot of mean differences}

The mean differences were plotted by subtracting the mean value of the upper and lower bounds as predicted by the proposed model from the experimental data.

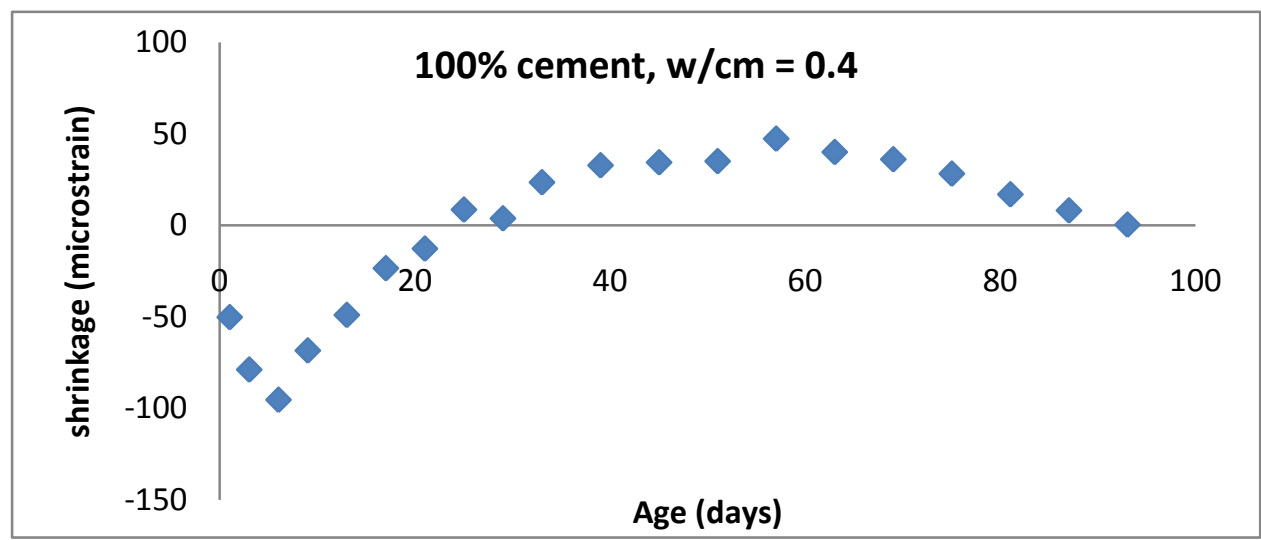

(a) $\mathrm{w} / \mathrm{cm}=0.4$

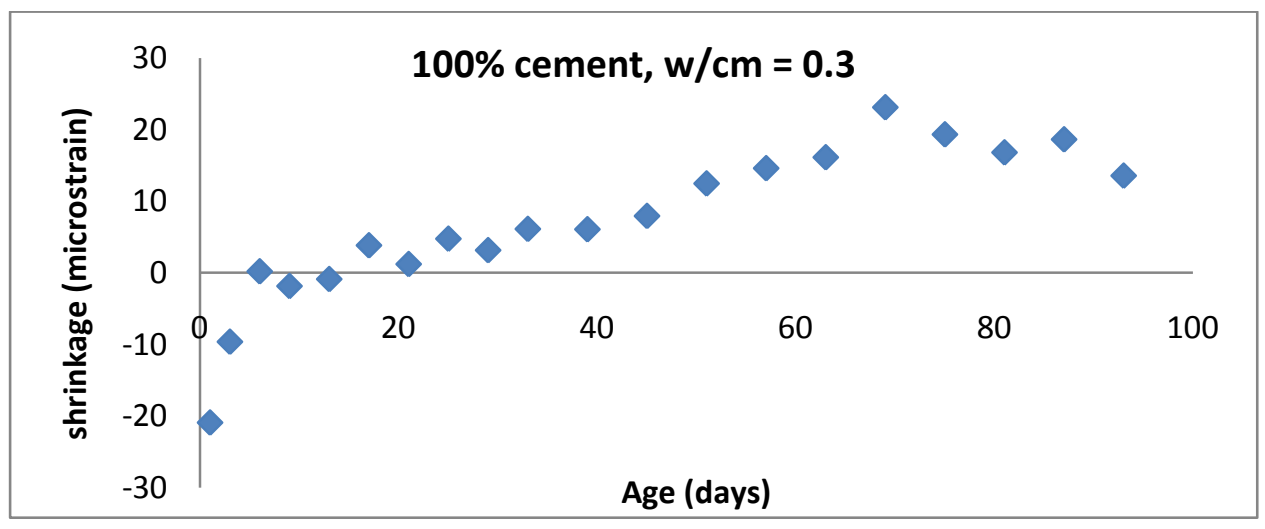

(b) $\mathrm{w} / \mathrm{cm}=0.3$

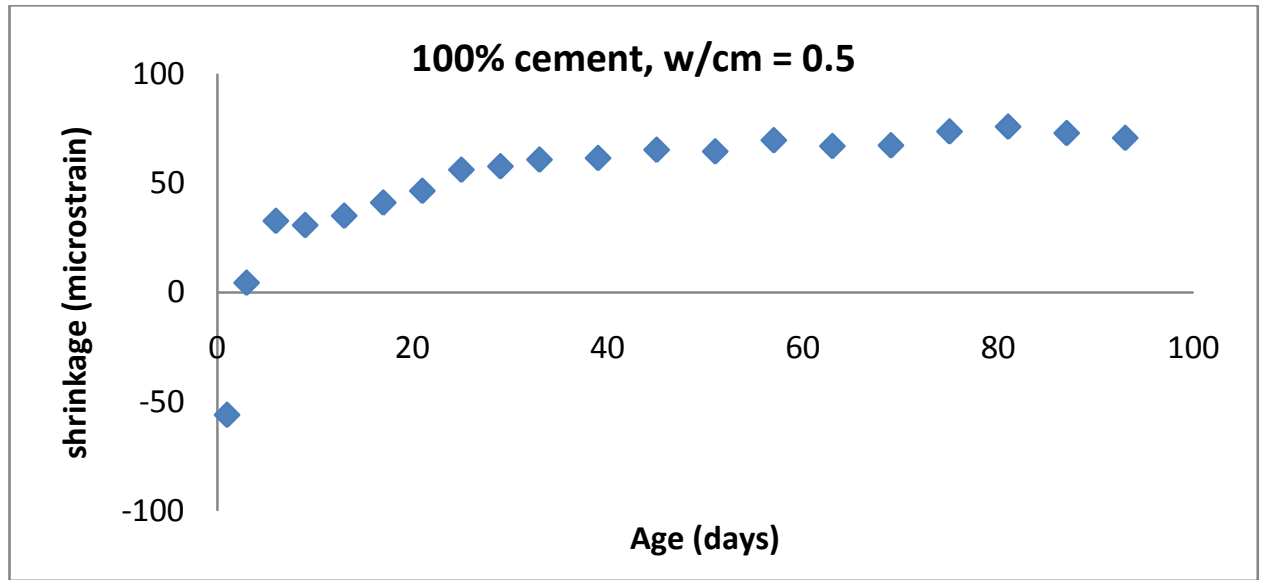

(c) $\mathrm{w} / \mathrm{cm}=0.5$

Fig 5.10 Plot of mean differences of experimental data with respect to the mean of the predicted upper and lower bounds of the proposed model in case of $100 \%$ cement mixes at different $\mathrm{w} / \mathrm{cm}$ ratios. 


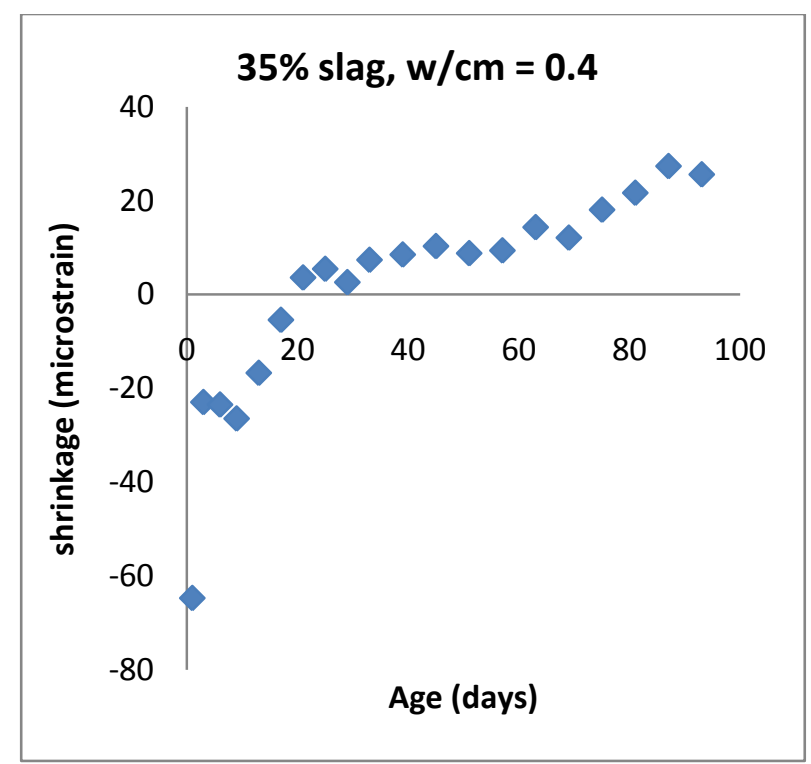

(a) $\mathrm{w} / \mathrm{cm}=0.4$

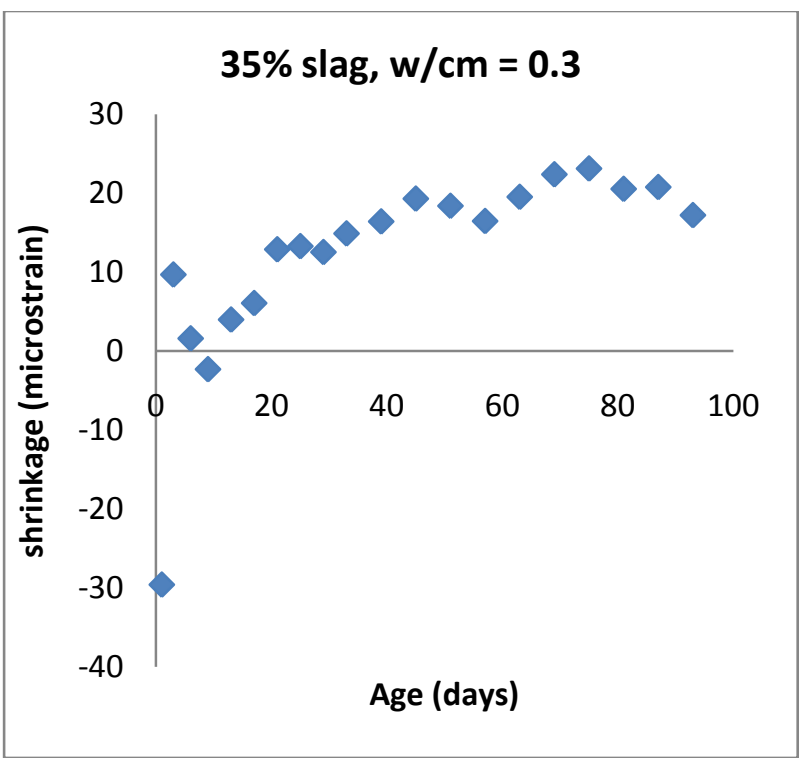

(b) $w / c m=0.3$

Fig 5.11 Plot of mean differences of experimental data with respect to the mean of the predicted upper and lower bounds of the proposed model in case of mixes containing replacement of cement by $35 \%$ slag at different $\mathrm{w} / \mathrm{cm}$ ratios.

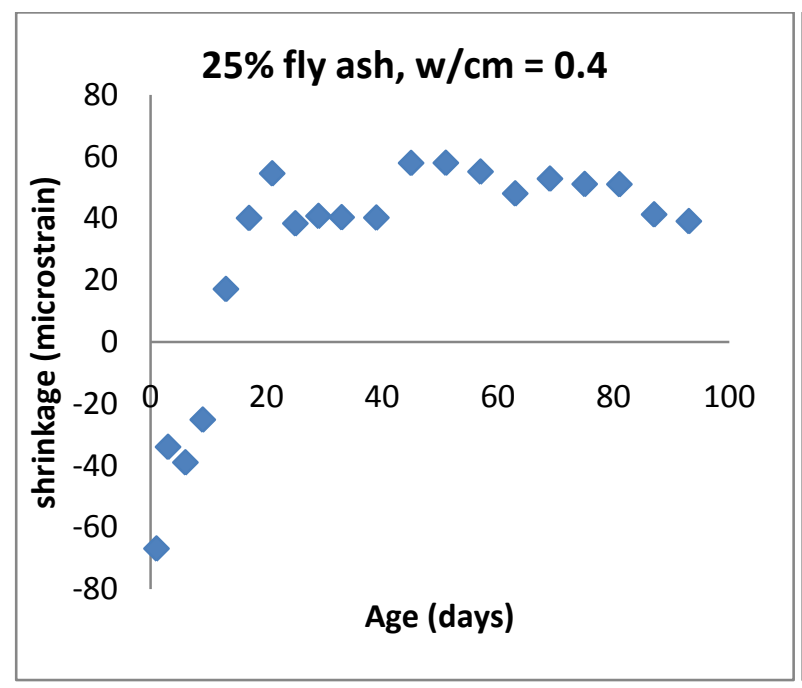

(a) $\mathrm{w} / \mathrm{cm}=0.4$

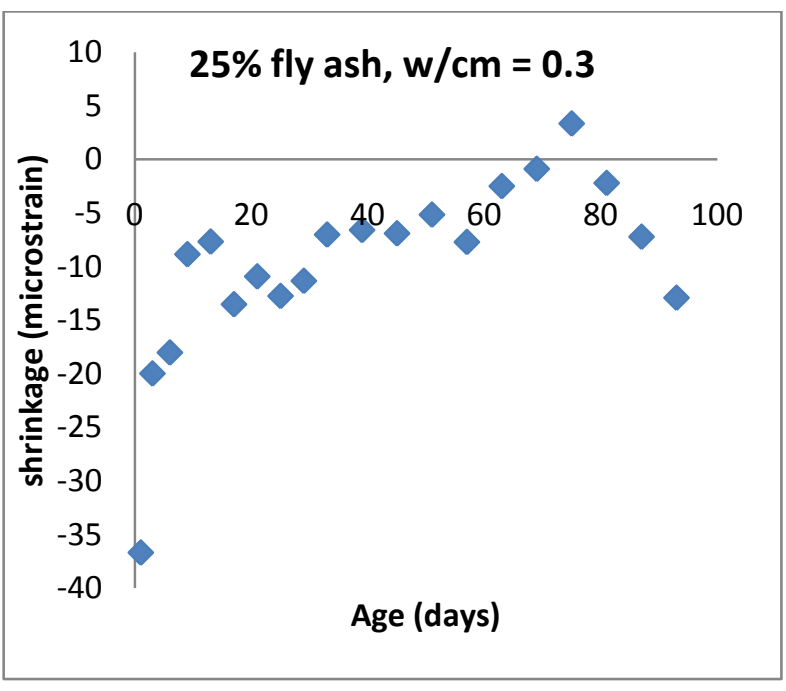

(b) $\mathrm{w} / \mathrm{cm}=0.3$

Fig 5.12 Plot of mean differences of experimental data with respect to the mean of the predicted upper and lower bounds of the proposed model in case of mixes containing replacement of cement by $25 \%$ fly ash at different $\mathrm{w} / \mathrm{cm}$ ratios. 


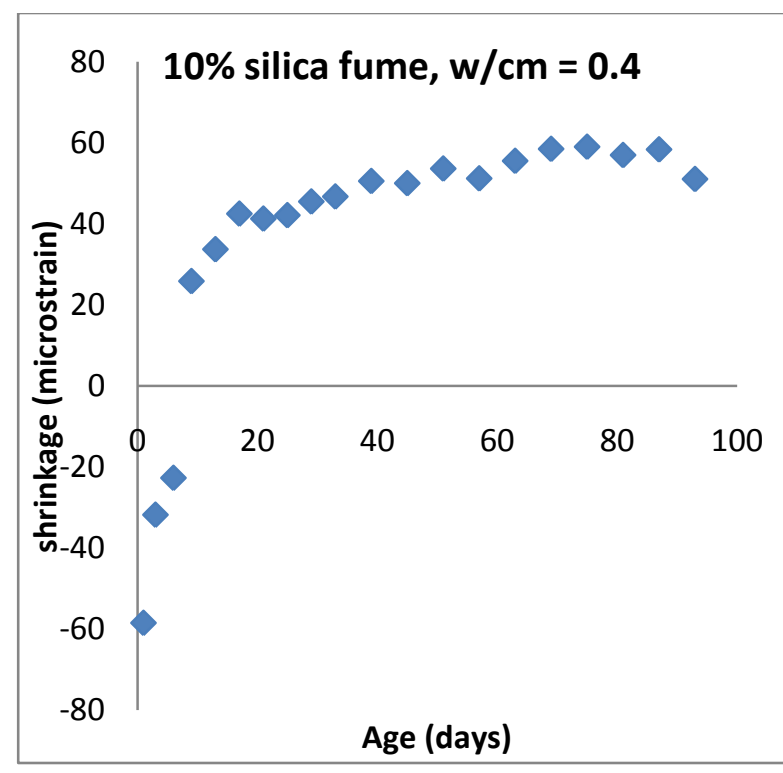

(a) $\mathrm{w} / \mathrm{cm}=0.4$

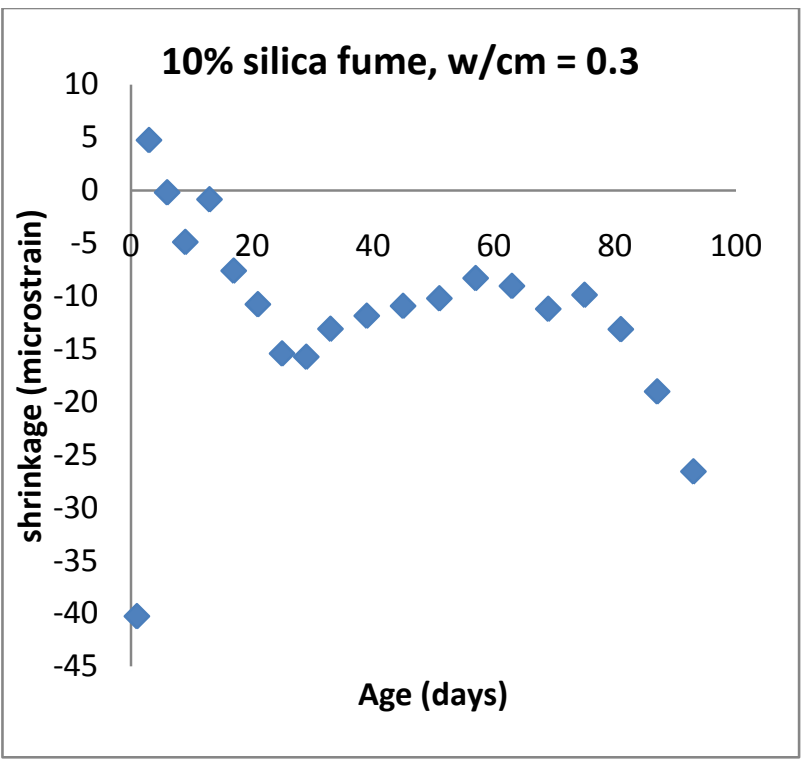

(b) $\mathrm{w} / \mathrm{cm}=0.3$

Fig 5.13 Plot of mean differences of experimental data with respect to the mean of the predicted upper and lower bounds of the proposed model in case of mixes containing replacement of cement by $10 \%$ silica fume at different $\mathrm{w} / \mathrm{cm}$ ratios.

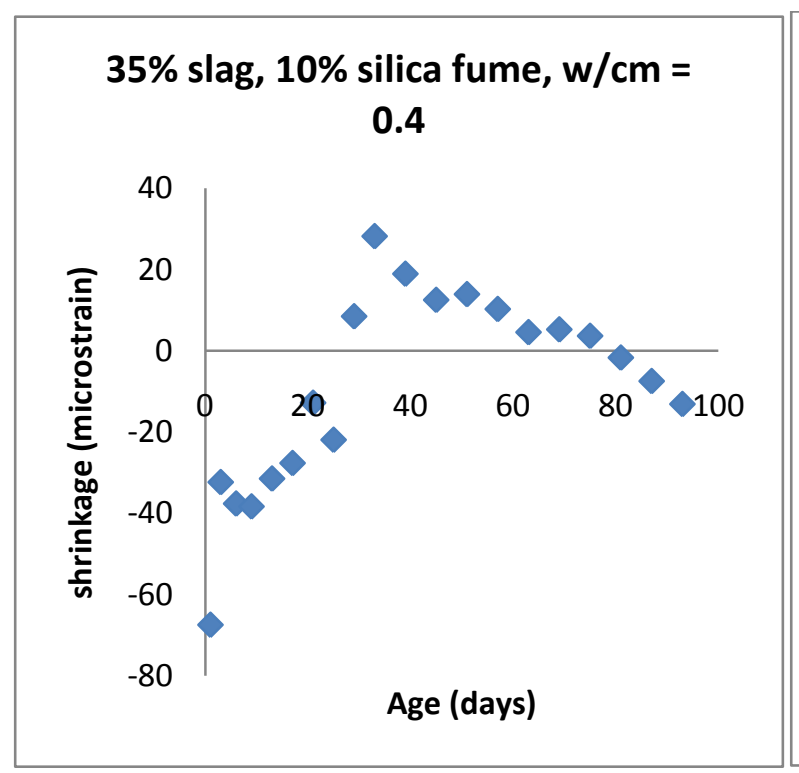

(a) $\mathrm{w} / \mathrm{cm}=0.4$
$35 \%$ slag, $10 \%$ silica fume, $\mathrm{w} / \mathrm{cm}=$ 0.3

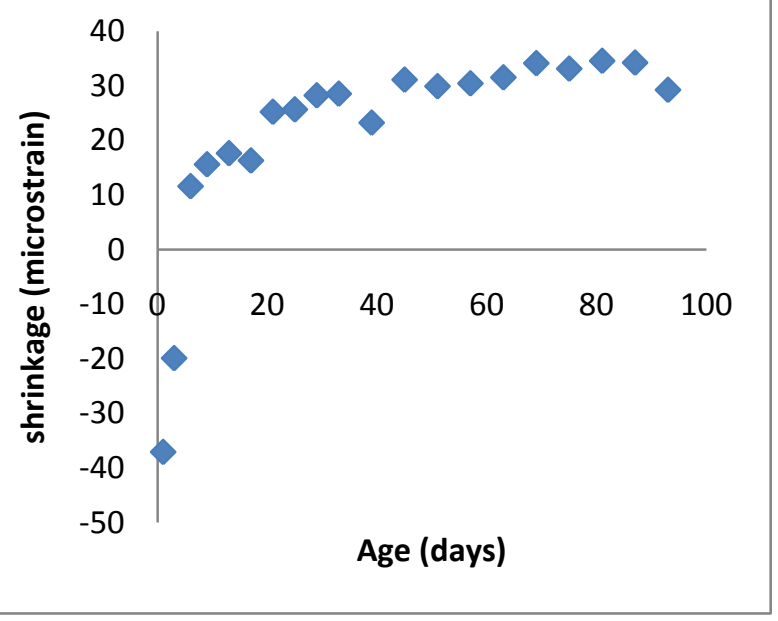

(b) $w / c m=0.3$

Fig 5.14 Plot of mean differences of experimental data with respect to the mean of the predicted upper and lower bounds of the proposed model in case of mixes containing replacement of cement by $35 \%$ slag and $10 \%$ silica fume at different $\mathrm{w} / \mathrm{cm}$ ratios. 


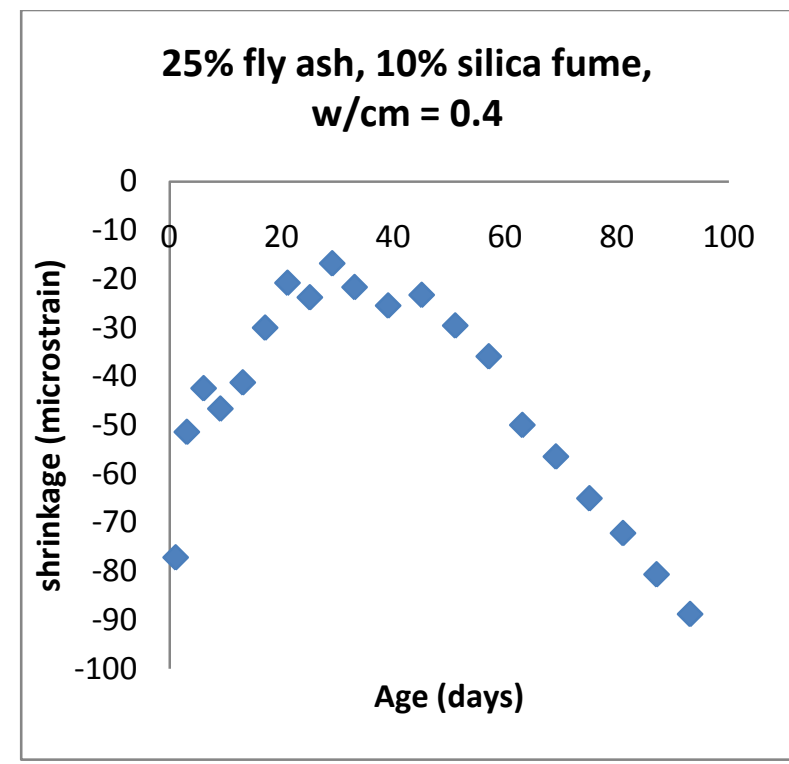

(a) $\mathrm{w} / \mathrm{cm}=0.4$
25 fly ash, $10 \%$ silica fume, $\mathrm{w} / \mathrm{cm}=$

0.3

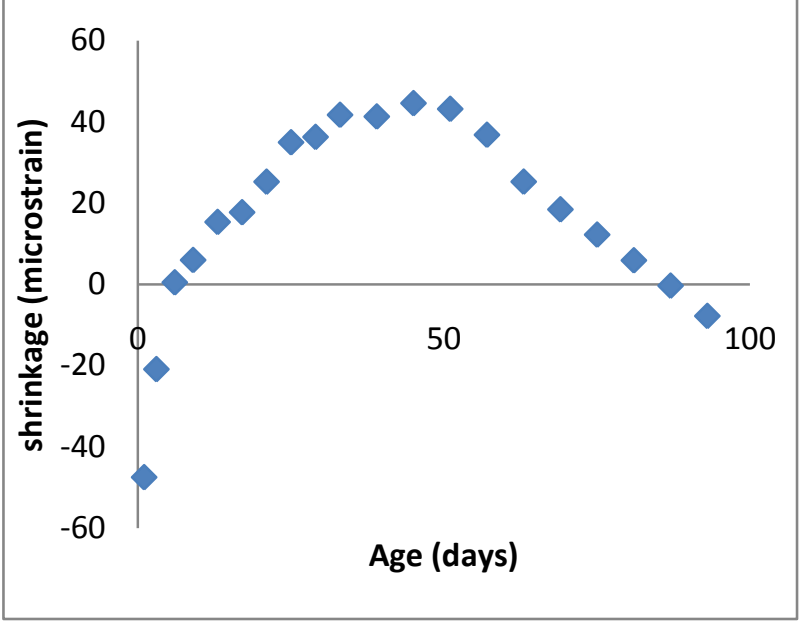

(b) $\mathrm{w} / \mathrm{cm}=0.3$

Fig 5.15 Plot of mean differences of experimental data with respect to the mean of the predicted upper and lower bounds of the proposed model in case of mixes containing replacement of cement by $25 \%$ fly ash and $10 \%$ silica fume at different $\mathrm{w} / \mathrm{cm}$ ratios.

The plots of the residual show that the difference of the experimental data from the mean of the predicted values never exceeded $70 \sim 80$ microstrains, which showed fairly close agreement between experimental and predicted data.

Most of the plots exhibited positive mean differences which indicated non-conservative nature of the model, except (i) $25 \%$ fly ash, w/cm $=0.3$ (Fig. 14a), (ii) $10 \%$ silica fume, $\mathrm{w} / \mathrm{cm}=0.3$ (Fig. 13b), and (iii) $25 \%$ fly ash and $10 \%$ silica fume, $w / c m=0.4$ (Fig. $5.15 a$ ). The negative value of the mean difference implies conservative prediction of shrinkage strains in these cases. 


\subsubsection{Comparison with available models}

\subsubsection{ACI and modified ACI (by Huo et al. 2001)}

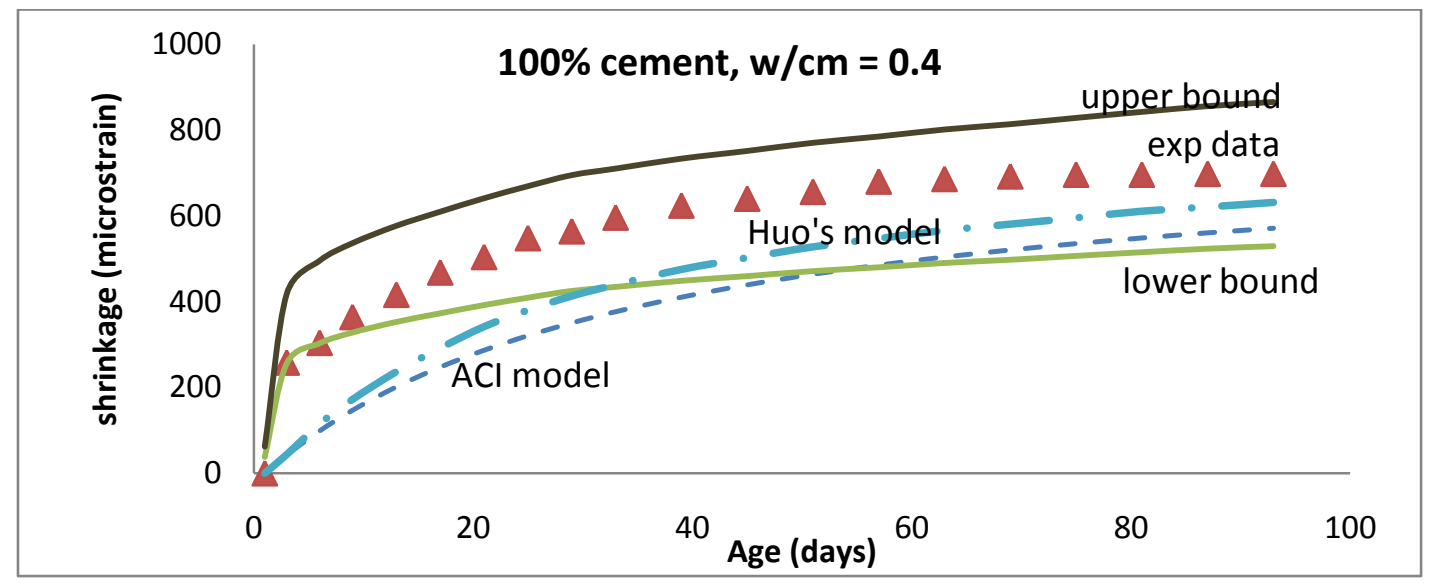

(a) $\mathrm{w} / \mathrm{cm}=0.4$

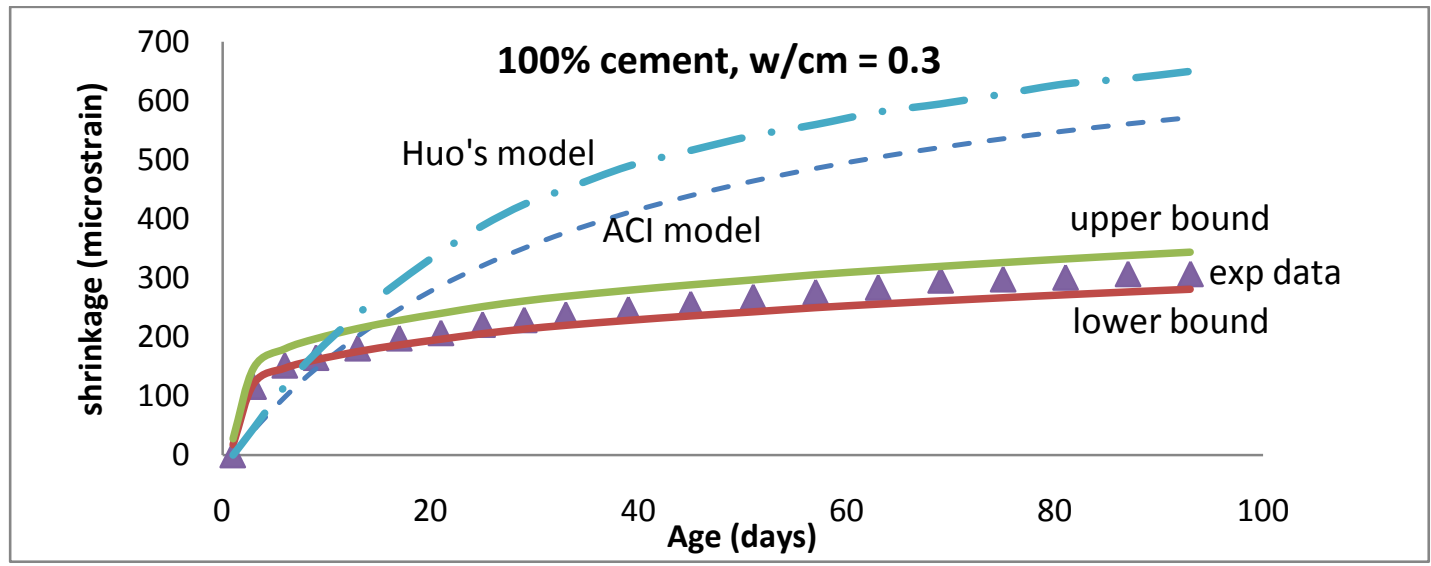

(b) $\mathrm{w} / \mathrm{cm}=0.3$

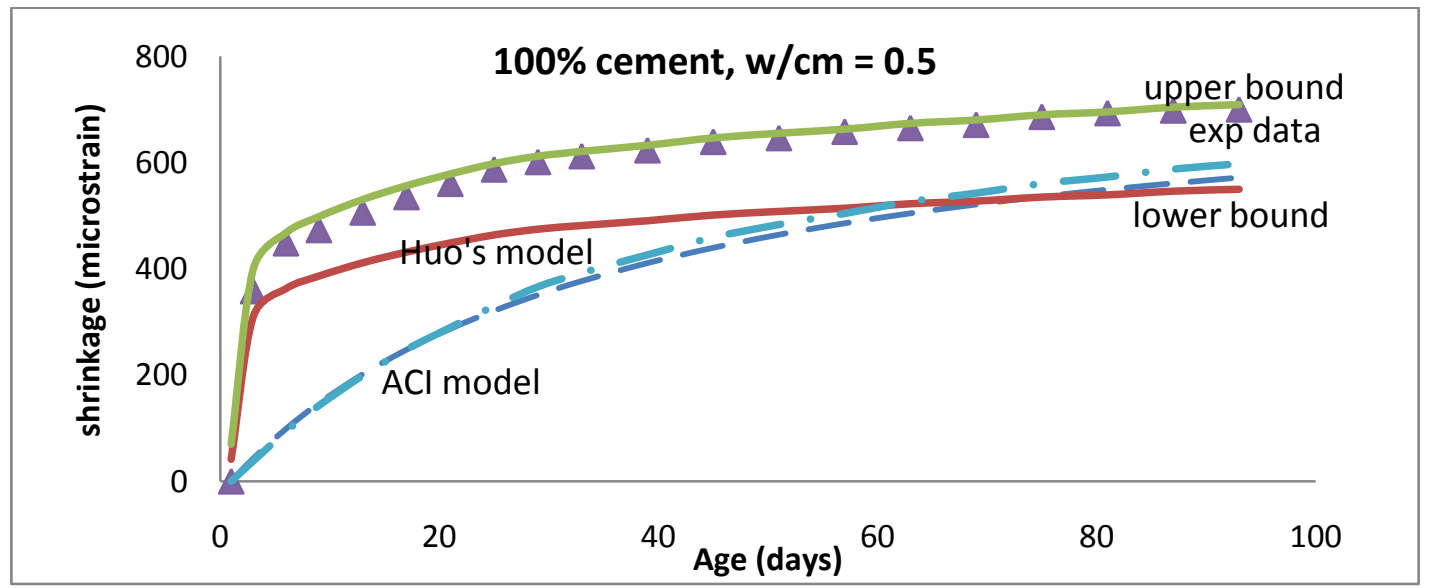

(c) $\mathrm{w} / \mathrm{cm}=0.5$

Fig. 5.16 Comparison of the ACI (and the modified ACI by Huo et al. 2001) with the upper and lower bounds of the proposed model with experimental data in case of $100 \%$ cement mixes at three $\mathrm{w} / \mathrm{cm}$ ratios. 


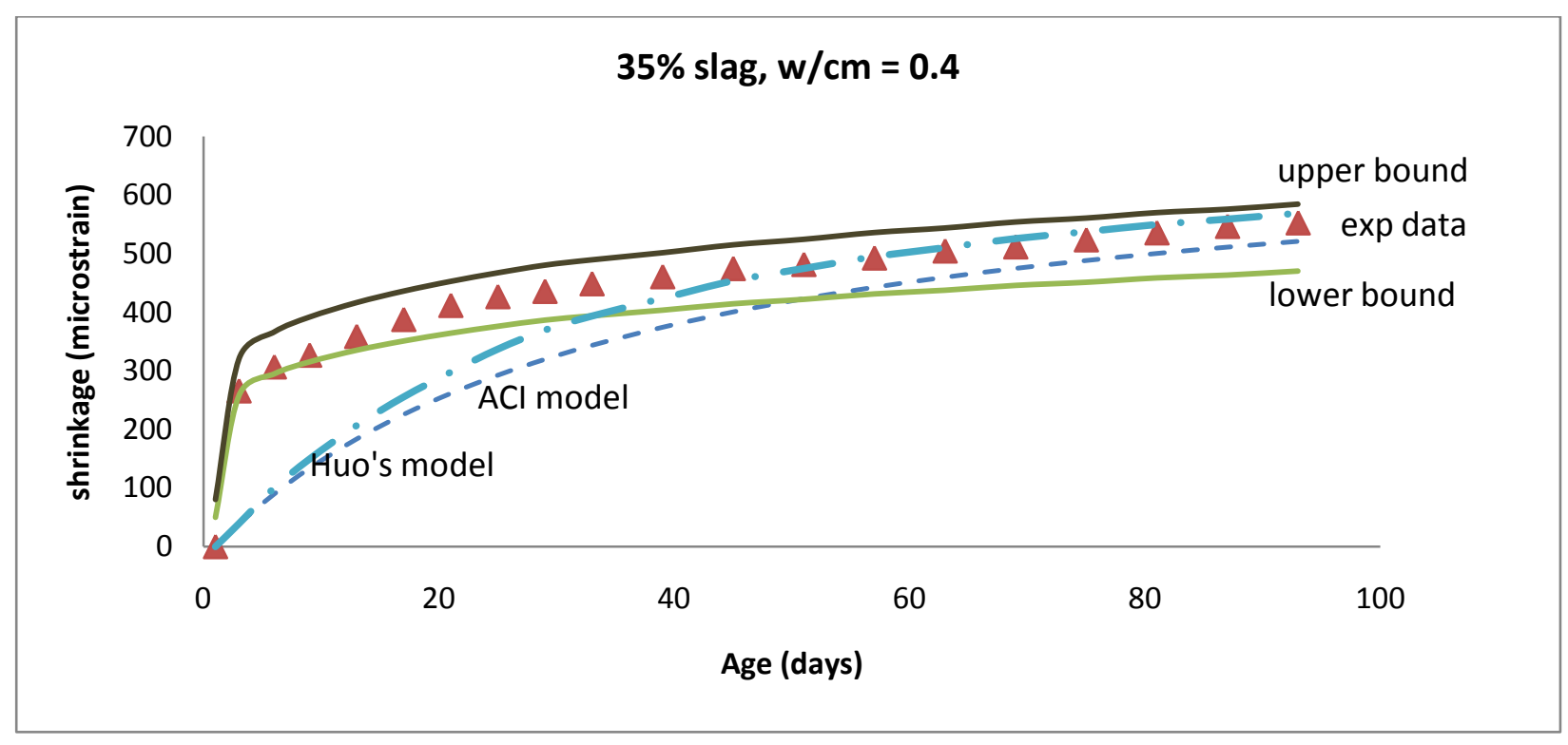

(a) $\mathrm{w} / \mathrm{cm}=0.4$

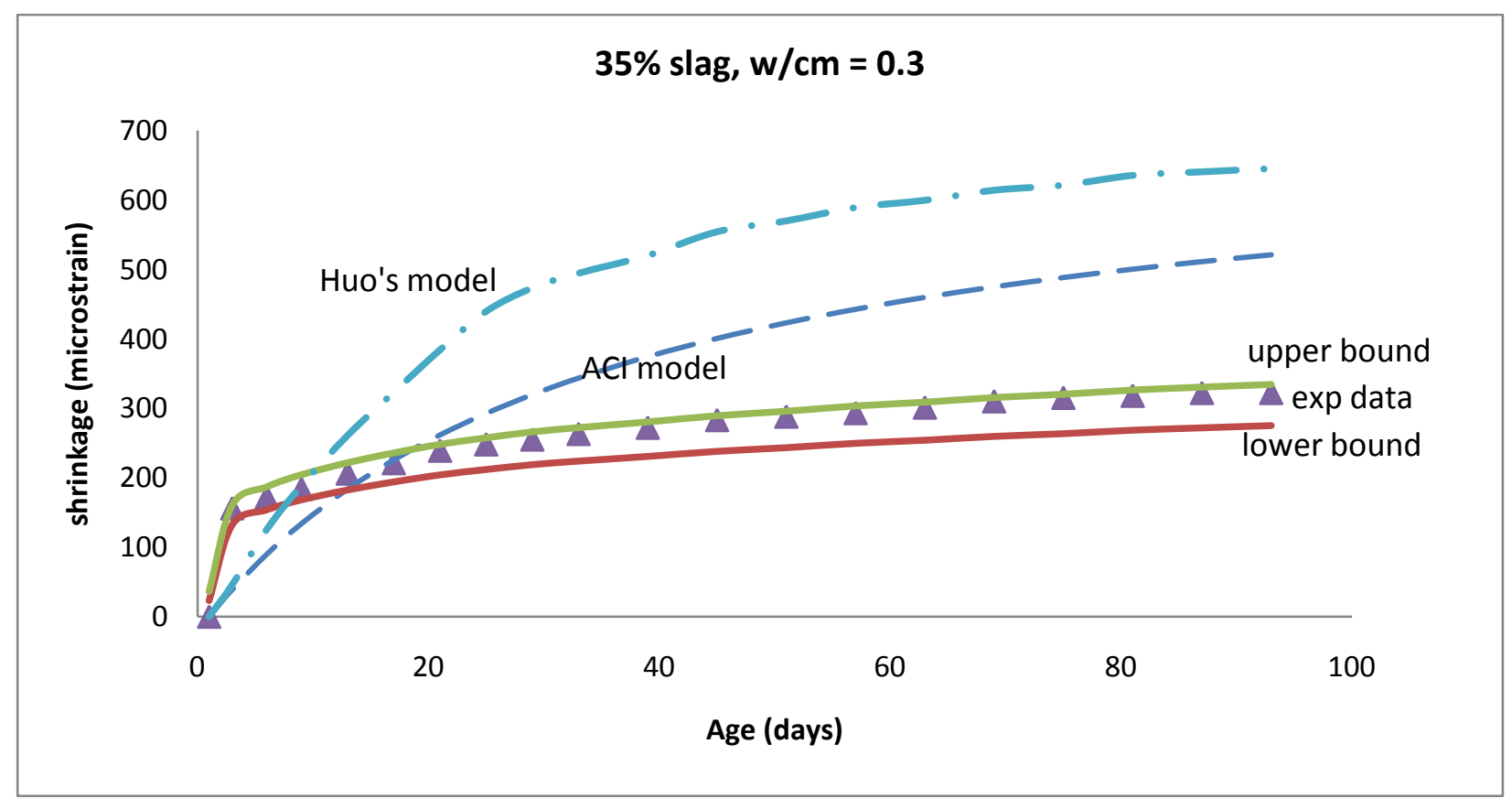

(b) $\mathrm{w} / \mathrm{cm}=0.3$

Fig. 5.17 Comparison of the ACI (and the modified ACI by Huo et al. 2001) with the upper and lower bounds of the proposed model with experimental data in case of mixes containing replacement of cement by $35 \%$ slag at two $\mathrm{w} / \mathrm{cm}$ ratios. 


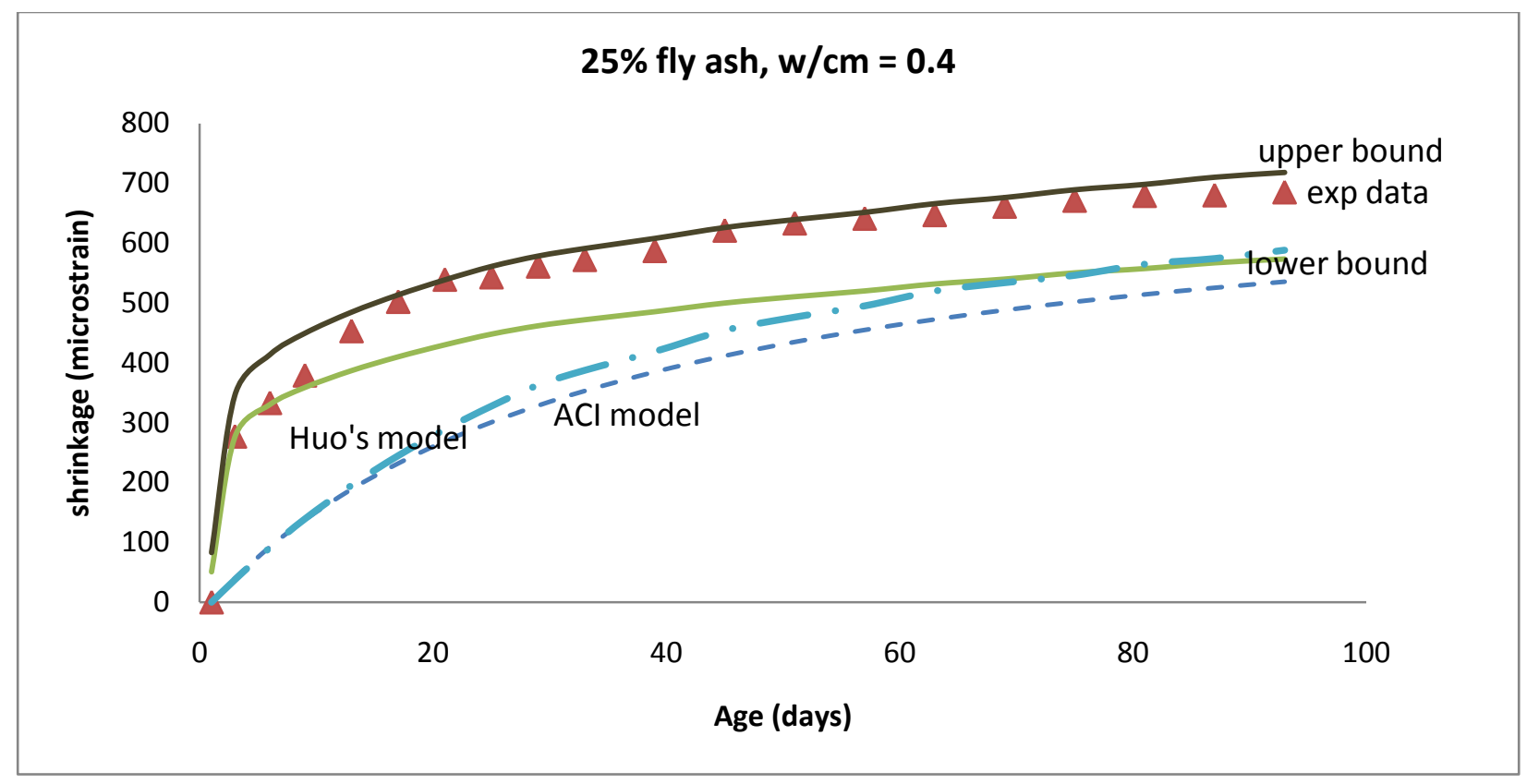

(a) $\mathrm{w} / \mathrm{cm}=0.4$

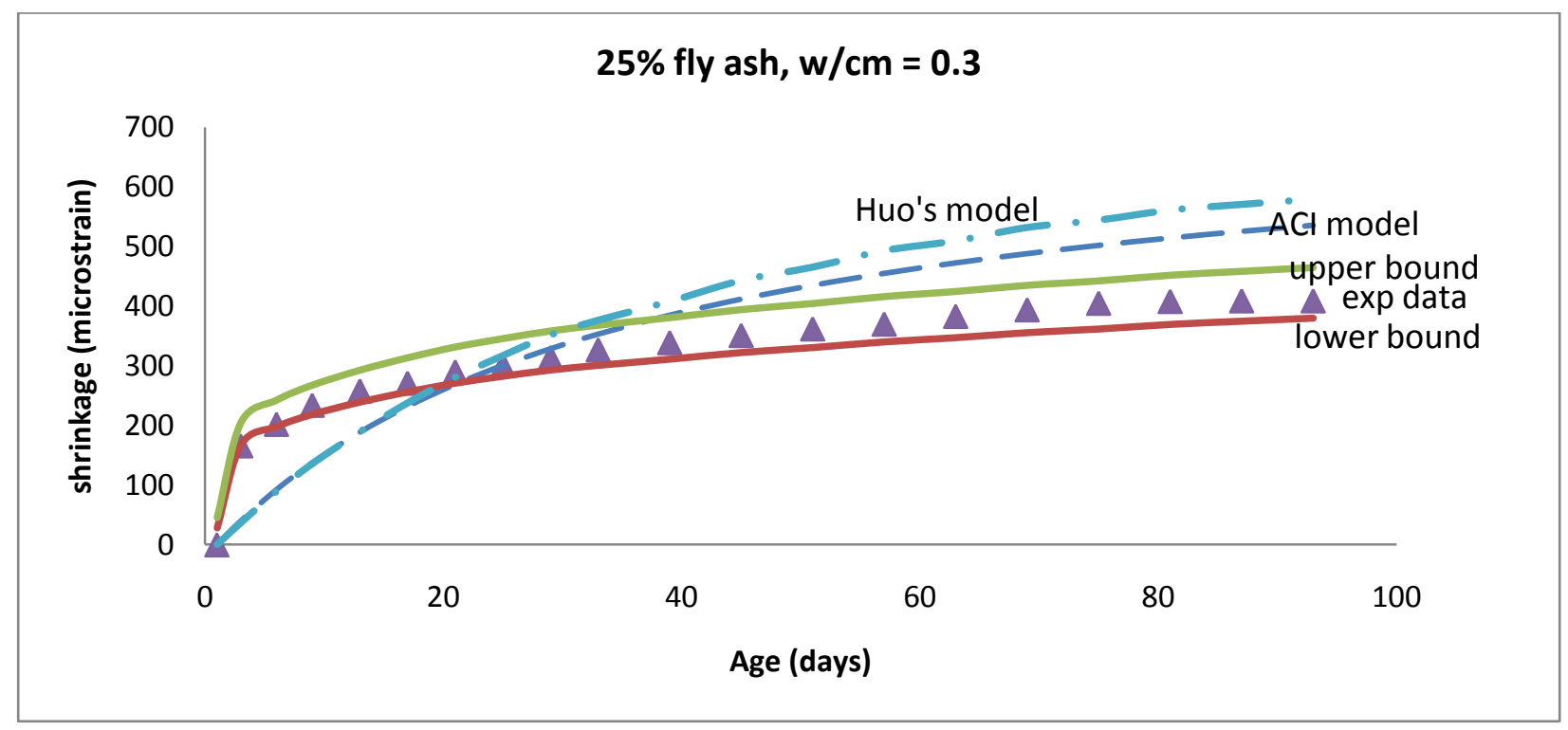

(b) $w / c m=0.3$

Fig. 5.18 Comparison of the ACI (and the modified ACI by Huo et al. 2001) with the upper and lower bounds of the proposed model with experimental data in case of mixes containing replacement of cement by $25 \%$ fly ash at two $\mathrm{w} / \mathrm{cm}$ ratios. 


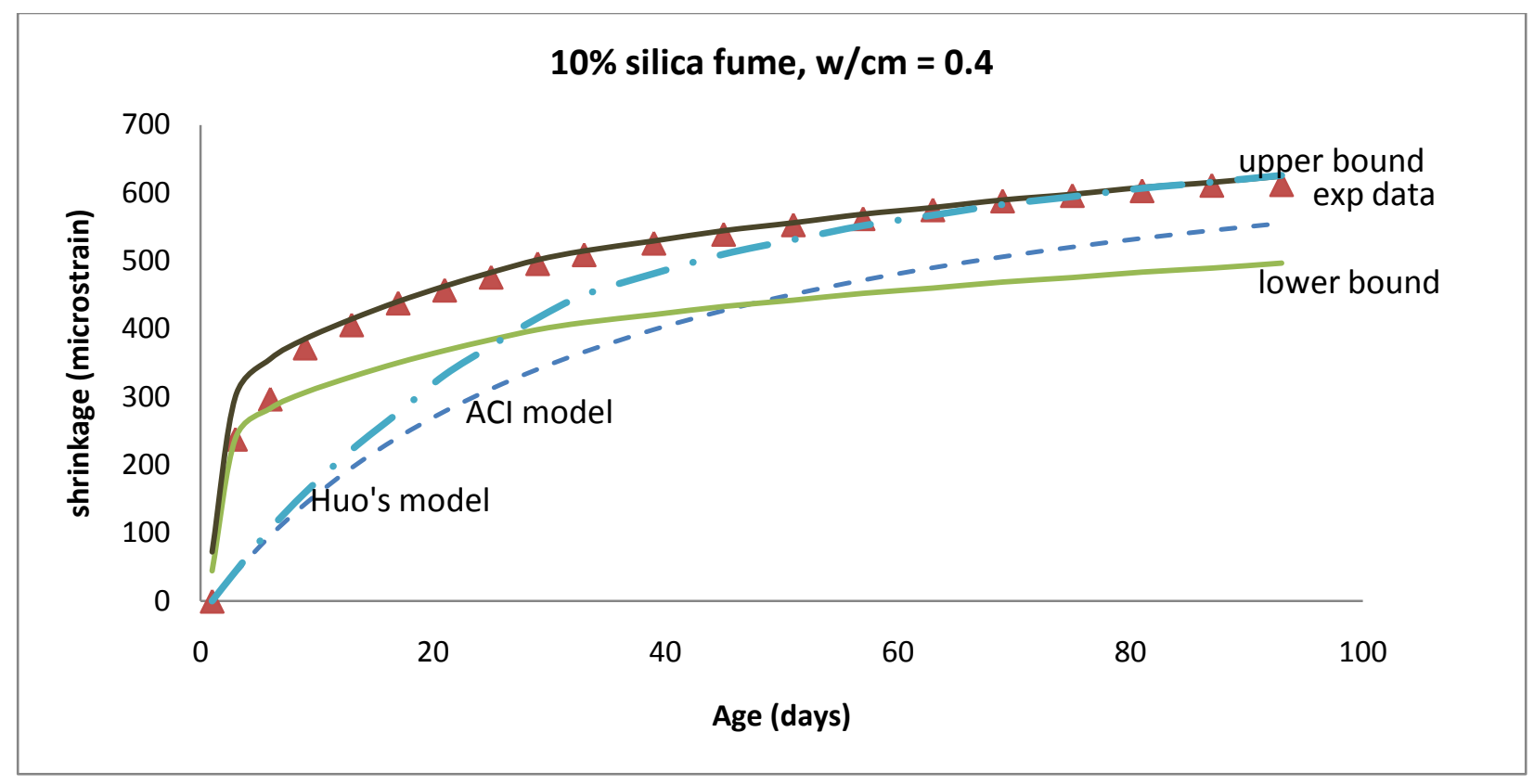

(a) $\mathrm{w} / \mathrm{cm}=0.4$

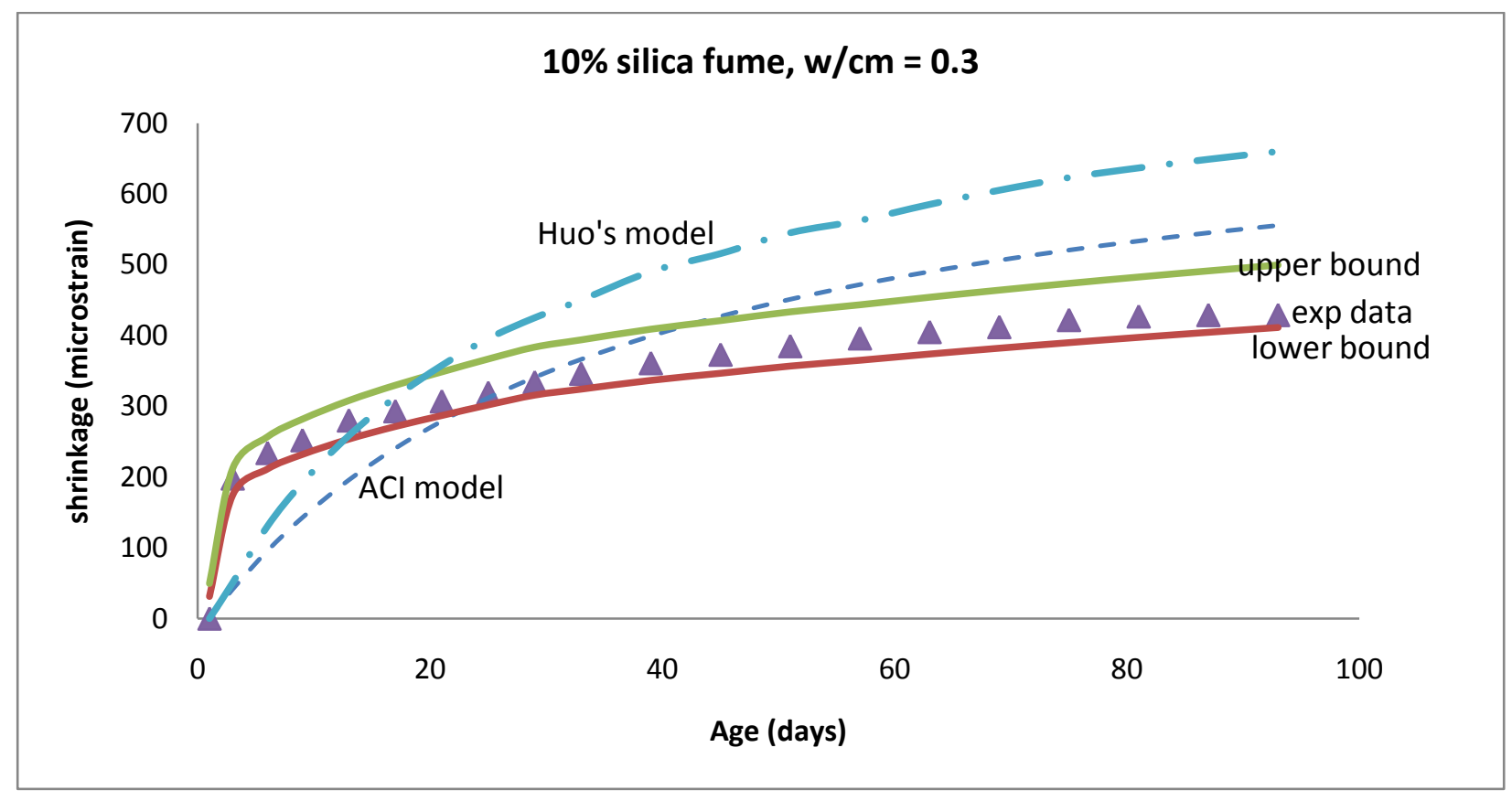

(b) $\mathrm{w} / \mathrm{cm}=0.3$

Fig. 5.19 Comparison of the ACI (and the modified ACI by Huo et al. 2001) with the upper and lower bounds of the proposed model with experimental data in case of mixes containing replacement of cement by $10 \%$ silica fume at two $\mathrm{w} / \mathrm{cm}$ ratios. 


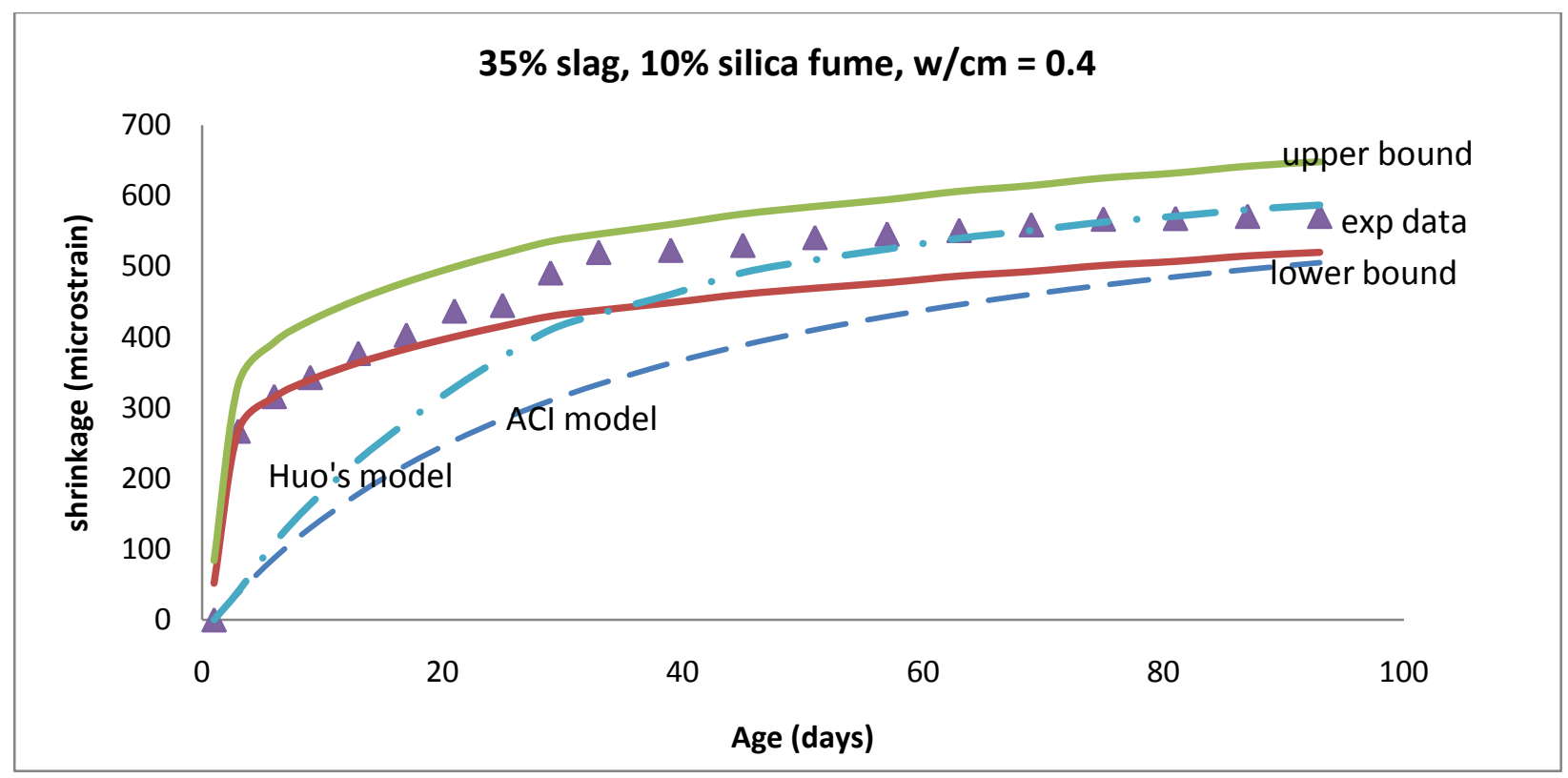

(a) $\mathrm{w} / \mathrm{cm}=0.4$

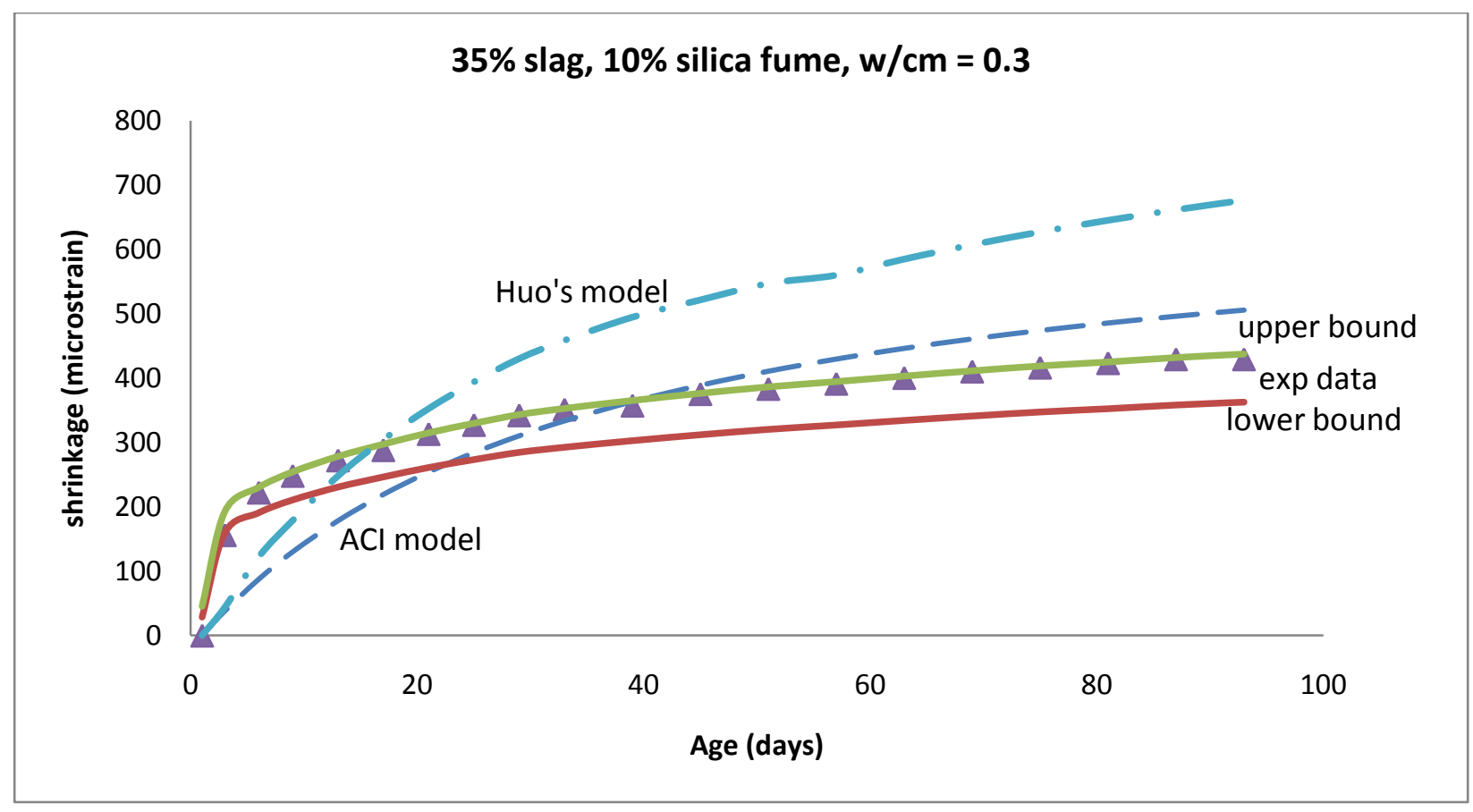

(b) $\mathrm{w} / \mathrm{cm}=0.3$

Fig. 5.20 Comparison of the ACI (and the modified ACI by Huo et al. 2001) with the upper and lower bounds of the proposed model with experimental data in case of mixes containing replacement of cement by $35 \%$ slag and $10 \%$ silica fume at two $\mathrm{w} / \mathrm{cm}$ ratios. 


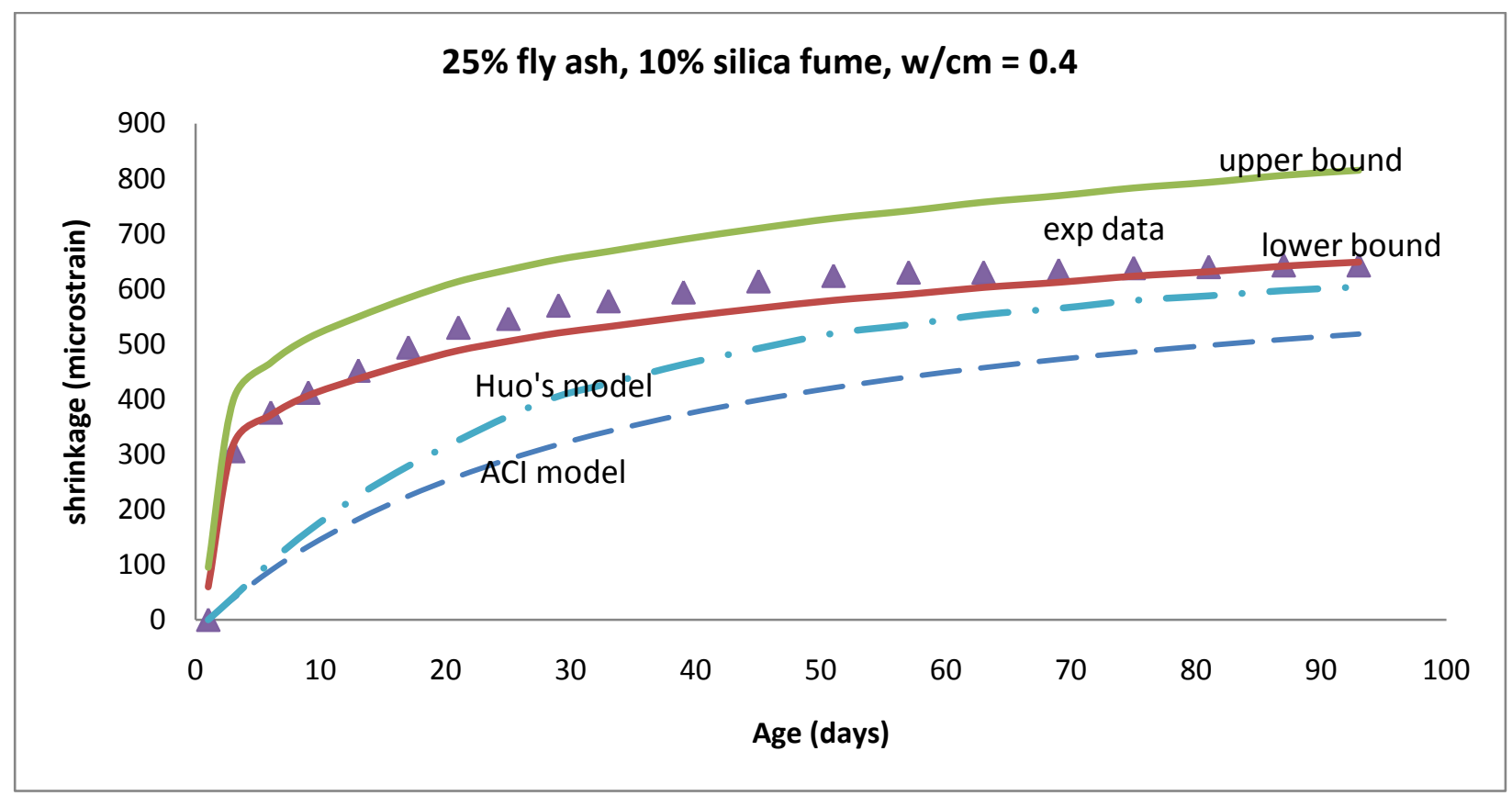

(a) $\mathrm{w} / \mathrm{cm}=0.4$

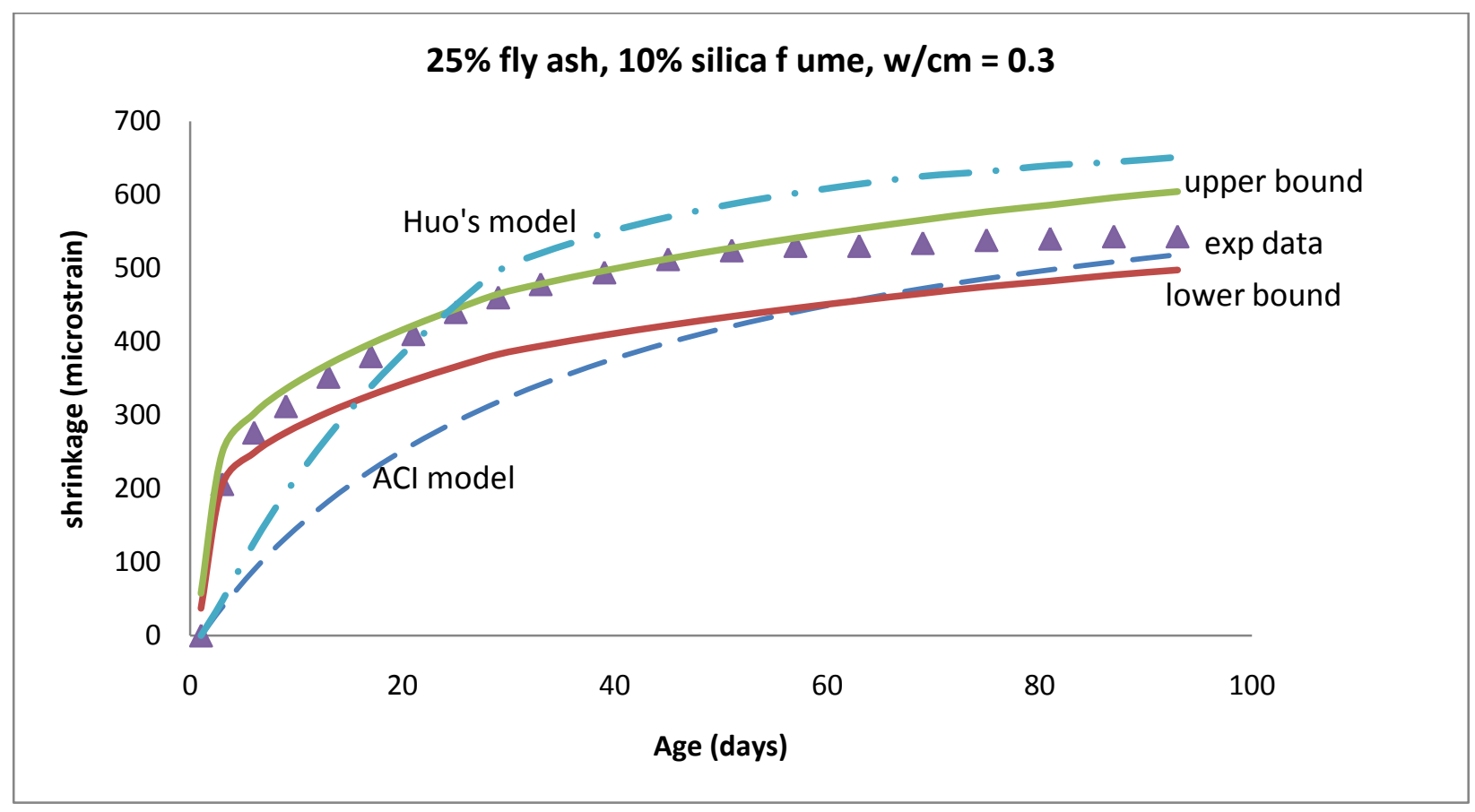

(b) $w / c m=0.3$

Fig. 5.21 Comparison of the ACI (and the modified ACI by Huo et al. 2001) with the upper and lower bounds of the proposed model with experimental data in case of mixes containing replacement of cement by $25 \%$ fly ash and $10 \%$ silica fume at two $\mathrm{w} / \mathrm{cm}$ ratios. 


\subsection{Observations on comparison of predicted model with ACI (and modified ACI by Huo et al. 2001) model}

The general trend of the comparison of the predicted model with the ACI (and the modified ACI by Huo et al. 2001) model showed a tendency of the ACI model to overestimate the predicted shrinkage strains at low $\mathrm{w} / \mathrm{cm}$ ratio case $(\mathrm{w} / \mathrm{cm}=0.3)$ and underestimate the predicted shrinkage strains at high $\mathrm{w} / \mathrm{cm}$ cases $(\mathrm{w} / \mathrm{cm}=0.5)$ in all the cases (Figs. 5.16 through 5.21). This happened because the prediction equation of the ACI model does not contain any factor which takes into account the influence of the $\mathrm{w} / \mathrm{cm}$ ratio. The ACI does not even take into account the effect of the compressive strength for high-performance concretes. The modified ACI model by Huo et al. (2001) introduced a function of the compressive strength in the prediction equation. As a result, for concretes with high compressive strengths, the shrinkage strains were overestimated by the modified ACI model (Figs. 5.17b, 5.19b, 5.20b). The high strength cases included mostly concretes containing replacement of portland cement by SCM at low $\mathrm{w} / \mathrm{cm}$ ratios $(\mathrm{w} / \mathrm{cm}=0.3)$. Evidently, the experimental data agreed much more with the model proposed in the present study than the ACI (and the modified ACI by HUo et al. 2001) model. 


\subsubsection{Bazant - Baweja B3 Model}

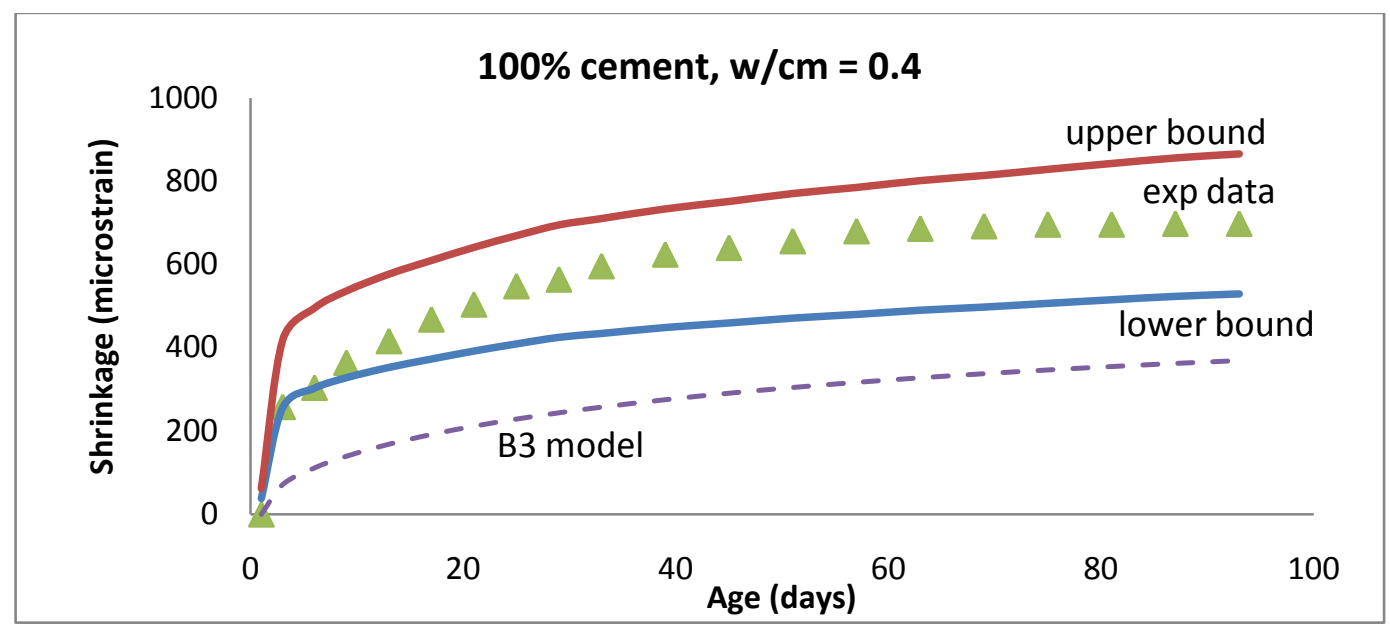

(a) $\mathrm{w} / \mathrm{cm}=0.4$

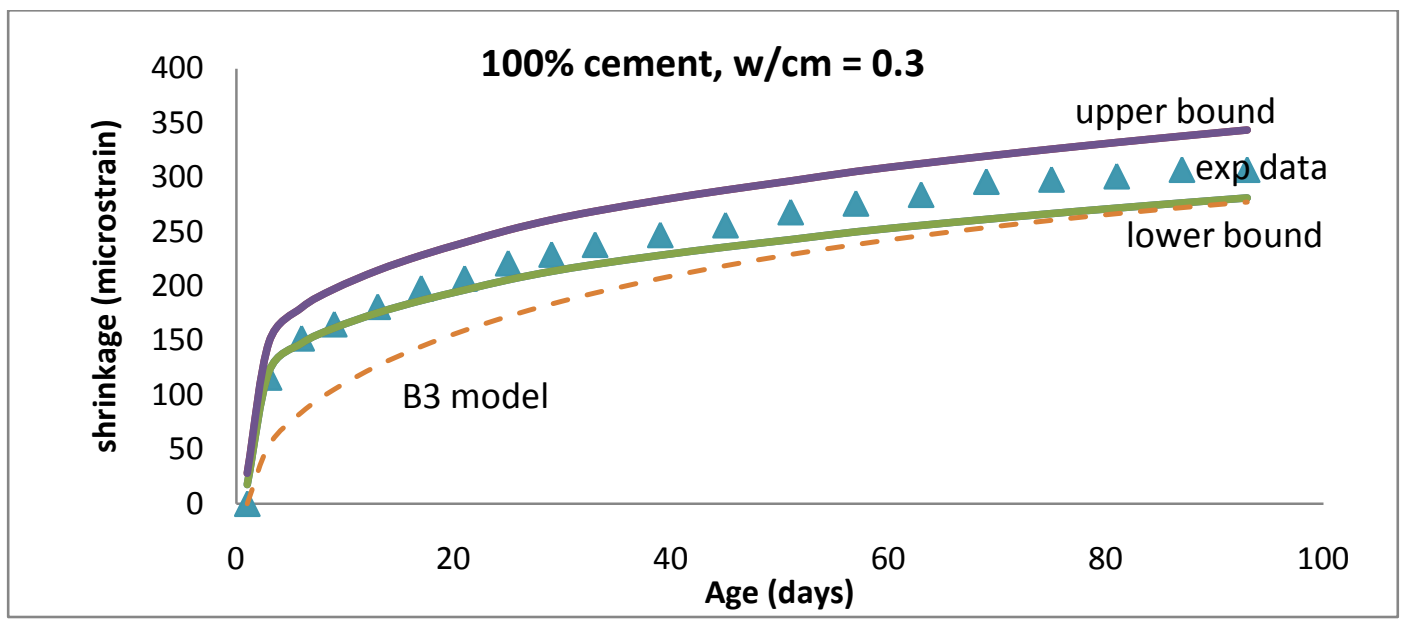

(b) $\mathrm{w} / \mathrm{cm}=0.3$

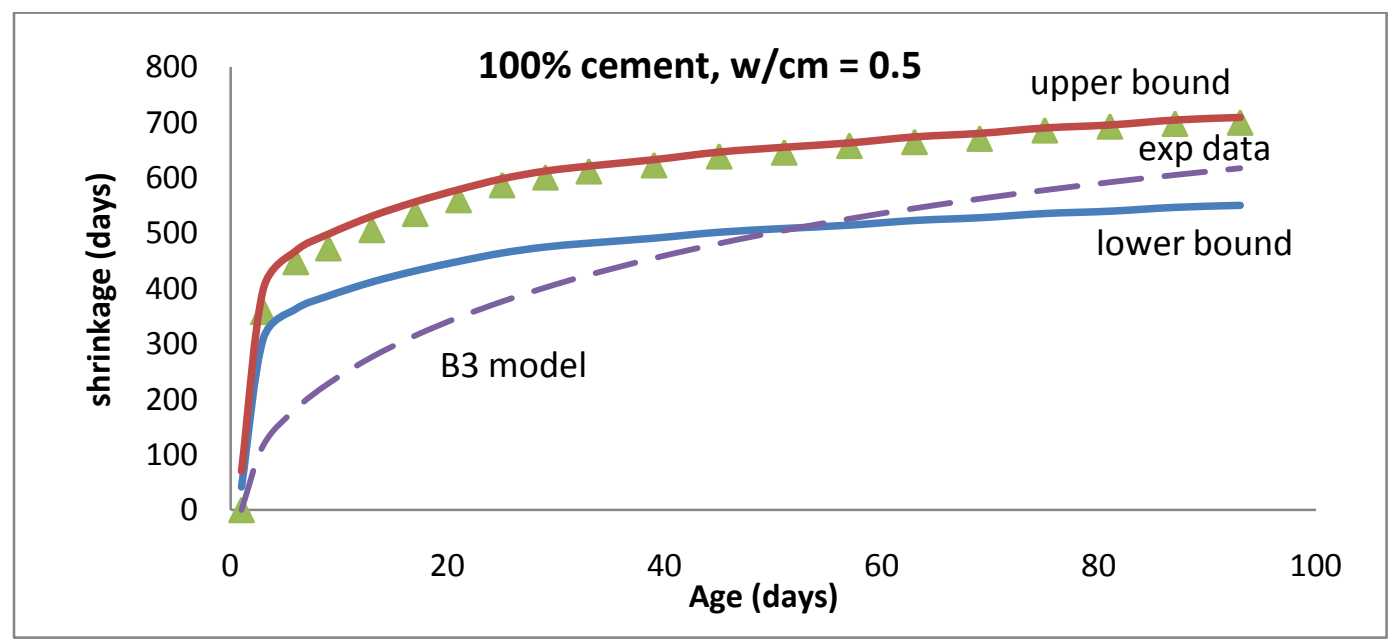

(c) $\mathrm{w} / \mathrm{cm}=0.5$

Fig. 5.22 Comparison of the B3 model with the upper and lower bounds of the proposed model with experimental data in case of $100 \%$ cement mixes at three $\mathrm{w} / \mathrm{cm}$ ratios. 


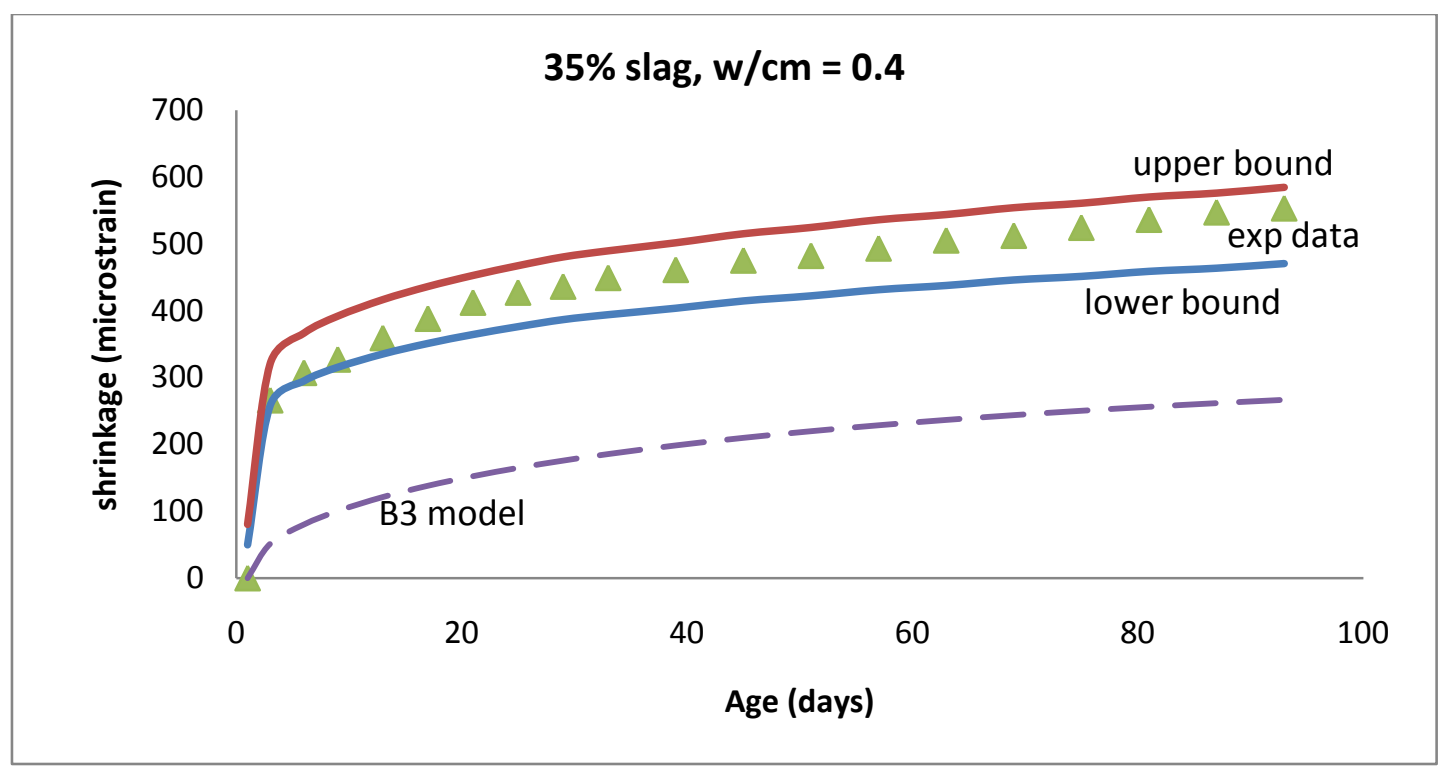

(a) $\mathrm{w} / \mathrm{cm}=0.4$

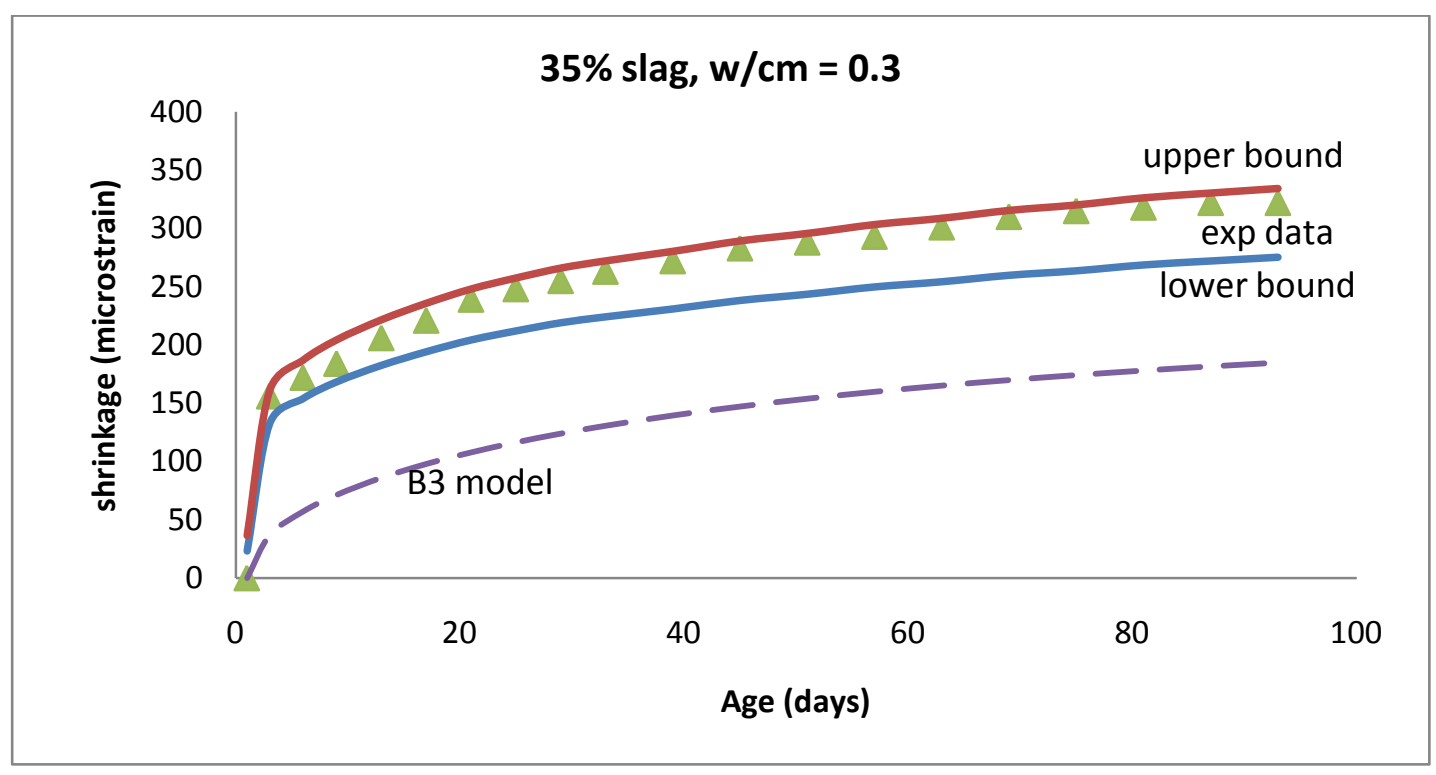

(b) $\mathrm{w} / \mathrm{cm}=0.3$

Fig. 5.23 Comparison of the B3 model with the upper and lower bounds of the proposed model with experimental data in case of mixes containing replacement of cement by $35 \%$ slag at two $\mathrm{w} / \mathrm{cm}$ ratios. 


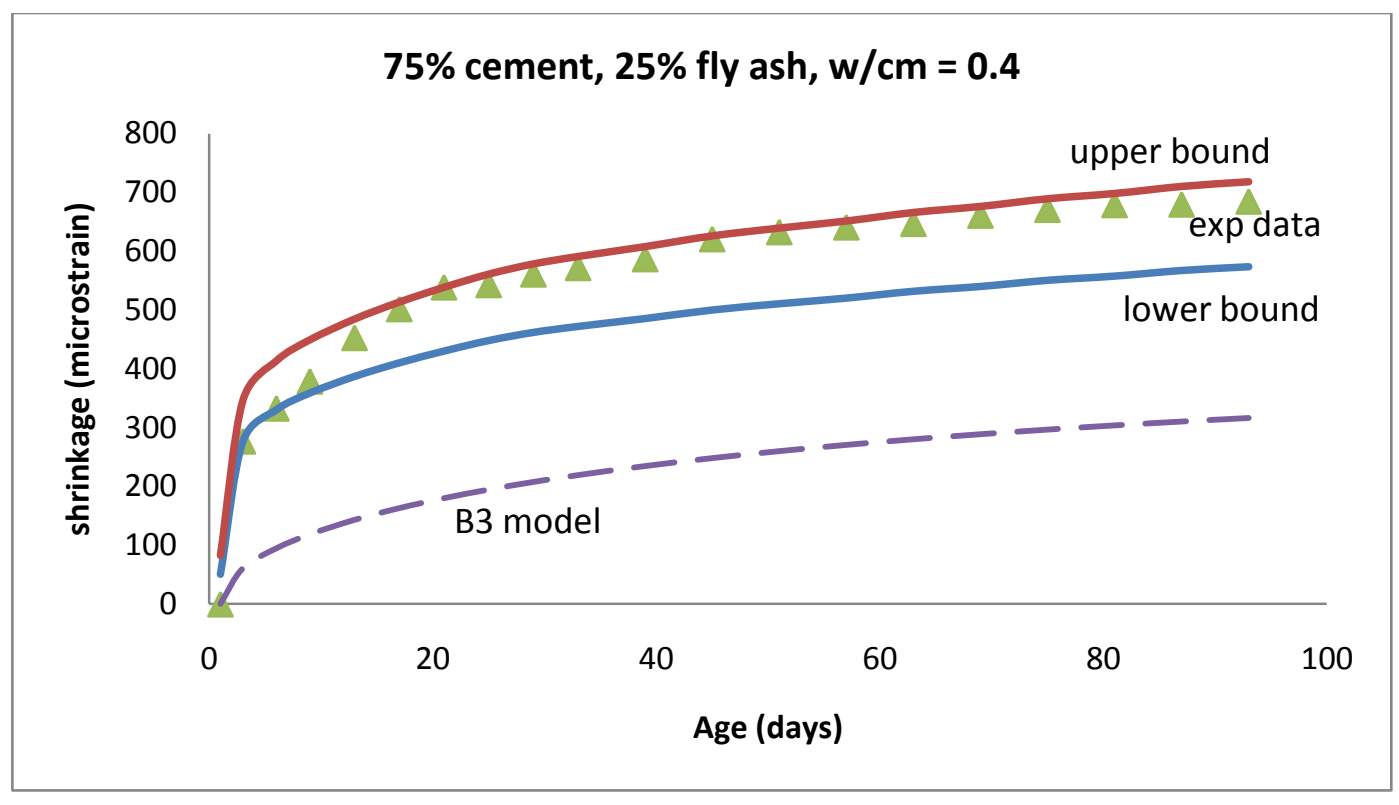

(a) $\mathrm{w} / \mathrm{cm}=0.4$

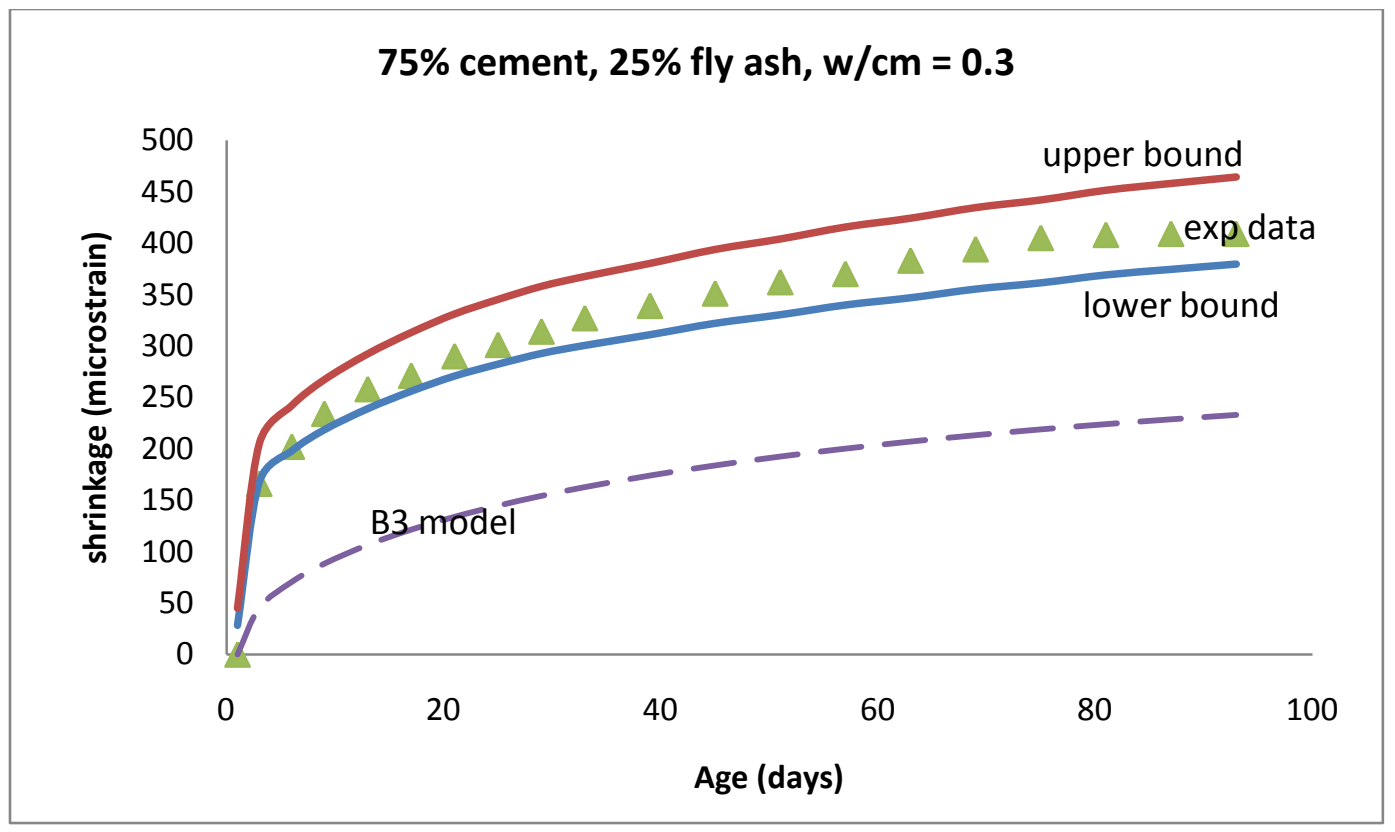

(b) $w / \mathrm{cm}=0.3$

Fig. 5.24 Comparison of the B3 model with the upper and lower bounds of the proposed model with experimental data in case of mixes containing replacement of cement by $25 \%$ fly ash at two $\mathrm{w} / \mathrm{cm}$ ratios. 


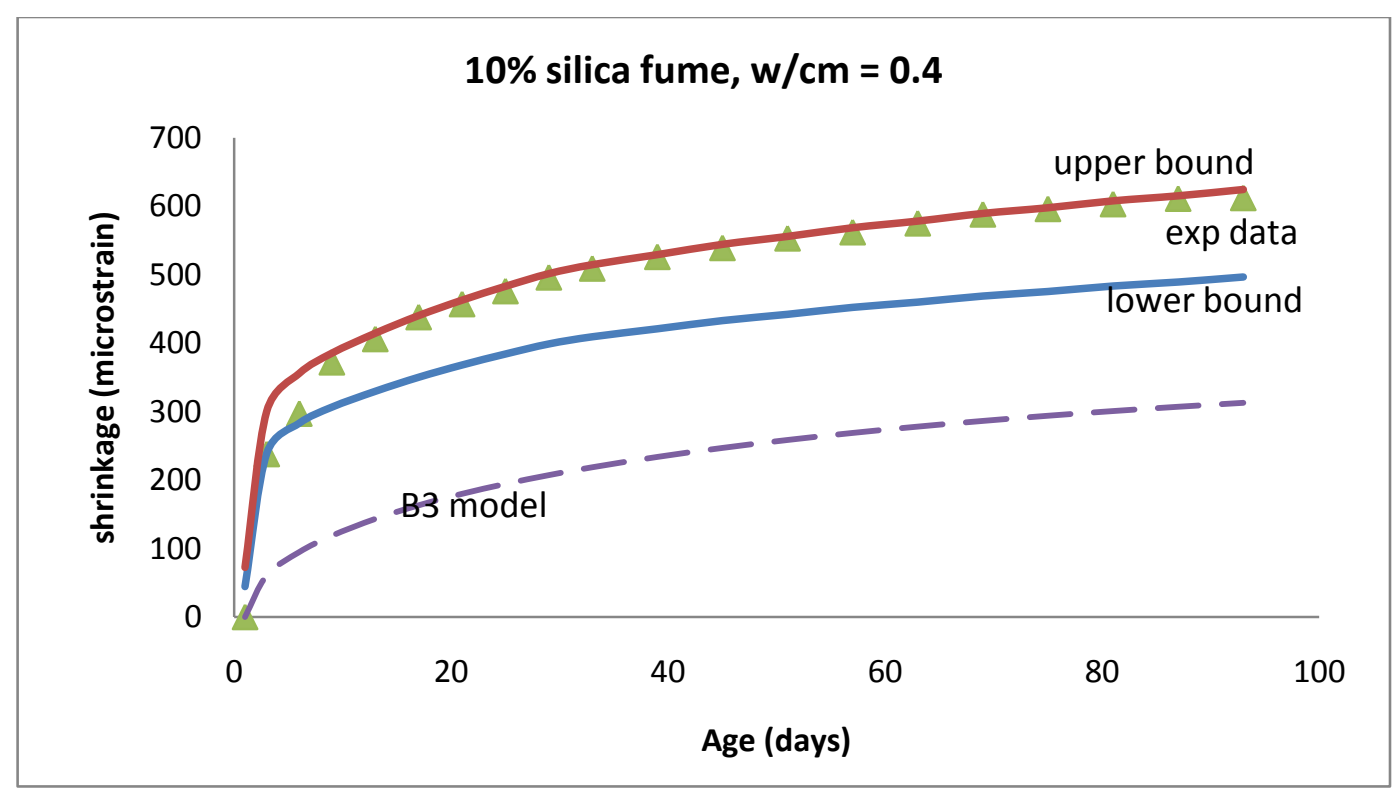

(a) $\mathrm{w} / \mathrm{cm}=0.4$

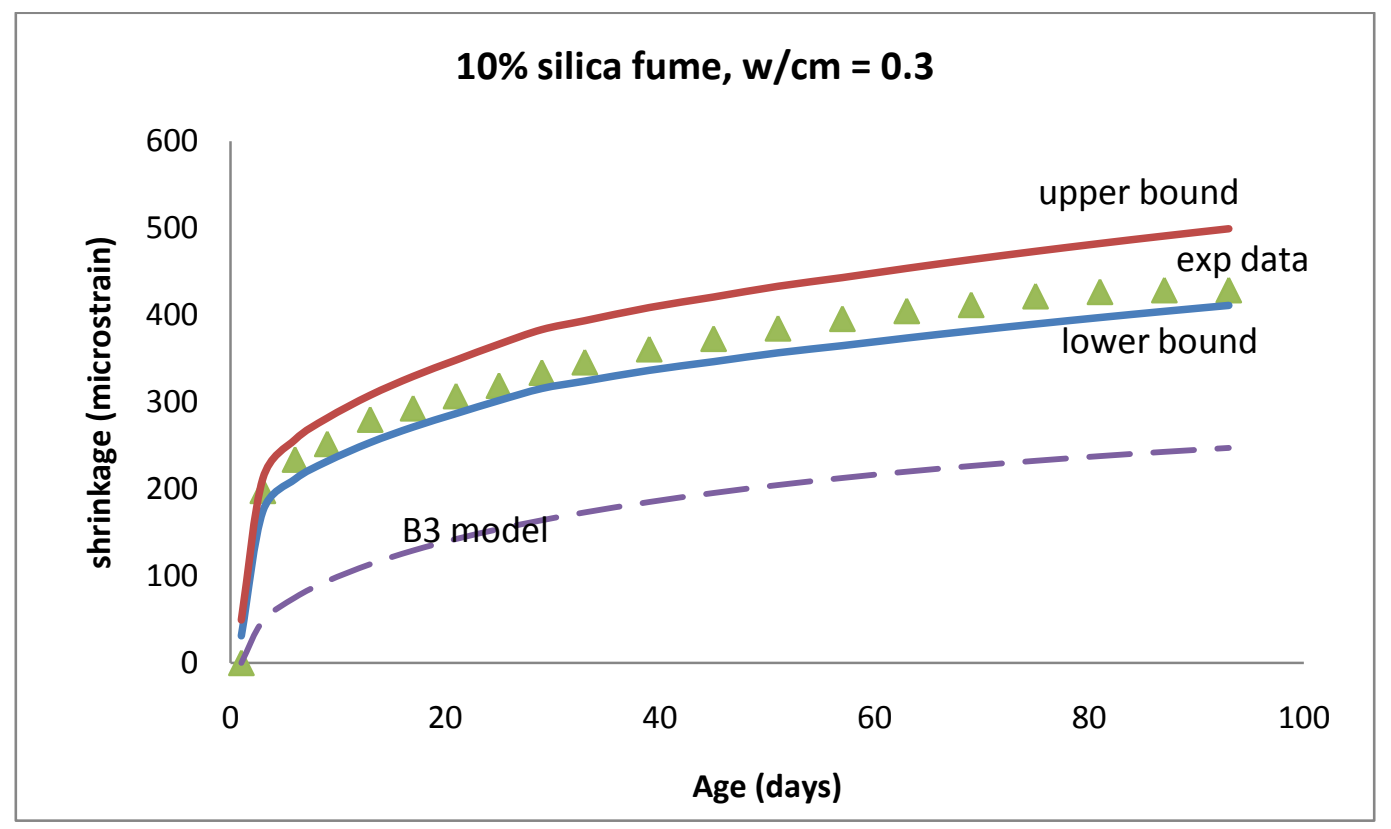

(b) $\mathrm{w} / \mathrm{cm}=0.3$

Fig. 5.25 Comparison of the B3 model with the upper and lower bounds of the proposed model with experimental data in case of mixes containing replacement of cement by $10 \%$ silica fume at two $\mathrm{w} / \mathrm{cm}$ ratios. 


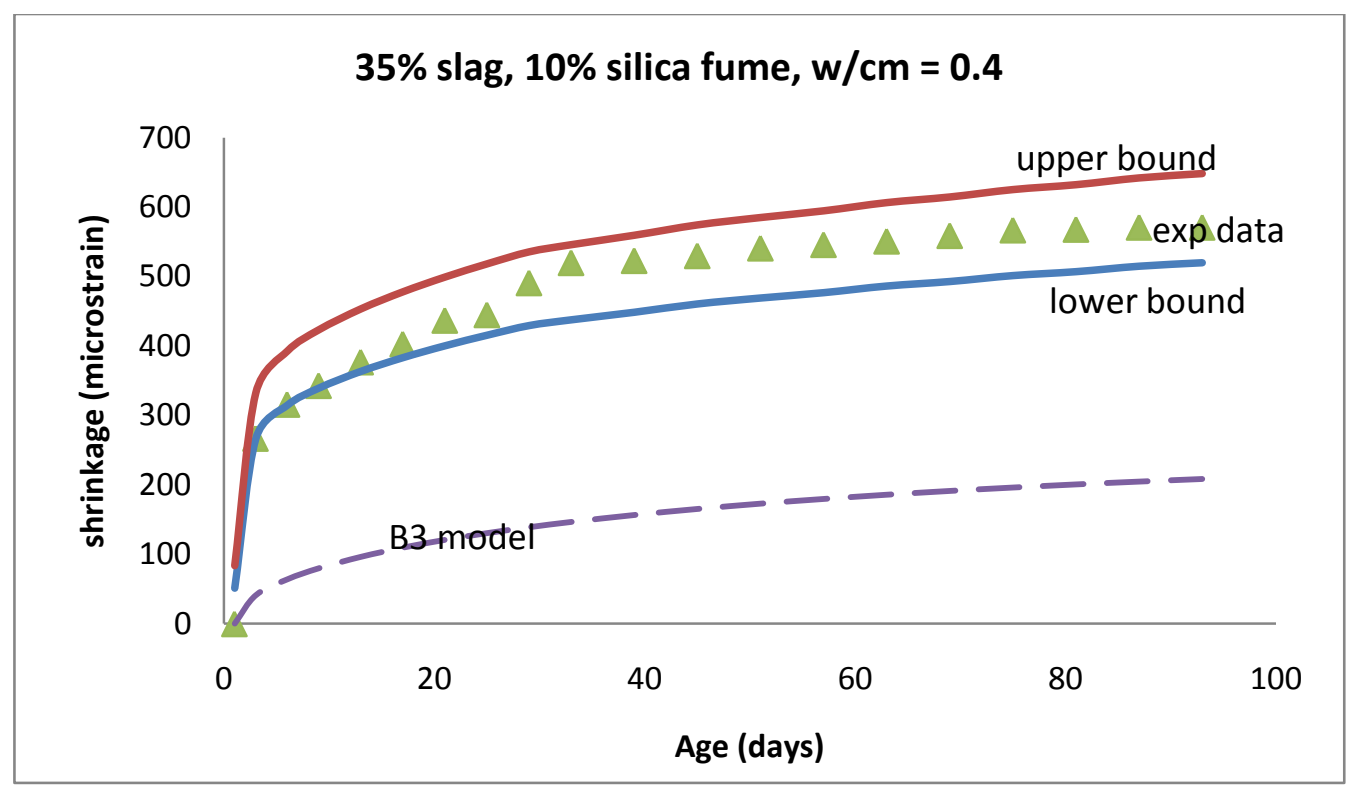

(a) $\mathrm{w} / \mathrm{cm}=0.4$

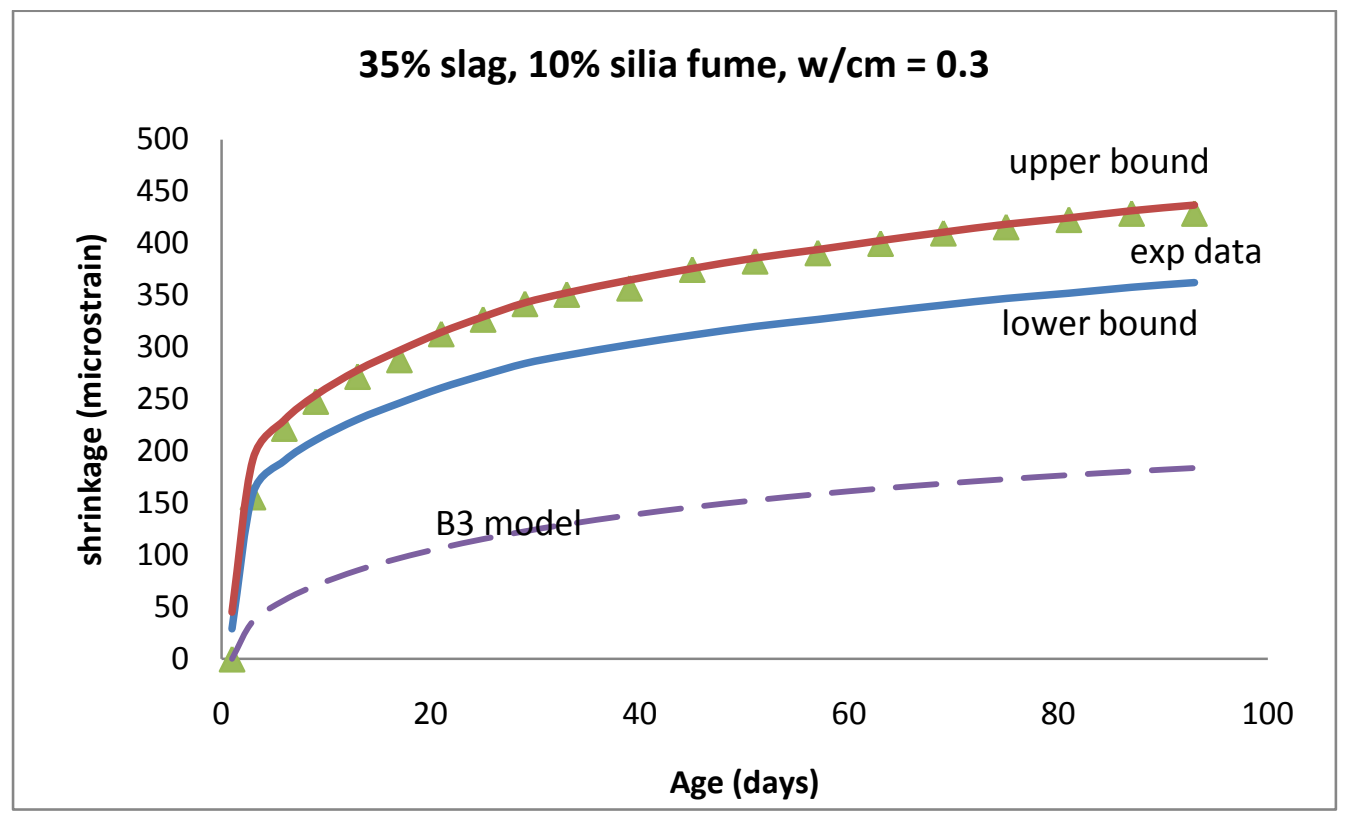

(b) $\mathrm{w} / \mathrm{cm}=0.3$

Fig. 5.26 Comparison of the B3 model with the upper and lower bounds of the proposed model with experimental data in case of mixes containing replacement of cement by $35 \%$ slag and $10 \%$ silica fume at two $\mathrm{w} / \mathrm{cm}$ ratios. 


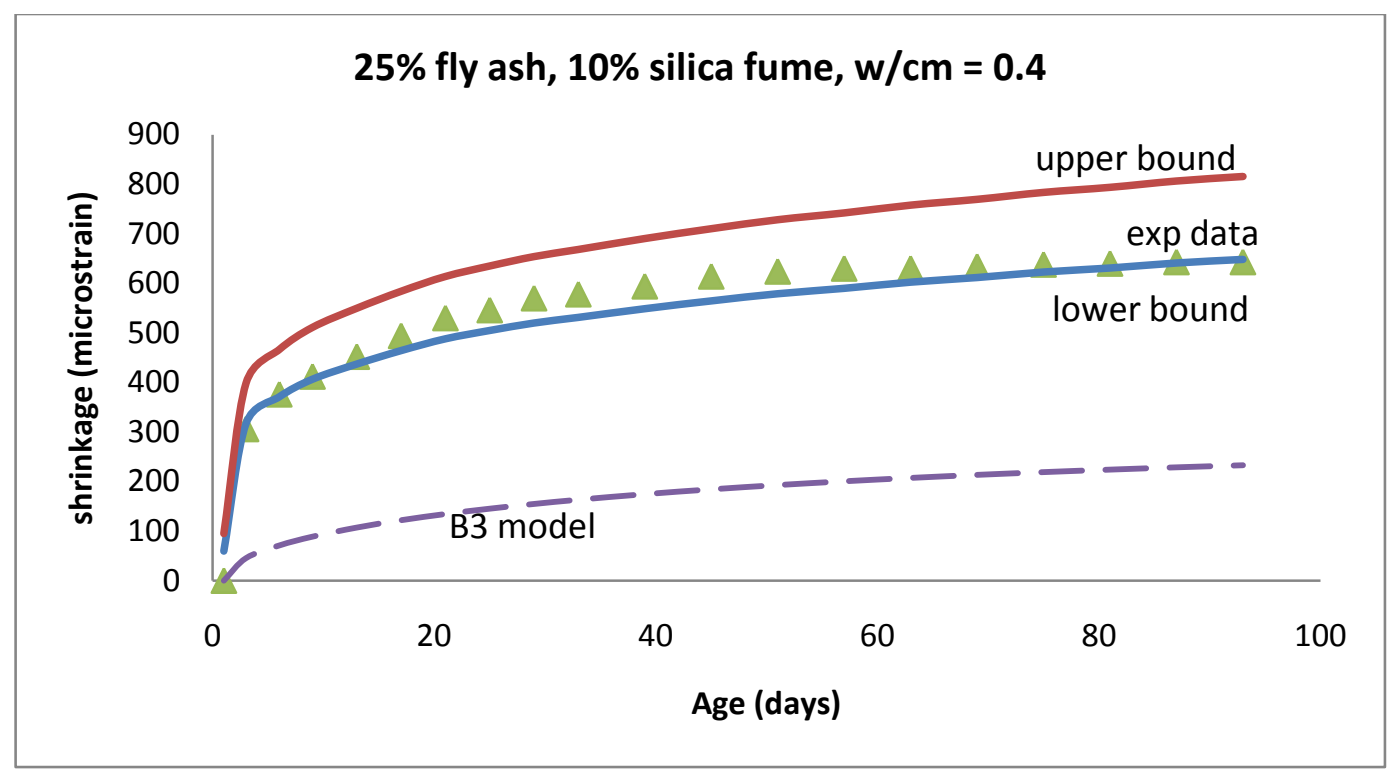

(a) $\mathrm{w} / \mathrm{cm}=0.4$

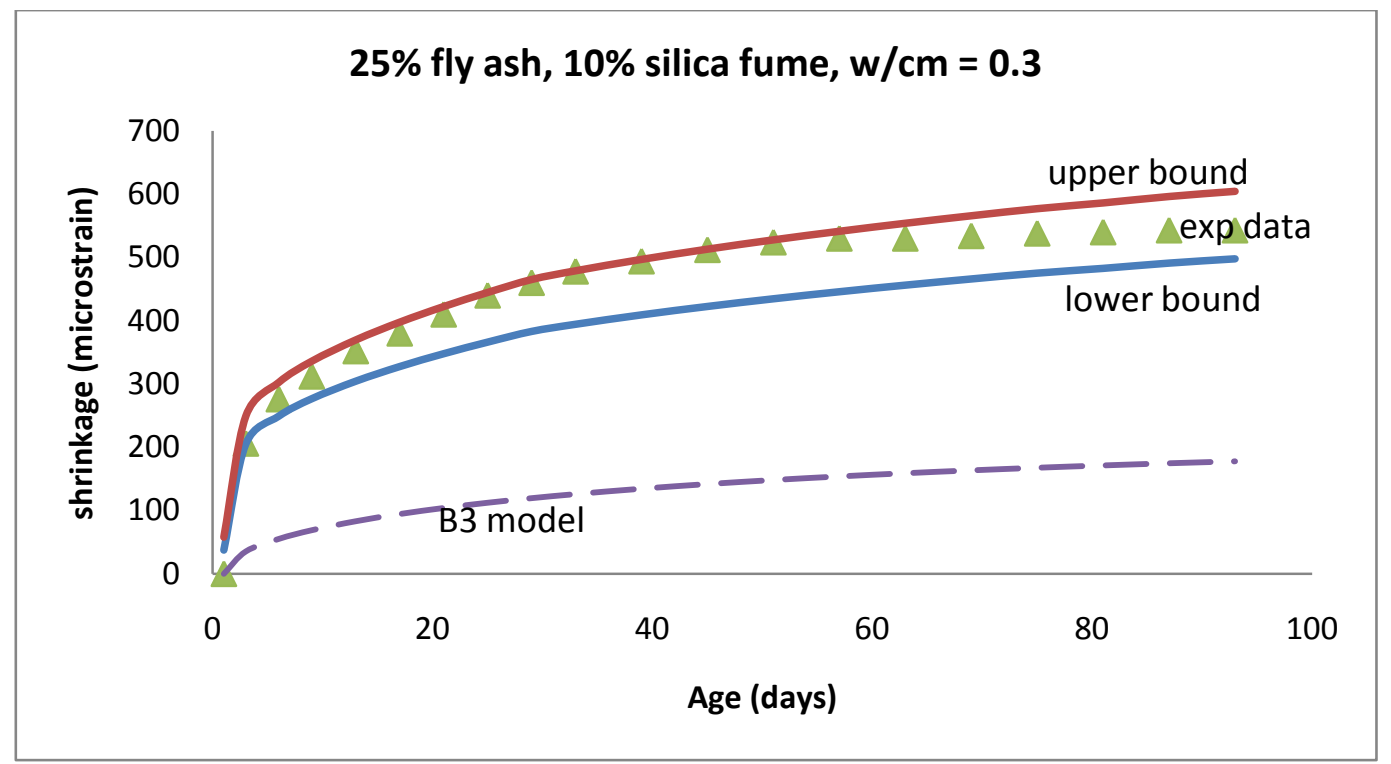

(b) $\mathrm{w} / \mathrm{cm}=0.3$

Fig. 5.27 Comparison of the B3 model with the upper and lower bounds of the proposed model with experimental data in case of mixes containing replacement of cement by $25 \%$ fly ash and $10 \%$ silica fume at two $\mathrm{w} / \mathrm{cm}$ ratios. 


\subsection{Observations on comparison of proposed model with B3 model}

In all of the cases (Figs. 5.22 through 5.27), it was observed that the B3 model made a significant underestimation of the concrete shrinkage strains. The B3 model does take into account the effect of the water content in the concrete, but there is no factor to accommodate the presence of the SCM in the mixes. Moreover, the shrinkage strain predicted by the $\mathrm{B} 3$ model is just a function of the elastic modulus of the concrete at a fixed age. That approach holds well in case of normal concretes but not in case of high performance concretes or concretes containing SCM. Thus, the proposed model was found to work relatively better than the B3 model in case of concretes containing replacement of cement by SCM. 


\subsubsection{CEB MC 90-99 model}

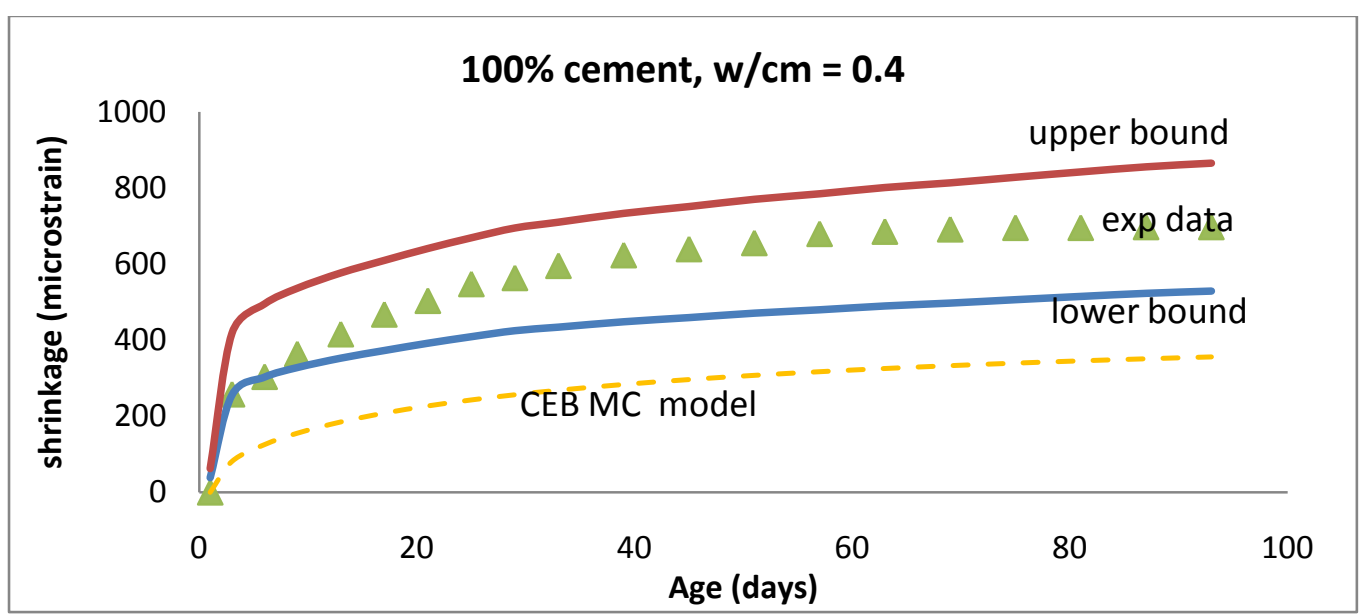

(a) $\mathrm{w} / \mathrm{cm}=0.4$

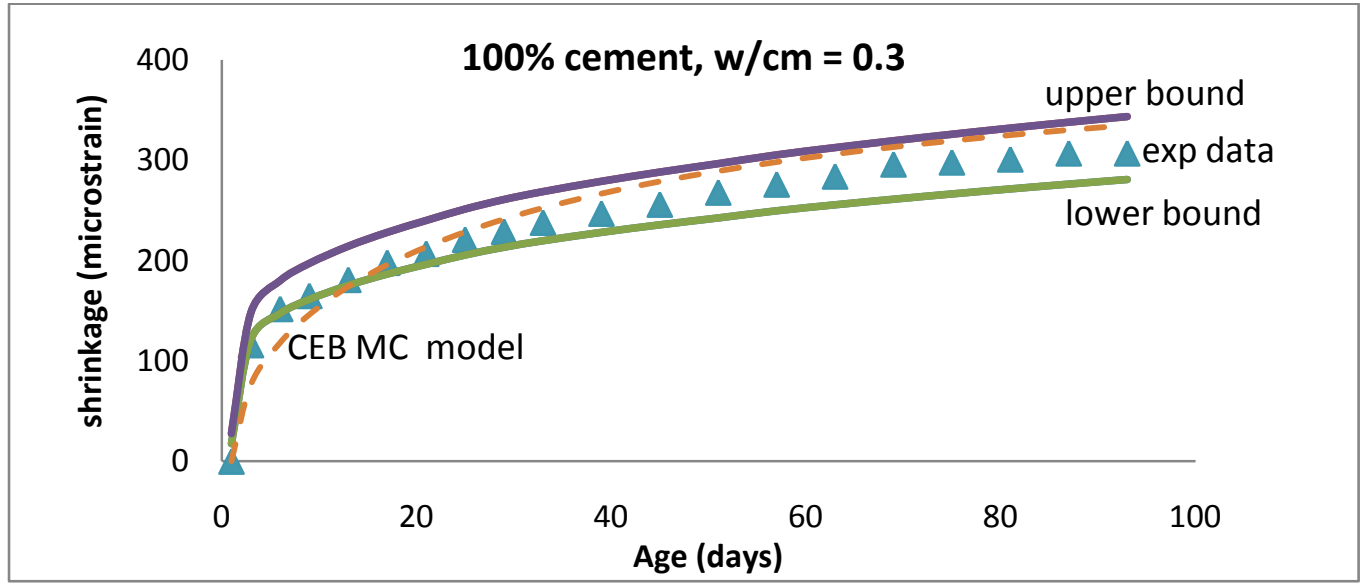

(b) $\mathrm{w} / \mathrm{cm}=0.3$

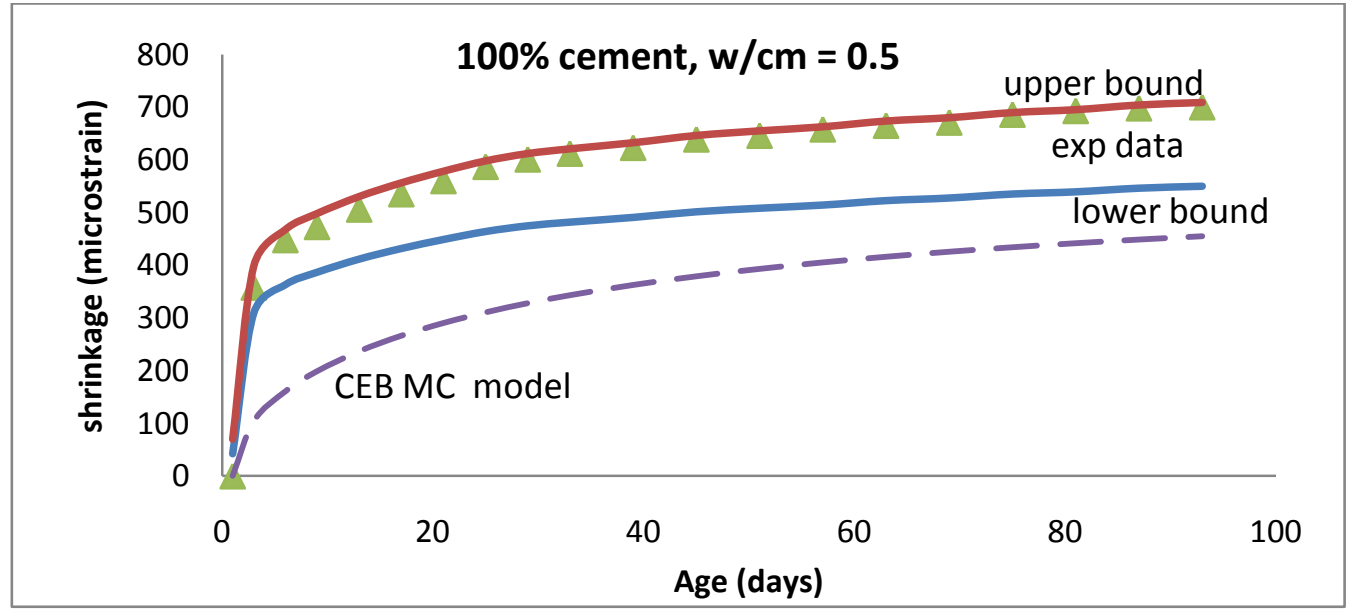

(c) $\mathrm{w} / \mathrm{cm}=0.5$

Fig. 5.28 Comparison of the CEB MC 90-99 model with the upper and lower bounds of the proposed model with experimental data in case of $100 \%$ cement mixes at three $\mathrm{w} / \mathrm{cm}$ ratios. 


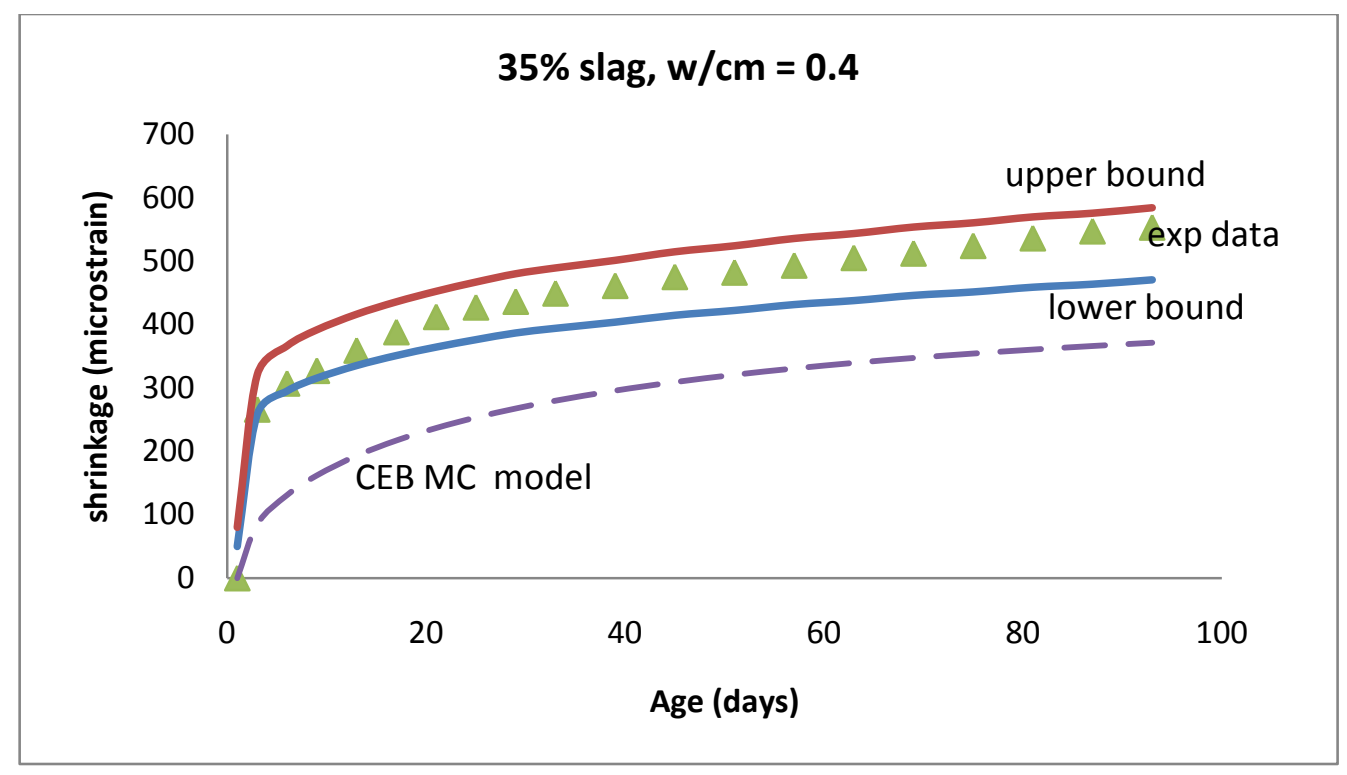

(a) $\mathrm{w} / \mathrm{cm}=0.4$

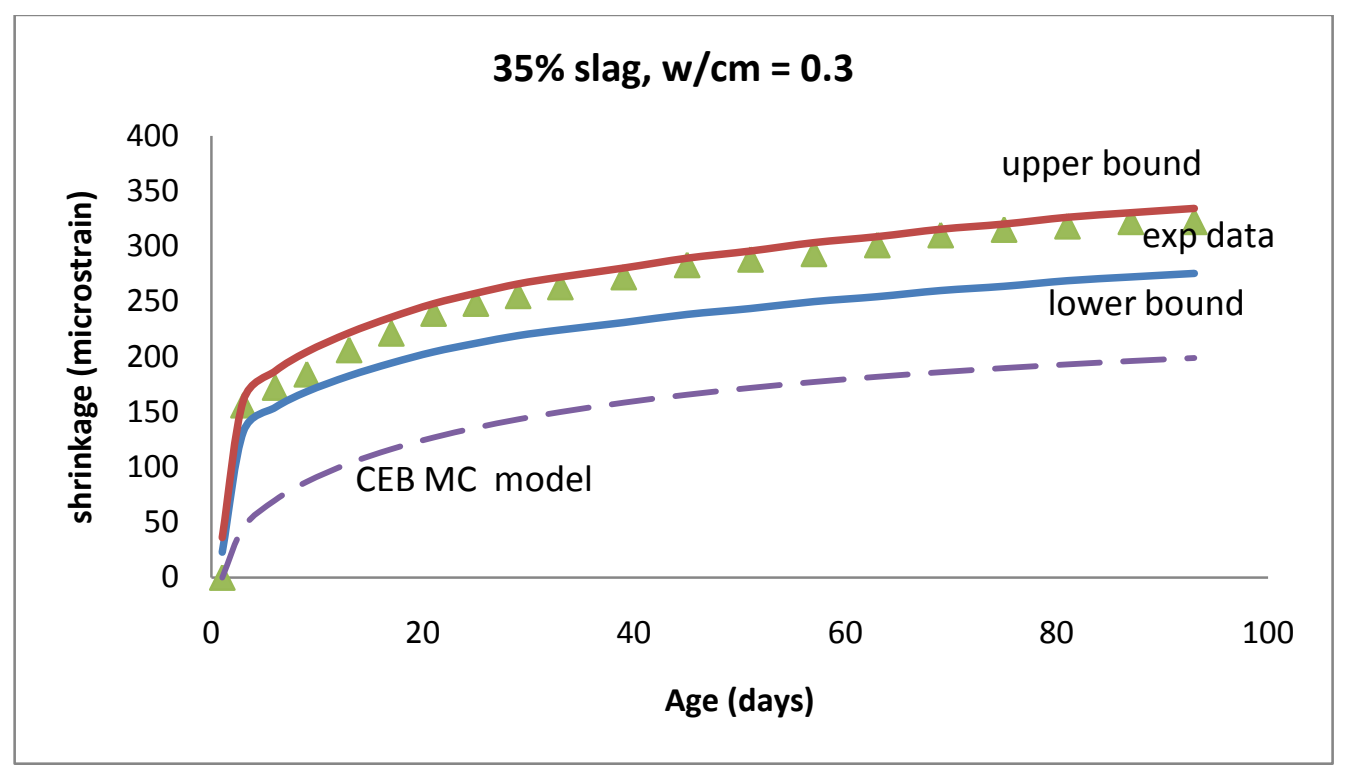

(b) $w / c m=0.3$

Fig. 5.29 Comparison of the CEB MC 90-99 model with the upper and lower bounds of the proposed model with experimental data in case of mixes containing replacement of cement by $35 \%$ slag at two $\mathrm{w} / \mathrm{cm}$ ratios. 


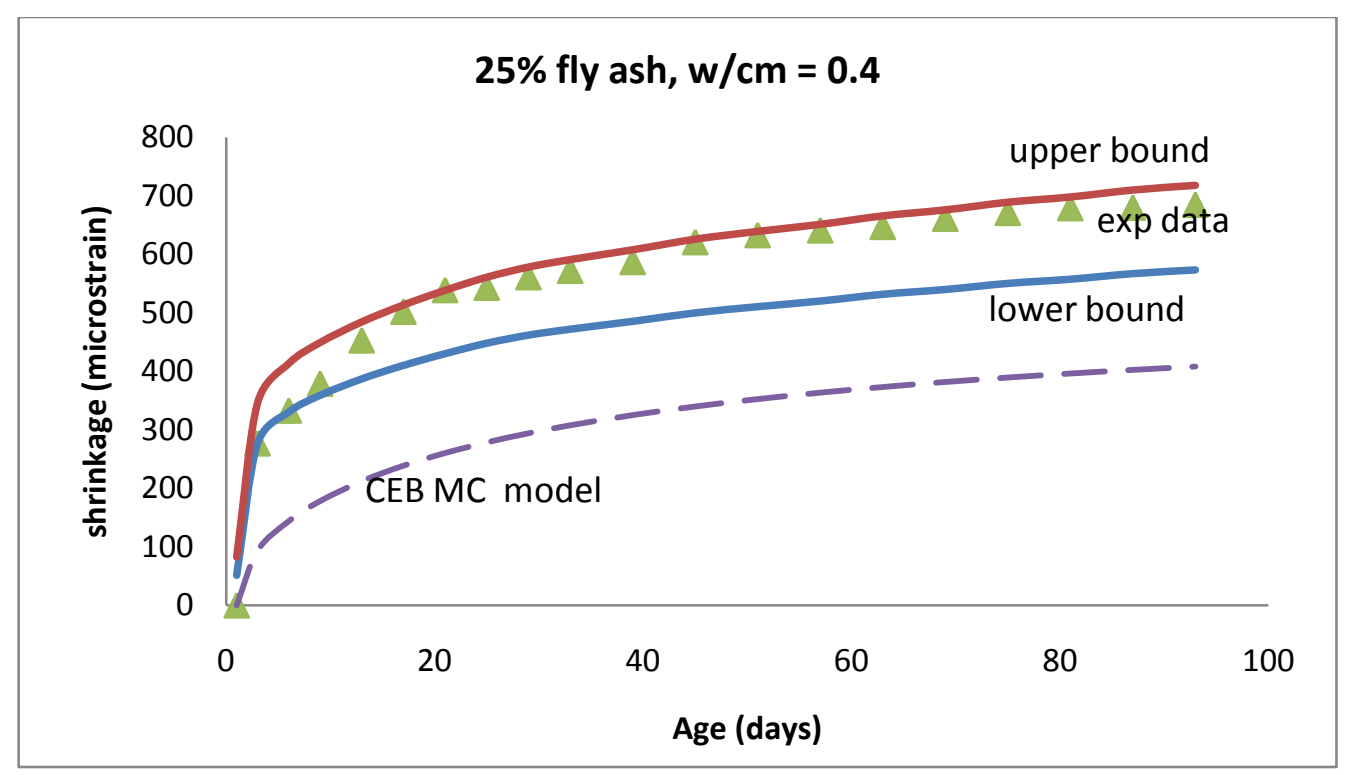

(a) $\mathrm{w} / \mathrm{cm}=0.4$

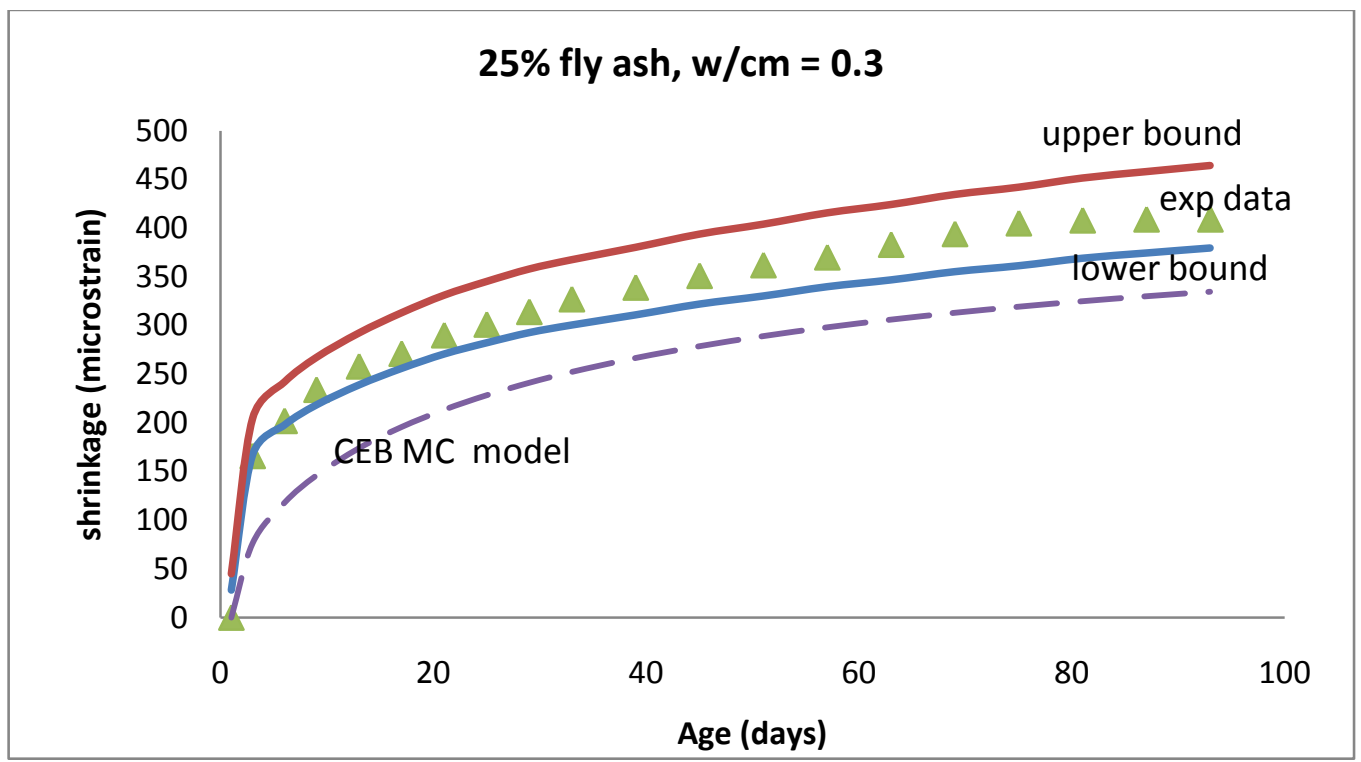

(b) $\mathrm{w} / \mathrm{cm}=0.3$

Fig. 5.30 Comparison of the CEB MC 90-99 model with the upper and lower bounds of the proposed model with experimental data in case of mixes containing replacement of cement by $25 \%$ fly ash at two $\mathrm{w} / \mathrm{cm}$ ratios. 


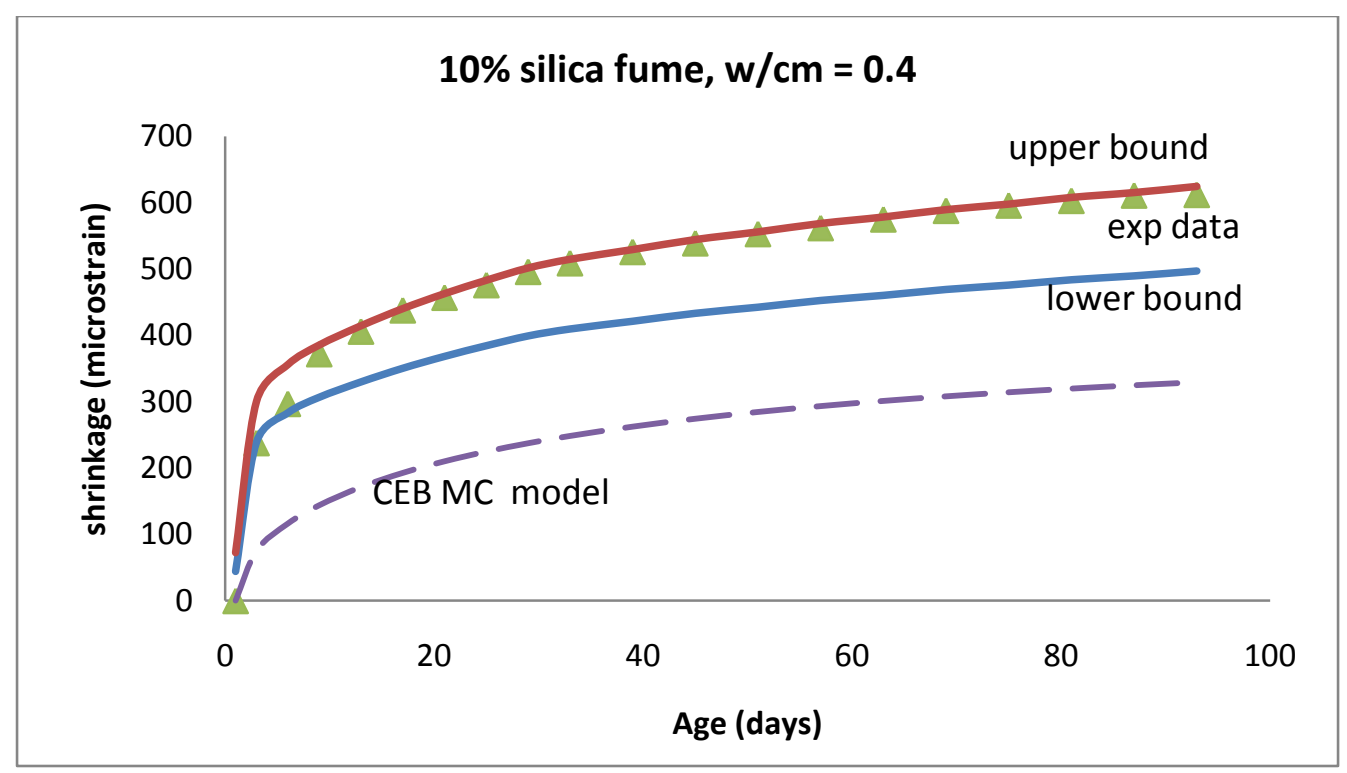

(a) $\mathrm{w} / \mathrm{cm}=0.4$

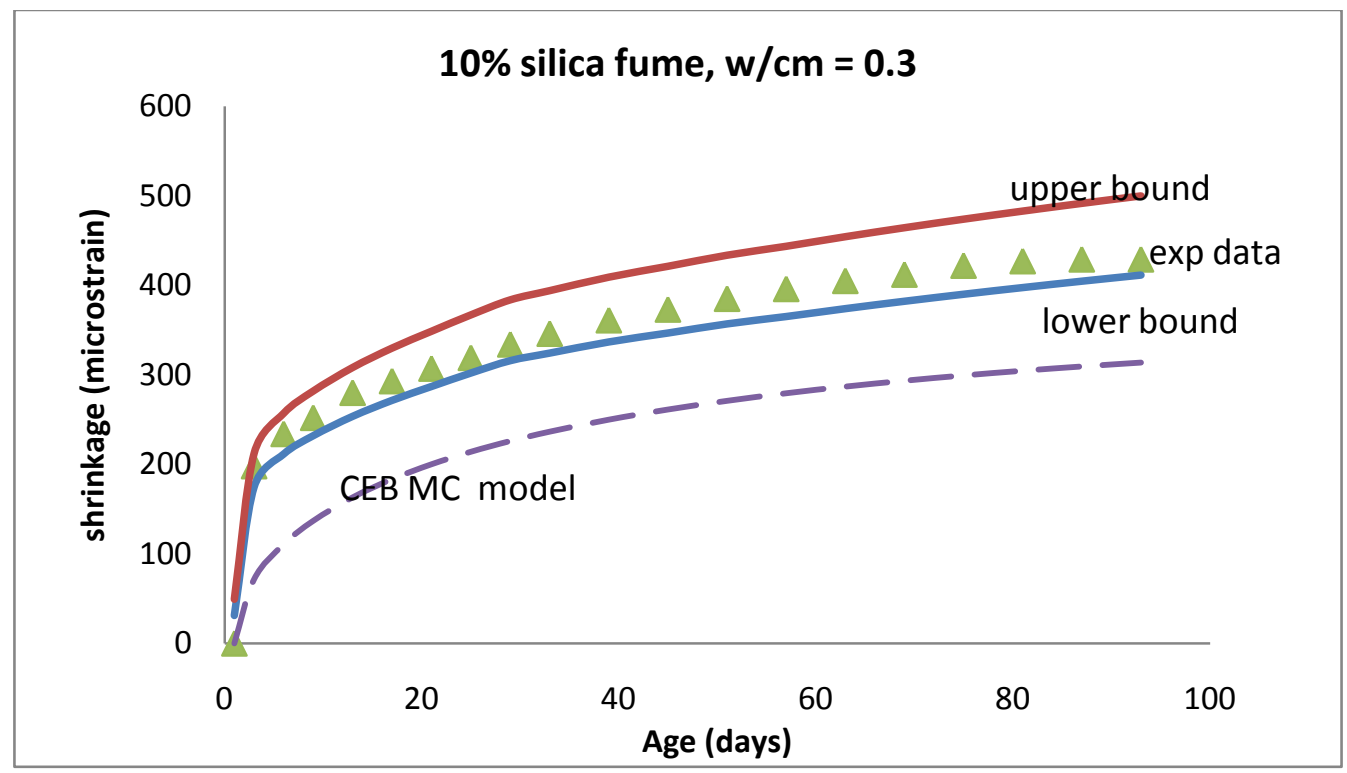

(b) $\mathrm{w} / \mathrm{cm}=0.3$

Fig. 5.31 Comparison of the CEB MC 90-99 model with the upper and lower bounds of the proposed model with experimental data in case of mixes containing replacement of cement by $10 \%$ silica fume at two $\mathrm{w} / \mathrm{cm}$ ratios. 


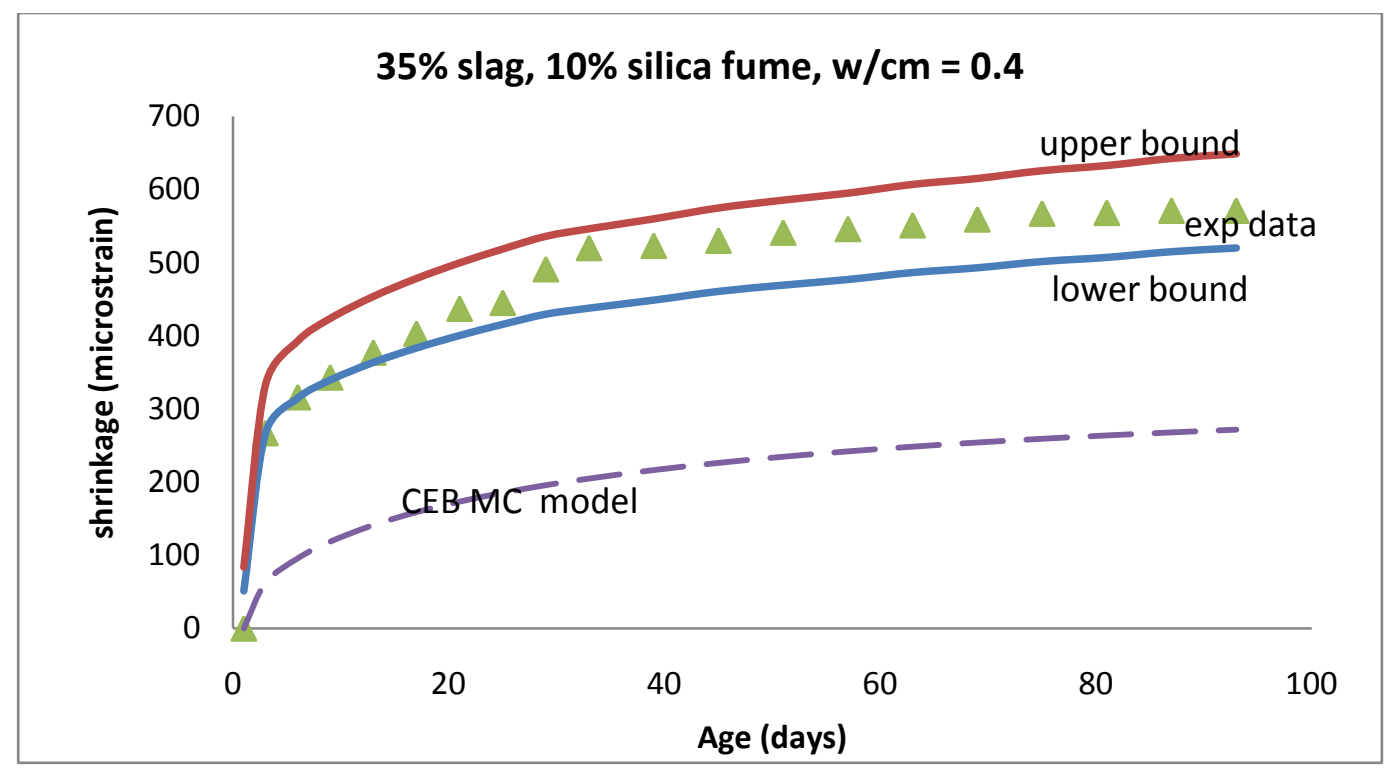

(a) $\mathrm{w} / \mathrm{cm}=0.4$

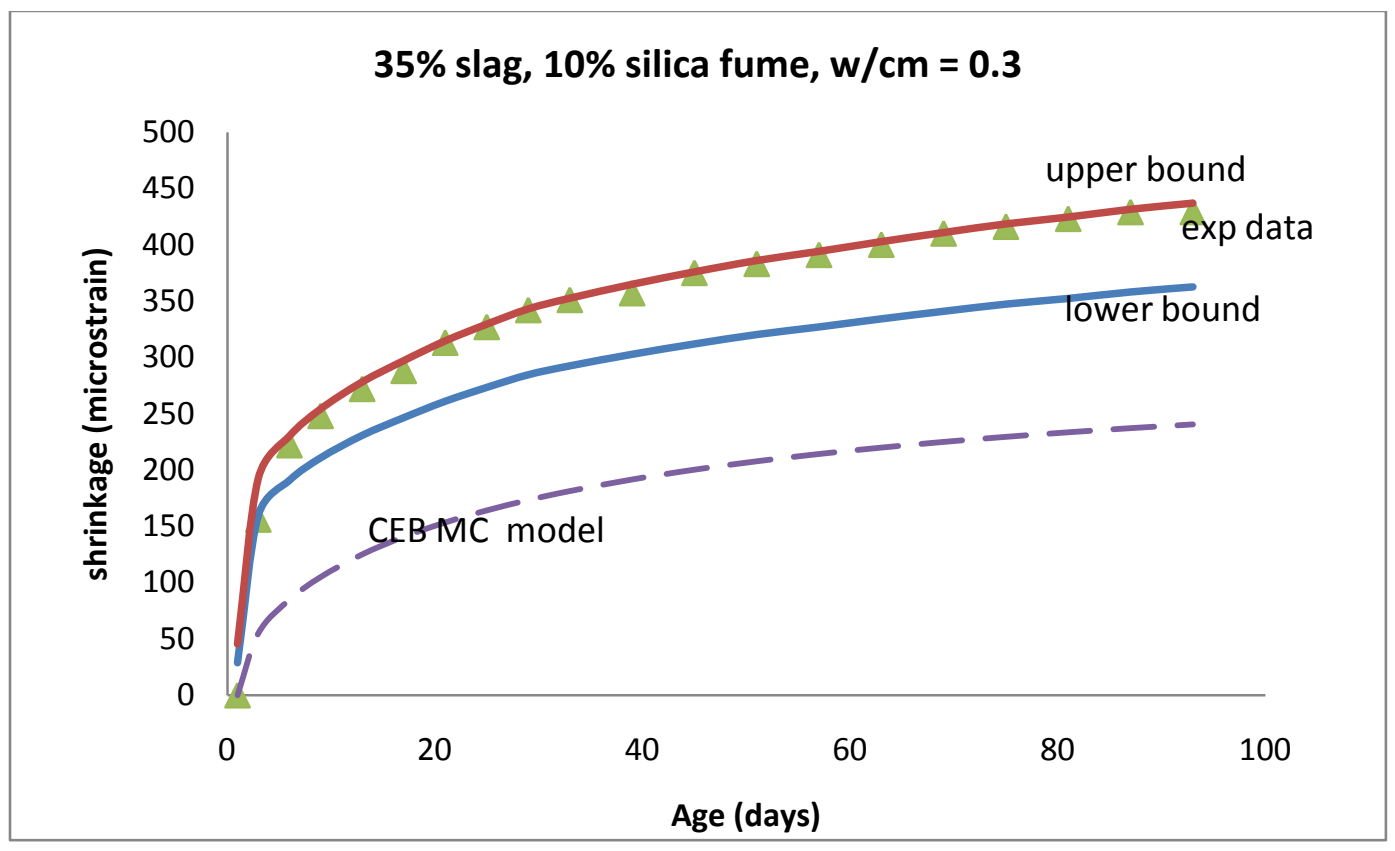

(b) $\mathrm{w} / \mathrm{cm}=0.3$

Fig. 5.32 Comparison of the CEB MC 90-99 model with the upper and lower bounds of the proposed model with experimental data in case of mixes containing replacement of cement by $35 \%$ slag and $10 \%$ silica fume at two $\mathrm{w} / \mathrm{cm}$ ratios. 


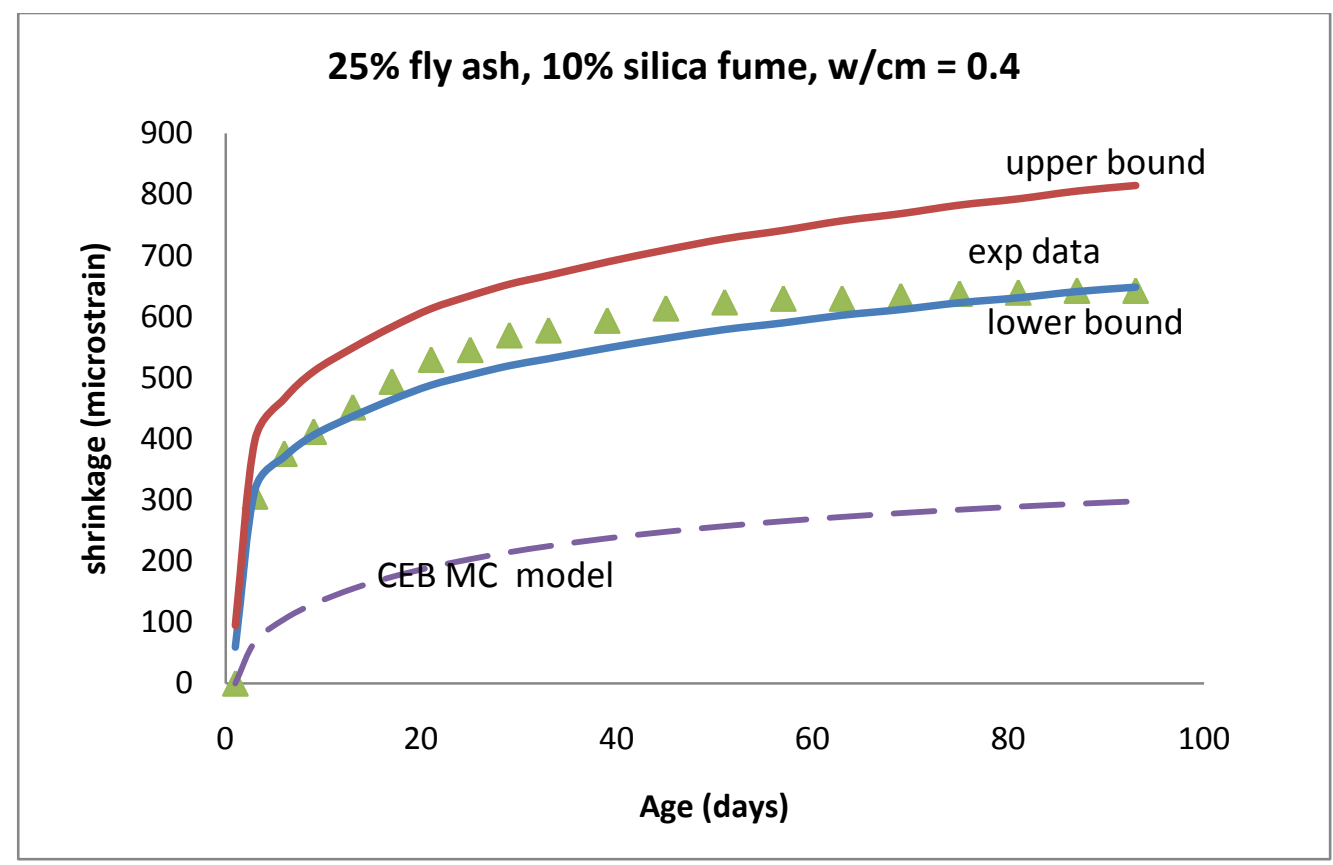

(a) $\mathrm{w} / \mathrm{cm}=0.4$

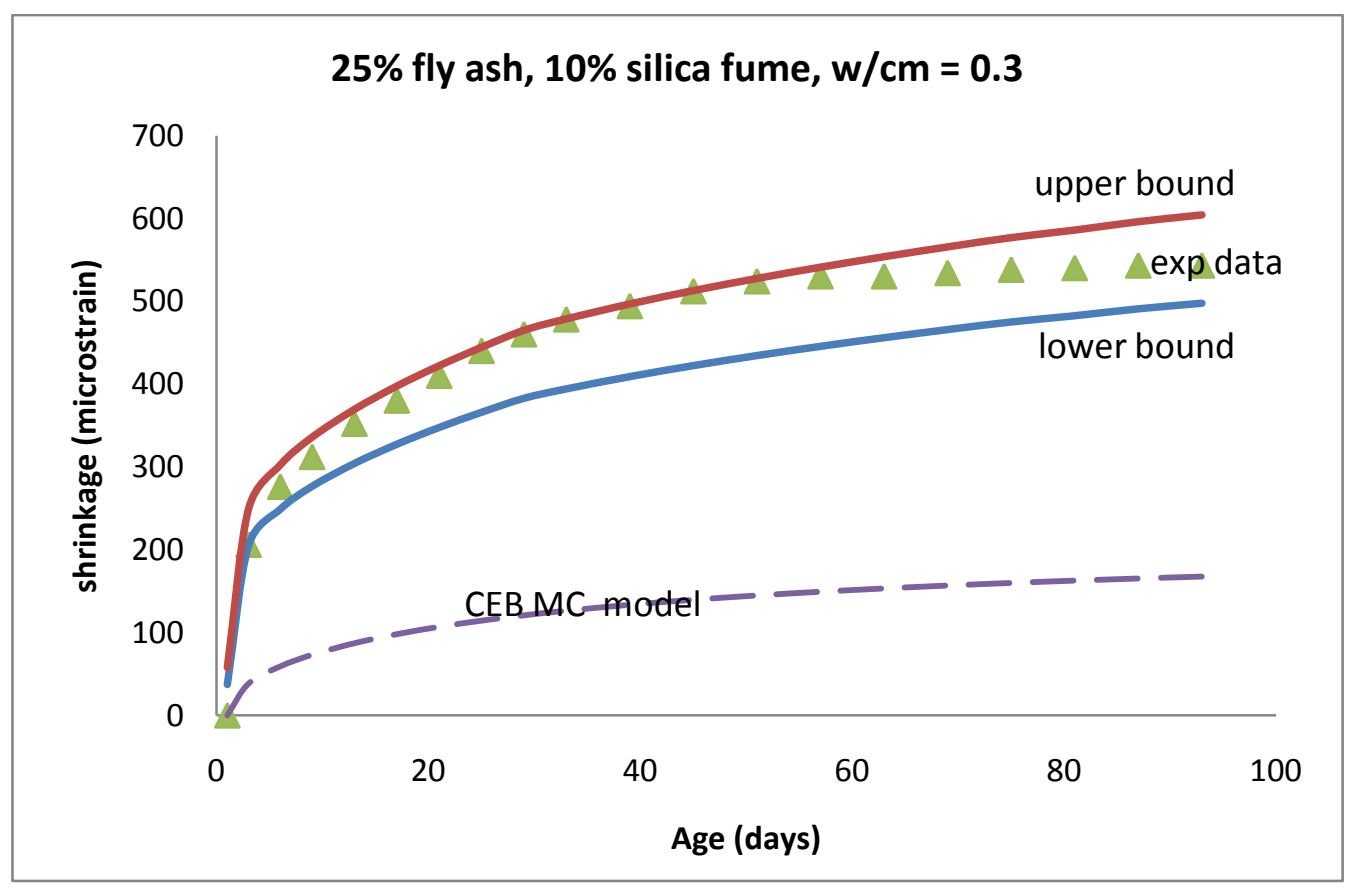

(b) $\mathrm{w} / \mathrm{cm}=0.3$

Fig. 5.33 Comparison of the CEB MC 90-99 model with the upper and lower bounds of the proposed model with experimental data in case of mixes containing replacement of cement by $25 \%$ fly ash and $10 \%$ silica fume at two $\mathrm{w} / \mathrm{cm}$ ratios. 


\subsection{Observations on comparison of predicted model with CEB MC 90-99 model}

Just like the B3 model, the CEB MC 90-99 model also made a significantly low estimation of the concrete shrinkage strains in all the cases (Figs. 5.28 through 5.33); the only exception being in the case of portland cement with no replacement at $w / c m=0.4$, which is the normal concrete (Fig. 5.29). The discrepancy was observed in the cases of concretes containing cement replacement by SCM as the CEB MC 90-99 model takes into account the effects of only the compressive strength at a given age as the governing factor of shrinkage and not the influence of the $\mathrm{w} / \mathrm{cm}$ ratio or the presence of SCM in the system. Thus, the proposed model was evidently more effective as compared to the proposed model in case of concretes containing replacement of cement by SCM. 


\subsubsection{GL 2000 model}

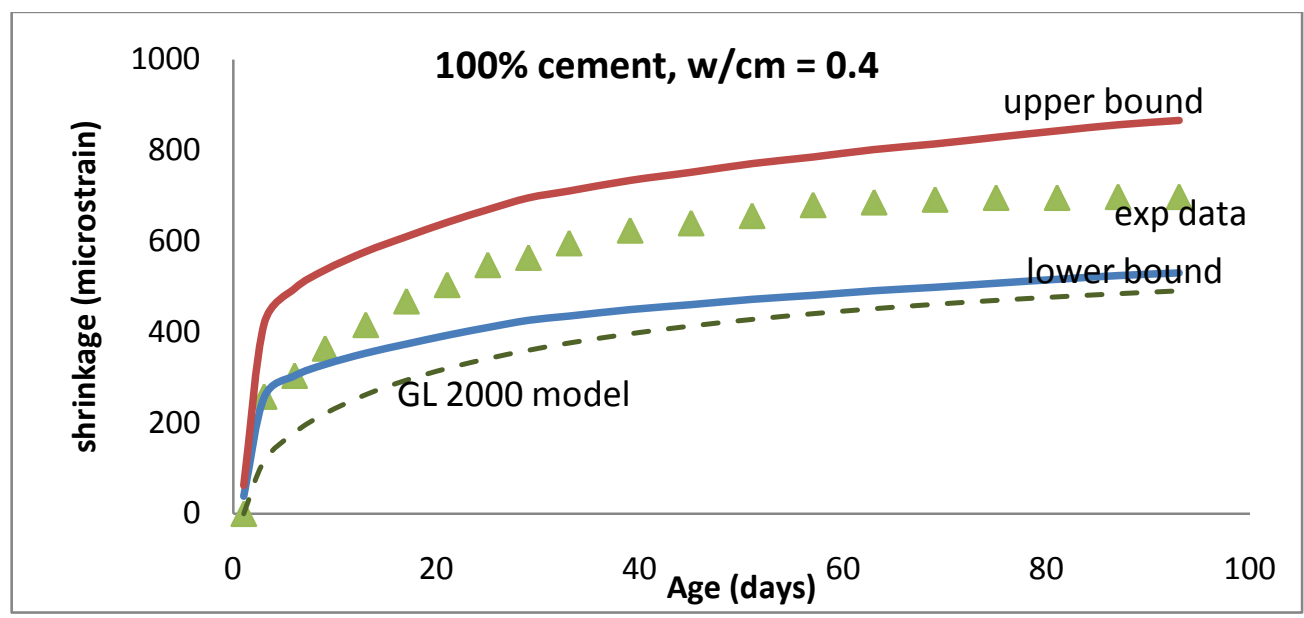

(a) $\mathrm{w} / \mathrm{cm}=0.4$

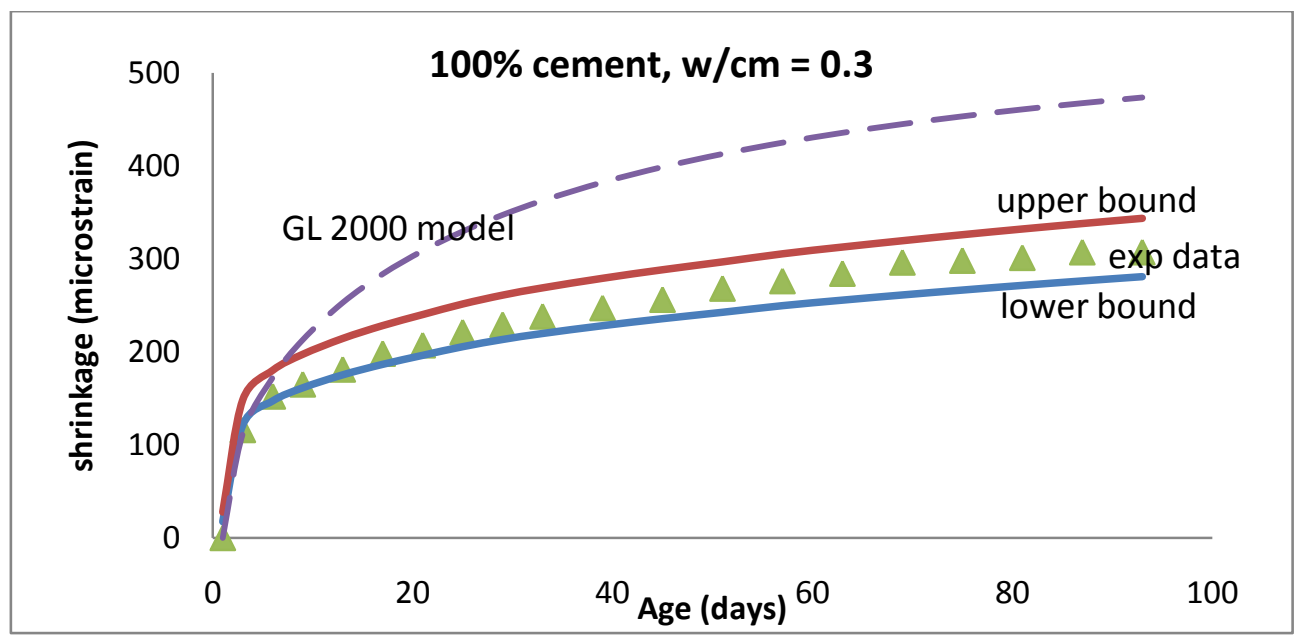

(b) $w / c m=0.3$

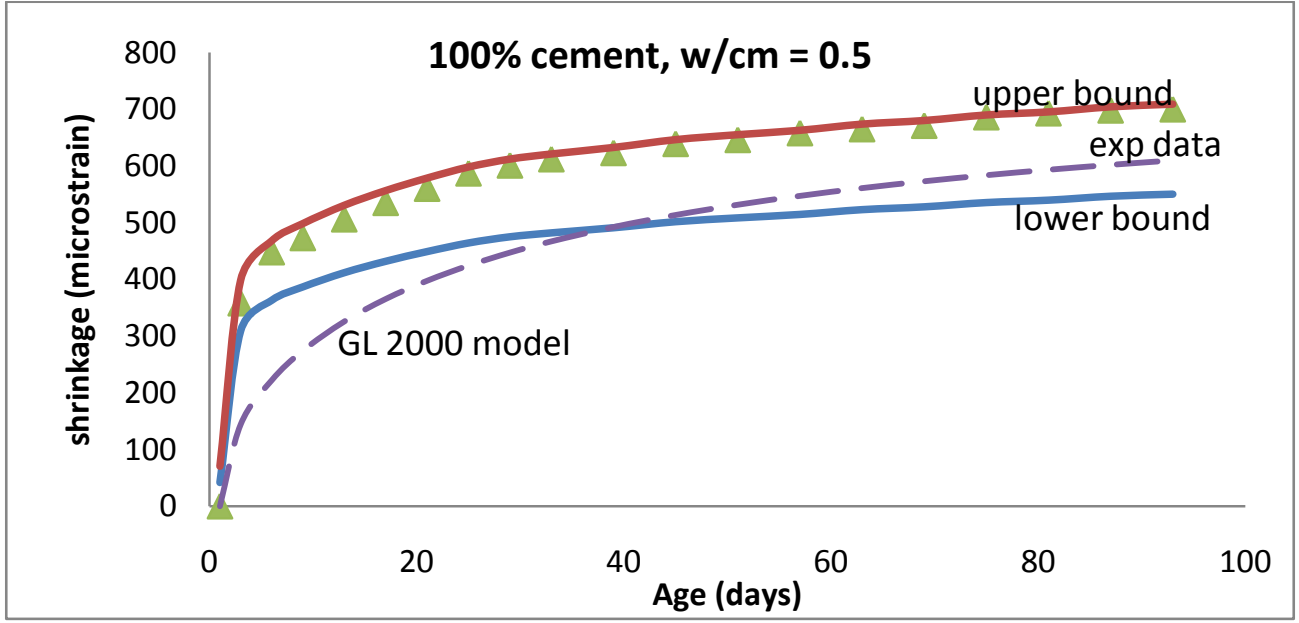

(c) $\mathrm{w} / \mathrm{cm}=0.5$

Fig. 5.34 Comparison of the GL 2000 model with the upper and lower bounds of the proposed model with experimental data in case of $100 \%$ cement mixes at three $\mathrm{w} / \mathrm{cm}$ ratios. 


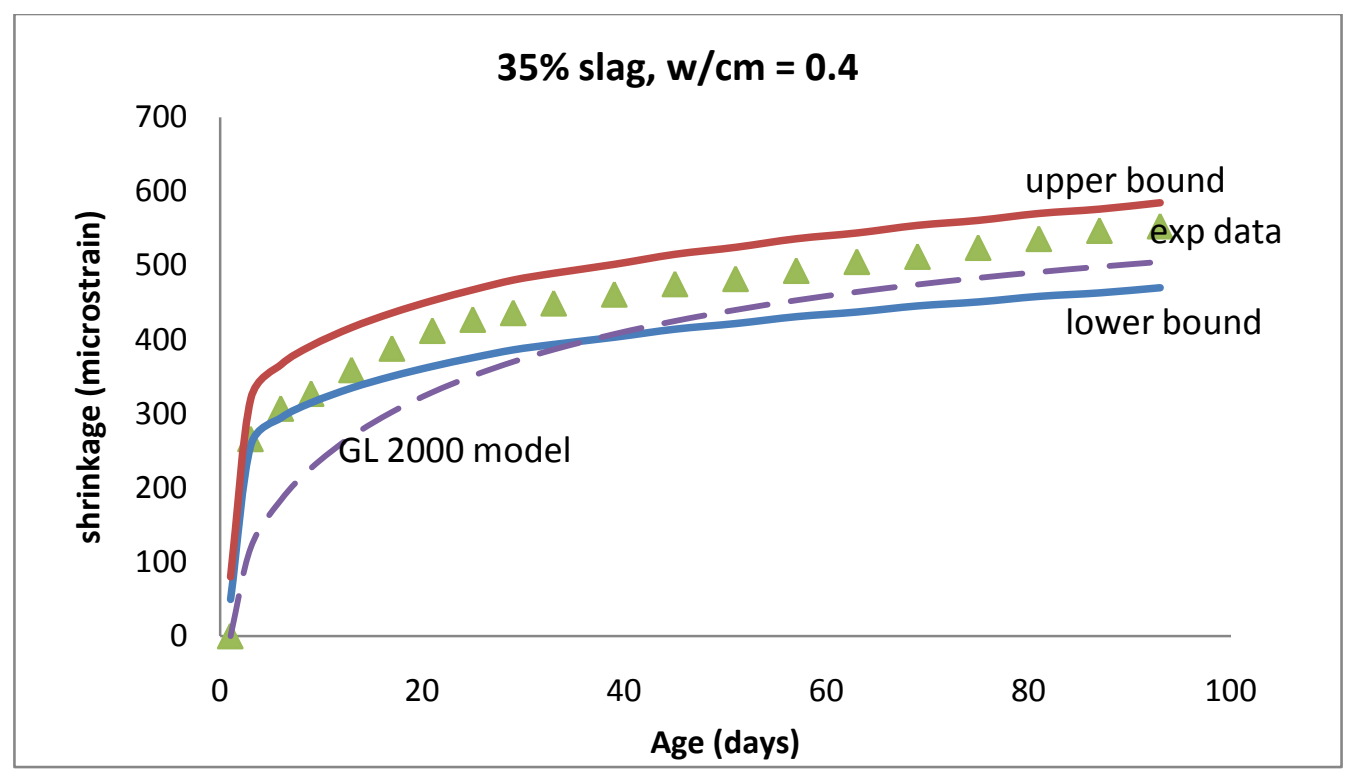

(a) $\mathrm{w} / \mathrm{cm}=0.4$

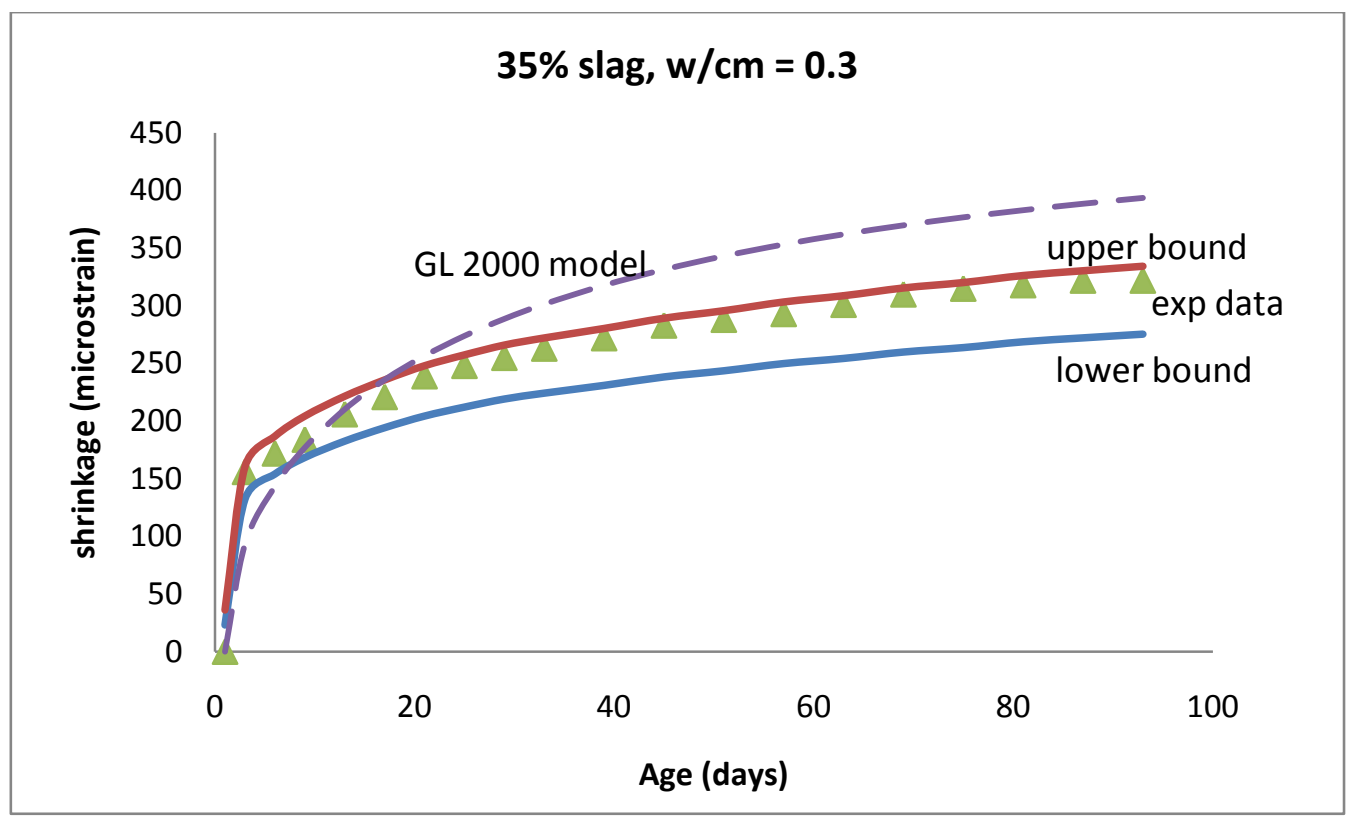

(b) $\mathrm{w} / \mathrm{cm}=0.3$

Fig. 5.35 Comparison of the GL 2000 model with the upper and lower bounds of the proposed model with experimental data in case of mixes containing replacement of cement by $35 \%$ slag at two $\mathrm{w} / \mathrm{cm}$ ratios. 


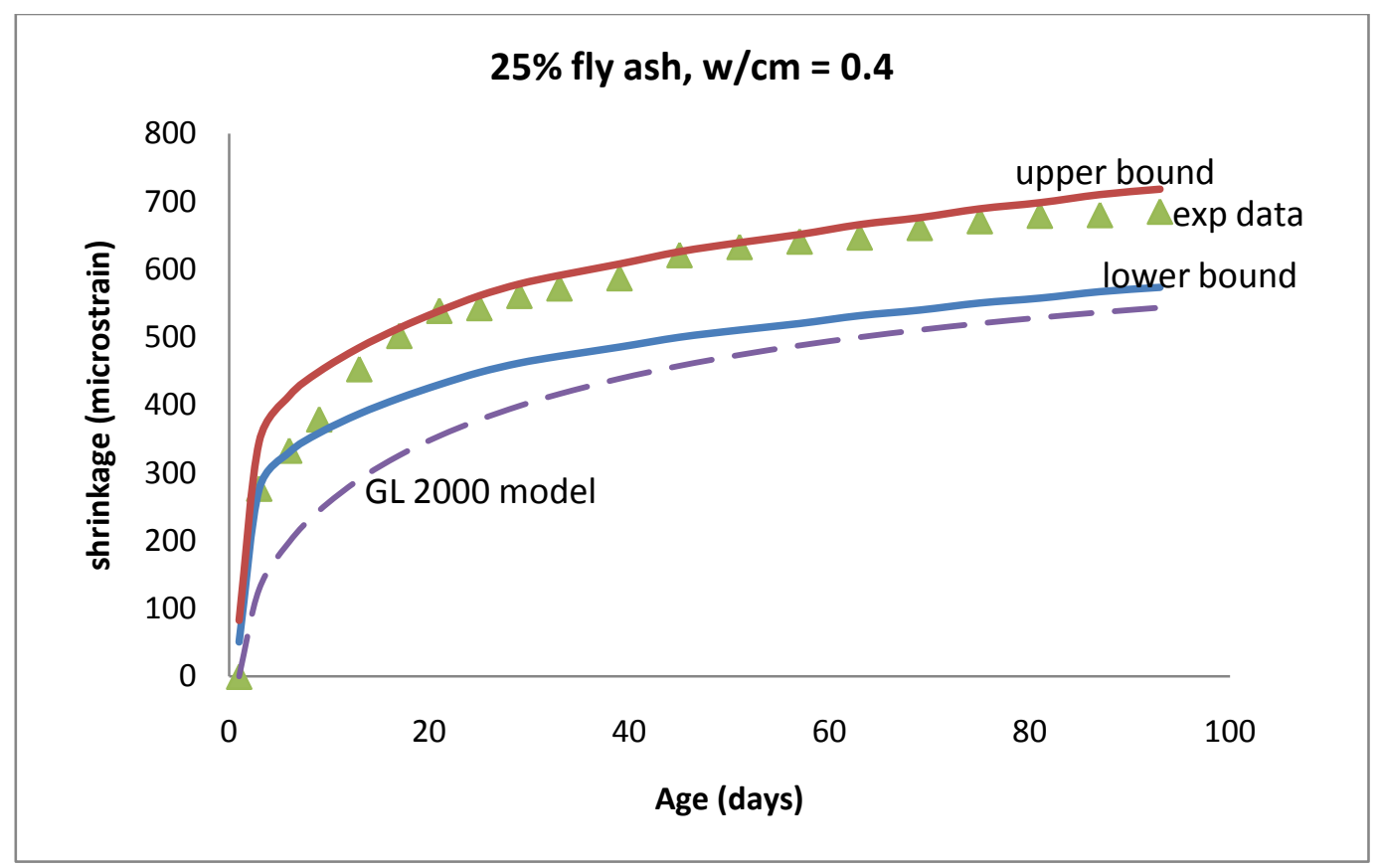

(a) $\mathrm{w} / \mathrm{cm}=0.4$

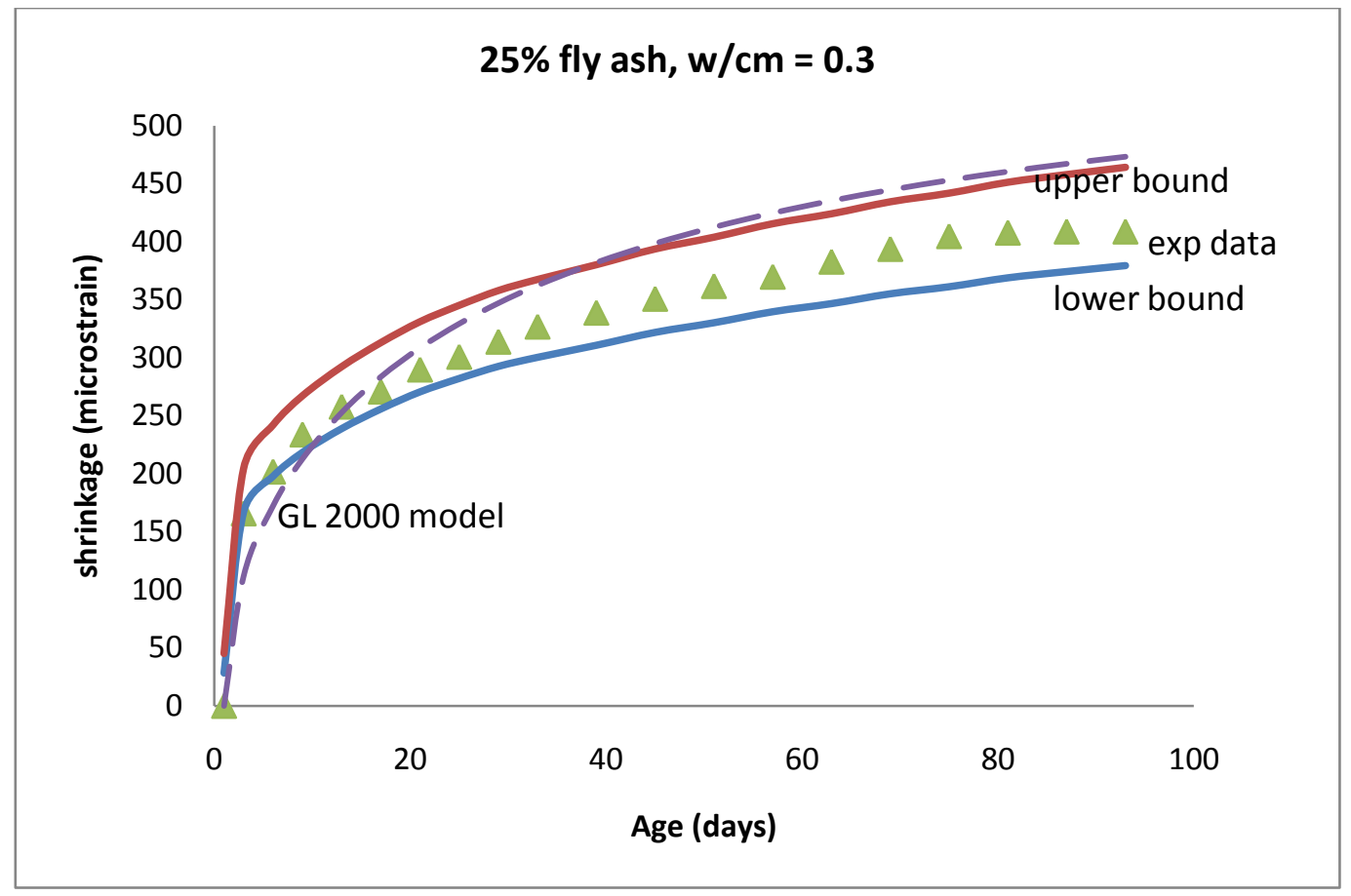

(b) $w / c m=0.3$

Fig. 5.36 Comparison of the GL 2000 model with the upper and lower bounds of the proposed model with experimental data in case of mixes containing replacement of cement by $25 \%$ fly ash at two $\mathrm{w} / \mathrm{cm}$ ratios. 


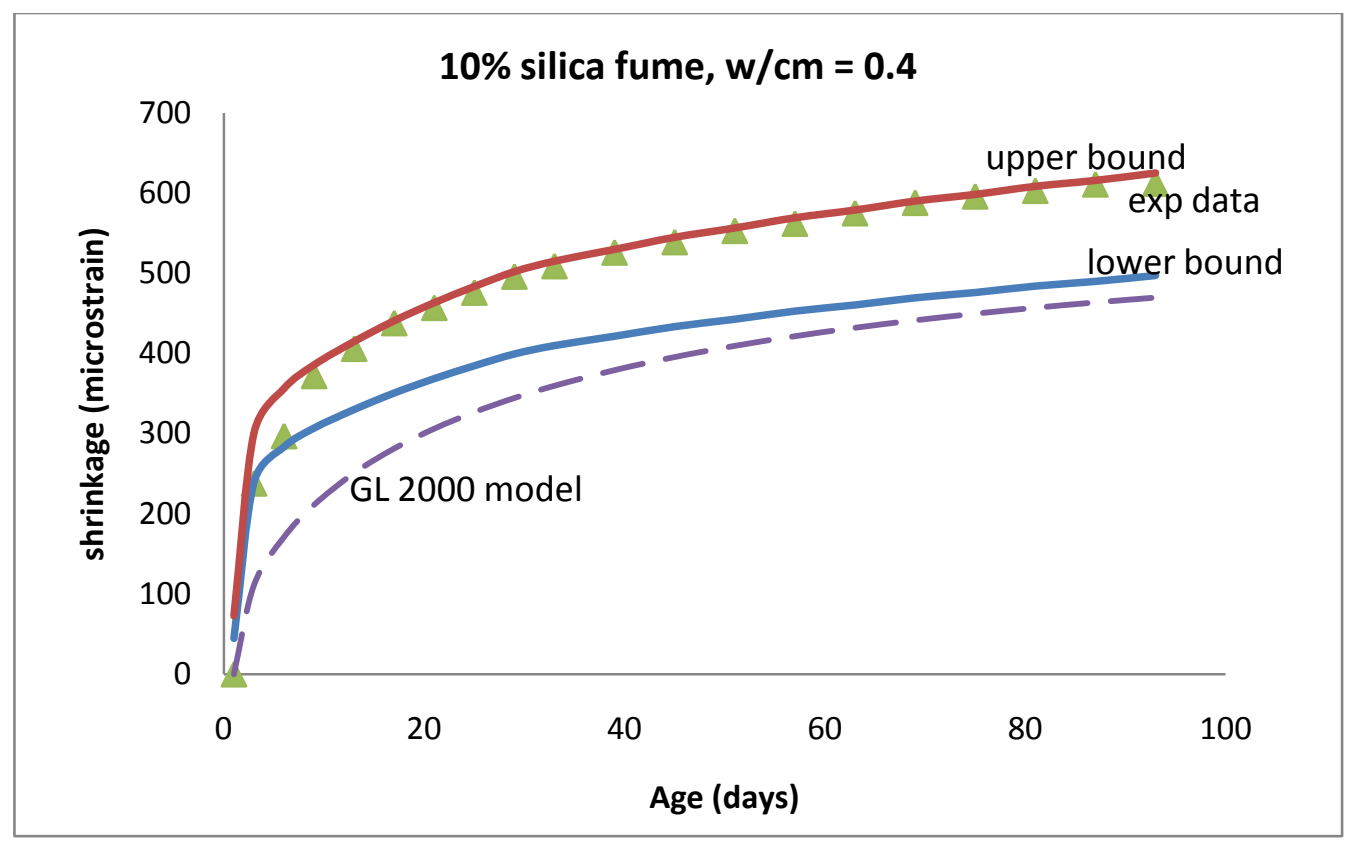

(a) $\mathrm{w} / \mathrm{cm}=0.4$

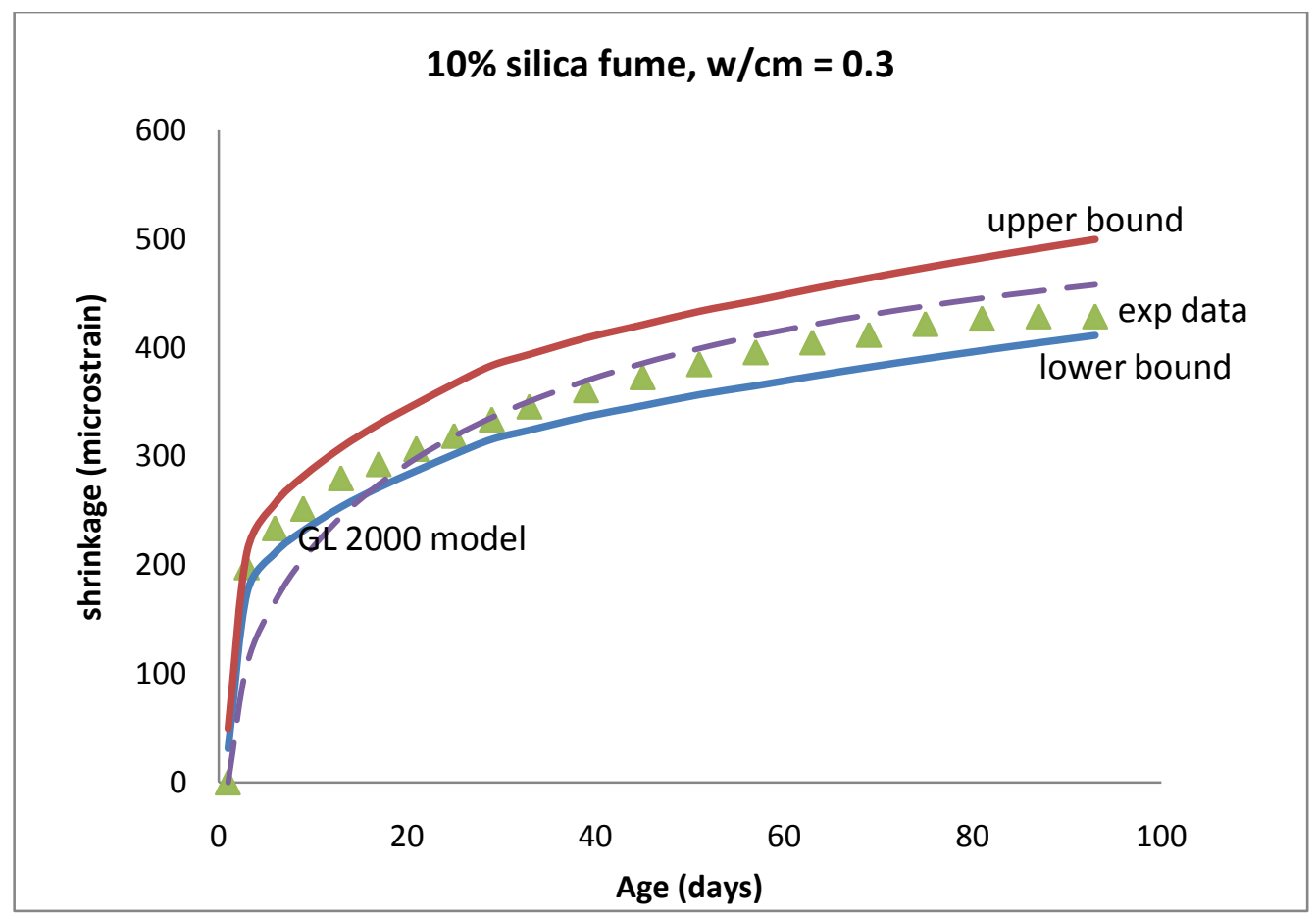

(b) $\mathrm{w} / \mathrm{cm}=0.3$

Fig. 5.37 Comparison of the GL 2000 model with the upper and lower bounds of the proposed model with experimental data in case of mixes containing replacement of cement by $10 \%$ silica fume at two $\mathrm{w} / \mathrm{cm}$ ratios. 


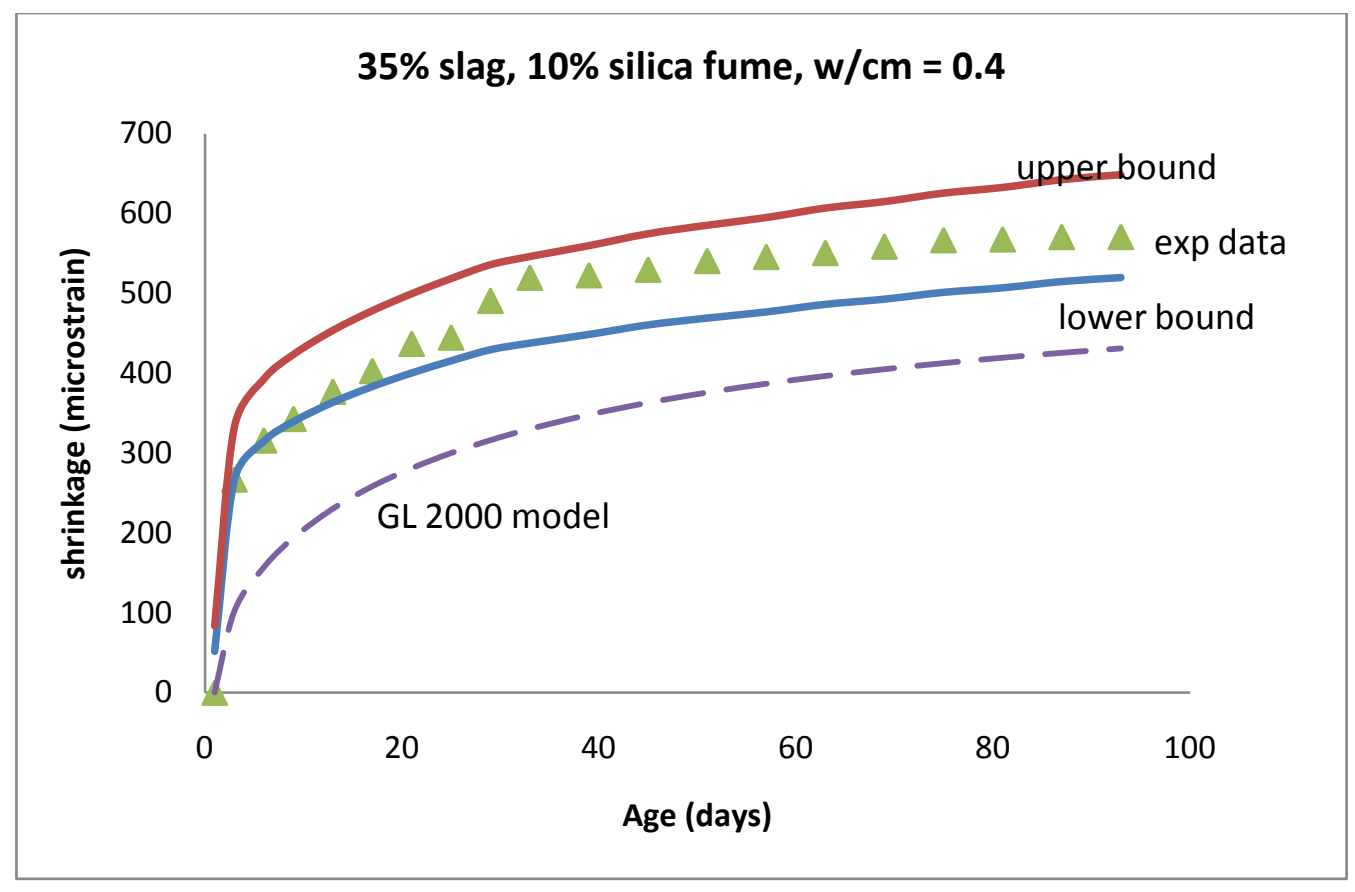

(a) $\mathrm{w} / \mathrm{cm}=0.4$

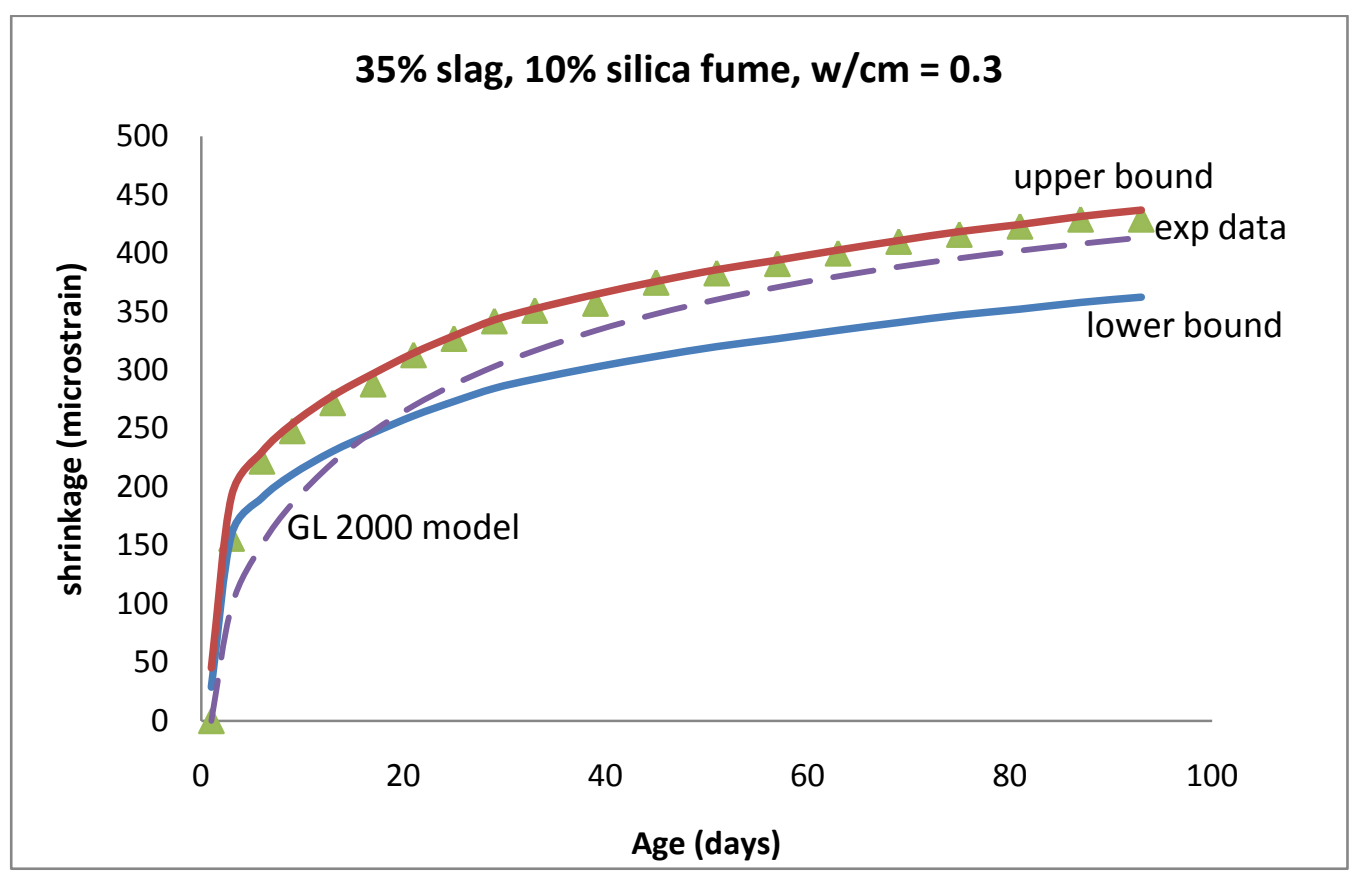

(b) $w / c m=0.3$

Fig. 5.38 Comparison of the GL 2000 model with the upper and lower bounds of the proposed model with experimental data in case of mixes containing replacement of cement by $35 \%$ slag and $10 \%$ silica fume at two $\mathrm{w} / \mathrm{cm}$ ratios. 


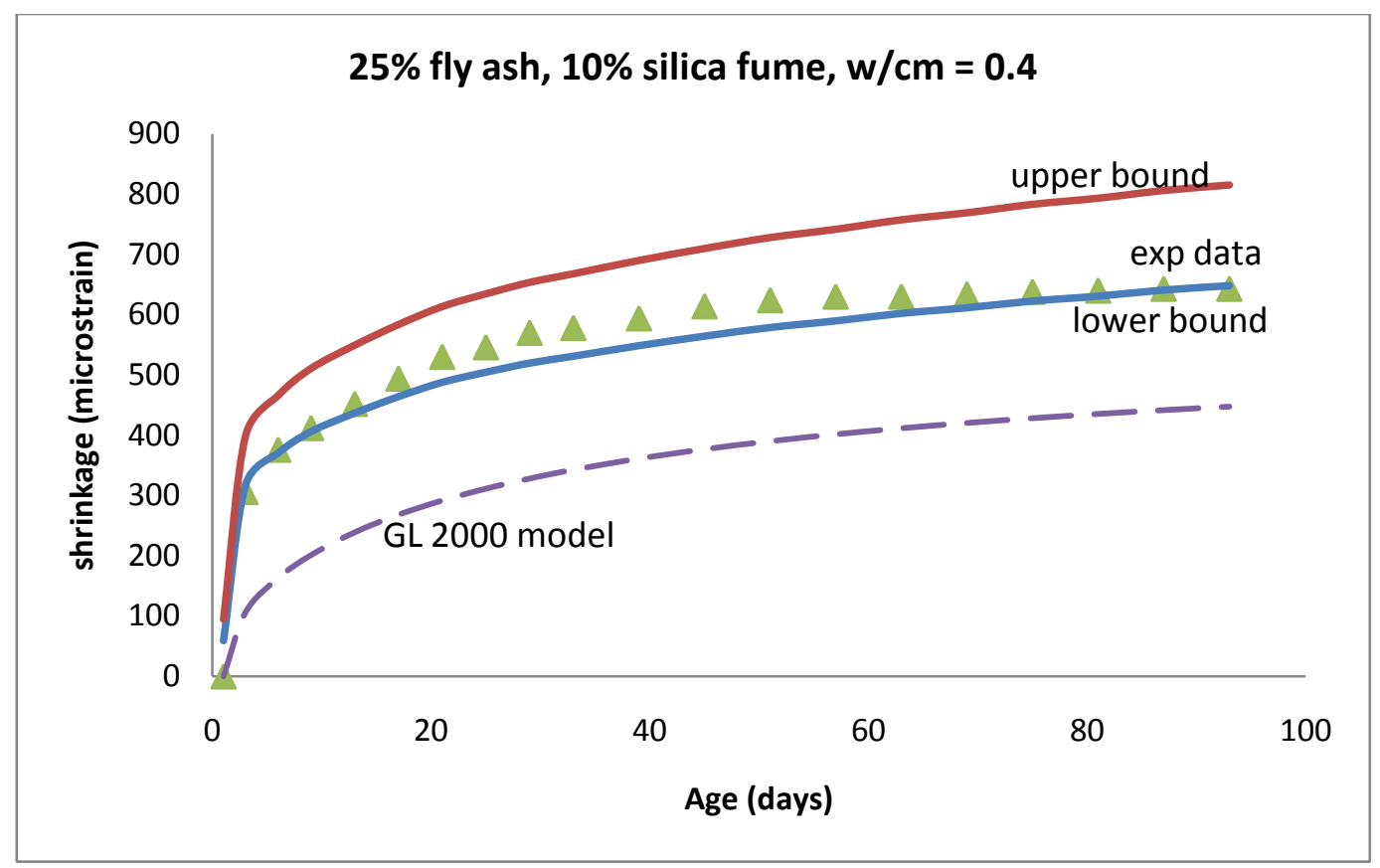

(a) $\mathrm{w} / \mathrm{cm}=0.4$

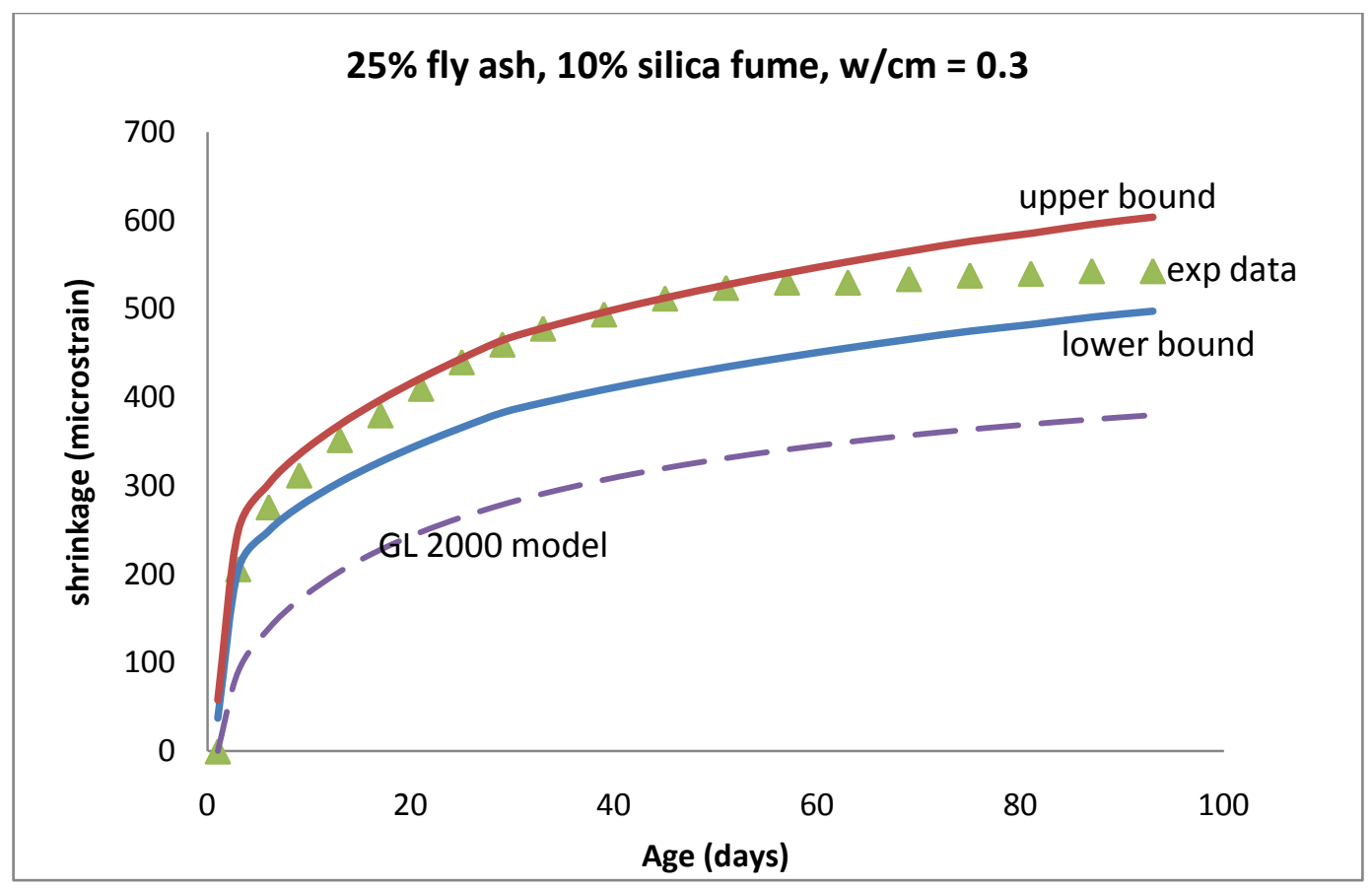

(b) $\mathrm{w} / \mathrm{cm}=0.3$

Fig. 5.39 Comparison of the GL 2000 model with the upper and lower bounds of the proposed model with experimental data in case of mixes containing replacement of cement by $35 \%$ slag at two $\mathrm{w} / \mathrm{cm}$ ratios. 


\subsection{Observations on comparison of proposed model with GL 2000 model}

The GL 2000 model was found to agree with the experimental data in some of the cases pretty well (Figs. 5.34 c, 5.35a, 5.36b, 5.37b, 5.38b) at the later ages, but it underestimated the shrinkage strains in all of the remaining cases. GL 2000 model had the closest agreement with the experimental data and the bounds of the proposed model as compared to the other available models. The differences from the experimental data in case of GL 2000 model were due to the absence of any factor depending on the SCM in the expression of shrinkage.

The overall comparison with the available models showed the proposed model in the predicted study to have the closest correlation with the experimental data. 


\subsection{Effect of $w / c m$ Ratio}

The $\mathrm{w} / \mathrm{cm}$ ratio has a significant influence on the final shrinkage of the concrete at any age. This effect is evident from the plot showing the shrinkage strains of concrete containing $100 \%$ portland cement (i.e. no replacement by SCM) at different ages for three different $\mathrm{w} / \mathrm{cm}$ ratios. The shrinkage observed was highest in case of the mix having a $\mathrm{w} / \mathrm{cm}$ ratio of 0.5 and least for the $0.3 \mathrm{w} / \mathrm{cm}$ ratio case. The findings were in accordance with those suggested by ACI 209R-92 (2009).

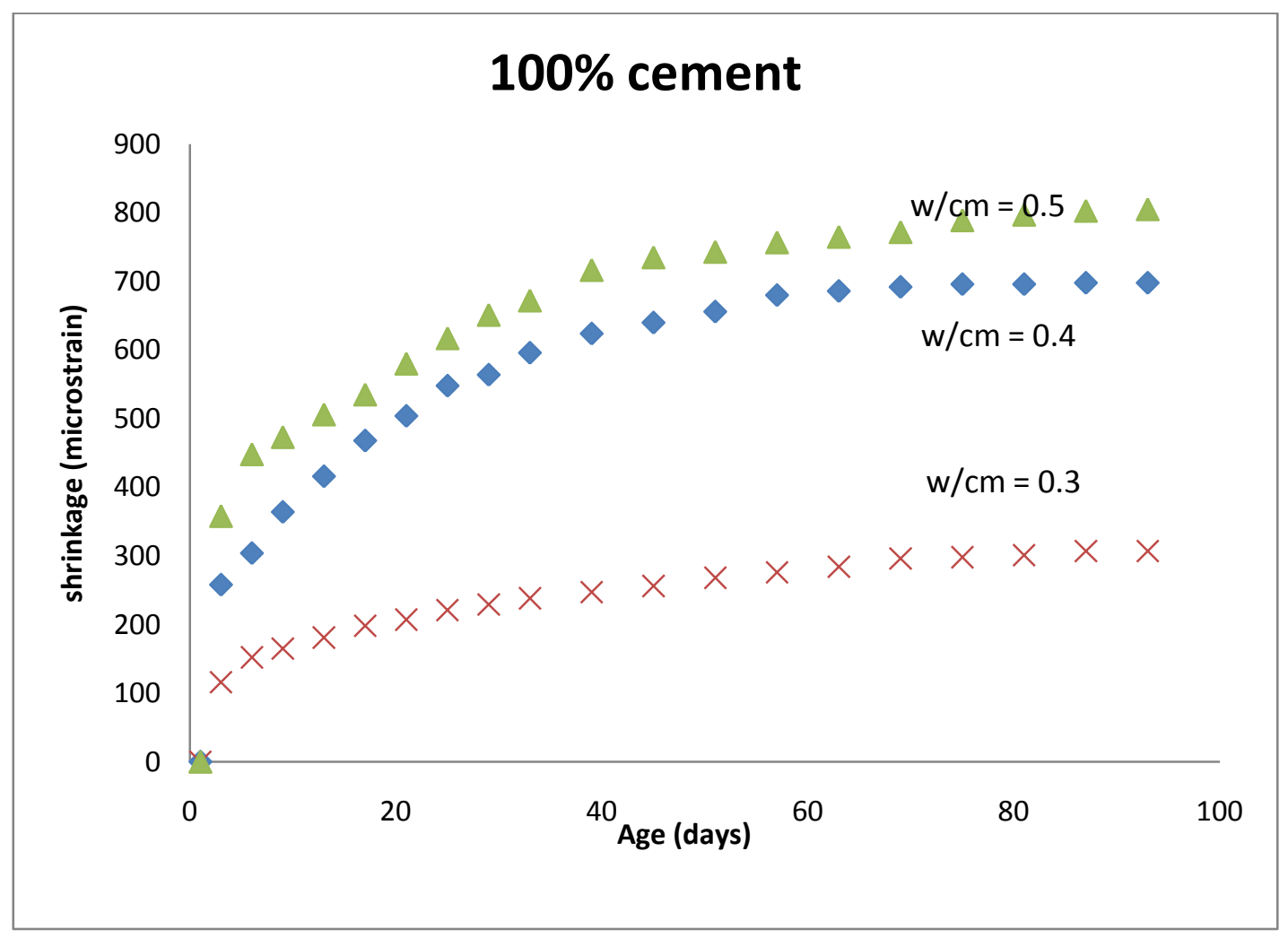

Fig. 5.40 Comparison of the concrete shrinkage strains at three different $\mathrm{w} / \mathrm{cm}$ ratios in case of $100 \%$ cement mix at different ages. 


\subsection{Effect of Varying Proportions of SCM}

The replacement of cement by SCM impacts the shrinkage strains of the corresponding concrete depending on the quantity and the type of supplementary material added. The comparisons of shrinkage strain have been shown in the following plots for $35 \%$ and $45 \%$ total replacement of cement by SCM with $100 \%$ cement cases at two different $\mathrm{w} / \mathrm{cm}$ ratios for each case.

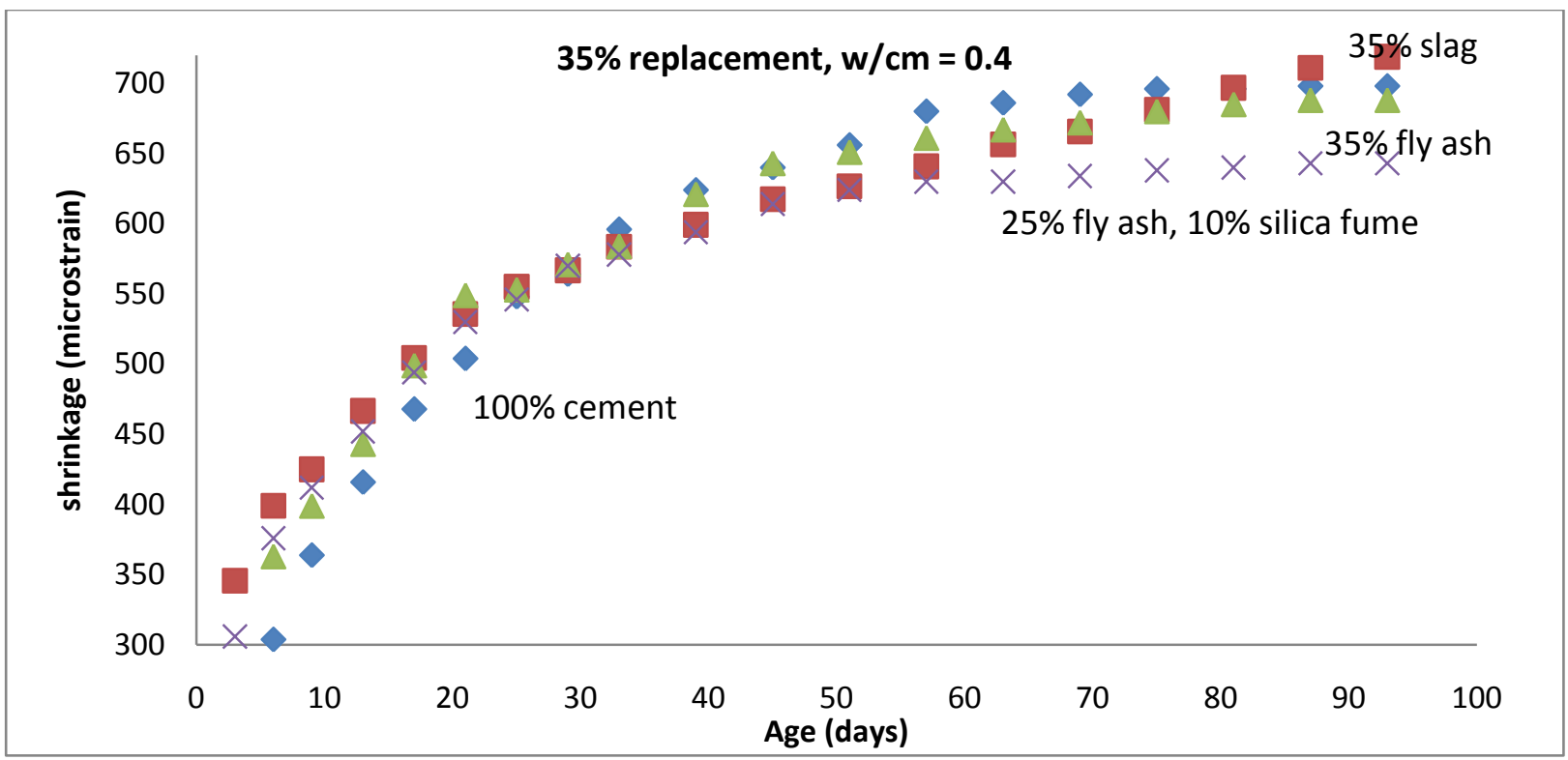

(a) $\mathrm{w} / \mathrm{cm}=0.4$

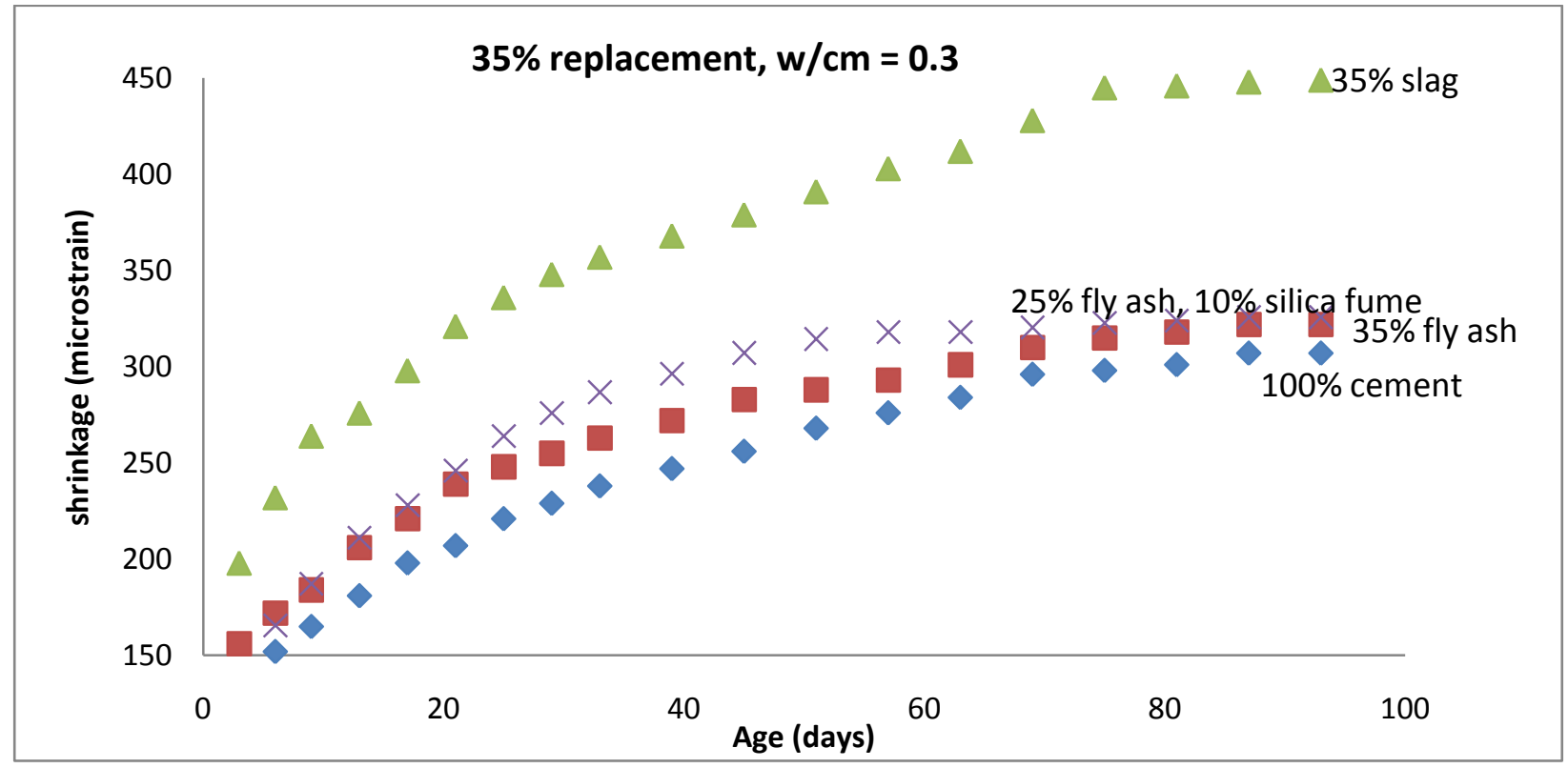

(b) $\mathrm{w} / \mathrm{cm}=0.3$

Fig. 5.41 Comparison of the concrete shrinkage strains with mixes containing a total of $35 \%$ replacement of cement by SCM for at two different $\mathrm{w} / \mathrm{cm}$ ratios. 


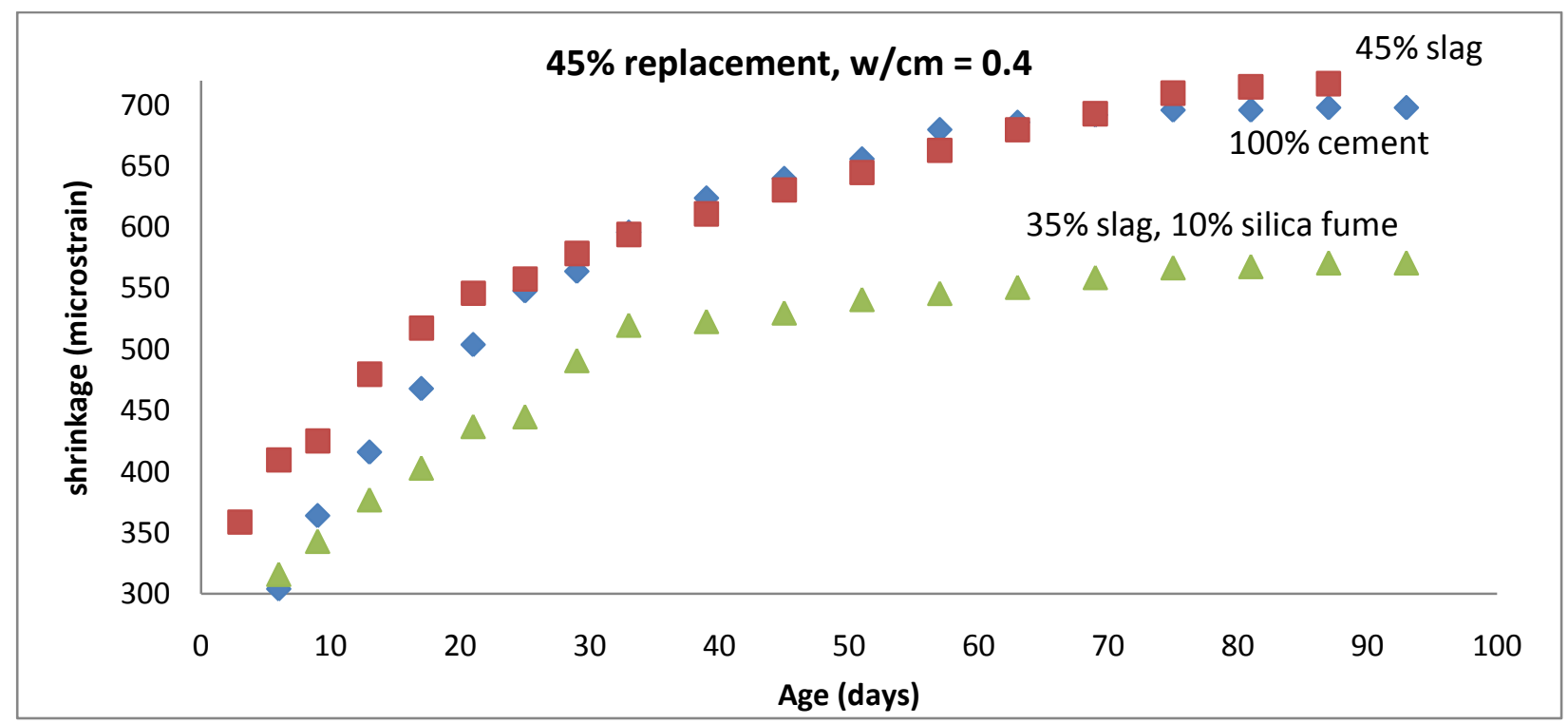

(a) $\mathrm{w} / \mathrm{cm}=0.4$

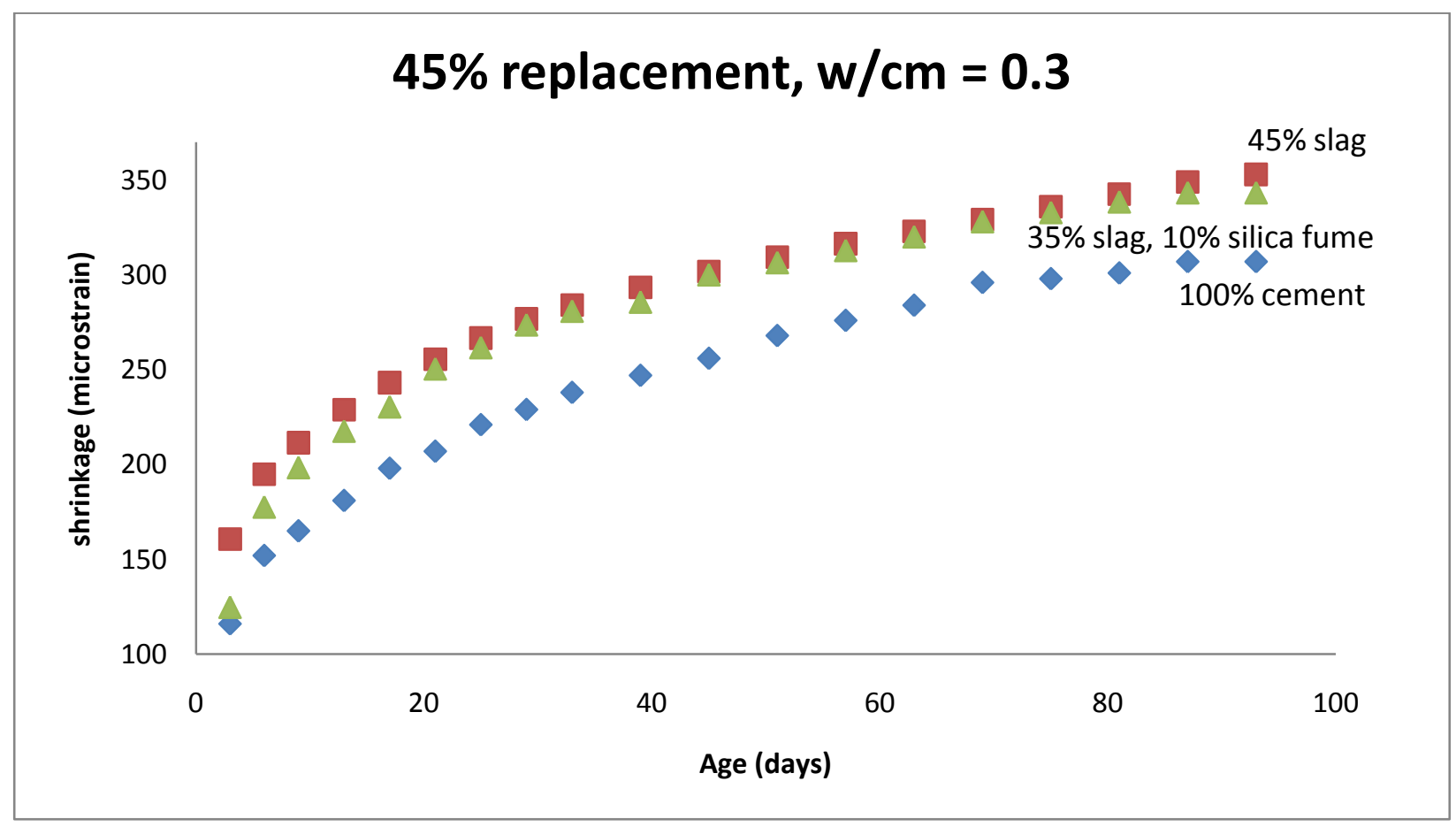

(b) $w / c m=0.3$

Fig. 5.42 Comparison of the concrete shrinkage strains with mixes containing a total of $45 \%$ replacement of cement by SCM for at two different $\mathrm{w} / \mathrm{cm}$ ratios. 
The replacement by slag caused the maximum shrinkage in both the cases of replacement of cement by SCM. The replacement by fly ash did not have any remarkable impact on the shrinkage strain of concrete as compared with that due to pure portland cement. The replacement of cement by silica fume reflected a considerable decrease in the shrinkage of concrete.

\subsection{Compressive Strength Measurement}

Compressive strengths of 101.6 diameter and $203.2 \mathrm{~mm}$ long cylinder specimens were measured in accordance with ASTM C 39 (Standard Test Method for Compressive Strength of Cylindrical Concrete Specimens). Each specimen was cured under water at $23 \pm 2^{0} \mathrm{C}$ for 24 hours. Tests were conducted at 1, 7, 28, and 90 days after casting. Average values of compressive strength of 24 mixtures are reported in table 5.1. The elastic modulus values are provided in the appendix.

Table 5.1 Compressive strength of cementitious paste and concrete at different ages and different $w / \mathrm{cm}$ ratios

\begin{tabular}{|c|c|c|c|c|c|c|c|c|}
\hline & \multicolumn{3}{|c|}{ Strength of Paste (Mpa) } & \multicolumn{3}{c|}{ Strength of concrete (Mpa) } \\
\hline Mix proportions & $1-d$ & $7-d$ & $28-d$ & $90-d$ & $1-d$ & $7-d$ & $28-d$ & $90-d$ \\
\hline $100 \%$ cement w/cm 0.3 & 16 & 30 & 45 & 51 & 25 & 45 & 58 & 70 \\
\hline $100 \%$ cement w/cm 0.4 & 13 & 25 & 38 & 43 & 21 & 44 & 54 & 61 \\
\hline $100 \%$ cement w/cm 0.5 & 5 & 20 & 30 & 34 & 7 & 22 & 35 & 43 \\
\hline $35 \%$ slag w/cm 0.3 & 18 & 34 & 51 & 58 & 26 & 59 & 84 & 95 \\
\hline $35 \%$ slag w/cm 0.4 & 11 & 21 & 31 & 35 & 14 & 39 & 51 & 57 \\
\hline $45 \%$ slag w/cm 0.3 & 11 & 34 & 51 & 64 & 14 & 43 & 58 & 82 \\
\hline $45 \%$ slag w/cm 0.4 & 8 & 21 & 32 & 36 & 10 & 30 & 51 & 58 \\
\hline $25 \%$ fly ash w/cm 0.3 & 23 & 44 & 66 & 75 & 28 & 50 & 58 & 81 \\
\hline $25 \%$ fly ash w/cm 0.4 & 12 & 23 & 34 & 38 & 15 & 26 & 44 & 59 \\
\hline $35 \%$ fly ash w/cm 0.3 & 21 & 40 & 60 & 68 & 34 & 66 & 86 & 92 \\
\hline $35 \%$ fly ash w/cm 0.4 & 11 & 20 & 30 & 34 & 14 & 24 & 39 & 54 \\
\hline $10 \%$ silica fume w/cm 0.3 & 20 & 37 & 56 & 64 & 35 & 57 & 62 & 83 \\
\hline $10 \%$ slica fume w/cm 0.4 & 16 & 31 & 47 & 53 & 26 & 38 & 59 & 67 \\
\hline $35 \%$ slag 10\% silica fume w/cm 0.3 & 20 & 39 & 66 & 74 & 23 & 59 & 76 & 116 \\
\hline $35 \%$ slag 10\% silica fume w/cm 0.4 & 12 & 23 & 35 & 39 & 16 & 49 & 70 & 76 \\
\hline $25 \%$ fly ash 10\% silica fume w/cm 0.3 & 21 & 40 & 70 & 79 & 32 & 60 & 90 & 99 \\
\hline $25 \%$ fly ash 10\% silica fume w/cm 0.4 & 15 & 29 & 43 & 49 & 22 & 44 & 65 & 77 \\
\hline $35 \%$ slag 15\% fly ash w/cm 0.3 & 4 & 26 & 65 & 78 & 6 & 35 & 84 & 93 \\
\hline $35 \%$ slag 15\% fly ash w/cm 0.4 & 2 & 12 & 43 & 57 & 3 & 15 & 58 & 76 \\
\hline
\end{tabular}

The conclusions based on all the results and formulations from chapters 4, and 5, and the prospects for future scope of extending the concepts of the present study have been discussed in Chapter 6. 


\subsection{Flow chart for sample calculation}

The following schematic flow chart has been furnished to provide a sample calculation for the various parameters discussed throughout the course of this study.

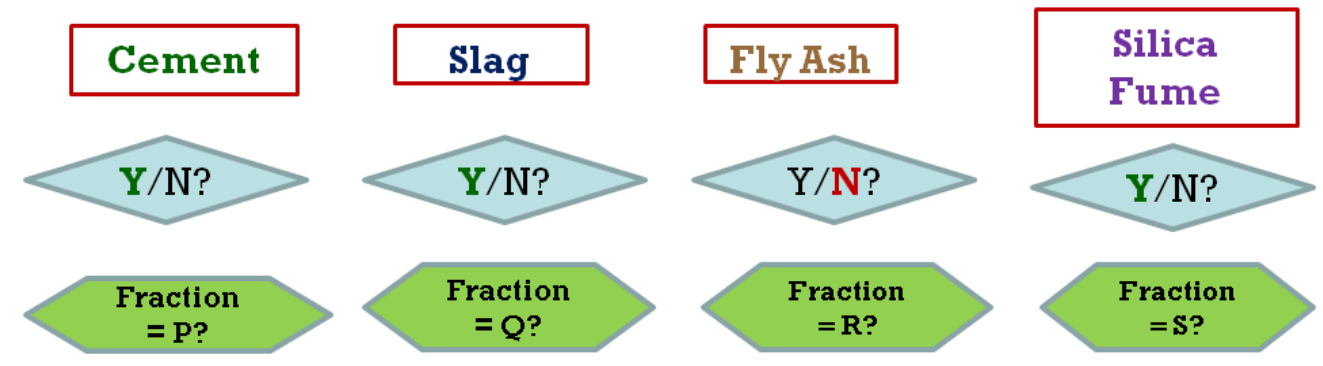

Mix: $55 \%$ cement, $35 \%$ slag, $10 \%$ silica fume

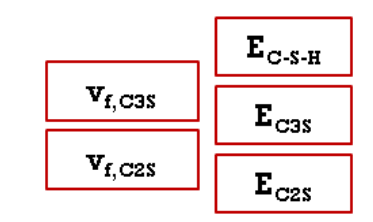

$\mathrm{V}_{\mathrm{CH}}=\alpha\left(102.3+\mathrm{V}_{\mathrm{AF}} * 1.753-39.4 * \mathrm{n}\right) * \mathrm{P}+\alpha_{\mathrm{slag}} \mathrm{Q}\left(-39.7 * \mathrm{n}^{\prime}+105.4\right)$ $-\left(\mathrm{s} * \mathrm{~S} * \alpha_{\mathrm{SF}} / 2.2\right) *\left(1.21 * \mathrm{n}^{\prime}\right)$

$\mathrm{V}_{\mathrm{s}}=$ vol. fraction of sand in mortar

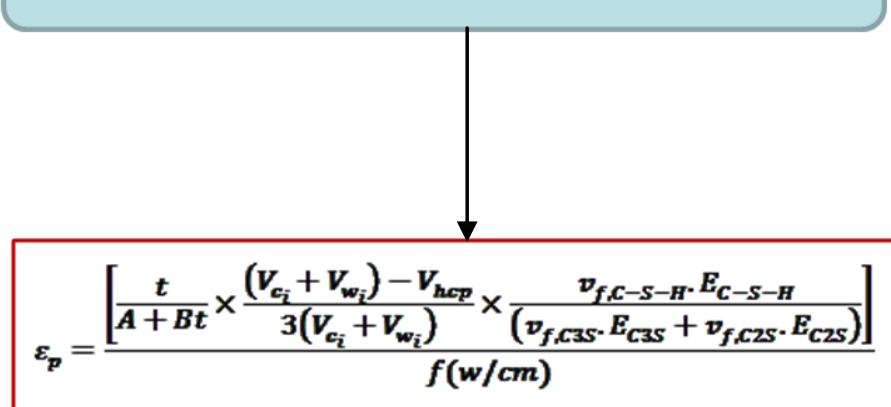
$E_{p}=$ elastic modulus of paste
$E_{\mathrm{s}}=$ elastic modulus of sand

$$
\begin{aligned}
& \varepsilon_{m}=\frac{\left\lfloor 1-V_{s}\right\rfloor\left[n_{1}+1-\left(n_{1}-1\right) V_{s}\right.}{n_{1}+1+\left(n_{1}-1\right) V_{s}} \times \varepsilon_{p} \\
& \varepsilon_{c}=\frac{\left[1-V_{a}\right\rfloor\left[n_{2}+1-\left(n_{2}-1\right) V_{a}\right]}{n_{2}+1+\left(n_{2}-1\right) V_{a}} \times \varepsilon_{m}
\end{aligned}
$$

$$
\varepsilon_{c, \text { eff }}=\gamma_{s h} \cdot \varepsilon_{c}
$$




\section{CHAPTER 6}

\section{CONCLUSIONS}

This chapter discusses the conclusions based on the test results and accuracy of the techniques implemented for analytical purposes and the proposed shrinkage model. Also the suggestions for future works have been suggested.

\subsection{Estimation of C-S-H}

From chapter 4 it is evident that the information on C-S-H formation for different SCM can be obtained quite accurately using a combination of microanalysis data and statistical optimization techniques. The relative quantities of C-S-H(I) and C-S-H(II) provide an indication of the reactivity of SCM.

The following conclusions can be drawn from the plots of $\mathrm{C}-\mathrm{S}-\mathrm{H}$ quantities vs. time as provided in chapter 4.

1. Replacement of cement by slag and fly ash delayed the C-S-H(II) formation due to their relatively slower reactivity between 0 to 7 days, as compared to the addition of silica fume which has much higher rate of reaction, as corroborated by previous researchers.

2. Between 60 to 90 days the addition of slag, fly ash or silica fume as SCM produced greater total quantity of C-S-H as compared to the case of zero replacement of cement due to the formation of the additional C-S-H(II) through pozzolanic and/or slag reactions.

3. In case of slag and fly ash, as proportion of replacement increased, the degree of reaction between 0 to 7 days reduced accordingly while the amount of total $\mathrm{C}-\mathrm{S}-\mathrm{H}$ formation between 28 and 90 days increased.

4. On the contrary, replacement of cement by silica fume as SCM accelerated the process of hydration at early age.

5. In case of the ternary mixtures, slag and silica fume produced greater total quantity of $\mathrm{C}-\mathrm{S}-\mathrm{H}$ at all ages, as compared to the other combinations of SCM. 
6. Fly ash and silica fume on the other hand showed relatively slower rates of reaction as compared to slag and silica fume between 0 to 7 days, with subsequent increase in reactivity at the later ages.

7. When slag and fly ash were used as combination, they showed very slow initial rates of reaction, but at later ages the rates of reaction increased significantly.

\subsection{Shrinkage Model}

1. The general trend of the comparison of the predicted model with the ACI (and the modified ACI by Huo et al. 2001) model showed a tendency of the ACI model to overestimate the predicted shrinkage strains at low $\mathrm{w} / \mathrm{cm}$ ratio case $(\mathrm{w} / \mathrm{cm}=0.3)$ and underestimate the predicted shrinkage strains at high $\mathrm{w} / \mathrm{cm}$ cases $(\mathrm{w} / \mathrm{cm}=0.5)$ in all the cases (Figs. 5.16 through 5.21).

2. The B3 model made a significant underestimation of the concrete shrinkage strains.

3. The CEB MC 90-99 model also made a significantly low estimation of the concrete shrinkage strains in all the cases (Figs. 5.28 through 5.33); the only exception being in the case of portland cement with no replacement at $\mathrm{w} / \mathrm{cm}=0.4$, which is the normal concrete (Fig. 5.29).

4. The GL 2000 model had the closest agreement with the experimental data and the bounds of the proposed model as compared to the other available models. The overall comparison with the available models showed the proposed model in the predicted study to have the closest correlation with the experimental data.

\subsection{Suggestions for Future Work}

1. A comprehensive data base can be formed for constants A and B (table 4.6) using different types of SCM and for different $w / \mathrm{cm}$. This will modify the proposed model to enable to use for a wider range of $\mathrm{w} / \mathrm{cm}$ ratios and SCM. 
2. Other microscopic techniques like X-ray diffraction (XRD) and differential scanning calorimetry (DSC) can be used to estimate the reduction in $\mathrm{CH}$ during hydration in presence of SCM. The information may be used to indirectly validate the estimated $\mathrm{C}-\mathrm{S}-\mathrm{H}$ formation with time by the procedure mentioned in the present study.

3. The scanning electron microscopy (SEM) image analysis, mercury intrusion porosimetry, nitrogen absorption, or any other suitable techniques can be used to estimate the porosity and pore size distributions. This information can be included in the proposed shrinkage and equation to incorporate the effects of porosity and pore size distribution.

4. The proposed model for shrinkage should be tested with more data collected from different sources and validated with long-term data for other SCM and w/cm cases.

5. The concept of shrinkage determination can be extended to evaluating the timedependent deformation under sustained loading of the creep deformation.

6. The assumptions which were made in this study to make the model simplified and relatively easier to use for practical purposes, can be avoided, if the concept of numerical modeling is introduced with the help of commercially available software like ABAQUS or COMSOL. 


\section{References}

1. ACI Committee 209, 2009, "Prediction of Creep, Shrinkage, and Temperature Effects In Concrete Structures(ACI 209R-92)", American Concrete Institute, Farmington Hills, MI.

2. Almudaiheem, Jamal A. and Hansen, Will, 1987," Effect of Specimen Size and Shape on Drying Shrinkage of Concrete", ACI Materials Journal, Vol.84 , No. 3, pp. 130-135.

3. American Society for Testing and Materials, 2004, Annual Book of ASTM Standards, vol. 04.02, Concrete and Aggregates.

4. ASTM C 39M-03, "Standard Test Method for Compressive Strength of Cylindrical Concrete Specimens", 2004 Annual Book of ASTM Standards, Vol. 04.02, Concrete and Aggregates, American Society for Testing and Materials, pp. 21-27.

5. ASTM C 143M-03," Standard Test Method for Slump of Hydraulic Cement Concrete", 2004 Annual Book of ASTM Standards, Vol. 04.02, Concrete and Aggregates, American Society for Testing and Materials, pp. 95-98.

6. ASTM C 157M-04," Standard Test Method for Length change of Hardened HydraulicCement Mortar and Concrete", 2004 Annual Book of ASTM Standards, Vol. 04.02, Concrete and Aggregates, American Society for Testing and Materials, pp. 104-110.

7. ASTM C 192M-02," Standard Test Method for Making and Curing Test specimens in the Laboratory", 2004 Annual Book of ASTM Standards, Vol. 04.02, Concrete and Aggregates, American Society for Testing and Materials, pp.126-133.

8. ASTM C 231-03," Standard Test Method for Air Content of Freshly Mixed Concrete by the Pressure Method ", 2004 Annual Book of ASTM Standards, Vol. 04.02, Concrete and Aggregates, American Society for Testing and Materials, pp. 146-153.

9. ASTM C 260-04,"Specification for Air-Entraining Admixtures for Concrete", 2004 Annual Book of ASTM Standards, vol. 04.02, Concrete and Aggregates, American Society for Testing and Materials, pp. 165-67. 
10. ASTM C 490-04," Standard Practice for Use of Apparatus for the Determination of Length Change of Hardened Cement, Paste, Mortar, and Concrete ", 2004 Annual Book of ASTM Standards, Vol. 04.02, Concrete and Aggregates, American Society for Testing and Materials, pp. 266-270.

11. ASTM C 494M-04," Specification for Chemical Admixtures for Concrete", 2004 Annual Book of ASTM Standards, Vol. 04.02, Concrete and Aggregates, American Society for Testing and Materials, pp. 271-279.

12. ASTM C 618-03," Standard Test Method for Coal Fly Ash and Raw or Calcined Natural Pozzolan for use as a Mineral Admixture in Concrete", 2004 Annual Book of ASTM Standards, Vol.04.02, Concrete and Aggregates, American Society for Testing and Materials, pp. 319-325.

13. ASTM C 494M-04," Standard specification for Ground Granulated Blast Furnace Slag for Use in Concrete and Mortar", 2004 Annual Book of ASTM Standards, Vol. 04.02, Concrete and Aggregates, American Society for Testing and Materials, pp. 528-532.

14. ASTM C 1240-04," Standard Test Method for Use of Silica Fume as Mineral Admixture in Hydraulic-Cement Concrete, Mortar and Grout", 2004 Annual Book of ASTM Standards, Vol. 04.02, Concrete and Aggregates, American Society for Testing and Materials, pp. 662-668.

15. Bazaara, M.S., Sherali, H.D., Shetty, C.M., 2006. Nonlinear programming: theory and algorithms. John Wiley and Sons, Hoboken, NJ, USA.

16. Bazant, Z.P., 1995," Creep and shrinkage prediction model for analysis and design of concrete structures-model B3", Materials and Structures, Vol. 28, pp. 357-365.

17. Bazant, Z. P., and Panula, L., 1978, "Practical prediction of time-dependent deformations on concrete", Materials and Structures (RILEM, Paris): Part I: "Shrinkage", Vol. 11 , pp. $307-316$.

18. Bazant, Z.P.; Wittman, F.H., Kim J.K. and Alou F., 1987, "Statistical Extrapolation of Shrinkage Data- Part I: Regression", ACI Materials Journal, Vol. 84, pp. 20-34. 
19. Bazant, Z.P.; Wittman, F.H., Kim J.K. and Alou F., 1987,"Statistical Extrapolation of Shrinkage Data- Part II: Bayesian Updating", ACI Materials Journal, Vol. 84, pp. 83-91.

20. Bentz, D. P., 1995, " A Three-Dimensional Cement Hydration and Microstructural Program. I. Hydration Rate, Heat of Hydration and Chemical Shrinkage", NISTIR 5756, http://ciks.cbt.nist.gov/bentz/nistir5756/node15.html. Last accessed 1st November 2010.

21. Bentz, Dale P.; Quenard, Daniel A.; Baroghel-Bouny, Veronique, Garboczi, Edward J.; Jennings, H.M., 1995,"Modeling drying shrinkage of cement paste and mortar Part 1. Structural models from nanometers to millimeters", Materials and Structures, Vol. 28, pp. 450-458.

22. Bentz, D. P. Virtual Cement and Concrete Testing Laboratory (VCCTL) Consortium: Questions and Answers, Building and Fire Research Laboratory, National Institute of Standards and Technology 2000.

23. Bissonnette, B.; Marchand J.; Charron J. P.; Delagrave, A. and Barcelo, L., 2001," Early Age Bahavior of Cement-Based Materials", Material Science of Concrete VI, Edited by Mindess, S. and Skalny, J., The American Ceramic Society.

24. Brooks, J.J., 1989, " Influence of mix proportions, plasticizers and superplasticizers on creep and drying shrinkage of concrete", Magazine of Concrete Research, Vol. 41, No. 148, pp. 145-154.

25. Brooks, J.J. and Neville, A.M., 1992, "Creep and shrinkage of concrete as affected by admixtures and cement replacement materials", Creep and Shrinkage of Concrete: Effect of Materials and Environment, ACI SP-135, pp. 19-36.

26. CEB-FIP Model Code, 1990.

27. Chindraprasirt, P., Jaturapitakul, C., and Sinsiri, T, 2005, "Effect of fly ash fineness on compressive strength and pore size of blended cement paste", Cement and Concrete Composites, Vol. 27, pp. $425-428$.

28. Diamond, Sidney, 2004, "The microstructure of cement paste and concrete- a visual primer", Cement and Concrete Composites, Vol. 26, pp. 919-933. 
29. Daimon, M.; Abo-el-enein, S.A.; Hosaka, G.; Goto, S. and Kondo, R., 1977, "Pore Structure of Calcium Silicate Hydrate in Hydrated Tricalcium Silicate", Journal of the American Ceramic Society, Vol. 60, No.3-4, pp. 110-114.

30. Drud, A., CONOPT User Guide. ARKI Consulting and Development A/S, Bagsvaerd, Denmark. Available at: http://www.gams.com/dd/docs/solvers/conopt.pdf. Last accessed 14th July 2010.

31. Eckardt, S. and Konke, C., 2006, "Simulation of damage in concrete structures using multiscale models", Computational Modeling of Concrete Structures - Meschke, de Borst, Mang \& Bicanic (eds), Taylor \& Francis Group, London.

32. Eguchi, K. and Teranishi, K., "Prediction equation of concrete based on composite model", Cement and Concrete Research, Vol. 35, 2005, pp. 483 - 493.

33. Famy, C., Brough, A. R., and Taylor, H. F. W., 2003, "The C-S-H gel of Portland cement mortars: Part I. The interpretation of energy-dispersive X-ray microanalyses from scanning electron microscopy, with some observations on C-S-H, AFm and AFt phase compositions", Cement and Concrete Research, Vol. 23, pp. 1389 - 1398.

34. Feng, X., Garboczi, E. J., Bentz, D. P., Stutzman, P. E., and Mason, T. O. , "Estimation of the Degree of Hydration of Blended Cement Pastes by a Scanning Electron Microscopy Point-Count Procedure", Cement and Concrete Research, Vol. 34, No. 10, 2004, pp. $1787-1793$.

35. Feldman, R.F. and Sereda, 1968," A model for Hydrated Portland Cement Paste as Deduced from Sorption-Length Change and Mechanical Properties", Materials and Structures, Vol.1, No.6, pp. 509-519.

36. Ferraris, C.F. and Wittman, F.H., 1987, "Shrinkage mechanisms of hardened cement paste", Cement and Concrete Research, Vol. 17, pp. 453-464.

37. Gallucci, E., Mathur, P., and Scrivener, K., 2010," Microstructural Development of Early Age Hydration Shells Around Cement Grains", Cement and Concrete Research, Vol. 40, pp. $4-13$. 
38. Garboczi, E. J., 2000, "Modeling the linear elastic properties of portland cement paste", http://ciks.cbt.nist.gov/ garbocz/paper148/node7.htm. Last accessed 6th December 2010.

39. Gardner, N.J. and Lockman M.J., 2001, "Design Provision for Dying Shrinkage and Creep of Normal-Strength Concrete", ACI Materials Journal, Vol. 98, No. 3, pp. 236-246

40. Gardner, N.J. and Zhao, J.W., 1994, "Creep and Shrinkage Revisited", ACI Materials Journal, Vol. 90, No. 1, pp. 3-10.

41. Harrison, A.M., Taylor, H.F.W., and Winter, N.B., 1985, Cement and Concrete Research, Vol. 15, pp. 775.

42. Hashin, Z. and Shtrikman, S., "A variational approach to the theory of the elastic behavior of multiphase materials", Journal of the Mechanics and Physics of Solids, Vol. 11, 1963 , pp. $127-140$.

43. Holt, E.E., "Early Age Autogenous Shrinkage of Concrete", Technical Research Center of Finland, ESPOO, 2001.

44. Hua, C.; Acker, P. and Ehrlacher, A., 1995, "Analysis and model of autogenous shrinkage of hardening cement paste - Part I: Modeling at macroscopic scale", Cement and Concrete Research, Vol. 25, Nos. 10, pp. 1457-1468.

45. Huo, X.S.; Al-Omaishi, Nabil and Tadros M.K., 2001, "Creep, Shrinkage and Modulus of High Performance Concrete", ACI Materials Journal, Vol. 98, No. 6, pp. 440-449.

46. Jennings, H.M., " A model for microstructure of calcium silicate hydrate in cement paste", Cement and Concrete Research, Vol. 30, 2000, pp. 101-116.

47. Jennings, H.M. and Johnson, S.K, 1986," Simulation of Microstructure Development during the Hydration of a Cement Compound", Journal of American Ceramic Society, Vol. 69, No.11, pp. 790-795. 
48. Juenger, Maria C.G and Jennings, H.M, 2002," Examining the relationship between the microstructure of calcium silicate hydrate and drying shrinkage of cement paste", Cement and Concrete Research, Vol.32, pp. 289-296.

49. Khan, B. Kh., Kravchenko, I. A., Bogatyreva, Zh. D., and Khorunzhii, V. Ya., "Crystallization properties of glasses based on ferronickel slag", Glass and Ceramics, Vol. 42, No. 2, 1985, pp. 4 - 6.

50. Khatri, R.P. and Sirivivatnanon, V. and Gross, W. 1995,"Effect of Different Supplementary Cementitous materials on mechanical properties of high performance concrete", Cement and Concrete Research, Vol. 25, No. 1, pp. 209-220.

51. Kishitani, K. and Baba, A., 1975, "Mechanism of Drying Shrinkage for Construction Material", Cement and Concrete, Vol. 346, pp. $29-40$.

52. Kristmann, M., 1977, Cement and Concrete Research, Vol. 7, pp. 649.

53. Maekawa, K., Ishida, T., Kishi, T., Multiscale Modeling of Structural Concrete, Taylor \& Francis, London and New York 2009.

54. Maekawa, K., Ishida, T., Kishi, T., "Multiscale Modeling of Structural Concrete, Integrated Material and Structural Mechanics", Journal of Advanced Concrete Technology Vol. 1, No. 2, 2003, pp. $91-126$.

55. Maekawa, K., Chaube, R., Kishi, T., Modeling of Concrete Performance, Hydration, Microstructure Formation and Mass Transport, E \& FN Spon, London 1999.

56. Matsunaga, T., Kim, J.K., Hardcastle, S., and Rohatgi, P.K., "Crystallinity and selected properties of fly ash particles", Materials Science and Engineering, Vol. 325, 2002, pp. 333-343.

57. Mehta, P. K., 1986, Concrete Structure, Properties and Materials, Prentice Hall, New Jersey.

58. Mehta, P. K., and Monteiro, P., 2005, Concrete Microstructure, Properties and Materials, Third Edition, McGraw Hill Professional Publishing. 
59. Mindess, S. and Young, J. F., 1981, Concrete, Prentice Hall, Inc., New Jersey.

60. McDonald, David B. and Roper Harold, 1993, "Accuracy of Prediction Models for Shrinkage of Concrete", ACI Materials Journal, Vol. 90, No. 3, pp. 265-272.

61. Mounanga, P., Khelidj, A., Loukili, A., Baroghel-Bouny, V., "Predicting $\mathrm{Ca}(\mathrm{OH})_{2}$ Content and Chemical Shrinkage of Hydrating Cement Pastes Using Analytical Approach", Cement and Concrete Research, Vol. 34, 2004, pp. 255 - 265.

62. Neubauer, C.M., Jennings, H.M., and Garboczi, E.J., "A three phase model of the elastic and shrinkage properties of mortar", Advanced Cement Based Materials, Vol. 4, 1996, pp. $6-20$.

63. Neville, A.M, 1996, Properties of Concrete, Addison Wesley Longman Limited, Harlow, England, 4th Edition.

64. Pickett, G., 1956, "Effect of aggregate on shrinkage of concrete and a hypothesis concerning shrinkage", Journal of ACI, Vol. 27, No. 5, pp. 581-590.

65. Powers, T.C., 1949, "The Nonevaporable Water Content of Hardened PortlandCement Paste-Its Significance for concrete Research and Its method of Determination", ASTM Bulletin, May 1949, pp. 68-76.

66. Powers, T.C., 1986, The properties of Fresh Concrete, John Wiley and Sons, Inc.

67. Ramachandran, V.S. and Beaudoin, J.J., 2001, Handbook of Analytical Techniques in Concrete Science and Technology, William Andrews Publishing.

68. Rilem TC 107-CSP, 1998, "Measurement of time-dependent strains of concrete", Materials and Structures, Vol. 31, October 1998, pp. 507-512.

69. Richardson, I.G., 1999, "The nature of C-S-H in hardened cements", Cement and Concrete Research, Vol. 29, pp.1131-1147. 
70. Rosenthal, R.E., 2008. GAMS - A user Guide. Gams Development Corporation, Washington D.C., USA.

71. Russsell. H.G., 1999,"ACI Defines High-Performance Concrete", Concrete International, Vol. 21, No.2, pp-56-57

72. Sarkar, S. L. and Ghosh, S. N. , Progress in Cement and Concrete, Mineral Admixture in Cement and Concrete, Volume 4, $1^{\text {st }}$ edition, Akademia Books International, New Delhi 1993.

73. Smadi, Mohammad M.; Slate Floyd O. and. Nilson, Arthur H, 1987,"Shrinkage and Creep of High-, Medium-, and Low-Strength Concretes, Including Overloads", ACI Materials Journal, Vol. 96, pp. 224-234.

74. Taylor, H.F.W, 1986," Proposed Structure for Calcium Silicate Hydrate Gel", Journal of the American Ceramic Society, Vol. 69, Issue 6, pp. 464-467.

75. Taylor, H.F.W., 1997, Cement Chemistry, 2nd Edition, Thomas Telford.

76. Tennis, Paul D. and Jennings, H.M., 2000, "Model for two types of calcium silicate hydrate in the microstructure of Portland cement pastes", Cement and Concrete Research, Vol. 30, pp. 855-863.

77. Velez, K., Maximilien, S. , Damidot, D. , Fantozzi, G. , Sorrentino F., "Determination by nanoindentation of elastic modulus and hardness of pure constituents of Portland cement clinker", Cement and Concrete Research, Vol. 31, No. 4, 2001, pp. 555-561.

78. Videla, Carlos; Covarrubias, Juan Pablo and Masana, Cristian, , 2004, "Updating Concrete Drying-Shrinkage Prediction Models for Local Materials", ACI Materials Journal, Vol. 101, No. 3, pp. 187-198.

79. Wittman, F.H, 1973," Interaction of Hardened Cement Paste and Water", Journal of the American Ceramic Society, Vol. 56, Issue 8, pp. 409-415. 
80. Wong, H. S., "Determining the Water-Cement Ratio, Cement Content, Water Content and Degree of Hydration of Hardened Cement Paste: Method Development and Validation on Paste Samples", Cement and Concrete Research, Vol. 39, No. 10, 2009, pp. 957 - 965.

81. Xi, Y., Willam, K., and Frangopol, D., 2000, "Multiscale Modeling of Interactive Diffusion Processes of Concrete", Journal of Engineering Mechanics, ASCE, Vol. 126, No. 3, pp. $258-265$.

82. Yamaguchi, G. and Takagi, S., 1969, in $5^{\text {th }}$ ISCC, Vol. 1, pp. 181. 


\section{APPENDIX}

Plots for comparison of experimental and predicted data for C-S-H(I) and C-S-H(II) based on optimized values of $n$ and $n$ ':

\section{Mix: 45\% slag}
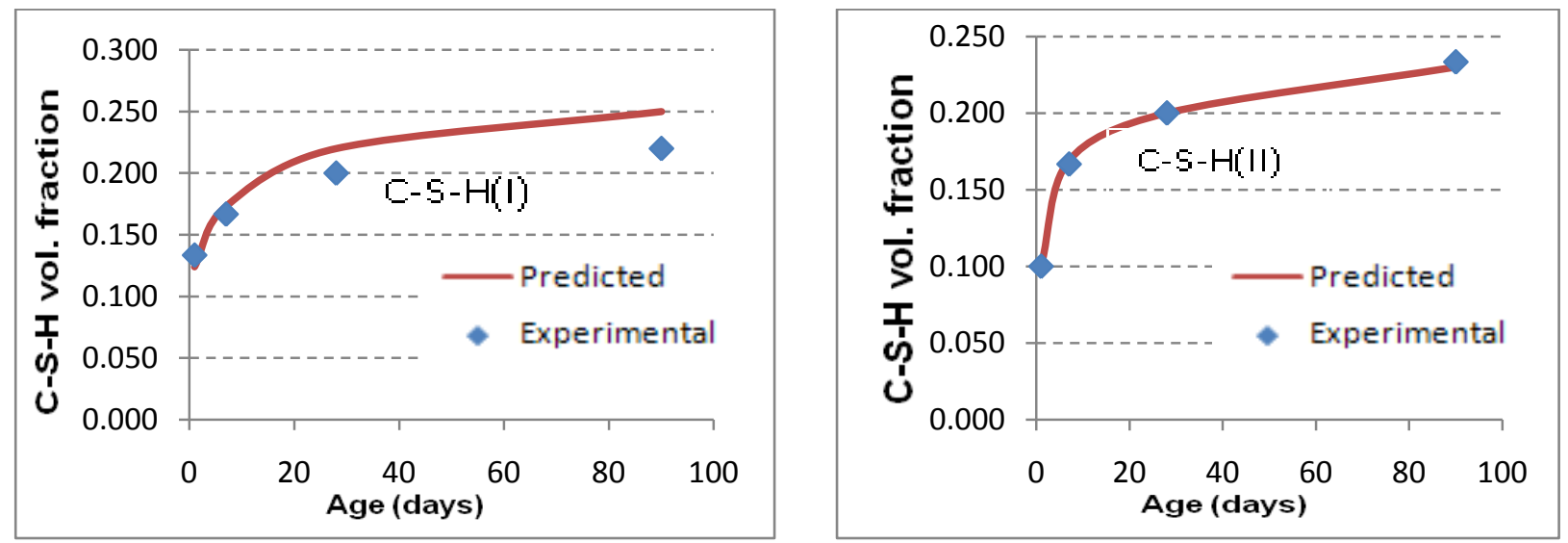

(a) $\mathrm{w} / \mathrm{cm}=0.3$
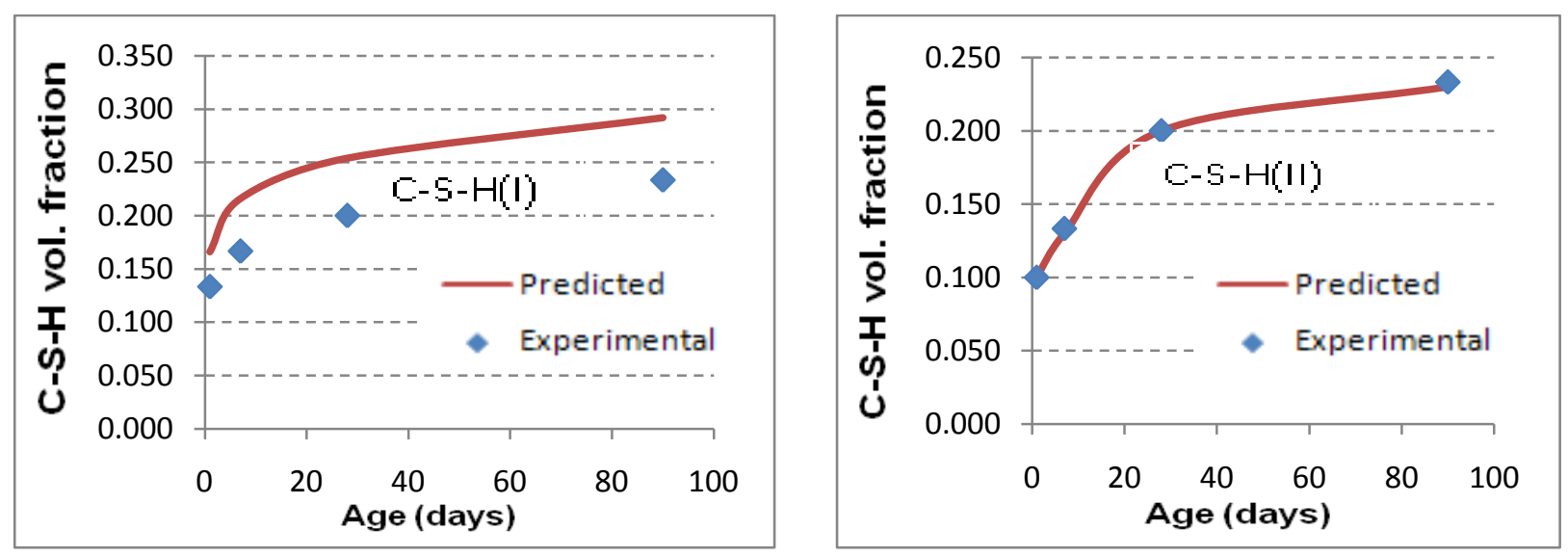

(b) $w / c m=0.4$ 
Mix: $35 \%$ fly ash
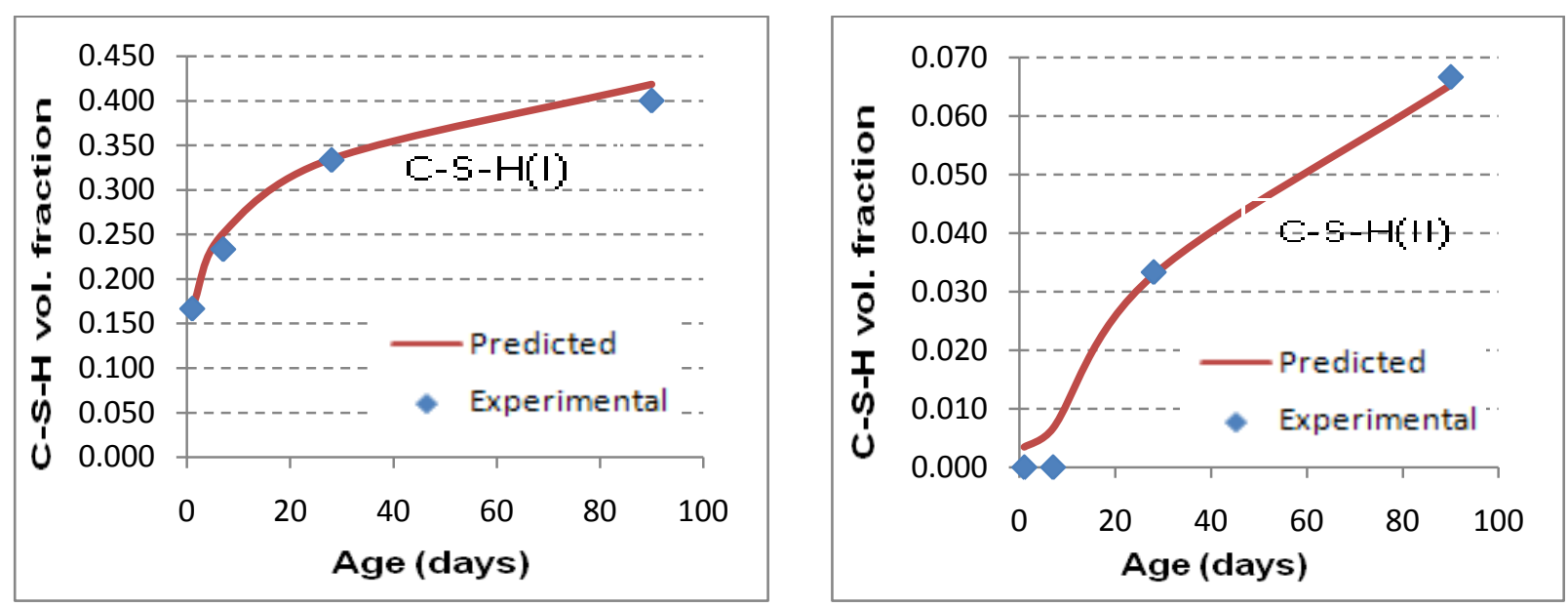

(a) $\mathrm{w} / \mathrm{cm}=0.3$
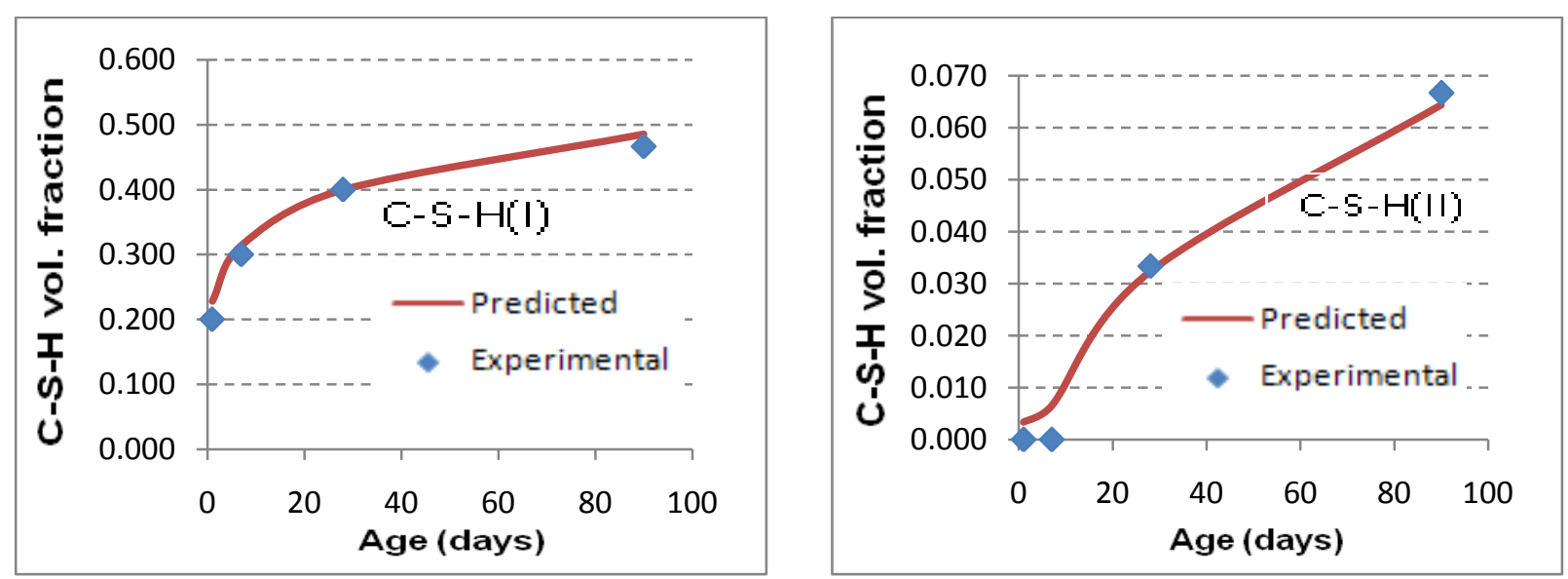

(b) $w / c m=0.4$ 
Mix: $35 \%$ slag, $15 \%$ fly ash
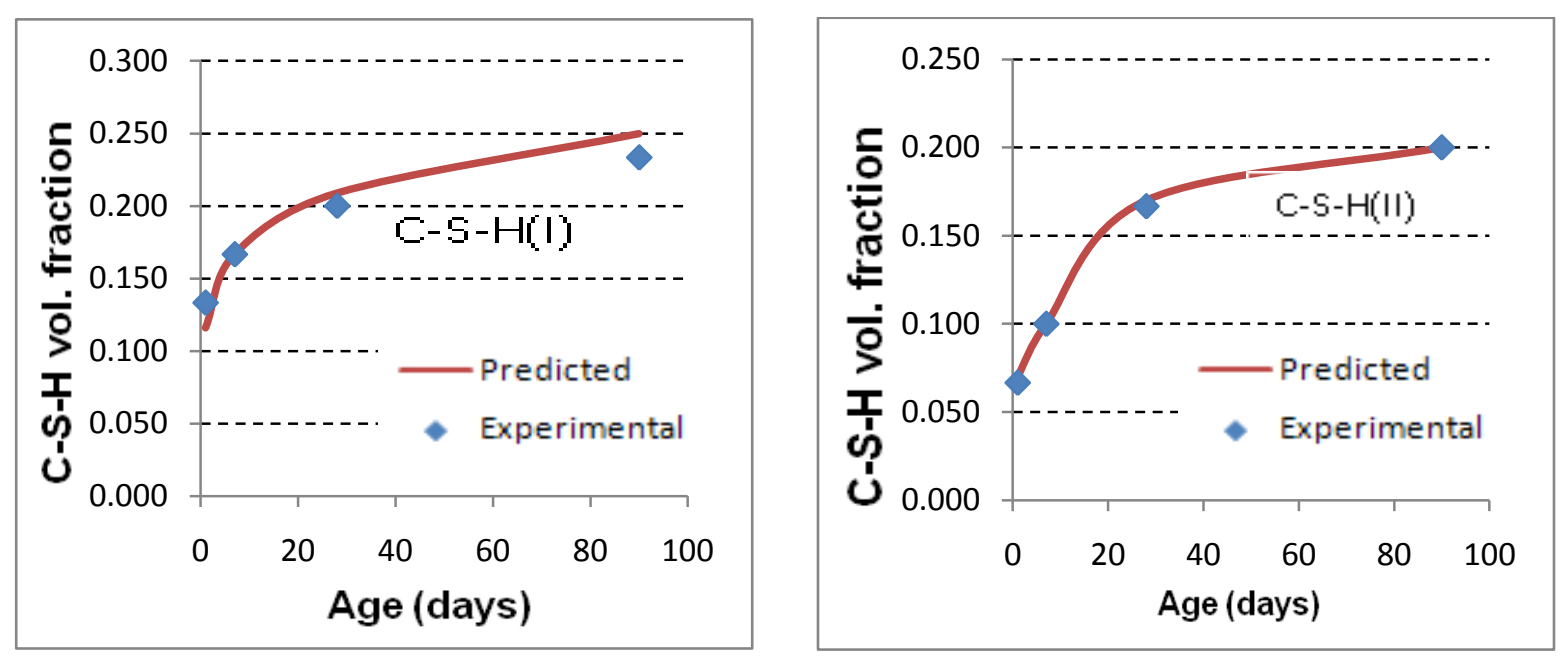

(a) $w / c m=0.3$
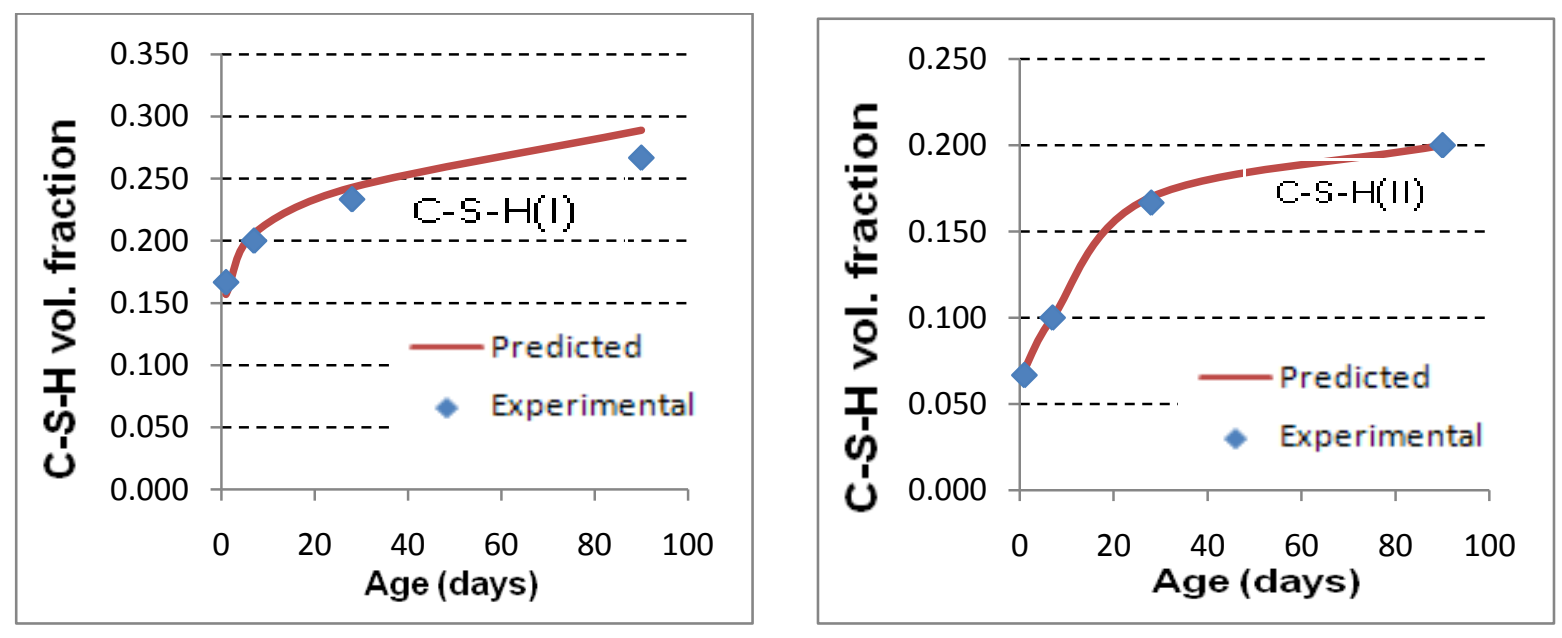

(b) $w / c m=0.4$ 
Plots for variation of C-S-H(I) and C-S-H(II) and the total C-S-H volumes with time for different proportions of SCM and different $w / \mathrm{cm}$ ratios:
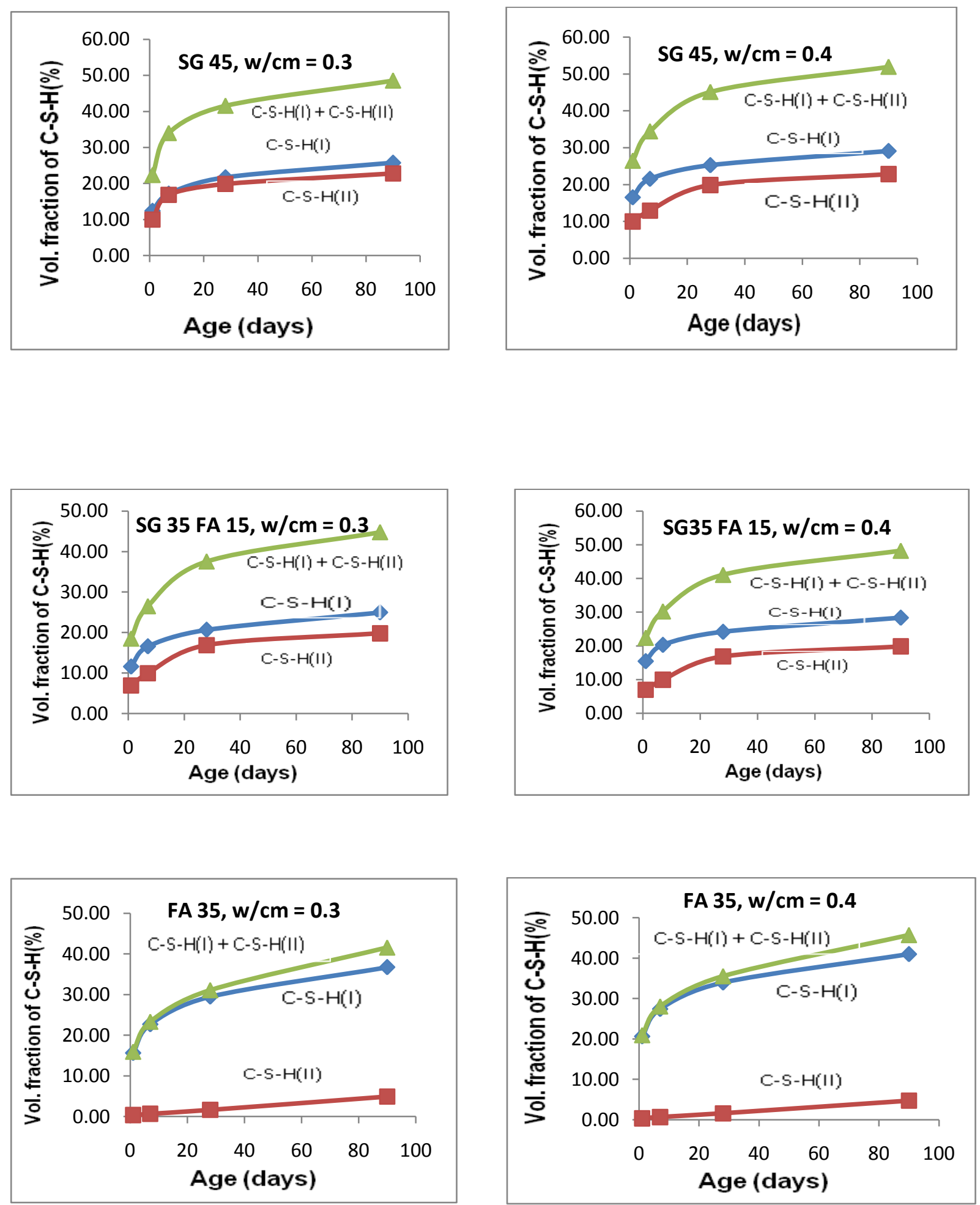

Plots for variation of pore volumes with time for different proportions of SCM and different $\mathrm{w} / \mathrm{cm}$ ratios: 

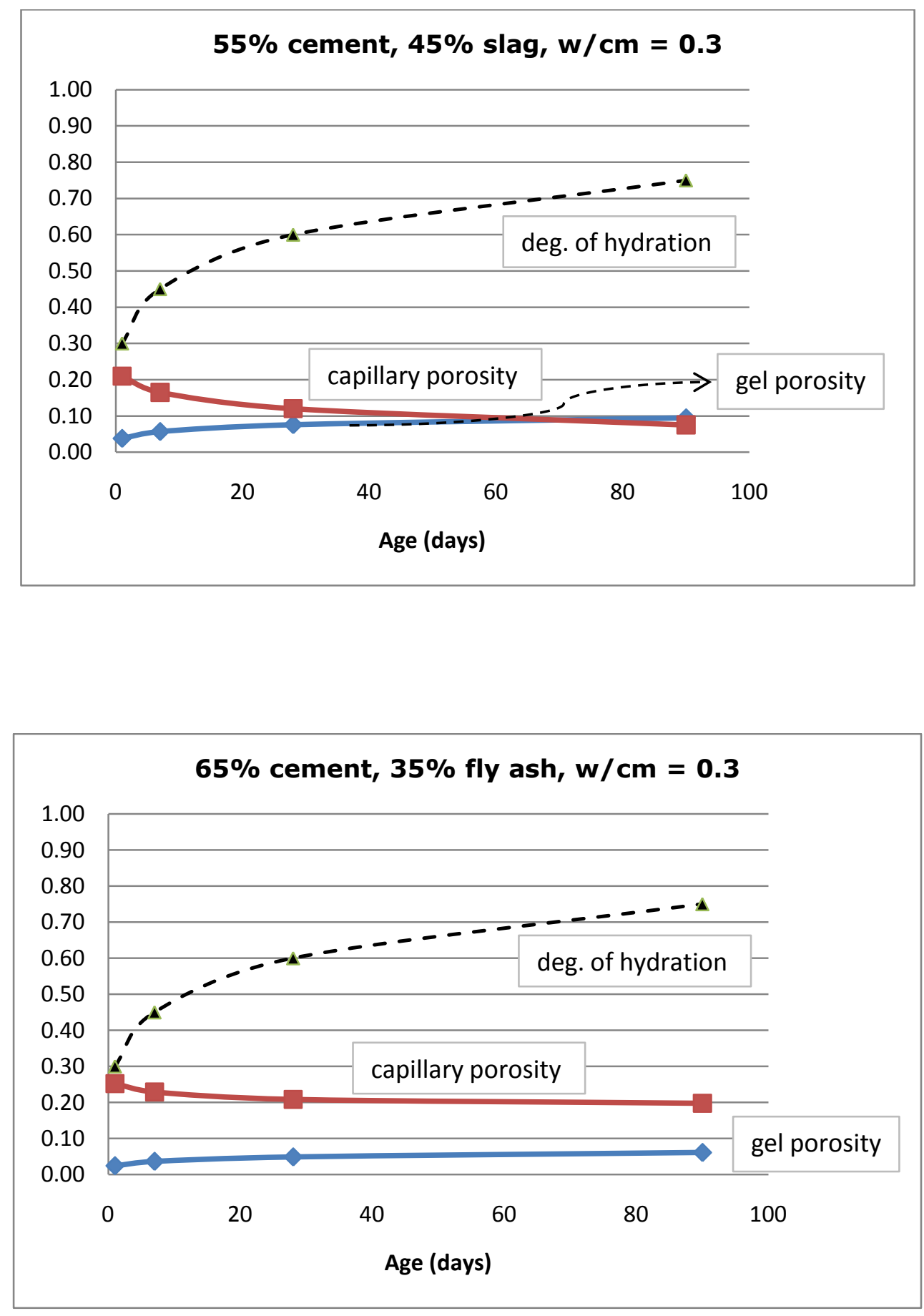

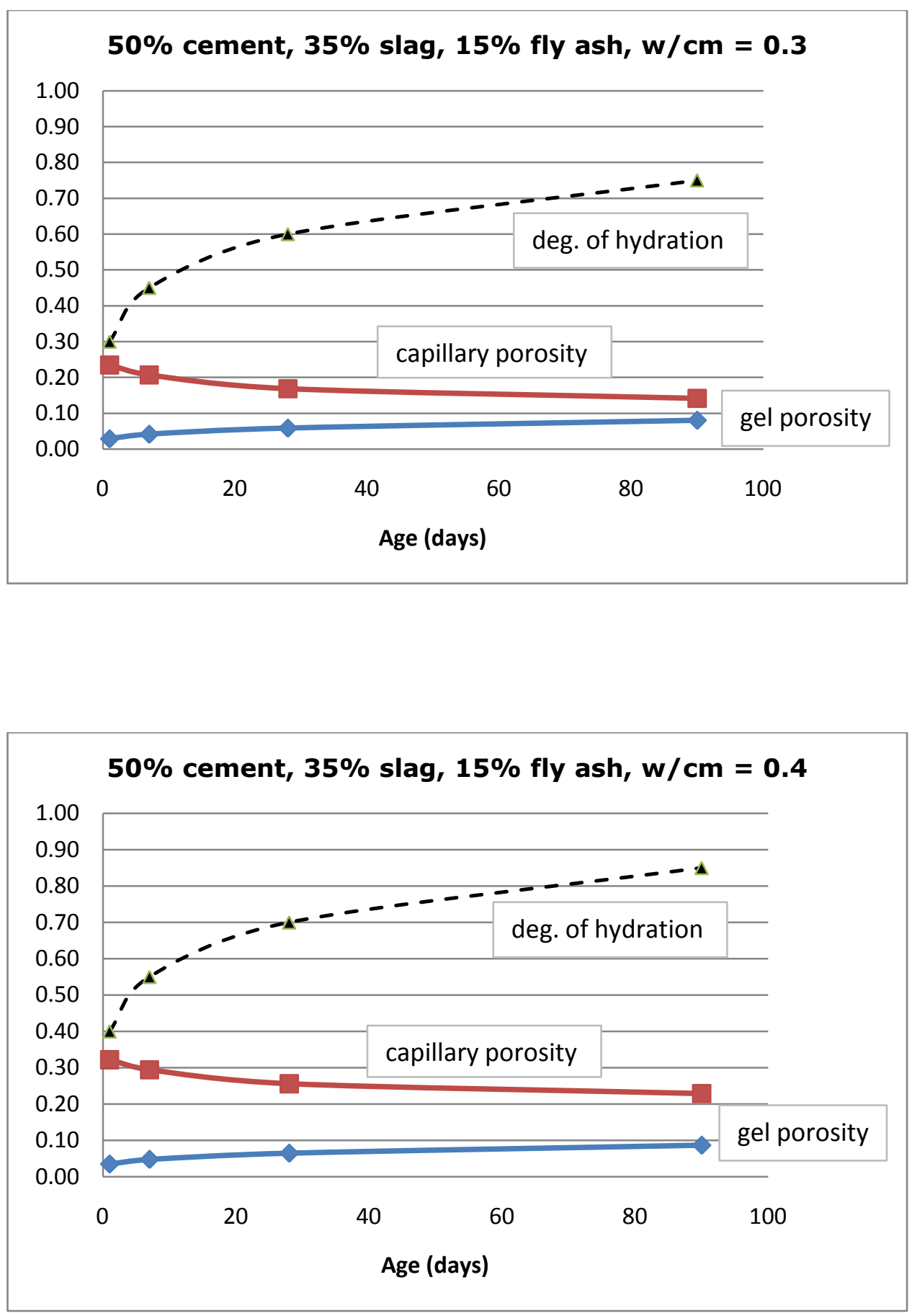


\section{Plots for isothermal calorimetry:}
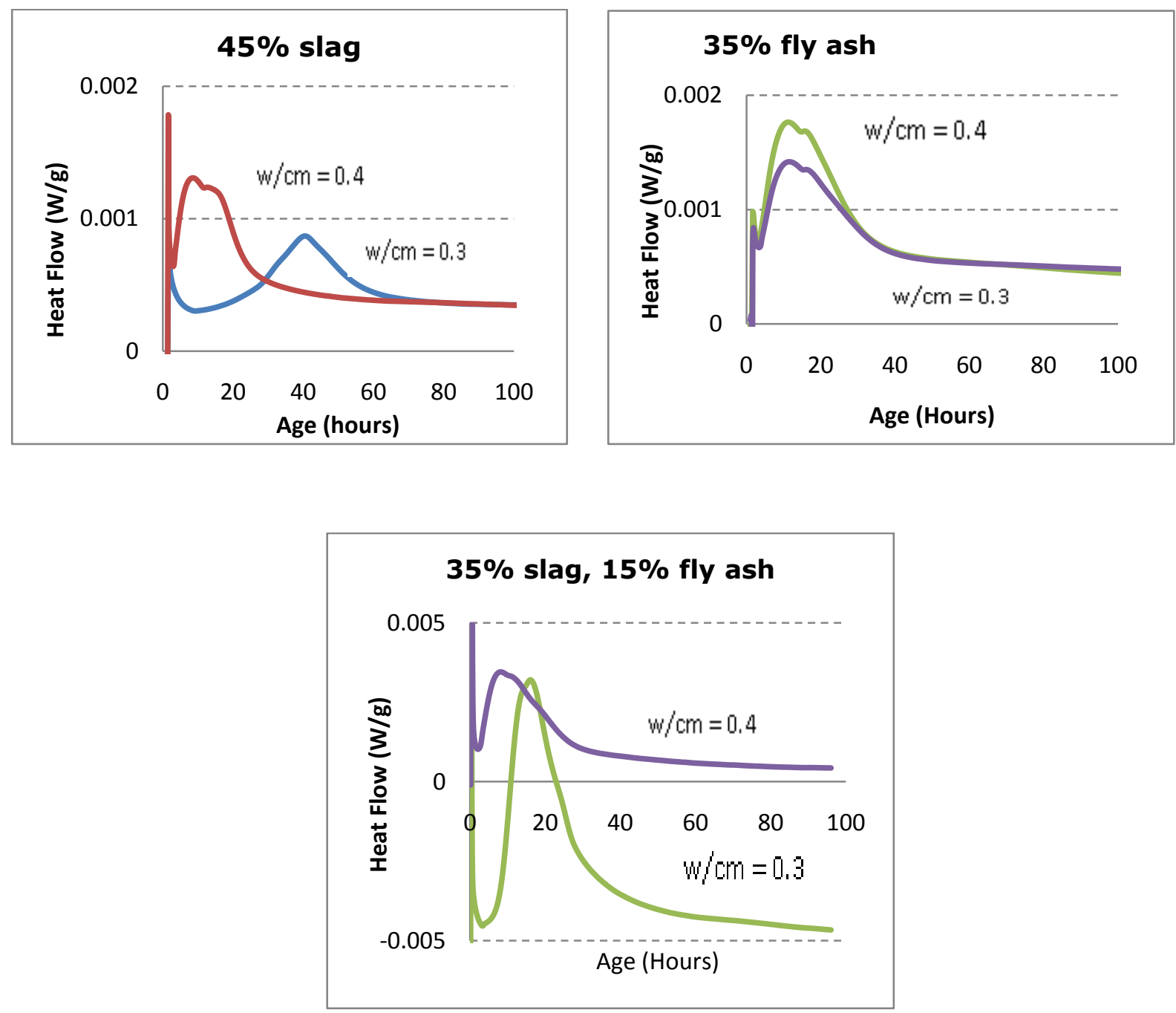
Plots for comparison with proposed model:
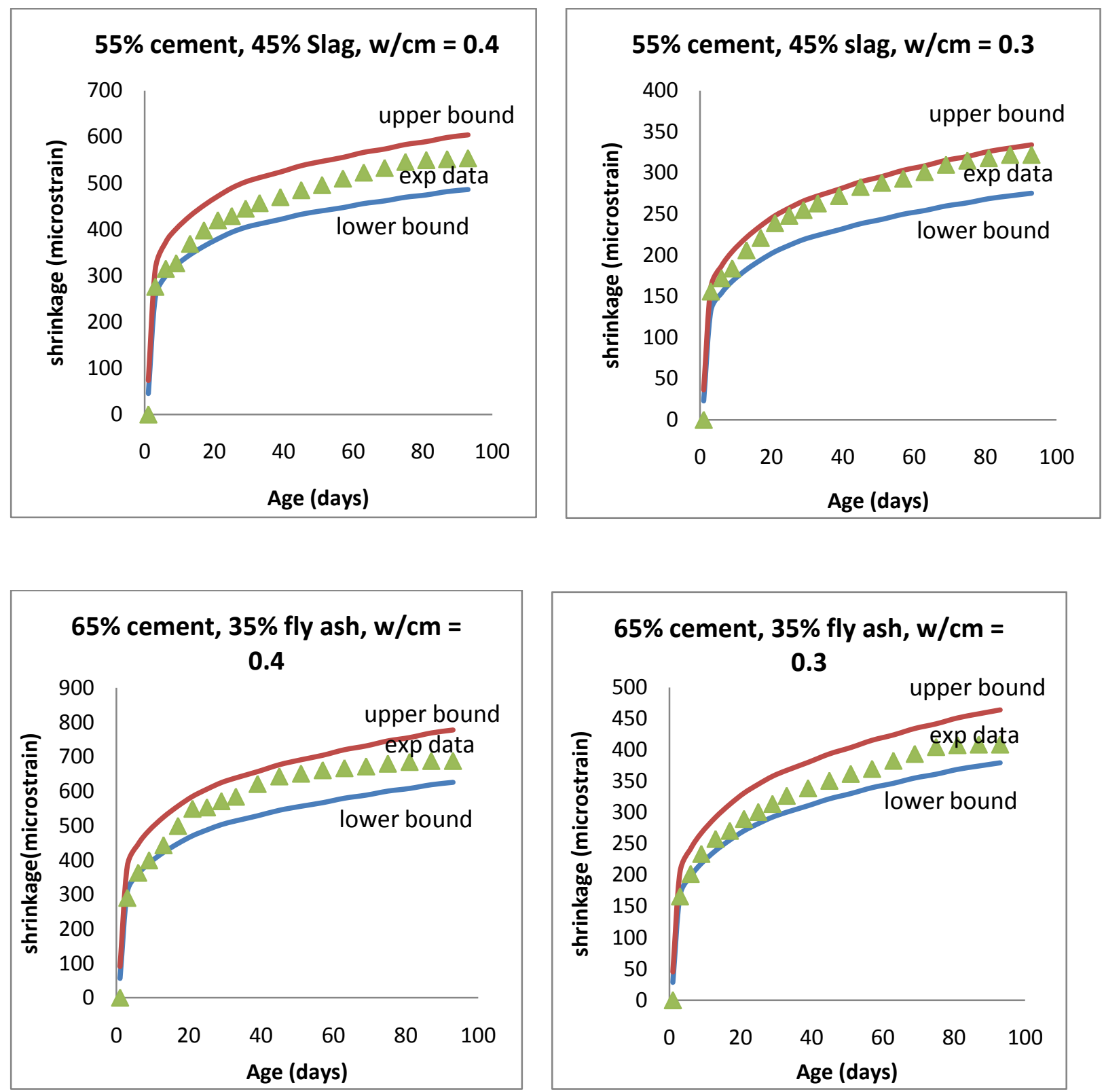

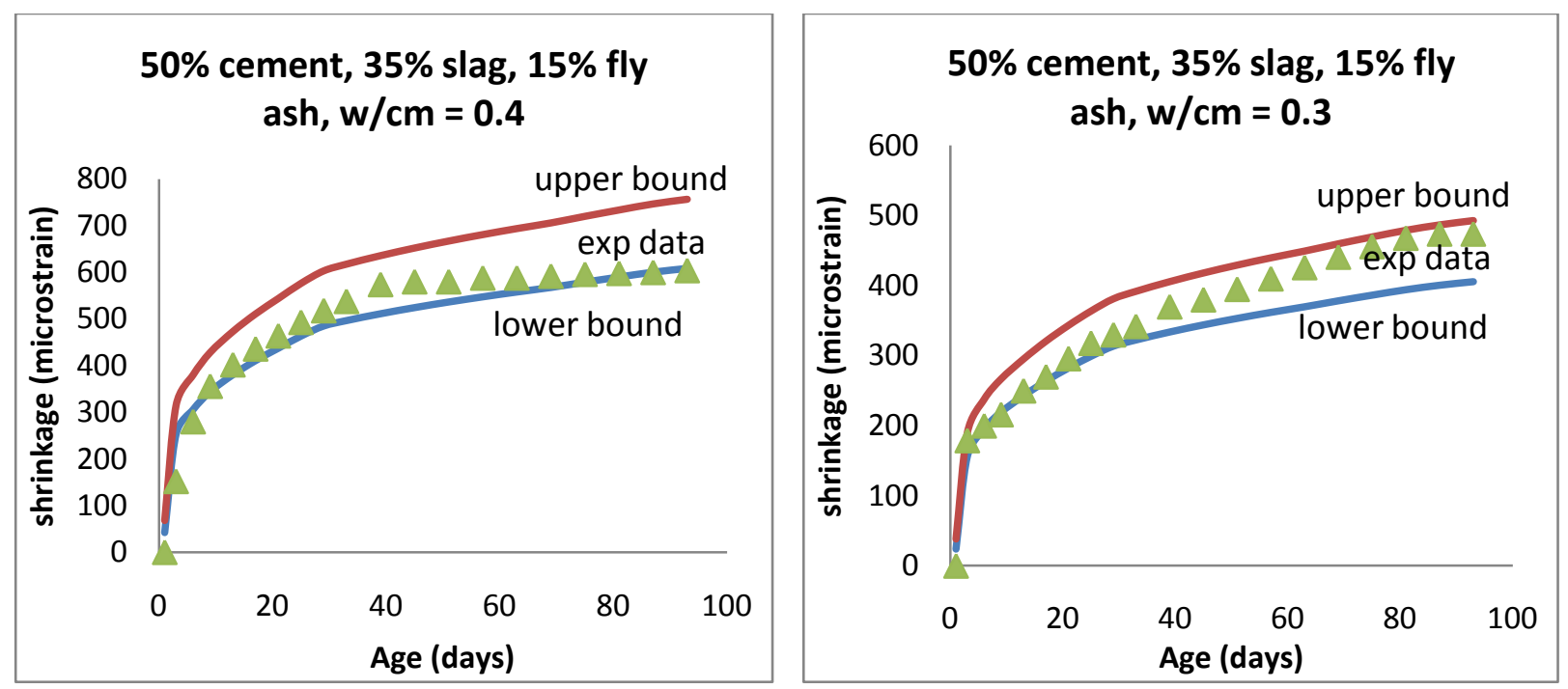

\section{Plots for residuals:}
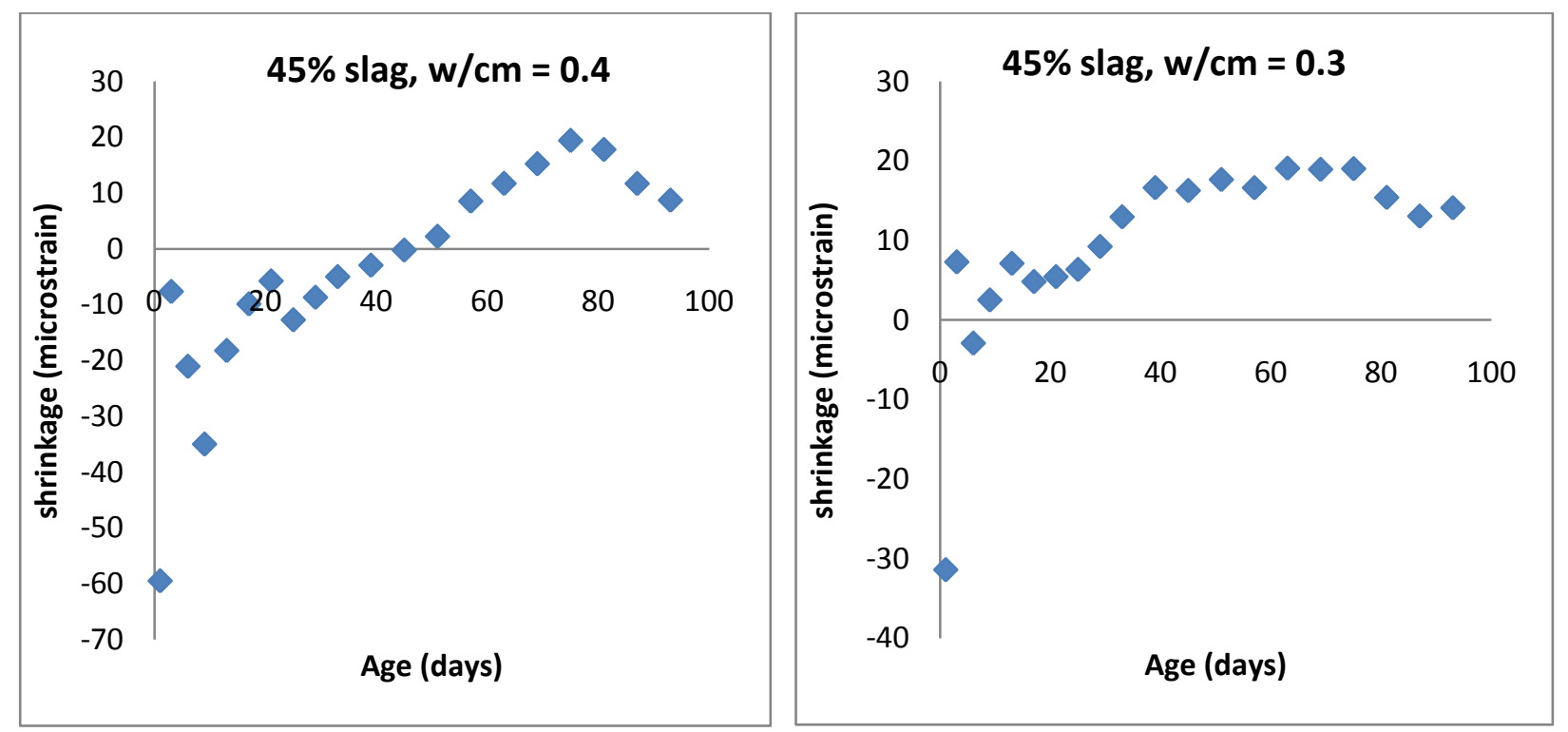

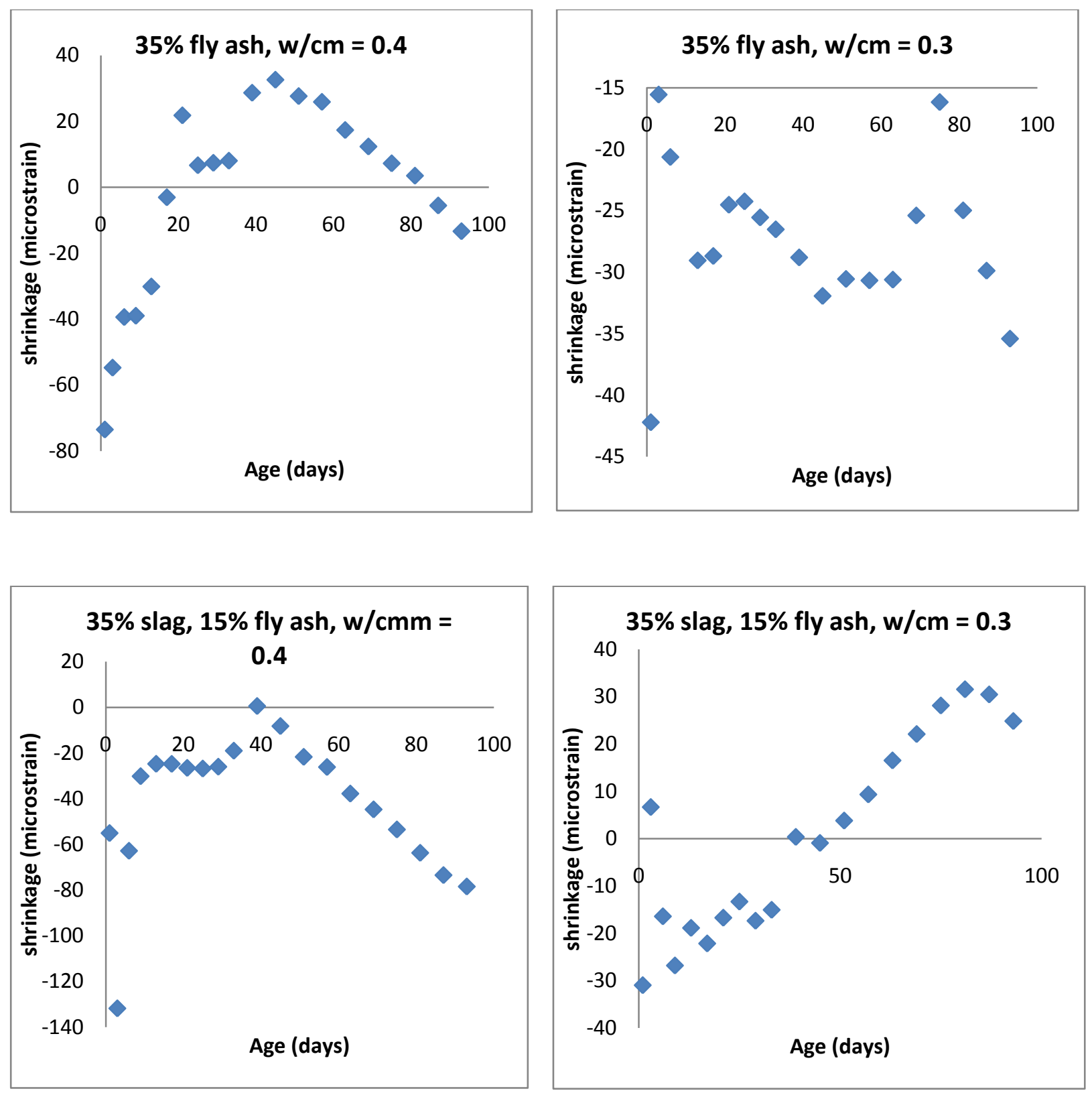
Plots for comparison with available models:
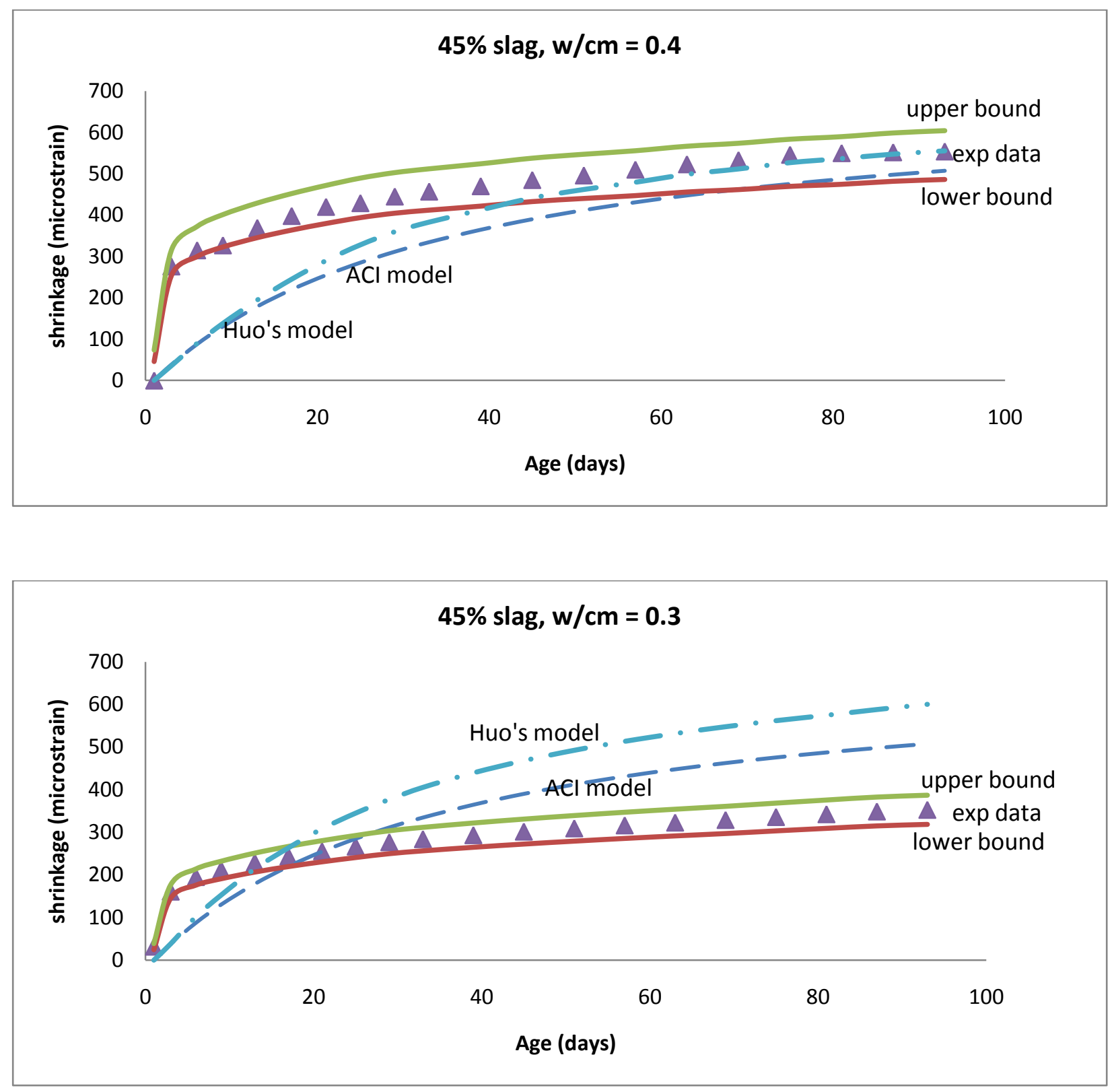

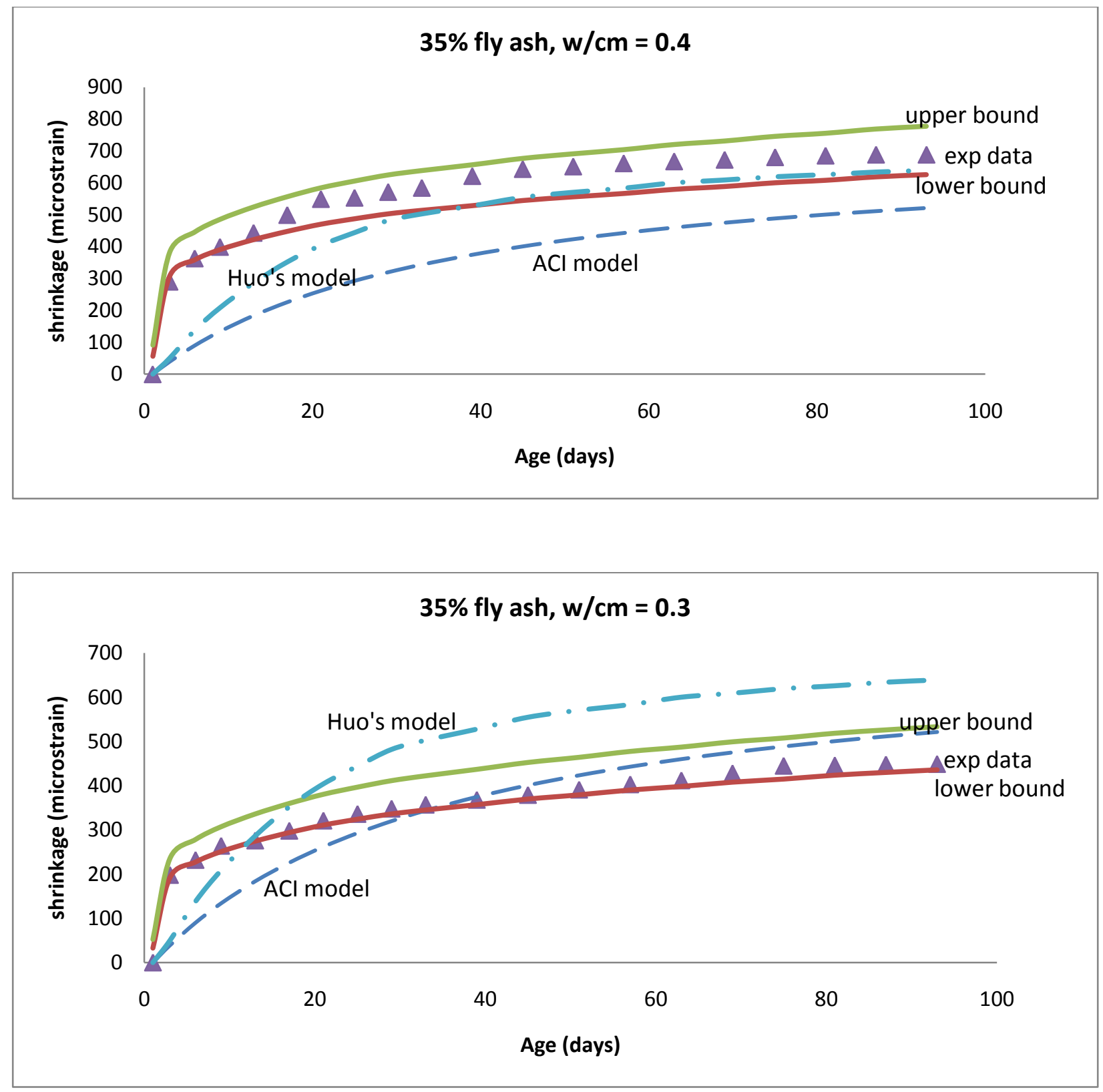

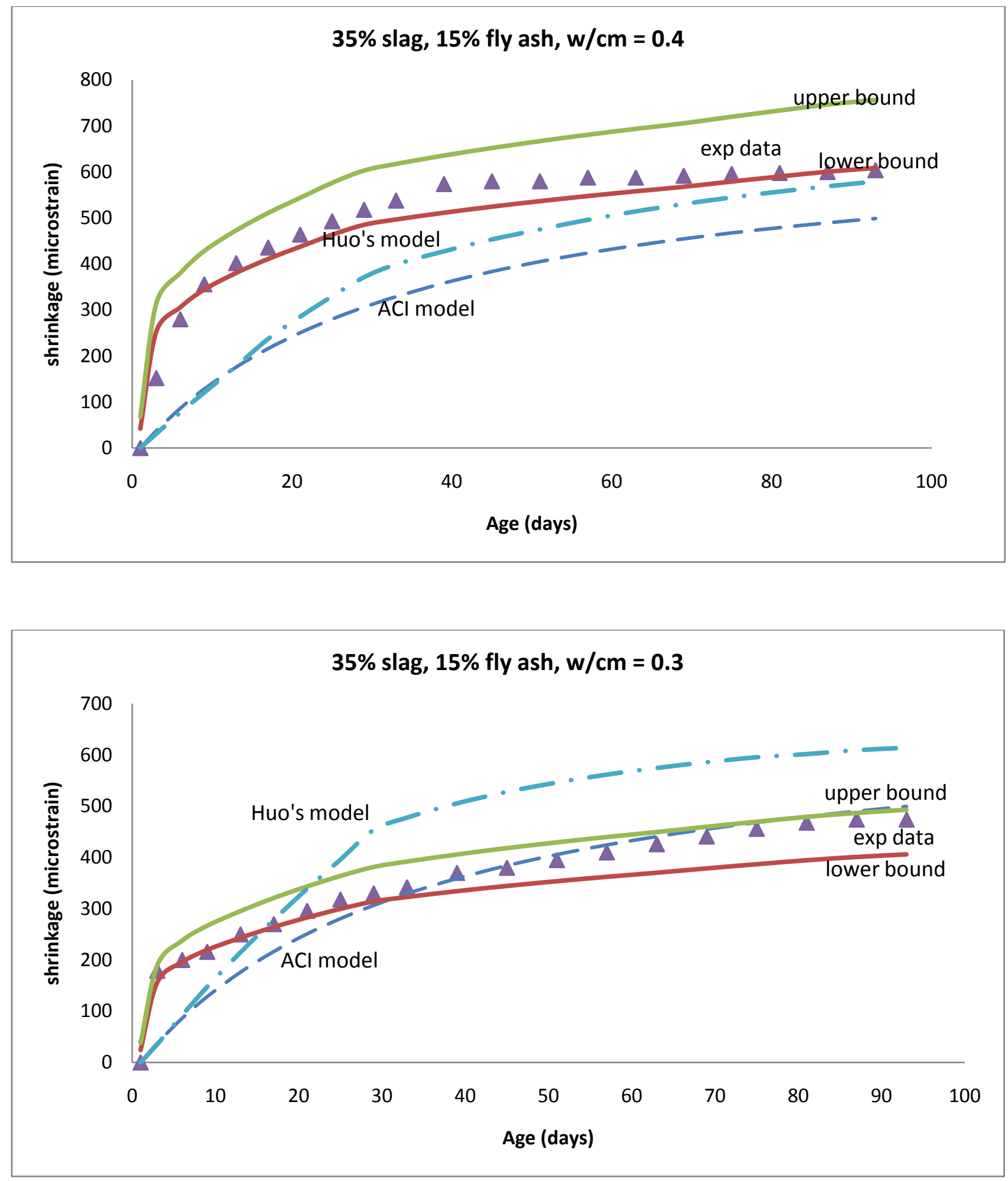

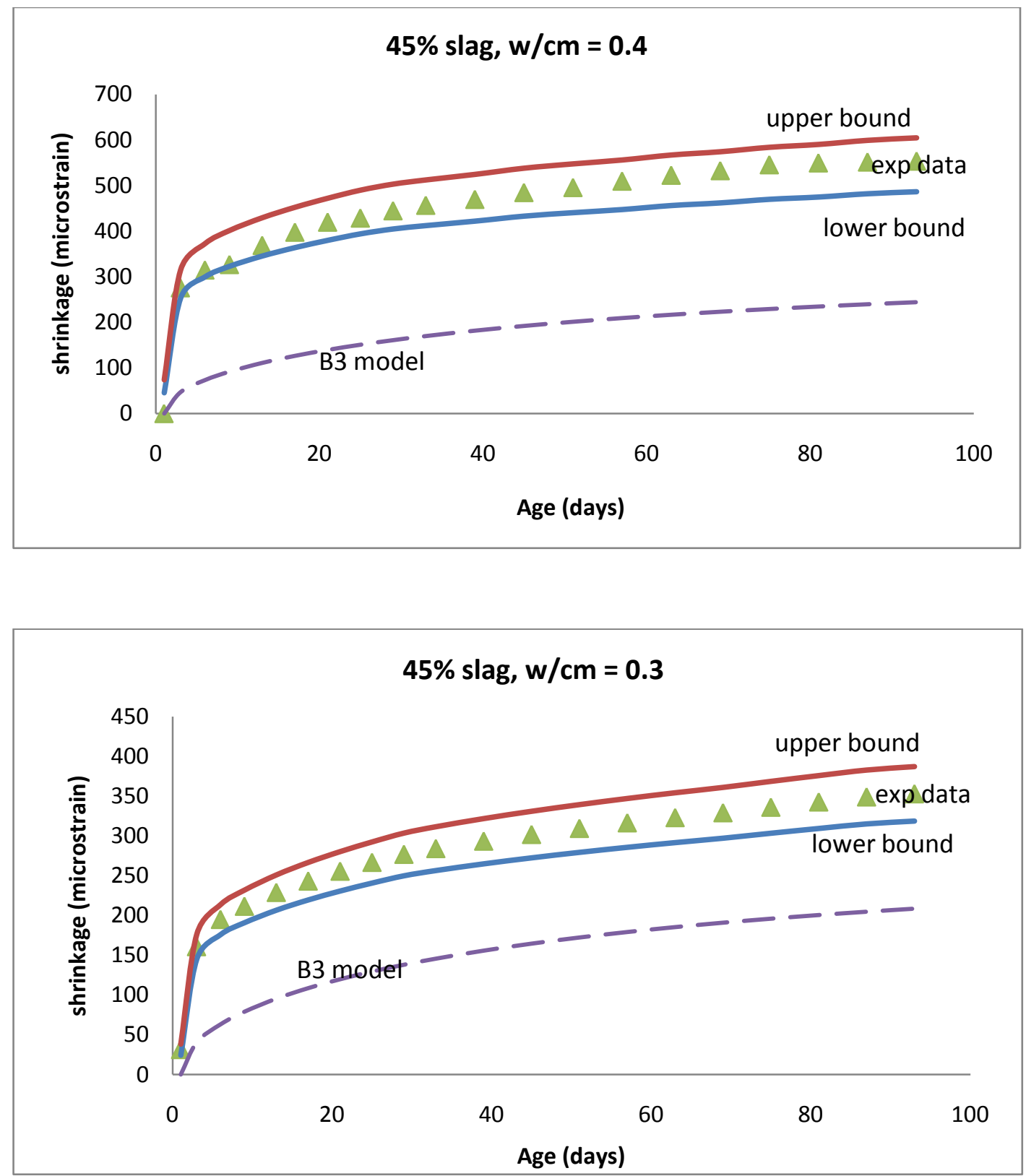

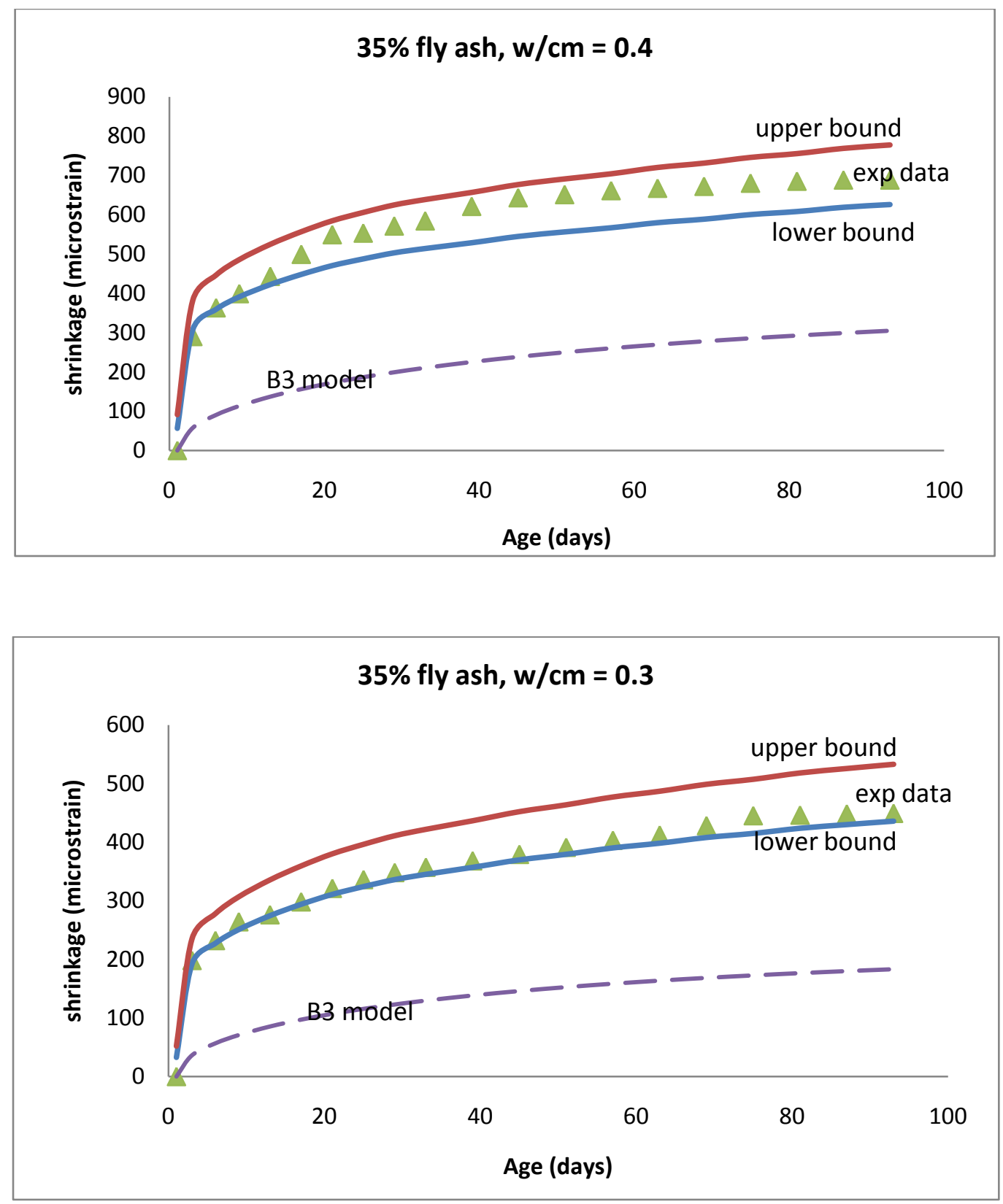

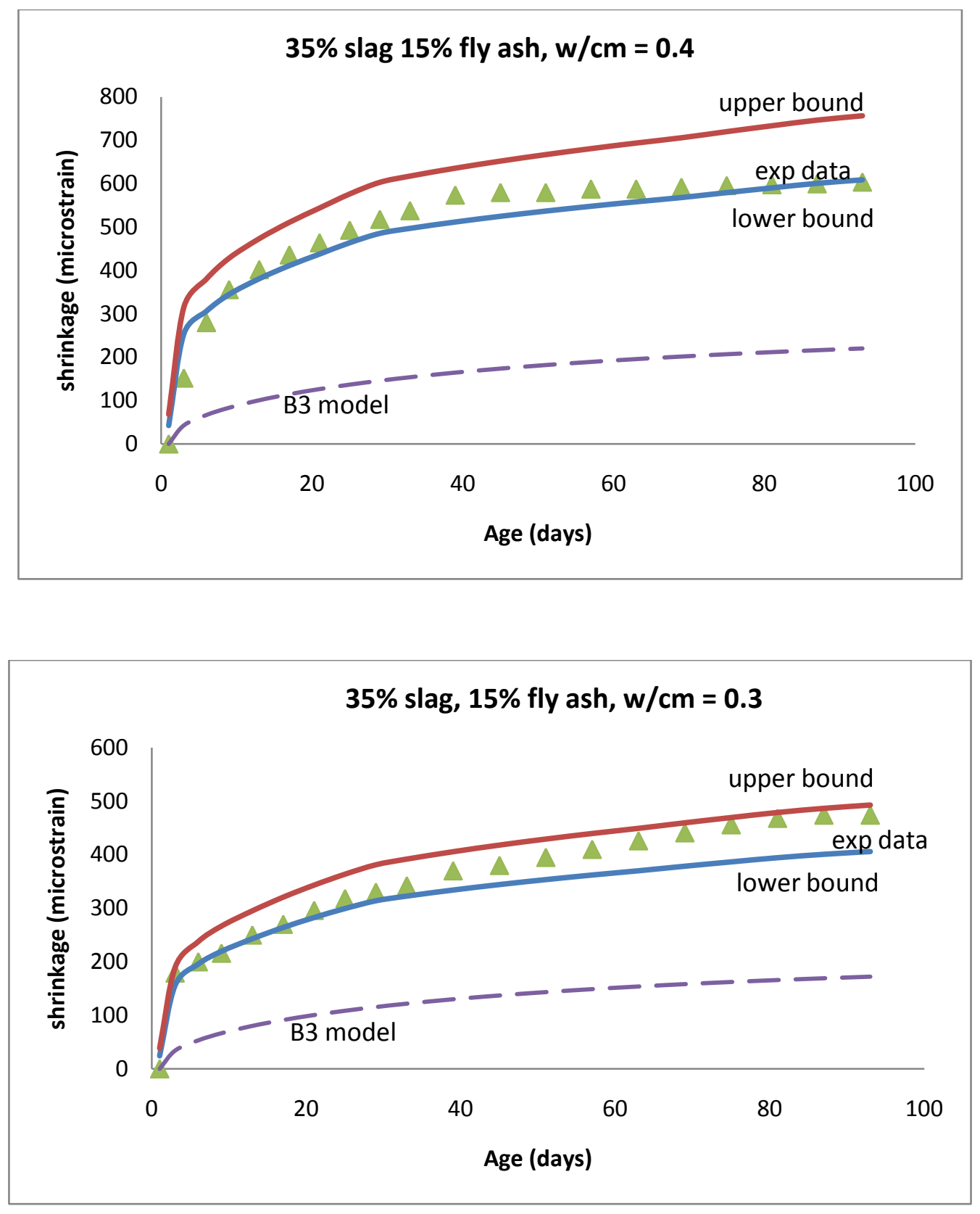

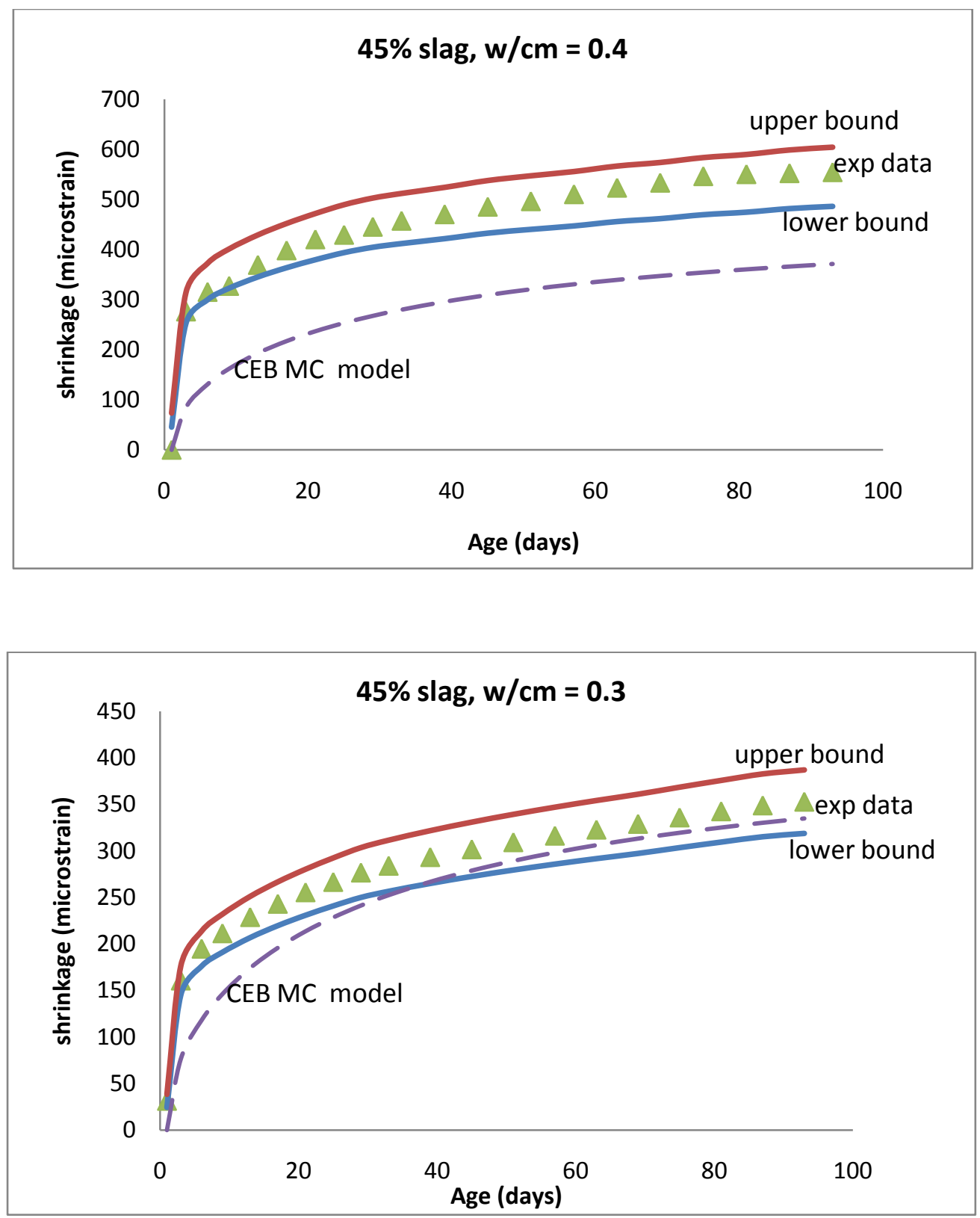

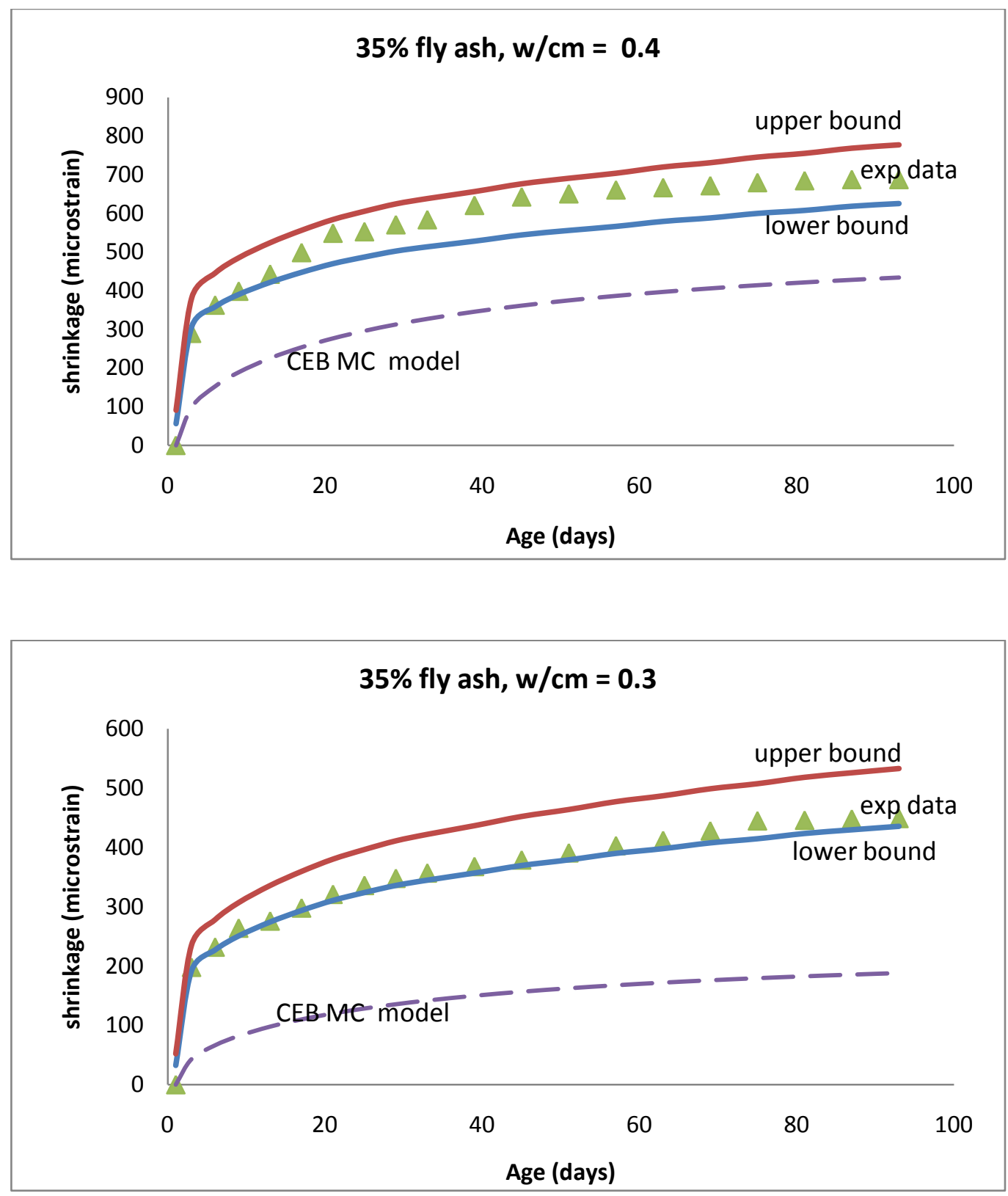

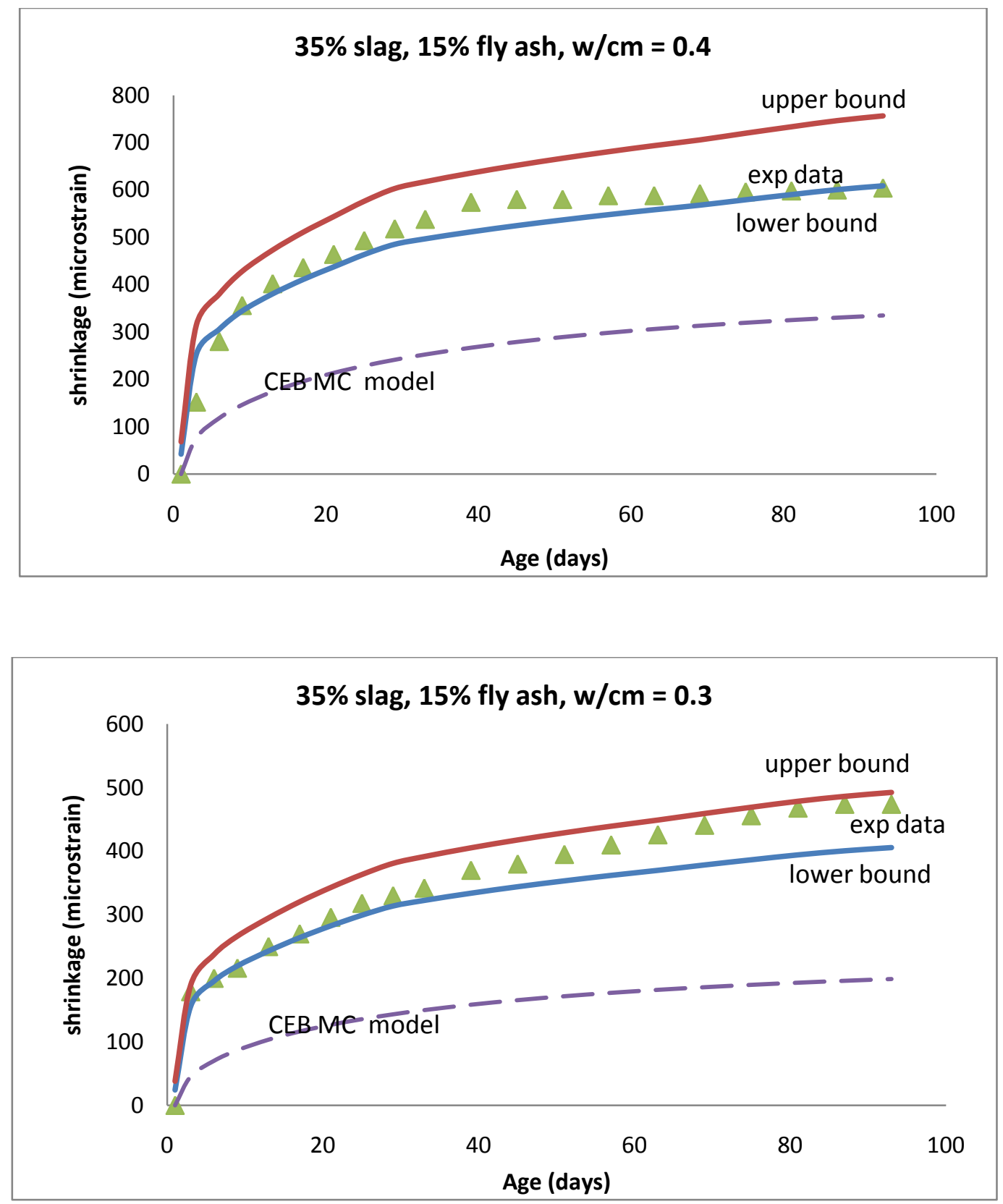

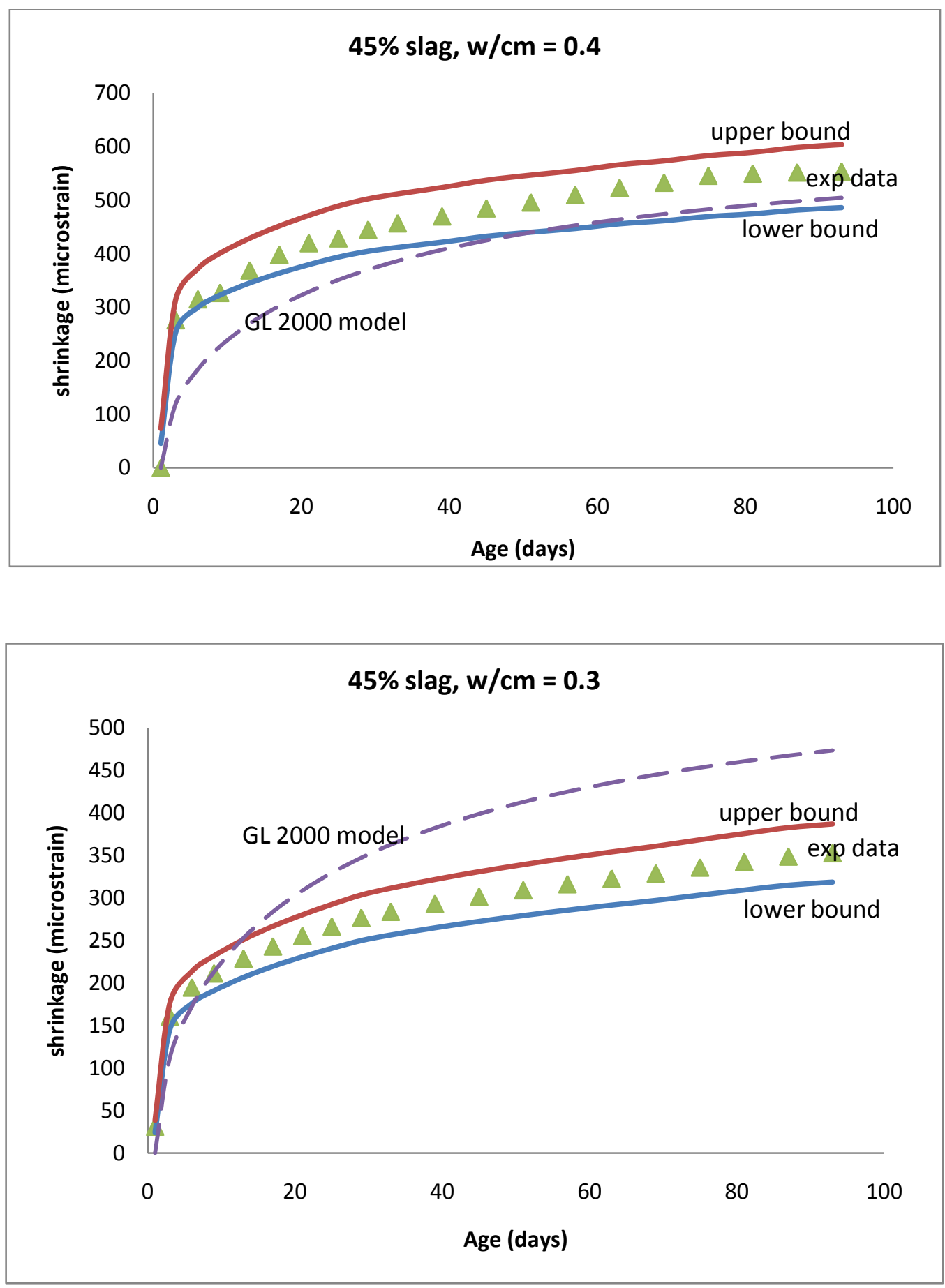

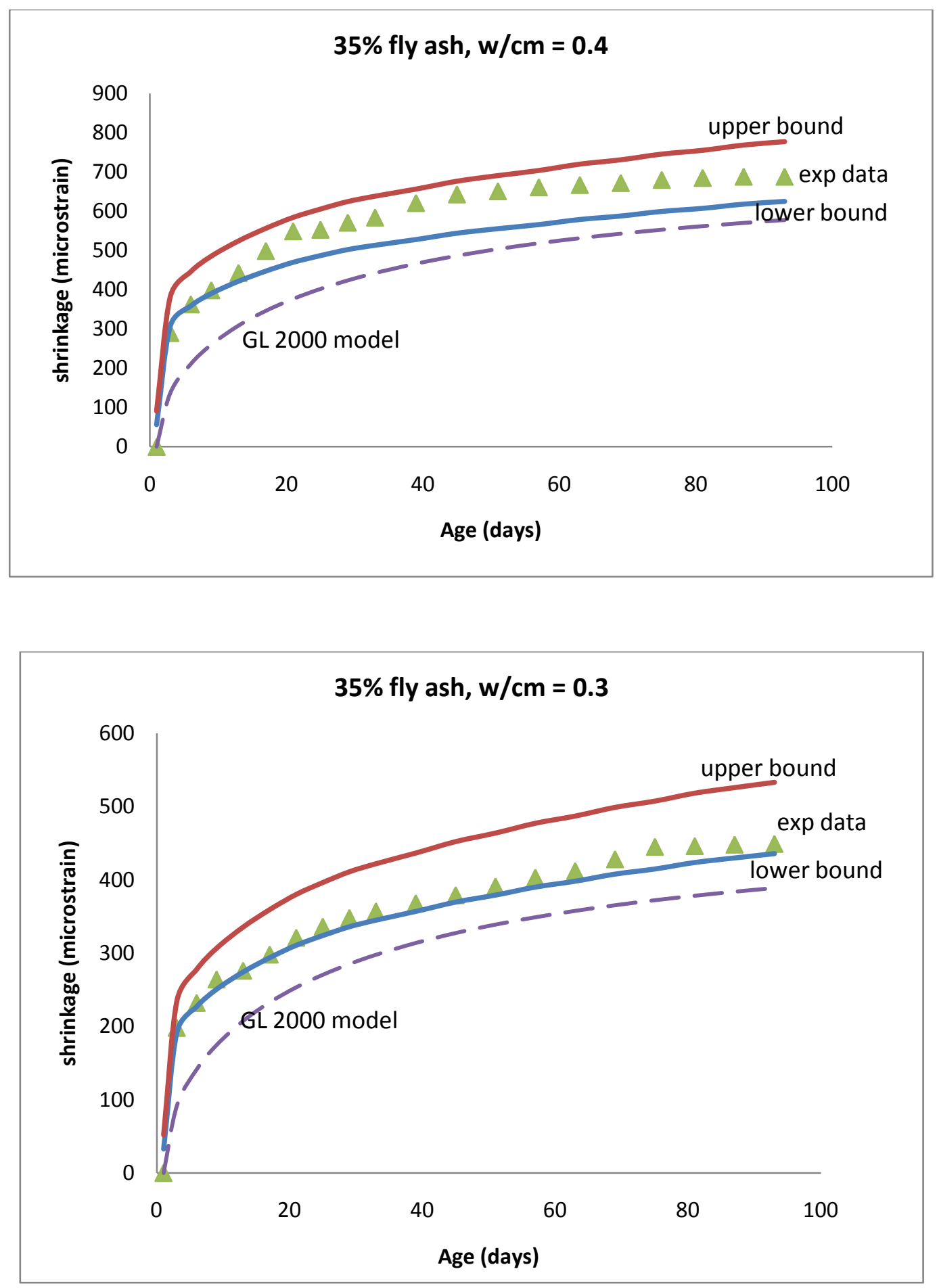

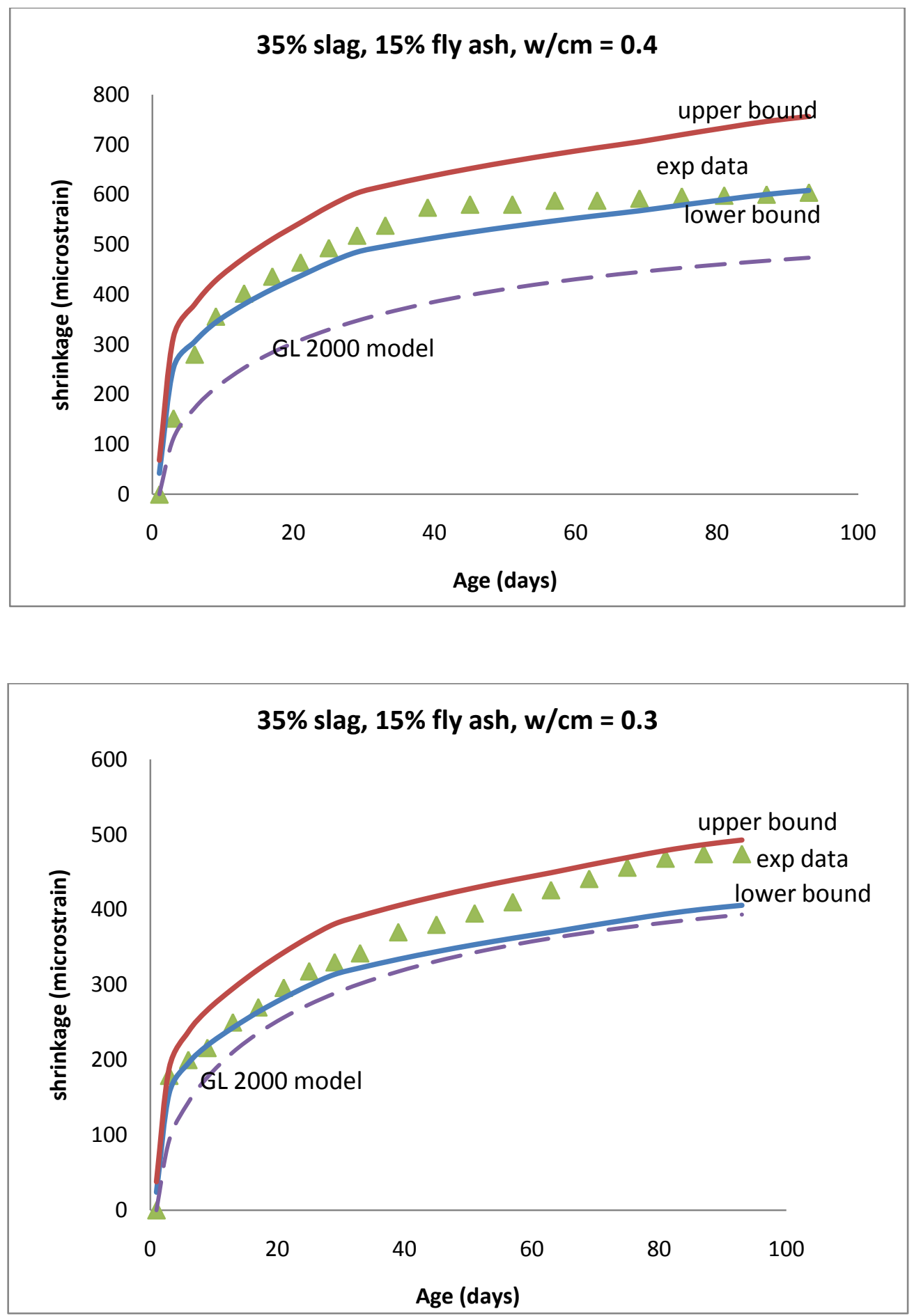
3D plots from EDS data
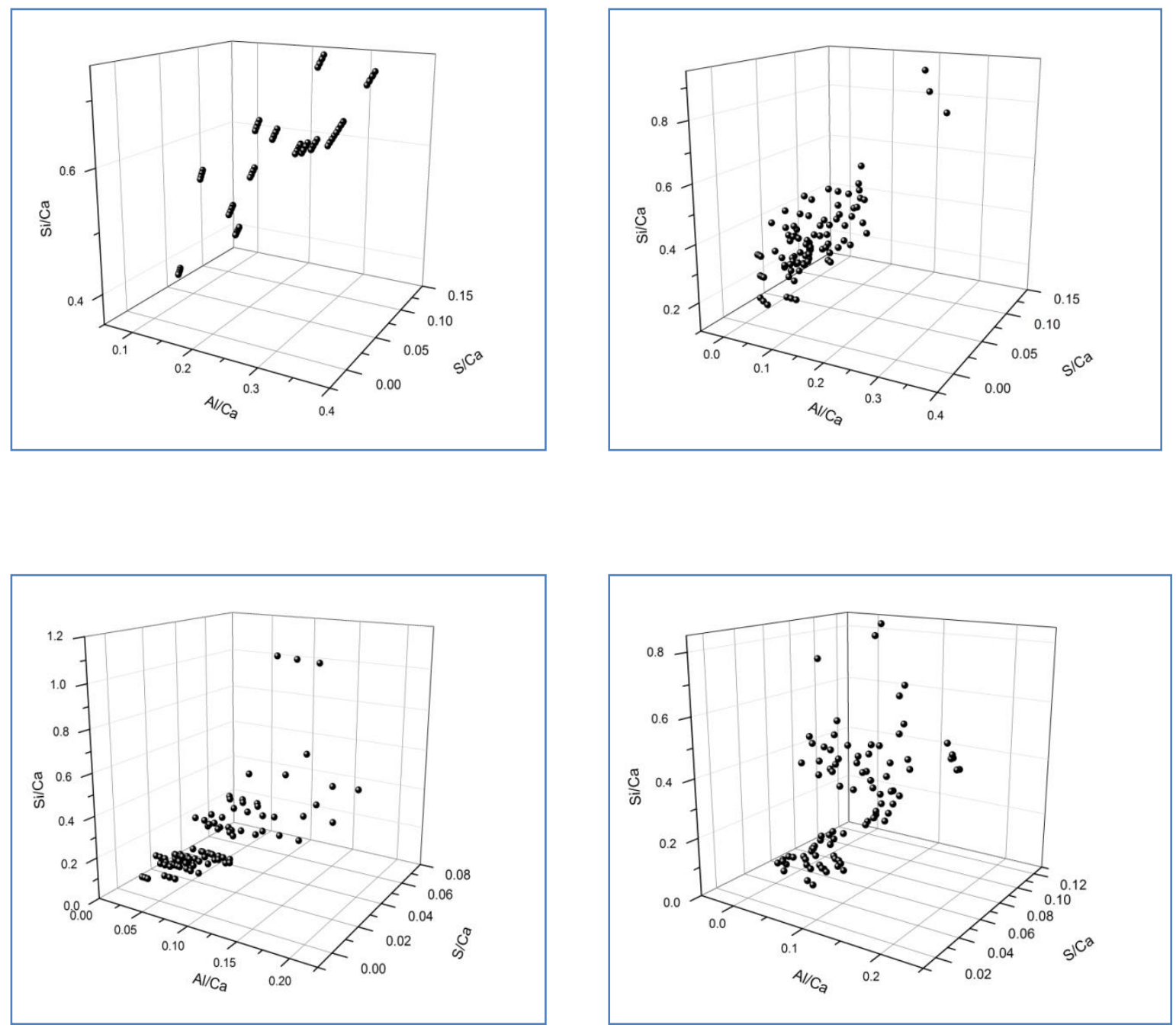

$25 \%$ slag, $\mathrm{w} / \mathrm{cm}=0.3$ 

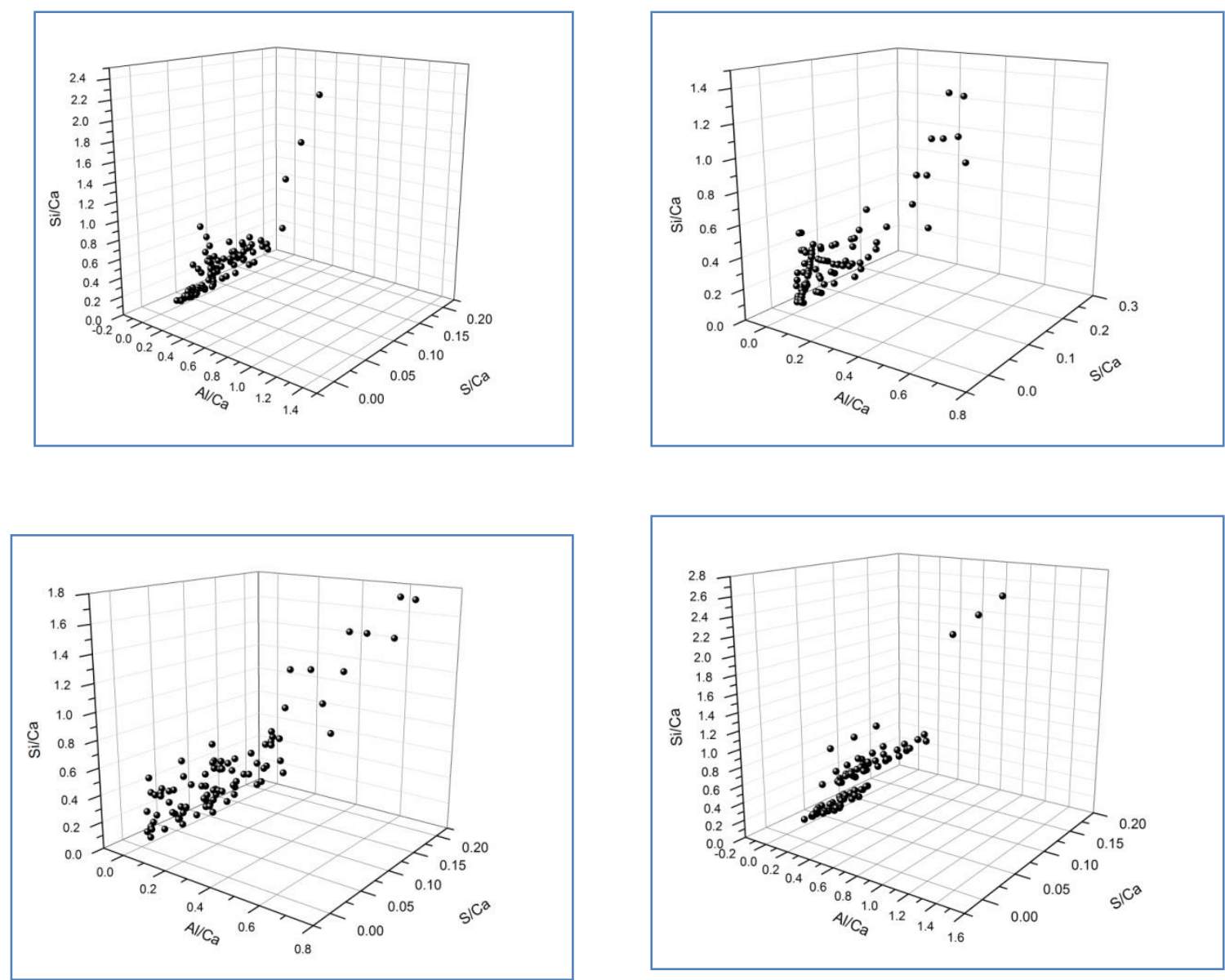

$25 \%$ fly ash, $\mathrm{w} / \mathrm{cm}=0.4$ 

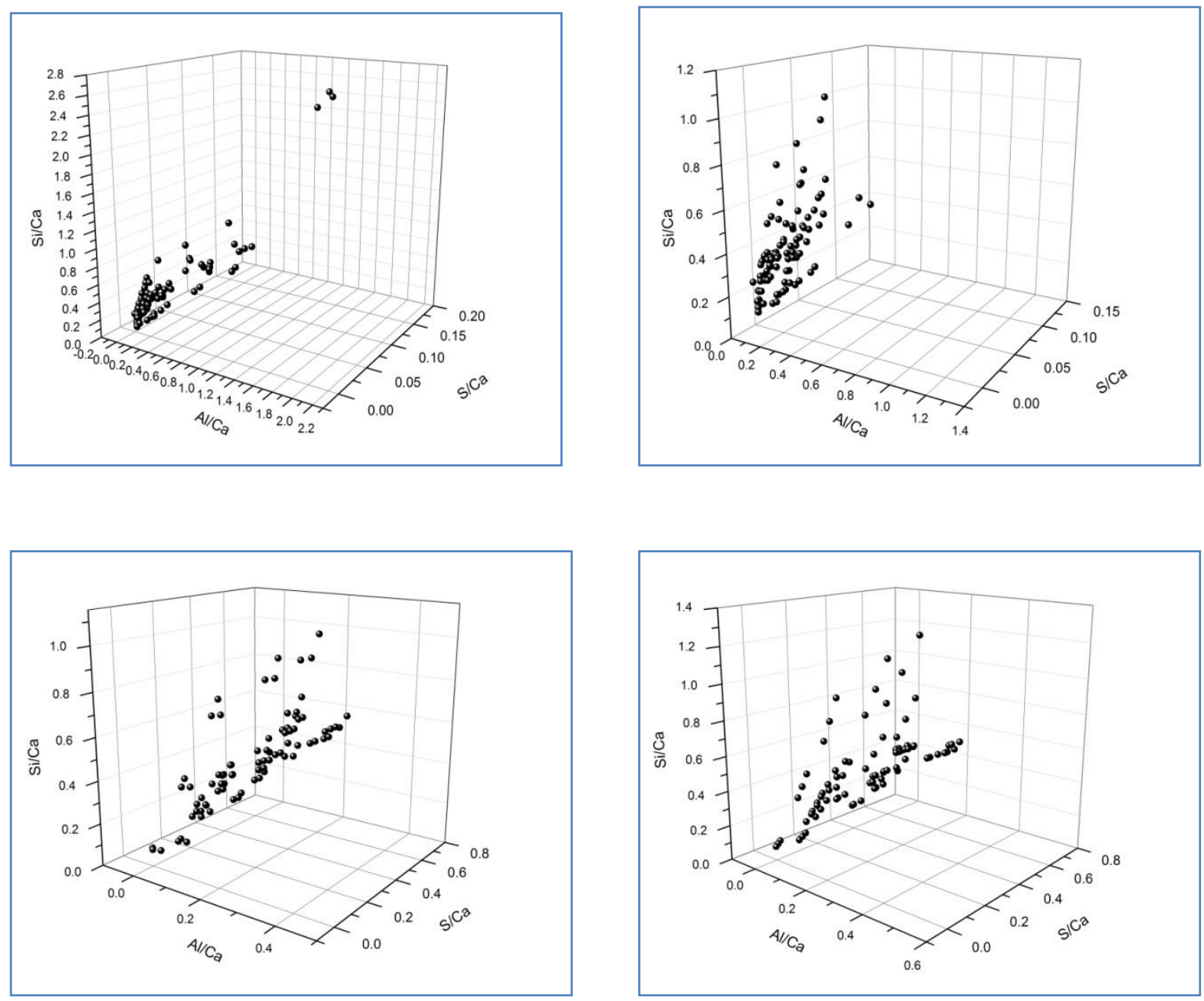

$35 \%$ fly ash, $w / c m=0.3$ 

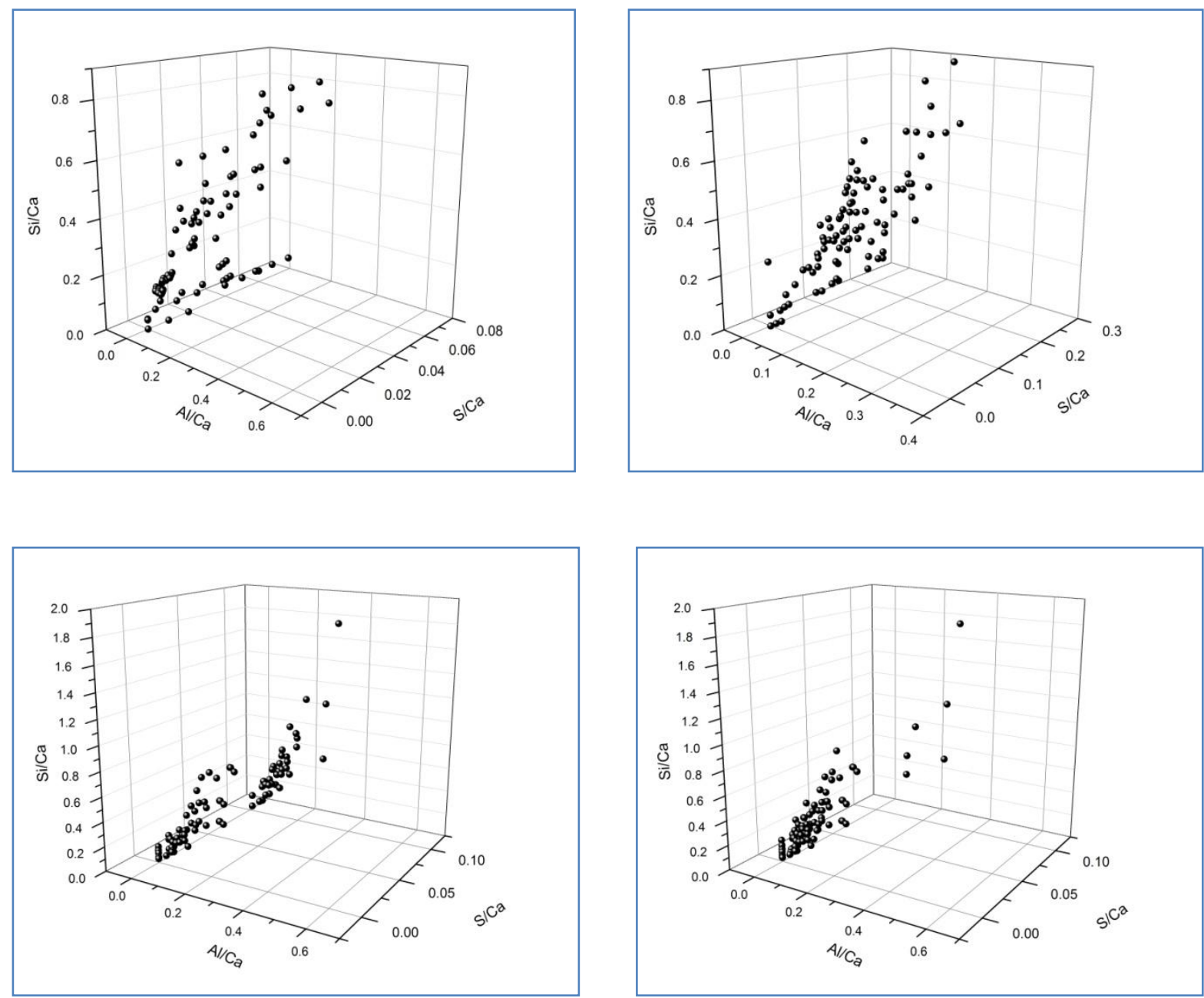

$35 \%$ fly ash, $\mathrm{w} / \mathrm{cm}=0.4$ 

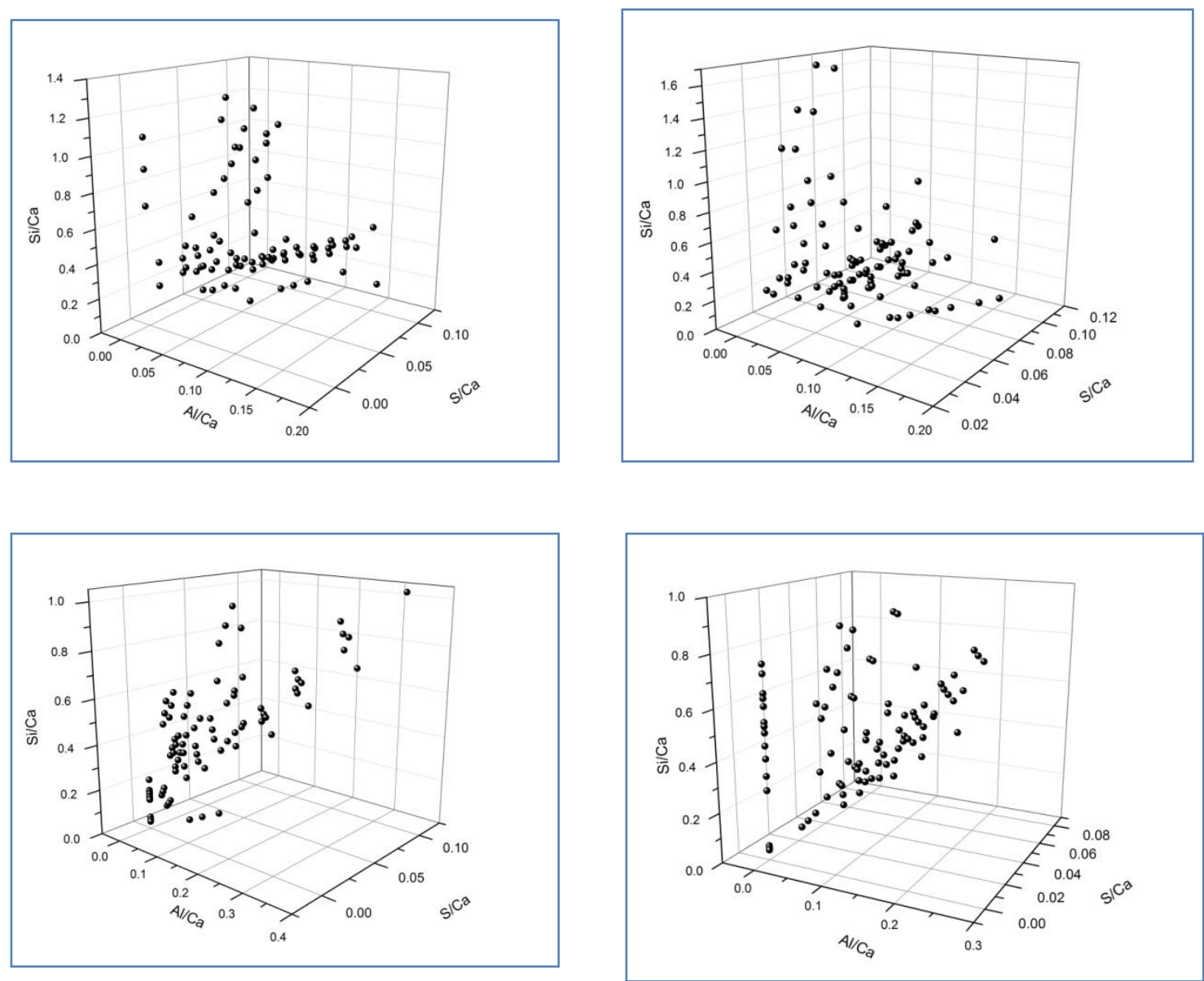

$10 \%$ silica fume, $\mathrm{w} / \mathrm{cm}=0.3$ 

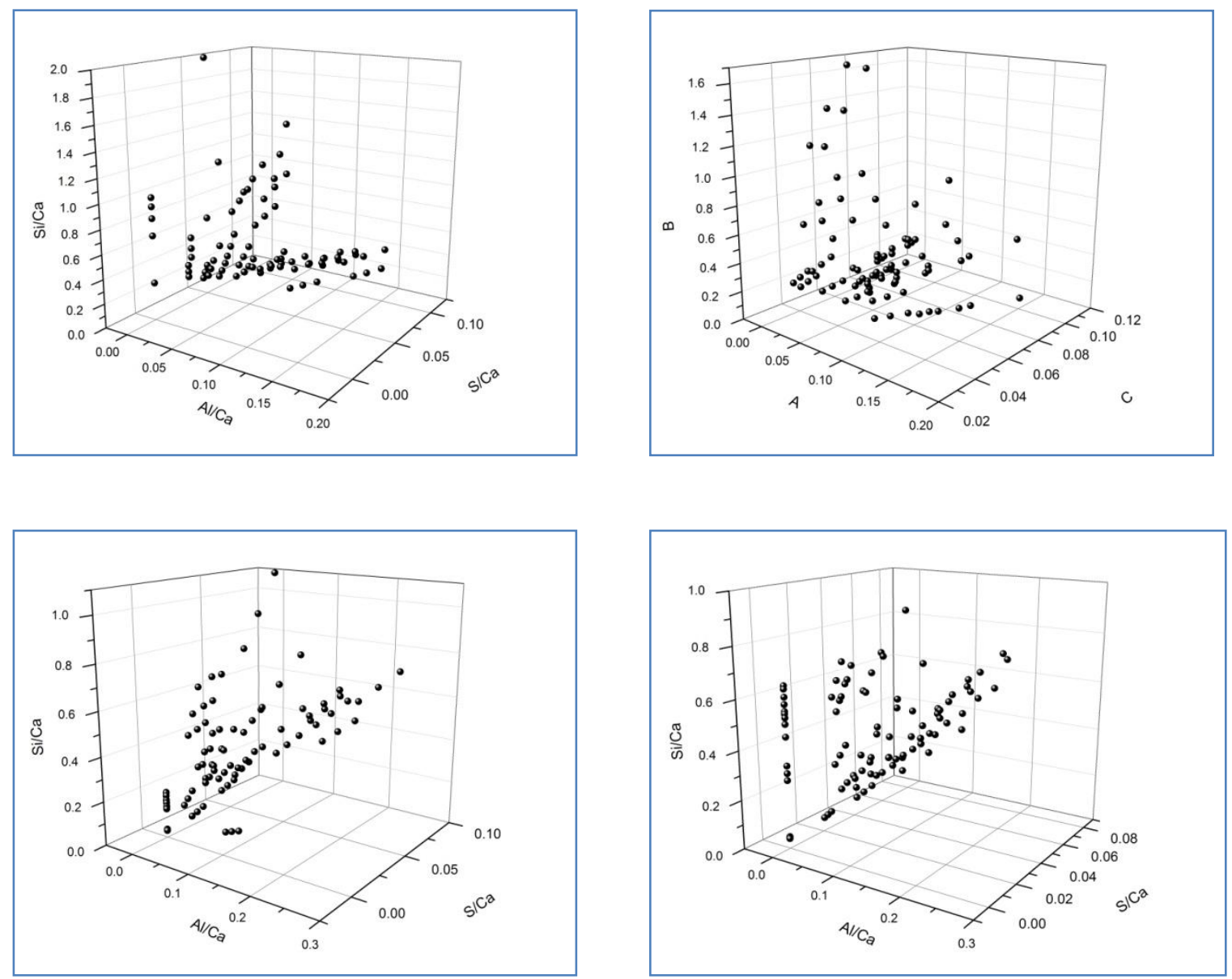

$10 \%$ silica fume, $\mathrm{w} / \mathrm{cm}=0.4$ 
Table: Capillary porosity of all the mixes at different $\mathrm{w} / \mathrm{cm}$ ratios and at different ages

\section{$100 \%$ cement}

\begin{tabular}{|c|c|c|c|c|c|c|c|c|}
\hline Pure Cement & Sp. Vol. of cement & w/c & vc+w/c & $\alpha$ & vol. gel pores & vhcp & vunhyd & Vc (cm3/g) \\
\cline { 2 - 9 } & 0.317 & 0.4 & 0.717 & 0.4 & 0.05 & 0.18 & 0.19 & 0.30 \\
\cline { 2 - 9 } & & & 0.717 & 0.55 & 0.07 & 0.25 & 0.14 & 0.26 \\
\cline { 2 - 9 } & & & 0.717 & 0.7 & 0.09 & 0.31 & 0.10 & 0.22 \\
\hline
\end{tabular}

\begin{tabular}{|c|c|c|c|c|c|c|c|c|}
\hline Pure Cement & Sp. Vol. of cement & w/c & vc+w/c & $\alpha$ & vol. gel pores & vhcp & vunhyd & Vc (cm3/g) \\
\cline { 2 - 9 } & 0.317 & 0.3 & 0.617 & 0.3 & 0.04 & 0.13 & 0.22 & 0.23 \\
\cline { 2 - 10 } & & & 0.617 & 0.45 & 0.05 & 0.20 & 0.17 & 0.20 \\
\cline { 2 - 10 } & & & 0.617 & 0.6 & 0.07 & 0.26 & 0.12 & 0.16 \\
\hline
\end{tabular}

\begin{tabular}{|c|c|c|c|c|c|c|c|c|}
\hline Pure Cement & Sp. Vol. of cement & w/c & vc+w/c & $\alpha$ & vol. gel pores & vhcp & vunhyd & Vc (cm3/g) \\
\cline { 2 - 9 } & 0.317 & 0.5 & 0.817 & 0.5 & 0.06 & 0.22 & 0.16 & 0.37 \\
\cline { 2 - 9 } & & & 0.817 & 0.65 & 0.08 & 0.29 & 0.11 & 0.34 \\
\cline { 2 - 10 } & & & 0.817 & 0.8 & 0.10 & 0.36 & 0.06 & 0.30 \\
\hline
\end{tabular}

\section{Replacement by slag}

\begin{tabular}{|c|c|c|c|c|c|c|c|c|}
\hline \multirow[t]{5}{*}{ SG35 } & Sp. Vol. of cement & $w / c$ & $v c+w / c$ & $\alpha$ & vol.gel pores & vhcp & vunhyd & $V_{c}(\mathrm{~cm} 3 / \mathrm{g})$ \\
\hline & 0.328 & 0.3 & 0.628 & 0.3 & 0.03 & 0.12 & 0.25 & 0.22 \\
\hline & & & 0.628 & 0.45 & 0.05 & 0.18 & 0.21 & 0.19 \\
\hline & & & 0.628 & 0.6 & 0.07 & 0.25 & 0.17 & 0.14 \\
\hline & & & 0.628 & 0.75 & 0.09 & 0.34 & 0.11 & 0.08 \\
\hline \multirow[t]{5}{*}{ SG35 } & Sp. Vol. of cement & $w / c$ & $\mathrm{vc}+\mathrm{w} / \mathrm{c}$ & $\alpha$ & vol.gel pores & vhcp & vunhyd & $\mathrm{Vc}(\mathrm{cm} 3 / \mathrm{g})$ \\
\hline & 0.328 & 0.4 & 0.728 & 0.4 & 0.04 & 0.15 & 0.23 & 0.30 \\
\hline & & & 0.728 & 0.55 & 0.06 & 0.22 & 0.19 & 0.26 \\
\hline & & & 0.728 & 0.7 & 0.08 & 0.28 & 0.14 & 0.22 \\
\hline & & & 0.728 & 0.85 & 0.10 & 0.36 & 0.10 & 0.17 \\
\hline
\end{tabular}

\begin{tabular}{|c|c|c|c|c|c|c|c|c|}
\hline \multirow{3}{*}{ SG45 } & Sp. Vol. of cement & $\mathrm{w} / \mathrm{c}$ & $\mathrm{vc}+\mathrm{w} / \mathrm{c}$ & $\alpha$ & vol. gel pores & vhcp & vunhyd & Vc (cm3/g) \\
\cline { 2 - 10 } & 0.331 & 0.3 & 0.631 & 0.3 & 0.04 & 0.14 & 0.25 & 0.21 \\
\cline { 2 - 10 } & & & 0.631 & 0.45 & 0.06 & 0.20 & 0.21 & 0.17 \\
\cline { 2 - 9 } & & & 0.631 & 0.6 & 0.08 & 0.27 & 0.16 & 0.12 \\
\cline { 2 - 9 } & & & 0.631 & 0.75 & 0.09 & 0.34 & 0.12 & 0.08 \\
\hline
\end{tabular}

\begin{tabular}{|l|c|c|c|c|c|c|c|c|}
\hline SG45 & Sp. Vol. of cement & $\mathrm{w} / \mathrm{c}$ & $\mathrm{vc}+\mathrm{w} / \mathrm{c}$ & $\alpha$ & vol. gel pores & vhcp & vunhyd & Vc (cm3/g) \\
\cline { 2 - 10 } & 0.331 & 0.4 & 0.731 & 0.4 & 0.04 & 0.16 & 0.23 & 0.30 \\
\cline { 2 - 10 } & & & 0.731 & 0.55 & 0.06 & 0.23 & 0.19 & 0.25 \\
\cline { 2 - 10 } & & & 0.731 & 0.7 & 0.08 & 0.30 & 0.15 & 0.21 \\
\cline { 2 - 9 } & & & 0.731 & 0.85 & 0.10 & 0.36 & 0.10 & 0.16 \\
\hline
\end{tabular}


Replacement by fly ash

\begin{tabular}{|c|c|c|c|c|c|c|c|c|}
\hline \multirow[t]{5}{*}{ FA25 } & Sp. Vol. of cement & $w / c$ & $v c+w / c$ & $\alpha$ & vol.gel pores & vhcp & vunhyd & $\mathrm{Vc}(\mathrm{cm} 3 / \mathrm{g})$ \\
\hline & \begin{tabular}{|l|}
0.339 \\
\end{tabular} & 0.3 & 0.639 & 0.3 & 0.03 & 0.10 & 0.27 & 0.24 \\
\hline & & & 0.639 & 0.45 & 0.04 & 0.15 & 0.22 & 0.23 \\
\hline & & & 0.639 & 0.6 & 0.06 & 0.20 & 0.18 & 0.20 \\
\hline & & & 0.639 & 0.75 & 0.07 & 0.25 & 0.13 & 0.18 \\
\hline \multirow[t]{5}{*}{ FA25 } & Sp. Vol. of cement & $w / c$ & $\mathrm{vc}+\mathrm{w} / \mathrm{c}$ & $\alpha$ & vol.gel pores & vhcp & vunhyd & $\mathrm{Vc}(\mathrm{cm} 3 / \mathrm{g})$ \\
\hline & \begin{tabular}{|l|}
0.339 \\
\end{tabular} & 0.4 & 0.739 & 0.4 & 0.04 & 0.13 & 0.24 & 0.33 \\
\hline & & & 0.739 & 0.55 & 0.05 & 0.18 & 0.19 & 0.31 \\
\hline & & & 0.739 & 0.7 & 0.07 & 0.23 & 0.15 & 0.29 \\
\hline & & & 0.739 & 0.85 & 0.08 & 0.28 & 0.11 & 0.27 \\
\hline \multirow[t]{5}{*}{ FA35 } & Sp. Vol. of cement & $w / c$ & $v c+w / c$ & $\alpha$ & vol.gel pores & vhcp & vunhyd & $\mathrm{Vc}(\mathrm{cm} 3 / \mathrm{g})$ \\
\hline & \begin{tabular}{|l|}
0.348 \\
\end{tabular} & 0.3 & 0.648 & 0.3 & 0.02 & 0.09 & 0.28 & 0.25 \\
\hline & & & 0.648 & 0.45 & 0.04 & 0.13 & 0.25 & 0.23 \\
\hline & & & 0.648 & 0.6 & 0.05 & 0.17 & 0.22 & 0.21 \\
\hline & & & 0.648 & 0.75 & 0.06 & 0.22 & 0.17 & 0.20 \\
\hline \multirow[t]{5}{*}{ FA35 } & Sp. Vol. of cement & $w / c$ & $\mathrm{vc}+\mathrm{w} / \mathrm{c}$ & $\alpha$ & vol.gel pores & vhcp & vunhyd & $\mathrm{Vc}(\mathrm{cm} 3 / \mathrm{g})$ \\
\hline & \begin{tabular}{|l|}
0.348 \\
\end{tabular} & 0.4 & 0.748 & 0.4 & 0.03 & 0.12 & 0.26 & 0.34 \\
\hline & & & 0.748 & 0.55 & 0.04 & 0.16 & 0.21 & 0.33 \\
\hline & & & 0.748 & 0.7 & 0.06 & 0.20 & 0.18 & 0.31 \\
\hline & & & 0.748 & 0.85 & 0.07 & 0.25 & 0.13 & 0.30 \\
\hline
\end{tabular}

\section{Replacement by Silica Fume}

\begin{tabular}{|c|c|c|c|c|c|c|c|c|}
\hline \multirow[t]{5}{*}{ SF10 } & Sp. Vol. of cement & $w / c$ & $\mathrm{vc}+\mathrm{w} / \mathrm{c}$ & $\alpha$ & vol. gel pores & vhcp & vunhyd & $\mathrm{Vc}(\mathrm{cm} 3 / \mathrm{g})$ \\
\hline & 0.333 & 0.3 & 0.633 & 0.3 & 0.03 & 0.12 & 0.23 & 0.25 \\
\hline & & & 0.633 & 0.45 & 0.05 & 0.18 & 0.16 & 0.24 \\
\hline & & & 0.633 & 0.6 & 0.07 & 0.24 & 0.12 & 0.21 \\
\hline & & & 0.633 & 0.75 & 0.08 & 0.30 & 0.07 & 0.18 \\
\hline \multirow[t]{5}{*}{ SF10 } & Sp. Vol. of cement & $w / c$ & $\mathrm{vc}+\mathrm{w} / \mathrm{c}$ & $\alpha$ & vol.gel pores & vhcp & vunhyd & $\mathrm{Vc}(\mathrm{cm} 3 / \mathrm{g})$ \\
\hline & \begin{tabular}{|l|}
0.333 \\
\end{tabular} & 0.4 & 0.733 & 0.4 & 0.04 & 0.16 & 0.20 & 0.33 \\
\hline & & & 0.733 & 0.55 & 0.06 & 0.22 & 0.13 & 0.32 \\
\hline & & & 0.733 & 0.7 & 0.08 & 0.28 & 0.09 & 0.29 \\
\hline & & & 0.733 & 0.85 & 0.10 & 0.34 & 0.04 & 0.25 \\
\hline
\end{tabular}


Replacement by combinations of slag, silica fume and fly ash

\begin{tabular}{|c|c|c|c|c|c|c|c|c|}
\hline \multirow[t]{5}{*}{ SG35 SF 10} & Sp. Vol. of cement & $w / c$ & $v c+w / c$ & $\alpha$ & vol.gel pores & vhcp & vunhyd & $\mathrm{Vc}(\mathrm{cm} 3 / \mathrm{g})$ \\
\hline & \begin{tabular}{|l|}
0.344 \\
\end{tabular} & 0.3 & 0.644 & 0.3 & 0.03 & 0.11 & 0.26 & 0.25 \\
\hline & & & 0.644 & 0.45 & 0.04 & 0.16 & 0.20 & 0.24 \\
\hline & & & 0.644 & 0.6 & 0.06 & 0.22 & 0.16 & 0.20 \\
\hline & & & 0.644 & 0.75 & 0.09 & 0.30 & 0.11 & 0.15 \\
\hline \multirow[t]{5}{*}{ SG35 SF 10} & Sp. Vol. of cement & $w / c$ & $\mathrm{vc}+\mathrm{w} / \mathrm{c}$ & $\alpha$ & vol.gel pores & vhcp & vunhyd & $\mathrm{Vc}(\mathrm{cm} 3 / \mathrm{g})$ \\
\hline & \begin{tabular}{|l|}
0.344 \\
\end{tabular} & 0.4 & 0.744 & 0.4 & 0.04 & 0.13 & 0.24 & 0.33 \\
\hline & & & 0.744 & 0.55 & 0.05 & 0.18 & 0.18 & 0.33 \\
\hline & & & 0.744 & 0.7 & 0.07 & 0.25 & 0.14 & 0.29 \\
\hline & & & 0.744 & 0.85 & 0.09 & 0.33 & 0.09 & 0.23 \\
\hline
\end{tabular}

\begin{tabular}{|c|c|c|c|c|c|c|c|c|}
\hline SG35 FA 15 & Sp. Vol. of cement & $w / c$ & vc+w/c & $\alpha$ & vol. gel pores & vhcp & vunhyd & Vc (cm3/g) \\
\cline { 2 - 10 } & 0.341 & 0.3 & 0.641 & 0.3 & 0.03 & 0.10 & 0.27 & 0.23 \\
\cline { 2 - 10 } & & & 0.641 & 0.45 & 0.04 & 0.15 & 0.24 & 0.21 \\
\cline { 2 - 10 } & & & 0.641 & 0.6 & 0.06 & 0.21 & 0.20 & 0.17 \\
\cline { 2 - 9 } & & & 0.641 & 0.75 & 0.08 & 0.29 & 0.13 & 0.14 \\
\hline
\end{tabular}

\begin{tabular}{|c|c|c|c|c|c|c|c|c|}
\hline SG35 FA 15 & Sp. Vol. of cement & $w / c$ & vc+w/c & $\alpha$ & vol. gel pores & vhcp & vunhyd & Vc (cm3/g) \\
\cline { 2 - 9 } & 0.341 & 0.4 & 0.741 & 0.4 & 0.04 & 0.13 & 0.26 & 0.32 \\
\cline { 2 - 9 } & & & 0.741 & 0.55 & 0.05 & 0.17 & 0.23 & 0.29 \\
\cline { 2 - 9 } & & & 0.741 & 0.7 & 0.06 & 0.23 & 0.19 & 0.26 \\
\cline { 2 - 9 } & & & 0.741 & 0.85 & 0.09 & 0.31 & 0.12 & 0.23 \\
\hline
\end{tabular}

\begin{tabular}{|c|c|c|c|c|c|c|c|c|}
\hline FA 25 SF 10 & Sp. Vol. of cement & w/c & vc+w/c & $\alpha$ & vol. gel pores & vhcp & vunhyd & Vc (cm3/g) \\
\cline { 2 - 9 } & 0.355 & 0.3 & 0.655 & 0.3 & 0.02 & 0.09 & 0.28 & 0.27 \\
\cline { 2 - 10 } & & & 0.655 & 0.45 & 0.04 & 0.13 & 0.22 & 0.27 \\
\cline { 2 - 9 } & & & 0.655 & 0.6 & 0.05 & 0.17 & 0.18 & 0.25 \\
\cline { 2 - 9 } & & & 0.655 & 0.75 & 0.06 & 0.22 & 0.14 & 0.24 \\
\hline
\end{tabular}

\begin{tabular}{|c|c|c|c|c|c|c|c|c|}
\hline FA 25 SF 10 & Sp. Vol. of cement & w/c & vc+w/c & $\alpha$ & vol. gel pores & vhcp & vunhyd & Vc (cm3/g) \\
\cline { 2 - 9 } & 0.355 & 0.4 & 0.755 & 0.4 & 0.03 & 0.12 & 0.25 & 0.35 \\
\cline { 2 - 9 } & & & 0.755 & 0.55 & 0.04 & 0.16 & 0.20 & 0.35 \\
\cline { 2 - 9 } & & & 0.755 & 0.7 & 0.06 & 0.20 & 0.16 & 0.33 \\
\cline { 2 - 9 } & & & 0.755 & 0.85 & 0.07 & 0.25 & 0.12 & 0.32 \\
\hline
\end{tabular}


Table 4.8: Chemical shrinkage for pure portland cement

\begin{tabular}{|c|c|c|c|c|c|}
\hline $\begin{array}{c}\mathrm{W} / \mathrm{cm} \\
\text { ratio }\end{array}$ & $\begin{array}{c}\text { Age } \\
\text { (days) }\end{array}$ & $\alpha$ & $\Delta \mathrm{V} / \mathrm{V}$ & $\begin{array}{c}\Delta \mathrm{L} / \mathrm{L} \\
\mathrm{chem}\end{array}$ & $\begin{array}{c}\Delta \mathrm{L} / \mathrm{L} \\
\text { total }\end{array}$ \\
\hline 0.4 & 1 & 0.4 & 0.003 & 0.0011 & 2649 \\
\hline & 7 & 0.55 & 0.004 & 0.0015 & 3643 \\
\hline & 28 & 0.7 & 0.006 & 0.0019 & 4636 \\
\hline & 90 & 0.85 & 0.007 & 0.0023 & 5630 \\
\hline
\end{tabular}

\begin{tabular}{|c|c|c|c|c|c|}
\hline $\begin{array}{c}\mathrm{W} / \mathrm{cm} \\
\text { ratio }\end{array}$ & $\begin{array}{c}\text { Age } \\
\text { (days) }\end{array}$ & $\alpha$ & $\Delta \mathrm{V} / \mathrm{V}$ & $\begin{array}{c}\Delta \mathrm{L} / \mathrm{L} \\
\text { chem }\end{array}$ & $\begin{array}{c}\Delta \mathrm{L} / \mathrm{L} \\
\text { total }\end{array}$ \\
\hline 0.3 & 1 & 0.3 & 0.002 & 0.0008 & 1987 \\
\hline & 7 & 0.45 & 0.004 & 0.0012 & 2980 \\
\hline & 28 & 0.6 & 0.005 & 0.0016 & 3974 \\
\hline & 90 & 0.75 & 0.006 & 0.0020 & 4967 \\
\hline
\end{tabular}

\begin{tabular}{|c|c|c|c|c|c|}
\hline $\begin{array}{c}\text { W/cm } \\
\text { ratio }\end{array}$ & $\begin{array}{c}\text { Age } \\
\text { (days) }\end{array}$ & $\alpha$ & $\Delta \mathrm{V} / \mathrm{V}$ & $\begin{array}{c}\Delta \mathrm{L} / \mathrm{L} \\
\text { chem }\end{array}$ & $\begin{array}{c}\Delta \mathrm{L} / \mathrm{L} \\
\text { total }\end{array}$ \\
\hline 0.5 & 1 & 0.5 & 0.004 & 0.0013 & 3312 \\
\hline & 7 & 0.65 & 0.005 & 0.0017 & 4305 \\
\hline & 28 & 0.8 & 0.006 & 0.0021 & 5298 \\
\hline & 90 & 0.9 & 0.007 & 0.0024 & 5961 \\
\hline
\end{tabular}




\section{Table: Chemical Shrinkage of different mixes at different ages and}

different $w / \mathrm{cm}$ ratios

\section{0\% Cement}

\begin{tabular}{|c|c|c|c|c|c|c|c|c|c|c|c|}
\hline Mix & w/cm & vol. water & $\mathrm{Vi}$ & acem & asg & afa & asf & Vhcp $(\mathrm{mL} / 100 \mathrm{~g})$ & $\Delta(\mathrm{mL} / 100 \mathrm{~g})$ & $\Delta \%$ & $\mu \varepsilon \mathrm{V}$ \\
\hline 1-d & 0.4 & 126 & 226 & 0.4 & & & & 56.16 & 34.24 & 15 & $\mathbf{1 5 1 5}$ \\
\hline 7-d & 0.4 & 126 & 226 & 0.55 & & & & 77.22 & 47.08 & 21 & 2083 \\
\hline 28-d & 0.4 & 126 & 226 & 0.7 & & & & 98.28 & 59.92 & 27 & 2651 \\
\hline 90-d & 0.4 & 126 & 226 & 0.85 & & & & 119.34 & 72.76 & 32 & 3220 \\
\hline
\end{tabular}

\begin{tabular}{|c|c|c|c|c|c|c|c|c|c|c|c|}
\hline Mix & $\mathrm{w} / \mathrm{cm}$ & vol. water & $\mathrm{Vi}$ & acem & $\alpha \mathrm{sg}$ & afa & asf & $\mathrm{Vhcp}(\mathrm{mL} / 100 \mathrm{~g})$ & $\Delta(\mathrm{mL} / 100 \mathrm{~g})$ & $\Delta \%$ & $\mu \varepsilon \mathrm{V}$ \\
\hline 1-d & 0.3 & 94.5 & 194.5 & 0.3 & & & & 41.19 & 17.16 & 9 & 882 \\
\hline 7-d & 0.3 & 94.5 & 194.5 & 0.45 & & & & 61.79 & 25.74 & 13 & 1323 \\
\hline 28-d & 0.3 & 94.5 & 194.5 & 0.6 & & & & 82.38 & 34.32 & 18 & 1764 \\
\hline 90-d & 0.3 & 94.5 & 194.5 & 0.75 & & & & 102.98 & 42.89 & 22 & 2205 \\
\hline
\end{tabular}

\begin{tabular}{|c|c|c|c|c|c|c|c|c|c|c|c|}
\hline Mix & $\mathrm{w} / \mathrm{cm}$ & vol. water & $\mathrm{Vi}$ & $\alpha \mathrm{cem}$ & $\alpha \mathrm{sg}$ & afa & $\alpha$ sf & $\mathrm{Vhcp}(\mathrm{mL} / 100 \mathrm{~g})$ & $\Delta(\mathrm{mL} / 100 \mathrm{~g})$ & $\Delta \%$ & $\mu \varepsilon \mathrm{V}$ \\
\hline $1-\mathrm{d}$ & 0.5 & 157.5 & 257.5 & 0.5 & & & & 78.34 & 50.41 & 20 & 1958 \\
\hline $7-\mathrm{d}$ & 0.5 & 157.5 & 257.5 & 0.65 & & & & 101.84 & 65.53 & 25 & 2545 \\
\hline 28-d & 0.5 & 157.5 & 257.5 & 0.8 & & & & 125.35 & 80.65 & 31 & 3132 \\
\hline 90-d & 0.5 & 157.5 & 257.5 & 0.9 & & & & 141.01 & 90.74 & 35 & 3524 \\
\hline
\end{tabular}

\section{$35 \%$ Slag}

\begin{tabular}{|c|c|c|c|c|c|c|c|c|c|c|c|}
\hline Mix & w/cm & vol. water & Vi & acem & asg & afa & asf & Vhcp (mL/100g) & $\Delta(\mathrm{mL} / 100 \mathrm{~g})$ & $\Delta \%$ & $\mu \varepsilon \mathrm{V}$ \\
\hline 1-d & 0.4 & 121.997 & 221.997 & 0.4 & 0.16 & & & 47.61 & 41.19 & 19 & $\mathbf{1 8 5 6}$ \\
\hline 7-d & 0.4 & 121.997 & 221.997 & 0.55 & 0.24 & & & 66.85 & 55.25 & 25 & 2489 \\
\hline 28-d & 0.4 & 121.997 & 221.997 & 0.7 & 0.33 & & & 86.78 & 68.62 & 31 & 3091 \\
\hline 90-d & 0.4 & 121.997 & 221.997 & 0.85 & 0.46 & & & 109.49 & 79.21 & 36 & 3568 \\
\hline
\end{tabular}

\begin{tabular}{|c|c|c|c|c|c|c|c|c|c|c|c|}
\hline Mix & $\mathrm{w} / \mathrm{cm}$ & vol. water & $\mathrm{Vi}$ & acem & $\alpha s g$ & afa & asf & Vhcp (mL/100g) & $\Delta(\mathrm{mL} / 100 \mathrm{~g})$ & $\Delta \%$ & $\mu \varepsilon V$ \\
\hline 1-d & 0.3 & 91.49773 & 191.4977 & 0.3 & 0.151 & & & 37.25 & 20.20 & 11 & 1055 \\
\hline $7-d$ & 0.3 & 91.49773 & 191.4977 & 0.45 & 0.2 & & & 54.04 & 32.13 & 17 & 1678 \\
\hline $28-d$ & 0.3 & 91.49773 & 191.4977 & 0.6 & 0.314 & & & 75.34 & 39.56 & 21 & 2066 \\
\hline $90-d$ & 0.3 & 91.49773 & 191.4977 & 0.75 & 0.5 & & & 101.64 & 41.99 & 22 & 2193 \\
\hline
\end{tabular}

\section{5\% Slag}

\begin{tabular}{|c|c|c|c|c|c|c|c|c|c|c|c|}
\hline Mix & $w / c m$ & vol. water & $\mathrm{Vi}$ & $\alpha c e m$ & $\alpha s g$ & $\alpha f a$ & $\alpha s f$ & $V h c p(\mathrm{~mL} / 100 \mathrm{~g})$ & $\Delta(\mathrm{mL} / 100 \mathrm{~g})$ & $\Delta \%$ & $\mu \varepsilon \mathrm{V}$ \\
\hline 1-d & 0.4 & 120.8996 & 220.8996 & 0.4 & 0.16 & & & 45.17 & 43.19 & 20 & 1955 \\
\hline 7-d & 0.4 & 120.8996 & 220.8996 & 0.55 & 0.24 & & & 63.89 & 57.61 & 26 & 2608 \\
\hline 28-d & 0.4 & 120.8996 & 220.8996 & 0.7 & 0.33 & & & 83.50 & 71.13 & 32 & 3220 \\
\hline 90-d & 0.4 & 120.8996 & 220.8996 & 0.85 & 0.46 & & & 106.69 & 81.08 & 37 & 3670 \\
\hline
\end{tabular}

\begin{tabular}{|c|c|c|c|c|c|c|c|c|c|c|c|}
\hline Mix & w/cm & vol. water & Vi & acem & $\alpha s g$ & afa & asf & Vhcp $(\mathrm{mL} / 100 \mathrm{~g})$ & $\Delta(\mathrm{mL} / 100 \mathrm{~g})$ & $\Delta \%$ & $\mu \varepsilon \mathrm{V}$ \\
\hline 1-d & 0.3 & 90.67466 & 190.6747 & 0.3 & 0.151 & & & 36.13 & 21.07 & 11 & $\mathbf{1 1 0 5}$ \\
\hline 7-d & 0.3 & 90.67466 & 190.6747 & 0.45 & 0.2 & & & 51.83 & 33.97 & 18 & 1782 \\
\hline 28-d & 0.3 & 90.67466 & 190.6747 & 0.6 & 0.314 & & & 73.33 & 41.07 & 22 & 2154 \\
\hline 90-d & 0.3 & 90.67466 & 190.6747 & 0.75 & 0.5 & & & 101.26 & 41.75 & 22 & 2189 \\
\hline
\end{tabular}


Table: Predicted shrinkage strains of paste, mortar and concrete for different mixes at different ages and different $\mathrm{w} / \mathrm{cm}$ ratios

\begin{tabular}{|c|c|c|c|c|c|c|c|c|c|c|c|c|}
\hline Mix & & $\mathrm{w} / \mathrm{cm}$ & $\mu \varepsilon p$ & $f c^{\prime} p$ & Ep & $\mu \varepsilon \mathrm{m}$ & $\mathrm{Em}(-)$ & $\mathrm{Em}(+)$ & Em, avg & $\mu \varepsilon c(-)$ & $\mu \varepsilon c(+)$ & $\mu \varepsilon \mathrm{c}$, avg \\
\hline \multirow[t]{4}{*}{ 100\% cement } & $1-d$ & 0.4 & 1515 & 16 & 21 & 472 & 39 & 63 & 51 & 167 & 210 & 189 \\
\hline & $7-d$ & 0.4 & 2083 & 31 & 27 & 729 & 39 & 63 & 51 & 258 & 324 & 292 \\
\hline & $28-d$ & 0.4 & 2651 & 46 & 30 & 998 & 39 & 63 & 51 & 353 & 444 & 400 \\
\hline & $90-d$ & 0.4 & 3220 & 52 & 32 & 1241 & 39 & 63 & 51 & 439 & 552 & 498 \\
\hline & & & & & & & & & & & & \\
\hline Mix & & $\mathrm{w} / \mathrm{cm}$ & & & & & & & & & & \\
\hline \multirow[t]{4}{*}{$100 \%$ cement } & $1-d$ & 0.3 & 882 & 16 & 21 & 220 & 47 & 71 & 59 & 85 & 103 & 94 \\
\hline & $7-d$ & 0.3 & 1323 & 30 & 26 & 368 & 47 & 71 & 59 & 142 & 173 & 158 \\
\hline & $28-d$ & 0.3 & 1764 & 45 & 30 & 529 & 47 & 71 & 59 & 204 & 249 & 227 \\
\hline & $90-d$ & 0.3 & 2205 & 51 & 32 & 678 & 47 & 71 & 59 & 261 & 319 & 291 \\
\hline & & & & & & & & & & & & \\
\hline Mix & & $\mathrm{w} / \mathrm{cm}$ & & & & & & & & & & \\
\hline \multirow[t]{4}{*}{$100 \%$ cement } & $1-d$ & 0.5 & 1958 & 5 & 15 & 814 & 33 & 57 & 45 & 268 & 345 & 308 \\
\hline & $7-d$ & 0.5 & 2545 & 20 & 23 & 1317 & 33 & 57 & 45 & 433 & 558 & 499 \\
\hline & $28-d$ & 0.5 & 3132 & 30 & 26 & 1742 & 33 & 57 & 45 & 573 & 739 & 660 \\
\hline & $90-d$ & 0.5 & 3524 & 34 & 28 & 2005 & 33 & 57 & 45 & 660 & 851 & 759 \\
\hline
\end{tabular}

\begin{tabular}{|c|c|c|c|c|c|c|c|c|c|c|c|c|}
\hline Mix & & $\mathrm{w} / \mathrm{cm}$ & & & & & & & & & & \\
\hline \multirow[t]{4}{*}{ SG 35} & $1-d$ & 0.4 & 1856 & 11 & 19 & 500 & 40 & 63 & 52 & 180 & 223 & 202 \\
\hline & $7-d$ & 0.4 & 2489 & 21 & 23 & 746 & 40 & 63 & 52 & 268 & 333 & 302 \\
\hline & $28-d$ & 0.4 & 3091 & 31 & 27 & 1207 & 40 & 63 & 52 & 434 & 539 & 489 \\
\hline & $90-d$ & 0.4 & 3568 & 35 & 28 & 1424 & 40 & 63 & 52 & 513 & 637 & 577 \\
\hline & & & & & & & & & & & & \\
\hline Mix & & $\mathrm{w} / \mathrm{cm}$ & & & & & & & & & & \\
\hline \multirow[t]{4}{*}{ SG 35} & 1-d & 0.3 & 1055 & 18 & 22 & 277 & 47 & 70 & 58 & 107 & 130 & 119 \\
\hline & $7-d$ & 0.3 & 1678 & 34 & 28 & 493 & 47 & 70 & 58 & 191 & 232 & 211 \\
\hline & $28-d$ & 0.3 & 2066 & 51 & 32 & 655 & 47 & 70 & 58 & 254 & 308 & 281 \\
\hline & $90-d$ & 0.3 & 2193 & 58 & 33 & 712 & 47 & 70 & 58 & 276 & 335 & 305 \\
\hline & & & & & & & & & & & & \\
\hline Mix & & $\mathrm{w} / \mathrm{cm}$ & & & & & & & & & & \\
\hline \multirow[t]{4}{*}{ SG 45} & 1-d & 0.4 & 1955 & 8 & 17 & 598 & 40 & 63 & 52 & 216 & 268 & 243 \\
\hline & 7-d & 0.4 & 2608 & 21 & 23 & 931 & 40 & 63 & 52 & 336 & 417 & 378 \\
\hline & $28-d$ & 0.4 & 3220 & 32 & 27 & 1238 & 40 & 63 & 52 & 447 & 555 & 503 \\
\hline & $90-d$ & 0.4 & 3670 & 36 & 28 & 1442 & 40 & 63 & 52 & 520 & 646 & 586 \\
\hline & & & & & & & & & & & & \\
\hline Mix & & $\mathrm{w} / \mathrm{cm}$ & & & & & & & & & & \\
\hline \multirow[t]{4}{*}{ SG 45} & $1-d$ & 0.3 & 1105 & 11 & 19 & 270 & 47 & 70 & 58 & 105 & 127 & 116 \\
\hline & $7-d$ & 0.3 & 1782 & 34 & 28 & 526 & 47 & 70 & 58 & 205 & 248 & 226 \\
\hline & $28-d$ & 0.3 & 2154 & 51 & 32 & 686 & 47 & 70 & 58 & 267 & 324 & 295 \\
\hline & $90-d$ & 0.3 & 2189 & 64 & 34 & 729 & 47 & 70 & 58 & 283 & 344 & 313 \\
\hline
\end{tabular}




\begin{tabular}{|c|c|c|c|c|c|c|c|c|c|c|c|c|}
\hline Mix & & $\mathrm{w} / \mathrm{cm}$ & & & & & & & & & & \\
\hline \multirow[t]{4}{*}{ FA 25} & $1-d$ & 0.3 & 1360 & 23 & 24 & 386 & 47 & 71 & 58 & 151 & 184 & 167 \\
\hline & 7-d & 0.3 & 2040 & 44 & 30 & 650 & 47 & 71 & 58 & 254 & 310 & 281 \\
\hline & $28-d$ & 0.3 & 2720 & 66 & 34 & 936 & 47 & 71 & 58 & 366 & 447 & 404 \\
\hline & $90-d$ & 0.3 & 3400 & 75 & 36 & 1199 & 47 & 71 & 58 & 468 & 572 & 518 \\
\hline Mix & & $\mathrm{w} / \mathrm{cm}$ & & & & & & & & & & \\
\hline \multirow[t]{4}{*}{ FA 25} & $1-d$ & 0.4 & 2067 & 12 & 19 & 659 & 40 & 64 & 52 & 239 & 299 & 270 \\
\hline & $7-d$ & 0.4 & 2842 & 23 & 24 & 1008 & 40 & 64 & 52 & 366 & 457 & 413 \\
\hline & $28-d$ & 0.4 & 3617 & 34 & 28 & 1374 & 40 & 64 & 52 & 498 & 623 & 563 \\
\hline & $90-d$ & 0.4 & 4391 & 38 & 29 & 1702 & 40 & 64 & 52 & 617 & 772 & 698 \\
\hline Mix & & $\mathrm{w} / \mathrm{cm}$ & & & & & & & & & & \\
\hline \multirow[t]{4}{*}{ FA 35} & $1-d$ & 0.4 & 2302 & 11 & 19 & 708 & 40 & 63 & 52 & 258 & 320 & 290 \\
\hline & $7-d$ & 0.4 & 3165 & 20 & 23 & 1071 & 40 & 63 & 52 & 391 & 484 & 439 \\
\hline & $28-d$ & 0.4 & 4027 & 30 & 26 & 1461 & 40 & 63 & 52 & 533 & 660 & 599 \\
\hline & $90-d$ & 0.4 & 4889 & 34 & 28 & 1814 & 40 & 63 & 52 & 661 & 820 & 744 \\
\hline Mix & & $\mathrm{w} / \mathrm{cm}$ & & & & & & & & & & \\
\hline \multirow[t]{4}{*}{ FA 35} & $1-d$ & 0.3 & 1562 & 21 & 23 & 448 & 47 & 71 & 59 & 176 & 215 & 196 \\
\hline & $7-d$ & 0.3 & 2343 & 40 & 29 & 752 & 47 & 71 & 59 & 295 & 360 & 329 \\
\hline & $28-d$ & 0.3 & 3123 & 60 & 33 & 1081 & 47 & 71 & 59 & 425 & 518 & 473 \\
\hline & $90-d$ & 0.3 & 3903 & 68 & 35 & 1383 & 47 & 71 & 59 & 543 & 663 & 606 \\
\hline
\end{tabular}

\begin{tabular}{|c|c|c|c|c|c|c|c|c|c|c|c|c|}
\hline Mix & & $\mathrm{w} / \mathrm{cm}$ & & & & & & & & & & \\
\hline \multirow[t]{4}{*}{ SF 10} & $1-d$ & 0.3 & 1049 & 20 & 23 & 287 & 47 & 70 & 58 & 112 & 136 & 123 \\
\hline & $7-d$ & 0.3 & 1573 & 37 & 28 & 480 & 47 & 70 & 58 & 187 & 227 & 206 \\
\hline & $28-d$ & 0.3 & 2098 & 56 & 33 & 692 & 47 & 70 & 58 & 270 & 327 & 297 \\
\hline & $90-d$ & 0.3 & 2622 & 64 & 34 & 888 & 47 & 70 & 58 & 346 & 420 & 381 \\
\hline Mix & & $\mathrm{w} / \mathrm{cm}$ & & & & & & & & & & \\
\hline \multirow[t]{4}{*}{ SF 10} & 1-d & 0.4 & 1703 & 16 & 21 & 561 & 39 & 63 & 51 & 201 & 252 & 227 \\
\hline & $7-d$ & 0.4 & 2341 & 31 & 27 & 865 & 39 & 63 & 51 & 309 & 388 & 350 \\
\hline & $28-d$ & 0.4 & 2980 & 47 & 31 & 1189 & 39 & 63 & 51 & 425 & 534 & 482 \\
\hline & $90-d$ & 0.4 & 3618 & 53 & 32 & 1477 & 39 & 63 & 51 & 528 & 663 & 598 \\
\hline
\end{tabular}




\begin{tabular}{|c|c|c|c|c|c|c|c|c|c|c|c|c|}
\hline Mix & & $\mathrm{w} / \mathrm{cm}$ & & & & & & & & & & \\
\hline \multirow[t]{4}{*}{ FA 25 SF 10} & $1-d$ & 0.4 & 2281 & 15 & 21 & 451 & 39 & 63 & 51 & 163 & 205 & 185 \\
\hline & 7-d & 0.4 & 3134 & 29 & 26 & 691 & 39 & 63 & 51 & 250 & 314 & 283 \\
\hline & 28-d & 0.4 & 3989 & 43 & 30 & 1100 & 39 & 63 & 51 & 399 & 500 & 451 \\
\hline & $90-d$ & 0.4 & 4844 & 49 & 31 & 1368 & 39 & 63 & 51 & 496 & 621 & 561 \\
\hline Mix & & $\mathrm{w} / \mathrm{cm}$ & & & & & & & & & & \\
\hline \multirow[t]{4}{*}{ FA 25 SF 10} & $1-d$ & 0.3 & 1546 & 21 & 23 & 376 & 47 & 70 & 57 & 149 & 180 & 163 \\
\hline & 7-d & 0.3 & 2316 & 40 & 29 & 631 & 47 & 70 & 57 & 249 & 301 & 273 \\
\hline & 28-d & 0.3 & 3090 & 70 & 35 & 933 & 47 & 70 & 57 & 368 & 446 & 404 \\
\hline & $90-d$ & 0.3 & 3862 & 79 & 36 & 1194 & 47 & 70 & 57 & 471 & 571 & 517 \\
\hline Mix & & $\mathrm{w} / \mathrm{cm}$ & & & & & & & & & & \\
\hline \multirow[t]{4}{*}{ SG 35 SF 10} & $1-d$ & 0.3 & 1228 & 20 & 23 & 347 & 47 & 69 & 57 & 136 & 164 & 149 \\
\hline & 7-d & 0.3 & 1938 & 39 & 29 & 616 & 47 & 69 & 57 & 241 & 290 & 265 \\
\hline & 28-d & 0.3 & 2411 & 66 & 34 & 845 & 47 & 69 & 57 & 331 & 399 & 363 \\
\hline & $90-d$ & 0.3 & 2617 & 74 & 36 & 938 & 47 & 69 & 57 & 368 & 442 & 403 \\
\hline Mix & & $\mathrm{w} / \mathrm{cm}$ & & & & & & & & & & \\
\hline \multirow[t]{4}{*}{ SG 35 SF 10} & $1-d$ & 0.4 & 2089 & 12 & 19 & 554 & 39 & 62 & 51 & 199 & 248 & 225 \\
\hline & 7-d & 0.4 & 2805 & 23 & 24 & 828 & 39 & 62 & 51 & 298 & 371 & 336 \\
\hline & $28-d$ & 0.4 & 3493 & 35 & 28 & 1110 & 39 & 62 & 51 & 399 & 497 & 450 \\
\hline & $90-d$ & 0.4 & 4052 & 39 & 29 & 1314 & 39 & 62 & 51 & 472 & 588 & 532 \\
\hline Mix & & $\mathrm{w} / \mathrm{cm}$ & & & & & & & & & & \\
\hline \multirow[t]{4}{*}{ SG 35 FA 15} & $1-d$ & 0.4 & 2225 & 2 & 11 & 464 & 40 & 63 & 52 & 169 & 209 & 190 \\
\hline & 7-d & 0.4 & 2996 & 12 & 19 & 796 & 40 & 63 & 52 & 290 & 359 & 326 \\
\hline & $28-d$ & 0.4 & 3735 & 43 & 30 & 1234 & 40 & 63 & 52 & 449 & 557 & 505 \\
\hline & $90-d$ & 0.4 & 4345 & 57 & 33 & 1514 & 40 & 63 & 52 & 551 & 683 & 619 \\
\hline Mix & & $\mathrm{w} / \mathrm{cm}$ & & & & & & & & & & \\
\hline \multirow[t]{4}{*}{ SG 35 SF 15} & 1-d & 0.3 & 1314 & 4 & 13 & 286 & 47 & 70 & 58 & 112 & 136 & 124 \\
\hline & 7-d & 0.3 & 1971 & 26 & 25 & 571 & 47 & 70 & 58 & 224 & 271 & 247 \\
\hline & $28-d$ & 0.3 & 2590 & 65 & 34 & 889 & 47 & 70 & 58 & 348 & 422 & 384 \\
\hline & $90-d$ & 0.3 & 3062 & 78 & 36 & 1088 & 47 & 70 & 58 & 426 & 517 & 470 \\
\hline
\end{tabular}


Table: Elastic modulus ranges for mortar at different $\mathbf{w} / \mathrm{cm}$ ratios

\begin{tabular}{|c|c|c|c|c|c|c|c|c|c|c|c|}
\hline \multicolumn{12}{|c|}{$w / c=0.3$} \\
\hline Mix & $\mathrm{S} / \mathrm{S}+\mathrm{C}$ & $\mathrm{C} / \mathrm{S}+\mathrm{C}$ & Kp & $G p$ & $K(-)$ & $\mathrm{K}(+)$ & $G(-)$ & $G(+)$ & Em(-) & $\mathrm{Em}(+)$ & Em, avg \\
\hline $100 \%$ cement & 0.685 & 0.315 & $\begin{array}{r}44.207 \\
\end{array}$ & 20.0 & 31.82 & 33.24 & 18.66 & 30.88 & 47 & 71 & 59 \\
\hline SG 35 & 0.678 & 0.322 & 40.9983 & 20.5 & 31.10 & 32.12 & 19.01 & 30.87 & 47 & 70 & 59 \\
\hline SG 45 & 0.676 & 0.324 & 39.9453 & 20.6 & 30.82 & 31.72 & 19.05 & 30.83 & 47 & 70 & 59 \\
\hline FA 25 & 0.670 & 0.330 & 44.8593 & 20.1 & 32.20 & 33.74 & 18.75 & 30.71 & 47 & 71 & 59 \\
\hline FA 35 & 0.665 & 0.335 & 44.9295 & 20.0 & 32.28 & 33.86 & 18.70 & 30.59 & 47 & 71 & 59 \\
\hline SF 10 & 0.674 & 0.326 & 42.8289 & 19.9 & 31.58 & 32.85 & 18.64 & 30.62 & 47 & 70 & 58 \\
\hline SG 35 SF 10 & 0.667 & 0.333 & 39.1434 & 20.2 & 30.62 & 31.45 & 18.78 & 30.46 & 47 & 69 & 58 \\
\hline FA 25 SF 10 & 0.660 & 0.340 & 43.0044 & 19.7 & 31.78 & 33.11 & 18.51 & 30.30 & 47 & 70 & 58 \\
\hline SG 35 SF 15 & 0.669 & 0.331 & 41.1036 & 20.4 & 31.21 & 32.26 & 18.94 & 30.68 & 47 & 70 & 59 \\
\hline
\end{tabular}

\begin{tabular}{|c|c|c|c|c|c|c|c|c|c|c|c|}
\hline \multicolumn{12}{|c|}{$w / c=0.4$} \\
\hline Mix & $\mathrm{S} / \mathrm{S}+\mathrm{C}$ & $\mathrm{C} / \mathrm{S}+\mathrm{C}$ & Kp & Gp & K(-) & $K(+)$ & $G(-)$ & $G(+)$ & $\operatorname{Em}(-)$ & $\operatorname{Em}(+)$ & Em, avg \\
\hline $100 \%$ cement & 0.685 & 0.315 & 33.37 & 15.4 & 28.00 & 28.37 & 15.44 & 28.13 & 39 & 63 & 51 \\
\hline SG 35 & 0.678 & 0.322 & 32.055 & 16.0 & 27.64 & 27.91 & 15.80 & 28.17 & 40 & 63 & 52 \\
\hline SG 45 & 0.676 & 0.324 & 31.509 & 16.0 & 27.46 & 27.69 & 15.82 & 28.12 & 40 & 63 & 51 \\
\hline FA 25 & 0.670 & 0.330 & 34.057 & 15.7 & 28.38 & 28.81 & 15.64 & 28.05 & 40 & 64 & 52 \\
\hline FA 35 & 0.665 & 0.335 & 34.0934 & 15.7 & 28.43 & 28.87 & 15.61 & 27.92 & 40 & 63 & 51 \\
\hline SF 10 & 0.674 & 0.326 & 33.0042 & 15.6 & 27.97 & 28.31 & 15.58 & 28.01 & 39 & 63 & 51 \\
\hline SG 35 SF 10 & 0.667 & 0.333 & 31.0932 & 15.8 & 27.31 & 27.53 & 15.66 & 27.82 & 39 & 62 & 51 \\
\hline FA 25 SF 10 & 0.660 & 0.340 & 33.0952 & 15.5 & 28.08 & 28.44 & 15.49 & 27.70 & 39 & 63 & 51 \\
\hline SG 35 SF 15 & 0.669 & 0.331 & 32.1096 & 15.9 & 27.70 & 27.98 & 15.75 & 27.99 & 40 & 63 & 51 \\
\hline
\end{tabular}

\begin{tabular}{|c|c|c|c|c|c|c|c|c|c|c|c|}
\hline \multicolumn{12}{|c|}{$w / c=0.5$} \\
\hline Mix & $\mathrm{S} / \mathrm{S}+\mathrm{C}$ & $\mathrm{C} / \mathrm{S}+\mathrm{C}$ & Kp & $G p$ & $K(-)$ & $\mathrm{K}(+)$ & $G(-)$ & $G(+)$ & $\operatorname{Em}(-)$ & $\mathrm{Em}(+)$ & Em, avg \\
\hline $100 \%$ cement & 0.685 & 0.315 & 25.345 & 12.5 & 24.33 & 24.35 & 13.03 & \begin{tabular}{|r|}
25.83 \\
\end{tabular} & 33 & 57 & 45 \\
\hline
\end{tabular}

